\title{
Ruthenium(II)-Catalyzed Direct C-H meta-Alkylations, Alkenylations and Alkyne Annulations
}

\author{
Dissertation \\ for the award of the degree \\ "Doctor rerum naturalium" (Dr. rer. nat.) \\ of the Georg-August-Universität Göttingen \\ within the doctoral program of chemistry \\ of the Georg-August University School of Science (GAUSS)
}

submitted by

Jie Li

from Yancheng (China)

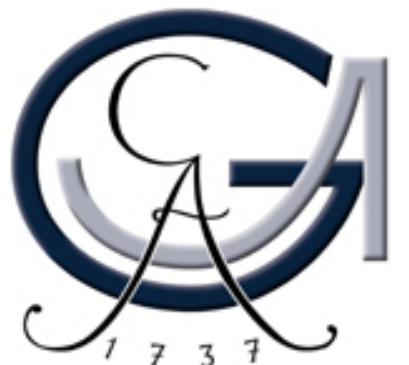

Göttingen, 2015 



\section{Thesis Committee}

Prof. Dr. L. Ackermann, Institute of Organic and Biomolecular Chemistry

Prof. Dr. F. Meyer, Institute of Inorganic Chemistry

\section{Members of the Examination Board}

Reviewer: Prof. Dr. L. Ackermann, Institute of Organic and Biomolecular Chemistry

Second Reviewer: Prof. Dr. F. Meyer, Institute of Inorganic Chemistry

\section{Further members of the Examination Board}

Prof. Dr. H. Laatsch, Institute of Organic and Biomolecular Chemistry

Prof. Dr. U. Diederichsen, Institute of Organic and Biomolecular Chemistry

Prof. Dr. D. Stalke, Institute of Inorganic Chemistry

Dr. A. Breder, Institute of Organic and Biomolecular Chemistry

Date of the oral examination: June $22^{\text {nd }}, 2015$ 



\section{Contents}

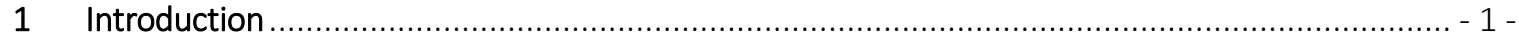

1.1 Transition Metal-Catalyzed C-H Bond Functionalization ....................................... 1 -

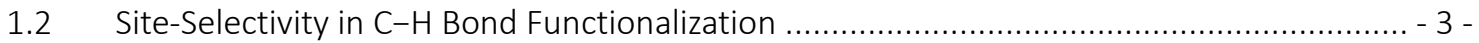

1.3 Transition Metal-Catalyzed Alkylation with Alkyl Halides ............................................ - 8 -

1.4 Transition Metal-Catalyzed Oxidative C-H Alkenylation......................................... 18 -

1.5 Transition Metal-Catalyzed Alkyne Annulations by $\mathrm{C}-\mathrm{H} /$ Het-H Functionalizations ........... - 25 -

2 Objectives

$31-$

3 Ruthenium(II)-Catalyzed meta-Selective $\mathrm{C}-\mathrm{H}$ Alkylations

3.1 Ruthenium(II)-Catalyzed meta-Selective C-H Alkylations by Heterocycle Assistance with Tertiary Alkyl Bromides

$-33-$

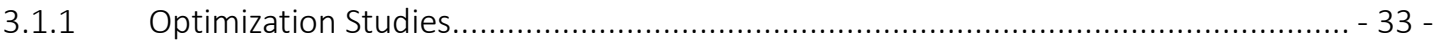

3.1.2 meta-C-H Alkylation with Tertiary Alkyl Bromides: Scope and Limitations............... - 36 -

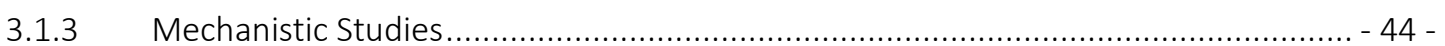

3.1.3.1 Intermolecular Competition Experiments ............................................ 44 -

3.1.3.2 Experiments with Deuterium-Labeled Substrates ............................................. 46 -

3.1.3.3 Experiments in the Presence of Radical Scavengers ......................................... - 47 -

3.1.3.4 Proposed Catalytic Cycle ................................................................... - 48 -

3.2 Ruthenium(II)-Catalyzed meta-Selective C-H Alkylations of Ketimines with Secondary and

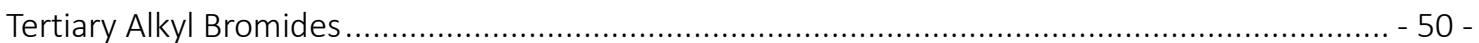

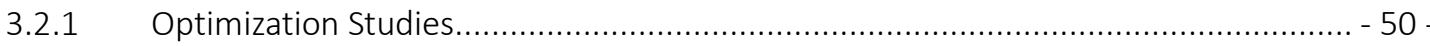

3.2.2 Direct meta-Alkylation with Tertiary Alkyl Bromides: Scope and Limitations............ - 51 -

3.2.3 Direct meta-Alkylation with Secondary Bromides: Scope and Limitations................ - 54 -

3.2.4 Direct meta- versus ortho-Alkylation with Cyclic Secondary Alkyl Bromides ............. - 57 -

3.2.5 Intramolecular Competition Experiments................................................. 59 -

3.2.6 Intermolecular Competition Experiments ............................................... - 60 -

3.3 Ruthenium(II)-Catalyzed meta-Selective C-H Alkylations of Aniline Derivatives with

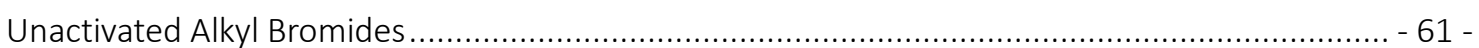

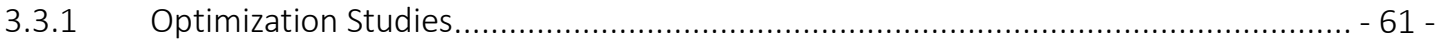

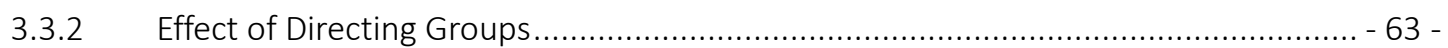

3.3.3 Direct meta-Alkylation with Tertiary Alkyl Bromides: Scope and Limitations............ - 63 -

3.3.4 Direct Alkylation with Primary and Secondary Alkyl Bromides .............................. - 66 -

3.3.5 Removal of the Directing Group ................................................................ 68 -

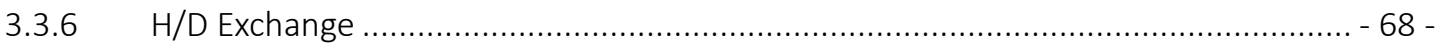

4 Ruthenium(II)-Catalyzed Oxidative C-H Alkenylation of Aryl Carbamates ............................ - 69 -

4.1 Optimization Studies

- $69-$ 


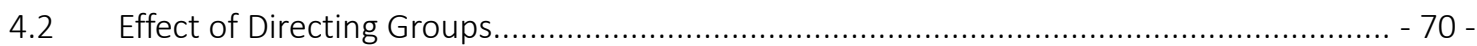

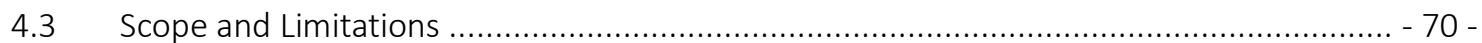

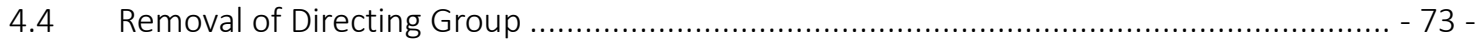

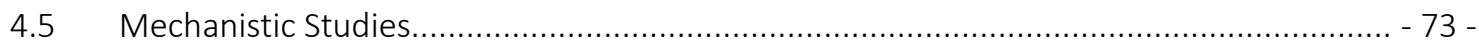

4.5.1 Intermolecular Competition Experiments .............................................................. - 73 -

4.5.2 Reaction with Isotopically Labelled Substrate........................................................ 74 -

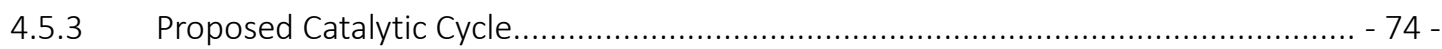

5 Cationic Ruthenium(II) Catalysts for $\mathrm{C}-\mathrm{H} / \mathrm{N}-\mathrm{O}$ Functionalizations of Oximes .............................. - 76 -

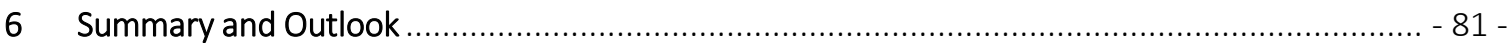

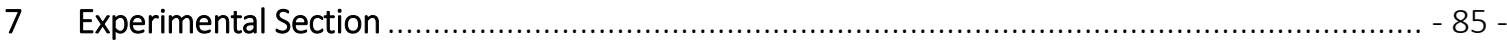

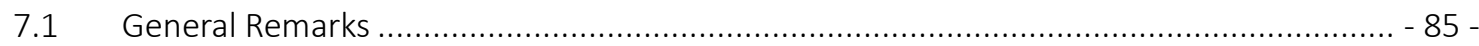

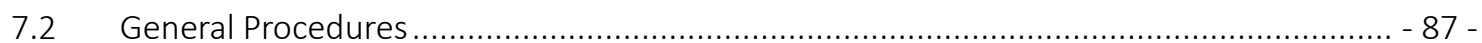

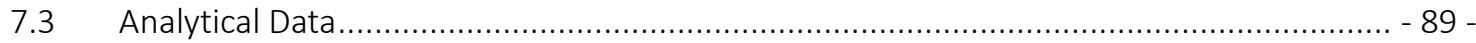

7.3.1 Analytical Data for the Products of the Ruthenium(II)-Catalyzed Direct meta-Alkylation ..$89-$

7.3.2 Analytical Data for the Products of the Ruthenium(II)-Catalyzed Direct meta-Selective Alkylation of Ketimines with Tertiary Alkyl Bromides.

7.3.3 Analytical Data for the Products of the Ruthenium(II)-Catalyzed Direct meta-Selective Alkylation with Secondary Alkyl Bromides.

7.3.4 Analytical Data for the Products of the Ruthenium-Catalyzed Direct meta-Selective Alkylations of N-(Pyrimidyl-2-yl)anilines and N-(Pyridin-2-yl)anilines

7.3.5 Analytical Data for the Products of Ruthenium(II)-Catalyzed Oxidative Alkenylation of Aryl Carbamates

7.3.6 Analytical Data for the Products of Ruthenium(II)-Catalyzed Isoquinoline Synthesis- 151 -

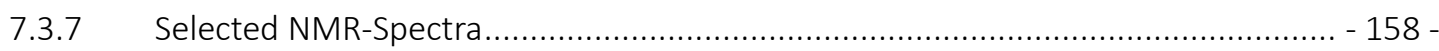

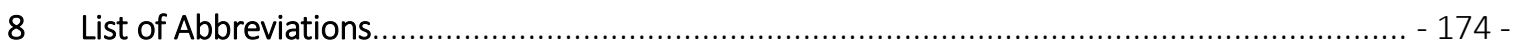

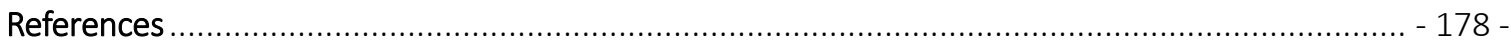

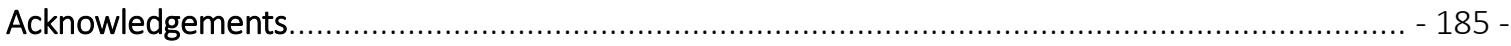

Resume 


\section{Introduction}

\subsection{Transition Metal-Catalyzed C-H Bond Functionalization}

In the past decades, transition metal-catalyzed cross-coupling reactions have been considered as one of the most powerful and reliable methods for chemo- and site-selective construction of carbon-carbon $\left(\mathrm{C}-\mathrm{C}\right.$ ) or carbon-heteroatom (C-Het) bonds. ${ }^{1-4}$ Besides academia, these reactions have also been widely employed in pharmaceutical, agrochemical, and fine chemical industries. ${ }^{5,6}$ For their magnificent contribution for palladium-catalyzed cross-coupling reactions, R. F. Heck, E. Negishi and $A$. Suzuki were awarded the Nobel Prize in chemistry in $2010 .^{7-9}$ The generally accepted mechanisms for these palladium-catalyzed cross-coupling transformations are illustrated in Scheme 1.1. In both types of coupling reactions, first step is the oxidative addition of the aryl halide (or pseudohalide) to the catalytically active palladium(0) species which initiates the catalytic cycle. At this stage the processes diverge. In the Mizoroki-Heck ${ }^{10,11}$ reaction, the reaction progresses by coordination of an alkene to the palladium(II) species followed by syn-migratory insertion and syn-6-hydride elimination to form the substituted alkene product, and subsequently base-assisted elimination to regenerate the active palladium(0). In the Negishi ${ }^{12}$ and Suzuki-Miyaura ${ }^{13}$ cross-coupling reactions, the oxidative addition is followed by transmetalation of an organometallic or main group element species to generate a Palladium(II) intermediate. Subsequent reductive elimination results in $\mathrm{C}-\mathrm{C}$ bond formation with the regeneration of palladium( 0 ) species to complete the catalytic cycle.

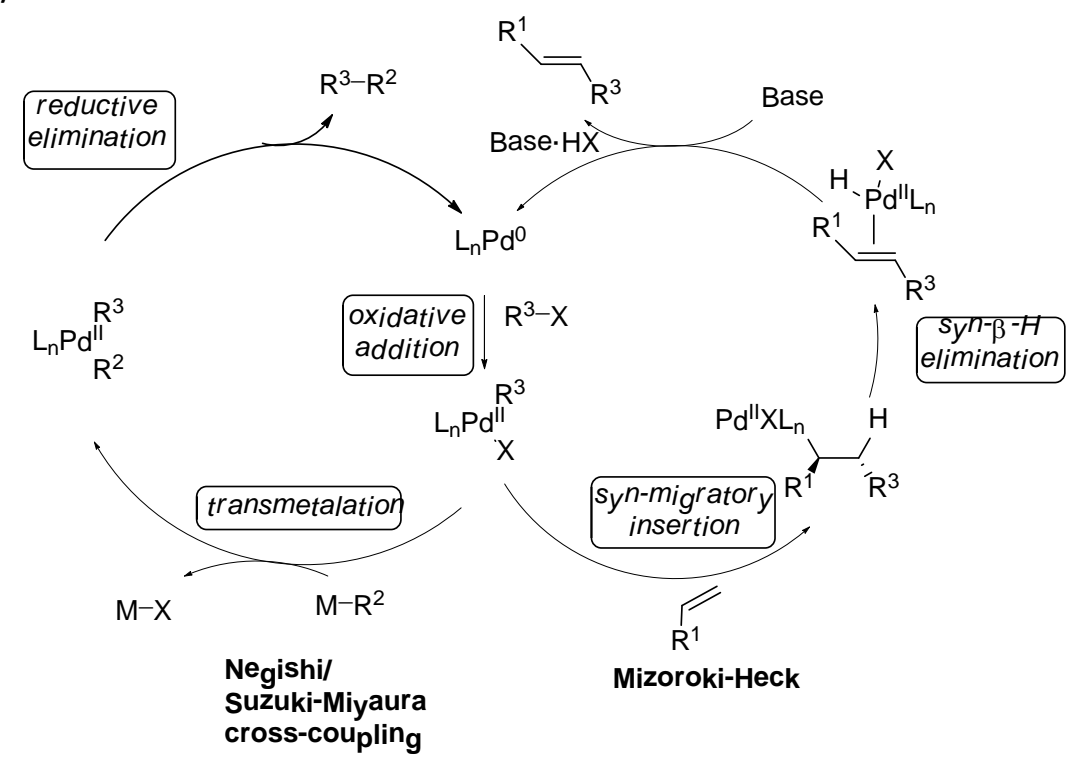

Scheme 1.1: General catalytic cycles for Mizoroki-Heck, Negishi, and Suzuki-Miyaura reactions

Despite the various applications of these reactions, the use of pre-functionalized starting materials and generation of stoichiometric amount of undesired byproducts remain major disadvantages. As a more atom- and step-economical ${ }^{14,15}$ alternative, $\mathrm{C}-\mathrm{H}$ functionalization has recently emerged as a valuable tool allowing the transformation of otherwise unreactive $\mathrm{C}-\mathrm{H}$ bonds (Scheme 1.2). ${ }^{16-24}$ Furthermore, the direct construction of $\mathrm{C}-\mathrm{C}$ bonds by functionalizing two $\mathrm{C}-\mathrm{H}$ bonds including $\mathrm{C}\left(\mathrm{sp}^{3}\right)-\mathrm{H}$ bonds, which was termed as cross-dehydrogenative coupling $(\mathrm{CDC}),{ }^{25}$ has been extensively studied. $^{26,27}$ 


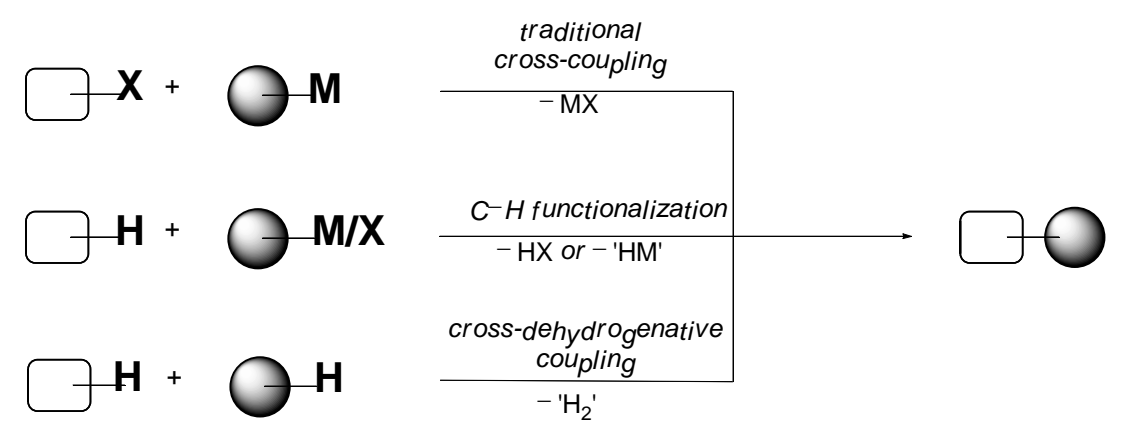

Scheme 1.2: Strategies for $\mathrm{C}-\mathrm{C}$ and $\mathrm{C}-\mathrm{Het}$ bond formation

Depending on the nature of the transition metal $M$ and the ligand set $L_{n}$, the elementary step of $C-H$ bond metalation was proposed to proceed via different pathways. Ackermann as well as Eisenstein and co-workers summarized four generally accepted pathways for this process which are shown in Scheme 1.3. ${ }^{17,28}$
a) oxidative addition
$\mathrm{L}_{n} \mathrm{M}+\underset{\mathrm{R}}{\mathrm{H}}$
$L_{n} M \underset{R}{\mathrm{R}}$

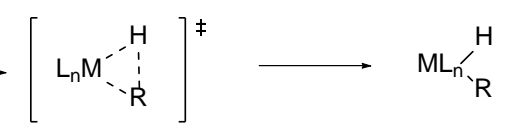
b) $\sigma$-bond metathesis
$\mathrm{ML}^{\prime}{ }^{\mathrm{R}^{\prime}}+\begin{aligned} & \mathrm{H} \\ & \mathrm{R}\end{aligned}$

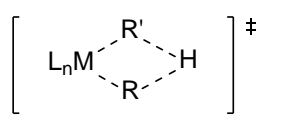
$\longrightarrow M_{{ }^{\prime} R}+{ }^{R^{\prime}}$
c) electrophilic substitution $\mathrm{L}_{\mathrm{n}} \mathrm{X}^{\mathrm{X}}+$
$M L_{n}<\underset{R}{X}<_{\oplus}^{H}$
$\longrightarrow \mathrm{ML}_{{ }^{\circ}{ }^{\circledR}}^{\oplus}+\underset{H}{\mathrm{H}}$
d) 1,2-addition
$\mathrm{L}_{\mathrm{n}} \mathrm{M}+$

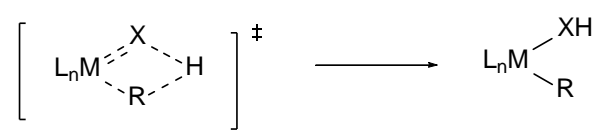

Scheme 1.3: Different mechanisms for $\mathrm{C}-\mathrm{H}$ metalation

Oxidative addition is a common mechanism in which a $\mathrm{C}-\mathrm{H}$ bond first coordinates to the metal vacant site and is then cleaved to form a $\mathrm{M}-\mathrm{H}$ bond and a $\mathrm{M}-\mathrm{C}$ bond (Scheme 1.3a). This process often occurs for electron-rich, low-valent late transition metals ( $\mathrm{Re}, \mathrm{Fe}, \mathrm{Ru}, \mathrm{Os}$, Ir and Pt). However, early group 3 and 4 transition metals as well as lanthanides ( $d^{0}$ configuration) usually do not undergo oxidative addition. Therefore, for these metals $\sigma$-bond metathesis (SBM) is more common (Scheme 1.3b). Similar reactivity is observed for late- or post-transition metals $\left(\mathrm{Pd}^{2+}, \mathrm{Pt}^{2+}, \mathrm{Pt}^{4+}, \mathrm{Hg}^{2+}\right)$ in strongly polar medium, electrophilic attack of the metal occurs in which the metal largely acts as a Lewis acid and thus classified as electrophilic substitution (Scheme 1.3c). $\mathrm{C}-\mathrm{H}$ bond activation can also proceed via 1,2-addition to unsaturated $\mathrm{M}-\mathrm{X}$ bonds (Scheme $1.3 \mathrm{~d}$ ).

In the early 1970s, work by Shaw and Gaunt highlighted the importance of stoichiometric amounts of $\mathrm{NaOAc}$ for successful cyclometalation of $\mathrm{N}, \mathrm{N}$-dimethylaminomethylferrocene (1) (Scheme 1.4). ${ }^{29}$ Subsequently, Reutov and co-workers found that carboxylic acids are competent additives for the same transformation and furnished products with moderate enantiomeric excess. ${ }^{30}$ More importantly, a transition state of concerted carboxylate-assisted intermolecular deprotonation ${ }^{17}$ was 
first proposed.
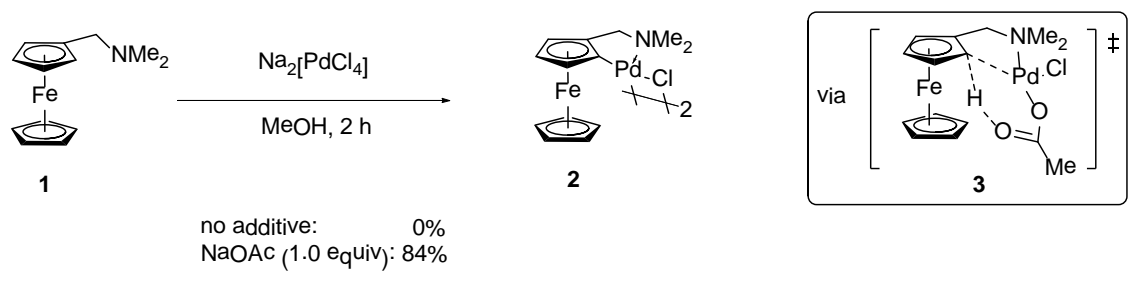

Scheme 1.4: Base-assisted cyclometalation and proposed transition state 3

In this context, theoretical calculations have offered new insight into the mechanism of base-assisted $\mathrm{C}-\mathrm{H}$ metalation. Based on computational studies, Davies and Macgregor described such reaction as ambiphilic metal-ligand activation (AMLA), ${ }^{31}$ whereas Fagnou used the term concerted-metalation-deprotonation (CMD). ${ }^{32}$ Both proposals favor a similar six-membered transition state, however, Davies and Macgregor suggested an agostic interaction between metal center and the $\mathrm{C}-\mathrm{H}$ bond (Scheme 1.5).

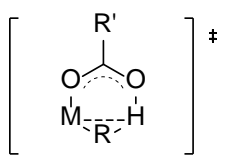

AMLA

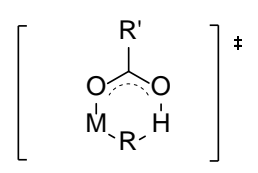

CMD

$$
\left[\begin{array}{c}
\mathrm{R}^{\prime} \\
\dot{X}^{\mathrm{X}} \mathrm{d}^{-} \\
\mathrm{M}^{\prime} \\
\mathrm{R}^{-} \cdot \mathrm{H}^{+}
\end{array}\right] \mathrm{d}^{+}
$$

IES

Scheme 1.5: Proposed transition state for base-assisted $\mathrm{C}-\mathrm{H}$ activation

The groups of Oxgaard and Goddard reported detailed experimental and computational studies on $\mathrm{C}-\mathrm{H}$ bond activation of benzene by iridium complexes. Herein, a four-membered transition state was proposed and described as internal electrophilic substitution (IES). ${ }^{33}$

\subsection{Site-Selectivity in C-H Bond Functionalization}

$\mathrm{C}-\mathrm{H}$ bonds are ubiquitous in nature, a characteristic which on one hand facilitates their usage as starting material for elaboration of more complex structures. However, on the other hand, this makes controlling the site-selectivity of $\mathrm{C}-\mathrm{H}$ functionalization a great challenge. In electrophilic aromatic substitution, it has been well established that electron-donating substituents direct incoming electrophiles to the ortho- (6) and para-positions (7), whereas electron-withdrawing substituents lead to the meta- position (8) (Scheme 1.6).

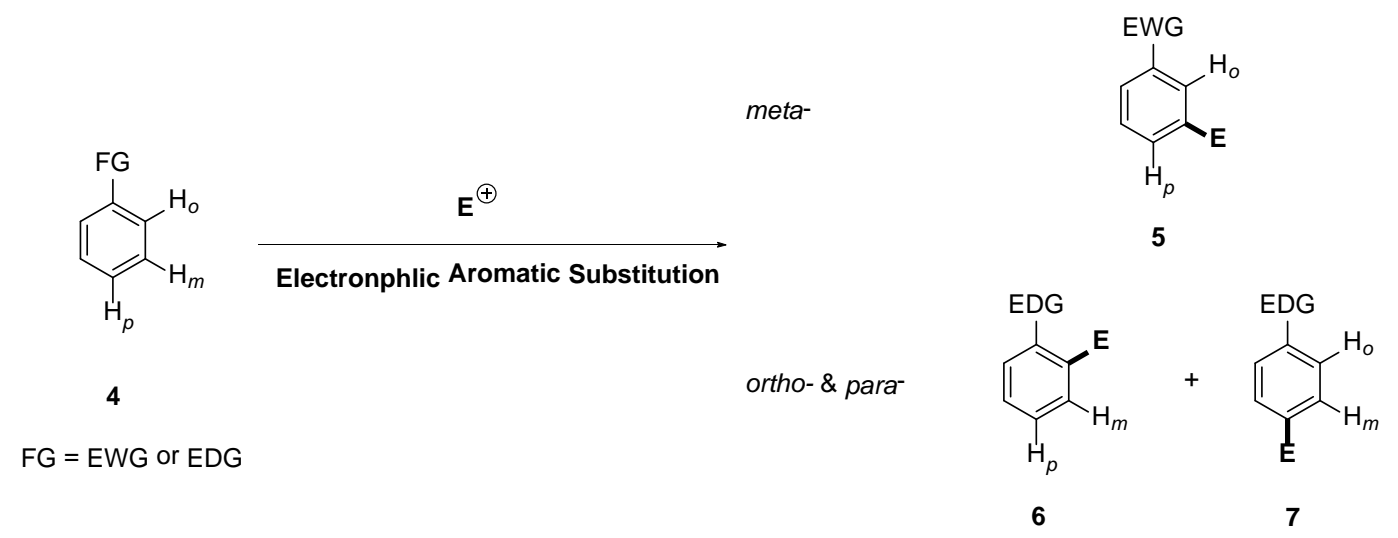

Scheme 1.6: Site-selectivity in electrophilic aromatic substitution 
In spite of the synthetic importance of this classic selectivity pattern, accessing the isomers which are not anticipated by these rules remained a challenge. Over the last few decades, $\mathrm{C}-\mathrm{H}$ functionalization involving the use of directing groups (DGs) has become the most common approach that allows access to ortho-functionalized aromatic compounds through chelation-assisted cyclometalation ${ }^{34,35}$ or weak coordination. ${ }^{20} \mathrm{~A}$ directing group usually bears a heteroatom of which the lone pair of electrons can coordinate to the transition metal complex [TM] (Scheme 1.7).

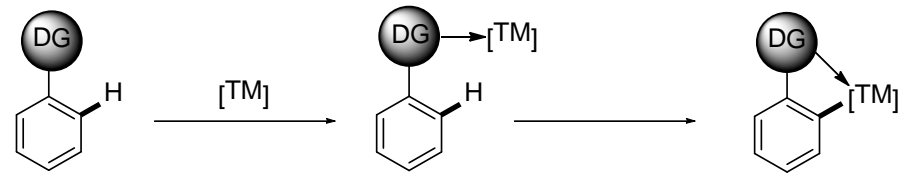

Scheme 1.7: Coordination mode of a DG in transition metal-catalyzed $\mathrm{C}-\mathrm{H}$ functionalization

The same principle has previously been utilized in the stoichiometric directed ortho-metalation (DoM), discovered independently by Gilman ${ }^{36}$ and Wittig ${ }^{37}$ in the late 1930s. In this approach, an aryllithium intermediate is formed by ortho-deprotonation following the chelation of lithium by the direct metalation group (DMG). Subsequent attack by an electrophile delivers the ortho-functionalized product. Scheme 1.8a shows a recent example of preparing ortho-substituted naphthalenes $\mathbf{9}$ and $\mathbf{1 0}$ via carbamate assisted DoM. ${ }^{38}$ It is worth noting that the DoM strategy can be employed for the preparation of meta-substituted products as well. For example, the group of Brown demonstrated that utilizing removable sulfoxide group as DMG smoothly gave rise to meta-substituted anisole 12 (Scheme $1.8 \mathrm{~b}$ ). ${ }^{39}$

a)

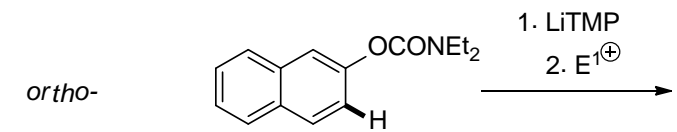<smiles>COc1ccccc1S(=O)CC(C)(C)C</smiles>

11

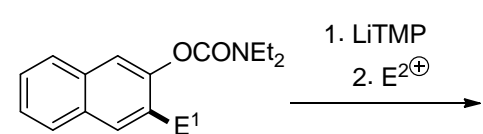

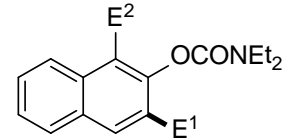

10

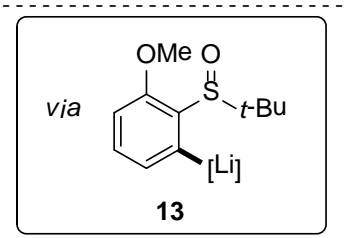

12

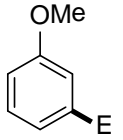

Scheme 1.8: Examples of site-selective DoMs

Although the DoM strategy usually exhibits high reactivity and efficiency, there remain certain drawbacks. First, the necessity of using stoichiometric amounts of strong base inevitably produces stoichiometric amounts of salt waste. Second, employing very reactive strong base largely limits the potential substrate scope in terms of functional group tolerance.

Besides using directing groups, the site-selectivity can also be controlled by employing electronically activated substrates. ${ }^{40}$ For example, the group of $\mathrm{Yu}$ developed palladium-catalyzed $\mathrm{C}-\mathrm{H}$ olefination of electron-deficient arenes $14,{ }^{41}$ wherein the most acidic meta- $\mathrm{C}-\mathrm{H}$ bond is predominately functionalized (Scheme 1.9). Systematic theoretical study of this reaction has been performed. It was calculated that the initial $\mathrm{C}-\mathrm{H}$ activation step proceeds via concerted metalation-deprotonation (CMD) pathway. ${ }^{42}$ 


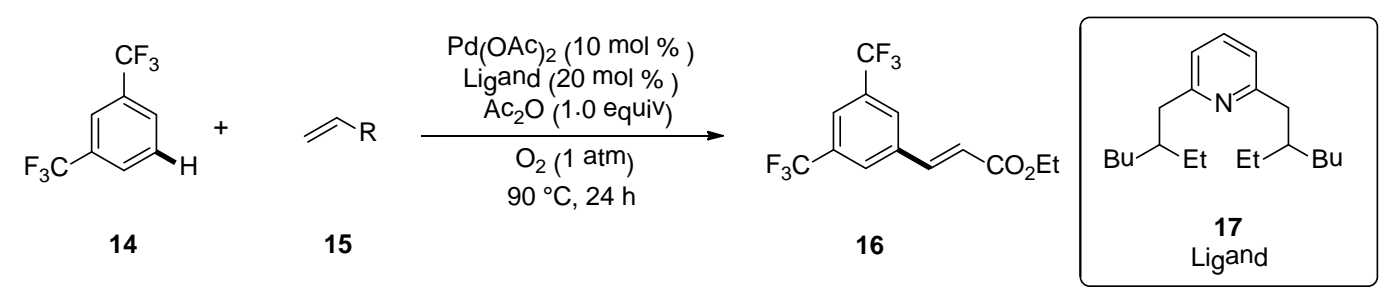

Scheme 1.9: meta-Selective C-H alkenylation of electron-deficient arene 14

Palladium-catalyzed norbornene-mediated ortho-selective $\mathrm{C}-\mathrm{H}$ functionalization of iodobezene derivatives 18, which is also known as the Catellani reaction, allows for the facile construction of up to three $\mathrm{C}-\mathrm{C}$ bonds in a site-selective fashion. ${ }^{43}$ Given its unique site-selectivity, considerable attention has been drawn in extending the synthetic utility of this transformation over the last decade. $^{44,45}$ Recently, the group of Dong developed an elegant example of employing Catellani reaction for site-selective $\mathrm{C}-\mathrm{H}$ amination of arenes $18 .^{46}$ Comparing to the well-known Buchwald-Hartwig amination, ${ }^{47}$ this novel approach provided amination products exclusively at ortho-position (19) rather than ipso-position (20) (Scheme 1.10). More importantly, this method offers broad implications for developing various dual functionalizations of arenes that involve ortho-C-Het bond formation.

catellani-type amination

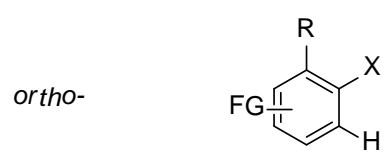

18

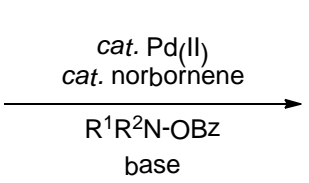

base

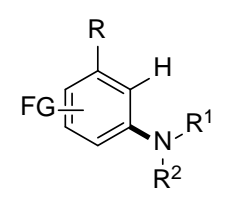

19

Buchwald-Hartwig amination ipso-<smiles>[X]c1ccccc1</smiles>

18

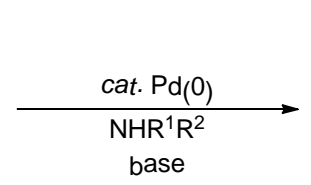

base

$$
\mathrm{X}=\mathrm{I}, \mathrm{Br}
$$<smiles>[R]c1ccccc1N([R])[R]</smiles>

20

Scheme 1.10: Different selectivity patterns in palladium-catalyzed aminations

Based on their previous work of using carboxylic acids as directing groups for formal meta-selective direct arylation of phenols, ${ }^{48}$ in 2014, Larrosa and co-workers modified their methodology by installing carboxylic acid as a traceless directing group in situ which enabled palladium-catalyzed ortho-selective arylation and can be cleaved under the same reaction conditions (Scheme 1.11). This improved method avoided the pre-functionalized phenols (21) and the overall meta-arylation process proceeded in a one-pot fashion. ${ }^{49,50}$ 


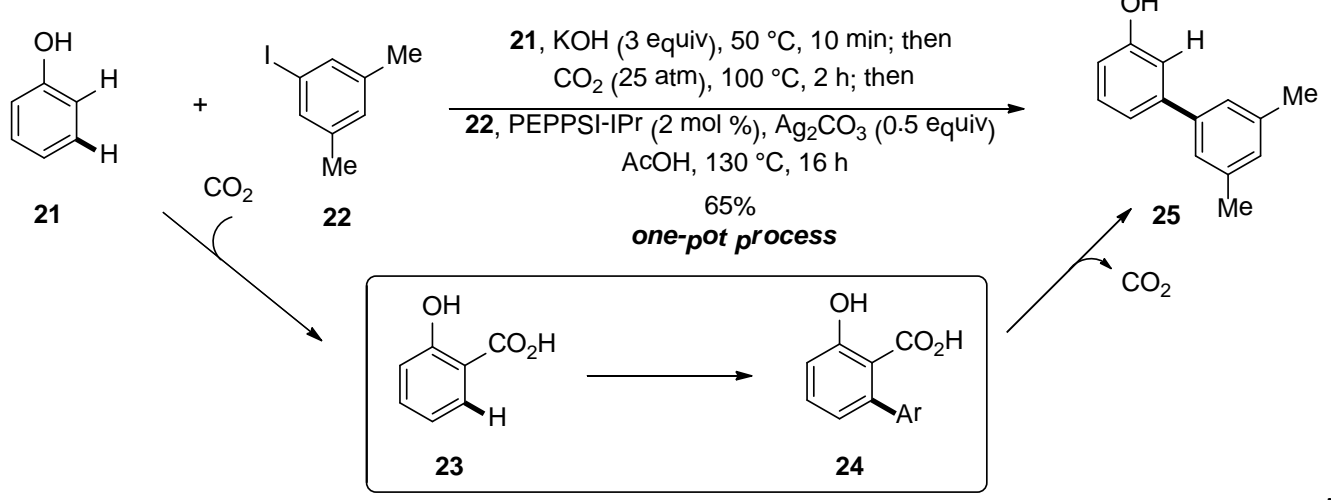

Scheme 1.11: One-pot direct meta-arylation of phenol 21

In spite of the above mentioned approaches for achieving meta- or formal meta-selective $\mathrm{C}-\mathrm{H}$ bond functionalizations, developing more general methods to directly access meta- or para-positions of aromatic compounds with high site-selectivity remains a challenge. ${ }^{51-53}$

One major breakthrough was achieved by the groups of Smith ${ }^{54}$ and Hartwig. ${ }^{55}$ They have reported one-pot iridium-catalyzed $\mathrm{C}-\mathrm{H}$ borylation and sequential functionalization of 1,3-disubstituted arenes at C-5 position. Most recently, Hartwig and co-workers disclosed rhodium-catalyzed meta-selective $\mathrm{C}-\mathrm{H}$ silylation of unactivated arenes $(\mathbf{2 6}){ }^{56,57}$ The resulted silylarene products $\mathbf{2 7}$ are very useful building blocks for organic synthesis (Scheme 1.12). In this type of transformations, regio-selectivity was proposed to be governed by a combination of the steric bulkiness around the catalyst and the substituents on the arenes. ${ }^{58}$<smiles>[R]c1cccc(C)c1</smiles>

26

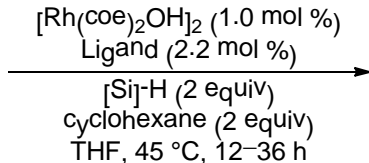

$\left.[\mathrm{Si}]=\operatorname{SiMe}_{(\mathrm{OTMS}}\right)_{2}$<smiles>[R]c1cc(O)cc([Hg])c1</smiles>

27

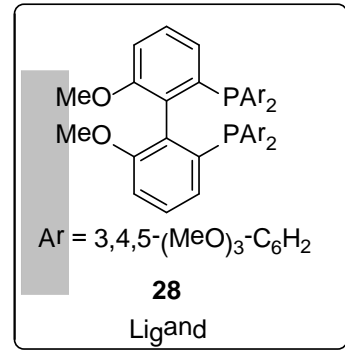

Ligand

Scheme 1.12: Rhodium-catalyzed meta-selective $\mathrm{C}-\mathrm{H}$ silylation

A second breakthrough in achieving meta-selectivity is through coordination of transition metal catalyst to a rational designed template which facilitates the approach of the catalyst to the remote meta-C-H bond. This novel method, in which the first palladium-catalyzed meta-selective alkenylation assisted by a removable nitrile-containing directing group in substrates 29 via a highly strained, tricyclic-cyclophane-type palladated intermediate was achieved (Scheme 1.13), was developed by the group of $Y u$ in $2012 .^{59}$ 


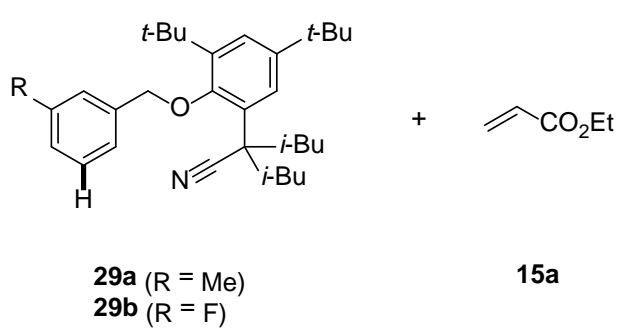

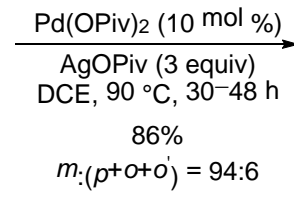

Scheme 1.13: Palladium-catalyzed meta-selective $\mathrm{C}-\mathrm{H}$ alkenylation

Subsequently, $Y u$ and co-workers developed other nitrile-containing directing groups based on the same strategy (Scheme 1.14). These directing groups successfully promoted meta-selective arylation, methylation and alkenylation of phenylpropanoic acid $\mathbf{3 1}$ and phenolic derivatives, ${ }^{60}$ meta-selective olefination and acetoxylation of anilines and tetrahydroquinolines $32,{ }^{61}$ meta-selective olefination, arylation, and acetoxylation of indolines $33,{ }^{62}$ and, most recently, meta-selective olefination of phenylacetic acid derivatives $34 .^{63}$ The group of Tan slightly modified the $Y u$ template by using a silicon atom for attachment in substrate 35, allowing for a facile introduction and deprotection strategy and thus increasing the synthetic practicality of the template. ${ }^{64}$

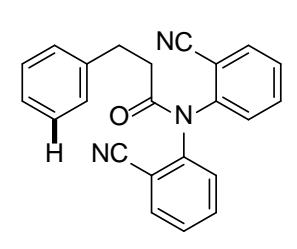

31

$Y u, 2013$

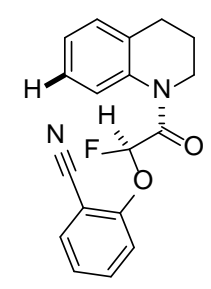

32

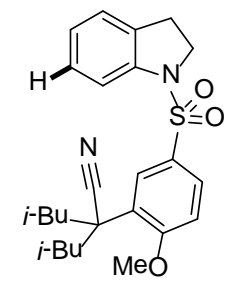

33

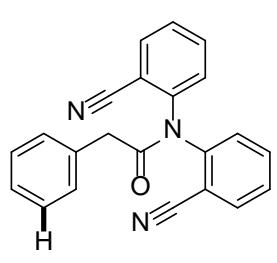

34

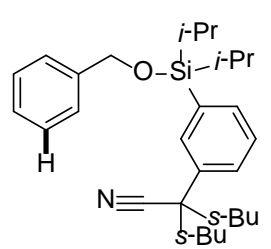

35

Tan, 2013

Scheme 1.14: Directing groups for palladium-catalyzed meta-C-H functionalization

As an alternative approach, Gaunt and co-workers reported copper-catalyzed meta-selective $\mathrm{C}-\mathrm{H}$ arylation of anilides $36^{65,66}$ and subsequently $\alpha$-aryl carbonyl compounds (Scheme 1.15$) .{ }^{67}$ Regarding the mechanism of this remarkable transformation, the authors initially proposed a copper intermediate. However, at slightly elevated temperature, this transformation took place smoothly in the absence of any copper catalyst.<smiles>[R][R]1ccccc1NC([R1])=O</smiles>

36<smiles>[R]C(=O)Nc1c[R1]cc(-c2ccccc2)c1</smiles>

37

Scheme 1.15: meta-selective $\mathrm{C}-\mathrm{H}$ arylation of anilides 36

Subsequently the same group described copper-catalyzed para-selective direct arylation of aniline and phenol derivatives. ${ }^{68}$ Again, reaction occurred in the absence of copper and ortho-arylation was observed when the para-position of aniline was blocked. This selectivity pattern is consistent with a classical electrophilic aromatic substitution. However, copper improved the reactivity of this transformation presumably by inducing dissociation of the triflate anion to form an activated aryliodonium species. 
In 2011, Frost and co-coworkers discovered that in contrast to palladium, ${ }^{56}$ ruthenium led to completely different site-selectivity in direct $\mathrm{C}-\mathrm{H}$ sulfonylation of 2-phenylpyridine derivatives (38a) (Scheme 1.16). ${ }^{69-71}$ In this novel approach, a cyclometalated ruthenium complex containing a Ru- $\mathrm{C}_{\text {aryl }}$ $\sigma$-bond was initially formed, and then the ruthenium center itself became a directing group, ${ }^{72,73}$ thus directing the electrophilic attack to the para-position with respect to the ruthenium by inductive and mesomeric effects.

Ruthenium-Catalyzed C-H sulfonylation

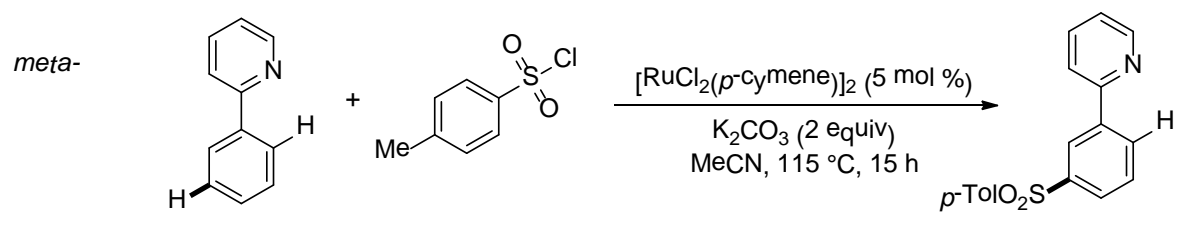

$38 a$

39

$40 a$

Palladium-Catalyzed C-H sulfonylation

ortho-<smiles>c1ccc(-c2ccccn2)cc1</smiles>

$38 a$

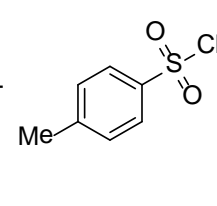

39

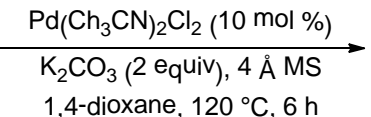

1.4-dioxane $120^{\circ} \mathrm{C}, 6 \mathrm{~h}$

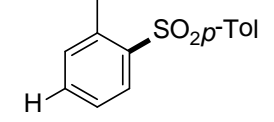

40b

Scheme 1.16: Different selectivity pattern in transition metal-catalyzed C-H sulfonylation

\subsection{Transition Metal-Catalyzed Alkylation with Alkyl Halides}

\section{Friedel-Crafts Alkylation}

Ever since Friedel and Crafts reported the first $\mathrm{AlCl}_{3}$-mediated electrophilic aromatic substitution of benzene (41a) with alkyl chlorides 42 in 1877 (Scheme 1.17), ${ }^{74}$ the Friedel-Crafts alkylation has been one of the most powerful $\mathrm{C}-\mathrm{C}$ bond forming processes in organic synthesis. However, it took more than a century for asymmetric catalytic versions of this transformation to be developed. ${ }^{75}$ Meanwhile, the substrate scope has been extended to include various aromatic compounds and alkylating agents.

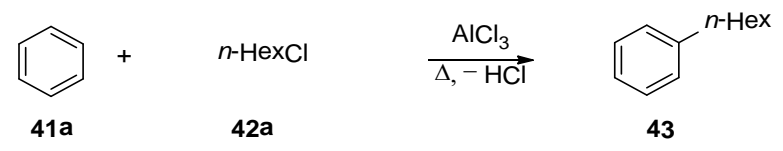

Scheme 1.17: Electrophilic aromatic alkylation as reported by Friedel and Crafts

Despite the fact that research towards developing new strategies for catalytic, stereoselective, ${ }^{76}$ enantioselective and environmentally benign ${ }^{77}$ Friedel-Crafts alkylation is still active, many innate limitations hinder the broader application of these methods. First, acid-labile functional groups are not tolerated. Second, the electrophiles often undergo rearrangements, thus limiting the utility for $n$-alkylations. Third, chemo- or regioselectivity is not perfect, and the electron-deficient arenes are much less reactive than the electron-rich ones. At last, the electronic effects prevent formation of products with alkyl group located meta- to electron-donating groups. 


\section{Transition Metal-Catalyzed Cross-Coupling}

In conventional cross-coupling chemistry, alkyl electrophiles bearing $\beta$-hydrogen atoms had been considered unsuitable substrates for mainly two reasons. First, the oxidative addition of alkyl C-Hal bonds to a metal center is more difficult than aryl-Hal and alkenyl-Hal ones due to their electron-rich nature. Second, the thus formed alkyl metal species are substantially less stable owing to a lack of $\pi$ electrons which can interact with empty $d$ orbitals of the metal. This instability easily gives rise to undesired side reactions, most prominently $\beta$-hydride eliminations. ${ }^{78}$

However, since the pioneering work of Kochi ${ }^{79}$ and Suzuki, ${ }^{80}$ a wide range of transition metals can readily catalyze the coupling of primary alkyl halides and organometallic regents. ${ }^{81,82}$ Compared with primary alkyl halides, secondary alkyl halides are more difficult to couple in conventional cross-coupling chemistry due to the increased energy barrier towards oxidative addition, which results from the increased steric hindrance. Nevertheless, tremendous progress has been made in coupling secondary alkyl halides during the past decade. ${ }^{83}$

In 2003, the group of Fu reported the first nickel-catalyzed Negishi coupling of secondary alkyl bromides $\mathbf{4 4}$ and iodides (Scheme 1.18a). This transformation proceeded smoothly in the presence of various functional groups, such as sulfon amides, ethers, acetals, esters, and amides. ${ }^{84}$ Shortly thereafter, the same group reported an asymmetric nickel-catalyzed Negishi coupling of secondary electrophiles (Scheme 1.18b) ${ }^{85}$ Coupling of racemic $\alpha$-bromoamides (47) under the catalysis with $\mathrm{NiCl}_{2}$ and $i \mathrm{Pr}$-Pybox led to a variety of functionalized $\alpha$-substituted amides (49) in good yields and high ee values.

a)
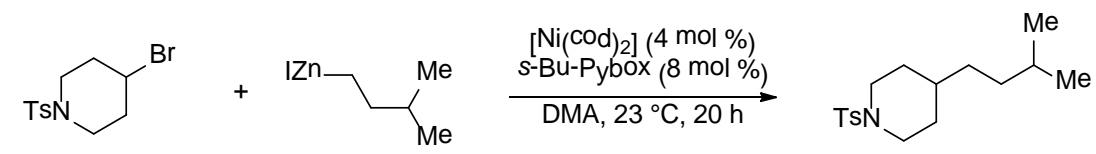

$66 \%$

$44 a$

45

46

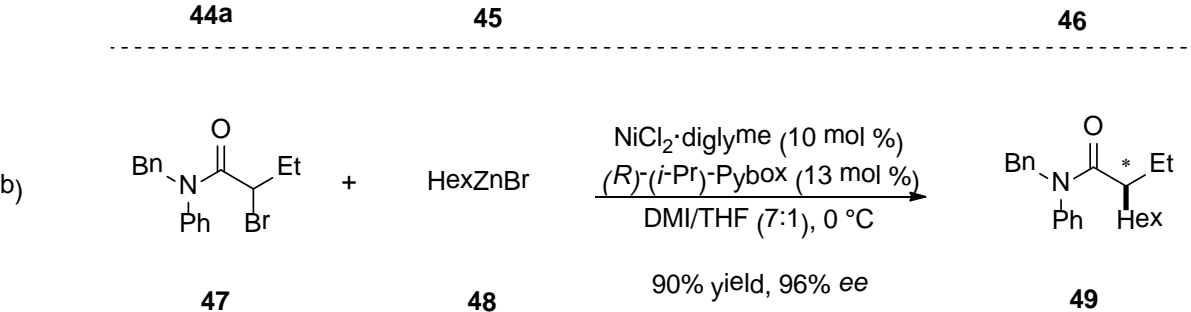

Scheme 1.18: Nickel-catalyzed Negishi coupling of secondary alkyl halides

Besides Negishi coupling, nickel-catalyzed Suzuki- ${ }^{86}$ Hiyama-,${ }^{87}$ Kumada- ${ }^{88}$ and Sonogashira-type coupling ${ }^{89}$ were also reported in an enantioselective fashion, with major contribution from the $\mathrm{Fu}$ group. Although nickel has been proven to be the most versatile metal for cross-coupling of alkyl halides, ${ }^{90}$ other transition metals, such as copper, ${ }^{91}$ iron, $^{92}$ cobalt $^{93}$ and palladium ${ }^{94}$ are also competent.

Although huge progress has been made towards coupling secondary alkyl halides in the past decade, until now, there are only a few publications concerning transition metal-catalyzed C-C bond formation with unactivated tertiary alkyl halides. In 2013, Fu and Zultanski reported the first nickel-catalyzed Suzuki coupling of tertiary alkyl halides $(\mathbf{5 0}) .{ }^{95}$ 


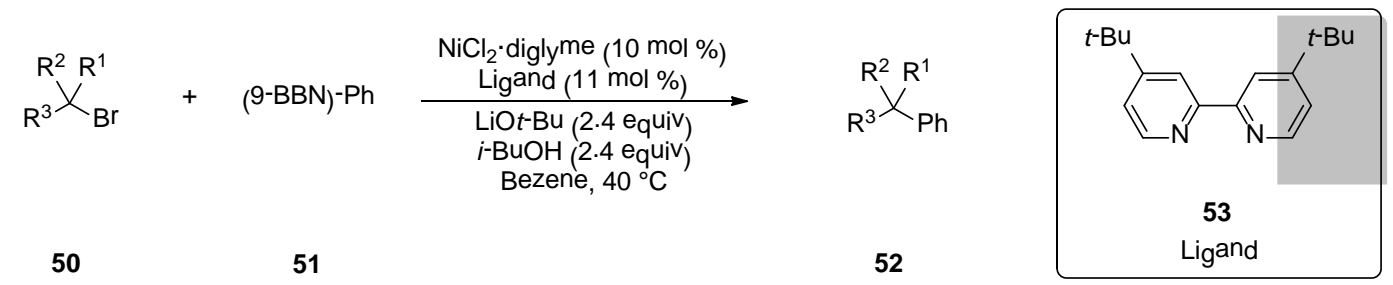

Scheme 1.19: Nickel-catalyzed Suzuki coupling of tertiary alkyl halides 50

The mechanism of nickel-catalyzed Negishi alkyl-alkyl cross-coupling has been studied independently by the groups of Vicic $^{96}$ and Phillips. ${ }^{97}$ Recently, Fu and coworkers also examined the pathway for Negishi arylation of secondary propargylic bromides. ${ }^{98}$ Both studies proposed catalytic cycles involving the transmetalation of organozinc regents and the reductive elimination to yield the products and most importantly, activation of the alkyl halides by single electron transfer (SET) ${ }^{99}$ to form free alkyl radicals. However, Vicic found that nickel(II) species were inactive in the alkyl-alkyl coupling and thus proposed transmetalation as the first step (Scheme 1.20a), while in Fu's experiments nickel(II) seemed to be the active catalyst (Scheme $1.20 \mathrm{~b}$ ).
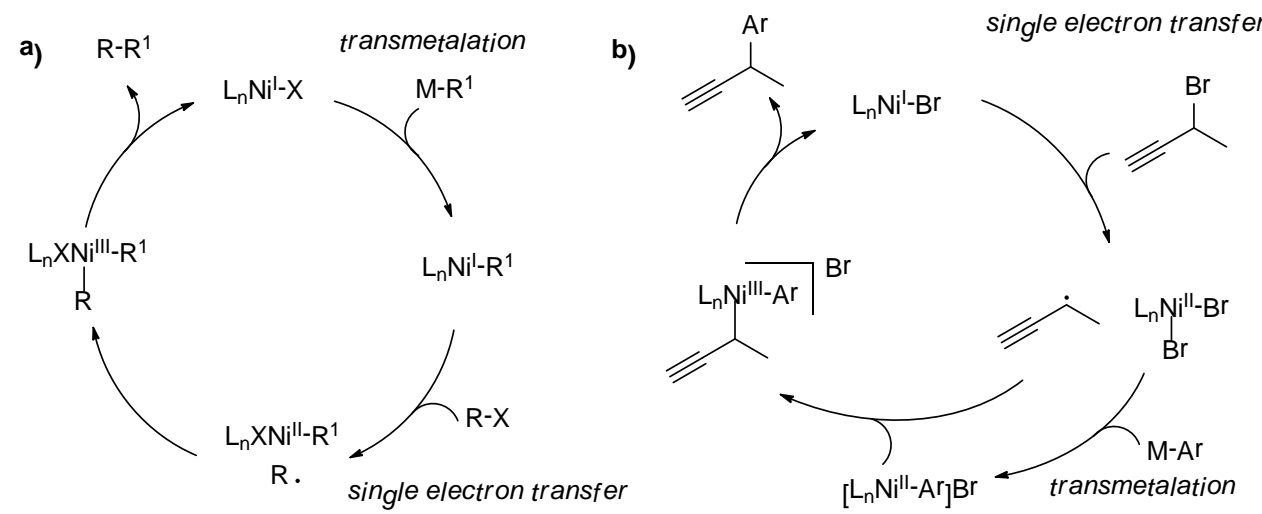

Scheme 1.20: Proposed mechanisms for nickel-catalyzed Negishi coupling: a) alky-alkyl coupling; b)

aryl-propargyl coupling

\section{Transition Metal-Catalyzed Direct C-H Alkylation}

An innate disadvantage of conventional cross-coupling of alkyl halides is the usage of pre-functionalized nucleophilic substrates which are often not commercially available. Preparation of these nucleophiles as well as the cross-couplings themselves potentially produces undesired byproducts. Thus, direct $\mathrm{C}-\mathrm{H}$ bond alkylation represents an economically attractive alternative. Indeed, during the last few years, tremendous progress has been achieved in the field of direct $\mathrm{C}-\mathrm{H}$ bond alkylation of (hetero)arenes, and different transition metals proved to be competent. ${ }^{100}$

\section{Intramolecular Direct C-H Alkylation}

One of the early examples of transition metal-catalyzed intramolecular $\mathrm{C}-\mathrm{H}$ benzylation was developed by the group of Wong. ${ }^{101}$ Initial intermolecular Suzuki-Miyaura cross-coupling afforded intermediate 57, which set the stage for a palladium-catalyzed intramolecular direct benzylation (Scheme 1.21). 


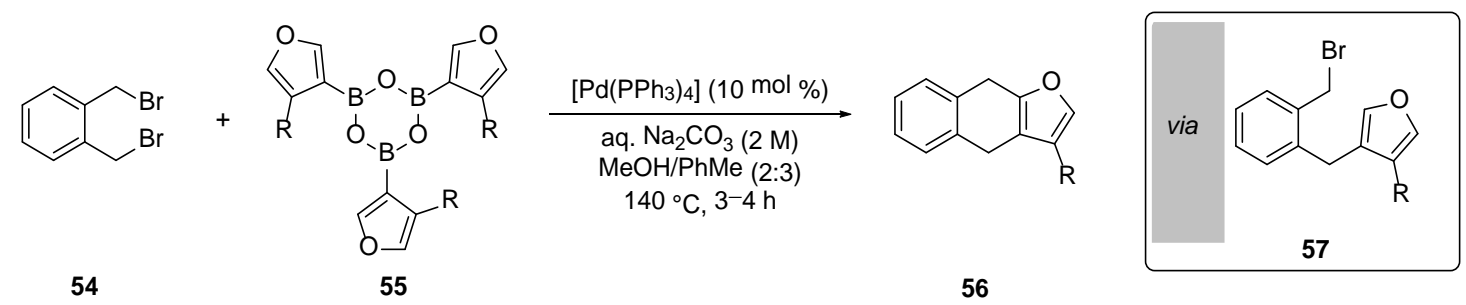

54

55

56

Scheme 1.21: Palladium-catalyzed direct intramolecular benzylation

In 2003, Buchwald and co-workers disclosed palladium-catalyzed oxindoles synthesis through intramolecular alkylation of $\alpha$-chloroacetanilides 58 (Scheme 1.22a). ${ }^{102}$ ortho- or meta-Substituted $\alpha$-chloroacetanilides delivered oxindoles 59 of which the less hindered ortho-positions were selectively alkylated. Subsequently, the group of Chang also reported synthesis of pyrroloindoles $\mathbf{6 1}$ via palladium-catalyzed intramolecular benzylation of pyrroles $\mathbf{6 0}$ under similar reaction conditions (Scheme 1.22b). ${ }^{103}$ Pyrroles bearing electron-withdrawing substituents were observed to react faster than the corresponding electron-rich derivatives, thus indicating a CMD-type mechanism.

a)<smiles>CN(C(=O)CCl)c1ccccc1</smiles>

58

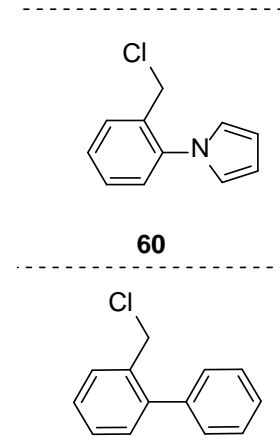

62

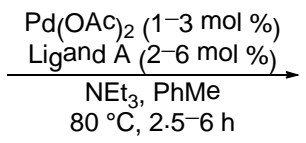

$94 \%$

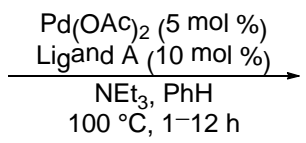

$97 \%$

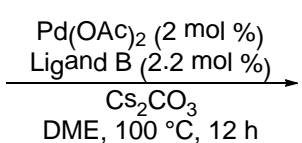

$89 \%$

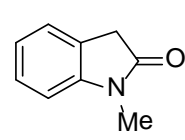

59

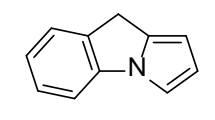

61

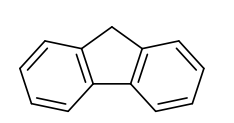

63

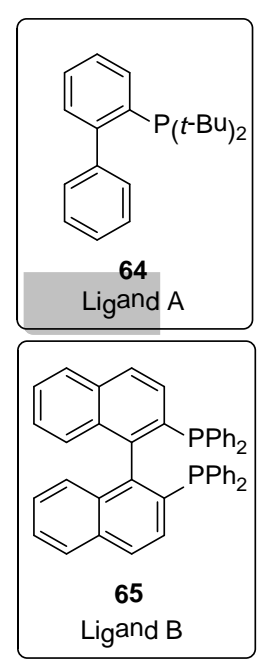

Ligand B

Scheme 1.22: Palladium-catalyzed direct intramolecular cyclizations

In a follow-up work, Chang and co-workers demonstrated that simple arenes $\mathbf{6 2}$ could also be cyclized with an optimized palladium/BINAP system (Scheme 1.22c). ${ }^{104}$ It is noteworthy that in all these intramolecular reactions described above, the halides were activated and thus underwent facile oxidative addition.

\section{Direct C-H Alkylation of Heteroarenes}

Besides arenes, heteroarenes were demonstrated as suitable substrates for transition metal-catalyzed direct C-H alkylation as well. In 2009, Hoarau and co-workers developed one of the earliest examples of palladium-catalyzed alkylation and benzylation of oxazoles 66 (Scheme 1.23a). ${ }^{105}$ The scope of heteroarenes for this transformation was significantly expanded by the group of Fagnou; various five-membered heteroarenes were functionalized at the most acidic $\mathrm{C}-\mathrm{H}$ bond (Scheme 1.23b). ${ }^{106}$ Addition of pivalic acid turned out to be beneficial for the overall efficiency, which indicated a CMD-type mechanism. 
a)

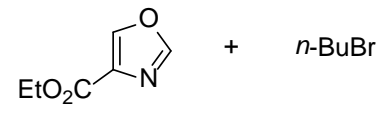

66

$42 b$
$\mathrm{Pd}(\mathrm{OAc}) 2(5 \mathrm{~mol} \%)$

$\underset{\mathrm{P} \text { (biphenyl-2-yl)Cy2 (10 mol \%) }}{\mathrm{Cs}_{2} \mathrm{CO}_{3}}$

1,4-dioxane, $110^{\circ} \mathrm{C}, 18 \mathrm{~h}$

$60 \%$<smiles>CCCCc1nc(C(=O)OCC)co1</smiles>

67

b)

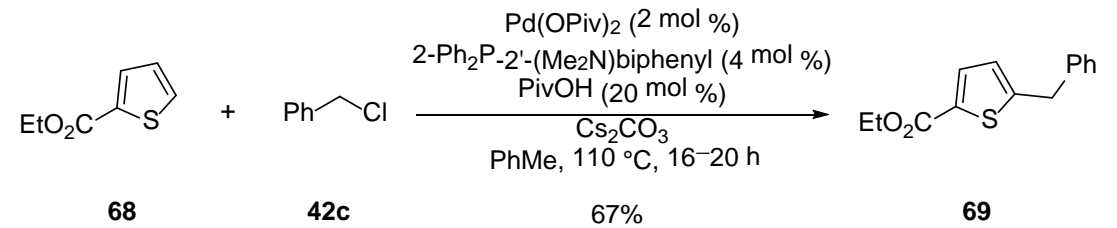

Scheme 1.23: Palladium-catalyzed direct alkylations of heteroarenes

Shortly thereafter, $\mathrm{Hu}$ and co-workers demonstrated that nickel complexes are also capable of promoting direct alkylation of heteroarenes. ${ }^{107}$ Interestingly, addition of cocatalytic amounts of Cul proved to be essential for achieving high yields (Scheme 1.24a). The groups of Miura ${ }^{108}$ and Ackermann ${ }^{109}$ independently showed that user-friendly [(Diglyme) $\mathrm{NiBr}_{2}$ ] also allowed for the effective direct $\mathrm{C}-\mathrm{H}$ alkylation of heteroarenes (Scheme 1.24b).

a)

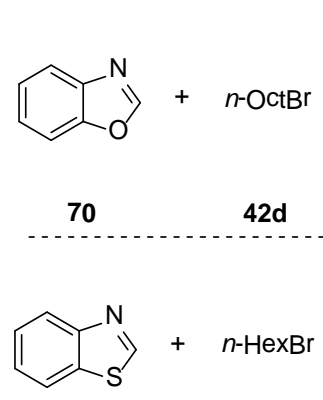

72

$42 \mathrm{e}$
Precatalyst 74 (5 mol \%)

$$
\underset{\mathrm{Cul}(7.5 \mathrm{~mol} \%)}{\stackrel{\mathrm{Nal}(20 \mathrm{~mol} \%)}{t \text {-BuOLi }}}
$$

$72 \%$

$$
\begin{aligned}
& {\left[\mathrm{NiBr}_{2} \cdot \text { diglyme] }(5 \mathrm{~mol} \%)\right.} \\
& \underset{\text { diglyme, } 120^{\circ} \mathrm{C}, 6 \mathrm{~h}}{\stackrel{\text { ter pyridine }(5 \mathrm{~mol} \%)}{\longrightarrow}}
\end{aligned}
$$

$46 \%$

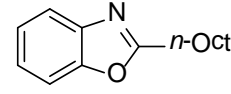

71

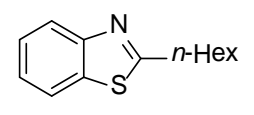

73

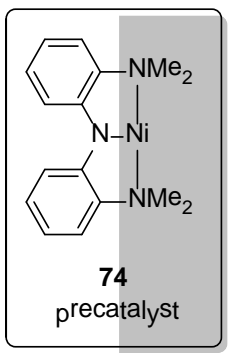

Scheme 1.24: Nickel-catalyzed direct alkylation of heteroarenes

Furthermore, in 2012, Hu and co-workers showed that not only primary alkyl halides, but also secondary alkyl halides $\mathbf{4 4}$ are suitable substrates for copper-catalyzed direct alkylation of heteroarenes 70 (Scheme 1.25a). ${ }^{110}$ Reactions with radical scavengers and other mechanistic studies suggested a radical mechanism. Recently, palladium-catalyzed direct alkylation of pyridine $\mathrm{N}$-oxides 76 and other heteroarenes with unactivated secondary alkyl halides were also independently reported by the groups of $\mathrm{Fu}^{111}$ and $W u^{112}$ (Scheme 1.25b,c). 
a)
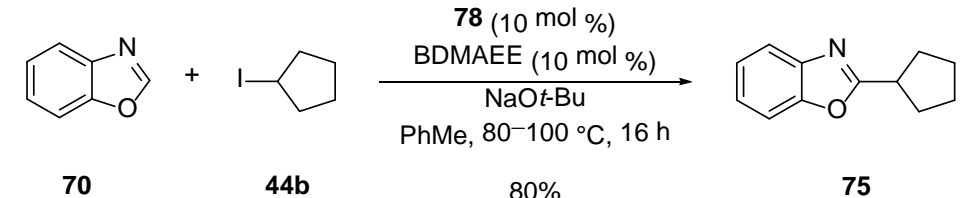
$80 \%$

75

b)
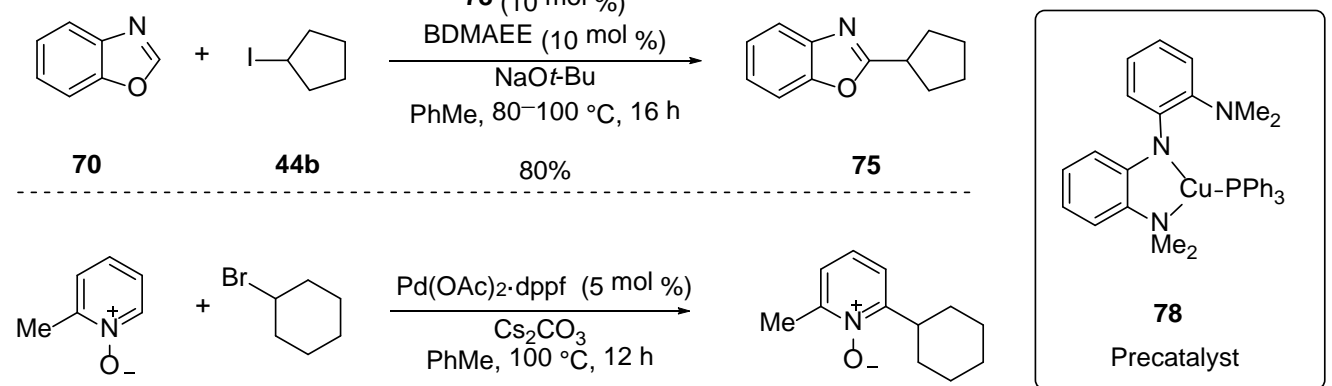

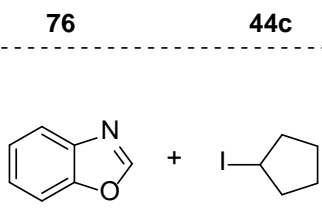

70

$44 b$

$90 \%$

77

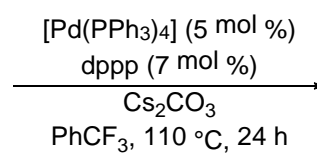

$65 \%$

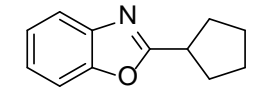

75

Scheme 1.25: Palladium or copper-catalyzed direct alkylation with secondary alkyl halides 44

\section{Norbornene-Mediated Direct C-H Alkylation}

While the electron-rich C3-position of indoles $\mathbf{7 9}$ can be easily alkylated by Friedel-Crafts alkylation, regioselective direct alkylation at $\mathrm{C2}$-position of free $\mathrm{N}-\mathrm{H}$ indoles is not straightforward. As already discussed in Chapter 1.2, Catellani reaction displays unique site-selectivity via manipulation of norbornene. Thus, Bach and co-workers took advantage of this strategy and achieved for the first time direct C2-alkylation of free $\mathrm{N}-\mathrm{H}$ indole derivatives 79 (Scheme 1.26). ${ }^{113}$

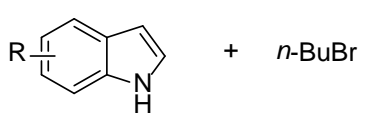

79

42b

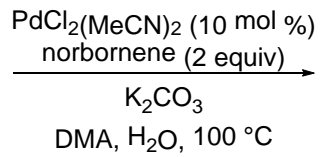

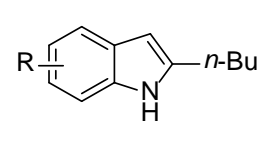

80

Scheme 1.26: Norbornene-mediated direct $\mathrm{C} 2$ alkylation of free $\mathrm{N}-\mathrm{H}$ indoles 79

The C2-alkylation process was originally assumed to initiate by the well-established C3-palladation. However, after comprehensive mechanistic study, Bach and co-workers proposed $\mathrm{N}$-palladation of indole to be the first step. ${ }^{114}$ The synthetic utility of this protocol for 2-alkylation of indoles was also demonstrated by its application in the total synthesis of Aspidosperma alkaloids.

\section{Monodentate Directing Group Assisted Direct C-H Alkylation}

With respect to directing group-assisted $\mathrm{C}-\mathrm{H}$ alkylation, Tremont and co-workers discovered that stoichiometrically palladated acetanilides reacted smoothly with alkyl iodides. ${ }^{115}$ Further investigation achieved a catalytic version of this transformation, albeit with a low turnover number of 1.5 (TON) (Scheme 1.27).

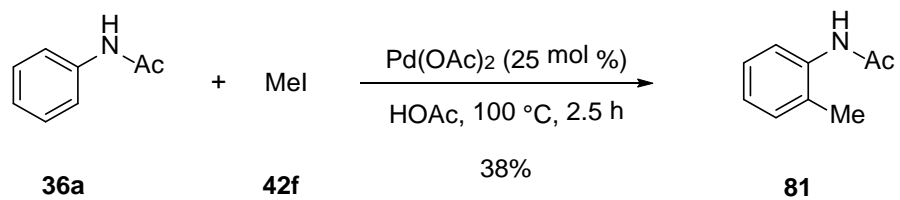

Scheme 1.27: Palladium-catalyzed direct alkylation of acetanilide $\mathbf{3 6} \mathbf{b}$ 
In 2009, Yu and co-workers disclosed palladium-catalyzed direct alkylation of benzoic acids 82 with either 1,2-dichloroethane or dibromomethane (Scheme 1.28). ${ }^{116}$ Mechanistic studies showed that ortho-selective alkylation took place first and subsequent intramolecular $\mathrm{S}_{\mathrm{N}} 2$ cyclization delivered desired lactones 83. Using alkyl bromides and chlorides instead of iodides allowed the catalytic cycle to be closed without using stoichiometric amounts of AgOAc.<smiles></smiles>

82

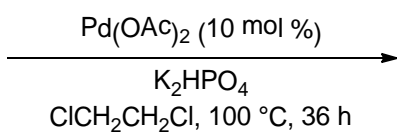

$\mathrm{ClCH}_{2} \mathrm{CH}_{2} \mathrm{Cl}, 100^{\circ} \mathrm{C}, 36 \mathrm{~h}$<smiles></smiles>

83

Scheme 1.28: Palladium-catalyzed direct alkylation of benzoic acids $\mathbf{8 2}$

Besides palladium catalysts, the group of Nakamura developed a cobalt-catalyzed direct alkylation of secondary benzamides 84, an important functional group and structure motif which can be further transformed (Scheme 1.29). ${ }^{117}$ Inexpensive DMPU was used as ligand and the reaction proceeded under very mild conditions.

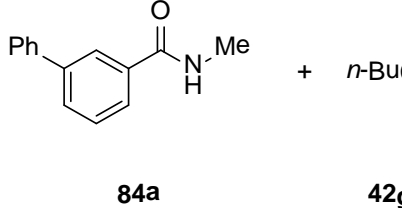

Scheme 1.29: Nickel-catalyzed direct alkylation of secondary benzamide $\mathbf{8 4 a}$

In 2013, the groups of Ackermann and Yoshikai reported cobalt/ $N$-heterocyclic carbene catalytic systems for the ortho-alkylation of arenes $\mathbf{3 8}$ and $\mathbf{8 6}$ with both primary and secondary alkyl chlorides and bromides, independently (Scheme 1.30). ${ }^{118-120} \mathrm{~A}$ radical mechanism was proposed based on the fact that both trans- and cis-isomers of 1-(tert-butyl)-4-cyclohexane afforded products with the same trans/cis isomeric ratio.<smiles>C/C(=N\N=O)c1ccccc1</smiles>

$86 a$<smiles>BrC1CCCCC1</smiles>

$44 c$

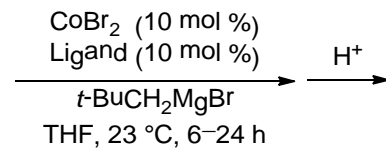

$90 \%$

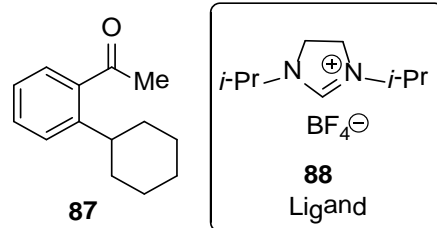

87 Ligand

Scheme 1.30: Cobalt-catalyzed direct alkylation with secondary alkyl bromide 44c

Recently, $Y u$ and co-workers achieved palladium-catalyzed direct $\mathrm{C}\left(\mathrm{sp}^{3}\right)-\mathrm{H}$ alkylation of electron-deficient secondary benzamides 89a with pyridine- and quinoline-based ligands 91 as crucial promoters (Scheme 1.31). ${ }^{121}$ Furthermore, this protocol allowed for the preparation of unnatural amino acids as well. 


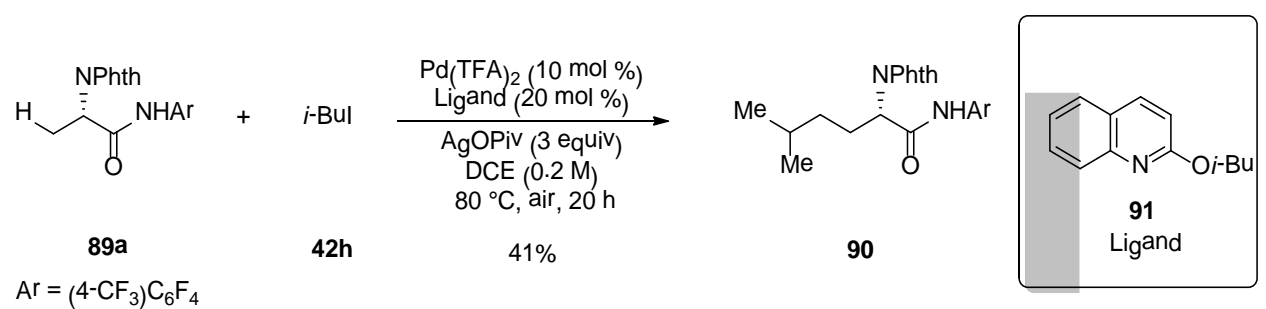

Scheme 1.31: Palladium-catalyzed direct alkylation of $\mathrm{C}\left(\mathrm{sp}^{3}\right)-\mathrm{H}$ bond

\section{Bidentate Directing Group-Assisted Direct C-H Alkylation}

Ever since Daugulis and co-workers' work on utilizing 8-aminoquinoline $(\mathrm{Q})$ and picolinamides (PA) as bidentate directing groups for promoting palladium-catalyzed $\mathrm{C}\left(\mathrm{sp}^{3}\right)-\mathrm{H}$ and $\mathrm{C}\left(\mathrm{sp}^{2}\right)-\mathrm{H}$ arylation of amides, ${ }^{122}$ many research groups have been intensively exploring the potential of this strategy in transition metal-catalyzed C-H bond functionalization. ${ }^{123,124}$

In 2010, the group of Daugulis reported several examples of palladium-catalyzed $\mathrm{C}\left(\mathrm{sp}^{3}\right)-\mathrm{H}$ alkylation of amides 92 assisted by 8-aminoquinoline (Scheme 1.32a). ${ }^{125}$ Shortly thereafter, Chen and co-workers extended the scope of palladium-catalyzed $\mathrm{C}\left(\mathrm{sp}^{2}\right)-\mathrm{H}$ alkylation by picolinamide assistance in substrate 94, various primary alkyl iodides were tolerated and the directing group could easily be cleaved (Scheme 1.32b). ${ }^{126}$ In 2012, Daugulis and co-workers published another method for unnatural amino acid preparation. However, only moderate yields were obtained via this $\mathrm{C}\left(\mathrm{sp}^{3}\right)-\mathrm{H}$ alkylation (Scheme 1.32c). ${ }^{127}$

a)

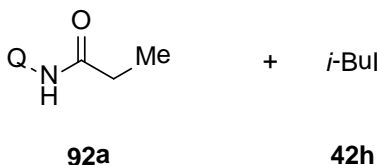

b)

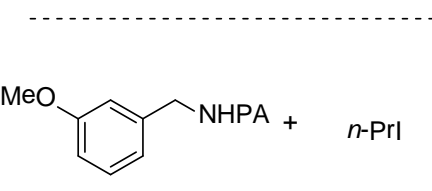

94

c) 42i

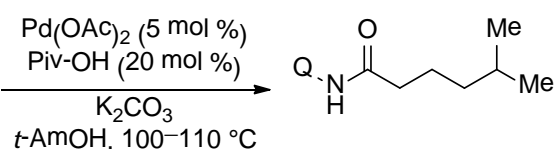

93

$58 \%$

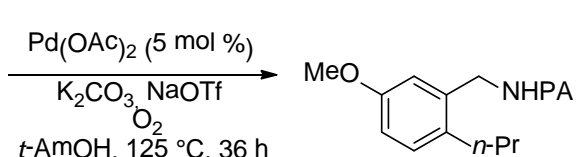

95

95\%

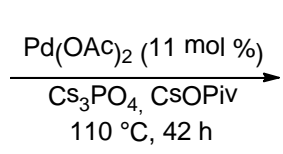

$42 \%$
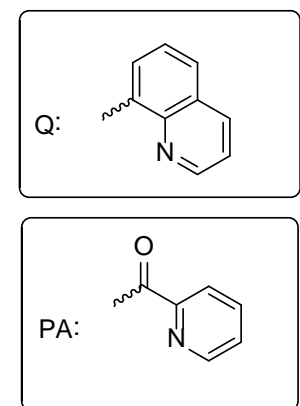

92b

42j

Scheme 1.32: Bidentate DG-assisted palladium-catalyzed direct alkylations

Following their previous publication of direct $\mathrm{C}\left(\mathrm{sp}^{2}\right)-\mathrm{H}$ alkylation, Chen and co-workers disclosed efficient palladium catalyst for the alkylation of $\mathrm{C}\left(\mathrm{sp}^{3}\right)-\mathrm{H}$ bonds of aliphatic amine substrates 97 via picolinamide assistance. ${ }^{128} \mathrm{Ag}_{2} \mathrm{CO}_{3}$ and dibenzyl phosphate $(\mathrm{BnO})_{2} \mathrm{PO}_{2} \mathrm{H}$ were determinant promoters of this reaction (Scheme 1.33a). This research group also succeeded in optimizing Daugulis' work on unnatural amino acids synthesis under essentially the same conditions (Scheme 1.33b). This approach provided a convenient and powerful solution to site-selective incorporation of isotopically labeled moieties into the carbon scaffolds of amino acids. ${ }^{129}$ Similar transformations were also 
reported by the group of Shi..$^{130,131}$
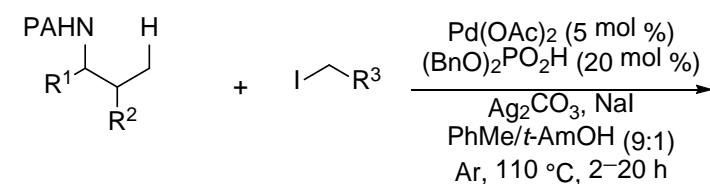

98

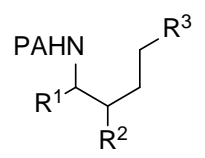

97

99

b)

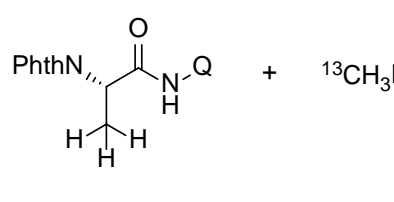

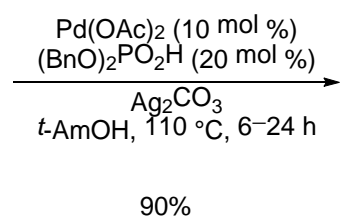

$42 \mathrm{k}$

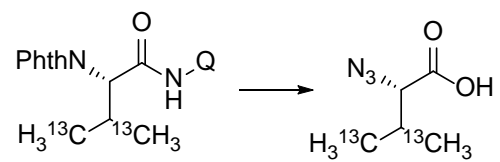

$96 b$
100

Scheme 1.33: Bidentate DG-assisted palladium-catalyzed direct alkylation of $\mathrm{C}\left(\mathrm{sp}^{3}\right)-\mathrm{H}$ bond

Besides palladium, Chatani and co-workers reported the first example of bidentate directing group-assisted nickel-catalyzed $\mathrm{C}-\mathrm{H}$ alkylation of benzamide derivatives 101 (Scheme 1.34a). ${ }^{132} \mathrm{~A}$ variety of functionalized primary alkyl bromides $\mathbf{4 2}$ were applicable in the alkylation reaction. Shortly thereafter, the group of Ackermann successfully utilized challenging secondary alkyl bromides $\mathbf{4 4}$ and trifluoroethyl iodide (42I) in this reaction (Scheme 1.34a). ${ }^{133}$ Furthermore, Ge and co-workers achieved nickel-catalyzed direct alkylation of unactivated $\mathrm{C}\left(\mathrm{sp}^{3}\right)-\mathrm{H}$ bonds with the assistance of 8-aminoquinoline (Scheme 1.34b). ${ }^{134}$ The reaction favored the $\mathrm{C}-\mathrm{H}$ bonds of methyl groups over the methylene $\mathrm{C}-\mathrm{H}$ bonds and tolerated various functional groups. It should be mentioned that inexpensive iron catalysts were also demonstrated to be competent in promoting bidentate directing group-assisted direct $\mathrm{C}-\mathrm{H}$ alkylation of $\mathrm{C}\left(\mathrm{sp}^{2}\right)-\mathrm{H}$ bonds with both primary and secondary alkyl electrophiles, as was independently reported by the groups of Nakamura ${ }^{135}$ and Cook. ${ }^{136,137}$

a)

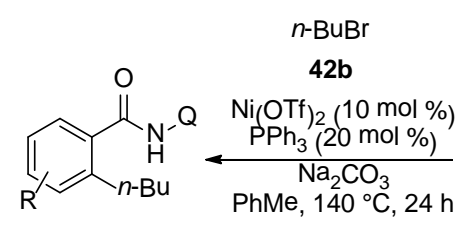

$102 \mathrm{a}$

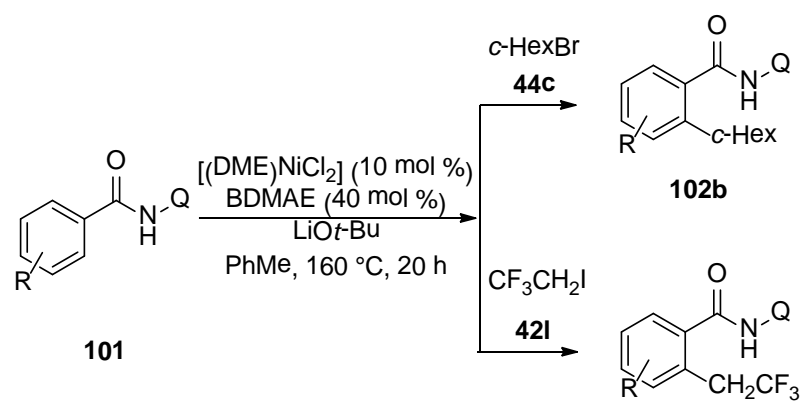

$102 c$ b)

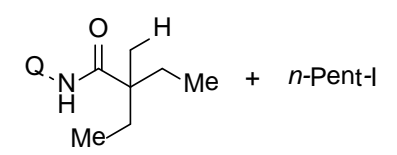

92C

$42 \mathrm{~m}$

$$
\begin{gathered}
\stackrel{\mathrm{Ni}(\mathrm{acac})_{2}(10 \mathrm{~mol} \%)}{\mathrm{dppbz}(10 \mathrm{~mol} \%)} \\
\stackrel{\mathrm{CS}_{2} \mathrm{CO}_{3}}{\text { PhMe, } 150^{\circ} \mathrm{C}, 12-24 \mathrm{~h}}
\end{gathered}
$$

$86 \%$

Scheme 1.34: Bidentate DG-assisted nickel-catalyzed direct alkylation

\section{Ruthenium(II)-Catalyzed Direct C-H Alkylation}

Based on their research on carboxylate-assisted ruthenium(II)-catalyzed direct arylations, ${ }^{138,139}$ Ackermann and co-workers successfully extended this catalytic system to unprecedented ruthenium(II)-catalyzed direct $\mathrm{C}-\mathrm{H}$ alkylation and benzylation of 2-phenylpyridines $38 .{ }^{140,141} \mathrm{Among}$ various screened carboxylates, sterically bulky $1-\mathrm{AdCO}_{2} \mathrm{H}$ proved to be the most efficient. Primary 
alkyl iodides, bromides, chlorides served as viable substrates, while alkyl bromides 42 e provided the best yields (Scheme 1.35a).

a)

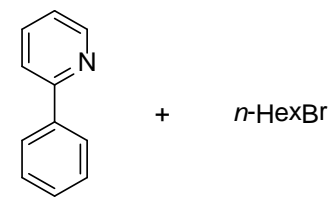

$38 a$

$42 e$

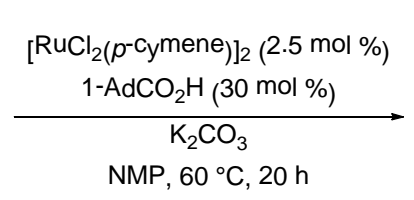

$73 \%$

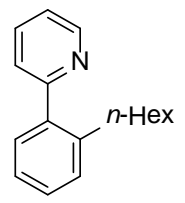

$103 a$

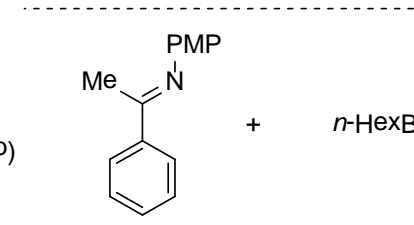

$86 a$

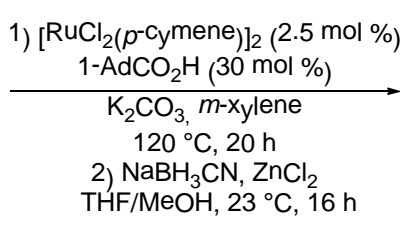

$73 \%$<smiles>CC(NP)c1ccccc1PC=[W]</smiles>

104

Scheme 1.35: Ruthenium(II)-catalyzed direct alkylation with primary alkyl halide $\mathbf{4 2 e}$

Furthermore, aromatic ketimines $\mathbf{8 6}$ could also be efficiently alkylated, which was exploited for the synthesis of secondary amines 104 through a sustainable one-pot-process (Scheme 1.35b). Further investigation by performing this direct alkylation in water yielded meta-alkylated by-product 105a (Scheme 1.36), ${ }^{142}$ This meta-alkylation took place under solvent-free reaction conditions as well, albeit in low yields.<smiles>COc1ccc(-c2ccccn2)cc1</smiles>

$38 b$

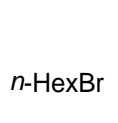

$42 \mathrm{e}$

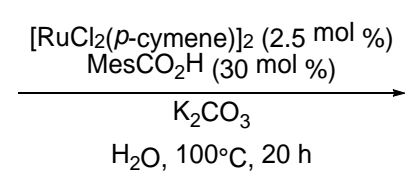

$\mathrm{H}_{2} \mathrm{O}, 100^{\circ} \mathrm{C}, 20 \mathrm{~h}$

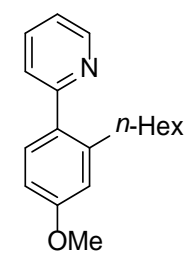

103b: $45 \%$

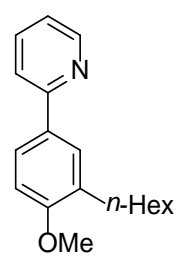

105a: $7 \%$

Scheme 1.36: Preliminary observation of ruthenium(II)-catalyzed direct meta-alkylation

Based on the mechanistic studies, a catalytic cycle proposed by Ackermann and co-workers is shown below in Scheme 1.37. This catalytic cycle initiated with the formation of a ruthenium(II) carboxylate complex 106, which reversibly activated the ortho- $\mathrm{C}-\mathrm{H}$ bond through carboxylate-assisted deprotonation (109) to form cyclometalated intermediate 108. Thereafter, complex 108 reacted with primary alkyl halides 42 via formal oxidative addition to yield intermediate 109. Finally, reductive elimination regioselectively gave rise to the alkylated arene 110, and thereby regenerated the active catalyst 106. 


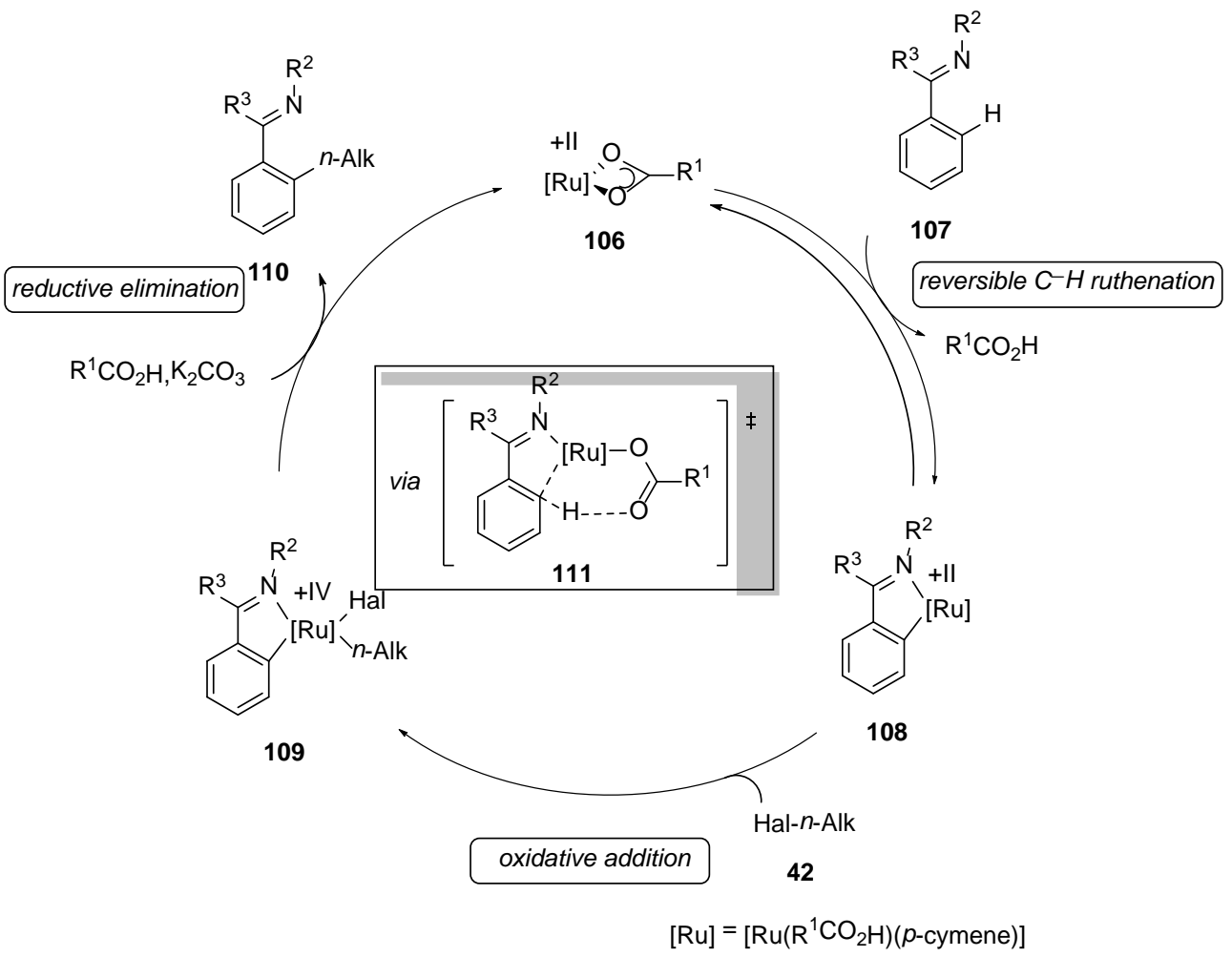

Scheme 1.37: Proposed catalytic cycle for ruthenium(II)-catalyzed direct alkylation

However, shortly thereafter, Ackermann and Hofmann demonstrated that meta-alkylation products can be isolated in high yields by using secondary alkyl halides $44 .^{143}$ The direct alkylations occurred under mild conditions with ample scope and tolerated valuable functional groups (Scheme 1.35).<smiles>c1ccc(-c2ccccc2)cc1</smiles>

$38 a$

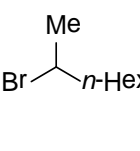

$44 d$

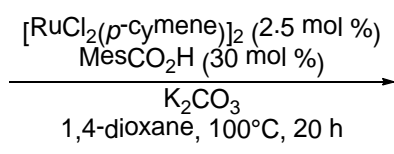

$60 \%$<smiles>CC(C)OCC(C)c1cccc(-c2ccccn2)c1</smiles>

$105 b$

Scheme 1.38: Ruthenium(II)-catalyzed direct meta-alkylation with secondary alkyl halide 44d

Concerning the mechanism, the authors proposed that cyclometalation activated the arene for a $S_{E}$ Ar-type alkylation with the secondary alkyl halides through the strong directing group effect of the $\mathrm{Ru}-\mathrm{C} \sigma$-bond, thus leading to a functionalization in the para- or ortho-position with respect to the $\mathrm{Ru}-\mathrm{C}$ bond. The detailed mechanism will be discussed in Chapter 3.1.

\subsection{Transition Metal-Catalyzed Oxidative C-H Alkenylation}

Encouraged by the need for green and sustainable chemistry, ${ }^{144}$ synthetic chemists are constantly seeking more efficient ways to construct $\mathrm{C}-\mathrm{C}$ bonds, the essential link in all organic molecules. In the early 1970s, Mizoroki ${ }^{10}$ and Heck ${ }^{11}$ disclosed palladium-catalyzed C-C bond forming reaction between an aryl halide and an alkene (see above). In fact, before achieving insertion of palladium into $\mathrm{Ar}-\mathrm{X}$ bond under catalytic condition, Heck also performed in situ synthesis of ArPdX complexes from 
palladium salts and aryl-metal complexes in the late 1960s. ${ }^{145,146}$ However, both methods produce stoichiometric amounts of byproducts. In consideration of the atom economy principle, ${ }^{147}$ direct C-C bond formation from two $\mathrm{C}-\mathrm{H}$ bonds would be the most promising approach.

In this context, in 1967 Fujiwara and Moritani achieved the synthesis of stilbene employing the reaction of the styrene- $\mathrm{PdCl}_{2}$ complex with benzene ${ }^{148}$ and, in 1968, the oxidative coupling between styrene $\mathbf{1 5}$ and benzene $\mathbf{4 1}$ with two turnovers of palladium. ${ }^{149}$ Shortly thereafter, they reported a catalytic version of this reaction (Scheme 1.39). ${ }^{150}$

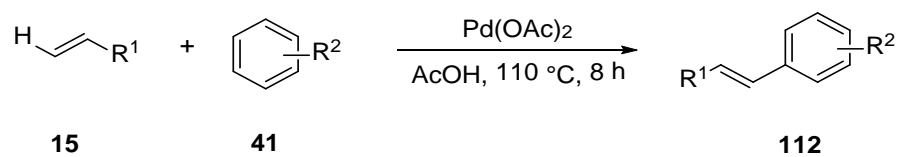

Scheme 1.39: Palladium-catalyzed Fujiwara-Moritani reaction

Since Fujiwara and Moritani's seminal work, enormous efforts have been devoted to optimizing and extending the scope of this reaction. ${ }^{26,151}$ In 2002, the groups of de Vries and van Leeuwen reported an exceptionally mild Fujiwara-Moritani reaction which employed anilide directing groups to control reactivity and site-selectivity (Scheme 1.40). The addition of $\mathrm{TsOH}$ played an important role in improving the reactivity, which was believed to increase the electrophilicity of the palladium catalyst and thus to facilitate $\mathrm{C}-\mathrm{H}$ palladation. ${ }^{152}$<smiles>C=CC(=O)OCCC</smiles>

$36 \mathrm{~b}$

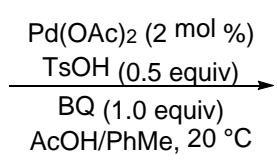

$91 \%$<smiles>CCCOC(=O)/C=C/c1ccc(C)cc1NC(C)=O</smiles>

113

Scheme 1.40: Palladium-catalyzed direct alkenylation of anilide 36b

In 2010, $Y u$ and co-workers disclosed the oxidative coupling between phenylacetic acid derivatives 114 and alkenes 15 (Scheme 1.41). ${ }^{153}$ Weak coordination between $\mathrm{C}=\mathrm{O}$ bond of the carboxylate and $\mathrm{Pd}(\mathrm{OAC})_{2}$ was proposed to facilitate the ortho- $\mathrm{C}-\mathrm{H}$ functionalization. Notably, introducing mono-protected amino acids (MPAAs) 116 as ligands enhanced both site-selectivity and reactivity. Electron-deficient substrates $\mathbf{1 1 4}$, which were previously inactive, could then undergo facile olefination.
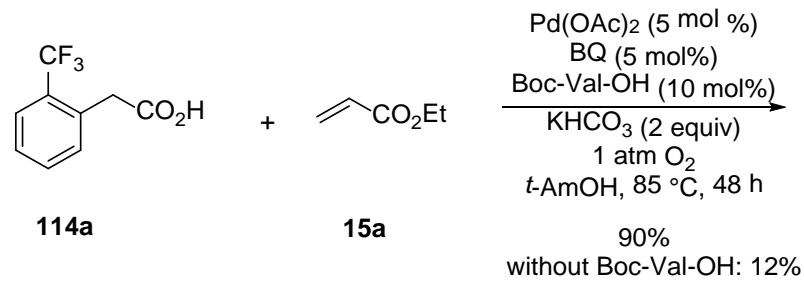<smiles>CCOC(=O)/C=C/c1cccc(C(F)(F)F)c1CC(=O)O</smiles>

$115 a$

Scheme 1.41: Palladium-catalyzed direct alkenylation of phenylacetic acid 114a

Moreover, MPAAs 116 are not only limited to enhance the reaction rate and regioselectivity, but can also function as chiral ligand to control enantioselectivity. ${ }^{154,155} \mathrm{Yu}$ and coworkers demonstrated that alkenylation of diphenylacetate sodium salt $\mathbf{1 1 4 b}$ was accompanied by desymmetrization to afford 
product 115b with modest to excellent enantioselectivities (Scheme 1.42).<smiles>CC(C)(C(=O)Nc1ccccc1)c1ccccc1</smiles>

$114 b$

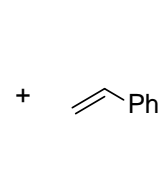

$15 \mathrm{c}$

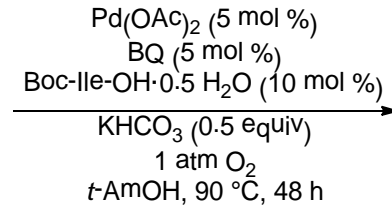

$73 \%$ yield, $97 \%$ ee<smiles>CC(C(=O)O)(c1ccccc1)c1ccccc1/C=C/c1ccccc1</smiles>

$115 b$

Scheme 1.42: Enantioselective palladium-catalyzed oxidative $\mathrm{C}-\mathrm{H}$ alkenylation

Subsequently, $\mathrm{Yu}$ and co-workers achieved the challenging $\mathrm{C}\left(\mathrm{sp}^{3}\right)-\mathrm{H}$ bond alkenylation of aliphatic secondary amides 89 (Scheme 1.43). ${ }^{156}$ As regards the mechanism, initial formation of a five-membered palladacycle assisted by amide directing group was proposed. LiCl served as a source of chloride anions which stabilized palladium( 0$)$ and facilitated the formation of chloride-bridged bimetallic palladium species.

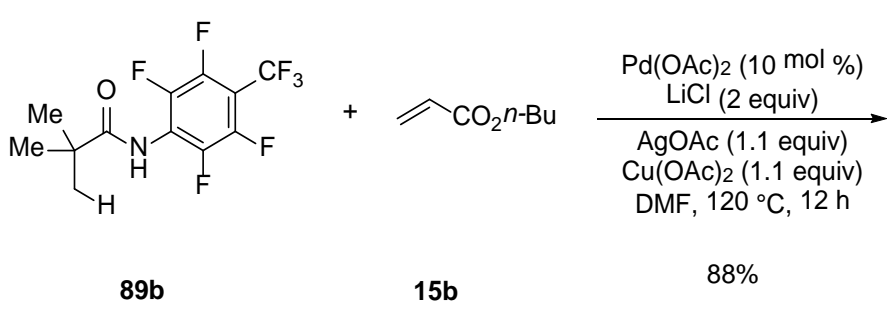

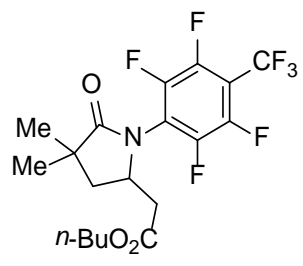

117

Scheme 1.43: Palladium-catalyzed direct alkenylation of $\mathrm{C}\left(\mathrm{sp}^{3}\right)-\mathrm{H}$ bond

Besides palladium, other transition metal catalysts have been reported for enabling the oxidative $\mathrm{C}-\mathrm{H}$ alkenylation reactions as well. In recent years, great effort has been devoted to rhodium-catalyzed oxidative $\mathrm{C}-\mathrm{H}$ alkenylation. ${ }^{157,158}$ Despite the relatively high cost of rhodium catalysts, it is still of major interests owing to the high efficiency, reactivity, and functional group tolerance.

An early contribution by Matsumoto, Yoshida, and coworkers achieved rhodium-catalyzed oxidative $\mathrm{C}-\mathrm{H}$ olefination of benzene with ethylene. ${ }^{159}$ In 2007, Satoh and Miura reported an example of rhodium-catalyzed $\mathrm{C}\left(\mathrm{sp}^{2}\right)-\mathrm{H}$ bond alkenylation (Scheme 1.44$) .{ }^{160}$ At low catalyst loadings, the olefination of benzoic acid 82a resulted in ortho-alkenylated lactone 118a, which arose from di-ortho-substitution and subsequent intramolecular oxa-Michael addition.
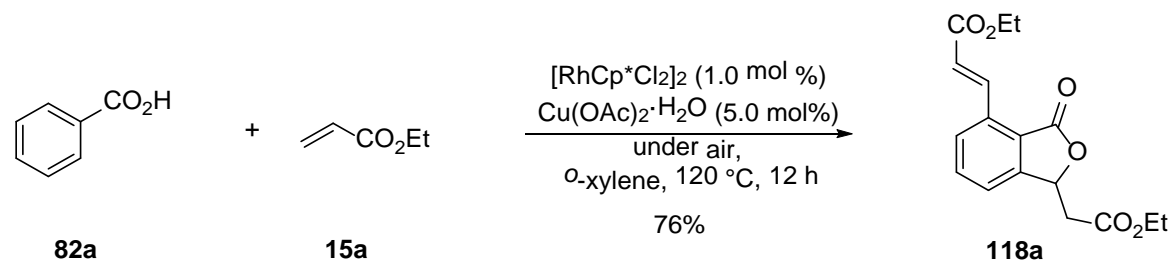

Scheme 1.44: Rhodium-catalyzed C-H alkenylation of benzoic acid (82a)

Patureau and Glorius reported a related rhodium-catalyzed ortho-alkenylation of anilides $\mathbf{3 6}$ using an in-situ generated cationic rhodium complex (Scheme 1.45). ${ }^{161}$ Comparing to palladium catalysts, lower catalyst loadings, good functional group tolerance and higher reactivity of electron-neutral olefins were realized. Under elevated pressure, ethylene reacted to yield the corresponding 
acetanilido-substituted styrene in moderate yield.

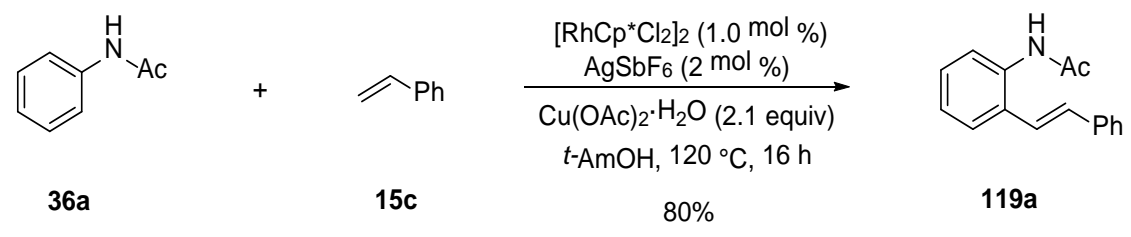

Scheme 1.45: Rhodium-catalyzed C-H alkenylation of anilide 36a

In contrast, significantly less expensive, yet highly reactive ruthenium catalysts have only recently been developed for facilitating oxidative C-H bond alkenylations on arenes. ${ }^{162}$ In 2001, Milstein and co-workers reported an example of synthesizing styrene derivatives (112a) via ruthenium-catalyzed oxidative coupling of arenes (41a) with olefins (Scheme 1.46). ${ }^{163}$ Whereas a range of ruthenium complexes, such as $\mathrm{RuCl}_{3} \cdot \mathrm{H}_{2} \mathrm{O}, \quad\left[\mathrm{Ru}(\mathrm{CO})_{3} \mathrm{Cl}_{2}\right]_{2}, \quad\left[\left(\eta^{6}-\mathrm{C}_{6} \mathrm{H}_{6}\right) \mathrm{RuCl}_{2}\right]_{2}, \quad \mathrm{Ru}(\mathrm{NO}) \mathrm{Cl}_{3} \cdot 5 \mathrm{H}_{2} \mathrm{O}$ and $\mathrm{Ru}\left(\mathrm{F}_{3} \mathrm{CCOCHCOCF}_{3}\right)_{3}$, enabled similar catalytic reactivities, yet $\mathrm{Ru}_{3}(\mathrm{CO})_{12}$ exhibited low efficiency. Carbon monoxide was proposed to stabilize a cationic ruthenium species, and a value of KIE $\approx 2$ was established with substrates $\mathrm{C}_{6} \mathrm{H}_{6}(41 \mathrm{a})$ and $\mathrm{C}_{6} \mathrm{D}_{6}$, indicating the $\mathrm{C}-\mathrm{H}$ bond metalation to be the rate-determining step. Unfortunately, low reactivity of the simple alkenes as well as the low regioselectivity limited this approach for practical application. Furthermore, this strategy was limited by the high temperature and high pressure of molecular oxygen and carbon monoxide.

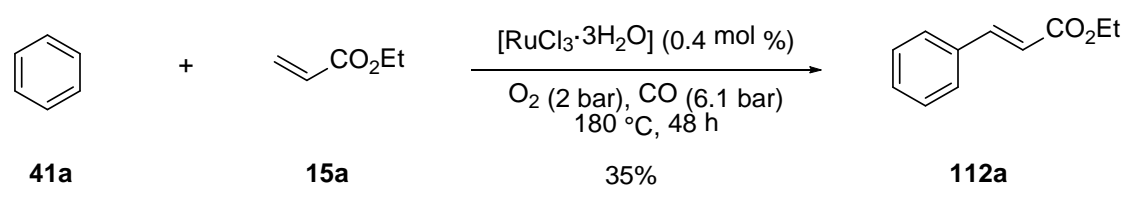

Scheme 1.46: Ruthenium-catalyzed C-H alkenylation of simple arene 41a

Fortunately, this limitation of low selectivity observed in alkenylations of simple arenes was successfully addressed by employing substrates with directing groups for chelating assistance. In 2010, the group of $Y i$ reported on oxidative $\mathrm{C}-\mathrm{H}$ alkenylation of benzamide derivatives $\mathbf{1 2 0}$ with unactivated alkenes (15d) enabled by cationic ruthenium hydride complex $\left[\left(\eta^{6}-\mathrm{C}_{6} \mathrm{H}_{6}\right)\left(\mathrm{PCy}_{3}\right)(\mathrm{CO}) \mathrm{RuH}^{+} \mathrm{BF}_{4}{ }^{-}\right.$(123) (Scheme 1.47). ${ }^{164}$ In contrast to previous work of the Milstein group, a negligible KIE of 1.1 was observed for the competition reaction between $\mathrm{C}_{6} \mathrm{H}_{5} \mathrm{C}(\mathrm{O}) \mathrm{NEt}_{2}(\mathbf{1 2 0 \mathrm { a }})$ and its deuterated analogue $\mathrm{C}_{6} \mathrm{D}_{5} \mathrm{C}(\mathrm{O}) \mathrm{NEt}_{2}$, thus suggesting a reversible arene $\mathrm{C}-\mathrm{H}$ bond metalation step. In the absence of an external oxidant, an excess of alkene $\mathbf{1 5}$ as well as the alkenylated product $\mathbf{1 2 1}$ served as the hydrogen scavenger. Unfortunately, participation of $\mathbf{1 2 1}$ led to a mixture of the products $\mathbf{1 2 1}$ and $\mathbf{1 2 2}$.

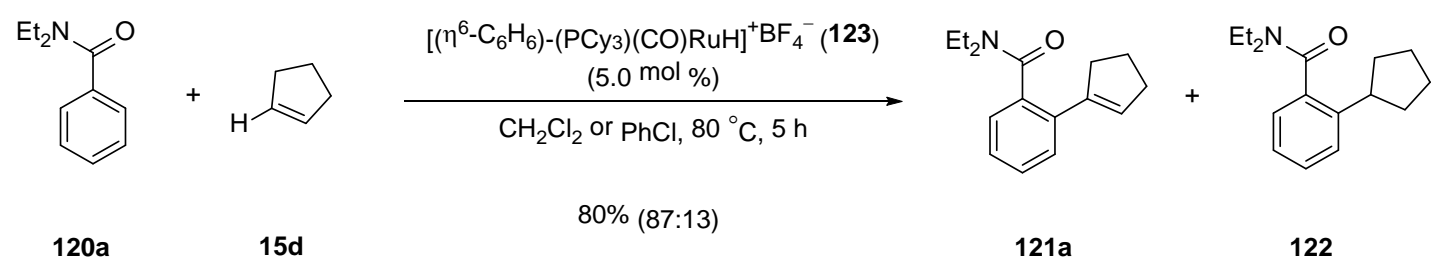

Scheme 1.47: Ruthenium-catalyzed C-H alkenylation of benzamide $120 \mathrm{a}$

In 2011, Ackermann and Pospech disclosed the lactone synthesis via ruthenium(II)-catalyzed oxidative 
$\mathrm{C}-\mathrm{H}$ bond alkenylation of benzoic acids 82 with acrylates or acrylonitrile (15e) in water (Scheme 1.48a). ${ }^{165}$ With stoichiometric amounts of $\mathrm{Cu}(\mathrm{OAc})_{2} \cdot \mathrm{H}_{2} \mathrm{O}$ as the oxidant, the reaction proceeded smoothly under mild reaction conditions. The ortho-alkenylated intermediate underwent immediate intramolecular oxa-Michael reaction and delivered lactone derivatives $\mathbf{1 1 8}$ in good yields.

a)<smiles>Cc1ccccc1C(=O)O</smiles>
82b

b)<smiles>O=C(Nc1ccccc1)c1ccccc1</smiles>

84b

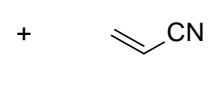

$15 e$

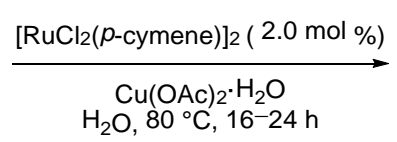

95\%<smiles>Cc1cccc2c1C(=O)OC2CC#N</smiles>
$118 b$

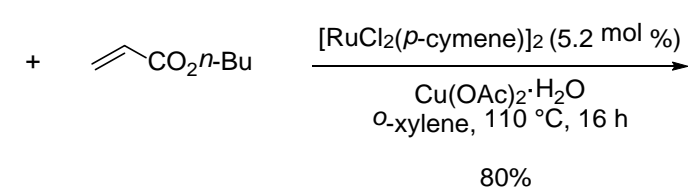

$15 b$

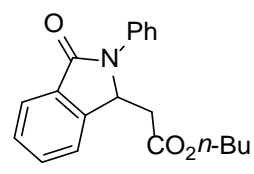

$124 a$

Scheme 1.48: Ruthenium(II)-catalyzed C-H alkenylation of benzoic acid (82b) and benzanilide (84b)

A similar phenomenon was observed by the groups of Satoh/Miura and Ackermann in the ruthenium(II)-catalyzed oxidative alkenylation of benzanilide (84b) (Scheme $1.48 \mathrm{~b}$ ). ${ }^{166}$ Indeed, the initially formed alkenylated derivative underwent intramolecular Michael reaction to give bicyclic benzamide 124a.

Subsequently, ruthenium(II)-catalyzed oxidative alkenylation of various amide derivatives were studied (Scheme 1.49). Satoh, Miura and co-workers demonstrated the oxidative alkenylation of $\mathrm{N}, \mathrm{N}$-dimethylbenzamide $(\mathbf{1 2 0 c})$ in the presence of co-catalytic $\mathrm{AgSbF}_{6},\left[\mathrm{RuCl}_{2}(p \text {-cymene) }]_{2}\right.$ and $\mathrm{Cu}(\mathrm{OAc})_{2} \cdot \mathrm{H}_{2} \mathrm{O} \cdot{ }^{167}$ Notably, no reaction would occur in the absence of the silver salt. $\mathrm{Li}$ and co-workers achieved alkenylation of cyclic $\mathrm{N}$-protected isoquinolones $120 \mathrm{~b}$ under similar reaction conditions. ${ }^{168}$ The Ackermann group showed that the use of less expensive $\mathrm{KPF}_{6}$ instead of $\mathrm{AgSbF}_{6}$ enabled olefination of $\mathrm{N}$-monosubstituted benzamides $84 \mathrm{c}$ using environmentally benign water as solvent. ${ }^{169}$ Moreover, this approach was not limited to aromatic amides. Ruthenium(II)-catalyzed oxidative alkenylation of acrylamines (125a) was also developed by Zhang and $\mathrm{Loh}^{170}$ and moderate to good yields and excellent site-selectivity were obtained. 


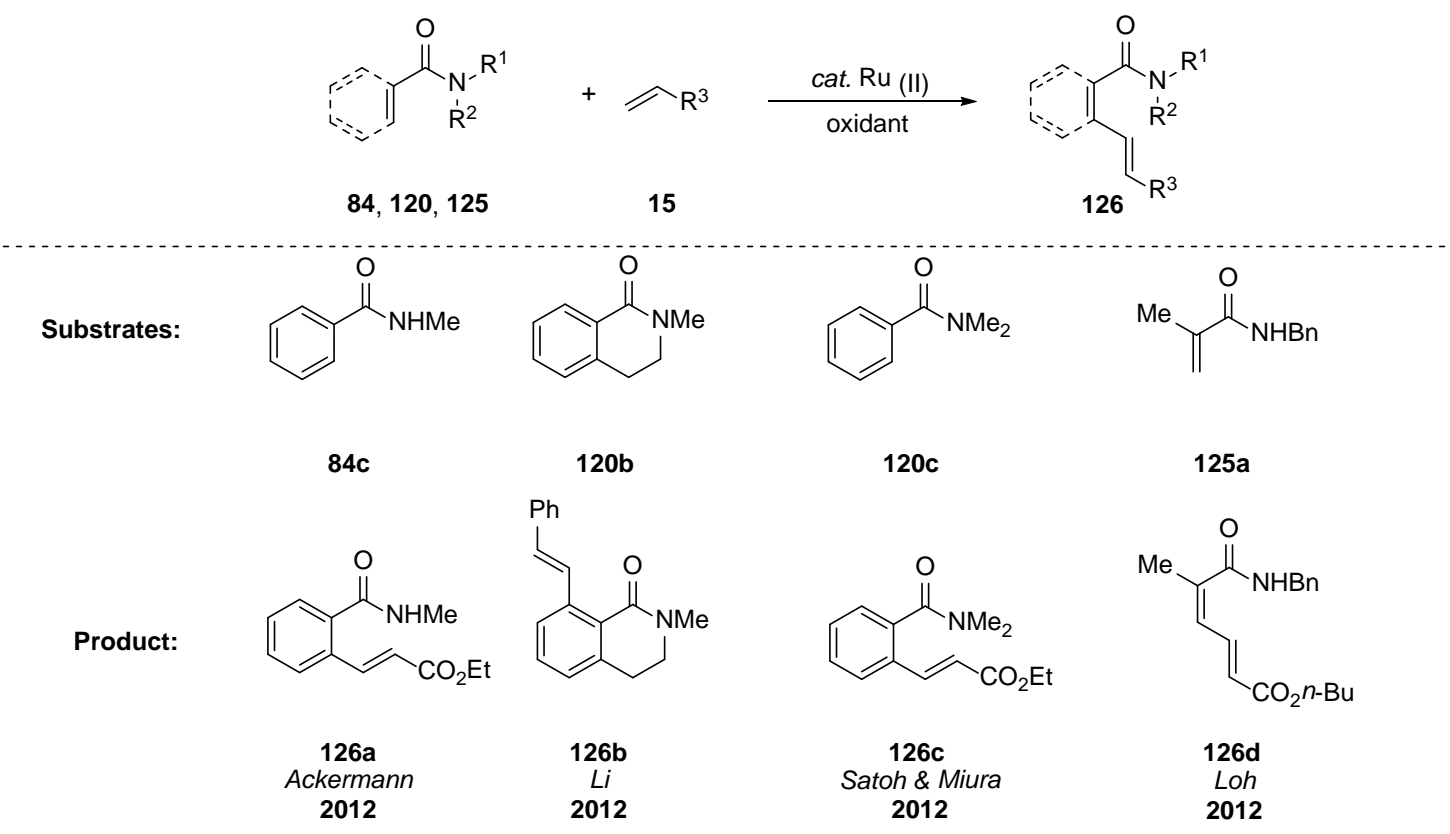

Scheme 1.49: Ruthenium(II)-catalyzed C-H alkenylation of benzamide derivatives

Alternatively, ruthenium(II)-catalyzed $\mathrm{C}-\mathrm{H}$ alkenylation of benzamides could be realized without external oxidant. Pre-functionalized starting materials bearing an internal oxidizing directing groups such as $\mathrm{N}$-methoxybenzamide $(\mathbf{1 2 7 a})^{171}$ and $\mathrm{N}$-hydroxybenzamides ${ }^{172}$ smoothly delivered olefinated $\mathrm{N}$-deprotected benzamide (128) (Scheme 1.50).

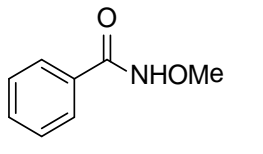

$127 a$

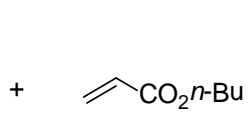

$15 b$

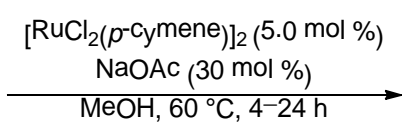

$87 \%$<smiles>CCOC(=O)/C=C/c1ccccc1C(N)=O</smiles>

128

Scheme 1.50: Ruthenium(II)-catalyzed C-H alkenylation of $\mathrm{N}$-methoxybenzamide (127a)

In addition to chelation-assisted olefination of benzamides, the groups of Ackermann and Jeganmohan independently studied ruthenium(II)-catalyzed oxidative alkenylation of readily available, yet weakly coordinating ${ }^{21}$ esters, ${ }^{173,174}$ and phenones. ${ }^{175}$ Thus, a catalytic system consisting of $\left[\mathrm{RuCl}_{2}(p \text {-cymene })\right]_{2}, \mathrm{AgSbF}_{6}$, and co-catalytic amounts of $\mathrm{Cu}(\mathrm{OAc})_{2} \cdot \mathrm{H}_{2} \mathrm{O}$ utilizing air as terminal oxidant allowed for efficient aerobic $\mathrm{C}-\mathrm{H}$ bond alkenylations of aryl esters, phenones $129\left(\mathrm{R}^{2}=\right.$ OAlk, Alk, respectively) utilizing air as a terminal oxidant (Scheme 1.51). Most recently, Loh and coworkers disclosed ruthenium(II)-catalyzed oxidative cross-coupling of acrylates. This protocol offered a straightforward and atom-economical synthesis of functionalized $(Z, E)$-muconate derivatives with good stereo- and chemo-selectivities. ${ }^{176}$<smiles>[R]C(=O)c1ccccc1</smiles>

129

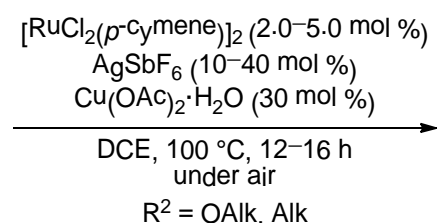

$\mathrm{R}^{2}=$ OAlk, Alk<smiles></smiles>

130

Scheme 1.51: Ruthenium(II)-catalyzed C-H alkenylation of esters, phenones and aldehydes 129 
Moreover, not only arenes bearing electron-withdrawing groups, but also electron-rich substrates could undergo facile alkenylation under ruthenium(II) catalysts. In 2012, Ackermann and co-workers reported on the first ruthenium(II)-catalyzed oxidative alkenylation of anilides $\mathbf{3 6}$ with alkenes $\mathbf{1 5}$ in water (Scheme 1.52). ${ }^{169}$ Intramolecular competition experiments with $\mathrm{N}$-benzoyl anilides delivered solely alkenylated products on the benzamide moieties.

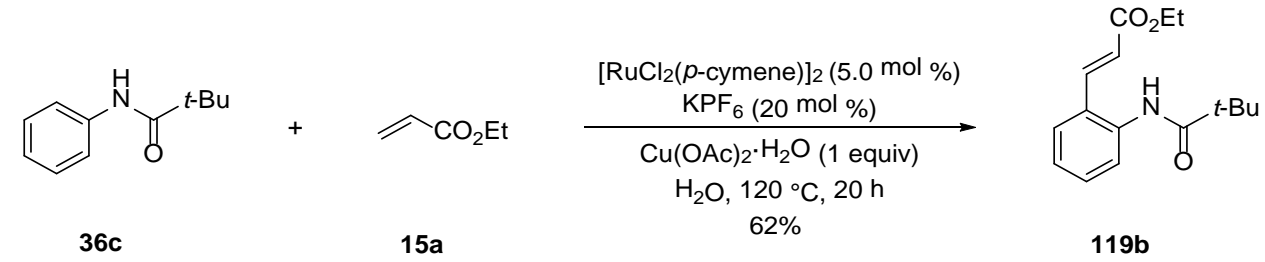

Scheme 1.52: Ruthenium(II)-catalyzed C-H alkenylation of anilide 36c

Ruthenium(II)-catalyzed oxidative alkenylation of arenes also proved viable by utilizing heterocyclic directing groups (Scheme 1.53). N-Arylpyrazoles $131,{ }^{166,177}$ 2-arylimidazoles $\mathbf{1 3 2}^{167}$ were demonstrated to be suitable substrates by the groups of Dixneuf, Bolm, Satoh and Miura. It should be mentioned that Ackermann and Ma reported on the ruthenium(II)-catalyzed oxidative olefination of phenol derivatives 133 bearing a pyridine directing group which can easily be removed. ${ }^{178}$ Recently, the groups of Liu and Ackermann disclosed ruthenium(II)-catalyzed oxidative alkenylation of arenes 134 and 135 assisted by 1,2,3-triazole directing group. ${ }^{179-181}$
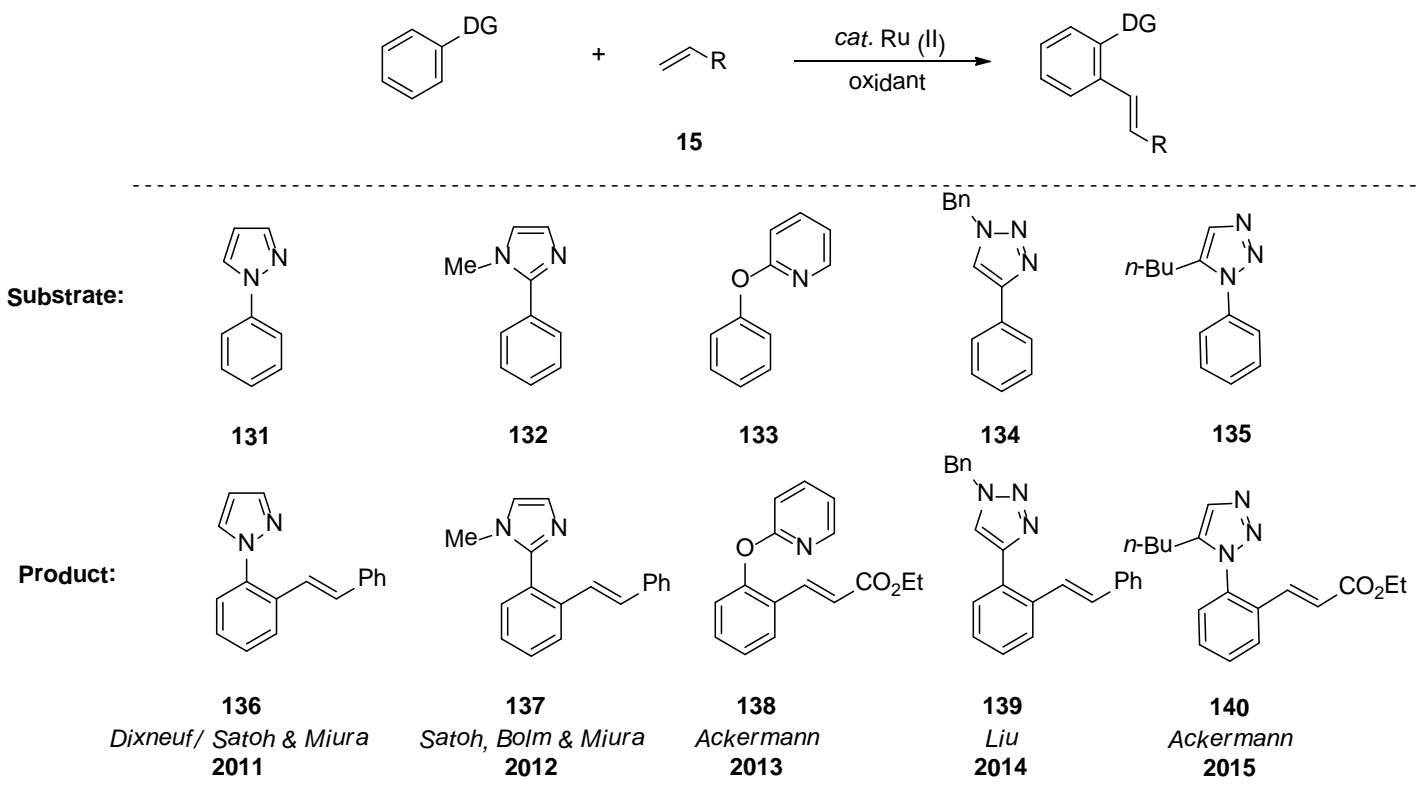

Scheme 1.53: Ruthenium(II)-catalyzed C-H alkenylations directed by heterocyclic DGs

Ruthenium(II)-catalyzed oxidative alkenylations of heterocyclic compounds were achieved with assistance of various directing groups employing the catalytic system described above, albeit with different catalytic efficacies. Thus, Satoh, Miura and co-workers disclosed carboxylic acid-directed ruthenium(II)-catalyzed oxidative alkenylation of thiophenes, benzothiophenes, benzofurans, pyrroles, and indoles. ${ }^{182}$ Subsequently, the groups of Prabhu and Wang reported on the ruthenium(II)-catalyzed C-2 alkenylation of indoles using either $N$-benzoyl ${ }^{183}$ or $N$-carbamoyl (79a) ${ }^{184}$ moiety as a directing group, respectively (Scheme 1.54). 


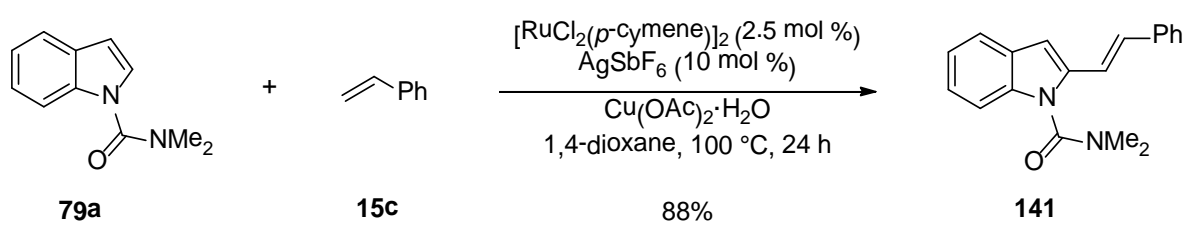

Scheme 1.54: Ruthenium(II)-catalyzed C-H alkenylation of $\mathrm{N}$-carbamoylindole 79a

Most recently, novel and synthetically useful directing groups have been utilized for ruthenium(II)-catalyzed oxidative alkenylations (Scheme 1.55). For instance, Ackermann and co-workers achieved direct $\mathrm{C}-\mathrm{H}$ olefination of amidines $142^{185}$ and of sulfonic acids $143 .{ }^{186}$ The group of Satoh and Miura disclosed free amino group-directed ortho-alkenylation and successive cyclization to produce (isoindol-1-yl)acetic acid derivatives 150. ${ }^{187}$ Azoxybenzenes 145 also underwent smooth oxidative alkenylation under ruthenium(II) catalysis. ${ }^{188}$ The group of Greaney reported on the cascade $\mathrm{C}-\mathrm{H}$ bond functionalization based on ruthenium(II)-catalyzed oxidative alkenylation. ${ }^{189}$ 1-Indanones 152, indeno-indenes, and indeno-furanones became accessible via this approach. Moreover, Jeganmohan and co-workers demonstrated a highly regio- and stereoselective synthesis of (Z)-3-methyleneisoindolin-1-ones $\mathbf{1 5 3}$ by ruthenium(II)-catalyzed annulation of aromatic nitrile 147a. ${ }^{190}$
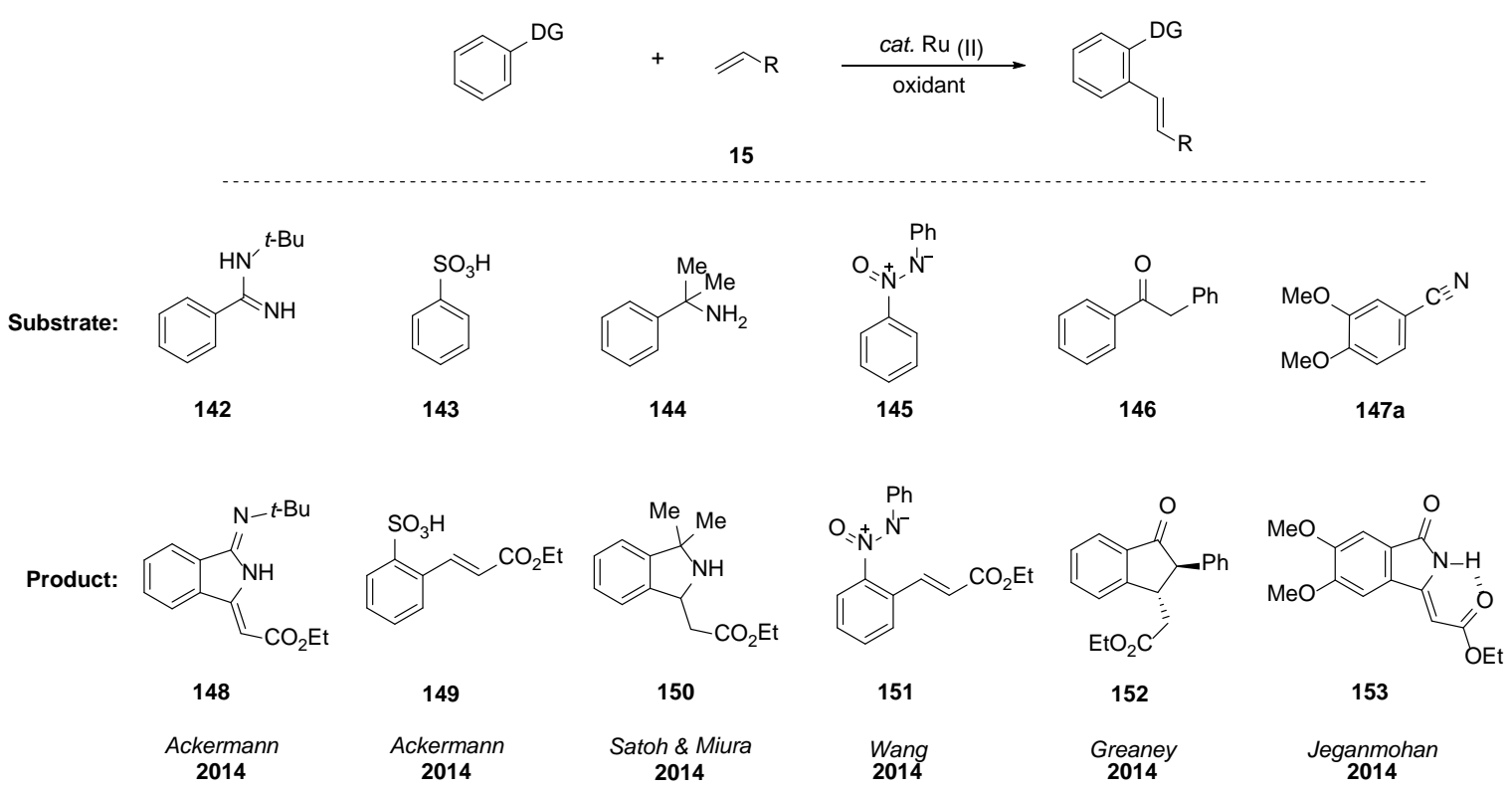

Scheme 1.55: Recent examples of ruthenium(II)-catalyzed oxidative $\mathrm{C}-\mathrm{H}$ alkenylation

\subsection{Transition Metal-Catalyzed Alkyne Annulations by $\mathrm{C}-\mathrm{H} /$ Het-H Functionalizations}

Aromatic heterocycles represent structural motifs which can be found in a great number of biologically active natural and synthetic compounds, pharmaceuticals, and agrochemicals. ${ }^{191}$ Moreover, aromatic heterocycles are widely used for synthesis of polymeric materials and dyes of high value. Chemists have been making great effort towards preparation of these heterocyclic compounds for decades. Among a variety of new synthetic methodologies, transition metal-catalyzed reactions are of particular interests for direct constructions of complex structures from readily 
accessible starting materials. ${ }^{192-194}$ Inspired by the traditional cross-coupling chemistry, palladium-catalyzed processes have emerged as a powerful tool in heterocycle synthesis, ${ }^{195,196}$ among which, the Larock indole-synthesis is extremely versatile and can be utilized in preparing a variety of indole derivatives 79 (Scheme 1.56). ${ }^{197}$ However, the same as in the traditional cross-coupling chemistry requirement of prefunctionalized starting materials, discussed above in Chapter 1.1, represents the major disadvantage of this approach.

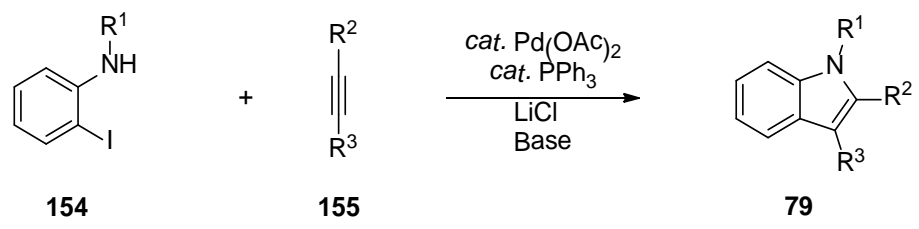

Scheme 1.56: Larock indole synthesis

Along with the rapid development of various transition metal-catalyzed $\mathrm{C}-\mathrm{H}$ bond functionalization methods, more attention have been drawn to apply these methodologies into synthesis of natural products and pharmaceuticals. ${ }^{198-200}$

In this context, the group of Miura and Satoh reported the rhodium-catalyzed annulation of benzoic acids 82 with internal alkynes 155, a variety of isocoumarin derivatives 156 were prepared using this method (Scheme 1.57). ${ }^{160,201}$

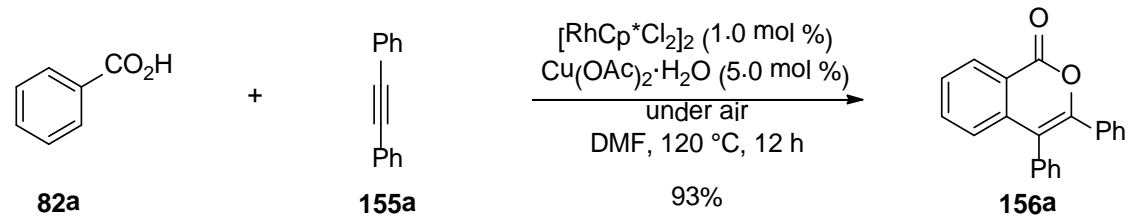

Scheme 1.57: Rhodium-catalyzed oxidative annulation with benzoic acid (82a)

Shortly thereafter, Fagnou and co-workers published a rhodium-catalyzed indole synthesis through $\mathrm{C}-\mathrm{H} / \mathrm{N}-\mathrm{H}$ bond functionalizations (Scheme 1.58). ${ }^{202}$ Acetanilides 36 underwent insertion of internal alkynes 155 through initial $\mathrm{C}-\mathrm{H}$ bond activation followed by oxidative annulation to produce substituted indoles 79. Subsequently, heterocycle synthesis employing rhodium catalysis has been extensively studied by the groups of Glorius, Fagnou, and Miura and Satoh, among others. ${ }^{157,203,204}$

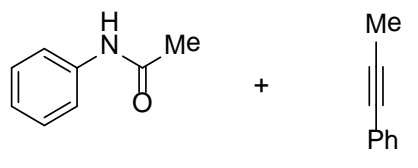

$36 \mathbf{a}$
$155 b$

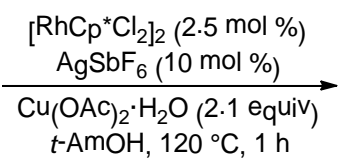

$79 \%$<smiles>Cc1c(-c2ccccc2)n(C(Cl)(Cl)Cl)c2ccccc12</smiles>

79c

Scheme 1.58: Rhodium-catalyzed indole synthesis via $\mathrm{C}-\mathrm{H} / \mathrm{N}-\mathrm{H}$ bond functionalizations

Encouraged by their success in carboxylate-assisted ruthenium(II)-catalyzed alkylation and arylation reactions, ${ }^{17,205}$ Ackermann and co-workers set out to study annulations by using less expensive ruthenium(II) catalysts. ${ }^{206}$ Thus, in 2011, they reported on the first ruthenium(II)-catalyzed alkyne annulations by $\mathrm{C}-\mathrm{H} / \mathrm{Het}-\mathrm{H}$ bonds functionalization (Scheme 1.59). ${ }^{207}$ This isoquinolone 157a 
synthesis proceeded smoothly with $\left[\mathrm{RuCl}_{2}(p \text {-cymene })\right]_{2}$ as the catalyst and stoichiometric amounts of $\mathrm{Cu}(\mathrm{OAc})_{2} \cdot \mathrm{H}_{2} \mathrm{O}$ as an oxidant.

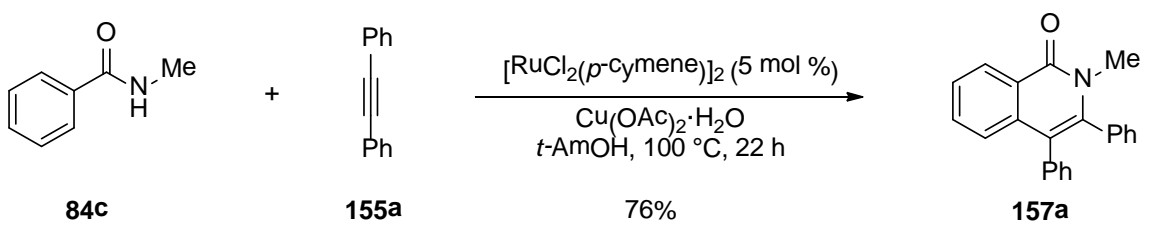

Scheme 1.59: Ruthenium(II)-catalyzed isoquinolone synthesis via $\mathrm{C}-\mathrm{H} / \mathrm{N}-\mathrm{H}$ bonds functionalizations

Experiments with isotopically labeled starting materials disclosed a KIE of 2.6, which indicated a kinetically relevant $\mathrm{C}-\mathrm{H}$ activation step. Based on mechanistic studies, the reaction was proposed to proceed by an initial ruthenation via acetate-assisted $\mathrm{C}-\mathrm{H}$ bond cleavage followed by migratory insertion of the alkyne, subsequent $\mathrm{C}-\mathrm{N}$ bond-forming reductive elimination and final reoxidation to generate the active Ru(II) species (Scheme 1.60).

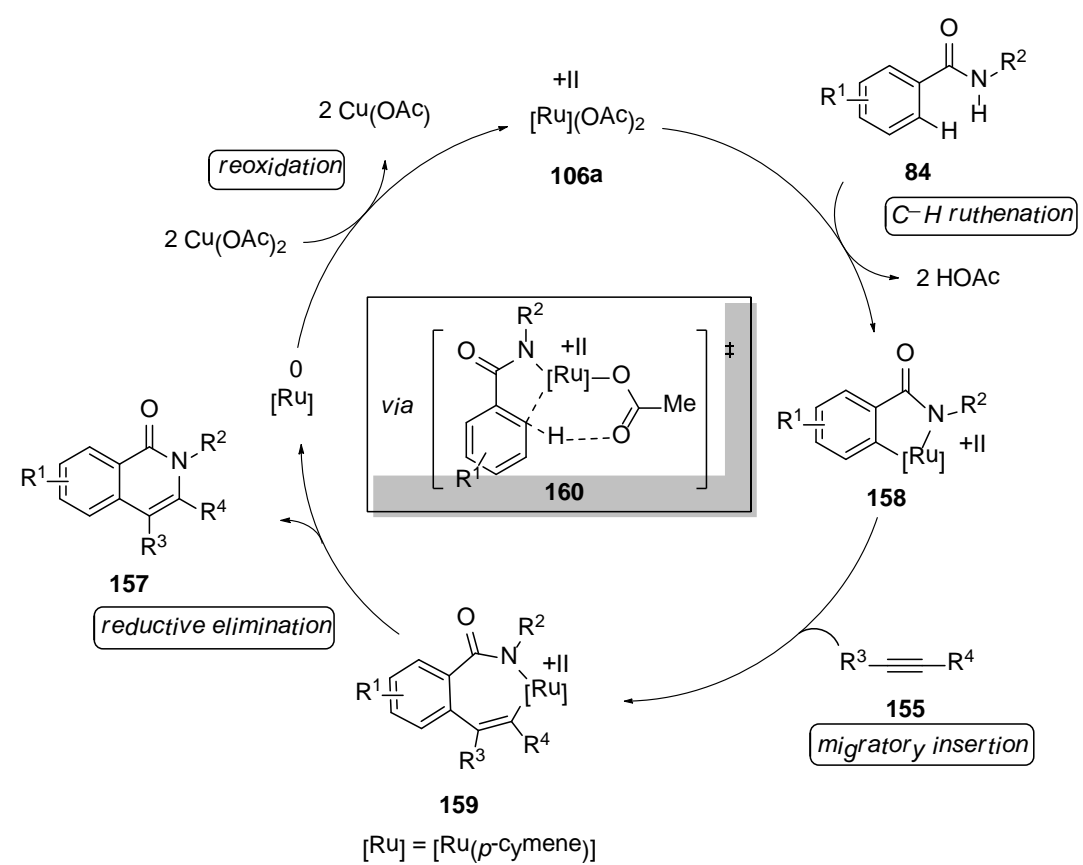

Scheme 1.60: Proposed catalytic cycle for ruthenium(II)-catalyzed oxidative annulation

Dixneuf and Wang carried out detailed mechanistic study regarding the $\mathrm{C}-\mathrm{H}$ bond ruthenation and the alkyne insertion. ${ }^{208,209}$ The structures of isolated key intermediates were in line with the mechanism proposed in Scheme 1.60 .

Encouraged by the initial success, the groups of Ackermann and others made efforts to extend the scope of ruthenium(II)-catalyzed oxidative alkyne annulations through $\mathrm{C}-\mathrm{H} / \mathrm{Het}-\mathrm{H}$ bond functionalization. In this context, various substituted heterocycles such as 2 -pyridones $164,{ }^{210}$ indoles 79, ${ }^{211}$ isocumarins (156), ${ }^{212,213}$ annulated pyrans (167), ${ }^{214}$ isochromenes (175), ${ }^{215}$ pyrroles (171), ${ }^{216}$ phosphaisocoumarins $172,{ }^{217}$ quinolinones $173,^{218}$ isoquinolones $157^{219}$ and isoquinolines $174 a^{185,220}$ were prepared in the last few years. 5-Aryl-1H-pyrazoles $162,{ }^{221} 2$-arylpyrroles and 2-arylindoles $\mathbf{7 9} \mathbf{9}^{222}$ also underwent smooth annulation with alkynes under ruthenium(II) catalyst (Scheme 1.61) 

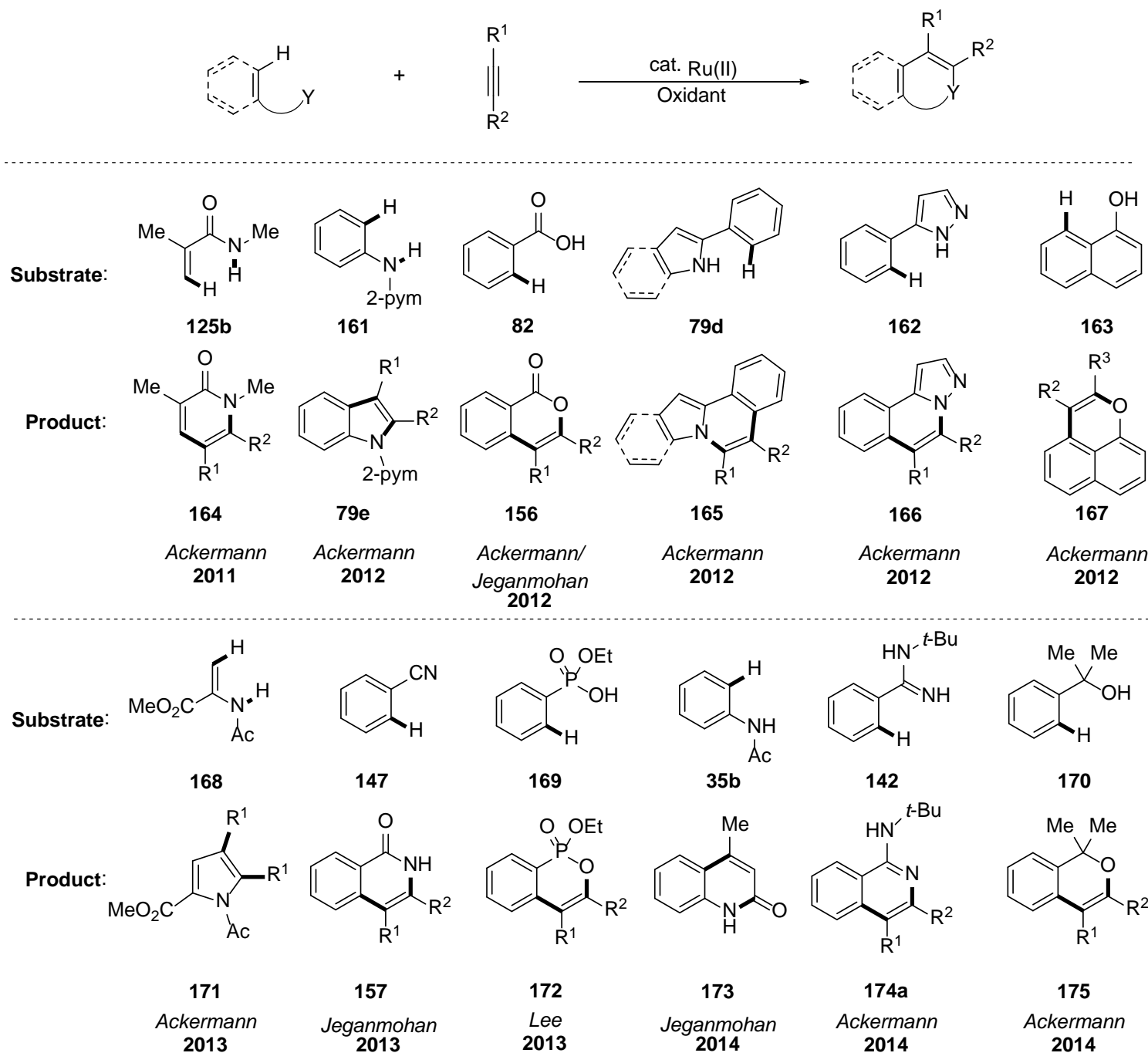

Scheme 1.61: Recent examples of ruthenium(II)-catalyzed oxidative annulation

In 2012, Lam and co-workers developed ruthenium(II)-catalyzed oxidative alkyne annulations by 2-aryl-1,3-dicarbonyl compounds $\mathbf{1 7 6}$ involving formal functionalization of $\mathrm{C}\left(\mathrm{sp}^{3}\right)-\mathrm{H}$ and $\mathrm{C}\left(\mathrm{sp}^{2}\right)-\mathrm{H}$ bonds, thus affording products $\mathbf{1 7 8}$ containing all-carbon quaternary centers (Scheme 1.62a). ${ }^{223}$

a)<smiles>[X]C(=O)C(C([X])=O)c1ccc([R])cc1</smiles>

176
$\mathrm{R}^{2} \frac{\overline{\overline{155}}}{\mathrm{R}^{3}}$

$\left.\mathrm{uCl}_{2}\left(p^{-\mathrm{Cymene}}\right)\right]_{2}$ $(2.5 \mathrm{~mol} \%)$

$\mathrm{Cu}(\mathrm{OAC})_{2} \cdot \mathrm{H}_{2} \mathrm{O}$

1,4-dioxane, $90{ }^{\circ} \mathrm{C}, 4 \mathrm{~h}$

$\mathrm{X}=\mathrm{C}, \mathrm{O}, \mathrm{NM}$

$\mathrm{Y}=\mathrm{CH}_{2}, \mathrm{CHMe}_{2}, \mathrm{CO}$

177

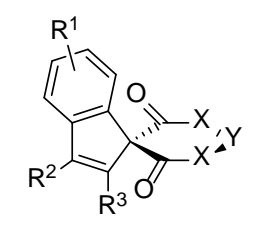

178

b)

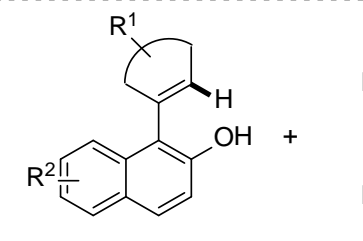

179

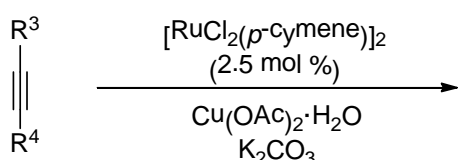

1,4-dioxane, $90^{\circ} \mathrm{C}, 48 \mathrm{~h}$

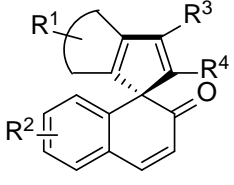

180

Scheme 1.62: Ruthenium(II)-catalyzed oxidative annulation via $C\left(\mathrm{sp}^{3}\right)-\mathrm{H} / \mathrm{C}\left(\mathrm{sp}^{2}\right)-\mathrm{H}$ functionalization 
The group of Luan also reported on a similar ruthenium(II)-catalyzed cyclization reaction of 1-aryl-2-naphthols 179. ${ }^{224}$ Dearomatized spirocyclic molecules bearing an all-carbon quaternary stereocenter could be obtained by this novel method with good yields and excellent site-selectivity (Scheme 1.62b).

However, due to the oxidative character of the reactions discussed above, stoichiometric amounts of external oxidants were required to regenerate the active catalyst. Very recently, Ackermann and co-workers developed unprecedented ruthenium(II)-catalyzed oxidative alkyne annulations with molecular oxygen as the sacrificial oxidant in the absence of any cooxidant (Scheme 1.63). ${ }^{225}$
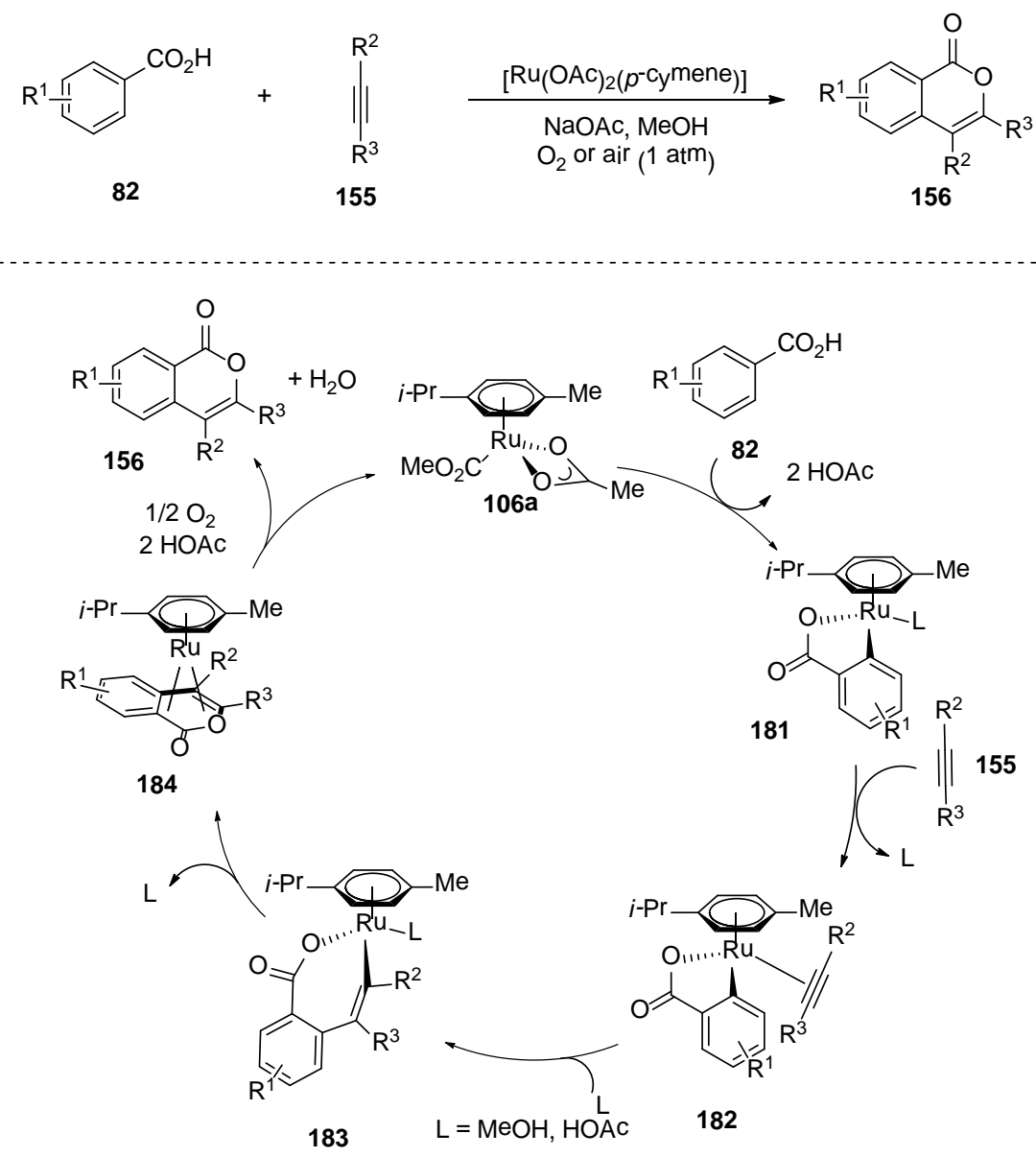

Scheme 1.63: Ruthenium(II)-catalyzed aerobic alkyne annulations and proposed catalytic cycle

This novel method prevented the use of copper or silver salts and thus generated water as the only byproduct. Moreover, a ruthenium(0) sandwich complex $\mathbf{1 8 4}$ was identified as a key intermediate of the catalytic cycle. Compound $\mathbf{1 8 4}$ was reoxidized by molecular oxygen to regenerate the active catalytic species 106a.

Alternatively, a recently emerged strategy of using directing/oxidizing groups as internal oxidant represented itself as an important alternative in $\mathrm{C}-\mathrm{H}$ functionalization. ${ }^{226}$ Fagnou and co-workers reported pioneering work of using internal oxidants for alkyne annulations involving $\mathrm{C}-\mathrm{H} / \mathrm{N}-\mathrm{O}$ bond cleavages in 2010. ${ }^{227}$ Hydroxamic acid esters $\mathbf{1 2 7}$ were employed as substrates for the rhodium-catalyzed annulation. The only byproduct of this reaction is methanol, and the reaction 
proceeded smoothly under mild conditions (Scheme 1.64).<smiles>[R]C#C[R]</smiles>

$127 a$

$$
\left.\right|_{\mathrm{R}^{3}} ^{\mathrm{R}^{2}}
$$

155

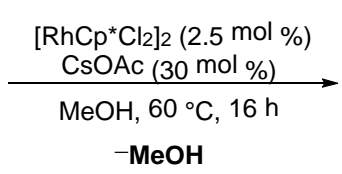

$-\mathrm{MeOH}$<smiles>[R][R1]1ccc2c([R])c([R])[nH]c(=O)c2c1</smiles>

157

Scheme 1.64: Rhodium-catalyzed isoquinolone synthesis via $\mathrm{C}-\mathrm{H} / \mathrm{N}-\mathrm{O}$ bond functionalizations

In 2011, the same strategy was independently applied in ruthenium(II)-catalyzed redox-neutral isoquinolone synthesis by the groups of Ackermann, ${ }^{228} \mathrm{Li}$ and Wang. ${ }^{229}$ Ackermann and co-workers also showed that free hydroxamic acids (127b) were competent substrates, and the reaction proceeded smoothly in water (Scheme 1.65). ${ }^{172}$

a)<smiles>CONC(=O)c1ccccc1</smiles>

$127 a$

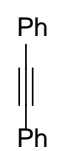

$155 a$

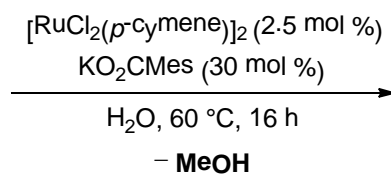

$81 \%$<smiles>O=c1[nH]c(-c2ccccc2)c(-c2ccccc2)c2ccccc12</smiles>

$157 \mathrm{c}$

b)<smiles>O=C(NO)c1ccccc1</smiles>

$$
\left.\right|_{\mathrm{Ph}} ^{\mathrm{Ph}}
$$

$155 a$

$$
\begin{gathered}
\underset{\left[\mathrm{RuCl}_{2}\left(\text { p-Cymene }^{-}\right)\right]_{2}(2.5 \mathrm{~mol} \%)}{3-\left(\mathrm{F}_{3} \mathrm{C}\right) \mathrm{C}_{6} \mathrm{H}_{4} \mathrm{CO}_{2} \mathrm{~K}(30 \mathrm{~mol} \%)} \\
\underset{\mathrm{H}_{2} \mathrm{O}, 100{ }^{\circ} \mathrm{C}, 18 \mathrm{~h}}{-}
\end{gathered}
$$

$69 \%$<smiles>O=c1[nH]c(-c2ccccc2)c(-c2ccccc2)c2ccccc12</smiles>

157c

Scheme 1.65: Ruthenium(II)-catalyzed isoquinolone synthesis via $\mathrm{C}-\mathrm{H} / \mathrm{N}-\mathrm{O}$ bond functionalizations

Most recently, Huang and co-workers reported the first ruthenium(II)-catalyzed redox-neutral annulation via $\mathrm{N}-\mathrm{N}$ bond cleavage (Scheme 1.66 ). ${ }^{230}$ In this case, pyrazolidin-3-one moiety in substrate 185 was demonstrated to operate as an internal oxidizing directing group. It's noteworthy that terminal alkynes, such as 155c, which were previously mostly incompetent in ruthenium(II)-catalyzed cyclizations, reacted smoothly and delivered indole products $\mathbf{1 8 6}$ as a single regioisomer.<smiles>O=C1CCN(c2ccccc2)N1</smiles>

185 $155 c$

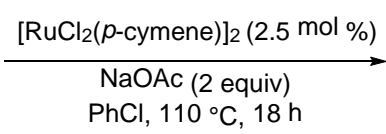

$83 \%$<smiles>NC(=O)CCn1c(-c2ccccc2)cc2ccccc21</smiles>

186

Scheme 1.66: Ruthenium(II)-catalyzed annulation via $\mathrm{C}-\mathrm{H} / \mathrm{N}-\mathrm{N}$ bond functionalizations 


\section{Objectives}

In recent years, transition metal-catalyzed $\mathrm{C}-\mathrm{H}$ bond functionalizations have become an indispensable tool for chemo-, site- and enantioselective direct construction of C-C and C-Het bonds. In particular, Ackermann and coworkers focused on developing new strategies for $\mathrm{C}-\mathrm{H}$ functionalizations employing significantly less expensive, yet highly reactive ruthenium(II) catalysts. In this context, carboxylate assistance was found to be crucial for promoting the efficiency of the $\mathrm{C}-\mathrm{H}$ activation step.

Ackermann and coworkers have disclosed ruthenium(II)-catalyzed $\mathrm{C}-\mathrm{H}$ alkylation of arenes with both primary and secondary alkyl halides. More importantly, direct alkylation with secondary alkyl bromides exhibited unique meta-selectivity. Despite the progress of employing secondary alkyl halides in traditional cross-coupling reactions, tertiary alkyl halides were less studied in either cross-coupling or $\mathrm{C}-\mathrm{H}$ bond functionalization. Thus, one major emphasis of this thesis is on developing ruthenium(II)-catalyzed direct alkylation reactions with tertiary alkyl halides $\mathbf{5 0}$. At the outset of this project, chelation-assisting heterocycles were employed as directing groups (107). Furthermore, given the significant advantages of monoprotected amino acid (MPAA) 116 as ligands in promoting palladium-catalyzed $\mathrm{C}-\mathrm{H}$ bond activation, we were also interested in testing their behavior in ruthenium(II)-catalyzed direct alkylation reactions.

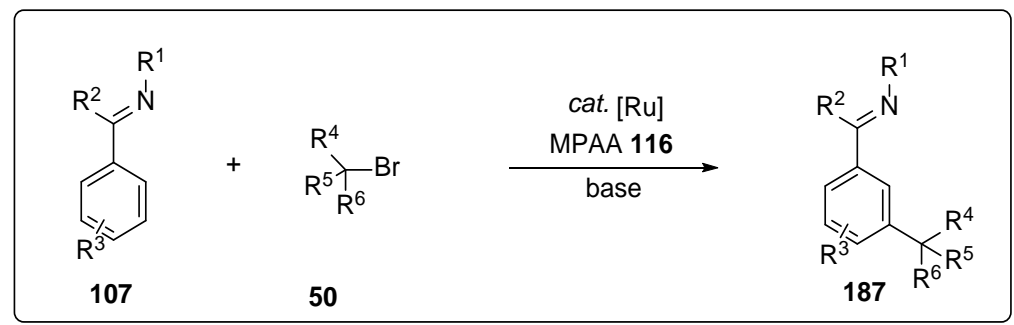

Scheme 2.1: Ruthenium(II)-catalyzed direct alkylation with tertiary alkyl halides

In addition, considering the synthetically usefulness of this novel transformation, we were interested in extending its scope to arenes bearing directing groups which can be readily removed or further functionalized. Thus, we probed ketimine derivatives 188 for ruthenium(II)-catalyzed direct alkylation with both tertiary and secondary alkyl halides $\mathbf{5 0}$ and 44. Although transition metal-catalyzed ortho-selective $\mathrm{C}-\mathrm{H}$ alkylation of ketimines was known, direct meta-alkylation with tertiary or secondary alkyl halides proved elusive. More importantly, simple one-pot hydrolysis could yield various meta-substituted ketones 189 which are indispensable intermediates in practical organic synthesis.

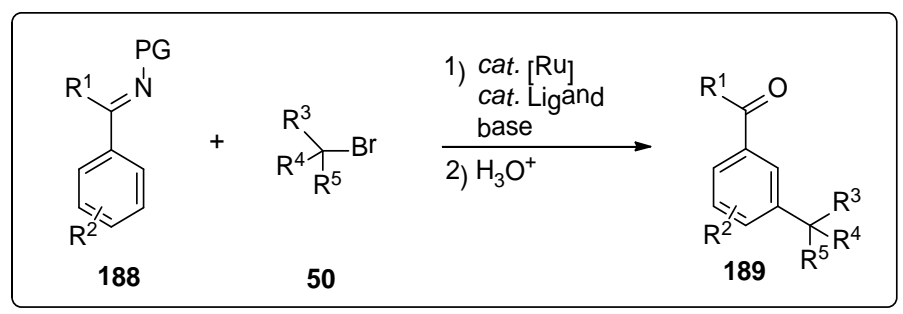

Scheme 2.2: Ruthenium(II)-catalyzed direct alkylation of ketimines 188

Moreover, besides electron-deficient arenes, we were also interested in ruthenium(II)-catalyzed direct alkylation of the electron-rich ones. Thus, $N$-(pyrimidyl-2-yl)anilines 161 were also examined as substrates for this direct meta-alkylation. Tertiary, secondary as well as primary alkyl bromides were probed in this reaction. Importantly, the pyrimidyl directing group could easily be cleaved under acidic conditions to furnish a range of meta-alkylated anilines 191. 


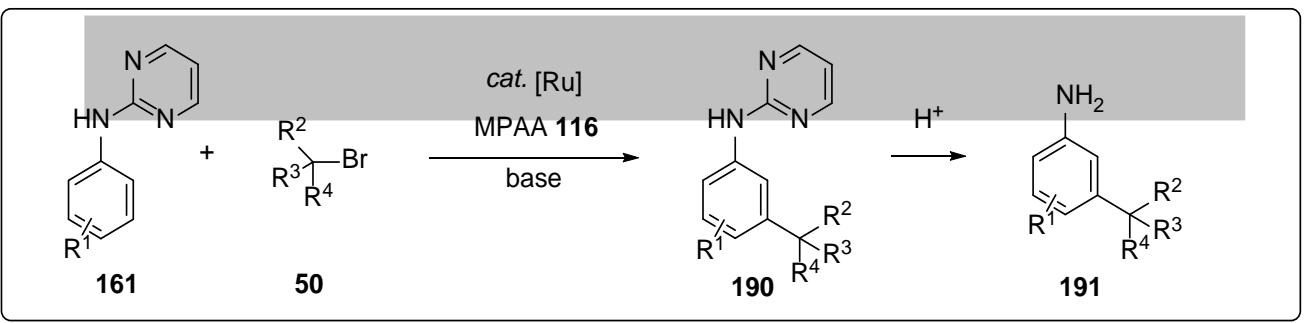

Scheme 2.3: Ruthenium(II)-catalyzed direct alkylation of $N$-(pyrimidyl-2-yl)anilines 161

Despite the rapid development of ruthenium(II)-catalyzed Fujiwara-Moritani reactions, direct oxidative alkenylation of electron-rich arenes were underdeveloped. Consequently, we were interested in developing the first ruthenium(II)-catalyzed oxidative $\mathrm{C}-\mathrm{H}$ alkenylation of phenol derivatives. Herein, we chose readily cleavable carbamates as directing groups in substrate 192 and hence facilitated the preparation of o-coumaric acid derivatives 193.

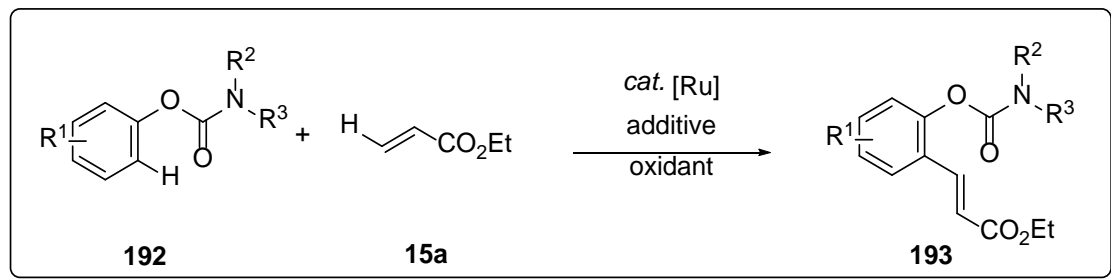

Scheme 2.4: Ruthenium(II)-catalyzed oxidative C-H alkenylation of phenol carbamates 192

Another project was to extend the scope of oximes for the ruthenium(II)-catalyzed redox-neutral alkyne annulations of alkynes 155 with oximes 194 via $\mathrm{C}-\mathrm{H} / \mathrm{N}-\mathrm{O}$ bonds functionalization. Moreover, well-defined cationic ruthenium(II) complex was examined as a catalyst for this transformation. A variety of symmetrically as well as unsymmetrically substituted alkynes $\mathbf{1 5 5}$ were tested with this cationic ruthenium(II) catalyst.

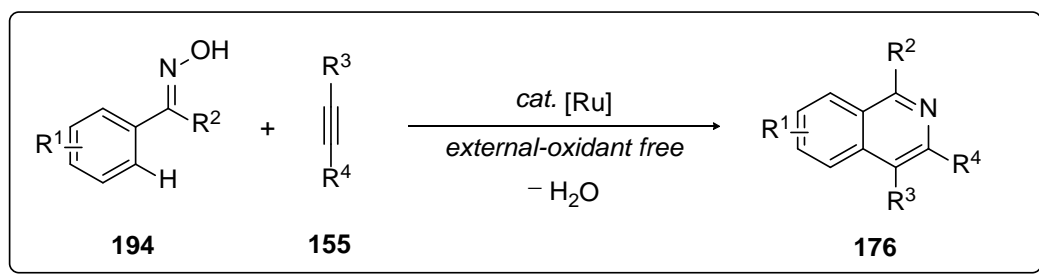

Scheme 2.5: Ruthenium(II)-catalyzed redox-neutral alkyne annulation with oximes 194 


\section{Ruthenium(II)-Catalyzed meta-Selective C-H Alkylations}

As indicated in Chapter 1.3, transition metal-catalyzed $\mathrm{C}-\mathrm{H}$ alkylation with unactivated alkyl halides has emerged as an economical alternative for the construction of $\mathrm{C}\left(\mathrm{sp}^{2}\right)-\mathrm{C}\left(\mathrm{sp}^{3}\right)$ bonds. Ackermann and coworkers have demonstrated that, among a variety of transition metals, relatively cheap ruthenium(II) complexes showed excellent catalytic capability for highly site-selective direct alkylations under mild reaction conditions. ${ }^{140,142}$ More importantly, unique meta-selectivity was observed when unactivated secondary alkyl halides were employed as the electrophiles (Chapter 1.2). ${ }^{143}$ In spite of the recent success in applying secondary alkyl halides in cross-coupling and $\mathrm{C}-\mathrm{H}$ functionalization, ${ }^{95}$ unactivated tertiary alkyl halides were very rarely explored. Therefore, we set out to develop the first example of ruthenium(II)-catalyzed direct $\mathrm{C}-\mathrm{H}$ alkylation with unactivated tertiary alkyl halides.

\subsection{Ruthenium(II)-Catalyzed meta-Selective $\mathrm{C}-\mathrm{H}$ Alkylations by Heterocycle}

\section{Assistance with Tertiary Alkyl Bromides}

\subsubsection{Optimization Studies}

At the outset of our studies, we adopted the reaction conditions for the ruthenium(II)-catalyzed direct meta-alkylation with secondary alkyl bromides, ${ }^{143}$ using 2-phenylpridine (38b) as the standard substrate for this challenging alkylation with $t$-butyl bromide (50a) (Table 3.1). To our delight, the desired meta-alkylated product 187 ba was obtained in $59 \%$ isolated yield (entry 1 ). Several other carboxylate co-catalysts also successfully delivered the target product, albeit in moderate yields (entries 2-5). While no reaction occurred in the absence of an additive (entry 6), high yield was obtained when Piv-Val-OH (116a) was introduced as a co-catalytic additive (entry 7). Although ruthenium(II)-amino acid complexes have been known for decades, ${ }^{231,232}$ they have been employed as catalysts for direct $\mathrm{C}-\mathrm{H}$ functionalizations only very recently. ${ }^{233}$ Decreasing the loading of $\left[\mathrm{RuCl}_{2}(p \text {-cymene) }]_{2}\right.$ to $1.0 \mathrm{~mol} \%$ led to a slightly lower yield (entry 8). A ruthenium(II)-amino acid complex 195 was independently prepared and showed excellent catalytic activity, furnishing desired product 187ba in even higher yield comparing to the in situ generated catalytic system (entry 9). Not surprisingly, this novel type of tertiary alkylation did not take place in the absence of ruthenium(II) catalyst or employing a Lewis acid catalyst, such as $\mathrm{AlCl}_{3}$ (entries 10-11). Palladium or rhodium catalyst could not promote this transformation under otherwise identical reaction conditions (entries 12-14). Other ruthenium catalysts were also tested, whereas $\left[\mathrm{RuCl}_{2}\left(\mathrm{PPh}_{3}\right)_{3}\right]$ delivered only $10 \%$ of GC-conversion, $\mathrm{Ru}_{3}(\mathrm{CO})_{12}$ showed no reactivity (entries 15-16). Encouraged by the excellent efficiency promoted by the Piv-Val-OH co-catalyst, we went on examining different MPAA ligands 116. Among selected amino acids, valine derivatives proved to be optimal (entries 17-19). Unprotected valine delivered coumpound $\mathbf{1 8 7}$ ba only in low yield, thus highlighting the importance of a protecting group on the nitrogen; other $N$-protected MPAAs afforded the meta-alkylated product 187ba in moderate yields (entries 20-25). Furthermore, among a variety of different solvents, 1,4-dioxane proved to be the solvent of choice (entries 26-31). Using stoichiometric quantities of acetates as bases in the absence of any co-catalyst gave product $\mathbf{1 8 7 b a}$ in only unsatisfying low yields (entries 32-35). 
Table 3.1: Optimization for ruthenium(II)-catalyzed direct meta-alkylation with $t$-BuBr (50a)<smiles>COc1ccc(-c2ccccn2)cc1</smiles>

38b $+\quad t$-BuBr

$50 a$

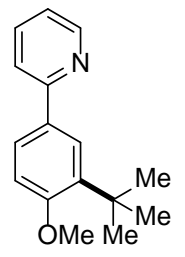

$187 \mathrm{ba}$

\begin{tabular}{|c|c|c|c|c|c|}
\hline Entry & Catalyst & Additive & Base & Solvent & Yield (\%) \\
\hline 1 & {$\left[\mathrm{RuCl}_{2}(p \text {-cymene })\right]_{2}$} & $\mathrm{MesCO}_{2} \mathrm{H}$ & $\mathrm{K}_{2} \mathrm{CO}_{3}$ & 1,4-dioxane & 59 \\
\hline 2 & {$\left[\mathrm{RuCl}_{2}(p \text {-cymene })\right]_{2}$} & 1- $\mathrm{AdCO}_{2} \mathrm{H}$ & $\mathrm{K}_{2} \mathrm{CO}_{3}$ & 1,4-dioxane & 58 \\
\hline 3 & {$\left[\mathrm{RuCl}_{2}(p \text {-cymene })\right]_{2}$} & $\mathrm{NaOAc}$ & $\mathrm{K}_{2} \mathrm{CO}_{3}$ & 1,4-dioxane & 38 \\
\hline 4 & {$\left[\mathrm{RuCl}_{2}(p \text {-cymene })\right]_{2}$} & KOAC & $\mathrm{K}_{2} \mathrm{CO}_{3}$ & 1,4-dioxane & 50 \\
\hline 5 & {$\left[\mathrm{RuCl}_{2}(p \text {-cymene })\right]_{2}$} & $\mathrm{CsOAC}$ & $\mathrm{K}_{2} \mathrm{CO}_{3}$ & 1,4-dioxane & 51 \\
\hline 6 & {$\left[\mathrm{RuCl}_{2}(p \text {-cymene })\right]_{2}$} & --- & $\mathrm{K}_{2} \mathrm{CO}_{3}$ & 1,4-dioxane & 0 \\
\hline 7 & {$\left[\mathrm{RuCl}_{2}(p \text {-cymene })\right]_{2}$} & $116 \mathbf{a}$ & $\mathrm{K}_{2} \mathrm{CO}_{3}$ & 1,4-dioxane & 76 \\
\hline 8 & {$\left[\mathrm{RuCl}_{2}(p \text {-cymene })\right]_{2}$} & $\begin{array}{l}\mathrm{116} \\
\mathrm{H}-\mathrm{Bu}\end{array}$ & $\mathrm{K}_{2} \mathrm{CO}_{3}$ & 1,4-dioxane & $66^{b}$ \\
\hline 9 & $\begin{array}{c}{[\text { RuCl(O-Val-Piv)(p-cymene)] }} \\
195\end{array}$ & & $\mathrm{~K}_{2} \mathrm{CO}_{3}$ & 1,4-dioxane & $80^{c}$ \\
\hline 10 & - & $\mathbf{1 1 6 a}$ & $\mathrm{K}_{2} \mathrm{CO}_{3}$ & 1,4-dioxane & 0 \\
\hline 11 & $\mathrm{AlCl}_{3}$ & $116 a$ & $\mathrm{~K}_{2} \mathrm{CO}_{3}$ & 1,4-dioxane & 0 \\
\hline 12 & $\operatorname{Pd}(\mathrm{OAc})_{2}$ & 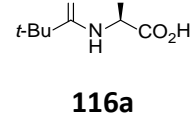 & $\mathrm{K}_{2} \mathrm{CO}_{3}$ & 1,4-dioxane & 0 \\
\hline 13 & {$\left[\mathrm{Cp}^{*} \mathrm{RhCl}_{2}\right]_{2}$} & $\begin{array}{c}116 \mathrm{~B} \\
\mathrm{H}\end{array}$ & $\mathrm{K}_{2} \mathrm{CO}_{3}$ & 1,4-dioxane & 0 \\
\hline 14 & {$[\mathrm{Rh}(\operatorname{cod}) \mathrm{Cl}]_{2}$} & 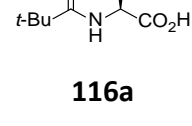 & $\mathrm{K}_{2} \mathrm{CO}_{3}$ & 1,4-dioxane & 0 \\
\hline 15 & {$\left[\mathrm{RuCl}_{2}\left(\mathrm{PPh}_{3}\right)_{3}\right]$} & 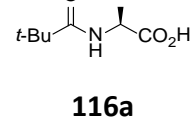 & $\mathrm{K}_{2} \mathrm{CO}_{3}$ & 1,4-dioxane & $10^{\mathrm{d}}$ \\
\hline
\end{tabular}


16

17

18

19

20

21

22

23

24

25

26

27

28

29
$\mathrm{Ru}_{3}(\mathrm{CO})_{12}$

$\left[\operatorname{RuCl}_{2}(p \text {-cymene })\right]_{2}$

$\left[\operatorname{RuCl}_{2}(p \text {-cymene })\right]_{2}$

$\left[\mathrm{RuCl}_{2}(p \text {-cymene })\right]_{2}$

$\left[\operatorname{RuCl}_{2}(p \text {-cymene })\right]_{2}$

$\left[\operatorname{RuCl}_{2}(p \text {-cymene })\right]_{2}$

$\left[\operatorname{RuCl}_{2}(p \text {-cymene })\right]_{2}$

$\left[\mathrm{RuCl}_{2}(p \text {-cymene })\right]_{2}$

$\left[\mathrm{RuCl}_{2}(p \text {-cymene })\right]_{2}$

$\left[\mathrm{RuCl}_{2}(p \text {-cymene })\right]_{2}$

$\left[\mathrm{RuCl}_{2}(p \text {-cymene })\right]_{2}$

$\left[\mathrm{RuCl}_{2}(p \text {-cymene })\right]_{2}$

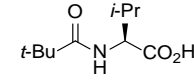

$116 a$

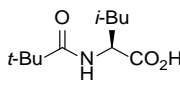

$\mathrm{K}_{2} \mathrm{CO}_{3}$

1,4-dioxane

55

$116 b$

${ }_{t-\mathrm{Bu}} \stackrel{\mathrm{O}}{\mathrm{N}_{\mathrm{H}}} \widehat{\mathrm{CO}}_{2}$

$\mathrm{K}_{2} \mathrm{CO}_{3}$

1,4-dioxane

48

$116 c$

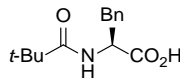

$\mathrm{K}_{2} \mathrm{CO}_{3}$

1,4-dioxane

53

$116 d$

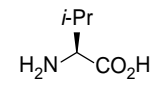

$\mathrm{K}_{2} \mathrm{CO}_{3} \quad$ 1,4-dioxane

19

$116 \mathrm{e}$

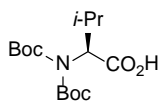

$\mathrm{K}_{2} \mathrm{CO}_{3} \quad$ 1,4-dioxane

46

$116 f$

$\underset{\text { Boc }}{\mathrm{Me}} \underset{\mathrm{CO}_{2} \mathrm{H}}{i-\mathrm{Pr}}$

$\mathrm{K}_{2} \mathrm{CO}_{3} \quad$ 1,4-dioxane

42

$116 \mathrm{~g}$

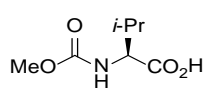

$116 \mathrm{~h}$

${ }_{-\mathrm{H}}^{\mathrm{Bac}} \stackrel{\mathrm{Pr}}{\mathrm{C}_{\mathrm{CO}_{2} \mathrm{H}}}$

$\mathrm{K}_{2} \mathrm{CO}_{3} \quad$ 1,4-dioxane

61

$116 i$

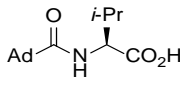

$\mathrm{K}_{2} \mathrm{CO}_{3}$

1,4-dioxane

55

116j

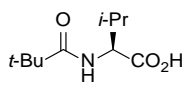

$\mathrm{K}_{2} \mathrm{CO}_{3}$

DME

71

$116 a$

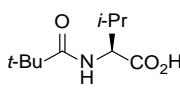

$\mathrm{K}_{2} \mathrm{CO}_{3}$

t-AmOH

14

$116 a$

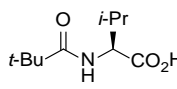

$\mathrm{K}_{2} \mathrm{CO}_{3}$

PhMe

74

$116 a$

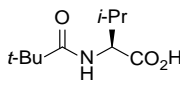

$\mathrm{K}_{2} \mathrm{CO}_{3}$

$\mathrm{H}_{2} \mathrm{O}$

0 


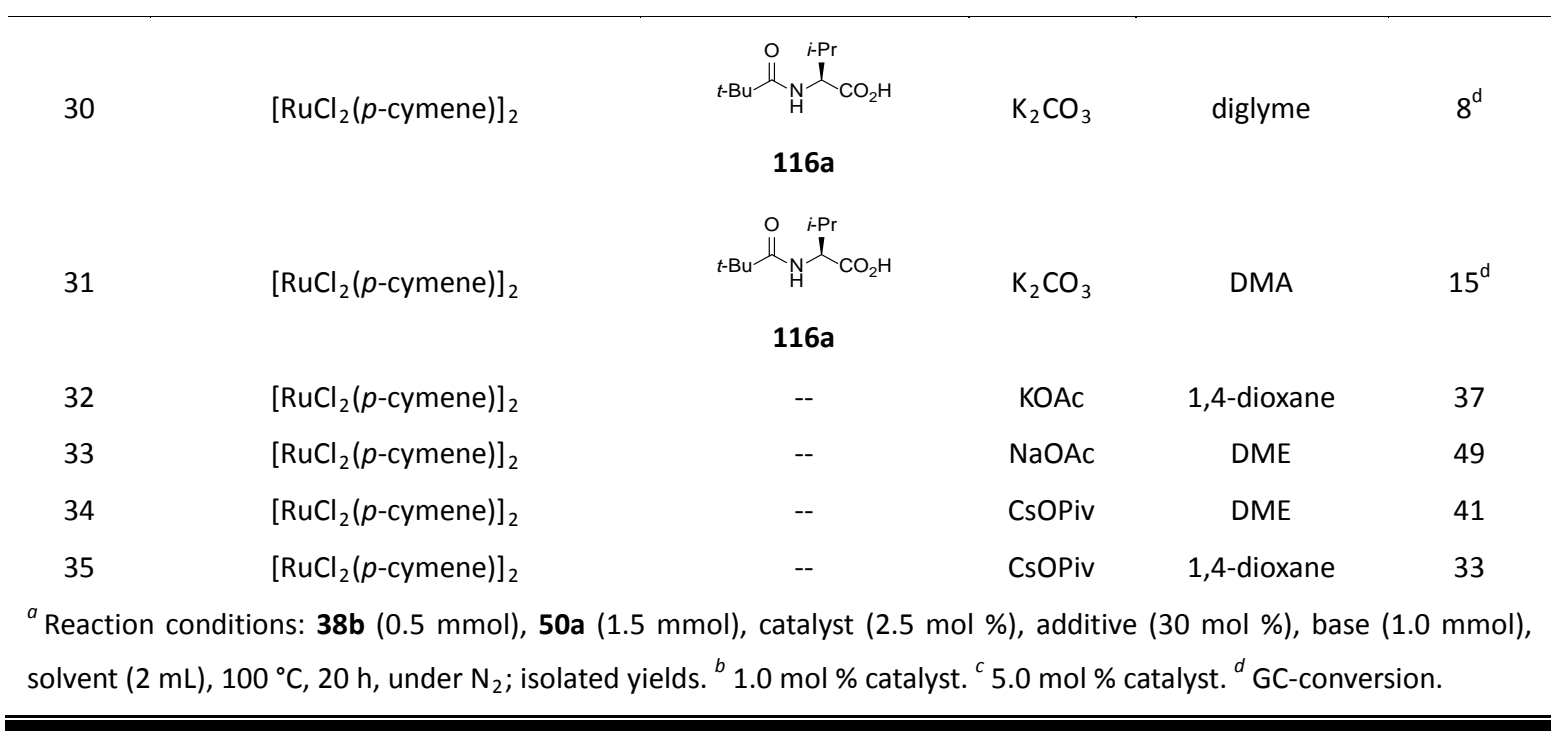

\subsection{2 meta-C-H Alkylation with Tertiary Alkyl Bromides: Scope and Limitations}

With the optimized conditions in hand, we subsequently explored the scope and limitations of this meta-selective alkylation. Various unactivated tertiary alkyl bromides $\mathbf{5 0}$ were tested with both in-situ generated ruthenium(II) catalyst and the single-component complex 195. In most cases, these two systems delivered comparable yields (Table 3.2). Thus, 1-methylcyclohexyl bromide (50b) gave the

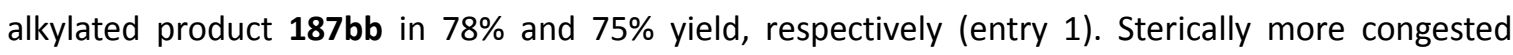
tertiary alkyl bromides also afforded desired products in moderate yields (entries 2-4). More importantly, tertiary alkyl bromides bearing functional groups, such as ether (50f), olefin (50 $\mathbf{g}$ ), chloride (50h) and phenyl groups (50i and 50j), were well tolerated (entries 5-9). Interestingly, despite the well-established method of ruthenium(II)-catalyzed alkylation with primary alkyl chlorides, compound $\mathbf{1 8 7 b h}$ was not contaminated with any primary alkylated byproduct (entry 7 ).

Table 3.2: Scope of direct meta-alkylation with tertiary alkyl bromides 50

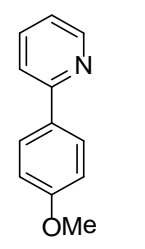

38b

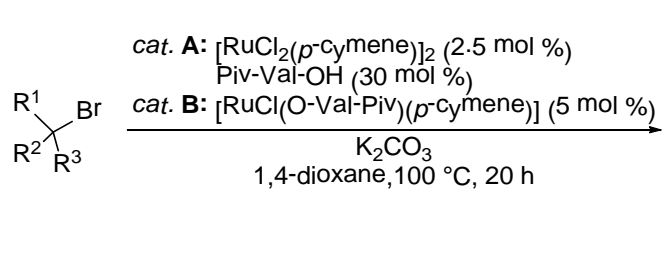

50

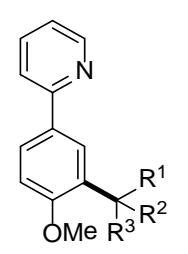

187

\begin{tabular}{|c|c|c|c|}
\hline Entry & Tertiary Bromide 50 & Product 187 & Yield (\%) \\
\hline 1 & $\mathrm{Br} \widehat{\mathrm{Me}}$ & OMeMe & $\begin{array}{l}\text { A: } 78 \\
\text { B: } 75\end{array}$ \\
\hline & $50 b$ & $187 \mathrm{bb}$ & \\
\hline
\end{tabular}


2<smiles>CCCC(C)(C)Br</smiles>

$50 c$

3<smiles>CCC(C)(C)Br</smiles>

50d

4

5

6

$$
\mathrm{Br} \underbrace{\mathrm{Et}}_{\text {Et }} \mathrm{Et}
$$

50 e

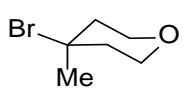

$50 f$

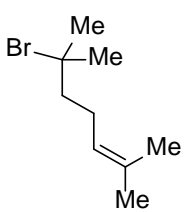

$50 \mathrm{~g}$

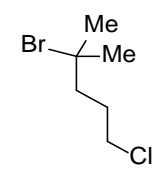

$50 \mathrm{~h}$

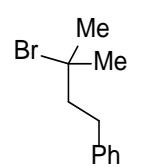

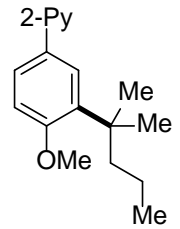

$187 \mathrm{bc}$

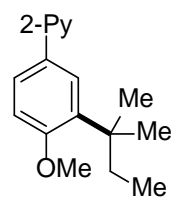

$187 \mathrm{bd}$<smiles>[R7]c1ccc(OC)c(C(CC)(CC)CC)c1</smiles>

187be

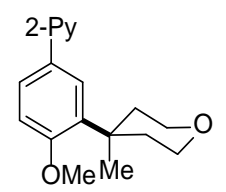

A: 78

B: 75

187bf

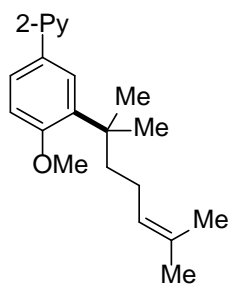

187bg

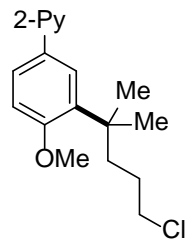

A: 59

B: 59

187bh

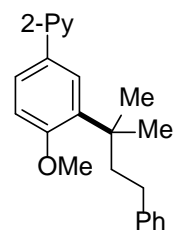

A: 66

B: 59 


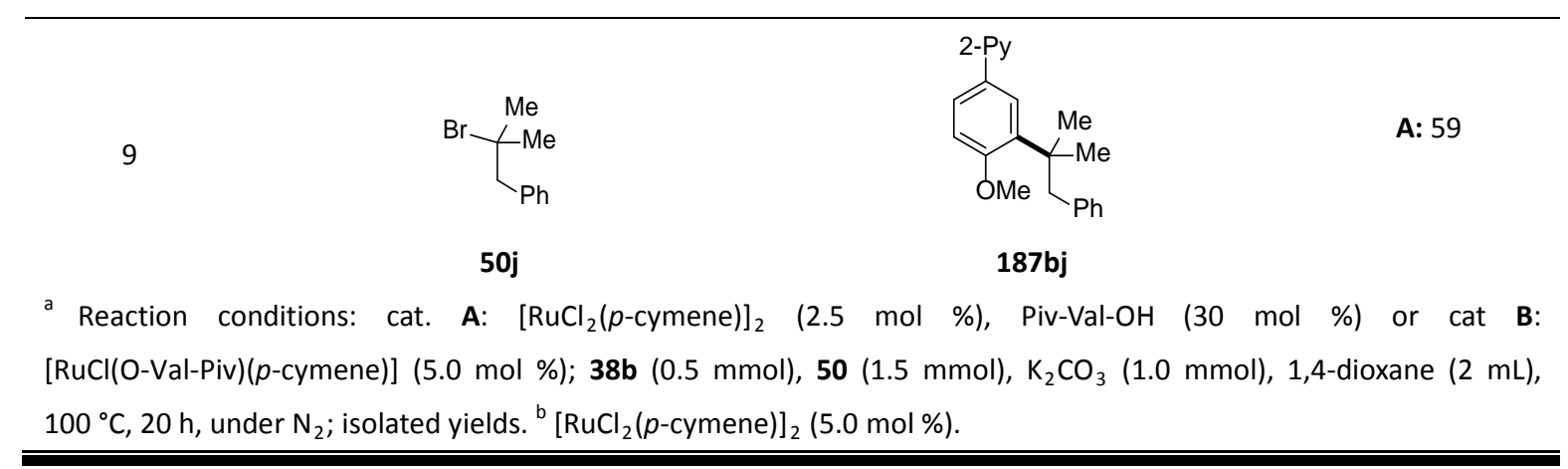

Subsequently, the influence of electron-donating and electron-withdrawing substituents on the aryl moiety upon the efficiency of the alkylation was examined (Table 3.3). Unsubstituted 2-phenylpyridine (38a) was smoothly converted in good yield under both conditions (entry 1). Phenylpyridines bearing electron-withdrawing fluoro (38c), acetyl (38d) and ester (38e) groups in the para-position (entries $2-4$ ) as well as $p$-tolylpyridine $\mathbf{3 8 f}$ (entry 5) selectively delivered meta-selective products in moderate to good yields. It is noteworthy that these functional groups could be valuable for further functionalization. However, surprisingly low yields were observed for electron-deficient trifluoromethyl- or cyano-substituted substrates $\mathbf{3 8} \mathrm{g}$ and 38h, respectively (entries 6 and 7). The same held true for the vinyl-containing substrate 38i (entry 8). Substituents in the 3-, 4-, or 5- position on the pyridine moiety in substrates $\mathbf{3 8}$ generally did not significantly affect the reaction outcome, affording the meta-alkylated products in moderate to good yields (entries 9-15).

Table 3.3: Scope for meta-C-H alkylation of para-substituted 2-phenylpyridines 38
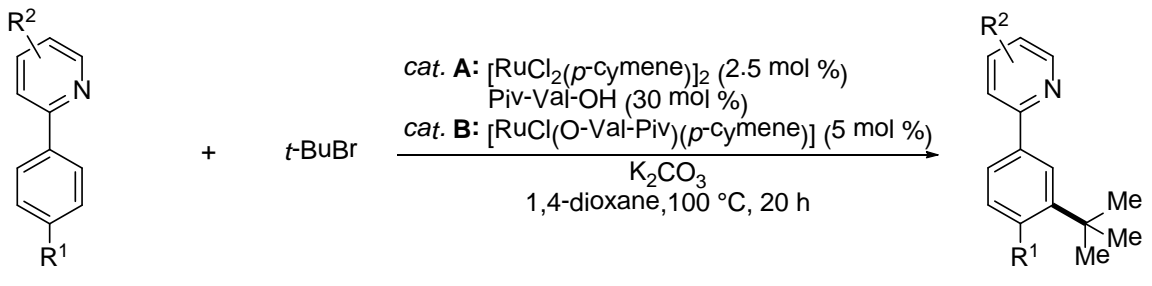

38

$50 a$

187

Entry Phenylpyridine 38 Yield (\%)


4<smiles>COC(=O)c1ccc(Br)cc1</smiles>

$38 \mathrm{e}$

5

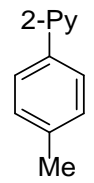

$38 f$

CF

$38 \mathrm{~g}$

CN

$38 \mathrm{~h}$

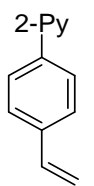

$38 \mathrm{i}$<smiles>COc1cccnc1-c1ccccc1</smiles>

38j<smiles>Cc1cccnc1-c1ccccc1</smiles>

$38 k$<smiles>Cc1ccc(-c2ccccc2)nc1</smiles><smiles>COC(=O)c1ccc(Br)cc1C(C)(C)C</smiles>

187ea<smiles>Cc1ccc(Br)cc1C(C)(C)C</smiles>

$187 f a$<smiles>CC(C)(C)c1cc(Br)ccc1C(F)(F)F</smiles>

187ga<smiles>CCCCCCC(C)(C)c1cc(C#N)ccc1C(C)(C)C</smiles>

187ha<smiles>C=Cc1ccc([18O])cc1C(C)(C)C</smiles>

A: 20

187ia<smiles>COc1cccnc1-c1cccc(C(C)(C)C)c1</smiles>

A: 72

B: 71

187ja<smiles>Cc1cccnc1-c1cccc(C(C)(C)C)c1</smiles>

A: 61

B: 79<smiles>Cc1ccc(-c2cccc(C(C)(C)C)c2)nc1</smiles>

A: 57

B: 65 
12<smiles>Fc1ccc(-c2ccccc2)nc1</smiles>

$38 \mathrm{~m}$<smiles>c1ccc(-c2ccc(-c3ccccc3)nc2)cc1</smiles>

$38 n$

$\mathrm{Me}$<smiles>COc1ccc(-c2cc(Cl)ccn2)cc1</smiles>

380

15<smiles>CC(=O)c1ccnc(-c2ccccc2)c1</smiles>

$38 p$<smiles>CC(C)(C)c1cccc(-c2ccc(F)cn2)c1</smiles>

A: 56

A: 24

A: 52

B: 74

A: $48^{\mathrm{b}}$<smiles>CC(=O)c1ccnc(-c2cccc(C(C)(C)C)c2)c1</smiles>

187pa

a Reaction conditions: cat. A: $\left[\mathrm{RuCl}_{2}(p \text {-cymene })\right]_{2} \quad(2.5 \mathrm{~mol} \%)$, Piv-Val-OH $(30 \mathrm{~mol} \%)$ or cat B: [RuCl(O-Val-Piv)(p-cymene)] (5.0 mol \%); 38 (0.5 mmol), 50a $(1.5 \mathrm{mmol}), \mathrm{K}_{2} \mathrm{CO}_{3}(1.0 \mathrm{mmol}), 1,4$-dioxane $(2 \mathrm{~mL})$, $100{ }^{\circ} \mathrm{C}, 20 \mathrm{~h}$, under $\mathrm{N}_{2}$; isolated yields. ${ }^{\mathrm{b}} 10 \mathrm{~mol} \%[\mathrm{Ru}]$.

Summarizing the results of alkylations of ortho- and meta-substituted 2-phenylpyridines $\mathbf{3 8}$ (Table 3.4), it is particularly noteworthy that ortho-substituted arene $\mathbf{3 8 q}$ furnished the products $\mathbf{1 8 7}$ being substituted exclusively at the sterically more congested meta-position (entries 1 and 2). meta-Methoxy substituted arene $\mathbf{3 8} \mathrm{r}$ selectively furnished the product $187 \mathrm{rb}$ alkylated in meta-position, with respect to both methoxy and pyridyl substituents, although with lower efficacy (entry 3). Furthermore, meta-selective alkylation of naphthalene derivative 38s gave rise to 4-substituted product 187sa, albeit in low yield (entry 4). 
Table 3.4: Scope for meta-alkylation of ortho- and meta-substituted 2-phenylpyridines 38<smiles>c1ccc(-c2ccccn2)cc1</smiles>

38

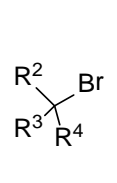

50

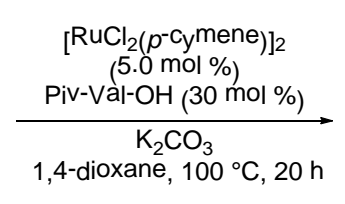

1,4-dioxane, $100^{\circ} \mathrm{C}, 20 \mathrm{~h}$

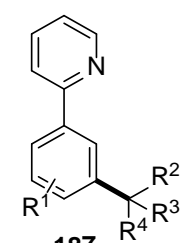

187

Entry 2 Phenylpyridine 37 37 Tertiary Bromide 50

Reaction conditions: 38 (0.5 mmol), $\mathbf{5 0}$ (1.5 mmol), $\left[\mathrm{RuCl}_{2}(p \text {-cymene) }]_{2}\right.$ (5.0 mol \%), Piv-Val-OH (30 mol \%), $\mathrm{K}_{2} \mathrm{CO}_{3}(1.0$ mmol), 1,4-dioxane $(2 \mathrm{~mL}), 100^{\circ} \mathrm{C}, 20 \mathrm{~h}$, under $\mathrm{N}_{2}$; isolated yields.

Taking the importance of heteroarenes as key motifs in various bioactive compounds into consideration, we were delighted to observe alkylation of substituted thiophene $38 \mathbf{t}$ in a meta-selective fashion as well (Scheme 3.1).

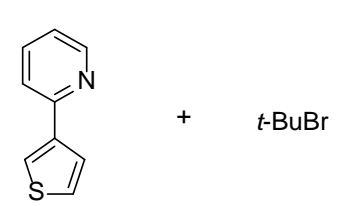

$38 t$

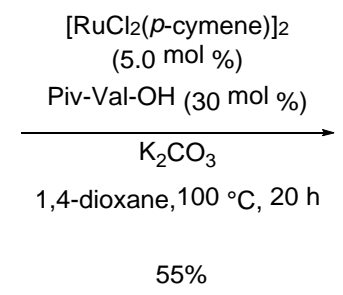

$55 \%$

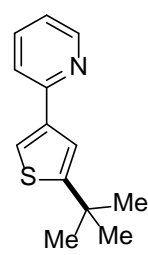

187 ta

Scheme 3.1: Direct meta-alkylation of 2-(thiophen-3-yl)pyridine (37t)

Besides pyridine, synthetically useful the pyrazole heteroarene could serve as a directing group for the ruthenium(II)-catalyzed meta-alkylation as well (Table 3.5). 1-Phenylpyrazole derivatives 131 bearing either electron-donating or electron-withdrawing groups could be smoothly meta-alkylated 
with a range of tertiary alkyl bromides (entries 1-4). However, moderate to low yields were observed when electron-neutral 1-phenylpyrazole (131c) (entries 5-6) or electron-deficient one 131d (entries 7 and 9) were subjected to the optimized reaction condition. In accordance with the reactivity of ortho-substituted 2-phenylpyridines 38 discussed above, direct alkylation of ortho-substituted 1-phenylpyrazole 131e only took place at the sterically more congested meta-C-H bond (entries 9).

Table 3.5: Scope for meta-C-H alkylation of substituted 1-phenylpyrazoles 131

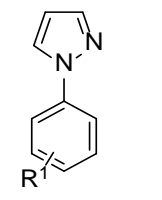

131

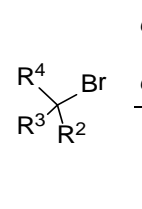

50

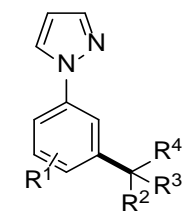

196

Entry Substrate 131


6<smiles>c1ccc(-n2cccn2)cc1</smiles>

131c

7<smiles>CC(=O)c1ccc(-n2cccn2)cc1</smiles>

131d

8<smiles>CC(=O)c1ccc(-n2cccn2)cc1</smiles>

131d<smiles>COc1ccccc1-n1cccn1</smiles>

131e<smiles>CC=CC([Mg])(Br)CC</smiles>

$50 \mathrm{~b}$

$t$-BuBr

$50 a$

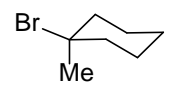

$50 \mathrm{~b}$

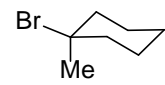

50b<smiles>CCCC(C)(C)c1cccc(-n2cccn2)c1</smiles>

196cb<smiles>CC(=O)c1ccc(-n2cccn2)cc1C(C)(C)C</smiles>

196da<smiles>CCCC(C)(C)c1cc(-n2cccn2)ccc1C(C)=O</smiles>

196db
A: 29

A: 38

A: 21

A: 24

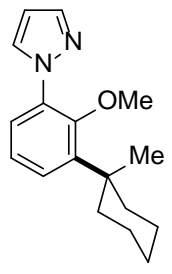

196eb

${ }^{\mathrm{a}}$ Reaction conditions: A: $\left[\mathrm{RuCl}_{2}(p \text {-cymene) }]_{2}\right.$ (5.0 mol \%), Piv-Val-OH (30 mol \%); B: [RuCl(O-Val-Piv)(p-cymene)] (195) (10 mol \%); 131 (0.5 mmol), 50 (1.5 mmol), $\mathrm{K}_{2} \mathrm{CO}_{3}(1.0 \mathrm{mmol}), 1$,4-dioxane $(2 \mathrm{~mL}), 100{ }^{\circ} \mathrm{C}, 20 \mathrm{~h}$, under $\mathrm{N}_{2}$; isolated yields.

Moreover, 2-phenylpyrimidine derivatives 197 appeared to be suitable substrates for the ruthenium(II)-catalyzed meta-selective direct alkylation as well (Table 3.6). Both the in situ formed catalytic system and the ruthenium(II) complex 195 were applicable. Unsubstituted arene 197a smoothly delivered meta-alkylated product 198aa in moderate yields (entry 1). While electron-rich arene 197b showed lower efficacy (entry 2), high yield was obtained for electron-deficient arene 197c under catalysis with the ruthenium(II)-Piv-Val-OH complex 195 (entry 3). 
Table 3.6: Direct meta-C-H alkylation of substituted pyrimidine 197<smiles></smiles>

197

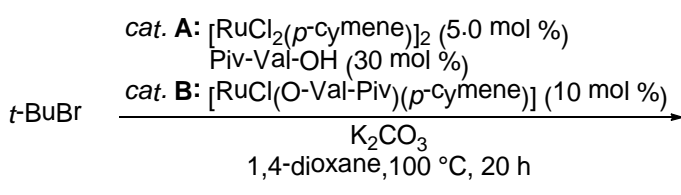

$50 a$

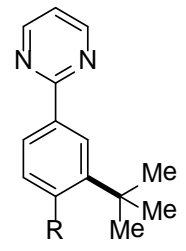

198

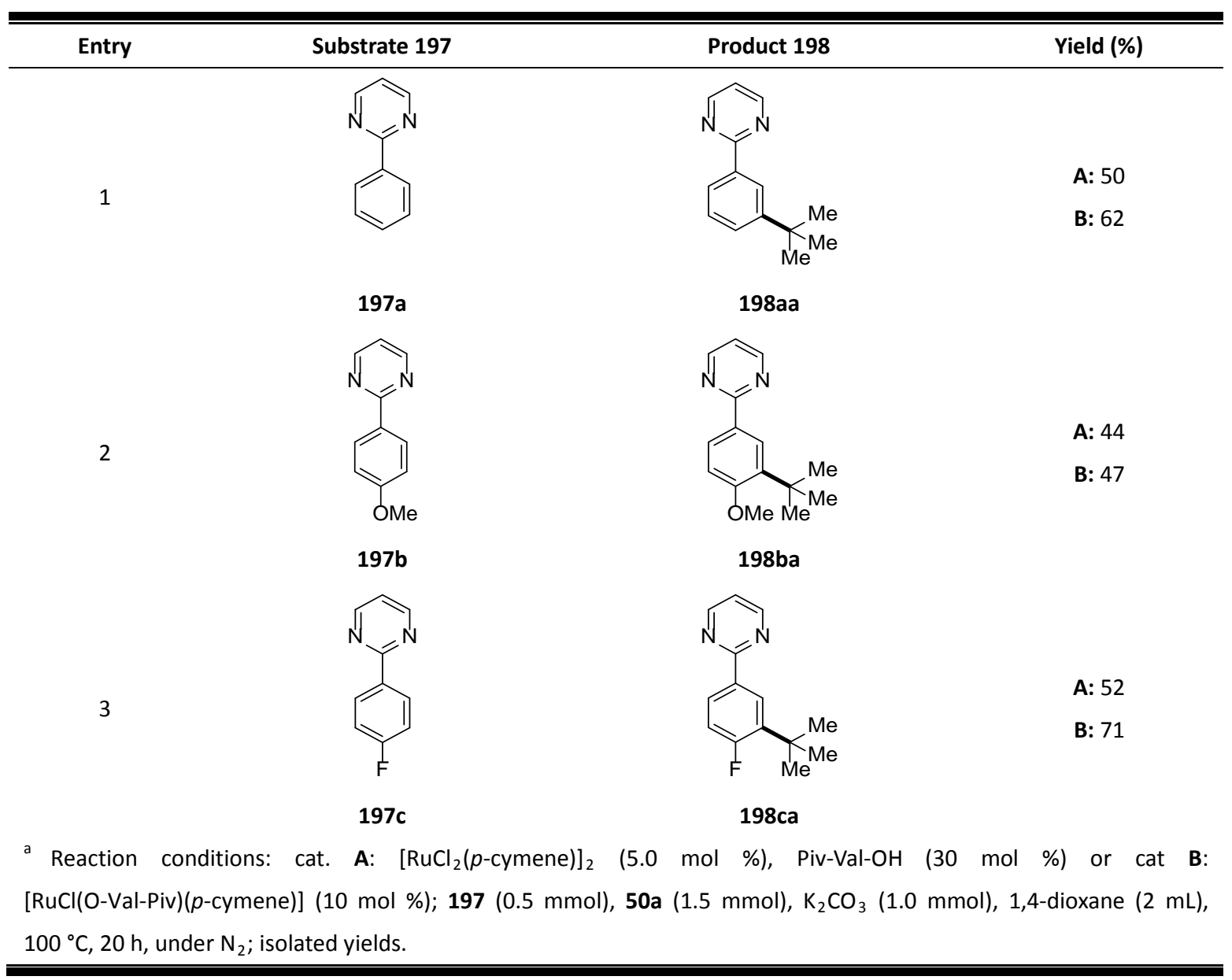

\subsubsection{Mechanistic Studies}

Given the unique meta-selectivity of our ruthenium(II)-catalyzed direct alkylation, we performed detailed mechanistic studies to delineate its mode of action. To this end, we conducted intermolecular competition experiments and experiments with isotopically labeled starting materials.

\subsubsection{Intermolecular Competition Experiments}

Intermolecular competition experiments between para-substituted 2-phenylpyridines (38) were performed, in which a 1.25 fold excess of both substrates was treated with bromide 50a as the limiting reagent under otherwise identical optimized reaction conditions. The ratio of products was determined by ${ }^{1} \mathrm{H}$-NMR after aqueous workup. 


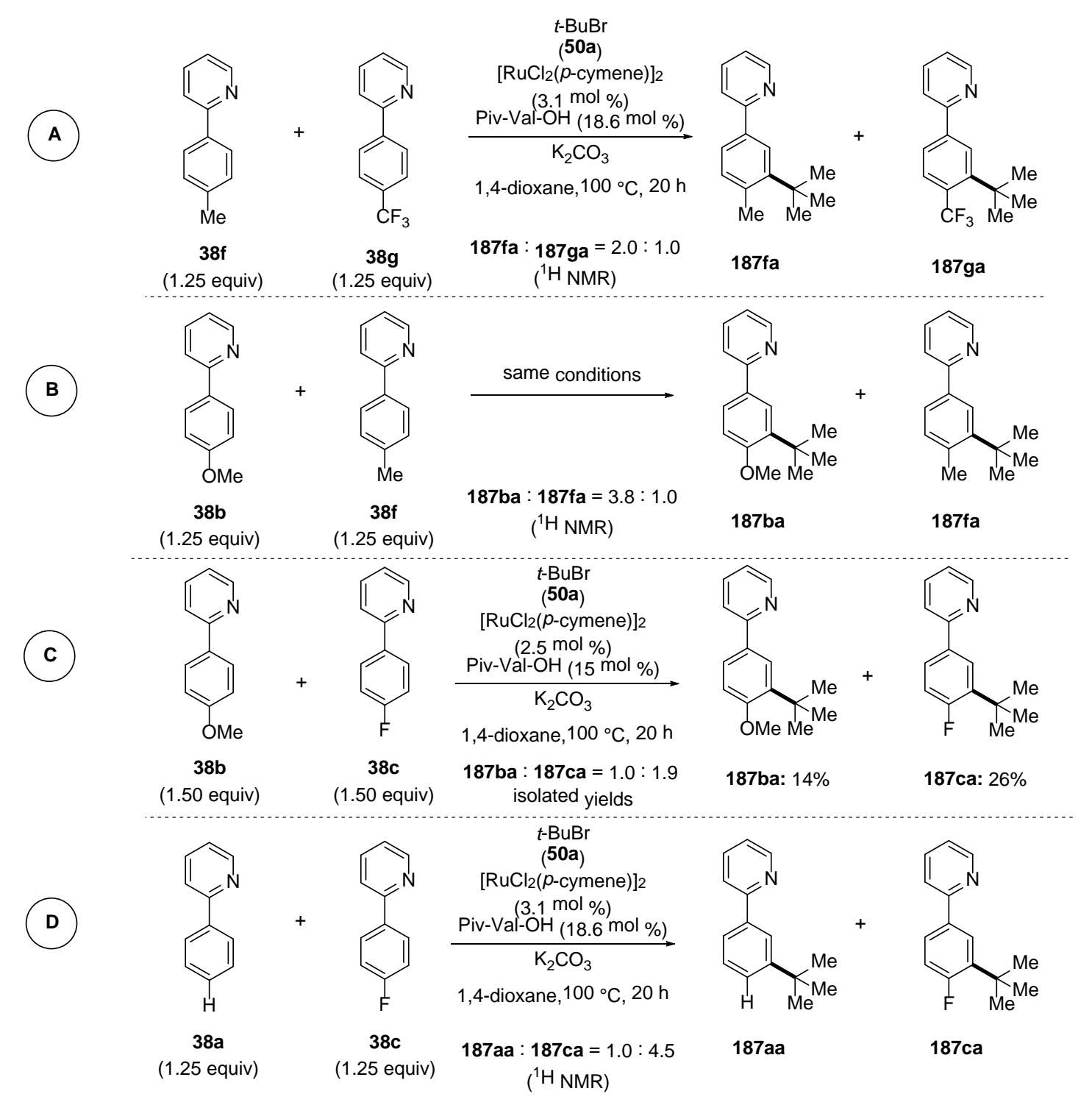

Scheme 3.2: Intermolecular competition experiments between substituted 2-phenylpyridines $\mathbf{3 8}$

Experiment $\mathbf{A}$ showed electron-rich substrate $\mathbf{3 8 f}$ to be more reactive in comparison to its trifluoromethyl-substituted analogue 38g. Similar result could be observed in experiment B, in which arene $\mathbf{3 8 b}$ with electronically more donating substituent reacted more rapidly than methyl-containing compound 38f. Interesting results were obtained from experiments $\mathbf{C}$ and $\mathbf{D}$. Thus, electron-deficient fluoro-substituted arene $\mathbf{3 8 c}$ was found to be more reactive than both methoxy substituted $\mathbf{3 8 b}$ and unsubstituted 38a. This phenomenon could be rationalized as the result of ortho-orienting effect of the fluorine substituent. ${ }^{234}$

Subsequently, we performed competition experiments between tertiary alkyl bromide 50b and primary alkyl bromide $\mathbf{4 2 e}$ as well as between $\mathbf{5 0 f}$ and secondary alkyl bromide $\mathbf{4 4 d}$. These results showed no special preference of either reaction. The reaction rates appeared to be comparable and still conserving the individual regioselectivity mode for each electrophile. 


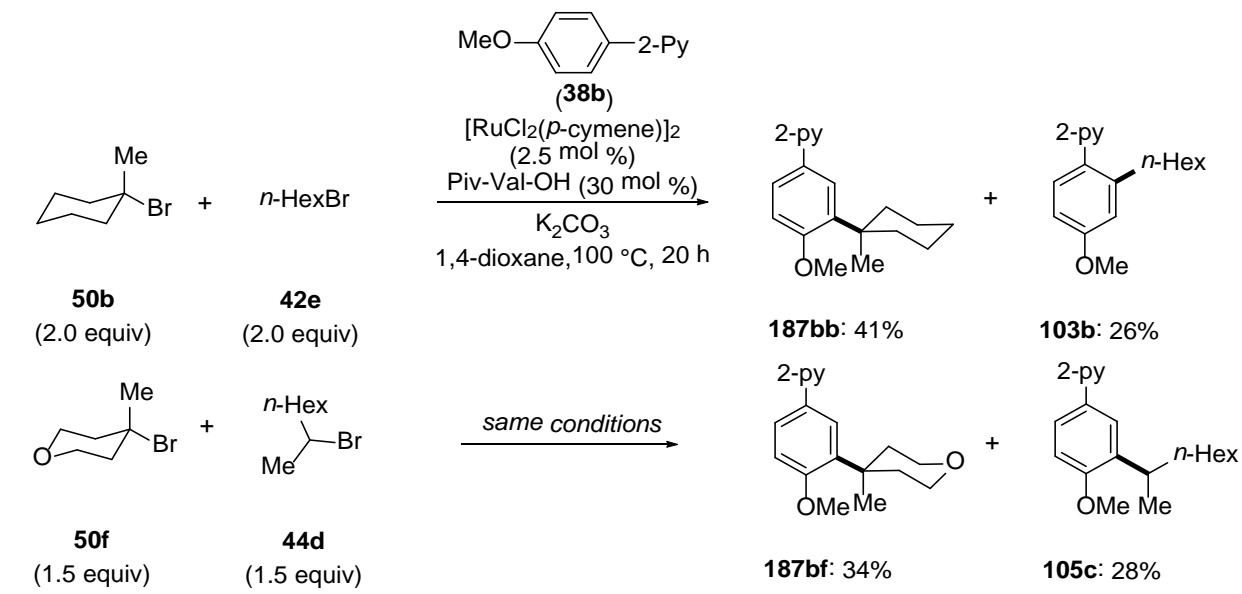

Scheme 3.3: Intermolecular competition experiments between alkyl bromides $4 \mathbf{2 e}$, $44 \mathrm{~d}$ and $\mathbf{5 0 b}$, 50f

\subsubsection{Experiments with Deuterium-Labeled Substrates}

As shown in Scheme 3.4, upon alkylation of deuterated 2-phenylpyridine $\left[\mathrm{D}_{5}\right]-38$ a under the optimized reaction conditions, significant $\mathrm{D} / \mathrm{H}$ exchanges in the ortho-positions of both substrate and product were observed. We found $81 \%$ and $58 \%$ hydrogen incorporation in the product $\left[D_{n}\right]-187$ aa as well as $57 \%$ hydrogen incorporation in the recovered starting material $\left[D_{n}\right]-38 a$. This result provided strong support for the $\mathrm{C}-\mathrm{H}$ bond metalation step to proceed initially in the ortho-position of the arene. Moreover, the $\mathrm{D} / \mathrm{H}$-exchange caused by adventitious water in the stoichiometric base and by the acid moiety in the co-catalytic additive Piv-Val-OH indicated the ortho $\mathrm{C}-\mathrm{H}$ bond metalation to be reversible in nature.

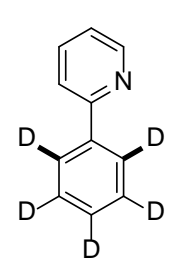

[D5]-38a

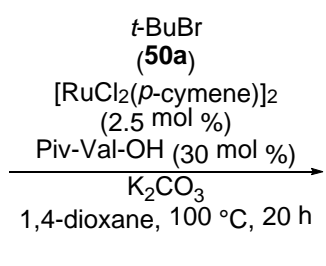

Scheme 3.4: $\mathrm{D} / \mathrm{H}$ exchange during direct meta-alkylation of $\left[\mathrm{D}_{5}\right]$-phenylpyridine 38a

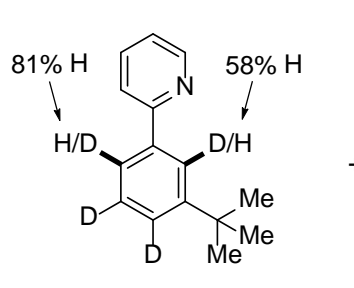

[Dn]-187aa: 54\%

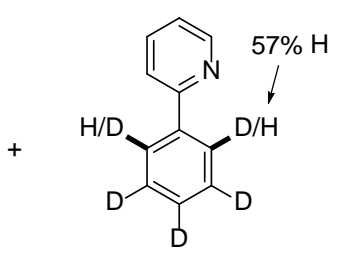

[Dn]-38a: 19\%

We also performed our standard reaction in the presence of small amounts of $\mathrm{D}_{2} \mathrm{O}$ (Scheme 3.5). In accordance with our previously discussed reaction of $\left[D_{5}\right]-38$ a (Scheme 3.4), a significant amount of deuterium incorporation in the ortho-positions of both product and recovered starting material was observed.

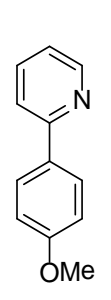

$38 b$

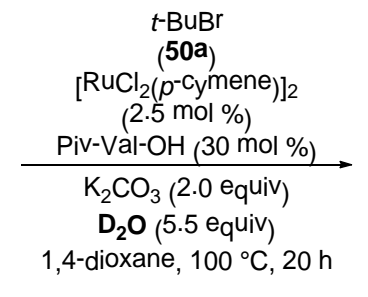

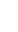

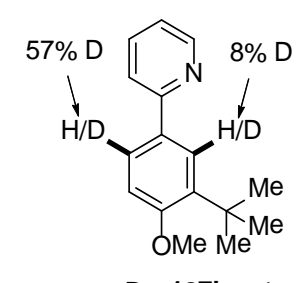

$\left[D_{n}\right]^{-187 b a: ~} 4 \%$

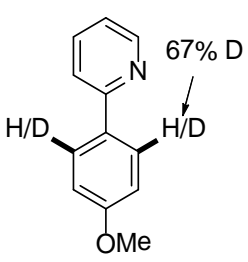

$\left[D_{n}\right]^{-38 b: 82 \%}$

Scheme 3.5: Direct meta-alkylation of arene $38 \mathbf{b}$ in the presence of $D_{2} \mathrm{O}$ 
To probe the mechanism of the cleavage of the meta- $\mathrm{C}-\mathrm{H}$ bond and the formation of the $\mathrm{C}-\mathrm{C}$ bond, $\left[\mathrm{D}_{3}\right]$-38a was also subjected to the optimized reaction conditions. The reaction smoothly delivered meta-alkylated product $\left[D_{2}\right]-187$ aa in $46 \%$ isolated yield together with $32 \%$ of recovered substrate $\left[D_{3}\right]$-38a (Scheme 3.6). Detailed ${ }^{1} H$ NMR studies showed no hydrogen incorporation in any meta-positions neither of the product nor of the recovered starting material, thus indicating the meta- $\mathrm{C}-\mathrm{H}$ bond cleavage and $\mathrm{C}-\mathrm{C}$ bond forming step to be irreversible.<smiles>[2H]c1cc(-c2ccccn2)cc([2H])c1[2H]</smiles>

$\left[\mathrm{D}_{3}\right]-\mathbf{3 8 a}$

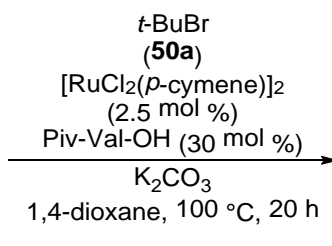

Scheme 3.

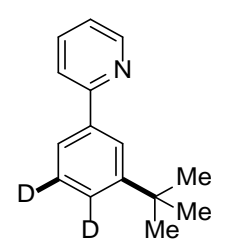

[D2]-187aa: $46 \%$

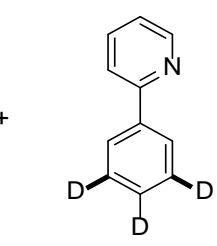

[D3]-38a: $32 \%$

Moreover, we performed an intermolecular competition experiment between equimolar amounts of 2-phenylpyridines 38a and $\left[D_{3}\right]$-38a under the optimized reaction conditions. On the average of 2 runs, a KIE of 1.44 was established.

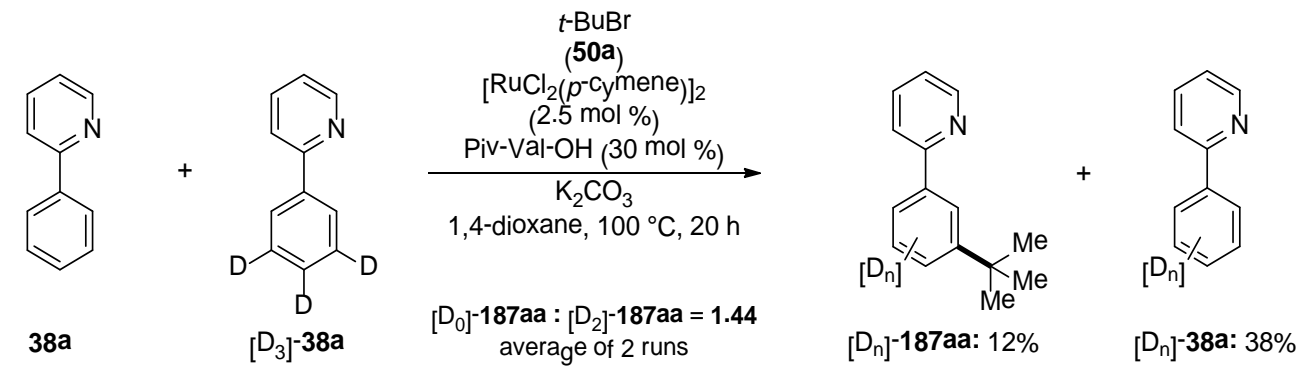

Scheme 3.7: KIE study through competition between arenes $\left[D_{0}\right]-37 a$ and $\left[D_{3}\right]-37 a$

\subsubsection{Experiments in the Presence of Radical Scavengers}

In order to gain some understanding about the $\mathrm{C}-\mathrm{C}$ bond formation, we performed reactions in the presence of different radical scavengers 199 to see, if any kind of alkyl radical was formed in this novel transformation (Table 3.7). Stoichiometric amounts of TEMPO (199a) completely inhibited the reaction. However, this observation could not finally confirm a radical mechanism. For instance, it is known that ruthenium hydride smoothly react with TEMPO to form a ruthenium-TEMPO complex. ${ }^{235}$ On the contrary, other representative scavengers such as BHT (199b) and E-stilbene (199d) did not affect the reaction outcome, furnishing product $187 \mathrm{ba}$ in comparable yields. When 1,1-diphenylethylene (199c) was added, only $9 \%$ of the meta-alkylated product 187 ba was obtained. 
Table 3.7: $\mathrm{C}-\mathrm{H}$ meta-alkylation in the presence of radical scavengers 199

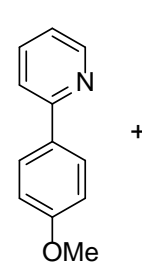

$38 b$

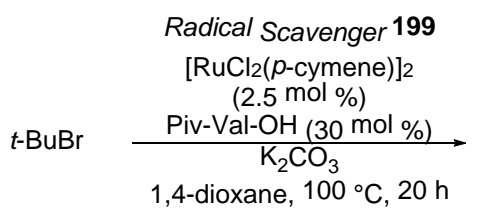

$50 a$

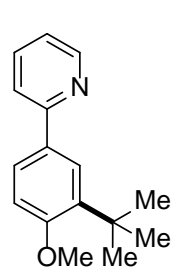

$187 \mathrm{ba}$

\begin{tabular}{ll}
\hline Entry & Yield (\%) \\
\hline & \\
3 & \\
4 &
\end{tabular}

\subsubsection{Proposed Catalytic Cycle}

Based on the experimental studies summarized above and taken into account the studies of ruthenium(II)-catalyzed meta-alkylation with secondary alkyl halides ${ }^{143}$ and ruthenium(II)-catalyzed meta-sulfonylation, ${ }^{70}$ we propose a plausible catalytic cycle which is shown in Scheme 3.8.

Initially, the ruthenium(II)-MPAA complex 195 undergoes ligand exchange with substrate $\mathbf{3 8 a}$ and is coordinated by the nitrogen atom of the pyridine directing group to form complex 200. Subsequently, the amino acid enables the reversible cyclometalation via transition state 201, thus forming a five-membered ruthenacycle 202. The strong directing group effect of the $R u-C\left(s p^{2}\right) \sigma$-bond introduces the irreversible tert-alkylation predominantly in the remote para-position. ${ }^{73}$ However, the exact pathway for the C-C bond forming step is still not understood, and tertiary alkyl cation or radical could be involved as well. Finally, the proto-demetalation step delivers the meta-alkylated product 187aa and regenerating the catalytically active species 195 . 


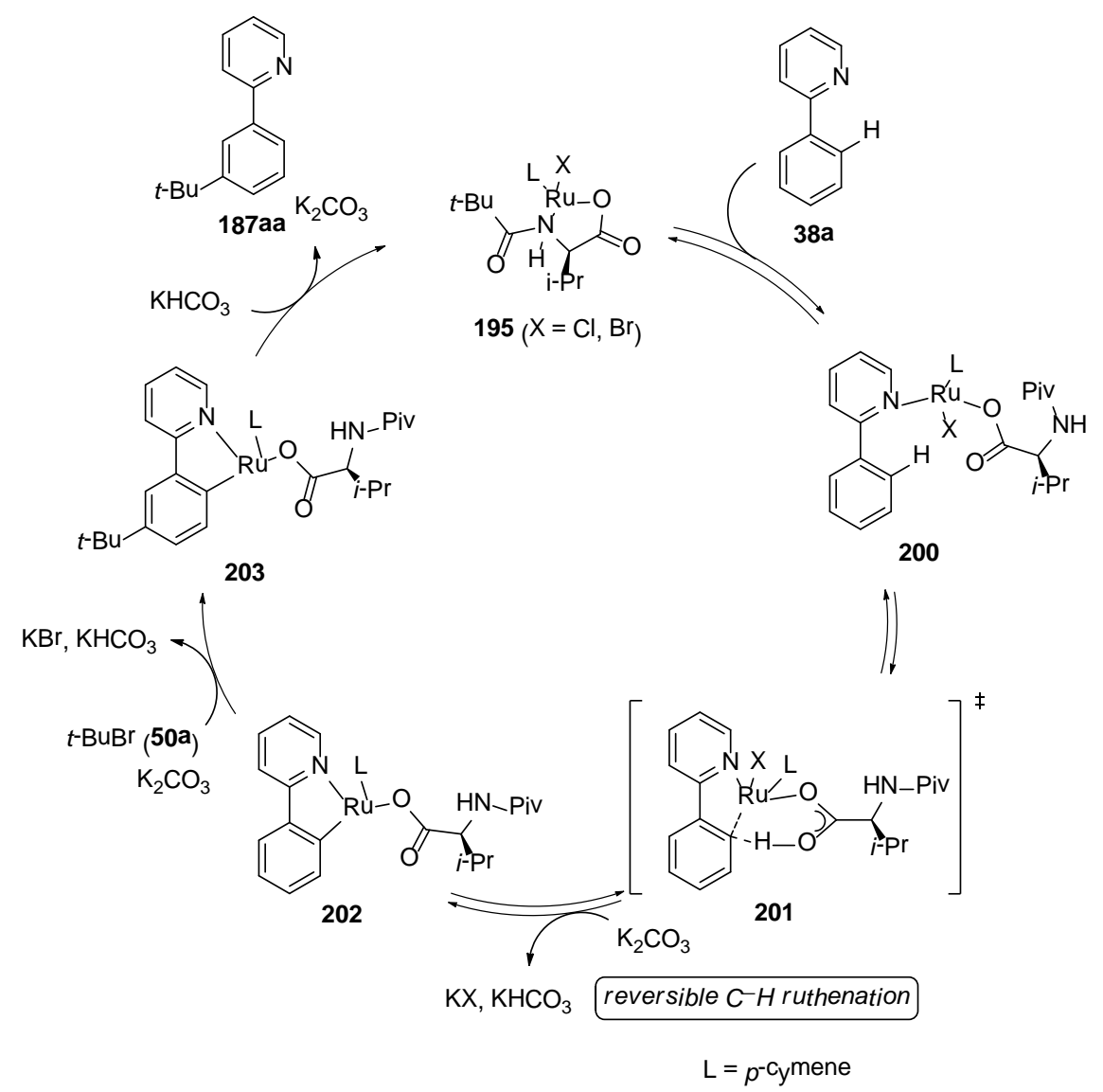

Scheme 3.8: Proposed catalytic cycle for the ruthenium(II)-catalyzed direct meta-alkylation with bromide 50a

Moreover, Houk, $\mathrm{Yu}$ and $\mathrm{Wu}$ have investigated the role of $\mathrm{N}$-acyl amino acid in palladium-catalyzed remote $\mathrm{C}-\mathrm{H}$ activation of tethered arenes. ${ }^{236}$ Computational studies suggested the MPAA ligand not only to stabilize the monomeric palladium complex but also to serve as the internal base for proton abstraction. Hence, a similar transition state $\mathbf{2 0 5}$ for the ruthenium(II)-catalyzed meta-alkylation enabled by MPAA ligand could be possible.

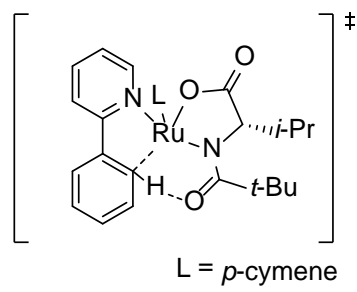

205

Scheme 3.9: Possible transition state 205 for the ruthenium(II)-catalyzed direct meta-alkylation 


\subsection{Ruthenium(II)-Catalyzed meta-Selective $\mathrm{C}-\mathrm{H}$ Alkylations of Ketimines with Secondary and Tertiary Alkyl Bromides}

Inspired by the success of our ruthenium(II)-catalyzed direct meta-alkylation reactions of 2-phenylpyridines 38, 1-phenylpyrazoles 131 and 2-phenylpyrimidines 197 described above, we became intrigued to enlarge the synthetically usefulness of this unprecedented meta-selective tertiary alkylation by modifying the directing group from heterocycles to those which can be readily manipulated. Since the Ackermann group reported on the ruthenium(II)-catalyzed ortho-alkylation of ketimines with primary alkyl bromides and given the versatile application of ketimines, ${ }^{142}$ we set out to develop ruthenium(II)-catalyzed direct meta-alkylation of ketimines 188 with both tertiary and secondary alkyl bromides.

\subsubsection{Optimization Studies}

Preliminary studies by $N$. Hoffmann on the ruthenium(II)-catalyzed secondary alkylation of ketimines showed that ketimine 188a bearing electron-withdrawing substituent could be meta-alkylated with both cyclic and acyclic secondary alkyl bromides. ${ }^{237}$ Although only unsatisfactory low yields were obtained, it was a proof of principle that ketimines are suitable substrates for this transformation. At the outset of our studies, we subjected substituted ketimine 188aa to our standard reaction conditions for the meta-alkylation of 2-phenylpyridines; the results are summarized in Table 3.8. To our delight, the desired meta-alkylated acetophenone 189ab was obtained in 22\% yield after one-pot hydrolysis (entry 1 ). Whereas $\mathrm{MesCO}_{2} \mathrm{H}$ provided only $26 \% \mathrm{NMR}$ conversion, the desired product $189 \mathrm{ab}$ was obtained in $50 \%$ yield when using $1-\mathrm{AdCO}_{2} \mathrm{H}$ as an additive (entries 2 and 3). Decreasing the reaction temperature to $100{ }^{\circ} \mathrm{C}$ completely shut down the reaction. Moreover, elevating the reaction temperature to $140{ }^{\circ} \mathrm{C}$ led to lower yields (entries 4 and 5 ). Among several solvents screened, toluene and $o$-xylene could give comparable results (entries 6-9). Using $\mathrm{Cs}_{2} \mathrm{CO}_{3}$ as a base instead of $\mathrm{K}_{2} \mathrm{CO}_{3}$ could also deliver the product in comparable $49 \%$ yield. On the contrary, $\mathrm{Na}_{2} \mathrm{CO}_{3}$ and $\mathrm{Ag}_{2} \mathrm{CO}_{3}$ proved to be unsuitable bases (entries 10-12). Furthermore, stoichiometric amount of base in the absence of co-catalyst only led to unsatisfactory low yields (entries 13 and 14). Subsequently, we tested different protecting groups on the imine moiety, among which 3,4,5-trimethoxyphenyl (TMP) proved to be the most efficient one (entries 16-21). As shown in entry 18, although a high GC-conversion was determined in this transformation, only 66\% NMR conversion and 52\% isolated product was obtained, which indicated an unsatisfactory mass balance. Generally, a pale spot could always be observed on the baseline of the TLC analysis in these reactions. However, attempts on isolating and identifying these by-products were unsuccessful. 
Table 3.8: Optimization for ruthenium(II)-catalyzed direct meta-alkylation of ketimines 188<smiles>CC(=NO)c1ccc(F)cc1</smiles>

188

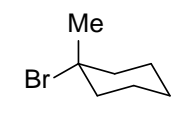

50b

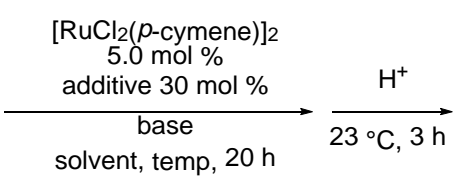

solvent, temp, $20 \mathrm{~h}$

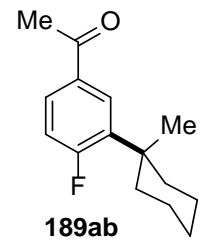

\begin{tabular}{|c|c|c|c|c|c|c|}
\hline Entry & PG & Additive & Base & Solvent & $\operatorname{Temp}\left({ }^{\circ} \mathrm{C}\right)$ & Yield (\%) \\
\hline 1 & PMP (188aa) & Piv-Val-OH & $\mathrm{K}_{2} \mathrm{CO}_{3}$ & 1,4-dioxane & 120 & 22 \\
\hline 2 & PMP & $\mathrm{MesCO}_{2} \mathrm{H}$ & $\mathrm{K}_{2} \mathrm{CO}_{3}$ & 1,4-dioxane & 120 & $26^{b}$ \\
\hline 3 & PMP & 1- $\mathrm{AdCO}_{2} \mathrm{H}$ & $\mathrm{K}_{2} \mathrm{CO}_{3}$ & 1,4-dioxane & 120 & 50 \\
\hline 4 & PMP & 1- $\mathrm{AdCO}_{2} \mathrm{H}$ & $\mathrm{K}_{2} \mathrm{CO}_{3}$ & 1,4-dioxane & 100 & 0 \\
\hline 5 & PMP & 1- $\mathrm{AdCO}_{2} \mathrm{H}$ & $\mathrm{K}_{2} \mathrm{CO}_{3}$ & 1,4-dioxane & 140 & 47 \\
\hline 6 & PMP & $1-\mathrm{AdCO}_{2} \mathrm{H}$ & $\mathrm{K}_{2} \mathrm{CO}_{3}$ & NMP & 120 & 0 \\
\hline 7 & PMP & 1- $\mathrm{AdCO}_{2} \mathrm{H}$ & $\mathrm{K}_{2} \mathrm{CO}_{3}$ & $o$-xylene & 120 & 49 \\
\hline 8 & PMP & 1- $\mathrm{AdCO}_{2} \mathrm{H}$ & $\mathrm{K}_{2} \mathrm{CO}_{3}$ & DME & 120 & 36 \\
\hline 9 & PMP & 1- $\mathrm{AdCO}_{2} \mathrm{H}$ & $\mathrm{K}_{2} \mathrm{CO}_{3}$ & PhMe & 120 & 52 \\
\hline 10 & PMP & 1- $\mathrm{AdCO}_{2} \mathrm{H}$ & $\mathrm{Na}_{2} \mathrm{CO}_{3}$ & PhMe & 120 & $<5$ \\
\hline 11 & PMP & 1- $\mathrm{AdCO}_{2} \mathrm{H}$ & $\mathrm{Cs}_{2} \mathrm{CO}_{3}$ & PhMe & 120 & 49 \\
\hline 12 & PMP & $1-\mathrm{AdCO}_{2} \mathrm{H}$ & $\mathrm{Ag}_{2} \mathrm{CO}_{3}$ & PhMe & 120 & 0 \\
\hline 13 & PMP & - & KOAC & PhMe & 120 & $30^{b}$ \\
\hline 14 & PMP & - & $\mathrm{NaOAC}$ & PhMe & 120 & $<5$ \\
\hline 15 & PMP & Piv-Val-OH & $\mathrm{K}_{2} \mathrm{CO}_{3}$ & PhMe & 120 & $30^{b}$ \\
\hline 16 & $\mathrm{Bn}(188 \mathrm{ab})$ & 1- $\mathrm{AdCO}_{2} \mathrm{H}$ & $\mathrm{K}_{2} \mathrm{CO}_{3}$ & PhMe & 120 & 30 \\
\hline 17 & оме & 1- $\mathrm{AdCO}_{2} \mathrm{H}$ & $\mathrm{K}_{2} \mathrm{CO}_{3}$ & PhMe & 120 & 58 \\
\hline 18 & & 1- $\mathrm{AdCO}_{2} \mathrm{H}$ & $\mathrm{K}_{2} \mathrm{CO}_{3}$ & 1,4-dioxane & 120 & $87^{c}, 66^{b}, 52$ \\
\hline 19 & (188a) & Piv-Val-OH & $\mathrm{K}_{2} \mathrm{CO}_{3}$ & PhMe & 120 & $26^{\mathrm{b}}$ \\
\hline 20 & (188ac) & 1- $\mathrm{AdCO}_{2} \mathrm{H}$ & $\mathrm{K}_{2} \mathrm{CO}_{3}$ & $\mathrm{PhMe}$ & 120 & 51 \\
\hline 21 & (188ad) & 1- $\mathrm{AdCO}_{2} \mathrm{H}$ & $\mathrm{K}_{2} \mathrm{CO}_{3}$ & PhMe & 120 & $50^{b}$ \\
\hline $\begin{array}{l}{ }^{\mathrm{a}} \text { Reactic } \\
(1.0 \mathrm{~mm} \\
{ }^{\mathrm{c}} \mathrm{GC} \text {-con }\end{array}$ & $\begin{array}{l}\text { ditions: } 188 \mathrm{a} \\
\text { lvent }(2 \mathrm{~mL})\end{array}$ & $\begin{array}{l}\mathrm{mol}), \mathbf{5 0 b}(1 . \\
\text { nder } \mathrm{N}_{2} ; \text { yiel }\end{array}$ & $\begin{array}{l}\text { hol), [RuCl } \\
\text { solated p }\end{array}$ & $\begin{array}{l}\text { /mene })]_{2}(5.0 \\
\text { ts. }{ }^{b} \mathrm{NMR} \text { yield }\end{array}$ & $\begin{array}{l}\text { ), additive } \\
\mathrm{CH}_{2} \mathrm{Br}_{2} \text { as i }\end{array}$ & $\begin{array}{l}\text { mol \%), base } \\
\text { nal standard. }\end{array}$ \\
\hline
\end{tabular}

\subsubsection{Direct meta-Alkylation with Tertiary Alkyl Bromides: Scope and Limitations}

With the optimized reaction conditions in hand, we subsequently explored the scope and limitations of the meta-selective alkylation in terms of differently substituted ketimines $\mathbf{1 8 8}$ and tertiary alkyl 
bromides 50 (Table 3.9). The parent $t-\mathrm{BuBr}$ (50a) smoothly delivered the desired product 189aa in 59\% yield (entry 1). Sterically more hindered tertiary alkyl bromides also afforded the corresponding products in moderate yields (entries 2-6). It should be emphasized that tertiary alkyl bromide 50h bearing the chlorine substituent was well tolerated (entry 4). Unsubstituted ketimines were also examined under the standard reaction conditions. Thus, meta-alkylated acetophenone $189 \mathrm{ba}$ and propiophenone 189ca were obtained in 54\% and 55\% yield, respectively (entries 7 and 8 ). When arenes 188 bearing electron-donating groups were tested, switching solvent from toluene to 1,4-dioxane was necessary to prevent the undesired benzylation. Both alkylations afforded products $189 \mathrm{da}$ and $189 \mathrm{eb}$ in $47 \%$ yield (entries 9 and 10). Electron-deficient propiophenone-derived ketimine $\mathbf{1 8 8 f}$ was tolerated in this transformation as well (entry 11 ).

Table 3.9: Direct meta-alkylation of ketimines $\mathbf{1 8 8}$ with tertiary alkyl bromides $\mathbf{5 0}$

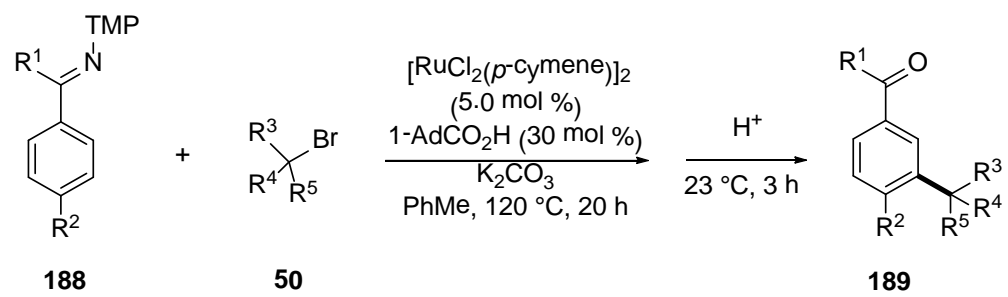

Entry Substrate 188




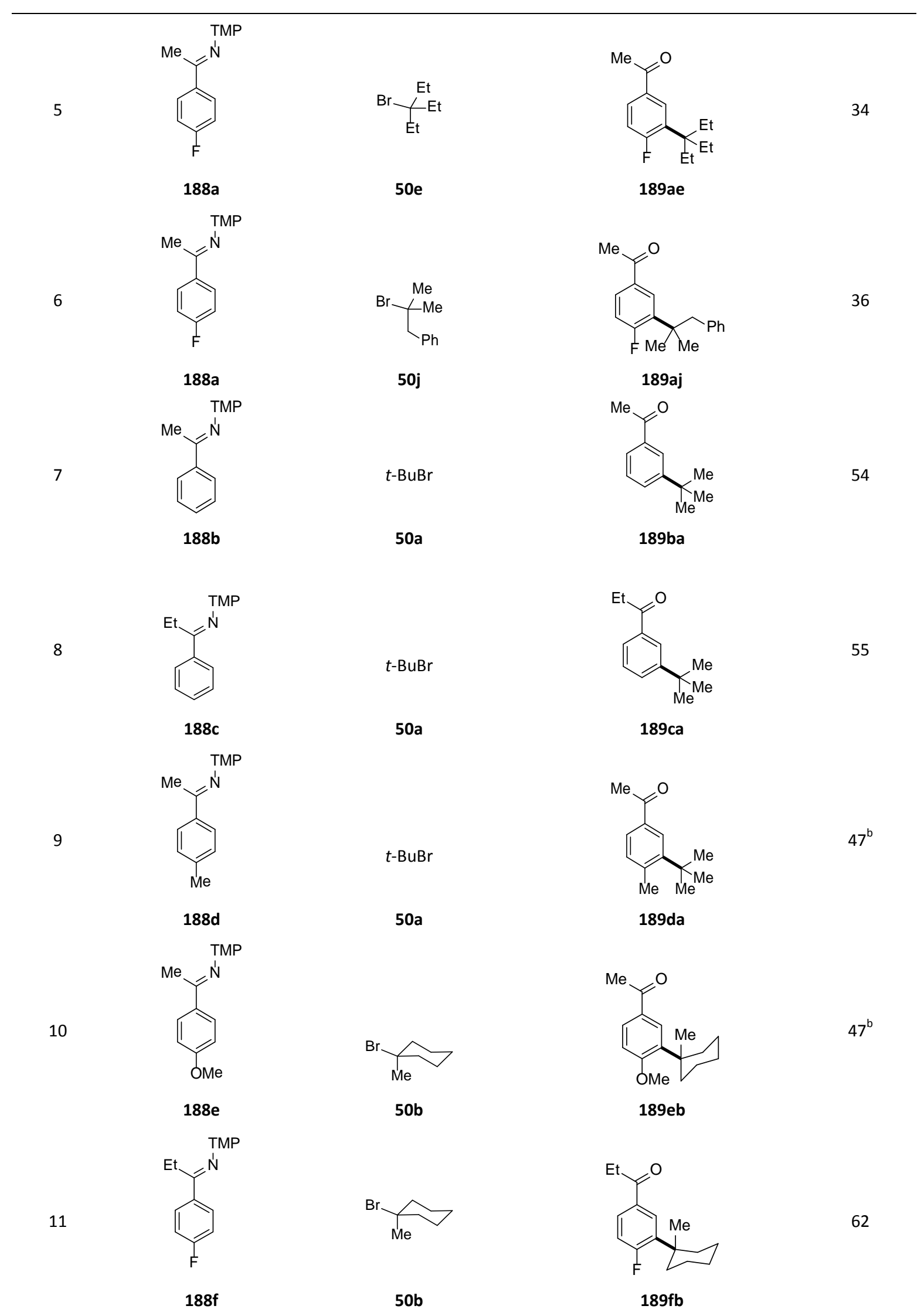




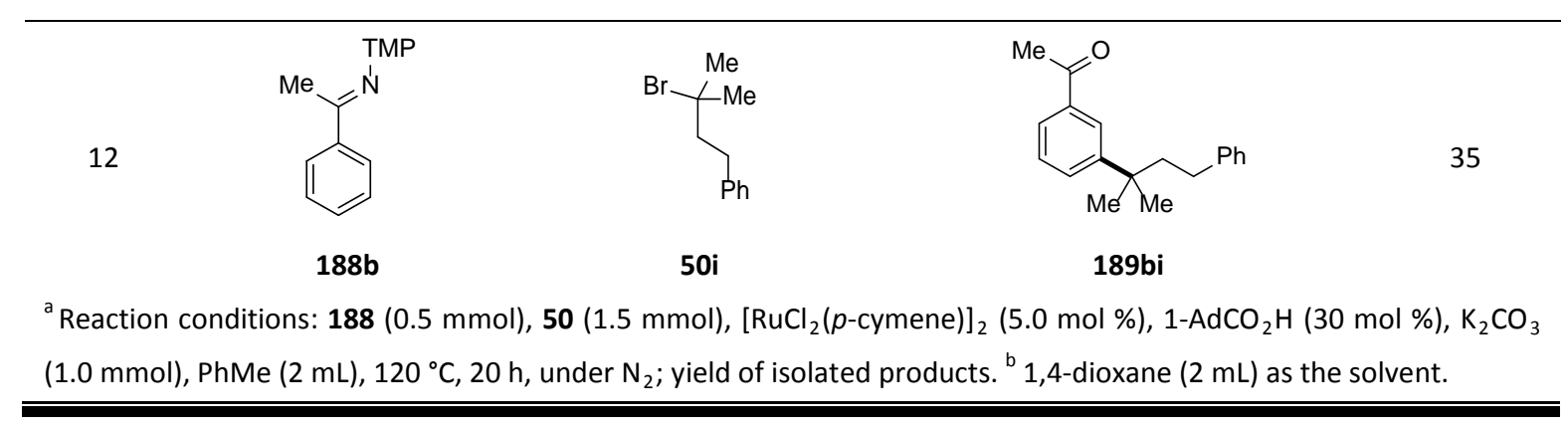

\subsubsection{Direct meta-Alkylation with Secondary Bromides: Scope and Limitations}

Besides tertiary alkyl bromides 50, we were pleased to find that secondary alkyl bromides 44 could also serve as electrophiles in the meta-C-H alkylation reactions. Differently substituted ketimines 188 were tested under the optimized reaction conditions with bromocycloheptane (44e) (Table 3.10). A generally broader scope of ketimines was observed compared to the tertiary alkyl bromides $\mathbf{5 0}$. Transformation of unsubstituted ketimines to the desired products 206 proceeded smoothly (entries 1 and 8). Ketimines bearing both electron-donating and electron-withdrawing groups were well tolerated and delivered meta-alkylated products in moderate to good yields (entries 2-7). It is worth noting that naphthalene derivative 188i selectively furnished meta-substituted product 206ie under the optimized reaction conditions (entry 9).

Table 3.10: Direct meta-C-H alkylation of ketimines 188 with secondary alkyl bromide $44 \mathrm{e}$<smiles>[Y6]N=C([R])c1cc[R]cc1</smiles>

188<smiles>BrC1CCCCCC1</smiles>

$44 e$

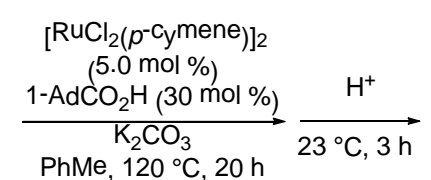

PhMe, $120^{\circ} \mathrm{C}, 20 \mathrm{~h}$

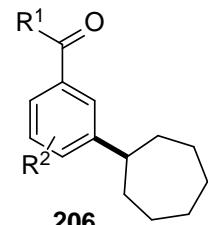

Entry Substrate 188 Yield (\%)


3<smiles>CC(=NN)c1ccc(C)cc1</smiles>

$188 d$<smiles>CC(=N[Na])c1ccc(-c2ccccc2)cc1</smiles>

$188 \mathrm{~g}$<smiles>CC(=N[Na])c1ccc(C(F)(F)F)cc1</smiles>

$188 \mathrm{~h}$<smiles>CC(=NN)c1ccc(F)cc1</smiles>

$188 a$<smiles>CCC(=NN)c1ccc(F)cc1</smiles>

$188 f$<smiles>CCC(=NN)c1ccccc1</smiles>

$188 \mathrm{c}$

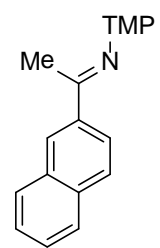

$188 \mathrm{i}$

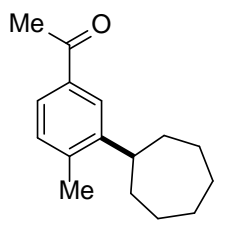

51

206de<smiles>CC(=O)c1ccc(-c2ccccc2)c(C2CCCCCC2)c1</smiles>

60

44<smiles>CC(=O)c1ccc(C(F)(F)F)c(C2CCCCCC2)c1</smiles>

64

$62^{b}$

53

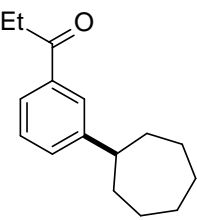

206ce

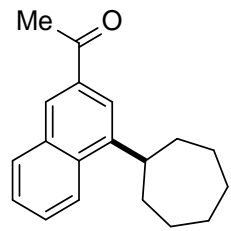

206ie

${ }^{\mathrm{a}}$ Reaction conditions: $188(0.5 \mathrm{mmol}), \mathbf{4 4 e}(1.5 \mathrm{mmol}),\left[\mathrm{RuCl}_{2}(p \text {-cymene })\right]_{2}(5.0 \mathrm{~mol} \%), 1-\mathrm{AdCO}_{2} \mathrm{H}(30 \mathrm{~mol} \%), \mathrm{K}_{2} \mathrm{CO}_{3}$ $(1.0 \mathrm{mmol}), \mathrm{PhMe}(2 \mathrm{~mL}), 120^{\circ} \mathrm{C}, 20 \mathrm{~h}$, under $\mathrm{N}_{2}$; yield of isolated products. ${ }^{\mathrm{b}} 1$,4-Dioxane $(2 \mathrm{~mL})$ as the solvent. 
Subsequently, we continued to explore the scope of acyclic secondary alkyl bromides $\mathbf{4 4}$ (Table 3.11). In contrast to the monoalkylation of ketimine 188a with cyclic secondary alkyl bromides 44 , the reaction with the acyclic secondary bromide $\mathbf{4 4 f}$ led to the formation of dialkylated product in large amounts, whereas the monoalkylated product 206af was isolated in low yield (entry 1). Unfortunately, the dialkylated products which could be observed on GC-MS analysis were difficult to isolate as pure compounds. To our delight, in the case of the 2-substituted naphthalene derivative 188i with its single meta-position, products 206i were obtained in excellent yields (entries 4-7).

Table 3.11: Direct meta-C-H alkylation of ketimines 188 with acyclic secondary alkyl bromides $\mathbf{4 4}$

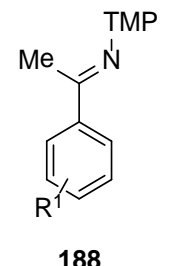<smiles>[R]C([18O])[18F]</smiles>

44

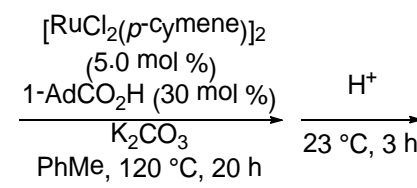

PhMe, $120^{\circ} \mathrm{C}, 20 \mathrm{~h}$

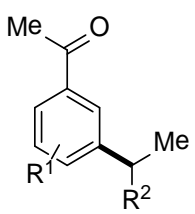

206

\begin{tabular}{|c|c|c|c|c|}
\hline Entry & Substrate 188 & Secondary Bromide 44 & Product 206 & Yield (\%) \\
\hline 1 & $\begin{array}{l}\text { TMP } \\
\hat{N}^{\prime}\end{array}$ & $44 f$ & & 206af: $43^{b}$ \\
\hline 2 & & $\begin{array}{l}n-\mathrm{Pr} \\
\mathbf{4 4 g}\end{array}$ & & 206ag: $46^{\mathrm{b}}$ \\
\hline 3 & 188a & 44d & 206 & 206ad: $40^{\mathrm{b}}$ \\
\hline 4 & & $\begin{array}{l}\text { Me } \\
44 h\end{array}$ & & 206ih: 77 \\
\hline 5 & & $\begin{array}{l}\text { Et } \\
\mathbf{4 4 f}\end{array}$ & & 206if: 74 \\
\hline 6 & $188 \mathrm{i}$ & $\begin{array}{l}n-\mathrm{Pr} \\
\mathbf{4 4 g}\end{array}$ & 206 & 206ig: 77 \\
\hline \multicolumn{5}{|c|}{$44 d$} \\
\hline $\begin{array}{l}{ }^{\mathrm{a}} \text { Reactio } \\
(1.0 \mathrm{~mm}\end{array}$ & $\begin{array}{l}\text { ons: } 188(0.5 \mathrm{r} \\
(2 \mathrm{~mL}), 120^{\circ} \mathrm{C}\end{array}$ & $\begin{array}{l}(1.5 \mathrm{mmol}),\left[\mathrm{RuCl}_{2}(p-\mathrm{c})\right. \\
\text { der } \mathrm{N}_{2} ; \text { yield of isolated }\end{array}$ & $\begin{array}{l}0 \mathrm{~mol} \%), 1-\mathrm{Ac} \\
14(0.75 \mathrm{mmol})\end{array}$ & $\mathrm{mol} \%), \mathrm{K}_{2} \mathrm{CO}$ \\
\hline
\end{tabular}

Furthermore, given the importance of amines as structural motifs in organic synthesis, we performed a one-pot reduction of the meta-alkylated ketimine products 188 . Not surprisingly, both unsubstituted ketimine $\mathbf{1 8 8 \mathrm { b }}$ and para-fluoroacetophenone imine 188a afforded secondary amines in good yields (Scheme 3.10). 


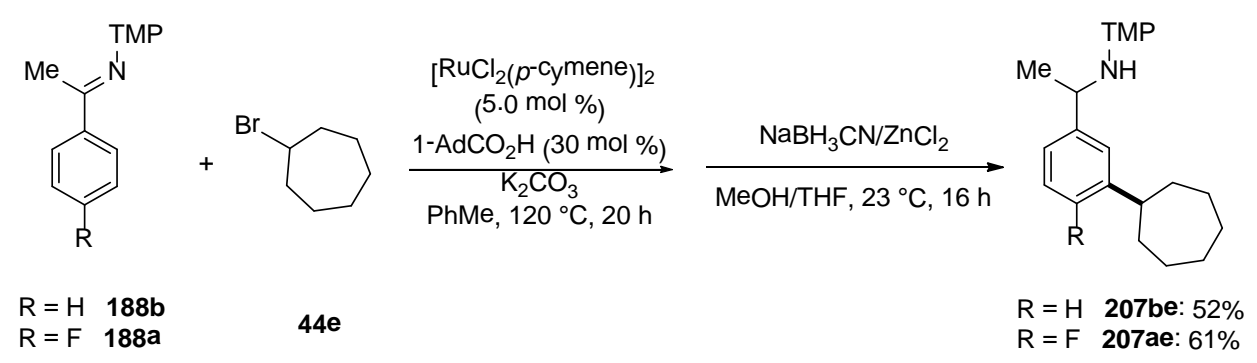

Scheme 3.10: One-pot synthesis of meta-alkylated secondary amines 207

\subsubsection{Direct meta-versus ortho-Alkylation with Cyclic Secondary Alkyl Bromides}

Besides bromocycloheptane (44e), we explored the reaction scope with different cyclic secondary alkyl bromides as well (Table 3.12). Unfortunately, bromocyclopropane (44i) proved unsuitable for this reaction (entry 1). However, cyclic alkyl bromides with ring sizes varying from 4 to 8 could be smoothly converted and gave alkylated product 206 in moderate yields (entries 2-5). Surprisingly, ruthenium(II)-catalyzed alkylation with bromocyclobutane (44j) turned out to exclusively yield ortho-functionalized product 206aj in 50\% yield (entry 2) ), as was disclosed by 2D NMR data for selected products.

Table 3.12: Direct alkylation of ketimines 188 with cyclic secondary alkyl bromides 44

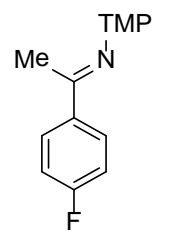

$188 \mathrm{a}$

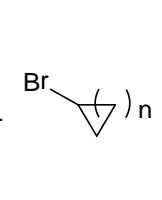

44

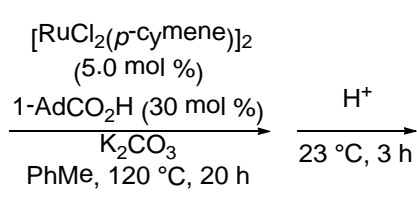

PhMe, $120^{\circ} \mathrm{C}, 20 \mathrm{~h}$

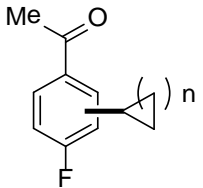

206

Entry Secondary Bromide 44 Yield (\%)




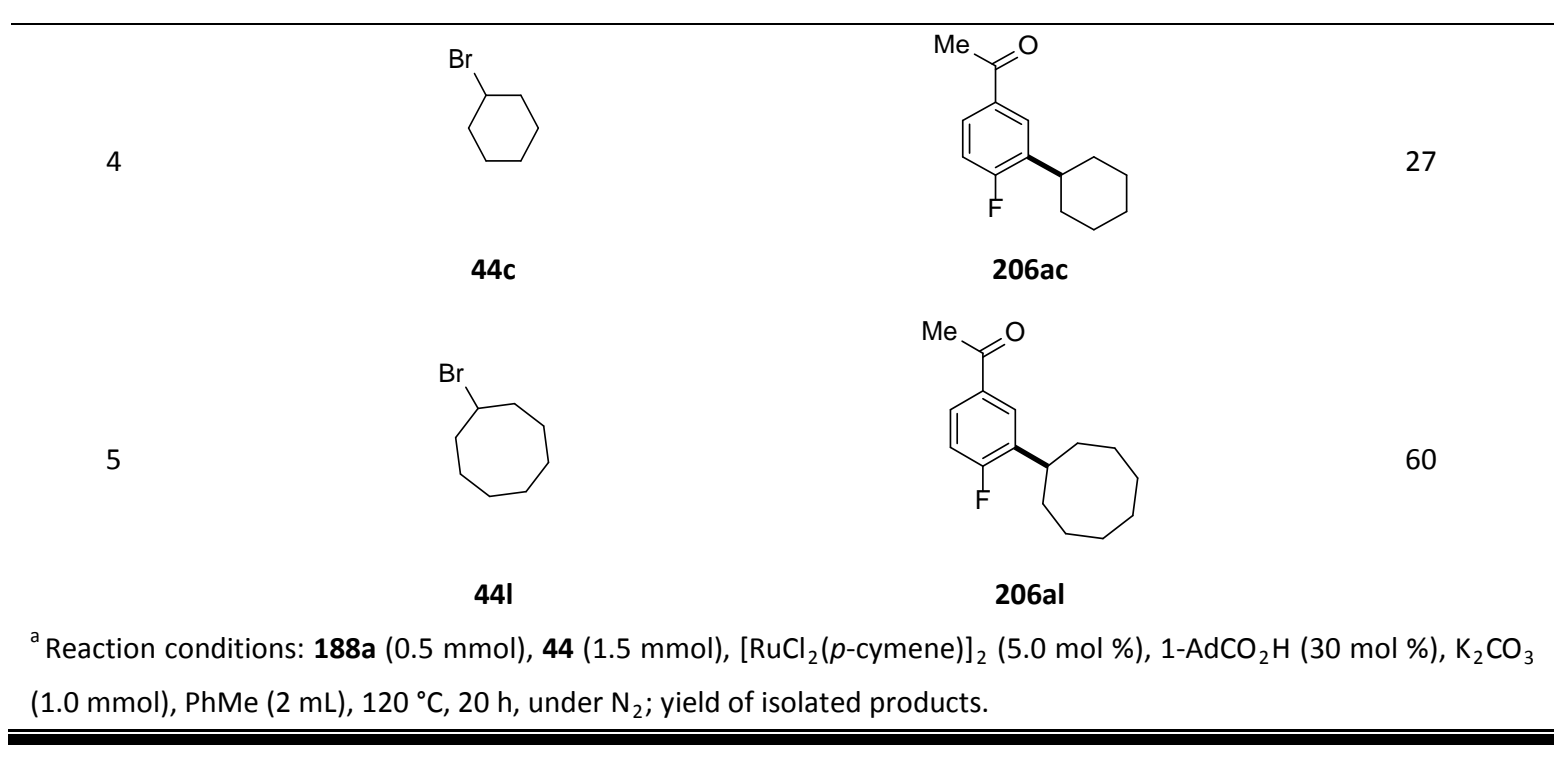

In order to test the universality of this phenomenon, we chose 2-phenylpyridine derivative $\mathbf{3 8 b}$ for the alkylation with cyclic secondary alkyl bromides $\mathbf{4 4}$ under the conditions optimized for the alkylation with tertiary bromides (Table 3.13). As above, we found no product formation in the reaction with bromocyclopropane $44 \mathbf{i}$ (entry 1 ). Furthermore, the ortho-selectivity pattern was observed for the alkylation with bromocyclobutane $\mathbf{4 4} \mathbf{j}$, however, in this case resulting in the dialkylation to furnish product 208bj (entry 2). Bromocyclopentane 44k again smoothly delivered meta-alkylated product 208bk in good yield (entry 3).

Table 3.13: Direct alkylation of 2-phenylpyridine 38b with cyclic secondary alkyl bromides 44

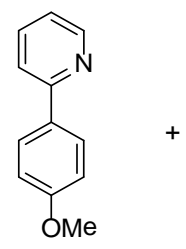

38b

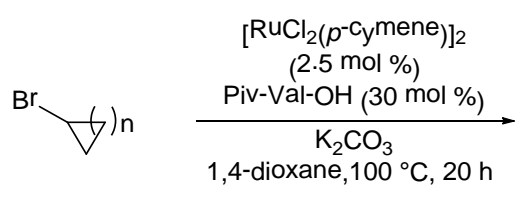

44

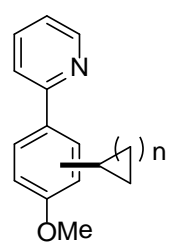

208

Entry Secondary Bromide $44 \quad$ Product 208


3

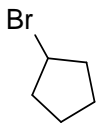

$44 k$

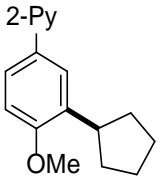

208bk

${ }^{\mathrm{a}}$ Reaction conditions: 37b $(0.5 \mathrm{mmol}), 44$ (1.5 mmol), $\left[\mathrm{RuCl}_{2}(p \text {-cymene) }]_{2}(5.0 \mathrm{~mol} \%)\right.$, Piv-Val-OH (30 mol \%), $\mathrm{K}_{2} \mathrm{CO}_{3}$ $(1.0 \mathrm{mmol}), 1,4$-dioxane $(2 \mathrm{~mL}), 100^{\circ} \mathrm{C}, 20 \mathrm{~h}$, under $\mathrm{N}_{2}$; yield of isolated products.

Intermolecular competition reaction between bromocyclobutane (44j) and bromocyclopentane (44k) was performed under the standard reaction conditions (Scheme 3.11). As expected, ortho-alkylated compound 206aj was isolated as a pure product. However, we also obtained the ortho,meta-dialkylated ketone $\mathbf{2 0 9}$ which should result from either a sequential ruthenium(II)-catalyzed ortho-alkylation of meta-alkylated product 206ak or meta-alkylation of ortho-alkylated compound 206aj. Thus, no particular difference in reaction rates was found between these two cyclic alkyl bromides. More importantly, each alkyl bromide gave rise to the corresponding site-selectively substituted product.

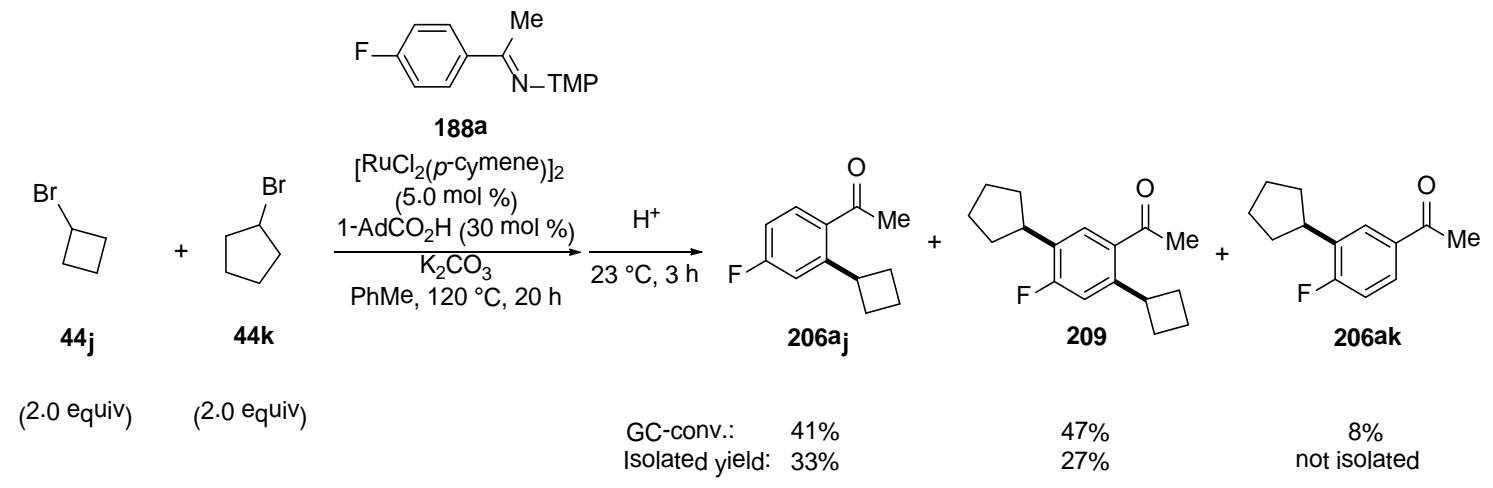

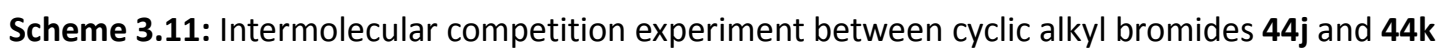

Ruthenium(II)-catalyzed direct alkylation with exo-bromonorbornane $(44 \mathrm{~m})$ led to interesting results as well (Scheme 3.12). Both ortho- and meta-alkylated products exo-206im and exo-206im' were isolated in a ratio of $2.4: 1$ with retention of the thermodynamically more stable exo-configuration of the norbornyl moiety and without formation of Wagner-Meerwein-rearranged skeletons.

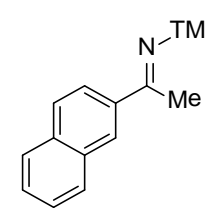

$188 \mathrm{i}$

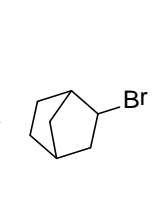

exo-44m

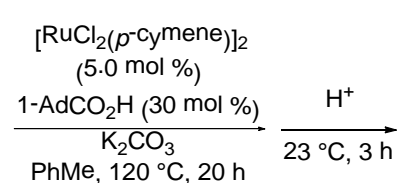

PhMe, $120^{\circ} \mathrm{C}, 20 \mathrm{~h}$

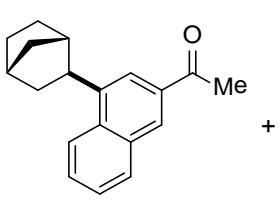

exo-206im: $46 \%$

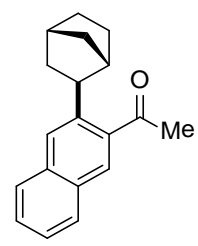

exo-206im':19\%

Scheme 3.12: Ruthenium(II)-catalyzed direct norbornylation of ketimine 188i

\subsubsection{Intramolecular Competition Experiments}

Importantly, alkylation of ketimine $\mathbf{1 8 8 \mathbf { j }}$ could be considered as an intramolecular competition reaction, the result of which showed that the arene bearing the fluorine substituent was selectively converted (Scheme 3.13). 
<smiles>N=C(c1ccccc1)c1ccc(F)cc1</smiles>

188j<smiles>BrC1CCCCCC1</smiles>

$44 \mathrm{e}$

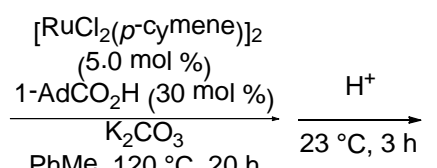

$62 \%$

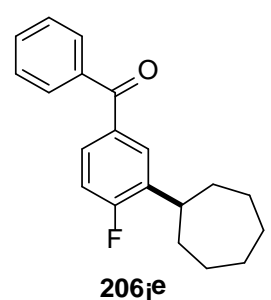

206je

Scheme 3.13: Intramolecular competition experiments of ketimine 188j

\subsubsection{Intermolecular Competition Experiments}

Intermolecular competition experiments between substituted ketimines 188, during which a 1.25 fold excess of both substrates $\mathbf{1 8 8}$ was treated with bromocycloheptane (44e) as the limiting reagent under otherwise identical reaction conditions, were performed (Scheme 3.14). The ratio of products was determined by ${ }^{1} \mathrm{H}$ NMR after aqueous workup.

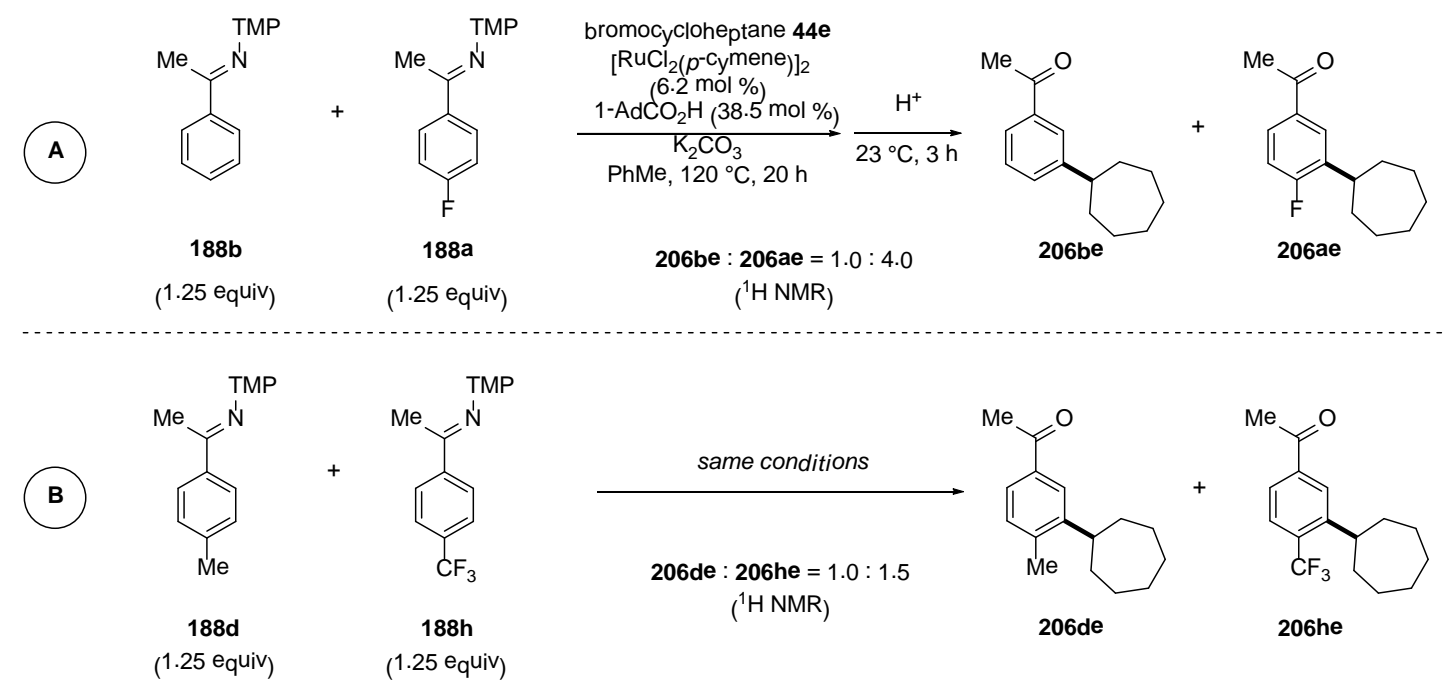

Scheme 3.14: Intermolecular competition experiments between ketimines 188

Experiment $\mathbf{A}$ showed electron-deficient fluoro-substituted arene 188a to be more reactive than the unsubstituted ketimine $\mathbf{1 8 8 b}$. This could be accounted for by the ortho-orienting effect of the fluorine substituent. However, the trifluoromethyl-bearing substrate $188 \mathrm{~h}$ was more reactive than the methyl substituted $188 \mathrm{~d}$ as well, presumably due to the increased acidity of the $\mathrm{C}-\mathrm{H}$ bond in the neighboring position. This observation contrasts with the previous one made for meta-alkylation of 2-phenylpyridines 38 (Scheme 3.2), but in line with the effects observed in ruthenium(II)-catalyzed ortho-selective alkylation of ketimines with primary alkyl halides. ${ }^{142}$ 


\title{
3.3 Ruthenium(II)-Catalyzed meta-Selective C-H Alkylations of Aniline Derivatives
}

\author{
with Unactivated Alkyl Bromides
}

$\mathrm{N}$-(Pyrimidine-2-yl)anilines $\mathbf{1 6 1}$ are important structural motifs in biologically active and naturally occurring compounds and pharmacologically active substances (Scheme 3.15). Among them, Imatinib (210) and Nilotinib (211) are in the list of the top-selling drugs. Therefore, it is of particular interest to synthesize aniline derivatives via $\mathrm{C}-\mathrm{H}$ bond functionalization. Ackermann and co-workers have reported ruthenium(II)- ${ }^{211}$ or nickel-catalyzed ${ }^{238} \mathrm{C}-\mathrm{H} / \mathrm{N}-\mathrm{H}$ bond functionalization of $\mathrm{N}$-(pyrimidine-2-yl)anilines $\mathbf{1 6 1}$ where the pyrimidyl group served as a removable directing group. However, direct alkylations of arenes $\mathbf{1 6 1}$ have thus far proved elusive. Herein, we wish to extend our scope of ruthenium(II)-catalyzed direct meta-alkylation to $N$-(pyrimidine-2-yl)aniline derivatives 161. More importantly, the pyrimidyl moiety can readily be cleaved, thus providing access to meta-alkylated aniline derivatives.<smiles>Cc1ccc(NC(=O)c2ccc(CN3CCN(C)CC3)cc2)cc1Nc1nccc(-c2cccnc2)n1</smiles><smiles></smiles><smiles>CC(C)(C)ON1CCC(c2cccc(Nc3ncc4cc(Br)ccc4n3)c2)CC1</smiles>

212

antitumor agent<smiles>COc1ncccc1C1CC=NC(Nc2cccc(C3CCN(C(=O)OCc4ccccc4)CC3)c2)N1</smiles>

213

kinase inhibitor<smiles>c1cnc(Nc2cccc(C3CCCNC3)c2)nc1</smiles>

214

kinase inhibito

Scheme 3.15: N-2-Pyrimidyl anilines 161 in drugs and bioactive compounds

\subsubsection{Optimization Studies}

At the outset of our studies, we adopted the reaction conditions optimized for the ruthenium(II)-catalyzed meta-alkylation of 2-phenylpyridines 38 (Table 3.14). To our delight, the desired product 215aa was isolated in 66\% yield (entry 1). Other MPAAs as well as different $\mathrm{N}$-protecting groups showed lower efficiency (entries 2-8). Unprotected valine (116e) was also capable to promote this transformation, albeit with lower efficacy (entry 9). Among a variety of solvents, 1,4-dioxane proved to be most efficient (entries 10-14). However, ${ }^{1} \mathrm{H}$ NMR only showed a mass balance of $80 \%$, which is similar to the case of meta-C-H alkylation of ketimines 188 . 
Table 3.14: Optimization for the direct meta-alkylation of $N$-(pyrimidine-2-yl)aniline 161a
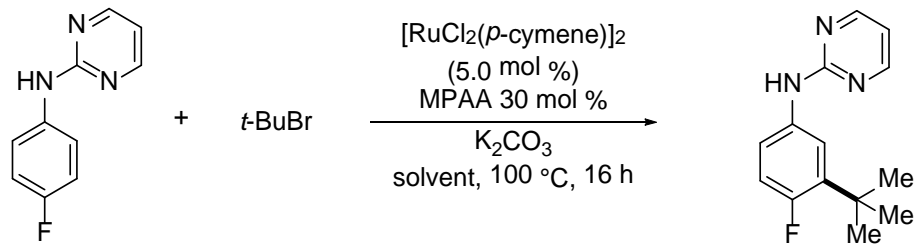

$161 a$

$50 a$

215aa

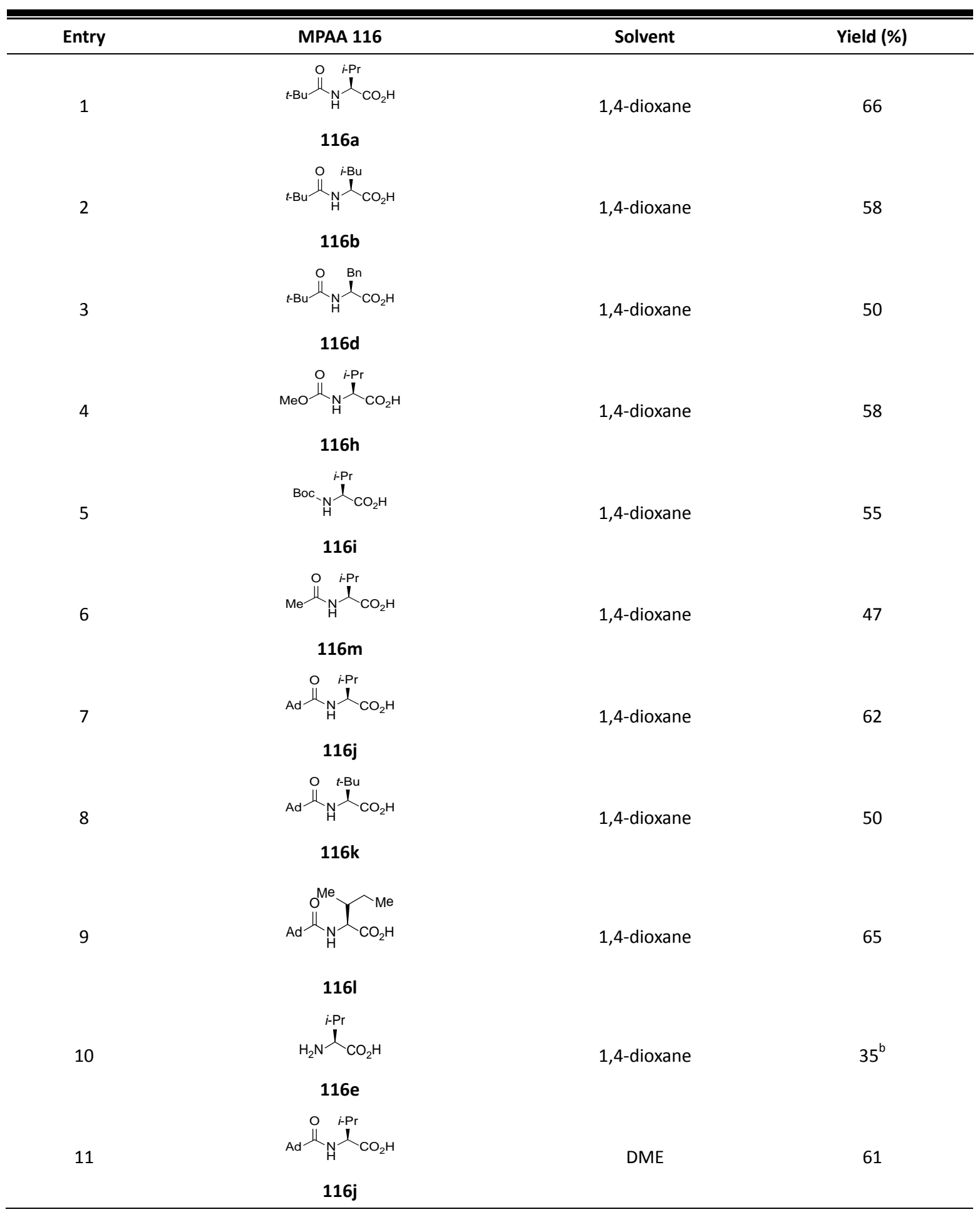


12

13

14

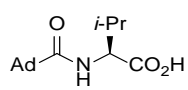

116

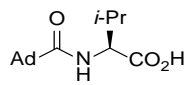

116j

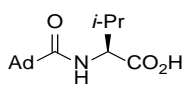

116j
DCE

$20^{\mathrm{b}}$

$t-\mathrm{AmOH}$

$34^{\mathrm{b}}$

PhMe

$25^{\mathrm{b}}$

${ }^{a}$ Reaction conditions: 161a (0.5 mmol), 50a (1.5 mmol), $\left[\mathrm{RuCl}_{2} \text { (p-cymene) }\right]_{2}(5.0 \mathrm{~mol} \%), \mathrm{MPAA} 116(30 \mathrm{~mol} \%), \mathrm{K}_{2} \mathrm{CO}_{3}$ (1.0 mmol), solvent $(2 \mathrm{~mL}), 100{ }^{\circ} \mathrm{C}, 16 \mathrm{~h}$, under $\mathrm{N}_{2}$; isolated yields. ${ }^{\mathrm{b}} \mathrm{GC}$-conversion.

\subsubsection{Effect of Directing Groups}

Furthermore, we probed the effect of the different directing group for this ruthenium(II)-catalyzed direct meta-alkylation (Scheme 3.16). Switching the pyrimidyl group to the pyridyl one under otherwise identical reaction conditions resulted in a 30\% lower isolated yield of the product 217, indicating pyridyl to be the less efficient directing group in this transformation. A simple phenyl substitution failed to yield any product $\mathbf{2 1 8}$. This observation clearly showed the necessity of a chelating heteroatom in the directing group for this reaction. Moreover, this indirectly proved this reaction not to be a simple electrophilic aromatic substitution, in which the ruthenium(II) complex functioned only as a Lewis acid. Besides, electron-donating amines are well-known ortho- and para-directing groups. Thus, this mechanism could cause an alternative to meta-selective functionalizations reaction of aniline derivatives.
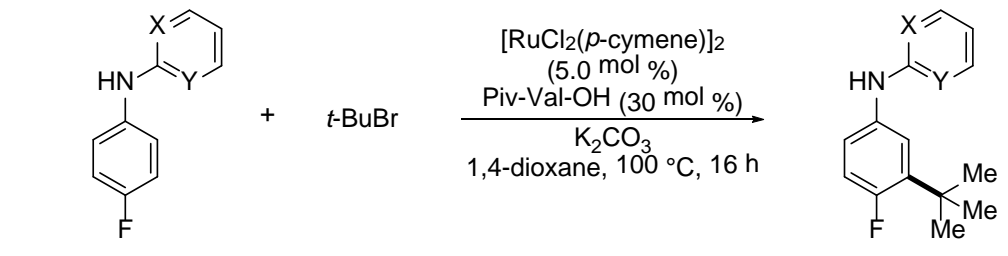

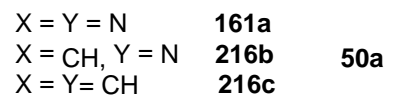

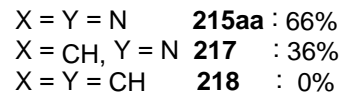

Scheme 3.16: Directing group effect in the direct meta-alkylation of aniline derivatives

\subsubsection{Direct meta-Alkylation with Tertiary Alkyl Bromides: Scope and Limitations}

With the optimized reaction conditions in hand, we subsequently explored the scope and limitations of the meta-selective alkylation with a range of tertiary alkyl bromides $\mathbf{5 0}$ (Table 3.15). Cyclic tertiary bromide $\mathbf{5 0 b}$ delivered the desired product $212 \mathrm{ab}$ in $60 \%$ yield (entry 1 ). Sterically hindered tertiary alkyl bromides 50 also afforded the corresponding products in moderate yields (entries 2-3). It should be emphasized that alkyl bromide $50 \mathrm{~h}$ with a chlorine substituent was well tolerated (entry 4).

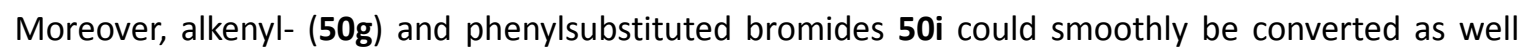
(entries 5 and 6). 
Table 3.15: Scope for ruthenium(II)-catalyzed meta-alkylation with tertiary alkyl bromides $\mathbf{5 0}$

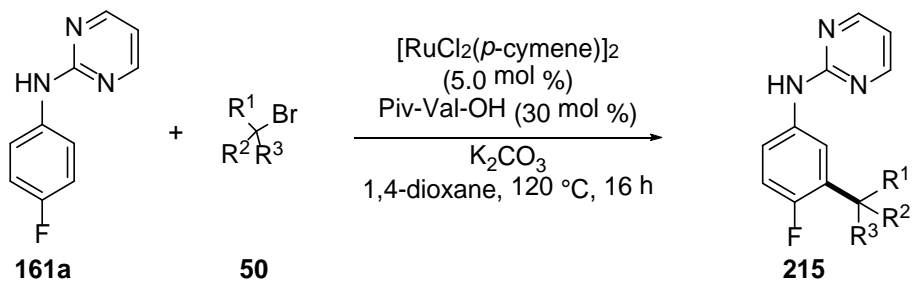

Entry Tertiary Bromide 50


6

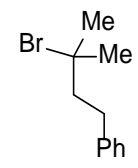

$50 \mathrm{i}$<smiles>CC(C)(CCc1ccccc1)c1cc(Nc2ncccn2)ccc1F</smiles>

215ai

${ }^{a}$ Reaction conditions: 161a (0.5 mmol), 50 (1.5 mmol), $\left[\mathrm{RuCl}_{2}(p \text {-cymene })\right]_{2}(2.5 \mathrm{~mol} \%)$, Piv-Val-OH (30 mol \%), $\mathrm{K}_{2} \mathrm{CO}_{3}$ (1.0 mmol), 1,4-dioxane $(2 \mathrm{~mL}), 120^{\circ} \mathrm{C}, 20 \mathrm{~h}$, under $\mathrm{N}_{2}$; isolated yields.

Thereafter, we explored the scope of substituted $N$-(pyrimidine-2-yl)anilines $\mathbf{1 6 1}$ for the direct meta-selective alkylation (Table 3.16). To our delight, arenes bearing bromine (161b) and chlorine (161c) substituents were smoothly converted, giving the meta-alkylated products 215ba and 215ca in moderate yields (entries 1 and 2). Likewise, electron-neutral as well as electron-rich arenes delivered the target compounds 215da and 215ea in good yields as well (entries 3 and 4). Notably, switching the ligand to $\mathrm{Ad}$-lle-OH enabled the direct meta-alkylation of challenging ortho-substituted substrates. Aniline derivate $161 \mathrm{f}$ and $161 \mathrm{~g}$ furnished alkylation products exclusively at the sterically more congested meta-C-H bond (entries 5 and 6). 2,4-Substituted aniline $161 \mathrm{~h}$ was smoothly alkylated at the 3-position, highlighting the excellent site-selectivity of this approach (entry 7).

Table 3.16: Scope for direct meta-alkylation of $N$-(pyrimidine-2-yl)anilines 161

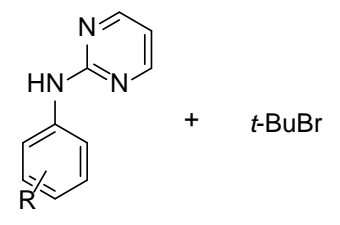

161

$50 a$

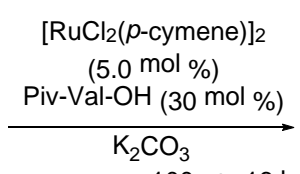

1,4-dioxane, $100{ }^{\circ} \mathrm{C}, 16 \mathrm{~h}$

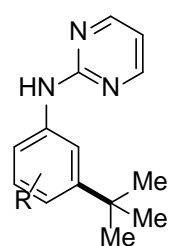

215

Entry


3<smiles>COc1ccc(Nc2ncccn2)cc1</smiles><smiles>COc1ccc(Nc2ncccn2)cc1C(C)(C)C</smiles>

161d

\section{5da}<smiles>c1ccc(Nc2ncccn2)cc1</smiles><smiles>CC(C)(C)c1cccc(Nc2ncccn2)c1</smiles>

$161 \mathrm{e}$

215ea

5<smiles>Fc1ccccc1Nc1ncccn1</smiles><smiles>CC(C)(C)c1cccc(Nc2ncccn2)c1F</smiles>

$61^{\mathrm{c}}$

$161 f$

$215 f a$<smiles>COc1ccccc1Nc1ncccn1</smiles><smiles>COc1c(Nc2ncccn2)cccc1C(C)(C)C</smiles>

$40^{\mathrm{b}, \mathrm{c}}$

161g

215ga<smiles>Fc1ccc(Nc2ncccn2)c(F)c1</smiles><smiles>CC(C)(C)c1c(F)ccc(Nc2ncccn2)c1F</smiles>

$55^{\mathrm{b}, \mathrm{c}}$

$161 \mathrm{~h}$

${ }^{a}$ Reaction conditions: 161 (0.5 mmol), 50a (1.5 mmol), $\left[\mathrm{RuCl}_{2}(p \text {-cymene) }]_{2}\right.$ (5 mol \%), Piv-Val-OH (30 mol \%), $\mathrm{K}_{2} \mathrm{CO}_{3}$ (1.0 mmol), 1,4-dioxane $(2 \mathrm{~mL}), 100{ }^{\circ} \mathrm{C}, 20 \mathrm{~h}$, under $\mathrm{N}_{2}$; isolated yields; ${ }^{\mathrm{b}} 120^{\circ} \mathrm{C} .{ }^{\mathrm{C}}$ Ad-Ile-OH instead of Piv-Val-OH.

\subsubsection{Direct Alkylation with Primary and Secondary Alkyl Bromides}

Furthermore, we probed if this optimized catalytic system could be applied for the alkylation with primary and secondary alkyl bromides (Scheme 3.17). However, only trace quantity of the product 219 was detected when 1-bromohexane (42e) was employed. Bromocycloheptane (44e) was able to deliver the desired product under standard conditions, albeit only in a unsatisfactory low yield. Replacing MPAA ligand by $1-\mathrm{AdCO}_{2} \mathrm{H}$ could improve the yield to $45 \%$, unfortunately, the yield could not be further improved by raising the reaction temperature. 
<smiles>Fc1ccc(Nc2ncccn2)cc1</smiles>

$161 \mathrm{a}$<smiles>Fc1ccc(Nc2ncccn2)cc1</smiles>

$161 \mathrm{a}$
$n-\mathrm{HexBr}$

$42 e$

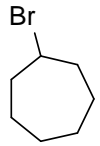

$44 \mathrm{e}$

$$
\begin{gathered}
\begin{array}{c}
{\left[\mathrm{RuCl}_{2}(p \text {-cymene })\right]_{2}} \\
(5.0 \mathrm{~mol} \%)
\end{array} \\
\stackrel{\text { Piv-Val-OH }(30 \mathrm{~mol} \%)}{\longrightarrow} \\
\begin{array}{c}
\mathrm{K}_{2} \mathrm{CO}_{3} \\
\text { 1,4-dioxane, } 100{ }^{\circ} \mathrm{C}, 16 \mathrm{~h}
\end{array}
\end{gathered}
$$

$$
\begin{gathered}
\begin{array}{c}
{\left[\mathrm{RuCl}_{2}(p \text {-cymene })\right]_{2}} \\
(5.0 \mathrm{~mol} \%)
\end{array} \\
\text { additive }(30 \mathrm{~mol} \%) \\
\mathrm{K}_{2} \mathrm{CO}_{3}
\end{gathered}
$$<smiles>Oc1cc(F)ccc1Nc1ncccn1</smiles>

219

trace

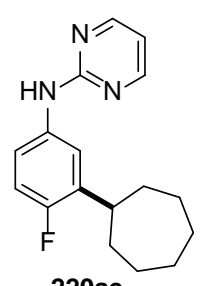

220ae

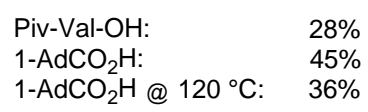

Scheme 3.17: Direct alkylations with primary and secondary alkyl bromides $42 \mathrm{e}$ and $44 \mathrm{e}$

Given the fact that $N$-(pyrimidine-2-yl)anilines containing the piperidine moiety are important constituents in antitumor reagents and kinase inhibitors, we were interested in preparing these analogues employing our ruthenium(II)-catalyzed meta-selective direct alkylation strategy (Table 3.17). We chose fluoro-substituted aniline $\mathbf{1 6 1 f}$ as the standard substrate, $N$-Boc-protected piperidine $\mathbf{4 4 n}$ as the alkylating reagent. Under the optimized reaction conditions, the desired product $\mathbf{2 2 0}$ could be obtained in $32 \%$ isolated yield (entry 1 ). However, other carboxylates as well as MPAAs provided only low conversions (entries 2-4). Subsequently, we tested different protecting groups on the piperidine nitrogen. However, alkylation with neither pivaloyl- nor tosyl-protected piperidine $\mathbf{4 4}$ allowed to improve the yield (entries 5-6).

Table 3.17: Direct meta-alkylation with 4-bromopiperidine derivative 44

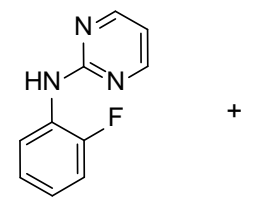

$161 f$<smiles>O=CN1CCC(Br)CC1</smiles>

44

.

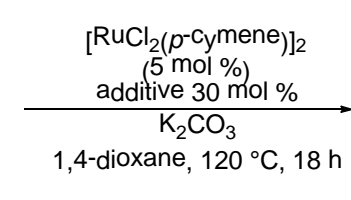

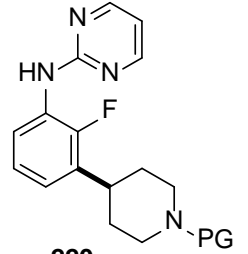

220

\begin{tabular}{cccc}
\hline \hline Entry & PG & Additive & Yield (\%) \\
\hline 1 & Boc (44n) & $1-\mathrm{AdCO}_{2} \mathrm{H}$ & 32 \\
2 & $\operatorname{Boc}(\mathbf{4 4 n})$ & $\mathrm{MesCO}_{2} \mathrm{H}$ & $<5$ \\
3 & $\operatorname{Boc}(\mathbf{4 4 n})$ & Piv-Val-OH & $<5$ \\
4 & $\operatorname{Boc}(\mathbf{4 4 n})$ & $\mathrm{Ad}-\mathrm{Ile}-\mathrm{OH}$ & $<5$ \\
5 & $\operatorname{Piv}(\mathbf{4 4 0})$ & $1-\mathrm{AdCO}_{2} \mathrm{H}$ & 20 \\
6 & $\mathrm{Ts}(\mathbf{4 4 a )}$ & $1-\mathrm{AdCO}_{2} \mathrm{H}$ & $<5$
\end{tabular}

${ }^{a}$ Reaction conditions: 161f $(0.25 \mathrm{mmol}), 44$ (0.75 mmol), $\left[\mathrm{RuCl}_{2}(p \text {-cymene) }]_{2}(5 \mathrm{~mol} \%)\right.$, additive (30 mol \%), $\mathrm{K}_{2} \mathrm{CO}_{3}$ ( $0.75 \mathrm{mmol}), 1,4$-dioxane $(2 \mathrm{~mL}), 120^{\circ} \mathrm{C}, 18 \mathrm{~h}$, under $\mathrm{N}_{2}$; isolated yields. 


\subsubsection{Removal of the Directing Group}

Importantly, the pyrimidyl directing group could readily be cleaved under acidic conditions, providing meta-alkylated aniline derivative 191 in high yield (Scheme 3.18). Thus, our new methodology offered a novel approach for the synthesis of meta-substituted anilines.

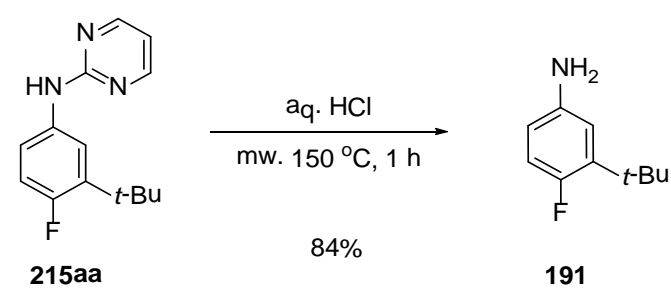

Scheme 3.18: Removal of the directing group

\subsubsection{H/D Exchange}

In order to gain insight into the reaction mechanism of the ruthenium(II)-catalyzed meta-selective direct alkylation of aniline derivatives 161, we performed an experiment in the presence of $D_{2} \mathrm{O}$ under the optimized reaction conditions. As shown in Scheme 3.18, a significant H/D exchange was observed in the ortho-position of both the product $\left[D_{n}\right]-215 a a$ and the recovered starting material $\left[D_{n}\right]-161 a$, thus indicating the reversible nature of the ortho- $\mathrm{C}-\mathrm{H}$ bond metalation.

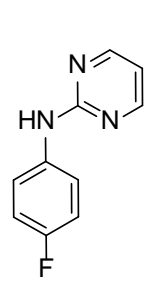

$161 a$

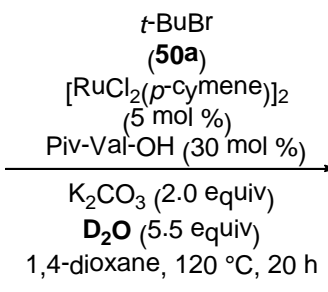

1,4-dioxane, $120^{\circ} \mathrm{C}, 20 \mathrm{~h}$

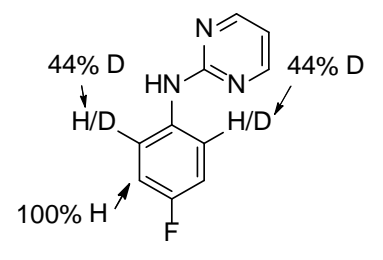

$\left[D_{n}\right]^{-161 a: ~ 63 \% ~}$

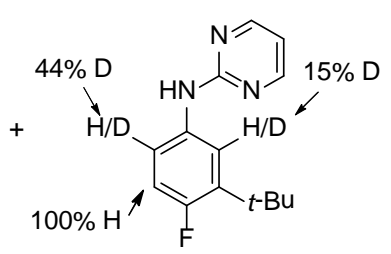

$\left[D_{n}\right]^{-215 a a: ~ 10 \% ~}$

Scheme 3.19: Direct meta-alkylation of aniline 161a in the presence of $D_{2} O$

Most probably, the mechanism of these meta-alkylation corresponds to those discussed above (Scheme 3.9). 


\section{Ruthenium(II)-Catalyzed Oxidative $\mathrm{C}-\mathrm{H}$ Alkenylation of Aryl}

\section{Carbamates}

As discussed above in Chapter 1.4, significant progress has been accomplished in ruthenium(II)-catalyzed environmentally benign twofold $\mathrm{C}-\mathrm{H}$ bond alkenylations. In contrast, the use of air- and moisture stable ruthenium(II) complexes for challenging oxidative $\mathrm{C}-\mathrm{H}$ bond alkenylations with widely accessible phenol derivatives has unfortunately proven to be elusive until recently. ${ }^{178}$ In the course of our continuing efforts in step-economical $\mathrm{C}-\mathrm{H}$ bond functionalizations, we devised reaction conditions for ruthenium(II)-catalyzed cross-dehydrogenative alkenylations of aryl carbamates bearing removable directing groups. ${ }^{239-241}$ Importantly, aryl carbamates are key intermediates in organic synthesis, and serve as versatile organic electrophiles in transition metal catalysis. $^{242,243}$

\subsection{Optimization Studies}

At the outset of our studies, we optimized reaction conditions for the oxidative alkenylation of aryl carbamate 192a (Table 4.1). Preliminary studies with a naphthyl carbamate indicated that the desired oxidative alkenylation was not viable with $\mathrm{CsOAc}_{\text {or }} \mathrm{KPF}_{6}$ as the co-catalytic additive. However, satisfactory results were gratifyingly achieved when employing 10 mol\% of $\mathrm{AgSbF}_{6}$. The desired olefination did not occur in the absence of the ruthenium complex $\left[\operatorname{RuCl}_{2}(p \text {-cymene) }]_{2}\right.$ (entry 1$)$. Among a set of representative solvents, DME turned out to be the optimal one (entries 2-6), and the catalytic system was found to be air-stable (entry 7). The use of a combination of $\mathrm{CuBr}_{2}$ and $\mathrm{NaOAc}$ as terminal oxidant failed to deliver the desired product (entry 8). Notably, the cross-dehydrogenative alkenylation failed to proceed in the absence of $\mathrm{AgSbF}_{6}$ as the co-catalyst (entry 9), thus being suggestive of the formation of a cationic ruthenium(II) catalyst. Yet, the preformed cationic complex $\left.\left[\mathrm{Ru}_{2} \mathrm{Cl}_{3} \text { (p-cymene }\right)_{2}\right]\left[\mathrm{PF}_{6}\right]$ bearing the $\mathrm{PF}_{6}{ }^{-}$counteranion did not deliver the desired product under otherwise identical reaction conditions (entry 10$)$.

Table 4.1: Optimization of oxidative alkenylation with carbamate 192a

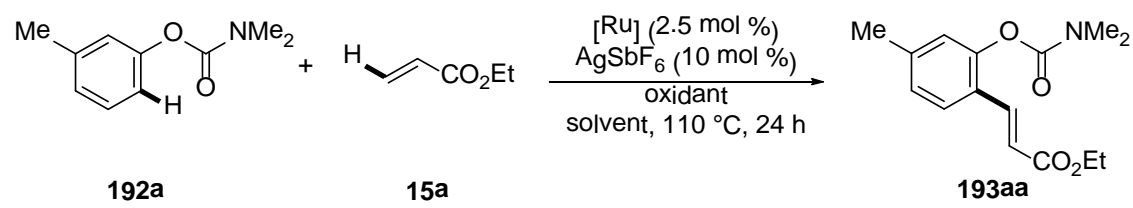

\begin{tabular}{ccccc}
\hline \hline Entry & \multicolumn{1}{c}{ Catalyst } & Oxidant & Solvent & Yield (\%) \\
\hline 1 & -- & $\mathrm{Cu}(\mathrm{OAc})_{2} \cdot \mathrm{H}_{2} \mathrm{O}$ & $\mathrm{DME}$ & 0 \\
2 & {$\left[\mathrm{RuCl}_{2}(p \text {-cymene })\right]_{2}$} & $\mathrm{Cu}(\mathrm{OAc})_{2} \cdot \mathrm{H}_{2} \mathrm{O}$ & $\mathrm{DMF}$ & 0 \\
3 & {$\left[\mathrm{RuCl}_{2}(p \text {-cymene })\right]_{2}$} & $\mathrm{Cu}(\mathrm{OAc})_{2} \cdot \mathrm{H}_{2} \mathrm{O}$ & $\mathrm{PhMe}$ & 0 \\
4 & {$\left[\mathrm{RuCl}_{2}(p \text {-cymene })\right]_{2}$} & $\mathrm{Cu}(\mathrm{OAc})_{2} \cdot \mathrm{H}_{2} \mathrm{O}$ & $\mathrm{DCE}$ & 40 \\
$\mathbf{5}$ & {$\left[\mathrm{RuCl}_{2}(p \text {-cymene })\right]_{2}$} & $\mathrm{Cu}(\mathrm{OAc})_{2} \cdot \mathrm{H}_{2} \mathrm{O}$ & $\mathrm{DME}$ & $\mathbf{8 4}$ \\
6 & {$\left[\mathrm{RuCl}_{2}(p \text {-cymene })\right]_{2}$} & $\mathrm{Cu}(\mathrm{OAc})_{2} \cdot \mathrm{H}_{2} \mathrm{O}$ & $t-\mathrm{AmOH}$ & 48 \\
7 & {$\left[\mathrm{RuCl}_{2}(p-\text {-cymene })\right]_{2}$} & $\mathrm{Cu}(\mathrm{OAc})_{2} \cdot \mathrm{H}_{2} \mathrm{O}$ & $\mathrm{DME}$ & $84^{\mathrm{b}}$ \\
8 & {$\left[\mathrm{RuCl}_{2}(p-\text {-cymene })\right]_{2}$} & $\mathrm{CuBr} 2 / \mathrm{NaOAc}$ & $\mathrm{DME}$ & 0
\end{tabular}


9

10

$$
\begin{gathered}
{\left[\mathrm{RuCl}_{2}(p \text {-cymene })\right]_{2}} \\
{\left[\mathrm{Ru}_{2} \mathrm{Cl}_{3}(p \text {-cymene })_{2}\right]\left[\mathrm{PF}_{6}\right]}
\end{gathered}
$$

$\mathrm{Cu}(\mathrm{OAC})_{2} \cdot \mathrm{H}_{2} \mathrm{O}$

$\mathrm{Cu}(\mathrm{OAc})_{2} \cdot \mathrm{H}_{2} \mathrm{O}$
DME

$0^{c}$

DME

${ }^{a}$ Reaction conditions: $192 \mathrm{a}(0.5 \mathrm{mmol}), 15 \mathrm{a}(1.0 \mathrm{mmol})$, catalyst $(2.5 \mathrm{~mol} \%)$, oxidant $(1.0 \mathrm{mmol})$, solvent $(3 \mathrm{~mL})$; isolated yields. ${ }^{\mathrm{b}}$ Under air. ${ }^{\mathrm{c}}$ Without $\mathrm{AgSbF}_{6}$.

\subsection{Effect of Directing Groups}

With the optimized catalytic system in hand, we tested the influence of the $\mathrm{N}$-substituents of the phenyl carbamates on the reaction efficacy (Scheme 4.1). Thus, $\mathrm{N}, \mathrm{N}$-dialkyl-substituted carbamates 192 and 221 furnished the desired products 193 and 222 in high yields, with atom-economical

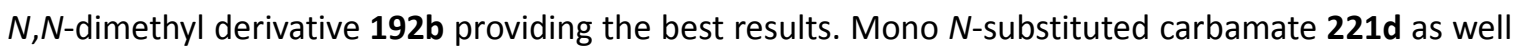
as $\mathrm{N}$-unsubstituted carbamate 221e proved to be unsuitable substrates for this oxidative alkenylation.

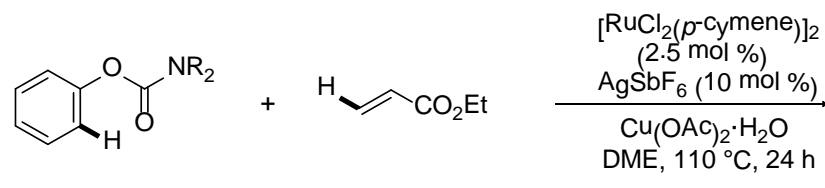

192,221

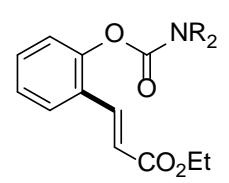

193,222<smiles>CCOC(=O)CCc1ccccc1OC(=O)N(C)C</smiles>

193ba: $68 \%$<smiles>CCNC(=O)Oc1ccccc1/C=C/COC(C)=O</smiles>

222ba: $67 \%$<smiles>CCOC(=O)/C=C/c1ccccc1OC(=O)N1CCCC1</smiles>

222ca: $55 \%$<smiles>CCOCCc1ccccc1OC(=O)NC</smiles>

222da: $0 \%$

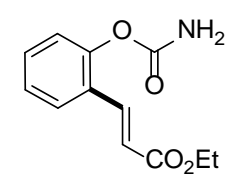

222ea: $0 \%$

Scheme 4.1 Effect of $\mathrm{N}$-substituents on $\mathrm{C}-\mathrm{H}$ bond alkenylation of cabarmates

\subsection{Scope and Limitations}

Subsequently, we probed the scope of the optimized catalyst in the twofold $\mathrm{C}-\mathrm{H}$ bond functionalizations with moisture-stable phenol derivatives 192 (Table 4.2). The cationic ruthenium(II) catalyst proved to be broadly applicable. Thus, substrates bearing ortho- and para-substituents were efficiently converted into the corresponding monoalkenylated products 193 (entries 1-13). Notably, valuable functional groups, such as aryl and alkyl fluorides (entries 5 and 11), chlorides (entries 7 and 16) or bromides (entries 12, 18 and 20), were well tolerated and therefore provide a handle for further elaborations. Furthermore, we observed that intramolecular competition experiments with meta-substituted substrates proceeded with high site-selectivities, furnishing alkenylated carbamates 193 as the sole products (entries 14-24).

Table 4.2: Scope of oxidative alkenylation with phenol carbamates 192

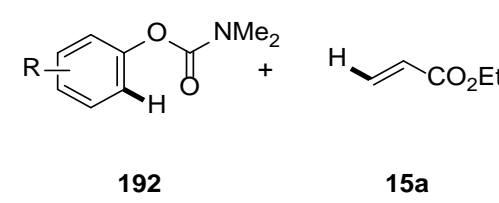

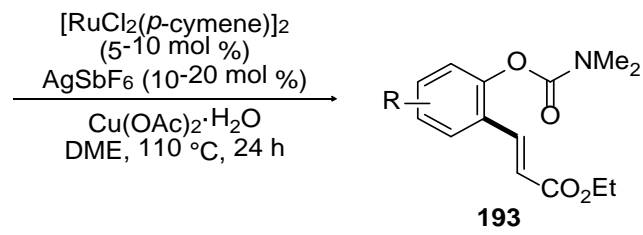




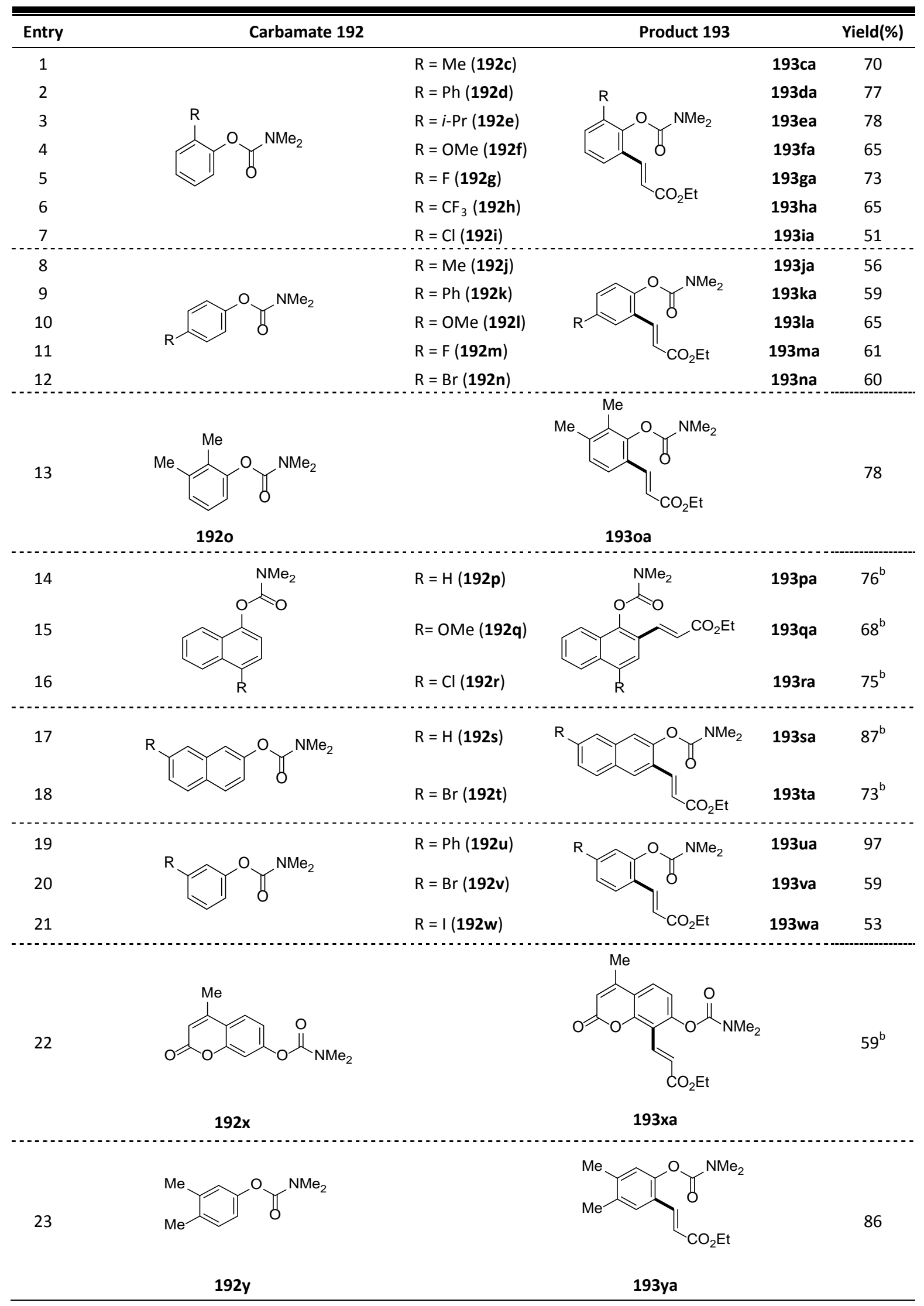


24<smiles>CN(C)C(=O)Oc1ccc2c(c1)OCO2</smiles>

$192 z$<smiles>CCOC(=O)/C=C/c1c(OC(N)=O)ccc2c1OCO2</smiles>

193za

a Reaction conditions: $192(0.5 \mathrm{mmol}), 15 \mathrm{a}(1.0 \mathrm{mmol}),\left[\mathrm{RuCl}_{2}(p-c y m e n e)\right]_{2}(2.5 \mathrm{~mol} \%), \mathrm{AgSbF}_{6}(10 \mathrm{~mol} \%)$, $\mathrm{Cu}(\mathrm{OAc})_{2} \cdot \mathrm{H}_{2} \mathrm{O}(1.0 \mathrm{mmol}), \mathrm{DME}(3 \mathrm{~mL}), 110{ }^{\circ} \mathrm{C}, 24 \mathrm{~h}$, under $\mathrm{N}_{2}$; isolated yields. ${ }^{\mathrm{b}}\left[\mathrm{RuCl}_{2}(p-c y m e n e)\right]_{2}(5.0 \mathrm{~mol} \%)$, $\mathrm{AgSbF}_{6}(20 \mathrm{~mol} \%)$.

Importantly, the double $\mathrm{C}-\mathrm{H}$ bond functionalization was not limited to the use of stoichiometric amounts of $\mathrm{Cu}(\mathrm{OAc})_{2} \cdot \mathrm{H}_{2} \mathrm{O}$. Indeed, aerobic oxidative alkenylations proved to be viable with $\mathrm{Cu}(\mathrm{OAc})_{2} \cdot \mathrm{H}_{2} \mathrm{O}$ as the cocatalyst under an atmosphere of ambient air, although in moderate yields (Scheme 4.2).

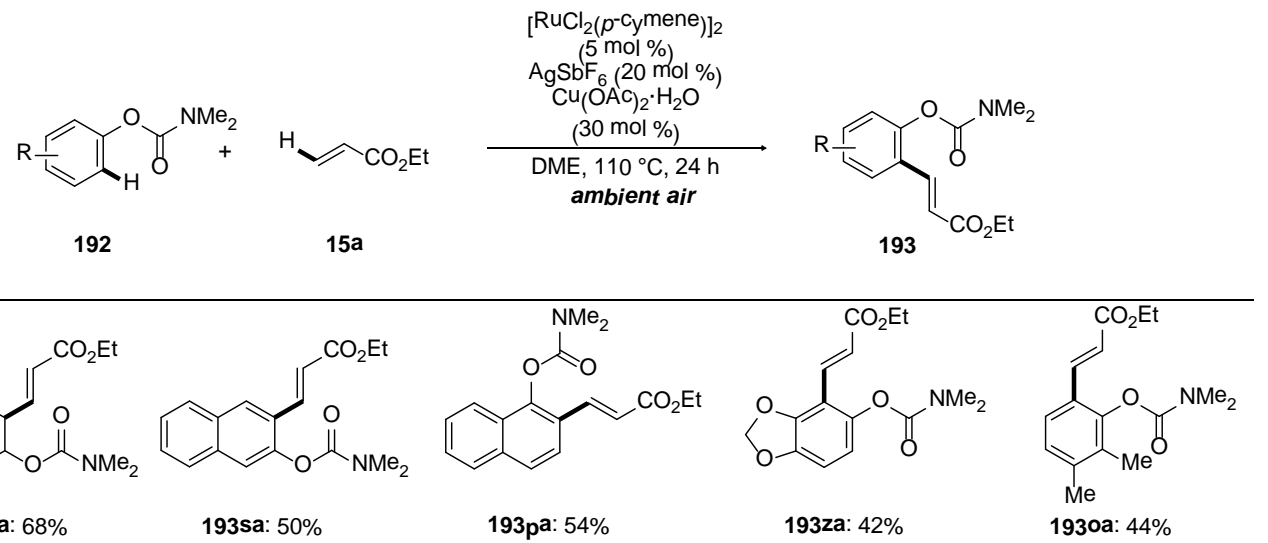

Scheme 4.2: Aerobic oxidative $\mathrm{C}-\mathrm{H}$ bond alkenylations

Unfortunately, the cationic ruthenium(II) catalyst provided only rather low conversions in alkenylations with acrylonitrile (15e), styrene (15c), 4-bromostyrene (15f) and methyl vinyl ketone (15g) (Table 4.3).

Table 4.3: Oxidative alkenylations with alkene derivatives 15

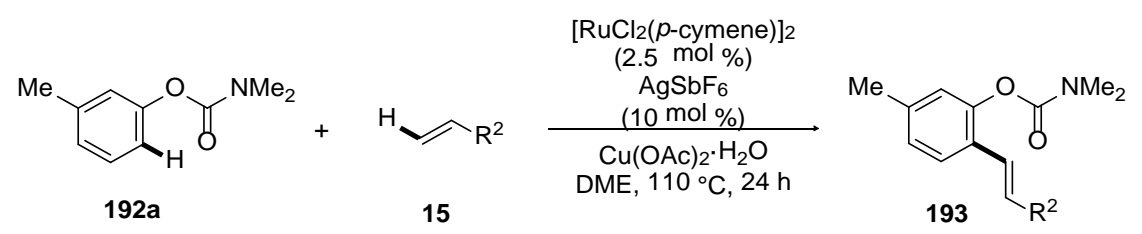

\begin{tabular}{ccc}
\hline \hline Entry & Alkene 15 & Conversion (\%) \\
\hline 1 & $\overbrace{\mathrm{CN}}$ & $<5$ \\
2 & $15 \mathrm{e}$ & 0 \\
$\mathrm{Ph}$ & $15 \mathrm{c}$ & \\
\hline
\end{tabular}


3

4<smiles>C=Cc1ccc(Br)cc1</smiles>

$15 f$

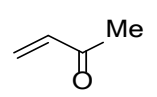

0

0

$15 \mathrm{~g}$

a Reaction Conditions: 192a $(0.5 \mathrm{mmol}), 15(1.0 \mathrm{mmol}),\left[\operatorname{RuCl}_{2}(p-c y m e n e)\right]_{2}(2.5 \mathrm{~mol} \%), \mathrm{AgSbF}_{6}(10 \mathrm{~mol} \%)$, $\mathrm{Cu}(\mathrm{OAc})_{2} \cdot \mathrm{H}_{2} \mathrm{O}(1.0 \mathrm{mmol}), \mathrm{DME}(3 \mathrm{~mL}), 110^{\circ} \mathrm{C}, 24 \mathrm{~h}$, under $\mathrm{N}_{2} ; \mathrm{GC}$-conversion.

\subsection{Removal of Directing Group}

Importantly, compounds $\mathbf{1 9 3}$ are of great synthetic value, as the carbamate directing groups can easily be cleaved under basic conditions, thus leading to o-coumaric acid derivative $\mathbf{2 2 3}$ in high yield (Scheme 4.3).<smiles>CCOC(=O)/C=C/c1ccc(C)cc1OC(=O)N(C)C</smiles>

$193 a a$

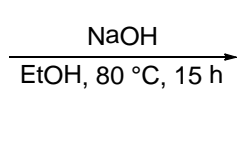

$\frac{\mathrm{NaOH}}{\mathrm{EtOH}, 80^{\circ} \mathrm{C}, 15 \mathrm{~h}}$

Scheme 4.3: Removal of directing group

The latter play an important role in chemistry of naturally occurring compounds. For example, as intermediates in phenylanine metabolism in enzymatic reactions catalyzed with 2-coumarate reductase. $^{244}$

\subsection{Mechanistic Studies}

\subsubsection{Intermolecular Competition Experiments}

Considering the remarkable activity and high selectivity of the cationic ruthenium(II) catalyst, we became interested in probing its mode of action. To this end, we conducted intermolecular competition experiments with differently substituted arenes 192, which revealed electron-rich substrates to be preferentially converted (Scheme 4.4). This result indicated an electrophilic activation manifold. 


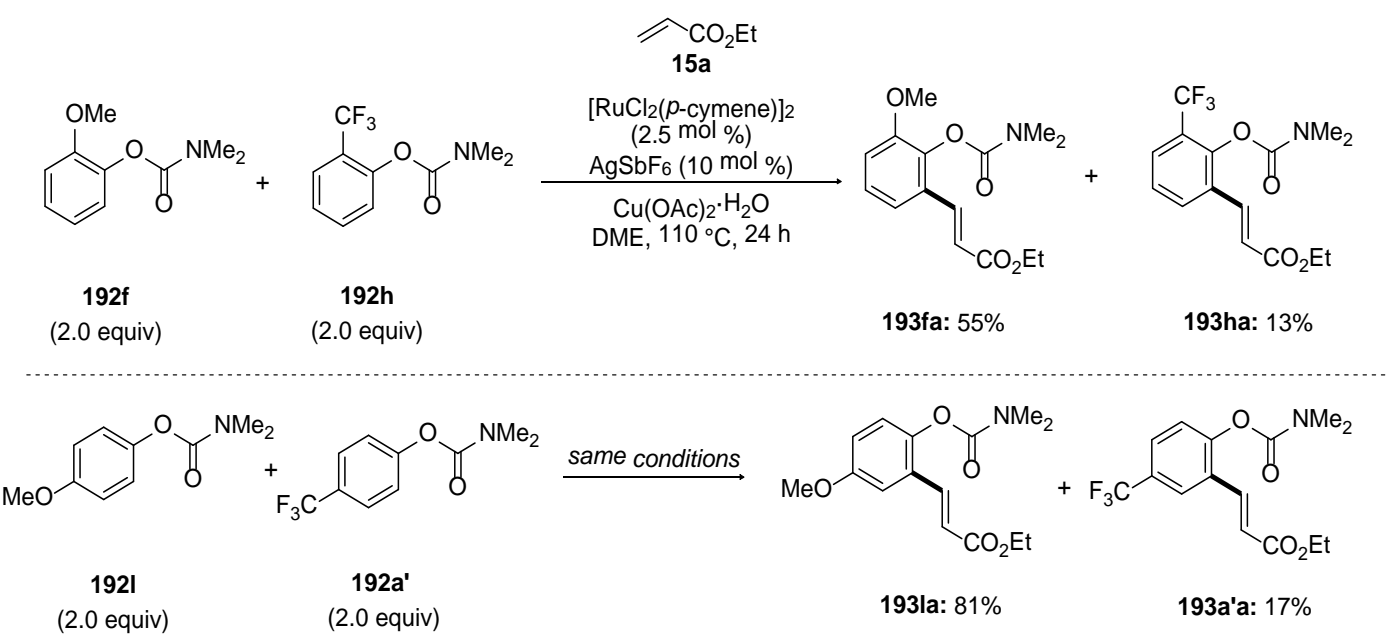

Scheme 4.4: Intermolecular competition experiments between carbamates 192

\subsubsection{Reaction with Isotopically Labelled Substrate}

Subsequently, we performed a reaction with deuterated labeled substrate $\left[\mathrm{D}_{5}\right]-\mathbf{2 2 1} \mathbf{b}$ under the standard reaction conditions (Scheme 4.5). A significant $\mathrm{D} / \mathrm{H}$ scrambling on the remaining ortho-position of the alkenylated product $\left[\mathrm{D}_{5}\right]-\mathbf{2 2 2}$ ba was observed. This finding clearly indicated the ruthenium(II)-catalyzed oxidative alkenylation proceeded with participation of a reversible $\mathrm{C}-\mathrm{H}$ bond metalation step.

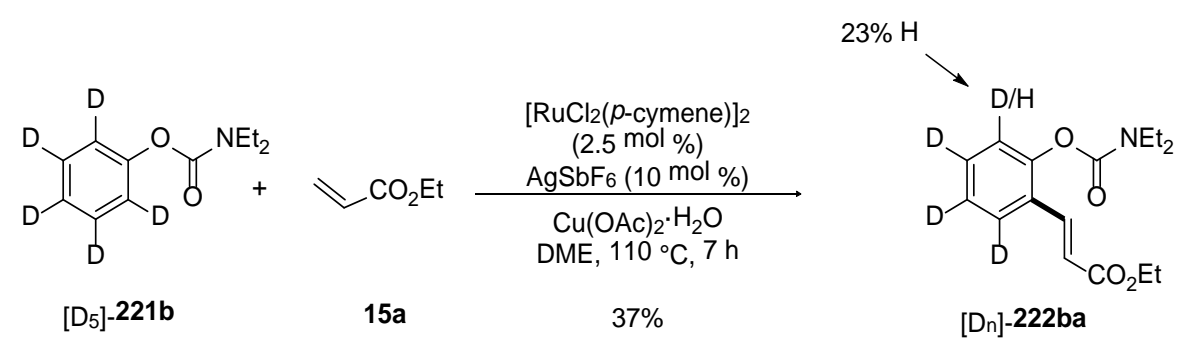

Scheme 4.5: Ruthenium(II)-catalyzed oxidative alkenylation of carbamate $\left[D_{5}\right]-221 b$

\subsubsection{Proposed Catalytic Cycle}

Based on these mechanistic studies as well as on our previous findings with cationic ruthenium(II) catalysts, we proposed the catalytic cycle which began with an initial base-assisted, reversible cycloruthenation (Scheme 4.6). Thereafter, migratory insertion of alkene and $\beta$-hydride elimination deliver product 191, while reductive elimination and reoxidation by $\mathrm{Cu}(\mathrm{OAc})_{2} \cdot \mathrm{H}_{2} \mathrm{O}$ regenerate the active cationic catalyst. 


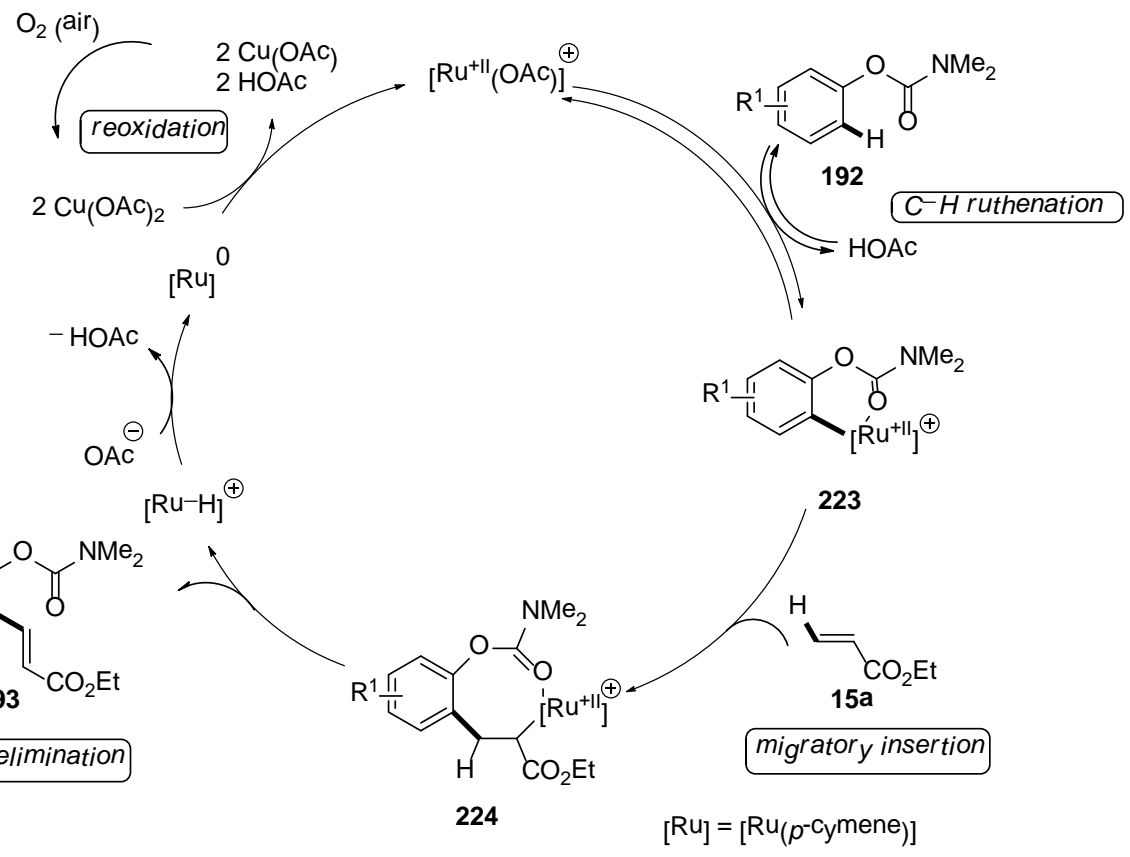

Scheme 4.6: Proposed mechanism for ruthenium(II)-catalyzed oxidative alkenylation 


\section{Cationic Ruthenium(II) Catalysts for $\mathrm{C}-\mathrm{H} / \mathrm{N}-\mathrm{O}$ Functionalizations of}

\section{Oximes}

Transition metal-catalyzed annulations of alkynes that involve sequential $\mathrm{C}-\mathrm{H}$ and $\mathrm{Het}-\mathrm{H}$ bond cleavages have become an important tool for the regioselective synthesis of decorated heterocycles (Chapter 1.5). Since the pioneering work of Ackermann and coworkers which employed less expensive ruthenium(II) catalysts for the oxidative annulation of alkynes by benzamides, ${ }^{207}$ several publications on ruthenium(II)-catalyzed oxidative annulation reactions have appeared during the last four years. ${ }^{206}$ Unfortunately, these transformations are restricted to the use of external oxidants. Hence, developing novel methods which employ internal oxidants continues to be of importance. For example, a redox-neutral approach for the preparation of isoquinolones has been reported by dehydrogenative annulations of alkynes with free hydroxamic acids. ${ }^{228}$ On this basis, C. Kornhaaß elaborated a redox-neutral annulation of alkynes with acetophenone oximes. ${ }^{245}$<smiles>C/C(=N\O)c1ccccc1</smiles>

$194 a$

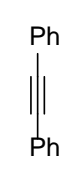

$155 a$

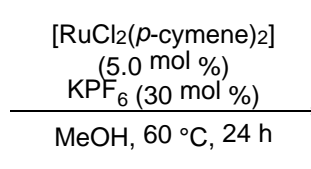

$81 \%$

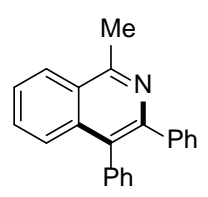

176aa

Scheme 5.1: Redox-neutral annulation with oximes as optimized by C. Kornhaaß

The optimized reaction conditions employed a catalytic system consisting of $\left[\mathrm{RuCl}_{2}(p \text {-cymene) }]_{2}\right.$ as the precatalyst and $\mathrm{KPF}_{6}$ as a co-catalytic additive. Since this dehydrogenative annulation is redox-neutral in nature, no external oxidant is needed, while $\mathrm{MeOH}$ proved to be the solvent of choice affording the isoquinoline 176aa in $81 \%$ yield under these conditions (Scheme 5.1). During the course of this transformation, a cationic ruthenium(II) species was most likely formed through abstraction of a chlorine atom from the precatalyst with a non-coordinating $\left[\mathrm{PF}_{6}\right]^{-}$anion. In order to support this concept, the presynthesized cationic complex $\left[\mathrm{Ru}_{2} \mathrm{Cl}_{3}(p \text {-cymene })_{2}\right]\left[\mathrm{PF}_{6}\right]$ was tested as the catalyst and furnished the desired product 176aa in good yield as well (Scheme 5.2).
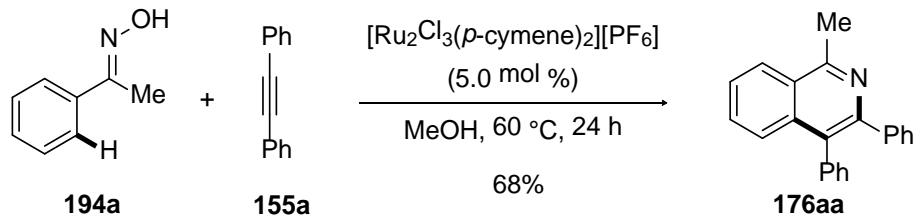

Scheme 5.2: Redox-neutral annulation using cationic ruthenium(II) complex

Under the optimized reaction conditions, a variety of differently substituted isoquinolines 194 bearing valuable electrophilic functional groups was chemoselectively accessed (Table 5.1). As shown in entry 1 , a tetralone oxime derivative $194 \mathrm{~b}$ can be converted into the corresponding isoquinoline 176ba in excellent yield. Elongation of the aliphatic chain in the oximes had no negative effect on the reaction outcome, smoothly delivering the desired products in high yields (entries 2 and 3). However, oximes containing isopropyl, cyclopropyl, cyclohexyl and benzyl groups demanded elevated reaction temperatures and additional molecular sieve to obtain high yields (entries $4-7$ ). Oxime 194b with a 
para-bromide substituent, which is valuable for post-synthetic elaboration, could also be converted in moderate yield (entry 8 ). In addition, indole derivative $\mathbf{1 9 4 j}$ also proved to be a suitable substrate, although the reaction resulted in a lower yield (entry 9).

Table 5.1: Scope of direct annulations of diphenylacetylene (155a) by oxime 194
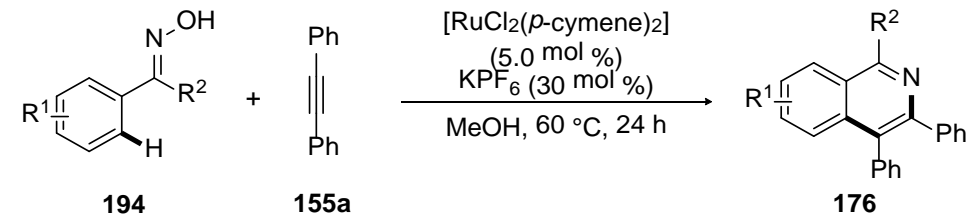

194

$155 a$

176

Entry


7

8<smiles>C/C(=N\O)c1ccc(Br)cc1</smiles>

$194 i$

9

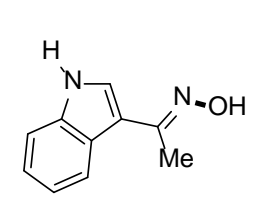

$194 j$<smiles>c1ccc(Cc2nc(-c3ccccc3)c(-c3ccccc3)c3ccccc23)cc1</smiles>

176ha<smiles>Cc1nc(-c2ccccc2)c(-c2ccccc2)c2cc(Br)ccc12</smiles>

176ia

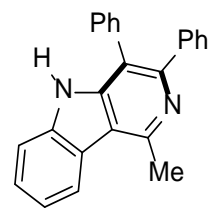

$176 j a$ $54^{b}$

$55^{b}$

$37^{\mathrm{c}}$

${ }^{a}$ Reaction conditions: 194 (0.5 mmol), 55a (1.0 mmol), $\left[\mathrm{RuCl}_{2}(p \text {-cymene) }]_{2}(5.0 \mathrm{~mol} \%), \mathrm{KPF}_{6}(30 \mathrm{~mol} \%), \mathrm{MeOH}(2\right.$ $\mathrm{mL}), 60{ }^{\circ} \mathrm{C}, 24 \mathrm{~h}$, under $\mathrm{N}_{2}$; isolated yields. ${ }^{\mathrm{b}} 4$ A Mol-sieves (100 mg per $\left.0.5 \mathrm{mmol} 194\right), 80^{\circ} \mathrm{C} .{ }^{\mathrm{C}} 4 \AA \mathrm{A}$ Mol-sieves, $100{ }^{\circ} \mathrm{C}$.

Given the remarkable efficacy of the in-situ generated ruthenium(II) catalyst, we subsequently probed the efficacy of presynthesized cationic complex $\left[\mathrm{Ru}_{2} \mathrm{Cl}_{3}(p \text {-cymene })_{2}\right]\left[\mathrm{PF}_{6}\right]$. Importantly, this well-defined complex displayed an activity as well as chemo-, regio- and siteselectivity being comparable to the one demonstrated by the in-situ formed catalytic system (Table 5.2, entries 1 and 2). Electron-rich methyl- (194k) as well as electron-deficient fluoro- (194l) and trifluoromethyl-containing $(\mathbf{1 9 4 m})$ oximes could all be converted to the desired isoquinolines in moderate to good yields (entries 3-5). Interestingly, when meta-substituted oximes were subjected to the reaction conditions, different regioselectivities were observed for the substrates with diverse electronic properties. Indeed, whereas $m$-methylacetophenone oxime (1940) only delivered the sterically less hindered product $\mathbf{1 7 6 0 a}$ (entry 7), annulation with oxime 194n containing a fused dioxolane-moiety took place at the sterically more congested $\mathrm{C}-\mathrm{H}$ bond (entry 6). This finding could be explained a secondary chelation effect caused by the oxygen atom in 3-position, which served as a secondary directing group through lone pair donation to the metal center. Such secondary directing group effect has recently been reported also for ruthenium(II)-catalyzed hydroarylation of olefins. ${ }^{246}$ Furthermore, this cationic ruthenium(II)-catalyzed annulation was not limited to the use of diphenylacetylene. Symmetrically substituted dialkylacetylene as well as unsymmetrical alkynes bearing both alkyl and aryl substituents also furnished the target products in moderate to good yield (entries 8-10). 
Table 5.2: Scope of direct annulations with well-defined cationic complex as the catalyst

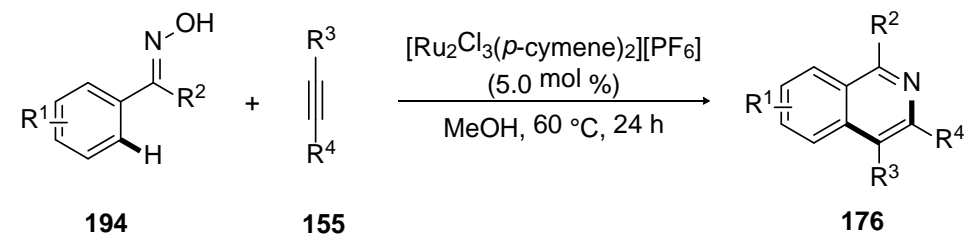

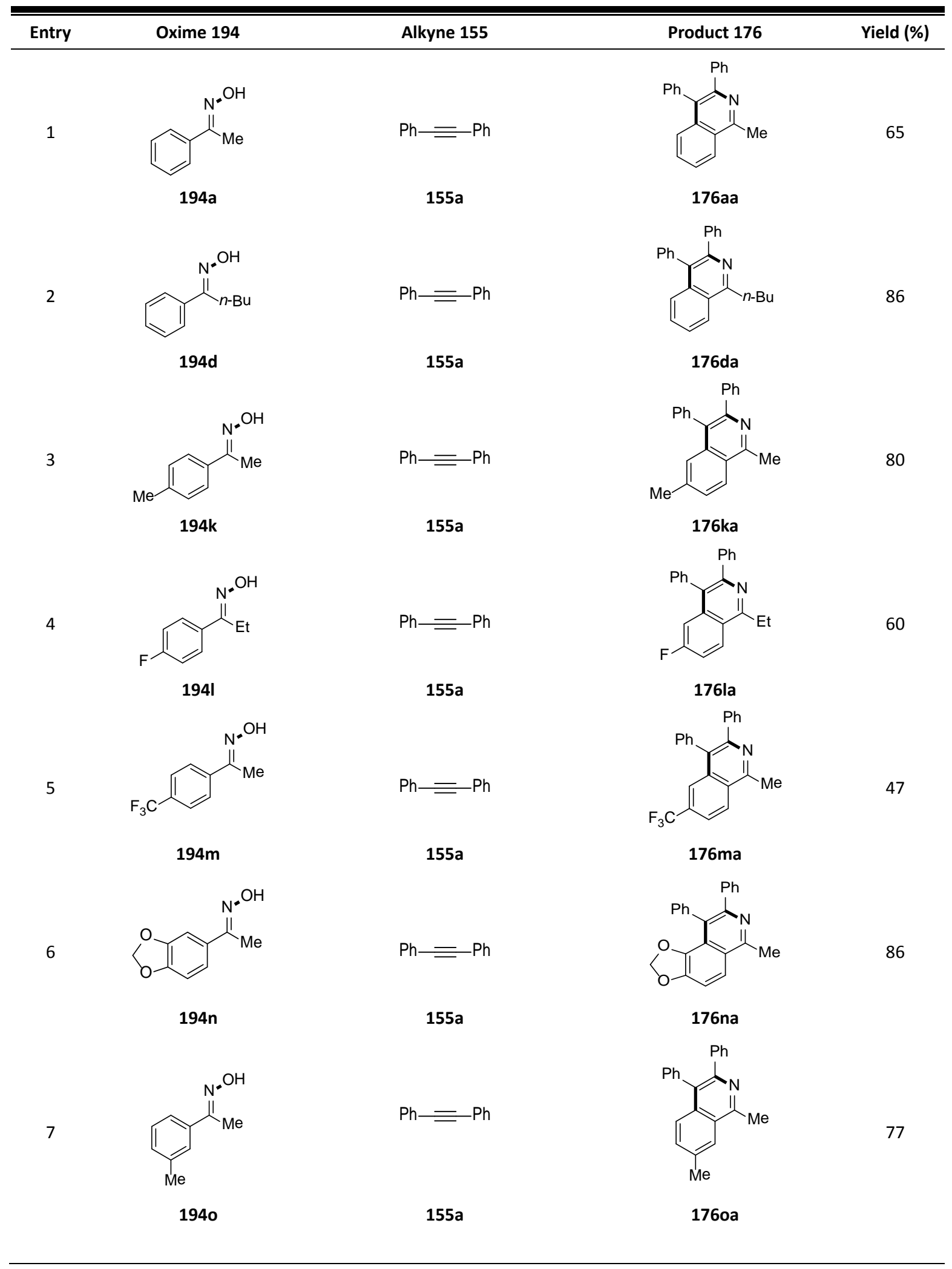


8<smiles>C/C(=N\O)c1ccccc1</smiles>

194a

9<smiles>C/C(=N\O)c1ccccc1</smiles>

194a

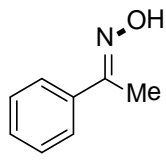

194a

$$
n-\operatorname{Pr}=n-\operatorname{Pr}
$$

$155 d$

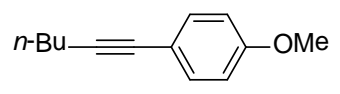

$155 e$

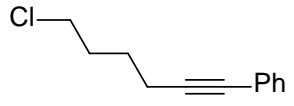

$155 f$

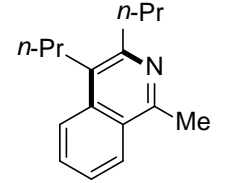

77

176ad

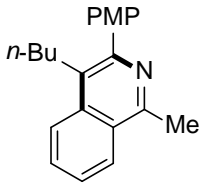

46

176ae

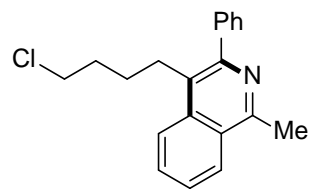

176af

${ }^{a}$ Reaction conditions: $192(0.5 \mathrm{mmol}), 155(1.0 \mathrm{mmol}),\left[\mathrm{Ru}_{2} \mathrm{Cl}_{3}(p \text {-cymene })_{2}\right]\left[\mathrm{PF}_{6}\right](5.0 \mathrm{~mol} \%), \mathrm{MeOH}(2 \mathrm{~mL}), 60^{\circ} \mathrm{C}, 24$ $\mathrm{h}$, under $\mathrm{N}_{2}$; isolated yields. 


\section{Summary and Outlook}

Ruthenium(II)-catalyzed $\mathrm{C}-\mathrm{H}$ functionalizations have recently emerged as a reliable tool for the efficient chemo- and site-selective construction of $\mathrm{C}-\mathrm{C}$ and $\mathrm{C}-\mathrm{Het}$ bonds. Within this thesis, efforts have been devoted to developing new synthetic methods employing versatile ruthenium(II) catalysts.

In the first project, a novel catalytic system consisting of $\left[\mathrm{RuCl}_{2}(p \text {-cymene) }]_{2}\right.$ and MPAAs as the ligands was elaborated and exhibited excellent activity and regioselectivity in unprecedented direct meta-alkylation with tertiary alkyl bromides $\mathbf{5 0}$. A broad substrate scope of 2-phenylpyridines $\mathbf{1 8 7}$ as well as tertiary alkyl halides $\mathbf{5 0}$ were found under the optimized reaction conditions. Various functional groups, including chloro, ether and ester were well tolerated (Scheme 6.1). Moreover, other $\mathrm{N}$-containing heterocycles, such as pyrimidine and pyrazole, served as competent directing groups for promoting this transformation in arenes 197 and 131, respectively. Interestingly, heteroarenes such as thiophene $\mathbf{3 8 t}$ could successfully be alkylated in a site-selective fashion.

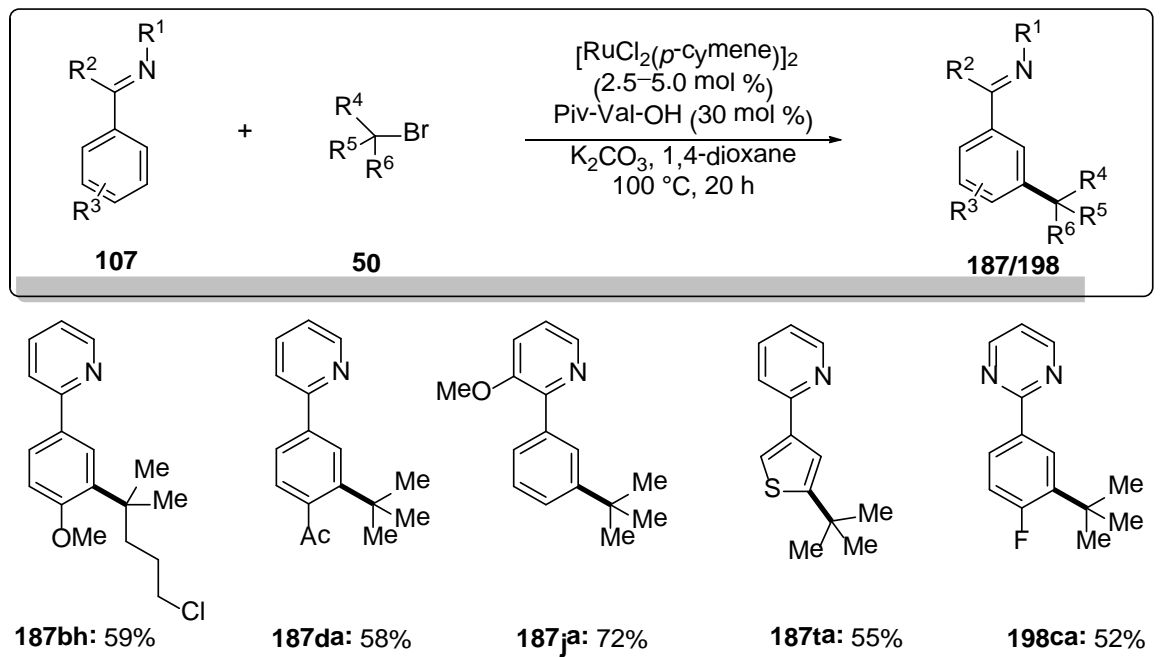

Scheme 6.1: Ruthenium(II)-catalyzed direct meta-alkylation with tertiary alkyl bromides $\mathbf{5 0}$

Importantly, ruthenium(II) catalysis also allowed for the facile direct meta-alkylation of ketimines $\mathbf{1 8 8 .}$ Electron-deficient ketimines $\mathbf{1 8 8}$ were favorably converted comparing to their election-rich analogues. Sterically hindered tertiary alkyl bromides $\mathbf{5 0}$ smoothly gave rise to the desired meta-alkylated products 189 . The auxiliary from the alkylated products can easily be removed within a one-pot hydrolysis, thus yielding a wide range of meta-functionalized aryl ketones 189 (Scheme 6.2). Futhermore, the imine double bond in the meta-alkylated ketimines underwent one-pot reduction, furnishing secondary amines $\mathbf{2 0 7}$ in good yields. Although the yields of these alkylations were moderate comparing to the case of heterocycle-directed reactions, compounds $\mathbf{1 8 9}$ and $\mathbf{2 0 7}$ are generally more useful building blocks in organic synthesis. 


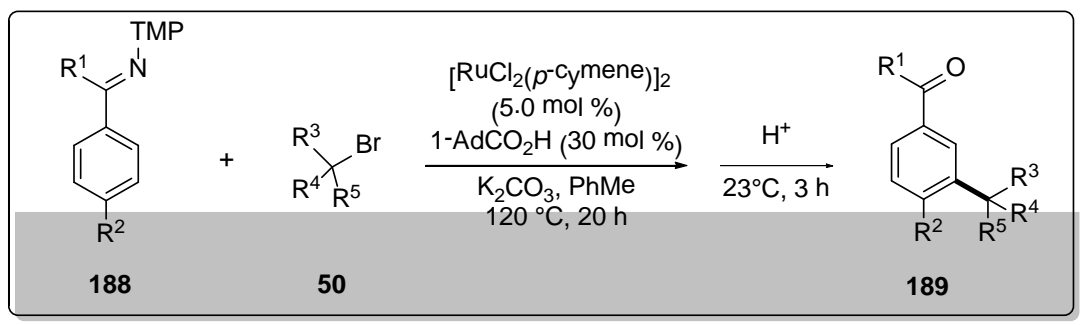<smiles>CC(=O)c1ccc(F)c(C(C)(C)C)c1</smiles>

189aa: $59 \%$

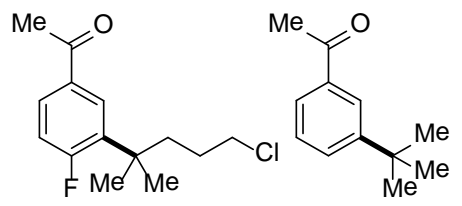

189ah: 50\%

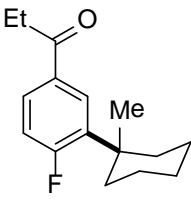

189fb: $62 \%$

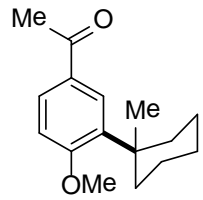

189eb: $47 \%$

Scheme 6.2: Ruthenium(II)-catalyzed direct meta-alkylation of ketimines 188

Not only tertiary alkyl bromides $\mathbf{5 0}$, but also secondary alkyl bromides $\mathbf{4 4}$, both cyclic and acyclic, were competent electrophiles for this novel transformation (scheme 6.3). Electron-rich as well electron-deficient ketimines $\mathbf{1 8 8}$ were smoothly converted. The intermolecular competition experiments revealed electron-deficient arenes to be preferentially alkylated.

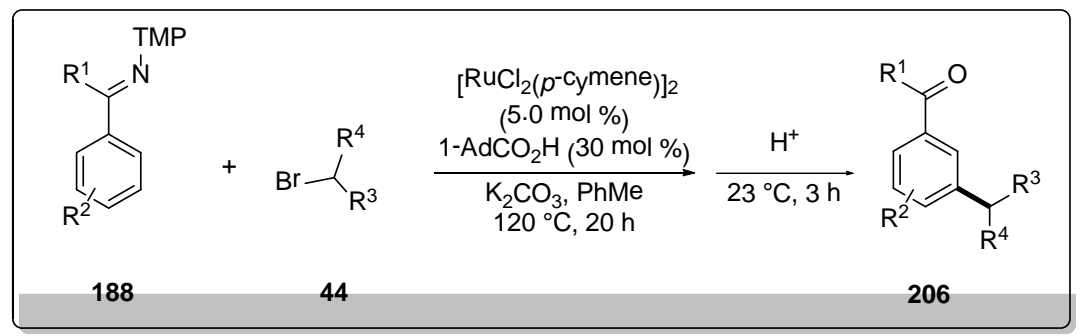

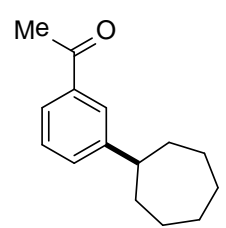

206be: $58 \%$

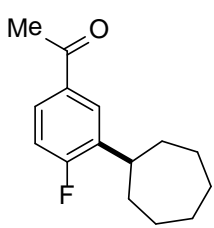

206ae: $60 \%$

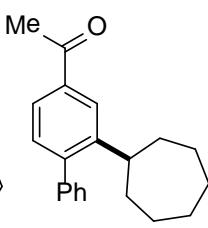

206ge: $60 \%$

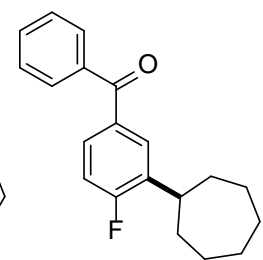

206je: $62 \%$<smiles>CC(=O)c1cc(C(C)(C)C)c2ccccc2c1</smiles>

206ih: $62 \%$

Scheme 6.3: Ruthenium(II)-catalyzed direct meta-alkylation with secondary alkyl bromides $\mathbf{4 4}$

Further investigation of this approach realized the ruthenium(II)-catalyzed direct alkylation of $N$-(pyrimidyl-2-yl)anilines 161 (Scheme 6.4). Again, the ruthenium(II)-MPAA catalytic system proved to be the most efficient. The direct alkylation smoothly took place at the meta-position of an electron-donating directing group, which in not anticipated by classical electrophilic aromatic substation. Another important aspect of this reaction is the $\mathrm{N}$-pyrimidyl could readily be cleaved, thus leading to meta-alkylated aniline 191. Moreover, excellent site-electivity was achieved when ortho- or even di-substituted anilines 161 were employed, furnishing selectively the meta-functionalized products in good yields. 


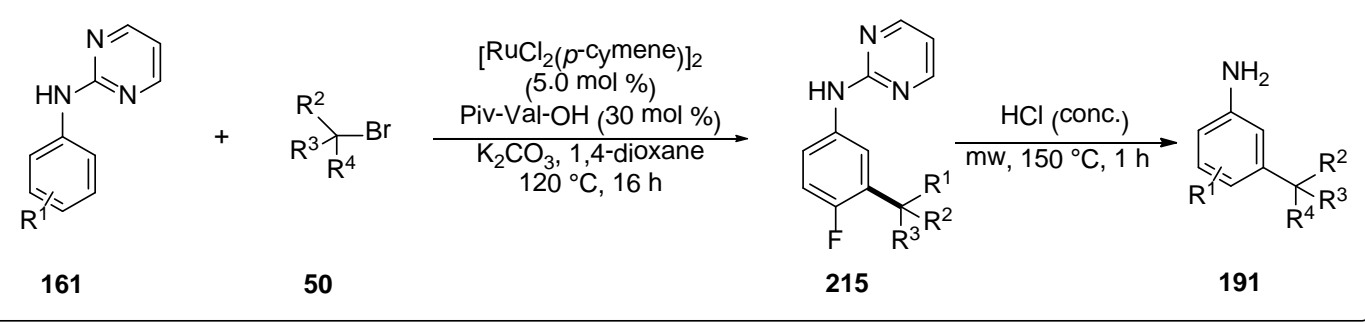

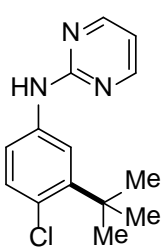

215ba: $58 \%$

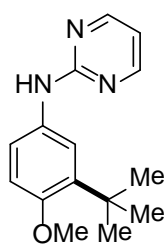

215da: $54 \%$

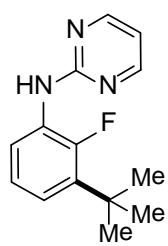

215fa: $61 \%^{\mathrm{a}}$

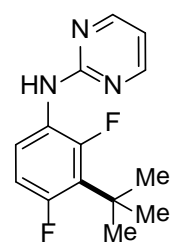

215ha: $55 \%^{\mathrm{a}}$

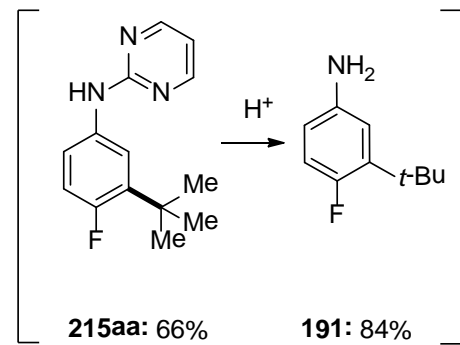

${ }^{a} \mathrm{Ad}-\mathrm{Ile}-\mathrm{OH}$ as additive

Scheme 6.4: Ruthenium(II)-catalyzed direct meta-alkylation of aniline derivatives 161

Future investigations of the ruthenium(II)-catalyzed direct meta-alkylation should be performed addressing three major issues. First of all, meta-alkylations accomplished in this thesis were realized via cyclometalation assisted by $\mathrm{N}$-containing directing group. Extending the substrate scope to readily available, weakly-coordinating directing groups including ketones or esters is of major interest. Secondly, since research directed towards enantioselective cross-coupling of secondary alkyl halides is active nowadays, developing transition metal-catalyzed enatioselective direct alkylation reactions should be an important goal. At last, despite the preliminary understanding of the reaction mechanism, detailed explanation of how the elementary steps of activation of the tertiary halide and $\mathrm{C}-\mathrm{C}$ bond formation take place remain unclear and need further elucidation. Better insight of the reaction mechanism is crucial for further development of ruthenium(II)-catalyzed meta-selective $\mathrm{C}-\mathrm{H}$ functionalization.

Within the second project, a ruthenium(II)-catalyzed cross-dehydrogenative coupling of aryl carbamates 192 with acrylates 15a was achieved (Scheme 6.5). The cationic ruthenium(II) catalyst enabled the highly efficient olefination of electron-rich arenes 192 with high site-selectivity. Carbamates bearing ortho-, meta-, or para-substitutions underwent facile alkenylation, delivering a broad range of protected phenols 193. Importantly, the weakly-coordinating cabarmate group could easily be removed, thus providing a practical method for the preparation of 0 -coumaric acids which are important intermediates in enzymology and useful building blocks in organic synthesis. 


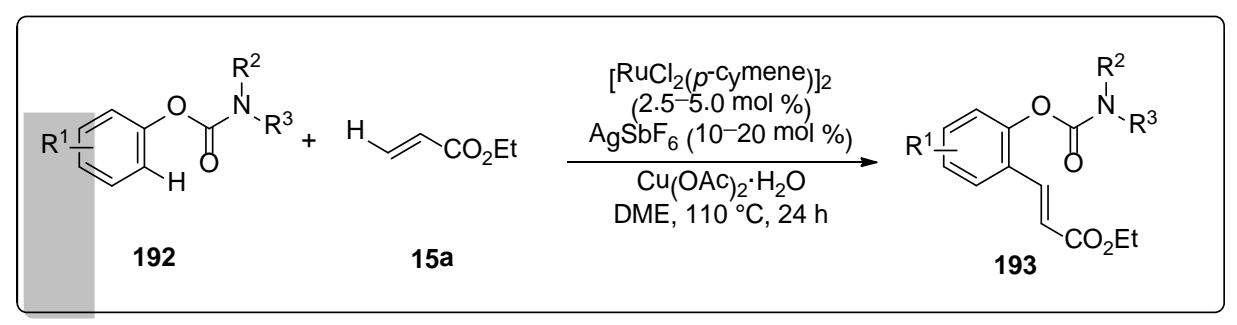<smiles>CCOC(=O)/C=C/c1cccc(-c2ccccc2)c1OC(=O)N(C)C</smiles>

193da: $77 \%$<smiles>CCOC(=O)Cc1ccc(-c2ccccc2)cc1OC(C)=O</smiles>

193ua: $97 \%$

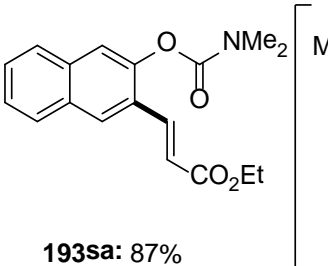

193sa: $87 \%$

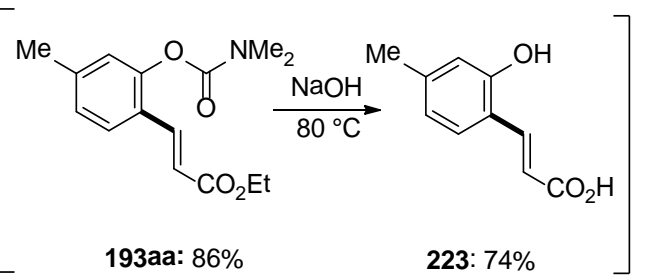

Scheme 6.5: Ruthenium(II)-catalyzed oxidative alkenylation of carbamate 192

The third project focused on redox-neutral annulations of alkynes 155 via ruthenium(II)-catalyzed $\mathrm{C}-\mathrm{H} / \mathrm{N}-\mathrm{O}$ bond functionalization of oximes 194. A well-defined cationic ruthenium(II)-catalyst allowed the synthesis of highly substituted isoquinolines 176 (Scheme 6.6). Electron-rich as well as electron-deficient oximes could be efficiently converted. Unsymmetrical aryl-alkyl-alkynes 155 bearing functional groups were regioselectively transformed to the corresponding isoquinolines.

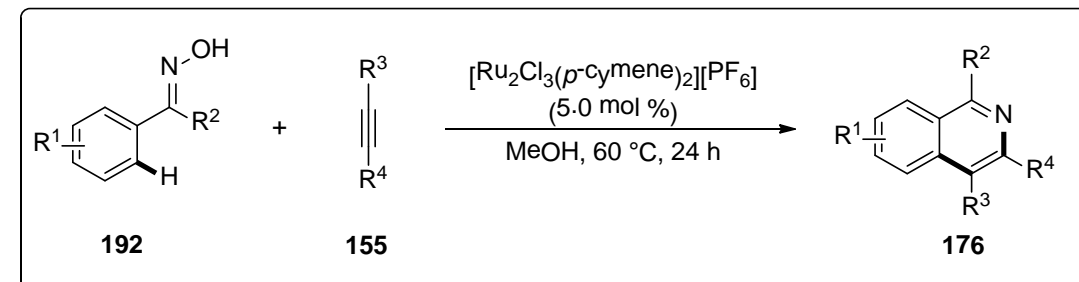<smiles>CCCc1nc(-c2ccccc2)c(-c2ccccc2)c2ccccc12</smiles>

176da: $86 \%$<smiles>Cc1nc(-c2ccccc2)c(-c2ccccc2)c2c3c(ccc12)OCO3</smiles>

176na: $86 \%$<smiles>Cc1ccc2c(-c3ccccc3)c(-c3ccccc3)nc([N+](=O)[O-])c2c1</smiles>

1760a: $77 \%$<smiles>Cc1nc(-c2ccccc2)c(CCCCCl)c2ccccc12</smiles>

176af: $72 \%$<smiles>CCCCc1c(N)nc(CCC)c2ccccc12</smiles>

176ae: $77 \%$

Scheme 6.6: Well-defined ruthenium(II) complex-catalyzed alkyne annulation

However, only poor yields were obtained with terminal alkynes in most of the ruthenium(II)-catalyzed annulation reactions. Presumably this is the result of dimerization of the terminal alkyne. Interestingly, in a recent published work, this shortage was successfully overcome via ruthenium(II)-catalyzed $\mathrm{C}-\mathrm{H} / \mathrm{N}-\mathrm{N}$ bond functionalization. ${ }^{230}$ This offered broad implications for future developments of ruthenium(II)-catalyzed alkyne annulations for more functionalized heterocycle synthesis. 


\section{Experimental Section}

\subsection{General Remarks}

Unless otherwise noticed, all reactions were performed under a $\mathrm{N}_{2}$ atmosphere using pre-dried glassware and standard Schlenk techniques.

\section{Solvents}

All solvents for reactions involving moisture-sensitive reagents were dried, distilled and stored under inert atmosphere ( $\mathrm{Ar}$ or $\mathrm{N}_{2}$ ) according to the following standard procedures. tert-Amylalcohol $(t-\mathrm{AmOH})$ was used as supplied by Merck or stirred over sodium chips for $5 \mathrm{~h}$ at $120{ }^{\circ} \mathrm{C}$ and distilled under ambient pressure; water $\left(\mathrm{H}_{2} \mathrm{O}\right)$ was degassed before its use applying repeated Freeze-Pump-Thaw degassing procedure; 1,2-dichloroethane (DCE), $i$ - $\mathrm{BuOH}, N, N$-dimethylformamide (DMF), acetonitrile (MeCN) and dimethylacetamide (DMA) were dried over $\mathrm{CaH}_{2}$ for $8 \mathrm{~h}$, degassed and distilled under reduced pressure; dichloromethane and tetrahydrofuran (THF) were purified using a solvent purification system (SPS) from MBRAUN; $N$-methyl-2-pyrrolidone (NMP) was stirred over $\mathrm{CaH}_{2}$ for $4 \mathrm{~h}$ at $150{ }^{\circ} \mathrm{C}$ and subsequently distilled under reduced pressure; methanol (MeOH) was distilled from magnesium methanolate; toluene was pre-dried over $\mathrm{KH}$ followed by distillation from sodium benzophenone ketyl; 1,4-dioxane was dried by distillation from sodium benzophenone ketyl.

\section{Vacuum}

The following pressures were measured on the used vacuum pump and were not corrected: membrane pump vacuum (MPV): 0.5 mbar, oil pump vacuum (OPV): 0.1 mbar.

\section{Melting Points (M. p.)}

Melting points were measured using a Stuart ${ }^{\circledR}$ Melting Point Apparatus SMP3 from BARLOWORLD SCIENTIFIC. Reported values are uncorrected.

\section{Chromatography}

Analytical thin layer chromatography (TLC) was performed on $0.25 \mathrm{~mm}$ silica gel 60F-plates (MACHEREY-NAGEL) with $254 \mathrm{~nm}$ fluorescent indicator from MERCK. Plates were visualized under UV-light or developed by treatment with a $\mathrm{KMnO}_{4}$ solution followed by careful applying a heat gun. Chromatographic purification of products was accomplished by flash column chromatography on MERCK silica gel, grade $60(0.040-0.063 \mathrm{~mm}$ and $0.063-0.200 \mathrm{~mm})$.

\section{Gas Chromatograpgy (GC)}

The conversion of the reactions was monitored applying coupled gas chromatography/mass spectrometry using G1760C GCDplus with mass detector HP 5971, 5890 Series // with mass detector HP 5972 from HEWLETT-PACKARD and 7890A GC-System with mass detector 5975C (Triplex-Axis-Detector) from AGILENT TECHNOLOGIES equipped with HP-5MS columns (30 $\mathrm{m} \times 0.25$ $\mathrm{mm} \times 0.25 \mathrm{~m}$ ) were used.

\section{High Performance Liquid Chromatography (HPLC)}

Preparative and analytical separations were performed on an HPLC-System from KNAUE (Smartline 
Pump 100, Dynamic Mixing Chamber, Injection- and Control-Valve, Smartline UV Detector 2500). Separation normal phase column $(250 \times 10 \mathrm{~mm})$ from MACHEREY-NAGEL $(\mathrm{MN})$ was used. Organic solvents of HPLC grade were employed. All samples were filtered through Polytetrafluorethylen Filter from ROTH ( $\varnothing 25 \mathrm{~mm}, 0.2 \mu \mathrm{m}$ ) or VWR ( $\varnothing 13 \mathrm{~mm}, 0.2 \mu \mathrm{m}$ ) prior to separation.

\section{Nuclear Magnetic Resonance Spectroscopy (NMR)}

Nuclear magnetic resonance (NMR) spectroscopy was performed at 300,400 or $600 \mathrm{MHz}\left({ }^{1} \mathrm{H} N M R\right)$, 75 or $125 \mathrm{MHz}\left({ }^{13} \mathrm{C}\right.$ NMR, APT) and $283 \mathrm{MHz}\left({ }^{19} \mathrm{~F}\right.$ NMR) on BRUKER AM 250, VARIAN Unity-300 and Inova 500 instruments. Chemical shifts are reported as $\delta$-values in ppm relative to the residual proton peak of the deuterated solvent or its carbon atom, respectively, or the standard trimethylsilyl (TMS) peak. For characterization of the observed resonance multiplicities the following abbreviations were applied: $s$ (singlet), $d$ (doublet), $t$ (triplet), $q$ (quartet), $m$ (multiplet), $d d$ (doublet of doublet), $d t$ (doublet of triplet), or analogue representations. The coupling constants $J$ are reported in Hertz $(\mathrm{Hz})$.

\section{Infrared Spectroscopy (IR)}

Infrared spectra were recorded on a BRUKER Alpha-P ATR-spectrometer. Liquid probes were measured as film and solid samples neat. Analysis of the spectral data has been done by using the OPUS 6. Absorption ( $\tilde{\mathrm{v}})$ is given in wave numbers $\left(\mathrm{cm}^{-1}\right)$. Spectra were recorded in the range of 4000 to $400 \mathrm{~cm}^{-1}$.

\section{Mass Spectrometry (MS)}

MS (EI) and HR-MS (EI) were measured on a Time-of-Flight mass spectrometer AccuTOF from JOEL. ESI-mass spectra were recorded on an Ion-Trap mass spectrometer LCQ from FINNIGAN or on a Time-of-Flight mass spectrometer microTOF from BRUKER. ESI-HR-MS spectra were recorded on a BRUKER APEX IV or a BRUKER DALTONIC [7T, Fourier Transform Ion Cyclotron Resonance (FTICR)] mass spectrometer. The ratios of mass to charge $(\mathrm{m} / \mathrm{z})$ are indicated, intensities relative to the base peak $(I=100)$ are written in parentheses.

\section{Reagents}

Chemicals obtained from commercial sources with purity above $95 \%$ were used without further purification. The following compounds are known and were synthesized according to previously described methods.

2-Phenylpyridines $\mathbf{3 8}{ }^{247}$ tertiary alkyl bromides $\mathbf{5 0 ,}{ }^{95}$ mono-protected amino acids $\mathbf{1 1 6},{ }^{248}$ 2-phenylpyrimidine $\quad 197 \mathrm{~b}-\mathrm{c},{ }^{247}$ ketimines $\quad 188^{249} \mathrm{~N}$-(pyrimidine-2-yl)anilines $161{ }^{211}$ $\mathrm{N}$-(4-fluorophenyl)pyridin-2-amine $\mathbf{2 1 6}$, ${ }^{250}$ secondary alkyl bromides $\mathbf{4 4 n - 0 ,}{ }^{251} \mathbf{4 4 a},{ }^{91}$ aryl carbamate 192, ${ }^{252}$ oxime $194 \mathbf{b}-\mathbf{j},{ }^{253}\left[\mathrm{Ru}_{2} \mathrm{Cl}_{3}(p \text {-cymene })_{2}\right]\left[\mathrm{PF}_{6}\right] .{ }^{211}$

The following compounds were obtained by the generous courtesy of the persons named below:

Karsten Rauch: $\left[\mathrm{RuCl}_{2}(p \text {-cymene })\right]_{2}$.

Dr. Christoph Kornhaaß: Oximes 194a, 194k-o, Alkynes 155d-f.

Dr. Nora Hofmann: Secondary alkyl bromide 44d.

M. Sc. Svenja Warratz: [RuCl(O-Val-Piv)( $p$-cymene)] (195).

M. Sc. Keshav Raghuvanshi: 1-Phenylprazoles 131a-e.

M. Sc. Sebastian Lackner: N-2-Pyrimidyl anilines 161d.

M. Sc. Zhixiong Ruan: N-2-Pyrimidyl aniline 161h. 
M. Sc. Weiping Liu: Aryl carbamate $\left[D_{5}\right]-221 b$.

M. Sc. Eloisa Eriko Ishikawa: Tertiary alkyl halide 50g, 4-fluoro-N-phenylaniline (216c)

Dr. Nora Hofmann \& Dr. Marvin Schinkel: 2-phenylpyridines 38g-38h, 38o-38p, 38q-38r, $\left[D_{5}\right]-38 a$, $\left[D_{3}\right]$-38a, 2-phenylpyrimidine 197a

\subsection{General Procedures}

\section{General Procedure A:}

Ruthenium(II)-catalyzed direct meta-alkylation

Substrate 38b (0.50 mmol), $\left[\mathrm{RuCl}_{2}(p \text {-cymene) }]_{2}\right.$ (7.7 mg, $\left.2.5 \mathrm{~mol} \%\right)$, Piv-Val-OH (30.0 mg, $\left.30 \mathrm{~mol} \%\right)$ and $\mathrm{K}_{2} \mathrm{CO}_{3}(138 \mathrm{mg}, 1.00 \mathrm{mmol})$ were placed in a pre-dried $25 \mathrm{~mL}$ pressure tube. The mixture was degassed and purged with $\mathrm{N}_{2}$ for 3 times. Tertiary alkyl bromide 50a $(1.50 \mathrm{mmol})$ and 1,4-dioxane $(2.0 \mathrm{~mL})$ were then added, and the mixture was stirred at $100^{\circ} \mathrm{C}$ for $20 \mathrm{~h}$. At ambient temperature, EtOAc (15 mL) was added, and the reaction mixture was filtered through a pad of silica gel. The solvents were removed in vacuo and purification of the residue by column chromatography ( $n$-hexane/EtOAc) yielded compound 187ba.

In several specific cases indicated below, Piv-Val-OH was replaced by $\mathrm{N}$-(1-adamantane-2-carbonyl)-L-isoleucine (1-Ad-lle-OH, $44.0 \mathrm{mg}, 30 \mathrm{~mol} \%$ ).

\section{General Procedure B:}

Ruthenium(II)-catalyzed direct meta-Alkylation using [RuCl(O-Val-Piv)(p-cymene)]

Substrate 38b (0.50 mmol), [RuCl(O-Val-Piv)(p-cymene)] (11.8 mg, $5.0 \mathrm{~mol} \%)$ and $\mathrm{K}_{2} \mathrm{CO}_{3}(138.0 \mathrm{mg}$, $1.00 \mathrm{mmol}$ ) were placed in a pre-dried $25 \mathrm{~mL}$ pressure tube. The mixture was degassed and purged with $\mathrm{N}_{2}$ for 3 times. Tertiary alkyl bromide $50 \mathrm{a}(1.50 \mathrm{mmol})$ and 1,4-dioxane $(2.0 \mathrm{~mL})$ were then added and the mixture was stirred at $100{ }^{\circ} \mathrm{C}$ for $20 \mathrm{~h}$. At ambient temperature, EtOAc (15 mL) was added and the reaction mixture was filtered through a pad of silica gel. The solvents were removed in vacuo and purification of the residue by column chromatography ( $n$-hexane/EtOAc) yielded compound 187ba.

\section{General Procedure C:}

\section{Ruthenium(II)-catalyzed direct meta-alkylation of ketimine 188}

Ketimine 188 (0.50 mmol), $\left[\mathrm{RuCl}_{2}(p \text {-cymene) }]_{2}(15.3 \mathrm{mg}, 2.5 \mu \mathrm{mol}, 5.0 \mathrm{~mol} \%), 1-\mathrm{AdCO}_{2} \mathrm{H}(27.8 \mathrm{mg}\right.$, $30 \mathrm{~mol} \%)$ and $\mathrm{K}_{2} \mathrm{CO}_{3}(138 \mathrm{mg}, 1.00 \mathrm{mmol})$ were placed in a pre-dried $25 \mathrm{~mL}$ pressure tube. The mixture was degassed and purged with $\mathrm{N}_{2}$ for 3 times. Tertiary alkyl bromide $50(1.50 \mathrm{mmol})$ and PhMe $(2.0 \mathrm{~mL})$ were then added and the mixture was stirred at $120{ }^{\circ} \mathrm{C}$ for $20 \mathrm{~h}$. At ambient temperature, $2 \mathrm{~N} \mathrm{HCl}(3.0 \mathrm{~mL})$ was added, and the resulting mixture was stirred for additional 3 hours, then extracted with EtOAc $(3 \times 20 \mathrm{~mL})$. The combined organic layers were dried over $\mathrm{Na}_{2} \mathrm{SO}_{4}$ and concentrated in vacuo. Purification of the residue by column chromatography ( $n$-hexane/EtOAc or $n$-pentane/Et ${ }_{2} \mathrm{O}$ ) yielded compound 189.

\section{General Procedure D:}

Ruthenium(II)-catalyzed oxidative alkenylation of aryl carbamate 192

In a $25 \mathrm{ml}$ schlenk tube, a suspension of carbamate $192(0.50 \mathrm{mmol})$, ethyl acrylate (15a) (100.1 mg, $1.00 \mathrm{mmol}),\left[\mathrm{RuCl}_{2}(p \text {-cymene })\right]_{2}(7.7 \mathrm{mg}, 2.5 \mathrm{~mol} \%), \mathrm{AgSbF}_{6}(17.2 \mathrm{mg}, 10 \mathrm{~mol} \%)$ and $\mathrm{Cu}(\mathrm{OAc})_{2} \cdot \mathrm{H}_{2} \mathrm{O}$ 
(200 mg, $1.00 \mathrm{mmol})$ in DME $(3.0 \mathrm{~mL})$ was stirred at $110^{\circ} \mathrm{C}$ for $24 \mathrm{~h}$ under an atmosphere of $\mathrm{N}_{2}$. At ambient temperature, EtOAc $(15 \mathrm{~mL})$ was added, and the mixture was filtered through a pad of silica gel. The solvents were removed in vacuo. Purification of the residue by column chromatography ( $n$-hexane/EtOAc) yielded compound 193.

\section{General Procedure E:}

Ruthenium(II)-catalyzed oxidative aerobic alkenylation of aryl carbamate 192 with cocatalytic amounts of $\mathrm{Cu}(\mathrm{OAC})_{2} \cdot \mathrm{H}_{2} \mathrm{O}$

In a $25 \mathrm{ml}$ schlenk tube, a suspension of carbamate $192(0.50 \mathrm{mmol})$, ethyl acrylate (15a) $(100.1 \mathrm{mg}$, $1.00 \mathrm{mmol}$ ), $\left[\mathrm{RuCl}_{2} \text { (p-cymene) }\right]_{2}(15.3 \mathrm{mg}, 5.0 \mathrm{~mol} \%), \mathrm{AgSbF}_{6}(34.4 \mathrm{mg}, 20 \mathrm{~mol} \%)$ and $\mathrm{Cu}(\mathrm{OAc})_{2} \cdot \mathrm{H}_{2} \mathrm{O}$ $(29.7 \mathrm{mg}, 30 \mathrm{mmol} \%)$ in DME $(3.0 \mathrm{~mL})$ was pre-stirred at ambient temperature for 10 min under $\mathrm{N}_{2}$. Thereafter, the reaction mixture was purged with air for $10 \mathrm{~min}$. Then, the reaction tube was sealed and the mixture was stirred at $110{ }^{\circ} \mathrm{C}$ for $24 \mathrm{~h}$ under an atmosphere of ambient air. At ambient temperature, EtOAc $(15 \mathrm{~mL})$ was added, and the mixture was filtered through a pad of silica gel. The solvents were removed in vacuo. Purification of the residue by column chromatography (n-hexane/EtOAc) yielded compound 193.

\section{General Procedure F:}

Synthesis of isoquinoline 176 via ruthenium(II)-catalyzed $\mathrm{C}-\mathrm{H} / \mathrm{N}-\mathrm{O}$ functionalizations

Oxime $194(0.50 \mathrm{mmol})$, alkyne $155(1.00 \mathrm{mmol}),\left[\operatorname{RuCl}_{2}(p \text {-cymene })\right]_{2}(15.3 \mathrm{mg}, 5.0 \mathrm{~mol} \%)$ and $\mathrm{KPF}_{6}$ (27.6 mg, $30 \mathrm{~mol} \%$ ) were placed in a pre-dried $25 \mathrm{~mL}$ Schlenk tube. The mixture was degassed and purged with $\mathrm{N}_{2}$ for 3 times. Dry $\mathrm{MeOH}(2.0 \mathrm{~mL}$ ) was added (and the liquid alkyne $\mathbf{1 5 5}$ was also added at this stage), and the reaction mixture was stirred at $60^{\circ} \mathrm{C}$ for $24 \mathrm{~h}$. At ambient temperature, EtOAc $(15 \mathrm{~mL})$, was added and the solvents were removed in vacuo. The product $\mathbf{1 7 6}$ was purified by column chromatography on silica gel ( $n$-hexane/EtOAc).

\section{General Procedure G:}

Synthesis of Isoquinoline 176 via well-defined cationic ruthenium(II) complex catalyzed $\mathrm{C}-\mathrm{H} / \mathrm{N}-\mathrm{O}$ functionalizations

Oxime 194 (0.50 mmol), solid alkyne 155 (1.00 mmol), $\left[\mathrm{Ru}_{2} \mathrm{Cl}_{3}(p \text {-cymene })_{2}\right]\left[\mathrm{PF}_{6}\right]$ (18.0 mg, $\left.5.0 \mathrm{~mol} \%\right)$ were placed to a pre-dried $25 \mathrm{~mL}$ Schlenk tube. The mixture was degassed and purged with $\mathrm{N}_{2}$ for 3 times. Dry $\mathrm{MeOH}(2.0 \mathrm{~mL}$ ) was added (and the liquid alkyne 155 was also added at this stage), and the reaction mixture was stirred at $60^{\circ} \mathrm{C}$ for $24 \mathrm{~h}$. At ambient temperature, EtOAc $(15 \mathrm{~mL})$ was added, and the solvents were removed in vacuo. The product $\mathbf{1 7 6}$ was purified by column chromatography on silica gel ( $n$-hexane/EtOAc). 


\subsection{Analytical Data}

7.3.1 Analytical Data for the Products of the Ruthenium(II)-Catalyzed Direct meta-Alkylation

\section{Synthesis of 2-[3-(tert-Butyl)-4-methoxyphenyl]pyridine (187ba)}

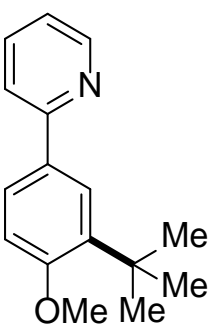

The general procedure $\mathbf{A}$ was followed using substrate $\mathbf{3 8 b}(93 \mathrm{mg}, 0.50 \mathrm{mmol})$ and $t$ - $\mathrm{BuBr}$ (50a) (206 mg, $1.50 \mathrm{mmol}$ ). After $20 \mathrm{~h}$, purification by column chromatography ( $n$-hexane/EtOAc 10:1) yielded 187ba (91 mg, 76\%) as a colorless oil.

The general procedure $\mathbf{B}$ was followed using substrate $\mathbf{3 8 b}(93 \mathrm{mg}, 0.50 \mathrm{mmol})$ and $t$-BuBr (50a) (206 mg, $1.50 \mathrm{mmol}$ ). After $20 \mathrm{~h}$, purification by column chromatography ( $n$-hexane/EtOAc 10:1) yielded 187ba (96 mg, 80\%) as a colorless

oil.

${ }^{1} \mathrm{H}$ NMR $\left(300 \mathrm{MHz}, \mathrm{CDCl}_{3}\right): \delta=8.66(\mathrm{~d}, J=4.9 \mathrm{~Hz}, 1 \mathrm{H}), 7.97(\mathrm{~d}, J=2.3 \mathrm{~Hz}, 1 \mathrm{H}), 7.81(\mathrm{dd}, J=8.5,2.3 \mathrm{~Hz}$, $1 \mathrm{H}), 7.73-7.64(\mathrm{~m}, 2 \mathrm{H}), 7.15$ (ddd, $J=6.8,4.9,1.9 \mathrm{~Hz}, 1 \mathrm{H}), 6.97(\mathrm{~d}, J=8.5 \mathrm{~Hz}, 1 \mathrm{H}), 3.90(\mathrm{~s}, 3 \mathrm{H}), 1.46(\mathrm{~s}$, $9 \mathrm{H})$.

${ }^{13} \mathrm{C}$ NMR $\left(75 \mathrm{MHz}, \mathrm{CDCl}_{3}\right): \delta=159.4\left(\mathrm{C}_{\mathrm{q}}\right), 157.8\left(\mathrm{C}_{\mathrm{q}}\right), 149.5(\mathrm{CH}), 138.4\left(\mathrm{C}_{\mathrm{q}}\right), 136.5(\mathrm{CH}), 131.4\left(\mathrm{C}_{\mathrm{q}}\right)$, 125.7 (CH), $125.4(\mathrm{CH}), 121.1(\mathrm{CH}), 120.0(\mathrm{CH}), 111.6(\mathrm{CH}), 55.1\left(\mathrm{CH}_{3}\right), 35.0\left(\mathrm{C}_{\mathrm{q}}\right), 29.7\left(\mathrm{CH}_{3}\right)$.

IR (neat): $\tilde{v}=3077,2954,1586,1463,1270,1091,819,741 \mathrm{~cm}^{-1}$.

MS (EI) $m / z$ (relative intensity) 241 (42) [M] ${ }^{+}, 226$ (100), 210 (15), 167 (15).

HR-MS (EI): $\mathrm{m} / z$ calcd for $\mathrm{C}_{16} \mathrm{H}_{19} \mathrm{NO}^{+}[\mathrm{M}]^{+} 241.1461$, found 241.1475 .

Synthesis of 2-[4-Methoxy-3-(1-methylcyclohexyl)phenyl]pyridine (187bb)

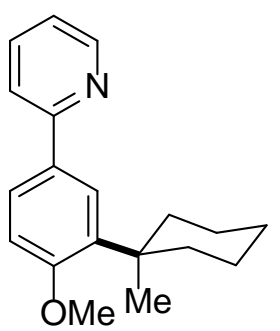

The general procedure $\mathbf{A}$ was followed using substrate $\mathbf{3 8 b}(93 \mathrm{mg}, 0.50 \mathrm{mmol})$ and bromide 50b (266 $\mathrm{mg}, 1.50 \mathrm{mmol}$ ). After $20 \mathrm{~h}$, purification by column chromatography ( $n$-hexane/EtOAc 20:1) yielded 187bb (110 mg, 78\%) as a colorless oil.

The general procedure $\mathbf{B}$ was followed using substrate $\mathbf{3 8} \mathbf{b}(93 \mathrm{mg}, 0.50 \mathrm{mmol}$ ) and bromide 50b (266 mg, $1.50 \mathrm{mmol}$ ). After $20 \mathrm{~h}$, purification by column chromatography ( $n$-hexane/EtOAc 20:1) yielded 187bb (106 mg, 76\%) as a

colorless oil.

${ }^{1} \mathrm{H}$ NMR $\left(300 \mathrm{MHz}, \mathrm{CDCl}_{3}\right): \delta=8.67(\mathrm{~d}, J=4.9 \mathrm{~Hz}, 1 \mathrm{H}), 8.00(\mathrm{~d}, J=2.4 \mathrm{~Hz}, 1 \mathrm{H}), 7.81(\mathrm{dd}, J=8.5,2.4 \mathrm{~Hz}$, $1 \mathrm{H}), 7.74-7.64(\mathrm{~m}, 2 \mathrm{H}), 7.15(\mathrm{ddd}, J=6.8,4.8,2.0 \mathrm{~Hz}, 1 \mathrm{H}), 6.98(\mathrm{~d}, J=8.5 \mathrm{~Hz}, 1 \mathrm{H}), 3.87(\mathrm{~s}, 3 \mathrm{H})$, 2.23-2.12 (m, 2H), 1.86-1.75 (m, 2H), 1.67-1.48 (m, 6H), $1.36(\mathrm{~s}, 3 \mathrm{H})$.

${ }^{13} \mathrm{C}$ NMR $\left(75 \mathrm{MHz}, \mathrm{CDCl}_{3}\right): \delta=159.6\left(\mathrm{C}_{\mathrm{q}}\right), 157.9\left(\mathrm{C}_{\mathrm{q}}\right), 149.5(\mathrm{CH}), 137.9\left(\mathrm{C}_{\mathrm{q}}\right), 136.5(\mathrm{CH}), 131.4\left(\mathrm{C}_{\mathrm{q}}\right)$, $126.4(\mathrm{CH}), 125.4(\mathrm{CH}), 121.1(\mathrm{CH}), 119.9(\mathrm{CH}), 111.9(\mathrm{CH}), 55.1\left(\mathrm{CH}_{3}\right), 38.3\left(\mathrm{C}_{\mathrm{q}}\right), 36.9\left(\mathrm{CH}_{2}\right), 26.6$ $\left(\mathrm{CH}_{2}\right), 25.1\left(\mathrm{CH}_{3}\right), 22.8\left(\mathrm{CH}_{2}\right)$.

IR (neat): $\tilde{v}=3077,2922,1724,1588,1429,1239,1120,1025,856,593 \mathrm{~cm}^{-1}$.

MS (EI) $\mathrm{m} / \mathrm{z}$ (relative intensity) 281 (100) [M] ${ }^{+}, 266$ (75), 198 (50), 167 (28).

HR-MS (EI): $m / z$ calcd for $\mathrm{C}_{19} \mathrm{H}_{22} \mathrm{NO}^{+}[\mathrm{M}-\mathrm{H}]^{+}, 280.1696$, found 280.1705 . 


\section{Synthesis of 2-[4-Methoxy-3-(2-methylpentan-2-yl)phenyl]pyridine (187bc)}

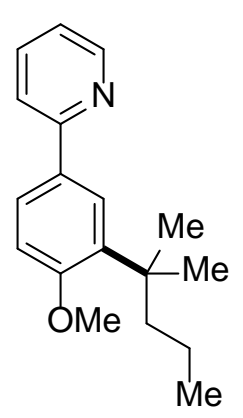

The general procedure $\mathbf{A}$ was followed using substrate $\mathbf{3 8 b}(93 \mathrm{mg}, 0.50 \mathrm{mmol})$ and bromide 50c (248 mg, $1.50 \mathrm{mmol}$ ). After $20 \mathrm{~h}$, purification by column chromatography ( $n$-hexane/EtOAc $20: 1$ ) yielded $187 \mathrm{bc}(80 \mathrm{mg}, 59 \%$ ) as a colorless oil.

The general procedure B was followed, using $38 \mathbf{b}(93 \mathrm{mg}, 0.50 \mathrm{mmol})$ and $\mathbf{5 0 c}$ (248 $\mathrm{mg}, \quad 1.50 \mathrm{mmol})$. After $20 \mathrm{~h}$, purification by column chromatography ( $n$-hexane/EtOAc 20:1) yielded $187 \mathrm{bc}$ (68 $\mathrm{mg}, 50 \%$ ) as a colorless oil.

${ }^{1} \mathrm{H}$ NMR $\left(300 \mathrm{MHz}, \mathrm{CDCl}_{3}\right): \delta=8.66(\mathrm{~d}, J=4.9 \mathrm{~Hz}, 1 \mathrm{H}), 7.91(\mathrm{~d}, J=2.4 \mathrm{~Hz}, 1 \mathrm{H}), 7.82$ (dd, $J=8.5,2.4 \mathrm{~Hz}, 1 \mathrm{H}$ ), 7.73-7.64 (m, 2H), 7.15 (ddd, $J=6.8,4.6,1.8 \mathrm{~Hz}, 1 \mathrm{H}), 6.95$ (d, $J=8.5 \mathrm{~Hz}, 1 \mathrm{H}$ ), $3.87(\mathrm{~s}, 3 \mathrm{H}), 1.87-1.80(\mathrm{~m}, 2 \mathrm{H}), 1.43(\mathrm{~s}, 6 \mathrm{H}), 1.12-0.98(\mathrm{~m}, 2 \mathrm{H}), 0.83(\mathrm{t}, J=7.3 \mathrm{~Hz}, 3 \mathrm{H})$.

${ }^{13} \mathrm{C} \mathrm{NMR}\left(75 \mathrm{MHz}, \mathrm{CDCl}_{3}\right): \delta=159.4\left(\mathrm{C}_{\mathrm{q}}\right), 157.8\left(\mathrm{C}_{\mathrm{q}}\right), 149.4(\mathrm{CH}), 137.0\left(\mathrm{C}_{\mathrm{q}}\right), 136.5(\mathrm{CH}), 131.3\left(\mathrm{C}_{\mathrm{q}}\right)$, $126.5(\mathrm{CH}), 125.6(\mathrm{CH}), 121.1(\mathrm{CH}), 119.9(\mathrm{CH}), 111.5(\mathrm{CH}), 55.1\left(\mathrm{CH}_{3}\right), 43.4\left(\mathrm{CH}_{2}\right), 38.4\left(\mathrm{C}_{\mathrm{q}}\right), 28.4$ $\left(\mathrm{CH}_{3}\right), 18.5\left(\mathrm{CH}_{2}\right), 14.9\left(\mathrm{CH}_{3}\right)$.

IR (neat): $\tilde{v}=3052,2954,1587,1562,1462,1429,1159,1096,1027,779 \mathrm{~cm}^{-1}$.

MS (EI) $m / z$ (relative intensity) 269 (20) [M] ${ }^{+}, 226$ (100), 198 (17), 167 (16).

HR-MS (EI): $m / z$ calcd for $\mathrm{C}_{18} \mathrm{H}_{23} \mathrm{NO}^{+}[\mathrm{M}]^{+} 269.1774$, found 269.1784 .

\section{Synthesis of 2-[4-Methoxy-3-(tert-pentyl)phenyl]pyridine (187bd)}

OMe

The general procedure $\mathbf{A}$ was followed using substrate $\mathbf{3 8 b}(93 \mathrm{mg}, 0.50 \mathrm{mmol}$ ) and bromide $50 \mathrm{~d}$ (226 mg, $1.50 \mathrm{mmol}$ ). After $20 \mathrm{~h}$, purification by column chromatography ( $n$-hexane/EtOAc $20: 1$ ) yielded $187 \mathrm{bd}$ ( $86 \mathrm{mg}, 67 \%$ ) as a colorless oil.

The general procedure $\mathbf{B}$ was followed using substrate $\mathbf{3 8 b}(93 \mathrm{mg}, 0.50 \mathrm{mmol})$ and bromide 50d (226 mg, $1.50 \mathrm{mmol})$. After $20 \mathrm{~h}$, purification by column chromatography ( $n$-hexane/EtOAc 20:1) yielded $187 \mathrm{bd}(77 \mathrm{mg}, 60 \%$ ) as a colorless oil.

${ }^{1} \mathrm{H}$ NMR $\left(300 \mathrm{MHz}, \mathrm{CDCl}_{3}\right): \delta=8.67(\mathrm{~d}, J=4.9 \mathrm{~Hz}, 1 \mathrm{H}), 7.91(\mathrm{~d}, J=2.3 \mathrm{~Hz}, 1 \mathrm{H}), 7.83(\mathrm{dd}, J=8.5,2.3 \mathrm{~Hz}$, $1 \mathrm{H}), 7.73-7.64(\mathrm{~m}, 2 \mathrm{H}), 7.15(\mathrm{ddd}, J=6.2,4.8,2.3 \mathrm{~Hz}, 1 \mathrm{H}), 6.95(\mathrm{~d}, J=8.5 \mathrm{~Hz}, 1 \mathrm{H}), 3.87(\mathrm{~s}, 3 \mathrm{H}), 1.90(\mathrm{q}$, $J=7.5 \mathrm{~Hz}, 2 \mathrm{H}), 1.42(\mathrm{~s}, 6 \mathrm{H}), 0.67(\mathrm{t}, J=7.5 \mathrm{~Hz}, 3 \mathrm{H})$.

${ }^{13} \mathrm{C} \mathrm{NMR}\left(75 \mathrm{MHz}, \mathrm{CDCl}_{3}\right): \delta=159.4\left(\mathrm{C}_{\mathrm{q}}\right), 157.8\left(\mathrm{C}_{\mathrm{q}}\right), 149.5(\mathrm{CH}), 136.7\left(\mathrm{C}_{\mathrm{q}}\right), 136.5(\mathrm{CH}), 131.3\left(\mathrm{C}_{\mathrm{q}}\right)$, $126.7(\mathrm{CH}), 125.6(\mathrm{CH}), 121.1(\mathrm{CH}), 119.9(\mathrm{CH}), 111.4(\mathrm{CH}), 55.1\left(\mathrm{CH}_{3}\right), 38.7\left(\mathrm{C}_{\mathrm{q}}\right), 33.1\left(\mathrm{CH}_{2}\right), 27.9$ $\left(\mathrm{CH}_{3}\right), 9.6\left(\mathrm{CH}_{3}\right)$.

IR (neat): $\tilde{v}=3050,2960,1586,1438,1396,1240,1180,1093,778 \mathrm{~cm}^{-1}$.

MS (EI) $m / z$ (relative intensity) 255 (27) [M] ${ }^{+}, 226$ (98), 198 (18), 167 (20).

HR-MS (EI): $m / z$ calcd for $\mathrm{C}_{17} \mathrm{H}_{21} \mathrm{NO}^{+}[\mathrm{M}]^{+} 255.1618$, found 255.1627 .

\section{Synthesis of 2-[3-(3-Ethylpentan-3-yl)-4-methoxyphenyl]pyridine (187be)}<smiles>CCC(CC)(CC)c1cc(-c2ccccn2)ccc1OC</smiles>

The general procedure $\mathbf{A}$ was followed using substrate $\mathbf{3 8 b}(93 \mathrm{mg}, 0.50 \mathrm{mmol}$ ) and bromide 50e (269 mg, $1.50 \mathrm{mmol}$ ). After $20 \mathrm{~h}$, purification by column chromatography ( $n$-hexane/EtOAc 20:1) yielded $187 \mathrm{be}$ (73 mg, 52\%) as a white solid. The general procedure $\mathbf{B}$ was followed using substrate $\mathbf{3 8 b}(93 \mathrm{mg}, 0.50 \mathrm{mmol}$ ) and bromide 50e (269 mg, $1.50 \mathrm{mmol}$ ). After $20 \mathrm{~h}$, purification by column chromatography ( $n$-hexane/EtOAc 20:1) yielded 187be (50 mg, 35\%) as a white solid. 
M. p.: $80-82^{\circ} \mathrm{C}$.

${ }^{1} \mathrm{H}$ NMR $\left(300 \mathrm{MHz}, \mathrm{CDCl}_{3}\right): \delta=8.66(\mathrm{~d}, J=4.9 \mathrm{~Hz}, 1 \mathrm{H}), 7.88(\mathrm{~d}, J=2.3 \mathrm{~Hz}, 1 \mathrm{H}), 7.83(\mathrm{dd}, J=8.4,2.3 \mathrm{~Hz}$, $1 \mathrm{H}$ ), 7.73-7.64 (m, 2H), 7.13 (ddd, $J=6.8,4.6,2.3 \mathrm{~Hz}, 1 \mathrm{H}$ ), $6.92(\mathrm{~d}, J=8.4 \mathrm{~Hz}, 1 \mathrm{H}$ ), $3.84(\mathrm{~s}, 3 \mathrm{H}), 1.86$ (q, $J=7.3 \mathrm{~Hz}, 6 \mathrm{H}), 0.64(\mathrm{t}, J=7.3 \mathrm{~Hz}, 9 \mathrm{H})$.

${ }^{13} \mathrm{C}$ NMR $\left(75 \mathrm{MHz}, \mathrm{CDCl}_{3}\right): \delta=159.6\left(\mathrm{C}_{\mathrm{q}}\right), 157.9\left(\mathrm{C}_{\mathrm{q}}\right), 149.5(\mathrm{CH}), 136.5(\mathrm{CH}), 134.8\left(\mathrm{C}_{\mathrm{q}}\right), 131.1\left(\mathrm{C}_{\mathrm{q}}\right)$, 128.3 (CH), $125.5(\mathrm{CH}), 121.1(\mathrm{CH}), 119.9(\mathrm{CH}), 111.5(\mathrm{CH}), 55.2\left(\mathrm{CH}_{3}\right), 44.6\left(\mathrm{C}_{\mathrm{q}}\right), 26.1\left(\mathrm{CH}_{2}\right), 8.5\left(\mathrm{CH}_{3}\right)$. IR (ATR): $\tilde{v}=2961,2938,2873,1562,1460,1439,1270,1238,1088,816 \mathrm{~cm}^{-1}$.

MS (EI) $m / z$ (relative intensity) 283 (23) [M] ${ }^{+}, 284$ (76), 212 (60), 198 (100), 167 (27).

HR-MS (EI): $m / z$ calcd for $\mathrm{C}_{19} \mathrm{H}_{25} \mathrm{NO}^{+}[\mathrm{M}]^{+}$283.1931, found 283.1933 .

\section{Synthesis of 2-[4-Methoxy-3-(4-methyltetrahydro-2H-pyran-4-yl)phenyl]pyridine (187bf)}<smiles>CCOCCC(C)(C)c1cc(-c2ccccn2)ccc1OC</smiles>

colorless oil.

The general procedure $\mathbf{A}$ was followed using substrate $\mathbf{3 8} \mathbf{b}(93 \mathrm{mg}, 0.50 \mathrm{mmol})$ and bromide $50 \mathrm{f}(269 \mathrm{mg}, 1.50 \mathrm{mmol})$. After $20 \mathrm{~h}$, purification by column chromatography ( $n$-hexane/EtOAc 10:1) yielded 187bf (110 mg, 78\%) as a colorless oil.

The general procedure $\mathbf{B}$ was followed using substrate $\mathbf{3 8 b}(93 \mathrm{mg}, 0.50 \mathrm{mmol}$ ) and bromide $50 \mathrm{f}(269 \mathrm{mg}, 1.50 \mathrm{mmol})$. After $20 \mathrm{~h}$, purification by column chromatography ( $n$-hexane/EtOAc 10:1) yielded 187bf (106 mg, 75\%) as a

${ }^{1} \mathrm{H}$ NMR $\left(300 \mathrm{MHz}, \mathrm{CDCl}_{3}\right): \delta=8.65(\mathrm{~d}, J=4.9 \mathrm{~Hz}, 1 \mathrm{H}), 7.92(\mathrm{~d}, J=2.3 \mathrm{~Hz}, 1 \mathrm{H}), 7.81(\mathrm{dd}, J=8.5,2.3 \mathrm{~Hz}$, $1 \mathrm{H}), 7.74-7.63(\mathrm{~m}, 2 \mathrm{H}), 7.17$ (ddd, $J=6.7,4.8,1.3 \mathrm{~Hz}, 1 \mathrm{H}), 6.99(\mathrm{~d}, J=8.5 \mathrm{~Hz}, 1 \mathrm{H}), 3.88(\mathrm{~s}, 3 \mathrm{H})$, 3.86-3.41 (m, 4H), 2.37-2.26 (m, 2H), 2.00-1.91 (m, 2H), $1.44(\mathrm{~s}, 3 \mathrm{H})$.

${ }^{13} \mathrm{C} \mathrm{NMR}\left(75 \mathrm{MHz}, \mathrm{CDCl}_{3}\right): \delta=159.4\left(\mathrm{C}_{\mathrm{q}}\right), 157.6\left(\mathrm{C}_{\mathrm{q}}\right), 149.5(\mathrm{CH}), 136.7\left(\mathrm{C}_{\mathrm{q}}\right), 136.6(\mathrm{CH}), 131.6\left(\mathrm{C}_{\mathrm{q}}\right)$, $125.9(\mathrm{CH}), 125.8(\mathrm{CH}), 121.3(\mathrm{CH}), 119.9(\mathrm{CH}), 111.9(\mathrm{CH}), 69.5\left(\mathrm{CH}_{2}\right), 55.1\left(\mathrm{CH}_{3}\right), 36.9\left(\mathrm{CH}_{2}\right), 35.9$ $\left(\mathrm{C}_{\mathrm{q}}\right), 24.1\left(\mathrm{CH}_{3}\right)$.

IR (neat): $\tilde{v}=3047,2949,1585,1269,1234,1023,779 \mathrm{~cm}^{-1}$.

MS (EI) $m / z$ (relative intensity) 283 (100) [M] ${ }^{+}, 268$ (27), 210 (60), 167 (37).

HR-MS (EI): $\mathrm{m} / z$ calcd for $\mathrm{C}_{18} \mathrm{H}_{20} \mathrm{NO}_{2}{ }^{+}[\mathrm{M}-\mathrm{H}]^{+} 282.1489$, found 282.1503 .

\section{Synthesis of 2-[3-(2,6-Dimethylhept-5-en-2-yl)-4-methoxyphenyl]pyridine (187bg)}

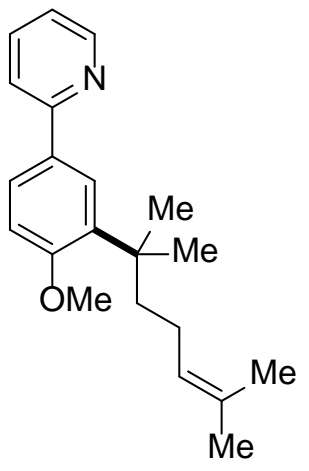

The general procedure $\mathbf{A}$ was followed, using substrate $\mathbf{3 8 b}(93 \mathrm{mg}, 0.50 \mathrm{mmol})$ and bromide $50 \mathrm{~g}$ (308 $\mathrm{mg}, 1.50 \mathrm{mmol})$ with $\left[\mathrm{RuCl}_{2}(p \text {-cymene) }]_{2}(15.3 \mathrm{mg}, 5.0\right.$ $\mathrm{mol} \%$ ), Piv-Val-OH (30.0 mg, $30 \mathrm{~mol} \%$ ), After $20 \mathrm{~h}$, purification by column chromatography ( $n$-hexane/EtOAc 10:1) yielded $187 \mathrm{bg}$ (95 mg, 61\%) as a colorless oil.

${ }^{1}$ H NMR $\left(300 \mathrm{MHz} \mathrm{CDCl}_{3}\right): \delta=8.64(\mathrm{ddd}, J=4.8,1.8,1.0 \mathrm{~Hz}, 1 \mathrm{H}), 7.88(\mathrm{~d}, J=$ $2.3 \mathrm{~Hz}, 1 \mathrm{H}$ ), 7.80 (dd, $J=8.5,2.3 \mathrm{~Hz}, 1 \mathrm{H}$ ), 7.71-7.61 (m, 2H), 7.13 (ddd, $J=7.0$, $4.8,1.5 \mathrm{~Hz}, 1 \mathrm{H}), 6.93(\mathrm{~d}, J=8.5 \mathrm{~Hz}, 1 \mathrm{H}), 5.05(\mathrm{tt}, J=7.1,1.4 \mathrm{~Hz}, 1 \mathrm{H}), 3.85(\mathrm{~s}$, $3 \mathrm{H}), 1.90-1.79(\mathrm{~m}, 2 \mathrm{H}), 1.71-1.62(\mathrm{~m}, 2 \mathrm{H}), 1.61(\mathrm{~d}, J=1.3 \mathrm{~Hz}, 3 \mathrm{H}), 1.46-1.44$

$(\mathrm{m}, 3 \mathrm{H}), 1.42(\mathrm{~s}, 6 \mathrm{H})$.

${ }^{13} \mathrm{C} \mathrm{NMR}\left(75 \mathrm{MHz}, \mathrm{CDCl}_{3}\right): \delta=159.3\left(\mathrm{C}_{\mathrm{q}}\right), 157.7\left(\mathrm{C}_{\mathrm{q}}\right), 149.4(\mathrm{CH}), 136.5\left(\mathrm{C}_{\mathrm{q}}\right), 136.4(\mathrm{CH}), 131.3\left(\mathrm{C}_{\mathrm{q}}\right)$, $130.5\left(\mathrm{C}_{\mathrm{q}}\right), 126.5(\mathrm{CH}), 125.6(\mathrm{CH}), 125.2(\mathrm{CH}), 121.0(\mathrm{CH}), 119.8(\mathrm{CH}), 111.3(\mathrm{CH}), 55.1\left(\mathrm{CH}_{3}\right), 40.9$ $\left(\mathrm{CH}_{2}\right), 38.4\left(\mathrm{CH}_{2}\right), 28.5\left(\mathrm{CH}_{3}\right), 25.7\left(\mathrm{CH}_{3}\right), 24.2\left(\mathrm{C}_{\mathrm{q}}\right), 17.4\left(\mathrm{CH}_{3}\right)$.

IR (neat): $\tilde{v}=2962,2911,1587,1463,1270,1180,1026,819 \mathrm{~cm}^{-1}$. 
MS (EI) $m / z$ (relative intensity) 309 (12) [M] ${ }^{+}, 278$ (18), 226 (100), 167 (20).

HR-MS (EI): $\mathrm{m} / z$ calcd for $\mathrm{C}_{21} \mathrm{H}_{27} \mathrm{NO}^{+}[\mathrm{M}]^{+} 309.2087$, found 309.2092.

\section{Synthesis of 2-[3-(5-Chloro-2-methylpentan-2-yl)-4-methoxyphenyl]pyridine (187bh)}

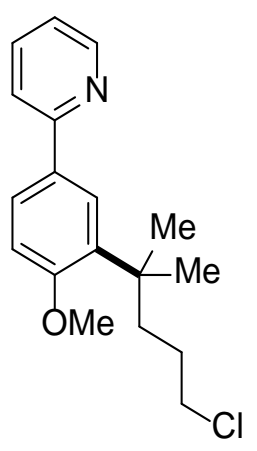

The general procedure A was followed using substrate $38 \mathrm{~b}(93 \mathrm{mg}, 0.50 \mathrm{mmol}$ ) and bromide 50h (299 mg, $1.50 \mathrm{mmol}$ ). After $20 \mathrm{~h}$, purification by column chromatography ( $n$-hexane/EtOAc $80: 1$ ) yielded $187 \mathrm{bh}(90 \mathrm{mg}, 59 \%$ ) as a colorless oil.

The general procedure $\mathbf{B}$ was followed using substrate $\mathbf{3 8 b}(93 \mathrm{mg}, 0.50 \mathrm{mmol})$ and bromide 50h (299 mg, $1.50 \mathrm{mmol})$. After $20 \mathrm{~h}$, purification by column chromatography ( $n$-hexane/EtOAc $80: 1$ ) yielded $187 \mathrm{bh}(90 \mathrm{mg}, 59 \%$ ) as a colorless oil.

${ }^{1} \mathrm{H}$ NMR $\left(300 \mathrm{MHz}, \mathrm{CDCl}_{3}\right): \delta=8.65(\mathrm{~d}, J=4.9 \mathrm{~Hz}, 1 \mathrm{H}), 7.89(\mathrm{~d}, J=2.3 \mathrm{~Hz}, 1 \mathrm{H}), 7.81$ (dd, $J=8.4,2.3 \mathrm{~Hz}, 1 \mathrm{H}), 7.74-7.63(\mathrm{~m}, 2 \mathrm{H}), 7.16$ (ddd, $J=6.9,4.9,1.9 \mathrm{~Hz}, 1 \mathrm{H}), 6.95(\mathrm{~d}, J=8.4 \mathrm{~Hz}, 1 \mathrm{H}$ ), $3.88(\mathrm{~s}, 3 \mathrm{H}), 3.43(\mathrm{t}, J=6.7 \mathrm{~Hz}, 2 \mathrm{H}), 2.05-1.96(\mathrm{~m}, 2 \mathrm{H}), 1.54-1.46(\mathrm{~m}, 2 \mathrm{H}), 1.44(\mathrm{~s}, 6 \mathrm{H})$.

${ }^{13} \mathrm{C} \mathrm{NMR}\left(75 \mathrm{MHz}, \mathrm{CDCl}_{3}\right): \delta=159.3\left(\mathrm{C}_{\mathrm{q}}\right), 157.7\left(\mathrm{C}_{\mathrm{q}}\right), 149.5(\mathrm{CH}), 136.6(\mathrm{CH}), 136.0\left(\mathrm{C}_{\mathrm{q}}\right), 131.5\left(\mathrm{C}_{\mathrm{q}}\right)$, $126.6(\mathrm{CH}), 126.0(\mathrm{CH}), 121.2(\mathrm{CH}), 112.0(\mathrm{CH}), 111.4(\mathrm{CH}), 55.2\left(\mathrm{CH}_{3}\right), 46.1\left(\mathrm{CH}_{2}\right), 38.1\left(\mathrm{C}_{\mathrm{q}}\right), 38.0$ $\left(\mathrm{CH}_{2}\right), 28.9\left(\mathrm{CH}_{2}\right), 28.4\left(\mathrm{CH}_{3}\right)$.

IR (neat): $\tilde{v}=3954,2955,2865,1603,1586,1498,1238,1087,1025,779 \mathrm{~cm}^{-1}$.

MS (EI) $m / z$ (relative intensity) 305/303 (5/16) [ $\left.\mathrm{M}^{+}\right], 226$ (100), 198 (14), 167 (14).

HR-MS (EI): $\mathrm{m} / z$ calcd for $\mathrm{C}_{18} \mathrm{H}_{22}{ }^{35} \mathrm{CINO}^{+}\left[\mathrm{M}^{+}\right]$303.1384, found 303.1390 .

\section{Synthesis of 2-[4-Methoxy-3-(2-methyl-4-phenylbutan-2-yl)phenyl]pyridine (187bi)}<smiles>COc1ccc(-c2ccccn2)cc1C(C)(C)CCc1ccccc1</smiles>

The general procedure $\mathbf{A}$ was followed using substrate $\mathbf{3 8 b}(93 \mathrm{mg}, 0.50 \mathrm{mmol})$ and bromide 50i (341 mg, $1.50 \mathrm{mmol}$ ). After $20 \mathrm{~h}$, purification by column chromatography ( $n$-hexane/EtOAc 20:1) yielded $187 \mathrm{bi}(110 \mathrm{mg}, 66 \%$ ) as a colorless oil.

The general procedure $\mathbf{B}$ was followed using substrate $\mathbf{3 8} \mathbf{b}(93 \mathrm{mg}, 0.50 \mathrm{mmol}$ ) and bromide 50i (341 mg, $1.50 \mathrm{mmol}$ ). After $20 \mathrm{~h}$, purification by column chromatography ( $n$-hexane/EtOAc 20:1) yielded 187bi (98 mg, 59\%) as a colorless oil.

${ }^{1} \mathrm{H}$ NMR $\left(300 \mathrm{MHz}, \mathrm{CDCl}_{3}\right): \delta=8.67(\mathrm{~d}, J=4.9 \mathrm{~Hz}, 1 \mathrm{H}), 7.96(\mathrm{~d}, J=2.3 \mathrm{~Hz}, 1 \mathrm{H}), 7.83(\mathrm{dd}, J=8.5,2.3 \mathrm{~Hz}$, $1 \mathrm{H}), 7.74-7.65(\mathrm{~m}, 2 \mathrm{H}), 7.25-7.19(\mathrm{~m}, 2 \mathrm{H}), 7.18-7.13(\mathrm{~m}, 2 \mathrm{H}), 7.10-7.06(\mathrm{~m}, 2 \mathrm{H}), 6.97(\mathrm{~d}, J=8.7 \mathrm{~Hz}$, $1 \mathrm{H}), 3.88(\mathrm{~s}, 3 \mathrm{H}), 2.34-2.26(\mathrm{~m}, 2 \mathrm{H}), 2.23-2.15(\mathrm{~m}, 2 \mathrm{H}), 1.48(\mathrm{~s}, 6 \mathrm{H})$.

${ }^{13} \mathrm{C}$ NMR $\left(75 \mathrm{MHz}, \mathrm{CDCl}_{3}\right): \delta=159.3\left(\mathrm{C}_{\mathrm{q}}\right), 157.7\left(\mathrm{C}_{\mathrm{q}}\right), 149.4(\mathrm{CH}), 143.6\left(\mathrm{C}_{\mathrm{q}}\right), 136.4(\mathrm{CH}), 136.2\left(\mathrm{C}_{\mathrm{q}}\right)$, $131.4\left(\mathrm{C}_{\mathrm{q}}\right), 128.2(\mathrm{CH}), 128.1(\mathrm{CH}), 126.6(\mathrm{CH}), 125.8(\mathrm{CH}), 125.2(\mathrm{CH}), 121.1(\mathrm{CH}), 119.9(\mathrm{CH}), 111.4$ $(\mathrm{CH}), 55.2\left(\mathrm{CH}_{3}\right), 43.0\left(\mathrm{CH}_{2}\right), 38.6\left(\mathrm{C}_{\mathrm{q}}\right), 32.1\left(\mathrm{CH}_{2}\right), 28.6\left(\mathrm{CH}_{3}\right)$.

IR (neat): $\tilde{v}=3024,2960,1586,1462,1429,1270,1237,1069,1026,779 \mathrm{~cm}^{-1}$.

MS (EI) $m / z$ (relative intensity) 331 (40) [M] $]^{+}, 226$ (100), 198 (15), 167 (17), 91 (20).

HR-MS (EI): $m / z$ calcd for $\mathrm{C}_{23} \mathrm{H}_{25} \mathrm{NO}^{+}[\mathrm{M}]^{+} 331.1931$, found 331.1926. 
Synthesis of 2-[4-Methoxy-3-(2-methyl-1-phenylpropan-2-yl)phenyl]pyridine (187bj)

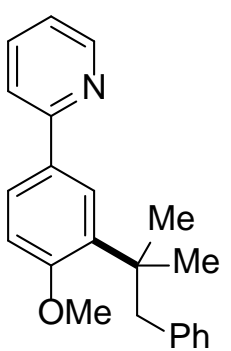

The general procedure A was followed, using substrate $\mathbf{3 8 b}(93 \mathrm{mg}, 0.50 \mathrm{mmol}$ ) and bromide 50j (320 mg, $1.50 \mathrm{mmol}$ ). After $20 \mathrm{~h}$, purification by column chromatography ( $n$-hexane/EtOAc 80:1) yielded $187 \mathrm{bj}$ (93 $\mathrm{mg}, 59 \%$ ) as a colorless oil.

${ }^{1} \mathbf{H}$ NMR $\left(300 \mathrm{MHz} \mathrm{CDCl}_{3}\right): \delta=8.61(\mathrm{~d}, J=4.9 \mathrm{~Hz}, 1 \mathrm{H}), 7.86(\mathrm{dd}, J=8.5,2.3 \mathrm{~Hz}, 1 \mathrm{H})$, 7.69-7.62 (m, 2H), 7.56 (d, J=8.1 Hz, 1H), 7.16-7.06 (m, 4H), $7.03(\mathrm{~d}, J=8.5 \mathrm{~Hz}, 1 \mathrm{H})$, 6.93-6.87 (m, 2H), $3.99(\mathrm{~s}, 3 \mathrm{H}), 3.19(\mathrm{~s}, 2 \mathrm{H}), 1.43(\mathrm{~s}, 6 \mathrm{H})$.

${ }^{13} \mathrm{C}$ NMR $\left(75 \mathrm{MHz}, \mathrm{CDCl}_{3}\right): \delta=159.3\left(\mathrm{C}_{\mathrm{q}}\right), 157.7\left(\mathrm{C}_{\mathrm{q}}\right), 149.4(\mathrm{CH}), 139.9\left(\mathrm{C}_{\mathrm{q}}\right), 136.5(\mathrm{CH}), 136.4\left(\mathrm{C}_{\mathrm{q}}\right)$, $131.5\left(\mathrm{C}_{\mathrm{q}}\right), 130.3(\mathrm{CH}), 127.1(\mathrm{CH}), 126.6(\mathrm{CH}), 126.0(\mathrm{CH}), 125.5(\mathrm{CH}), 121.2(\mathrm{CH}), 120.0(\mathrm{CH}), 111.5$ $(\mathrm{CH}), 55.2\left(\mathrm{CH}_{3}\right), 46.0\left(\mathrm{CH}_{2}\right), 39.3\left(\mathrm{C}_{\mathrm{q}}\right), 28.0\left(\mathrm{CH}_{3}\right)$.

IR (neat): $\tilde{v}=3002,2959,1586,1462,1270,1236,1086,1025,779 \mathrm{~cm}^{-1}$.

MS (EI) $m / z$ (relative intensity) 317 (5) [M] ${ }^{+}, 226$ (98), 198 (13), 167 (18), 91 (17).

HR-MS (EI): $m / z$ calcd for $\mathrm{C}_{22} \mathrm{H}_{23} \mathrm{NO}^{+}[\mathrm{M}]^{+} 317.1774$, found 317.1793.

\section{Synthesis of 2-[3-(tert-Butyl)phenyl]pyridine (187aa)}<smiles>CC(C)(C)c1cccc(-c2ccccn2)c1</smiles>

The general procedure A was followed using substrate $37 \mathrm{a}(78 \mathrm{mg}, 0.50 \mathrm{mmol})$ and bromide 50a (206 mg, $1.50 \mathrm{mmol}$ ). After $20 \mathrm{~h}$, purification by column chromatography ( $n$-hexane/EtOAc $80: 1$ ) yielded 187aa (69 mg, 65\%) as a colorless oil.

The general procedure B was followed using substrate $38 \mathrm{a}(78 \mathrm{mg}, 0.50 \mathrm{mmol}$ ) and bromide 50a (206 mg, $1.50 \mathrm{mmol}$ ). After $20 \mathrm{~h}$, purification by column chromatography ( $n$-hexane/EtOAc $80: 1$ ) yielded $187 \mathrm{aa}(62 \mathrm{mg}, 59 \%$ ) as a colorless oil.

${ }^{1} \mathbf{H}$ NMR $\left(300 \mathrm{MHz}, \mathrm{CDCl}_{3}\right): \delta=8.71(\mathrm{~d}, J=4.9 \mathrm{~Hz}, 1 \mathrm{H}), 8.06(\mathrm{t}, J=1.6 \mathrm{~Hz}, 1 \mathrm{H}), 7.80-7.71(\mathrm{~m}, 3 \mathrm{H})$, 7.50-7.39 (m, 2H), 7.25-7.19 (m, 1H), $1.41(\mathrm{~s}, 9 \mathrm{H})$.

${ }^{13} \mathrm{C}$ NMR $\left(75 \mathrm{MHz}, \mathrm{CDCl}_{3}\right): \delta=158.0\left(\mathrm{C}_{\mathrm{q}}\right), 151.6\left(\mathrm{C}_{\mathrm{q}}\right), 149.6(\mathrm{CH}), 139.2\left(\mathrm{C}_{\mathrm{q}}\right), 136.6(\mathrm{CH}), 128.4(\mathrm{CH})$, $126.0(\mathrm{CH}), 124.1(\mathrm{CH}), 123.9(\mathrm{CH}), 121.9(\mathrm{CH}), 120.7(\mathrm{CH}), 34.8\left(\mathrm{C}_{\mathrm{q}}\right), 29.7\left(\mathrm{CH}_{3}\right)$.

IR (neat): $\tilde{v}=3064,2961,1584,1564,1460,1431,1251,770 \mathrm{~cm}^{-1}$.

MS (EI) $m / z$ (relative intensity) 211 (34) [M] ${ }^{+}, 196$ (100), 167 (18), 155 (12).

HR-MS (EI): $m / z$ calcd for $\mathrm{C}_{15} \mathrm{H}_{16} \mathrm{~N}^{+}[\mathrm{M}-\mathrm{H}]^{+} 210.1277$, found 210.1287.

\section{Synthesis of 2-[3-(tert-Butyl)-4-fluorophenyl]pyridine (187ca)}<smiles>CC(C)(C)c1cc(-c2ccccn2)ccc1F</smiles>

The general procedure $\mathbf{A}$ was followed using substrate $38 \mathrm{c}(87 \mathrm{mg}, 0.50 \mathrm{mmol})$ and bromide 50a (206 mg, $1.50 \mathrm{mmol}$ ). After $20 \mathrm{~h}$, purification by column chromatography ( $n$-hexane/EtOAc $80: 1$ ) yielded $187 \mathrm{ca}$ (92 mg, $80 \%$ ) as a colorless oil.

The general procedure B was followed using substrate $38 \mathrm{c}(87 \mathrm{mg}, 0.50 \mathrm{mmol})$ and bromide 50a (206 mg, $1.50 \mathrm{mmol}$ ). After $20 \mathrm{~h}$, purification by column chromatography ( $n$-hexane/EtOAc $80: 1$ ) yielded $187 \mathrm{ca}$ (93 $\mathrm{mg}, 81 \%$ ) as a colorless oil.

${ }^{1} \mathrm{H}$ NMR (300 MHz, $\left.\mathrm{CDCl}_{3}\right): \delta=8.66(\mathrm{ddd}, J=4.9,1.9,0.9 \mathrm{~Hz}, 1 \mathrm{H}), 7.98(\mathrm{dd}, J=8.1,2.6 \mathrm{~Hz}, 1 \mathrm{H})$, 7.79-7.64 (m, 3H), 7.19 (ddd, $J=7.4,4.7,1.3 \mathrm{~Hz}, 1 \mathrm{H}), 7.09$ (ddd, $J=12.3,8.5,1.1 \mathrm{~Hz}, 1 \mathrm{H}), 1.43(\mathrm{~d}, J=$ $1.0 \mathrm{~Hz}, 9 \mathrm{H})$. 
${ }^{13} \mathrm{C} \mathrm{NMR}\left(75 \mathrm{MHz}, \mathrm{CDCl}_{3}\right): \delta=162.7\left(\mathrm{~d},{ }^{1} J_{\mathrm{C}-\mathrm{F}}=251 \mathrm{~Hz}, \mathrm{C}_{\mathrm{q}}\right), 157.1\left(\mathrm{C}_{\mathrm{q}}\right), 149.6(\mathrm{CH}), 137.3\left(\mathrm{~d},{ }^{2} J_{\mathrm{C}-\mathrm{F}}=12\right.$ $\left.\mathrm{Hz}, \mathrm{C}_{\mathrm{q}}\right), 136.7(\mathrm{CH}), 135.1\left(\mathrm{~d},{ }^{4} \mathrm{~J}_{\mathrm{C}-\mathrm{F}}=3 \mathrm{~Hz}, \mathrm{C}_{\mathrm{q}}\right), 126.2\left(\mathrm{~d},{ }^{3} \mathrm{~J}_{\mathrm{C}-\mathrm{F}}=2 \mathrm{~Hz}, \mathrm{CH}\right), 126.1\left(\mathrm{~d},{ }^{3} \mathrm{~J}_{\mathrm{C}-\mathrm{F}}=5 \mathrm{~Hz}, \mathrm{CH}\right)$, $121.8(\mathrm{CH}), 120.4(\mathrm{CH}), 116.5\left(\mathrm{~d},{ }^{2} J_{\mathrm{C}-\mathrm{F}}=24 \mathrm{~Hz}, \mathrm{CH}\right), 34.4\left(\mathrm{~d},{ }^{3} J_{\mathrm{C}-\mathrm{F}}=3 \mathrm{~Hz}, \mathrm{C}_{\mathrm{q}}\right), 29.9\left(\mathrm{~d},{ }^{4} J_{\mathrm{C}-\mathrm{F}}=3 \mathrm{~Hz}, \mathrm{CH}_{3}\right)$.

${ }^{19} \mathrm{~F} \mathrm{NMR}\left(282 \mathrm{MHz}, \mathrm{CDCl}_{3}\right): \delta=-109.4$ (s).

IR (neat): $\tilde{v}=3050,2958,1590,1460,1432,1364,1214,1088,778 \mathrm{~cm}^{-1}$.

MS (EI) $m / z$ (relative intensity) 229 (40) [M] ${ }^{+}, 214$ (100), 186 (36), 173 (10).

HR-MS (EI): $m / z$ calcd for $\mathrm{C}_{15} \mathrm{H}_{15} \mathrm{FN}^{+}[\mathrm{M}-\mathrm{H}]^{+} 228.1183$, found 228.1191 .

\section{Synthesis of 1-[2-(tert-Butyl)-4-(pyridin-2-yl)phenyl]ethan-1-one (187da)}

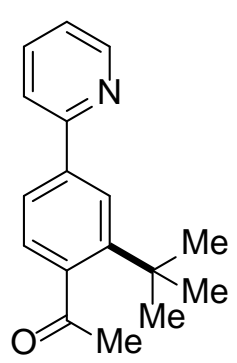

The general procedure $\mathbf{A}$ was followed using $\left[\mathrm{RuCl}_{2}(p \text {-cymene })\right]_{2}(15.3 \mathrm{mg}, 5.0$ mol \%), Piv-Val-OH (30.0 mg, $30 \mathrm{~mol} \%$ ), substrate 38d (99 mg, $0.50 \mathrm{mmol}$ ) and bromide 50a (206 mg, $1.50 \mathrm{mmol}$ ). After $20 \mathrm{~h}$, purification by column chromatography ( $n$-hexane/EtOAc 20:1) yielded $187 \mathrm{da} \mathrm{(74} \mathrm{mg,58 \% )} \mathrm{as} \mathrm{a} \mathrm{white}$ solid.

The general procedure $\mathbf{B}$ was followed using [RuCl(O-Val-Piv)(p-cymene)] (23.6 mg, $10.0 \mathrm{~mol} \%$ ), substrate $38 \mathrm{~d}(99 \mathrm{mg}, 0.50 \mathrm{mmol}$ ) and bromide 50a (206 mg, 1.50 mmol). After $20 \mathrm{~h}$, purification by column chromatography ( $n$-hexane/EtOAc 20:1) yielded 187da (69 $\mathrm{mg}, 54 \%)$ as a white solid.

M. p.: $84-86^{\circ} \mathrm{C}$.

${ }^{1} \mathrm{H}$ NMR $\left(300 \mathrm{MHz}, \mathrm{CDCl}_{3}\right): \delta=8.68(\mathrm{~d}, J=4.9 \mathrm{~Hz}, 1 \mathrm{H}), 8.12(\mathrm{~d}, J=1.6 \mathrm{~Hz}, 1 \mathrm{H}), 7.80-7.67(\mathrm{~m}, 3 \mathrm{H})$, 7.25-7.20 (m, 2H), $2.60(\mathrm{~s}, 3 \mathrm{H}), 1.42(\mathrm{~s}, 9 \mathrm{H})$.

${ }^{13} \mathrm{C} \mathrm{NMR}\left(75 \mathrm{MHz}, \mathrm{CDCl}_{3}\right): \delta=207.6\left(\mathrm{C}_{\mathrm{q}}\right), 157.0\left(\mathrm{C}_{\mathrm{q}}\right), 149.7(\mathrm{CH}), 147.4\left(\mathrm{C}_{\mathrm{q}}\right), 142.4\left(\mathrm{C}_{\mathrm{q}}\right), 140.0\left(\mathrm{C}_{\mathrm{q}}\right)$, $136.7(\mathrm{CH}), 126.5(\mathrm{CH}), 126.0(\mathrm{CH}), 123.8(\mathrm{CH}), 122.3(\mathrm{CH}), 120.7(\mathrm{CH}), 36.1\left(\mathrm{C}_{\mathrm{q}}\right), 32.5\left(\mathrm{CH}_{3}\right), 31.8$ $\left(\mathrm{CH}_{3}\right)$.

IR (ATR): $\tilde{v}=3060,3001,1693,1583,1465,1352,1240,1052,839 \mathrm{~cm}^{-1}$.

MS (EI) $m / z$ (relative intensity) 253 (5) [M] $]^{+}, 238$ (77), 220 (17), 167 (7).

HR-MS (EI): $m / z$ calcd for $\mathrm{C}_{17} \mathrm{H}_{19} \mathrm{NO}^{+}[\mathrm{M}]^{+} 253.1461$, found 253.1464 .

\section{Synthesis of Methyl 2-(tert-Butyl)-4-(pyridin-2-yl)benzoate (187ea)}<smiles>COC(=O)c1ccc(-c2ccccn2)cc1C(C)(C)C</smiles>

The general procedure $\mathbf{A}$ was followed using $\left[\mathrm{RuCl}_{2}(p \text {-cymene) }]_{2}(15.3 \mathrm{mg}, 5.0\right.$ $\mathrm{mol} \%$ ), Piv-Val-OH (30.0 mg, $30 \mathrm{~mol} \%)$, sbustrate $38 \mathrm{e}(107 \mathrm{mg}, 0.50 \mathrm{mmol}$ ) and bromide 50a (206 mg, $1.50 \mathrm{mmol}$ ). After $20 \mathrm{~h}$, purification by column chromatography ( $n$-hexane/EtOAc 20:1) yielded 187ea (68 mg, 51\%) as a colorless oil.

The general procedure B was followed using [RuCl(O-Val-Piv)( $p$-cymene)] (23.6 $\mathrm{mg}, 10.0 \mathrm{~mol} \%$ ), substrate $38 \mathrm{e}(107 \mathrm{mg}, 0.50 \mathrm{mmol}$ ) and bromide 50a (206 mg, $1.50 \mathrm{mmol}$ ). After $20 \mathrm{~h}$, purification by column chromatography ( $n$-hexane/EtOAc 20:1) yielded 187ea (67 $\mathrm{mg}, 50 \%$ ) as a colorless oil.

${ }^{1} \mathrm{H}$ NMR $\left(300 \mathrm{MHz}, \mathrm{CDCl}_{3}\right): \delta=8.68(\mathrm{~d}, J=4.9 \mathrm{~Hz}, 1 \mathrm{H}), 8.14(\mathrm{~d}, J=1.7 \mathrm{~Hz}, 1 \mathrm{H}), 7.79-7.67(\mathrm{~m}, 3 \mathrm{H}), 7.39$ (d, $J=8.0 \mathrm{~Hz}, 1 \mathrm{H}$ ), 6.50 (ddd, $J=6.8,4.9,1.9 \mathrm{~Hz}, 1 \mathrm{H}$ ), $3.89(\mathrm{~s}, 3 \mathrm{H}), 1.45(\mathrm{~s}, 9 \mathrm{H})$.

${ }^{13} \mathrm{C} \mathrm{NMR}\left(75 \mathrm{MHz}, \mathrm{CDCl}_{3}\right): \delta=172.3\left(\mathrm{C}_{\mathrm{q}}\right), 156.9\left(\mathrm{C}_{\mathrm{q}}\right), 149.7(\mathrm{CH}), 148.2\left(\mathrm{C}_{\mathrm{q}}\right), 140.6\left(\mathrm{C}_{\mathrm{q}}\right), 136.7(\mathrm{CH})$, $133.0\left(\mathrm{C}_{\mathrm{q}}\right), 129.2(\mathrm{CH}), 125.7(\mathrm{CH}), 123.8(\mathrm{CH}), 122.4(\mathrm{CH}), 120.8(\mathrm{CH}), 52.4\left(\mathrm{CH}_{3}\right), 36.0\left(\mathrm{C}_{\mathrm{q}}\right), 31.3$ $\left(\mathrm{CH}_{3}\right)$.

IR (neat): $\tilde{v}=3083,2950,2869,1723,1573,1464,1297,1121,1066,772 \mathrm{~cm}^{-1}$. 
MS (EI) m/z (relative intensity) 269 (23) [M] $]^{+}, 254$ (64), 222 (100), 194 (37), 167 (17).

HR-MS (EI): $\mathrm{m} / \mathrm{z}$ calcd for $\mathrm{C}_{17} \mathrm{H}_{19} \mathrm{NO}_{2}{ }^{+}[\mathrm{M}]^{+} 269.1410$, found 269.1418 .

\section{Synthesis of 2-[3-(tert-Butyl)-4-methylphenyl]pyridine (187fa)}

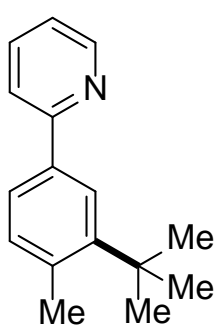

The general procedure $\mathbf{A}$ was followed using $\left[\mathrm{RuCl}_{2}(p \text {-cymene })\right]_{2}(15.3 \mathrm{mg}, 5.0$ mol \%), Piv-Val-OH (30.0 mg, $30 \mathrm{~mol} \%)$, substrate $38 \mathrm{f}(85 \mathrm{mg}, 0.50 \mathrm{mmol})$ and bromide 50a (206 mg, $1.50 \mathrm{mmol})$. After $20 \mathrm{~h}$, purification by column chromatography ( $n$-hexane/EtOAc 100:1) yielded $187 \mathrm{fa}(51 \mathrm{mg}, 45 \%$ ) as a colorless oil.

${ }^{1} \mathrm{H}$ NMR $\left(300 \mathrm{MHz}, \mathrm{CDCl}_{3}\right): \delta=8.66(\mathrm{~d}, J=4.9 \mathrm{~Hz}, 1 \mathrm{H}), 8.06(\mathrm{~d}, J=1.9 \mathrm{~Hz}, 1 \mathrm{H})$, 7.74-7.64 (m, 3H), 7.23-7.15 (m, 2H), $2.57(\mathrm{~s}, 3 \mathrm{H}), 1.47(\mathrm{~s}, 9 \mathrm{H})$.

${ }^{13} \mathrm{C}$ NMR $\left(75 \mathrm{MHz}, \mathrm{CDCl}_{3}\right): \delta=158.0\left(\mathrm{C}_{\mathrm{q}}\right), 149.5(\mathrm{CH}), 148.3\left(\mathrm{C}_{\mathrm{q}}\right), 137.3\left(\mathrm{C}_{\mathrm{q}}\right), 136.8\left(\mathrm{C}_{\mathrm{q}}\right), 136.6(\mathrm{CH})$, 133.2 (CH), $124.8(\mathrm{CH}), 124.2(\mathrm{CH}), 121.6(\mathrm{CH}), 120.4(\mathrm{CH}), 36.0\left(\mathrm{C}_{\mathrm{q}}\right), 30.8\left(\mathrm{CH}_{3}\right), 23.1\left(\mathrm{CH}_{3}\right)$.

IR (neat): $\tilde{v}=2957,2923,2870,1584,1463,1242,1087,776 \mathrm{~cm}^{-1}$.

MS (EI) m/z (relative intensity) 225 (33) [M] $]^{+}, 210$ (100), 195 (25), 183 (36).

HR-MS (EI): $m / z$ calcd for $\mathrm{C}_{16} \mathrm{H}_{19} \mathrm{~N}^{+}[\mathrm{M}]^{+} 225.1512$, found 225.1512 .

\section{Synthesis of 2-[3-(tert-Butyl)-4-(trifluoromethyl)phenyl]pyridine (187ga)}

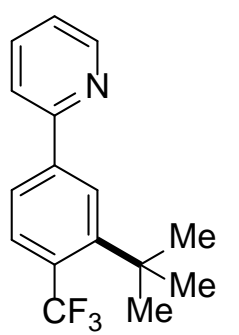

The general procedure A was followed, using substrate $38 \mathrm{~g}(112 \mathrm{mg}, 0.50 \mathrm{mmol})$ and bromide 50a (206 mg, $1.50 \mathrm{mmol}$ ). After $20 \mathrm{~h}$, purification by column chromatography ( $n$-hexane/EtOAc 20:1) yielded 187ga (37 mg, 26\%) as a colorless oil.

${ }^{1} \mathrm{H}$ NMR $\left(300 \mathrm{MHz}, \mathrm{CDCl}_{3}\right): \delta=8.71$ (ddd, $\left.J=4.8,1.1,1.1 \mathrm{~Hz}, 1 \mathrm{H}\right), 8.32(\mathrm{~s}, 1 \mathrm{H})$, 7.87-7.70 (m, 4H), 7.26 (ddd, $J=7.5,5.2,2.1 \mathrm{~Hz}, 1 \mathrm{H}), 1.51(\mathrm{~s}, 9 \mathrm{H})$.

${ }^{13} \mathrm{C} \mathrm{NMR}\left(75 \mathrm{MHz}, \mathrm{CDCl}_{3}\right) \delta=156.4\left(\mathrm{C}_{\mathrm{q}}\right), 149.9(\mathrm{CH}), 149.7\left(\mathrm{q},{ }^{3} \mathrm{~J}_{\mathrm{C}-\mathrm{F}}=2 \mathrm{~Hz}, \mathrm{C}_{\mathrm{q}}\right), 142.1$ $\left(\mathrm{C}_{\mathrm{q}}\right), 136.8(\mathrm{CH}), 128.9\left(\mathrm{q},{ }^{3} \mathrm{~J}_{\mathrm{C}-\mathrm{F}}=7 \mathrm{~Hz}, \mathrm{CH}\right), 128.4\left(\mathrm{q},{ }^{2} \mathrm{~J}_{\mathrm{C}-\mathrm{F}}=30 \mathrm{~Hz}, \mathrm{C}\right.$ ) $), 127.5(\mathrm{CH}), 125.1\left(\mathrm{q},{ }^{1} J_{\mathrm{C}-\mathrm{F}}=273\right.$ $\mathrm{Hz}, \mathrm{C}_{\mathrm{q}}$ ), $124.1(\mathrm{CH}), 122.7(\mathrm{CH}), 120.9(\mathrm{CH}), 36.8\left(\mathrm{C}_{\mathrm{q}}\right), 32.0\left(\mathrm{q},{ }^{5} \mathrm{~J}_{\mathrm{C}-\mathrm{F}}=3 \mathrm{~Hz}, \mathrm{CH}_{3}\right.$ ).

${ }^{19} \mathrm{~F} \mathrm{NMR}\left(282 \mathrm{MHz}, \mathrm{CDCl}_{3}\right): \delta=-152.8(\mathrm{~s})$.

IR (neat): $\tilde{v}=2961,2875,1587,1560,1436,1238,1106,1034,780 \mathrm{~cm}^{-1}$. MS (EI) $m / z$ (relative intensity) 279 (52) [M], 264 (100), 244 (83), 223 (62).

HR-MS (EI): $\mathrm{m} / z$ calcd for $\mathrm{C}_{16} \mathrm{H}_{16} \mathrm{~F}_{3} \mathrm{~N}^{+}[\mathrm{M}]^{+} 279.1229$, found 279.1230 .

\section{Synthesis of 2-(tert-Butyl)-4-(pyridin-2-yl)benzonitrile (187ha)}

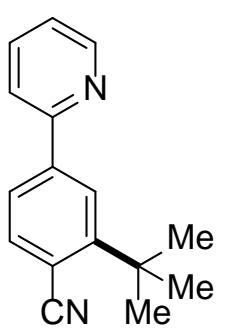

The general procedure $\mathbf{A}$ was followed using substrate $\mathbf{3 8} \mathrm{h}(90 \mathrm{mg}, 0.50 \mathrm{mmol})$ and bromide 50a (206 mg, $1.50 \mathrm{mmol}$ ). After $20 \mathrm{~h}$, purification by column chromatography ( $n$-hexane/EtOAc $20: 1$ ) yielded 187 ha $(17 \mathrm{mg}, 14 \%$ ) as a colorless oil.

${ }^{1} \mathrm{H}$ NMR $\left(300 \mathrm{MHz}, \mathrm{CDCl}_{3}\right): \delta=8.71$ (ddd, $\left.J=4.8,1.8,1.0 \mathrm{~Hz}, 1 \mathrm{H}\right), 8.14(\mathrm{~d}, J=1.7 \mathrm{~Hz}$, $1 \mathrm{H}$ ), 7.85-7.70 (m, $4 \mathrm{H}), 7.29$ (ddd, $J=7.2,4.8,1.4 \mathrm{~Hz}, 1 \mathrm{H}$ ), $1.57(\mathrm{~s}, 9 \mathrm{H})$.

${ }^{13} \mathrm{C} \mathrm{NMR}\left(75 \mathrm{MHz}, \mathrm{CDCl}_{3}\right): \delta=155.9\left(\mathrm{C}_{\mathrm{q}}\right), 154.2\left(\mathrm{C}_{\mathrm{q}}\right), 150.0(\mathrm{CH}), 143.2\left(\mathrm{C}_{\mathrm{q}}\right), 137.0$ $(\mathrm{CH}), 136.0(\mathrm{CH}), 125.0(\mathrm{CH}), 124.4(\mathrm{CH}), 123.1(\mathrm{CH}), 121.1(\mathrm{CH}), 120.3\left(\mathrm{C}_{q}\right), 110.8\left(\mathrm{C}_{\mathrm{q}}\right), 35.9\left(\mathrm{C}_{\mathrm{q}}\right), 30.2$ $\left(\mathrm{CH}_{3}\right)$.

IR (neat): $\tilde{v}=3052,2962,2871,2218,1586,1481,1433,1192,990 \mathrm{~cm}^{-1}$.

MS (EI) m/z (relative intensity) 236 (33) [M] $]^{+}, 221$ (100), 193 (33), 169 (16). 
HR-MS (EI): $\mathrm{m} / \mathrm{z}$ calcd for $\mathrm{C}_{16} \mathrm{H}_{16} \mathrm{~N}_{2}{ }^{+}[\mathrm{M}]^{+}$236.1308, found 236.1316.

\section{Synthesis of 2-[3-(tert-Butyl)-4-vinylphenyl]pyridine (187ia)}

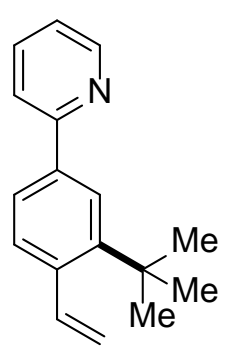

The general procedure A was followed using substrate $38 \mathrm{i}(91 \mathrm{mg}, 0.50 \mathrm{mmol})$ and bromide 50a (206 mg, $1.50 \mathrm{mmol}$ ). After $20 \mathrm{~h}$, purification by column chromatography ( $n$-hexane/EtOAc $20: 1$ ) yielded 187ia (24 mg, 20\%) as a colorless oil.

${ }^{1} \mathrm{H}$ NMR $\left(300 \mathrm{MHz}, \mathrm{CDCl}_{3}\right.$ ): $\delta=8.68$ (ddd, $\left.J=4.8,1.6,1.6 \mathrm{~Hz}, 1 \mathrm{H}\right), 8.04(\mathrm{~d}, J=1.9 \mathrm{~Hz}$, $1 \mathrm{H}), 7.78-7.67(\mathrm{~m}, 3 \mathrm{H}), 7.50(\mathrm{~d}, J=8.0 \mathrm{~Hz}, 1 \mathrm{H}), 7.42(\mathrm{dd}, J=17.1,10.8 \mathrm{~Hz}, 1 \mathrm{H}), 7.19$ (ddd, $J=5.9,4.8,2.7 \mathrm{~Hz}, 1 \mathrm{H}$ ), $5.52(\mathrm{dd}, J=17.1,1.6 \mathrm{~Hz}, 1 \mathrm{H}$ ), $5.28(\mathrm{dd}, J=10.8,1.6 \mathrm{~Hz}$,

1H), $1.48(\mathrm{~s}, 9 \mathrm{H})$.

${ }^{13} \mathrm{C}$ NMR $\left(75 \mathrm{MHz}, \mathrm{CDCl}_{3}\right) \delta=157.7\left(\mathrm{C}_{\mathrm{q}}\right), 149.6(\mathrm{CH}), 147.6\left(\mathrm{C}_{\mathrm{q}}\right), 138.7(\mathrm{CH}), 138.6\left(\mathrm{C}_{\mathrm{q}}\right), 138.4\left(\mathrm{C}_{\mathrm{q}}\right)$, $136.6(\mathrm{CH}), 129.5(\mathrm{CH}), 124.5(\mathrm{CH}), 124.5(\mathrm{CH}), 121.9(\mathrm{CH}), 120.5(\mathrm{CH}), 115.36\left(\mathrm{CH}_{2}\right), 35.9\left(\mathrm{C}_{\mathrm{q}}\right), 31.3$ $\left(\mathrm{CH}_{3}\right)$.

IR (neat): $\tilde{v}=3049,2964,1711,1681,1464,1366,1243,1071,781 \mathrm{~cm}^{-1}$.

MS (EI) $m / z$ (relative intensity) 237 (17) [M] ${ }^{+}, 222$ (52), 206 (22), 193 (6).

HR-MS (EI): $\mathrm{m} / \mathrm{z}$ calcd for $\mathrm{C}_{17} \mathrm{H}_{19} \mathrm{~N}^{+}[\mathrm{M}]^{+}$237.1512, found 237.1516.

\section{Synthesis of 2-[3-(tert-Butyl)phenyl]-3-methoxypyridine (187ja)}<smiles>COc1cccnc1-c1cccc(C(C)(C)C)c1</smiles>

The general procedure $\mathbf{A}$ was followed using substrate $38 \mathrm{j}$ (93 $\mathrm{mg}, 0.50 \mathrm{mmol}$ ) and bromide 50a (206 mg, $1.50 \mathrm{mmol}$ ). After $20 \mathrm{~h}$, purification by column chromatography ( $n$-hexane/EtOAc 10:1) yielded 187ja (87 mg, 72\%) as a colorless oil.

The general procedure $\mathbf{B}$ was followed using substrate $\mathbf{3 8 \mathrm { j }}(93 \mathrm{mg}, 0.50 \mathrm{mmol})$ and bromide 50a (206 mg, $1.50 \mathrm{mmol}$ ). After $20 \mathrm{~h}$, purification by column chromatography ( $n$-hexane/EtOAc 10:1) yielded 187ja (86 mg, 71\%) as a

colorless oil.

${ }^{1} \mathrm{H}$ NMR $\left(300 \mathrm{MHz}, \mathrm{CDCl}_{3}\right.$ ): $\delta=8.30$ (dd, $\left.J=4.6,1.4 \mathrm{~Hz}, 1 \mathrm{H}\right), 7.90$ (dd, $J=1.8,1.8 \mathrm{~Hz}, 1 \mathrm{H}$ ), 7.68 (ddd, $J$ $=7.2,1.8,1.8 \mathrm{~Hz}, 1 \mathrm{H}), 7.44-7.33(\mathrm{~m}, 2 \mathrm{H}), 7.28-7.17(\mathrm{~m}, 2 \mathrm{H}), 3.83(\mathrm{~s}, 3 \mathrm{H}), 1.36(\mathrm{~s}, 9 \mathrm{H})$.

${ }^{13} \mathrm{C}$ NMR $\left(75 \mathrm{MHz}, \mathrm{CDCl}_{3}\right): \delta=153.4\left(\mathrm{C}_{\mathrm{q}}\right), 150.5\left(\mathrm{C}_{\mathrm{q}}\right), 148.8\left(\mathrm{C}_{\mathrm{q}}\right), 141.2(\mathrm{CH}), 137.2\left(\mathrm{C}_{\mathrm{q}}\right), 127.5(\mathrm{CH})$, $126.5(\mathrm{CH}), 126.4(\mathrm{CH}), 125.3(\mathrm{CH}), 122.6(\mathrm{CH}), 118.3(\mathrm{CH}), 55.4\left(\mathrm{CH}_{3}\right), 34.7\left(\mathrm{C}_{\mathrm{q}}\right), 31.4\left(\mathrm{CH}_{3}\right)$.

IR (neat): $\tilde{v}=3060,2960,1579,1444,1408,1249,1128,1016,801 \mathrm{~cm}^{-1}$.

MS (EI) $m / z$ (relative intensity) $241(54)\left[\mathrm{M}^{+}, 226\right.$ (100), 211 (20), 185 (17).

HR-MS (EI): $m / z$ calcd for $\mathrm{C}_{16} \mathrm{H}_{19} \mathrm{NO}^{+}[\mathrm{M}]^{+} 241.1461$, found 241.1458 .

\section{Synthesis of 2-[3-(tert-Butyl)phenyl]-3-methylpyridine (187ka)}<smiles>Cc1cccnc1-c1cccc(C(C)(C)C)c1</smiles>

colorless oil.

The general procedure $\mathbf{A}$ was followed using substrate $\mathbf{3 8} \mathbf{k}(85 \mathrm{mg}, 0.50 \mathrm{mmol})$ and bromide 50a (206 mg, $1.50 \mathrm{mmol}$ ). After $20 \mathrm{~h}$, purification by column chromatography ( $n$-hexane/EtOAc 20:1) yielded 187ka (69 mg, 61\%) as a colorless oil.

The general procedure $\mathbf{B}$ was followed using substrate $38 \mathrm{k}(85 \mathrm{mg}, 0.50 \mathrm{mmol})$ and bromide 50a (206 mg, $1.50 \mathrm{mmol}$ ). After $20 \mathrm{~h}$, purification by column chromatography ( $n$-hexane/EtOAc 20:1) yielded 187ka (89 $\mathrm{mg}, 79 \%$ ) as a

${ }^{1} \mathrm{H}$ NMR $\left(300 \mathrm{MHz}, \mathrm{CDCl}_{3}\right): \delta=8.51(\mathrm{~d}, J=4.6 \mathrm{~Hz}, 1 \mathrm{H}), 7.57-7.50(\mathrm{~m}, 2 \mathrm{H}), 7.43-7.28(\mathrm{~m}, 3 \mathrm{H}), 7.15(\mathrm{dd}$, 
$J=7.7,4.6 \mathrm{~Hz}, 1 \mathrm{H}), 2.33(\mathrm{~s}, 3 \mathrm{H}), 1.34(\mathrm{~s}, 9 \mathrm{H})$.

${ }^{13} \mathrm{C}$ NMR $\left(75 \mathrm{MHz}, \mathrm{CDCl}_{3}\right): \delta=159.3\left(\mathrm{C}_{\mathrm{q}}\right), 150.8\left(\mathrm{C}_{\mathrm{q}}\right), 146.8(\mathrm{CH}), 140.1\left(\mathrm{C}_{\mathrm{q}}\right), 138.3(\mathrm{CH}), 130.8\left(\mathrm{C}_{\mathrm{q}}\right)$, $127.7(\mathrm{CH}), 126.0(\mathrm{CH}), 125.9(\mathrm{CH}), 124.8(\mathrm{CH}), 121.9(\mathrm{CH}), 34.7\left(\mathrm{C}_{\mathrm{q}}\right), 31.3\left(\mathrm{CH}_{3}\right), 20.1\left(\mathrm{CH}_{3}\right)$.

IR (neat): $\tilde{v}=3049,2959,1582,1565,1445,1250,1122,787 \mathrm{~cm}^{-1}$.

MS (EI) $m / z$ (relative intensity) 225 (55) [M] ${ }^{+}, 210$ (100), 194 (20), 168 (33).

HR-MS (EI): $m / z$ calcd for $\mathrm{C}_{16} \mathrm{H}_{19} \mathrm{~N}^{+}[\mathrm{M}]^{+} 225.1512$, found 225.1507 .

\section{Synthesis of 2-[3-(tert-Butyl)phenyl]-5-methylpyridine (187la)}

The general procedure A was followed using substrate $\mathbf{3 8 1}(85 \mathrm{mg}, 0.50 \mathrm{mmol}$ ) and<smiles>Cc1ccc(-c2cccc(C(C)(C)C)c2)nc1</smiles>
bromide 50a (206 mg, $1.50 \mathrm{mmol}$ ). After $20 \mathrm{~h}$, purification by column chromatography ( $n$-hexane/EtOAc 100:1) yielded 187la (64 mg, 57\%) as a colorless oil.

The general procedure B was followed using substrate 381 (85 $\mathrm{mg}, 0.50 \mathrm{mmol}$ ) and bromide 50a (206 mg, $1.50 \mathrm{mmol}$ ). After $20 \mathrm{~h}$, purification by column

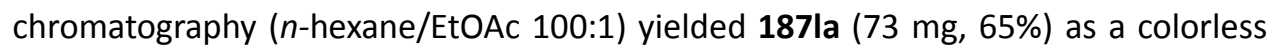
oil.

${ }^{1} \mathrm{H}$ NMR $\left(300 \mathrm{MHz}, \mathrm{CDCl}_{3}\right): \delta=8.51(\mathrm{dd}, J=1.4,0.8 \mathrm{~Hz}, 1 \mathrm{H}), 8.00(\mathrm{td}, J=1.9,0.6 \mathrm{~Hz}$, 1H), $7.72(\mathrm{dt}, J=7.1,1.9 \mathrm{~Hz}, 1 \mathrm{H}), 7.62-7.58(\mathrm{~m}, 1 \mathrm{H}), 7.55-7.50(\mathrm{~m}, 1 \mathrm{H}), 7.45-7.35(\mathrm{~m}, 2 \mathrm{H}), 2.35(\mathrm{~s}$, $3 \mathrm{H}), 1.38(\mathrm{~s}, 9 \mathrm{H})$.

${ }^{13} \mathrm{C}$ NMR $\left(75 \mathrm{MHz}, \mathrm{CDCl}_{3}\right): \delta=155.4\left(\mathrm{C}_{\mathrm{q}}\right), 151.5\left(\mathrm{C}_{\mathrm{q}}\right), 150.0(\mathrm{CH}), 139.2\left(\mathrm{C}_{\mathrm{q}}\right), 137.2(\mathrm{CH}), 131.3\left(\mathrm{C}_{\mathrm{q}}\right)$, $128.3(\mathrm{CH}), 125.7(\mathrm{CH}), 123.9(\mathrm{CH}), 123.7(\mathrm{CH}), 120.2(\mathrm{CH}), 34.8\left(\mathrm{C}_{\mathrm{q}}\right), 31.4\left(\mathrm{CH}_{3}\right), 18.1\left(\mathrm{CH}_{3}\right)$.

IR (neat): $\tilde{v}=3065,2961,2867,1599,1471,1253,999,832 \mathrm{~cm}^{-1}$.

MS (EI) $m / z$ (relative intensity) 225 (37) [M] ${ }^{+}, 210$ (100), 194 (20), 169 (17).

HR-MS (EI): $m / z$ calcd for $\mathrm{C}_{16} \mathrm{H}_{19} \mathrm{~N}^{+}[\mathrm{M}]^{+} 225.1512$, found 225.1517 .

\section{Synthesis of 2-[3-(tert-Butyl)phenyl]-5-fluoropyridine (187ma)}<smiles>CC(C)(C)c1cccc(-c2ccc(F)cn2)c1</smiles>

The general procedure A was followed using substrate $38 \mathrm{~m} \mathrm{(74} \mathrm{mg,} 0.43 \mathrm{mmol}$ ) and bromide 50a (206 mg, $1.50 \mathrm{mmol}$ ). After $20 \mathrm{~h}$, purification by column chromatography ( $n$-hexane/EtOAc 100:1) yielded $187 \mathrm{ma} \mathrm{(55} \mathrm{mg,56 \% )} \mathrm{as} \mathrm{a} \mathrm{colorless}$ oil.

${ }^{1} \mathrm{H}$ NMR $\left(300 \mathrm{MHz}, \mathrm{CDCl}_{3}\right): \delta=8.54(\mathrm{~d}, J=3.0 \mathrm{~Hz}, 1 \mathrm{H}), 7.98(\mathrm{dd}, J=2.0,2.0 \mathrm{~Hz}, 1 \mathrm{H})$, 7.73-7.67 (m, 2H), 7.48-7.36 (m, 3H), $1.38(\mathrm{~s}, 9 \mathrm{H})$.

${ }^{13} \mathrm{C}$ NMR $\left(75 \mathrm{MHz}, \mathrm{CDCl}_{3}\right): \delta=158.7\left(\mathrm{~d},{ }^{1} \mathrm{~J}_{\mathrm{C}-\mathrm{F}}=257 \mathrm{~Hz}, \mathrm{C}_{\mathrm{q}}\right), 154.3\left(\mathrm{~d},{ }^{4} \mathrm{~J}_{\mathrm{C}-\mathrm{F}}=4 \mathrm{~Hz}, \mathrm{C}_{\mathrm{q}}\right)$, $151.7\left(\mathrm{C}_{\mathrm{q}}\right), 138.2\left(\mathrm{C}_{\mathrm{q}}\right), 137.6\left(\mathrm{~d},{ }^{2} J_{\mathrm{C}-\mathrm{F}}=24 \mathrm{~Hz}, \mathrm{CH}\right), 128.5(\mathrm{CH}), 126.0(\mathrm{CH}), 124.0(\mathrm{CH})$, $123.8(\mathrm{CH}), 123.4\left(\mathrm{~d},{ }^{2} J_{\mathrm{C}-\mathrm{F}}=19 \mathrm{~Hz}, \mathrm{CH}\right), 121.5\left(\mathrm{~d},{ }^{3} J_{\mathrm{C}-\mathrm{F}}=4 \mathrm{~Hz}, \mathrm{CH}\right), 34.8\left(\mathrm{C}_{\mathrm{q}}\right), 31.4\left(\mathrm{CH}_{3}\right)$.

${ }^{19} \mathrm{~F} \mathrm{NMR}\left(282 \mathrm{MHz}, \mathrm{CDCl}_{3}\right): \delta=-130.2(\mathrm{~s})$.

IR (neat): $\tilde{v}=3065,2962,1671,1579,1468,1224,1017,834 \mathrm{~cm}^{-1}$.

MS (EI) $m / z$ (relative intensity) 229 (38) [M] ${ }^{+}, 214$ (100), 199 (23), 185 (21).

HR-MS (EI): $m / z$ calcd for $\mathrm{C}_{15} \mathrm{H}_{16} \mathrm{FN}^{+}[\mathrm{M}]^{+} 229.1261$, found 229.1260. 


\section{Synthesis of 2-[3-(tert-Butyl)phenyl]-5-phenylpyridine (187na)}

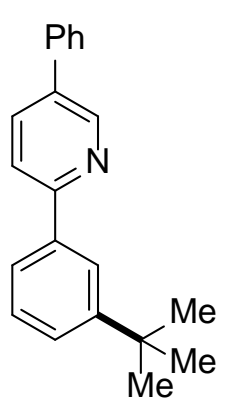

The general procedure $\mathbf{A}$ was followed using substrate $38 \mathrm{n}(116 \mathrm{mg}, 0.50 \mathrm{mmol})$ and bromide 50a (206 mg, $1.50 \mathrm{mmol}$ ). After $20 \mathrm{~h}$, purification by column chromatography ( $n$-hexane/EtOAc 20:1) yielded 187 na (35 mg, 24\%) as a white solid. M. p.: $133-135^{\circ} \mathrm{C}$.

${ }^{1} \mathrm{H}$ NMR $\left(300 \mathrm{MHz}, \mathrm{CDCl}_{3}\right): \delta=8.94(\mathrm{dd}, J=2.4,0.8 \mathrm{~Hz}, 1 \mathrm{H}), 8.10-8.08(\mathrm{~m}, 1 \mathrm{H}), 7.94$ $(\mathrm{dd}, J=8.7,2.4 \mathrm{~Hz}, 1 \mathrm{H}), 7.83-7.77(\mathrm{~m}, 2 \mathrm{H}), 7.65-7.61(\mathrm{~m}, 2 \mathrm{H}), 7.52-7.37(\mathrm{~m}, 5 \mathrm{H})$, $1.40(\mathrm{~s}, 9 \mathrm{H})$.

${ }^{13} \mathrm{C} \mathrm{NMR}\left(126 \mathrm{MHz}, \mathrm{CDCl}_{3}\right) \delta=156.8\left(\mathrm{C}_{\mathrm{q}}\right), 151.7\left(\mathrm{C}_{\mathrm{q}}\right), 148.0(\mathrm{CH}), 138.8\left(\mathrm{C}_{\mathrm{q}}\right), 137.7$ $\left(\mathrm{C}_{\mathrm{q}}\right), 135.0(\mathrm{CH}), 134.7\left(\mathrm{C}_{\mathrm{q}}\right), 129.1(\mathrm{CH}), 128.5(\mathrm{CH}), 128.0(\mathrm{CH}), 127.0(\mathrm{CH}), 126.1(\mathrm{CH}), 124.1(\mathrm{CH})$, $123.9(\mathrm{CH}), 120.5(\mathrm{CH}), 34.9\left(\mathrm{C}_{\mathrm{q}}\right), 31.4\left(\mathrm{CH}_{3}\right)$.

IR (ATR): $\tilde{v}=3409,3058,3020,1590,1472,1249,1077,993,773 \mathrm{~cm}^{-1}$.

MS (EI) $m / z$ (relative intensity) 287 (56) [M] ${ }^{+}, 272$ (100), 256 (17), 231 (24).

HR-MS (EI): $\mathrm{m} / \mathrm{z}$ calcd for $\mathrm{C}_{21} \mathrm{H}_{21} \mathrm{~N}^{+}[\mathrm{M}]^{+}$287.1669, found 287.1673.

\section{Synthesis of 2-[3-(tert-Butyl)-4-methoxyphenyl]-4-methylpyridine (187oa)}<smiles>COc1ccc(-c2cc(C)ccn2)cc1C(C)(C)C</smiles>

colorless oil.
The general procedure $\mathbf{A}$ was followed using substrate $\mathbf{3 8 0}(100 \mathrm{mg}, 0.50 \mathrm{mmol})$ and bromide 50a (206 mg, $1.50 \mathrm{mmol}$ ). After $20 \mathrm{~h}$, purification by column chromatography ( $n$-hexane/EtOAc 20:1) yielded 187oa (66 mg, 52\%) as a colorless oil.

The general procedure $\mathbf{B}$ was followed using substrate $\mathbf{3 8 0}(100 \mathrm{mg}, 0.50 \mathrm{mmol})$ and bromide $50 \mathrm{a}$ ( $206 \mathrm{mg}, 1.50 \mathrm{mmol}$ ). After $20 \mathrm{~h}$, purification by column chromatography ( $n$-hexane/EtOAc 20:1) yielded 187oa (95 mg, 74\%) as a

${ }^{1} \mathrm{H}$ NMR $\left(300 \mathrm{MHz}, \mathrm{CDCl}_{3}\right): \delta=8.50(\mathrm{~d}, J=5.0 \mathrm{~Hz}, 1 \mathrm{H}), 7.93(\mathrm{~d}, J=2.3 \mathrm{~Hz}, 1 \mathrm{H}), 7.77(\mathrm{dd}, J=8.5,2.3 \mathrm{~Hz}$, $1 \mathrm{H}), 7.46(\mathrm{dt}, J=1.5,0.8 \mathrm{~Hz}, 1 \mathrm{H}), 6.99-6.92(\mathrm{~m}, 2 \mathrm{H}), 3.87(\mathrm{~s}, 3 \mathrm{H}), 2.37(\mathrm{~s}, 3 \mathrm{H}), 1.43(\mathrm{~s}, 9 \mathrm{H})$.

${ }^{13} \mathrm{C}$ NMR $\left(75 \mathrm{MHz}, \mathrm{CDCl}_{3}\right): \delta=159.3\left(\mathrm{C}_{\mathrm{q}}\right), 157.7\left(\mathrm{C}_{\mathrm{q}}\right), 149.2(\mathrm{CH}), 147.4\left(\mathrm{C}_{\mathrm{q}}\right), 138.3\left(\mathrm{C}_{\mathrm{q}}\right), 131.5\left(\mathrm{C}_{\mathrm{q}}\right)$, $125.6(\mathrm{CH}), 125.4(\mathrm{CH}), 122.2(\mathrm{CH}), 120.9(\mathrm{CH}), 111.5(\mathrm{CH}), 55.1\left(\mathrm{CH}_{3}\right), 35.0\left(\mathrm{C}_{\mathrm{q}}\right), 29.7\left(\mathrm{CH}_{3}\right), 21.2$ $\left(\mathrm{CH}_{3}\right)$.

IR (neat): $\tilde{v}=2953,2913,1601,1556,1452,1234,1093,1027,810 \mathrm{~cm}^{-1}$.

MS (EI) $m / z$ (relative intensity) $255(41)\left[\mathrm{M}^{+}, 240\right.$ (100), 224 (18), 212 (12).

HR-MS (EI): $m / z$ calcd for $\mathrm{C}_{17} \mathrm{H}_{21} \mathrm{NO}^{+}[\mathrm{M}]^{+} 255.1618$, found 255.1626 .

\section{Synthesis of 1-\{2-[3-(tert-Butyl)phenyl]pyridin-4-yl\}ethan-1-one (187pa)}

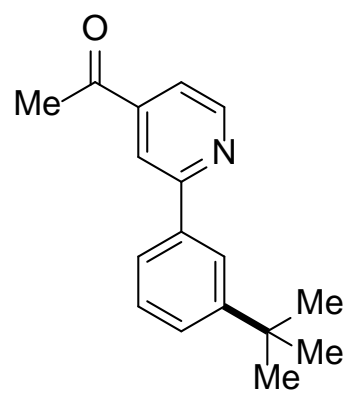

The general procedure $\mathbf{A}$ was followed using $\left[\mathrm{RuCl}_{2}(p \text {-cymene) }]_{2}(15.3 \mathrm{mg}\right.$, $5.0 \mathrm{~mol} \%$ ), Piv-Val-OH (30.0 mg, $30 \mathrm{~mol} \%$ ), substrate $38 \mathrm{p}(99 \mathrm{mg}, 0.50$ mmol) and bromide 50a (206 mg, $1.50 \mathrm{mmol}$ ). After $20 \mathrm{~h}$, purification by column chromatography ( $n$-hexane/EtOAc 20:1) yielded $187 \mathrm{pa} \mathrm{(61} \mathrm{mg,} \mathrm{48 \% )}$ as a white solid.

M. p.: $86-88^{\circ} \mathrm{C}$.

${ }^{1} \mathrm{H}$ NMR $\left(300 \mathrm{MHz}, \mathrm{CDCl}_{3}\right): \delta=9.22(\mathrm{dd}, J=2.3,0.9 \mathrm{~Hz}, 1 \mathrm{H}), 8.26(\mathrm{dd}, J=8.4$, $2.3 \mathrm{~Hz}, 1 \mathrm{H}$ ), 8.10 (dd, $J=1.9,1.9 \mathrm{~Hz}, 1 \mathrm{H}$ ), 7.84-7.79 (m, 2H), 7.50 (ddd, $J=$

7.9, 2.1, $1.2 \mathrm{~Hz}, 1 \mathrm{H}), 7.41$ (dd, J = 7.7, 7.7 Hz, 1H), $2.64(\mathrm{~s}, 3 \mathrm{H}), 1.38(\mathrm{~s}, 9 \mathrm{H})$. 
${ }^{13} \mathrm{C}$ NMR $\left(75 \mathrm{MHz}, \mathrm{CDCl}_{3}\right): \delta=196.5\left(\mathrm{C}_{\mathrm{q}}\right), 161.5\left(\mathrm{C}_{\mathrm{q}}\right), 151.9\left(\mathrm{C}_{\mathrm{q}}\right), 150.1(\mathrm{CH}), 137.9\left(\mathrm{C}_{\mathrm{q}}\right), 136.2(\mathrm{CH})$, $130.4\left(\mathrm{C}_{\mathrm{q}}\right), 128.6(\mathrm{CH}), 127.2(\mathrm{CH}), 124.6(\mathrm{CH}), 124.4(\mathrm{CH}), 120.3(\mathrm{CH}), 34.9\left(\mathrm{C}_{\mathrm{q}}\right), 31.3\left(\mathrm{CH}_{3}\right), 26.7$ $\left(\mathrm{CH}_{3}\right)$.

IR (ATR): $\tilde{v}=3024,2959,1593,1494,1453,1044,1027,809 \mathrm{~cm}^{-1}$.

MS (EI) $m / z$ (relative intensity) 253 (15) [M] ${ }^{+}, 238$ (45), 210 (6), 197 (6).

HR-MS (EI): $\mathrm{m} / z$ calcd for $\mathrm{C}_{17} \mathrm{H}_{19} \mathrm{NO}^{+}[\mathrm{M}]^{+} 253.1461$, found 253.1463 .

\section{Synthesis of 2-[2-Methoxy-3-(1-methylcyclohexyl)phenyl]pyridine (187qb)}

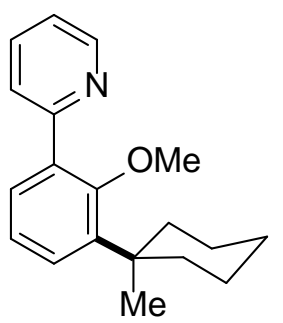

The general procedure $\mathbf{A}$ was followed using $\left[\mathrm{RuCl}_{2}(p \text {-cymene) }]_{2}(15.3 \mathrm{mg}, 5.0\right.$ $\mathrm{mol} \%)$, Piv-Val-OH (30.0 mg, $30 \mathrm{~mol} \%)$, substrate $\mathbf{3 8 q}(93 \mathrm{mg}, 0.50 \mathrm{mmol}$ ) and bromide 50b (266 mg, $1.50 \mathrm{mmol}$ ). After $20 \mathrm{~h}$, purification by column chromatography ( $n$-hexane/EtOAc 20:1) yielded 187qb (65 mg, 46\%) as a colorless oil.

${ }^{1} \mathbf{H}$ NMR $\left(300 \mathrm{MHz}, \mathrm{CDCl}_{3}\right): \delta=8.71(\mathrm{~d}, J=4.7 \mathrm{~Hz}, 1 \mathrm{H}), 7.74-7.65(\mathrm{~m}, 2 \mathrm{H}), 7.43$ (dd, $J=7.5,1.7 \mathrm{~Hz}, 1 \mathrm{H}$ ), 7.35 (dd, $J=8.0,1.7 \mathrm{~Hz}, 1 \mathrm{H}$ ), 7.20 (ddd, $J=6.5,4.9,2.2$

$\mathrm{Hz}, 1 \mathrm{H}), 7.12(\mathrm{dd}, J=7.8,7.8 \mathrm{~Hz}, 1 \mathrm{H}), 3.28(\mathrm{~s}, 3 \mathrm{H}), 2.20-2.11(\mathrm{~m}, 2 \mathrm{H}), 1.74-1.64(\mathrm{~m}, 2 \mathrm{H}), 1.59-1.40(\mathrm{~m}$, $6 \mathrm{H}), 1.31(\mathrm{~s}, 3 \mathrm{H})$.

${ }^{13} \mathrm{C} \mathrm{NMR}\left(75 \mathrm{MHz}, \mathrm{CDCl}_{3}\right): \delta=158.1\left(\mathrm{C}_{\mathrm{q}}\right), 157.9\left(\mathrm{C}_{\mathrm{q}}\right), 149.7(\mathrm{CH}), 142.0\left(\mathrm{C}_{\mathrm{q}}\right), 136.1(\mathrm{CH}), 134.5\left(\mathrm{C}_{\mathrm{q}}\right)$, $129.6(\mathrm{CH}), 128.5(\mathrm{CH}), 124.7(\mathrm{CH}), 123.5(\mathrm{CH}), 121.6(\mathrm{CH}), 61.2\left(\mathrm{CH}_{3}\right), 38.8\left(\mathrm{C}_{\mathrm{q}}\right), 37.9\left(\mathrm{CH}_{2}\right), 27.5$ $\left(\mathrm{CH}_{3}\right), 26.6\left(\mathrm{CH}_{2}\right), 23.0\left(\mathrm{CH}_{2}\right)$.

IR (neat): $\tilde{v}=3058,2923,1586,1407,1211,1005,775 \mathrm{~cm}^{-1}$.

MS (EI) $m / z$ (relative intensity) 281 (43) [M] ${ }^{+}, 266$ (90), 248 (47), 222 (36).

HR-MS (EI): $\mathrm{m} / \mathrm{z}$ calcd for $\mathrm{C}_{19} \mathrm{H}_{23} \mathrm{NO}^{+}[\mathrm{M}]^{+}$281.1774, found 281.1785 .

\section{Synthesis of 2-[3-(tert-Butyl)-2-methoxyphenyl]pyridine (187qa)}<smiles>COc1c(-c2ccccn2)cccc1C(C)(C)C</smiles>

The general procedure $\mathbf{A}$ was followed using $\left[\mathrm{RuCl}_{2}(p \text {-cymene })\right]_{2}(15.3 \mathrm{mg}, 5.0$ mol \%), Piv-Val-OH (30.0 mg, $30 \mathrm{~mol} \%$ ), substrate $38 \mathrm{q}(93 \mathrm{mg}, 0.50 \mathrm{mmol}$ ) and bromide 50a (206 mg, $1.50 \mathrm{mmol})$. After $20 \mathrm{~h}$, purification by column chromatography ( $n$-hexane/EtOAc 20:1) yielded 187qa (50 mg, 41\%) as a colorless oil.

${ }^{1} \mathrm{H}$ NMR $\left(300 \mathrm{MHz}, \mathrm{CDCl}_{3}\right): \delta=8.71(\mathrm{~d}, J=4.9 \mathrm{~Hz}, 1 \mathrm{H}), 7.76-7.66(\mathrm{~m}, 2 \mathrm{H}), 7.44(\mathrm{dd}, J$ $=7.4,1.7 \mathrm{~Hz}, 1 \mathrm{H}$ ), 7.34 (dd, $J=7.8,1.7 \mathrm{~Hz}, 1 \mathrm{H}$ ), 7.21 (ddd, $J=6.5,4.9,2.2 \mathrm{~Hz}, 1 \mathrm{H}$ ), $7.09(\mathrm{dd}, J=7.8,7.8 \mathrm{~Hz}, 1 \mathrm{H}), 3.31(\mathrm{~s}, 3 \mathrm{H}), 1.42(\mathrm{~s}, 9 \mathrm{H})$.

${ }^{13} \mathrm{C} \mathrm{NMR}\left(75 \mathrm{MHz}, \mathrm{CDCl}_{3}\right): \delta=157.8\left(\mathrm{C}_{\mathrm{q}}\right), 157.8\left(\mathrm{C}_{\mathrm{q}}\right), 149.7(\mathrm{CH}), 142.9\left(\mathrm{C}_{\mathrm{q}}\right), 136.1(\mathrm{CH}), 134.1\left(\mathrm{C}_{\mathrm{q}}\right)$, $129.8(\mathrm{CH}), 127.3(\mathrm{CH}), 124.6(\mathrm{CH}), 123.4(\mathrm{CH}), 121.7(\mathrm{CH}), 61.3\left(\mathrm{CH}_{3}\right), 35.1\left(\mathrm{C}_{\mathrm{q}}\right), 30.8\left(\mathrm{CH}_{3}\right)$.

IR (neat): $\tilde{v}=3051,2867,1587,1562,1473,1223,1006,760 \mathrm{~cm}^{-1}$.

MS (EI) $m / z$ (relative intensity) 241 (51) [M] ${ }^{+}, 226$ (83), 210 (100), 167 (32).

HR-MS (EI): $m / z$ calcd for $\mathrm{C}_{16} \mathrm{H}_{19} \mathrm{NO}^{+}[\mathrm{M}]^{+} 241.1461$, found 241.1465 .

\section{Synthesis of 2-[3-Methoxy-5-(1-methylcyclohexyl)phenyl]pyridine (187rb)}

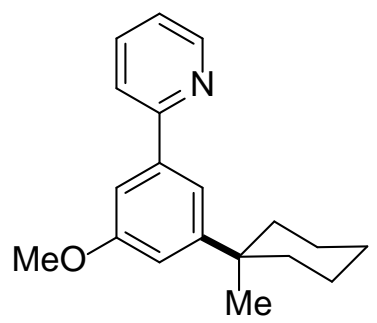

The general procedure $\mathbf{A}$ was followed using $\left[\mathrm{RuCl}_{2} \text { (p-cymene) }\right]_{2}(15.3 \mathrm{mg}$, $5.0 \mathrm{~mol} \%)$, Piv-Val-OH (30.0 mg, $30 \mathrm{~mol} \%$ ), substrate $38 \mathrm{r}(93 \mathrm{mg}, 0.50$ $\mathrm{mmol}$ ) and bromide 50b (266 mg, $1.50 \mathrm{mmol})$. After $20 \mathrm{~h}$, purification by column chromatography ( $n$-hexane/EtOAc 40:1) yielded 187rb (49 mg, 
$35 \%)$ as a colorless oil.

${ }^{1} \mathrm{H}$ NMR $\left(300 \mathrm{MHz}, \mathrm{CDCl}_{3}\right): \delta=8.67(\mathrm{~d}, J=4.9 \mathrm{~Hz}, 1 \mathrm{H}), 7.75-7.67(\mathrm{~m}, 2 \mathrm{H}), 7.56(\mathrm{dd}, J=1.6,1.6 \mathrm{~Hz}, 1 \mathrm{H})$, 7.36 (dd, $J=2.5,1.4 \mathrm{~Hz}, 1 \mathrm{H}$ ), 7.20 (ddd, $J=6.2,4.9,2.3 \mathrm{~Hz}, 1 \mathrm{H}), 6.99$ (dd, $J=2.5,1.4 \mathrm{~Hz}, 1 \mathrm{H}), 3.88(\mathrm{~s}$, $3 \mathrm{H}), 2.08-1.99(\mathrm{~m}, 2 \mathrm{H}), 1.64-1.40(\mathrm{~m}, 8 \mathrm{H}), 1.22(\mathrm{~s}, 3 \mathrm{H})$.

${ }^{13} \mathrm{C} \mathrm{NMR}\left(75 \mathrm{MHz}, \mathrm{CDCl}_{3}\right): \delta=166.0\left(\mathrm{C}_{\mathrm{q}}\right), 158.0\left(\mathrm{C}_{\mathrm{q}}\right), 152.2\left(\mathrm{C}_{\mathrm{q}}\right), 149.5(\mathrm{CH}), 140.6\left(\mathrm{C}_{\mathrm{q}}\right), 136.6(\mathrm{CH})$, $122.0(\mathrm{CH}), 120.8(\mathrm{CH}), 117.4(\mathrm{CH}), 113.9(\mathrm{CH}), 108.2(\mathrm{CH}), 55.3\left(\mathrm{CH}_{3}\right), 38.2\left(\mathrm{C}_{\mathrm{q}}\right), 38.0\left(\mathrm{CH}_{2}\right), 30.4$ $\left(\mathrm{CH}_{3}\right), 26.3\left(\mathrm{CH}_{2}\right), 22.7\left(\mathrm{CH}_{2}\right)$.

IR (neat): $\tilde{v}=2924,2854,1583,1450,1330,1214,1058,781 \mathrm{~cm}^{-1}$.

MS (EI) $m / z$ (relative intensity) 281 (100) [M] ${ }^{+}, 266$ (53), 252 (26), 226 (73).

HR-MS (EI): $m / z$ calcd for $\mathrm{C}_{19} \mathrm{H}_{23} \mathrm{NO}^{+}[\mathrm{M}]^{+} 281.1774$, found 281.1773 .

\section{Synthesis of 2-[4-(tert-Butyl)naphthalen-2-yl]pyridine (187sa)}<smiles>CC(C)(C)c1cc(-c2ccccn2)cc2ccccc12</smiles>

The general procedure $\mathbf{A}$ was followed using $\left[\operatorname{RuCl}_{2} \text { ( } p \text {-cymene) }\right]_{2}(15.3 \mathrm{mg}, 5.0$ mol \%), Piv-Val-OH (30.0 mg, $30 \mathrm{~mol} \%$ ), substrate $38 \mathrm{~s}$ (103 mg, $0.50 \mathrm{mmol}$ ) and bromide 50a (206 mg, $1.50 \mathrm{mmol}$ ). After $20 \mathrm{~h}$, purification by column chromatography ( $n$-hexane/EtOAc 40:1) yielded 187sa (29 mg, 22\%) as a colorless oil.

${ }^{1} \mathrm{H}$ NMR $\left(300 \mathrm{MHz}, \mathrm{CDCl}_{3}\right.$ ): $\delta=8.74$ (ddd, $J=4.8,1.9,1.0 \mathrm{~Hz}, 1 \mathrm{H}$ ), 8.47 (d, $J=$ $8.7 \mathrm{~Hz}, 1 \mathrm{H}), 8.29(\mathrm{dd}, J=1.7,0.9 \mathrm{~Hz}, 1 \mathrm{H}), 8.19(\mathrm{~d}, J=1.8 \mathrm{~Hz}, 1 \mathrm{H}), 7.97(\mathrm{dd}, J=7.8,1.9 \mathrm{~Hz}, 1 \mathrm{H}), 7.86(\mathrm{dt}$, $J=8.0,1.1 \mathrm{~Hz}, 1 \mathrm{H}$ ), 7.77 (ddd, $J=7.9,7.3,1.8 \mathrm{~Hz}, 1 \mathrm{H}), 7.56-7.39(\mathrm{~m}, 2 \mathrm{H}), 7.24$ (ddd, $J=7.2,4.8,1.2$ $\mathrm{Hz}, 1 \mathrm{H}), 1.69(\mathrm{~s}, 9 \mathrm{H})$.

${ }^{13} \mathrm{C} \mathrm{NMR}\left(126 \mathrm{MHz}, \mathrm{CDCl}_{3}\right) \delta=157.7\left(\mathrm{C}_{\mathrm{q}}\right), 149.6(\mathrm{CH}), 146.6\left(\mathrm{C}_{\mathrm{q}}\right), 136.6(\mathrm{CH}), 135.6\left(\mathrm{C}_{\mathrm{q}}\right), 135.1\left(\mathrm{C}_{\mathrm{q}}\right)$, $131.7\left(\mathrm{C}_{\mathrm{q}}\right), 130.4(\mathrm{CH}), 126.8(\mathrm{CH}), 125.7(\mathrm{CH}), 125.1(\mathrm{CH}), 124.9(\mathrm{CH}), 122.1(\mathrm{CH}), 121.9(\mathrm{CH}), 120.9$ $(\mathrm{CH}), 36.4\left(\mathrm{C}_{\mathrm{q}}\right), 31.9\left(\mathrm{CH}_{3}\right)$.

IR (neat): $\tilde{v}=3052,2957,1586,1563,1471,1364,1153,990,781 \mathrm{~cm}^{-1}$.

MS (EI) $m / z$ (relative intensity) 261 (58) [M] ${ }^{+}, 246$ (100), 231 (42), 217 (17).

HR-MS (EI): $m / z$ calcd for $\mathrm{C}_{19} \mathrm{H}_{19} \mathrm{~N}^{+}[\mathrm{M}]^{+} 261.1512$, found 261.1514

\section{Synthesis of 2-[5-(tert-butyl)thiophen-3-yl]pyridine (187ta)}

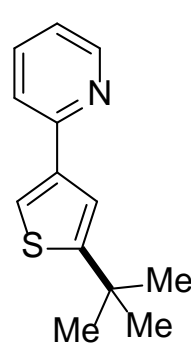

The general procedure $\mathbf{A}$ was followed using $\left[\mathrm{RuCl}_{2} \text { ( } p \text {-cymene) }\right]_{2}(15.3 \mathrm{mg}, 5.0 \mathrm{~mol} \%)$, Piv-Val-OH (30.0 mg, $30 \mathrm{~mol} \%)$, substrate $38 \mathrm{t}(81 \mathrm{mg}, 0.50 \mathrm{mmol})$ and bromide 50a (206 mg, $1.50 \mathrm{mmol}$ ). After $20 \mathrm{~h}$, purification by column chromatography ( $n$-hexane/EtOAc 40:1) yielded 187ta (60 mg, 55\%) as a colorless oil.

${ }^{1} \mathbf{H}$ NMR $\left(300 \mathrm{MHz}, \mathrm{CDCl}_{3}\right): \delta=8.58(\mathrm{~d}, J=4.9 \mathrm{~Hz}, 1 \mathrm{H}), 7.67-7.55(\mathrm{~m}, 3 \mathrm{H}), 7.40(\mathrm{~d}, J=$ $1.4 \mathrm{~Hz}, 1 \mathrm{H}$ ), 7.11 (ddd, J = 7.3, 4.9, $1.3 \mathrm{~Hz}, 1 \mathrm{H}), 1.41(\mathrm{~s}, 9 \mathrm{H})$.

${ }^{13} \mathrm{C} \mathrm{NMR}\left(75 \mathrm{MHz}, \mathrm{CDCl}_{3}\right): \delta=158.5\left(\mathrm{C}_{\mathrm{q}}\right), 153.9\left(\mathrm{C}_{\mathrm{q}}\right), 149.4(\mathrm{CH}), 141.3\left(\mathrm{C}_{\mathrm{q}}\right), 136.5(\mathrm{CH})$, $121.5(\mathrm{CH}), 120.5(\mathrm{CH}), 120.5(\mathrm{CH}), 120.1(\mathrm{CH}), 34.6\left(\mathrm{C}_{\mathrm{q}}\right), 34.2\left(\mathrm{CH}_{3}\right)$.

IR (neat): $\tilde{v}=3085,3060,1768,1704,1586,1483,1244,1064,747 \mathrm{~cm}^{-1}$.

MS (EI) $m / z$ (relative intensity) 217 (26) [M] $]^{+}, 202$ (100), 187 (10), 168 (8).

HR-MS (EI): $\mathrm{m} / z$ calcd for $\mathrm{C}_{13} \mathrm{H}_{15} \mathrm{NS}^{+}[\mathrm{M}]^{+} 217.0920$, found 217.0930 .

\section{Synthesis of 1-[3-(tert-Butyl)-4-fluorophenyl]-1H-pyrazole (196aa)}

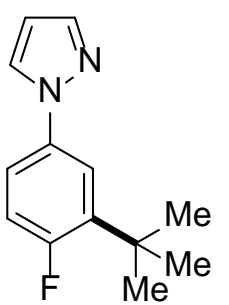

The general procedure $\mathbf{A}$ was followed using $\left[\mathrm{RuCl}_{2} \text { (p-cymene) }\right]_{2}(15.3 \mathrm{mg}, 5.0$ $\mathrm{mol} \%)$, Piv-Val-OH $(30.0 \mathrm{mg}, 30 \mathrm{~mol} \%)$, substrate $131 \mathrm{a}(81 \mathrm{mg}, 0.50 \mathrm{mmol}$ ) and 
bromide 50a (206 mg, $1.50 \mathrm{mmol}$ ). After $20 \mathrm{~h}$, purification by column chromatography ( $n$-hexane/EtOAc 10:1) yielded 196aa (79 mg, 72\%) as a colorless oil.

The general procedure B was followed using [RuCl(O-Val-Piv)(p-cymene)] (23.6 mg, $10.0 \mathrm{~mol} \%)$, substrate 131a ( $81 \mathrm{mg}, 0.50 \mathrm{mmol}$ ) and bromide 50a (206 mg, $1.50 \mathrm{mmol}$ ). After $20 \mathrm{~h}$, purification by column chromatography ( $n$-hexane/EtOAc $10: 1)$ yielded 196aa $(80 \mathrm{mg}, 73 \%)$ as a colorless oil.

${ }^{1} \mathrm{H}$ NMR $\left(300 \mathrm{MHz}, \mathrm{CDCl}_{3}\right): \delta=7.84(\mathrm{~d}, J=2.4 \mathrm{~Hz}, 1 \mathrm{H}), 7.71(\mathrm{~d}, J=1.7 \mathrm{~Hz}, 1 \mathrm{H}), 7.65(\mathrm{dd}, J=7.1,2.8 \mathrm{~Hz}$, $1 \mathrm{H}$ ), 7.42 (ddd, $J=8.8,3.9,2.8 \mathrm{~Hz}, 1 \mathrm{H}$ ), 7.07 (dd, $J=11.8,8.8 \mathrm{~Hz}, 1 \mathrm{H}$ ), 6.45 (dd, $J=2.2,2.2 \mathrm{~Hz}, 1 \mathrm{H}$ ), $1.42(\mathrm{~s}, 3 \mathrm{H})$.

${ }^{13} \mathrm{C}$ NMR $\left(75 \mathrm{MHz}, \mathrm{CDCl}_{3}\right): \delta=160.3\left(\mathrm{~d},{ }^{1} J_{\mathrm{C}-\mathrm{F}}=247 \mathrm{~Hz}, \mathrm{C}_{\mathrm{q}}\right), 140.9(\mathrm{CH}), 138.4\left(\mathrm{~d},{ }^{2} J_{\mathrm{C}-\mathrm{F}}=13 \mathrm{~Hz}, \mathrm{C}_{\mathrm{q}}\right)$, $136.2\left(\mathrm{~d},{ }^{4} \mathrm{~J}_{\mathrm{C}-\mathrm{F}}=2 \mathrm{~Hz}, \mathrm{C}_{\mathrm{q}}\right), 127.0(\mathrm{CH}), 119.1\left(\mathrm{~d},{ }^{3} \mathrm{~J}_{\mathrm{C}-\mathrm{F}}=6 \mathrm{~Hz}, \mathrm{CH}\right), 118.4\left(\mathrm{~d},{ }^{3} \mathrm{~J}_{\mathrm{C}-\mathrm{F}}=9 \mathrm{~Hz}, \mathrm{CH}\right), 116.9\left(\mathrm{~d},{ }^{2} \mathrm{~J}_{\mathrm{C}-\mathrm{F}}\right.$ $=26 \mathrm{~Hz}, \mathrm{CH}), 107.4(\mathrm{CH}), 34.5\left(\mathrm{~d},{ }^{3} \mathrm{~J}_{\mathrm{C}-\mathrm{F}}=3 \mathrm{~Hz}, \mathrm{C}_{\mathrm{q}}\right), 29.7\left(\mathrm{~d},{ }^{4} \mathrm{~J}_{\mathrm{C}-\mathrm{F}}=4 \mathrm{~Hz}, \mathrm{CH}_{3}\right)$.

${ }^{19} \mathrm{~F} \mathrm{NMR}\left(282 \mathrm{MHz}, \mathrm{CDCl}_{3}\right): \delta=-112.1(\mathrm{~s})$.

IR (neat): $\tilde{v}=3111,2960,1592,1490,1394,1211,1044,949 \mathrm{~cm}^{-1}$.

MS (EI) $m / z$ (relative intensity) $218(55)\left[\mathrm{M}^{+}, 203\right.$ (100), 175 (60), 133 (5).

HR-MS (EI): $m / z$ calcd for $\mathrm{C}_{13} \mathrm{H}_{15} \mathrm{FN}_{2}{ }^{+}[\mathrm{M}]^{+} 218.1214$, found 218.1216 .

\section{Synthesis of 1-[4-Fluoro-3-(1-methylcyclohexyl)phenyl]-1H-pyrazole (196ab)}

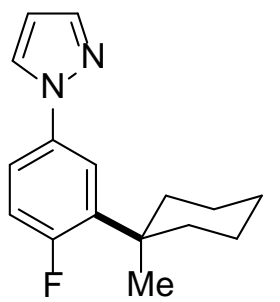

The general procedure $\mathbf{A}$ was followed using $\left[\mathrm{RuCl}_{2}(p \text {-cymene })\right]_{2}(15.3 \mathrm{mg}, 5.0$ mol \%), Piv-Val-OH (30.0 mg, $30 \mathrm{~mol} \%$ ), substrate 131a ( $81 \mathrm{mg}, 0.50 \mathrm{mmol}$ ) and bromide 50b (266 mg, $1.50 \mathrm{mmol}$ ). After $20 \mathrm{~h}$, purification by column chromatography ( $n$-hexane/EtOAc 10:1) yielded 196ab (87 mg, 67\%) as a colorless oil.

The general procedure B was followed using [RuCl(O-Val-Piv)(p-cymene)] (23.6 $\mathrm{mg}, 10.0 \mathrm{~mol} \%$ ), substrate $131 \mathrm{a}(81 \mathrm{mg}, 0.50 \mathrm{mmol}$ ) and bromide $50 \mathrm{~b}$ (266 mg, $1.50 \mathrm{mmol})$. After 20 h, purification by column chromatography ( $n$-hexane/EtOAc 10:1) yielded 196ab (83 mg, 64\%) as a colorless oil.

${ }^{1} \mathrm{H}$ NMR $\left(300 \mathrm{MHz}, \mathrm{CDCl}_{3}\right): \delta=7.82(\mathrm{~d}, J=2.4 \mathrm{~Hz}, 1 \mathrm{H}), 7.69(\mathrm{~d}, J=1.8 \mathrm{~Hz}, 1 \mathrm{H}), 7.66(\mathrm{dd}, J=7.1,2.8 \mathrm{~Hz}$, $1 \mathrm{H}$ ), 7.39 (ddd, J = 8.7, 3.9, $2.8 \mathrm{~Hz}, 1 \mathrm{H}$ ), 7.04 (dd, $J=12.2,8.7 \mathrm{~Hz}, 1 \mathrm{H}$ ), 6.43 (dd, $J=2.4,1.8 \mathrm{~Hz}, 1 \mathrm{H}$ ), 2.12-2.01 (m, 2H), 1.72-1.45(m, 8H), $1.31(\mathrm{~s}, 3 \mathrm{H})$.

${ }^{13} \mathrm{C} \mathrm{NMR}\left(75 \mathrm{MHz}, \mathrm{CDCl}_{3}\right): \delta=160.4\left(\mathrm{~d},{ }^{1} J_{\mathrm{C}-\mathrm{F}}=248 \mathrm{~Hz}, \mathrm{C}_{\mathrm{q}}\right), 140.9(\mathrm{CH}), 137.8\left(\mathrm{~d},{ }^{2} J_{\mathrm{C}-\mathrm{F}}=13 \mathrm{~Hz}, \mathrm{C}_{\mathrm{q}}\right)$, $136.3\left(\mathrm{~d},{ }^{4} \mathrm{~J}_{\mathrm{C}-\mathrm{F}}=3 \mathrm{~Hz}, \mathrm{C}_{\mathrm{q}}\right), 127.0(\mathrm{CH}), 120.0\left(\mathrm{~d},{ }^{3} \mathrm{~J}_{\mathrm{C}-\mathrm{F}}=6 \mathrm{~Hz}, \mathrm{CH}\right), 118.2\left(\mathrm{~d},{ }^{3} J_{\mathrm{C}-\mathrm{F}}=10 \mathrm{~Hz}, \mathrm{CH}\right), 117.2(\mathrm{~d}$, $\left.{ }^{2} J_{C-F}=28 \mathrm{~Hz}, \mathrm{CH}\right), 107.4(\mathrm{CH}), 38.0\left(\mathrm{~d},{ }^{3} \mathrm{~J}_{\mathrm{C}-\mathrm{F}}=3 \mathrm{~Hz}, \mathrm{C}_{\mathrm{q}}\right), 37.0\left(\mathrm{~d},{ }^{4} \mathrm{~J}_{\mathrm{C}-\mathrm{F}}=4 \mathrm{~Hz}, \mathrm{CH}_{2}\right), 26.4\left(\mathrm{~d},{ }^{4} J_{\mathrm{C}-\mathrm{F}}=4 \mathrm{~Hz}\right.$, $\left.\mathrm{CH}_{3}\right), 26.3\left(\mathrm{CH}_{2}\right), 22.6\left(\mathrm{CH}_{2}\right)$.

${ }^{19} \mathrm{~F} \mathrm{NMR}\left(282 \mathrm{MHz}, \mathrm{CDCl}_{3}\right): \delta=-111.5(\mathrm{~s})$.

IR (neat): $\tilde{v}=3112,2925,1593,1490,1451,1211,1043,947 \mathrm{~cm}^{-1}$.

MS (EI) $m / z$ (relative intensity) 258 (100) [M] $]^{+}, 243$ (74), 202 (49), 175 (35).

HR-MS (EI): $\mathrm{m} / z$ calcd for $\mathrm{C}_{16} \mathrm{H}_{19} \mathrm{FN}_{2}{ }^{+}[\mathrm{M}]^{+} 258.1527$, found 258.1529 .

\section{Synthesis of 1-[3-(tert-Butyl)-4-methoxyphenyl]-1H-pyrazole (196ba)}

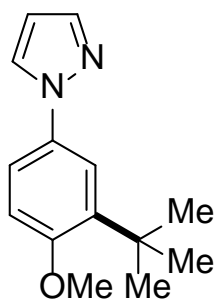

The general procedure $\mathbf{A}$ was followed using $\left[\mathrm{RuCl}_{2} \text { (p-cymene) }\right]_{2}(15.3 \mathrm{mg}, 5.0$ $\mathrm{mol} \%$ ), Piv-Val-OH (30.0 mg, $30 \mathrm{~mol} \%)$, substrate $131 \mathrm{~b}(93 \mathrm{mg}, 0.53 \mathrm{mmol}$ ) and bromide 50a (206 mg, $1.50 \mathrm{mmol}$ ). After $20 \mathrm{~h}$, purification by column chromatography ( $n$-hexane/EtOAc $40: 1$ ) yielded 196ba ( $82 \mathrm{mg}, 67 \%$ ) as a colorless 
oil.

The general procedure B was followed using [RuCl(O-Val-Piv)(p-cymene)] (23.6 mg, $10.0 \mathrm{~mol} \%)$, substrate 131b ( $87 \mathrm{mg}, 0.50 \mathrm{mmol}$ ) and bromide 50a (206 mg, $1.50 \mathrm{mmol}$ ). After $20 \mathrm{~h}$, purification by column chromatography ( $n$-hexane/EtOAc 40:1) yielded 196ba $(73 \mathrm{mg}, 63 \%)$ as a colorless oil.

${ }^{1} \mathrm{H}$ NMR $\left(300 \mathrm{MHz}, \mathrm{CDCl}_{3}\right): \delta=7.80(\mathrm{dd}, J=2.4,0.7 \mathrm{~Hz}, 1 \mathrm{H}), 7.68(\mathrm{~d}, J=1.7 \mathrm{~Hz}, 1 \mathrm{H}), 7.59(\mathrm{~d}, J=2.8 \mathrm{~Hz}$, $1 \mathrm{H}), 7.40(\mathrm{dd}, J=8.7,2.8 \mathrm{~Hz}, 1 \mathrm{H}), 6.90(\mathrm{~d}, J=8.7 \mathrm{~Hz}, 1 \mathrm{H}), 6.41(\mathrm{dd}, J=2.1,2.1 \mathrm{~Hz}, 1 \mathrm{H}), 3.85(\mathrm{~s}, 3 \mathrm{H})$, $1.40(\mathrm{~s}, 9 \mathrm{H})$.

${ }^{13} \mathrm{C}$ NMR $\left(75 \mathrm{MHz}, \mathrm{CDCl}_{3}\right): \delta=157.2\left(\mathrm{C}_{\mathrm{q}}\right), 140.4(\mathrm{CH}), 139.4\left(\mathrm{C}_{\mathrm{q}}\right), 133.5\left(\mathrm{C}_{\mathrm{q}}\right), 127.0(\mathrm{CH}), 119.0(\mathrm{CH})$, $118.2(\mathrm{CH}), 111.8(\mathrm{CH}), 106.9(\mathrm{CH}), 55.3\left(\mathrm{CH}_{3}\right), 35.0\left(\mathrm{C}_{\mathrm{q}}\right), 29.5\left(\mathrm{CH}_{3}\right)$.

IR (neat): $\tilde{v}=3111,2997,1592,1516,1428,1397,1045,1027,951 \mathrm{~cm}^{-1}$.

MS (EI) $m / z$ (relative intensity) 230 (63) [M] ${ }^{+}, 215$ (100), 200 (32), 187 (32).

HR-MS (EI): $\mathrm{m} / z$ calcd for $\mathrm{C}_{14} \mathrm{H}_{18} \mathrm{~N}_{2} \mathrm{O}^{+}[\mathrm{M}]^{+} 230.1414$, found 230.1410 .

\section{Synthesis of 1-[4-Methoxy-3-(2-methyl-4-phenylbutan-2-yl)phenyl]-1H-pyrazole (196bi)}

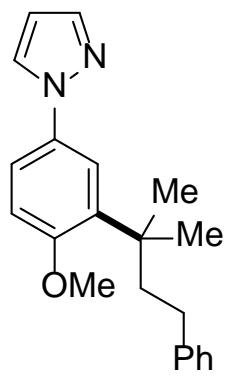

The general procedure $\mathbf{A}$ was followed using $\left[\mathrm{RuCl}_{2}(p \text {-cymene })\right]_{2}(15.3 \mathrm{mg}, 5.0$ mol \%), Piv-Val-OH (30.0 mg, $30 \mathrm{~mol} \%)$, substrate $131 \mathrm{~b}(87 \mathrm{mg}, 0.50 \mathrm{mmol}$ ) and bromide $50 \mathrm{i}$ (341 mg, $1.50 \mathrm{mmol}$ ). After $20 \mathrm{~h}$, purification by column chromatography ( $n$-hexane/EtOAc 10:1) yielded 196bi (93 mg, 58\%) as a colorless oil.

The general procedure B was followed using [RuCl(O-Val-Piv)(p-cymene)] (23.6 mg, $10.0 \mathrm{~mol} \%$ ), substrate $131 \mathrm{~b}$ ( $87 \mathrm{mg}, 0.50 \mathrm{mmol}$ ) and bromide $50 \mathrm{i}(341 \mathrm{mg}, 1.50$ mmol). After $20 \mathrm{~h}$, purification by column chromatography ( $n$-hexane/EtOAc 10:1)

yielded $196 \mathrm{bi}(87 \mathrm{mg}, 54 \%)$ as a colorless oil.

${ }^{1} \mathrm{H}$ NMR $\left(300 \mathrm{MHz}, \mathrm{CDCl}_{3}\right): \delta=7.86(\mathrm{~d}, J=2.4 \mathrm{~Hz}, 1 \mathrm{H}), 7.73(\mathrm{~d}, J=1.8 \mathrm{~Hz}, 1 \mathrm{H}), 7.63(\mathrm{~d}, J=2.8 \mathrm{~Hz}, 1 \mathrm{H})$, $7.46(\mathrm{dd}, J=8.7,2.8 \mathrm{~Hz}, 1 \mathrm{H}), 7.28-7.21(\mathrm{~m}, 2 \mathrm{H}), 7.17-7.08(\mathrm{~m}, 3 \mathrm{H}), 6.94(\mathrm{~d}, J=8.7 \mathrm{~Hz}, 1 \mathrm{H}), 6.47-6.45$ $(\mathrm{m}, 1 \mathrm{H}), 3.88(\mathrm{~s}, 3 \mathrm{H}), 2.34-2.26(\mathrm{~m}, 2 \mathrm{H}), 2.23-2.16(\mathrm{~m}, 2 \mathrm{H}), 1.48(\mathrm{~s}, 6 \mathrm{H})$.

${ }^{13} \mathrm{C} \mathrm{NMR}\left(75 \mathrm{MHz}, \mathrm{CDCl}_{3}\right): \delta=157.2\left(\mathrm{C}_{\mathrm{q}}\right), 143.5\left(\mathrm{C}_{\mathrm{q}}\right), 140.5(\mathrm{CH}), 137.4\left(\mathrm{C}_{\mathrm{q}}\right), 133.7\left(\mathrm{C}_{\mathrm{q}}\right), 128.3(\mathrm{CH})$, $128.2(\mathrm{CH}), 127.0(\mathrm{CH}), 125.4(\mathrm{CH}), 120.2(\mathrm{CH}), 118.4(\mathrm{CH}), 111.6(\mathrm{CH}), 107.0(\mathrm{CH}), 55.4\left(\mathrm{CH}_{3}\right), 42.7$ $\left(\mathrm{CH}_{2}\right), 38.7\left(\mathrm{CH}_{2}\right), 32.0\left(\mathrm{C}_{\mathrm{q}}\right), 28.4\left(\mathrm{CH}_{3}\right)$.

IR (neat): $\tilde{v}=3024,2959,1593,1516,1494,1235,1027,809 \mathrm{~cm}^{-1}$.

MS (EI) $m / z$ (relative intensity) $320(62)\left[\mathrm{M}^{+}, 215\right.$ (100), 187 (22), 157 (8), 91 (32).

HR-MS (EI): $m / z$ calcd for $\mathrm{C}_{21} \mathrm{H}_{24} \mathrm{~N}_{2} \mathrm{O}^{+}[\mathrm{M}]^{+} 320.1883$, found 320.1882 .

\section{1-[3-(tert-Butyl)phenyl]-1H-pyrazole (196ca)}<smiles>CC(C)(C)c1cccc(-n2cccn2)c1</smiles>

The general procedure $\mathbf{A}$ was followed using $\left[\mathrm{RuCl}_{2} \text { (p-cymene) }\right]_{2}$ (15.3 $\mathrm{mg}, 5.0$ $\mathrm{mol} \%$ ), Piv-Val-OH (30.0 mg, $30 \mathrm{~mol} \%)$, substrate $131 \mathrm{c}(72 \mathrm{mg}, 0.50 \mathrm{mmol}$ ) and bromide 50a (206 mg, $1.50 \mathrm{mmol}$ ). After $20 \mathrm{~h}$, purification by column chromatography ( $n$-hexane/EtOAc $80: 1$ ) yielded $196 \mathrm{ca}$ (44 $\mathrm{mg}, 44 \%$ ) as a colorless oil.

${ }^{1} \mathrm{H}$ NMR $\left(300 \mathrm{MHz}, \mathrm{CDCl}_{3}\right): \delta=7.90(\mathrm{~d}, J=2.4 \mathrm{~Hz}, 1 \mathrm{H}), 7.76-7.70(\mathrm{~m}, 2 \mathrm{H}), 7.46-7.29$ $(\mathrm{m}, 3 \mathrm{H}), 6.46-6.43(\mathrm{~m}, 1 \mathrm{H}), 1.36(\mathrm{~s}, 9 \mathrm{H})$.

${ }^{13} \mathrm{C}$ NMR $\left(75 \mathrm{MHz}, \mathrm{CDCl}_{3}\right): \delta=152.9\left(\mathrm{C}_{\mathrm{q}}\right), 140.9(\mathrm{CH}), 140.1\left(\mathrm{C}_{\mathrm{q}}\right), 128.9(\mathrm{CH}), 126.9(\mathrm{CH}), 123.6(\mathrm{CH})$, $116.8(\mathrm{CH}), 116.4(\mathrm{CH}), 107.3(\mathrm{CH}), 34.9\left(\mathrm{C}_{\mathrm{q}}\right), 31.2\left(\mathrm{CH}_{3}\right)$.

IR (neat): $\tilde{v}=2962,2866,1608,1588,1488,1405,1333,1198,1043,787 \mathrm{~cm}^{-1}$. 
MS (EI) $m / z$ (relative intensity) 200 (26) [M] ${ }^{+}, 185$ (100), 157 (13), 115 (6).

HR-MS (EI): $m / z$ calcd for $\mathrm{C}_{13} \mathrm{H}_{16} \mathrm{~N}_{2}^{+}[\mathrm{M}]^{+} 200.1308$, found 200.1319 .

\section{Synthesis of 1-[3-(1-Methylcyclohexyl)phenyl]-1H-pyrazole (196cb)}

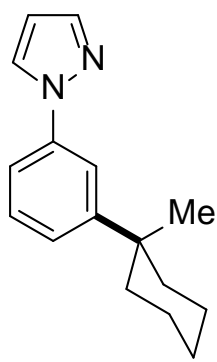

The general procedure $\mathbf{A}$ was followed using $\left[\mathrm{RuCl}_{2}(p \text {-cymene })\right]_{2}(15.3 \mathrm{mg}, 5.0$ $\mathrm{mol} \%)$, Piv-Val-OH (30.0 mg, $30 \mathrm{~mol} \%)$, substrate $131 \mathrm{c}(72 \mathrm{mg}, 0.50 \mathrm{mmol}$ ) and bromide 50b (266 mg, $1.50 \mathrm{mmol}$ ). After $20 \mathrm{~h}$, purification by column chromatography ( $n$-hexane/EtOAc $80: 1$ ) yielded $196 \mathrm{cb}$ (35 mg, 29\%) as a colorless oil.

${ }^{1} \mathrm{H}$ NMR $\left(300 \mathrm{MHz}, \mathrm{CDCl}_{3}\right): \delta=7.90(\mathrm{dd}, J=2.5,0.6 \mathrm{~Hz}, 1 \mathrm{H}), 7.74-7.71(\mathrm{~m}, 2 \mathrm{H})$, 7.45-7.28 (m, 3H), 6.45-6.43 (m, 1H), 2.08-1.98 (m, 2H), 1.63-1.41 (m, 8H), $1.22(\mathrm{~s}$,

$3 \mathrm{H})$.

${ }^{13} \mathrm{C} \mathrm{NMR}\left(75 \mathrm{MHz}, \mathrm{CDCl}_{3}\right): \delta=151.8\left(\mathrm{C}_{\mathrm{q}}\right), 140.8(\mathrm{CH}), 140.2\left(\mathrm{C}_{\mathrm{q}}\right), 129.0(\mathrm{CH}), 126.8(\mathrm{CH}), 124.1(\mathrm{CH})$, $117.3(\mathrm{CH}), 116.2(\mathrm{CH}), 107.2(\mathrm{CH}), 38.2\left(\mathrm{C}_{\mathrm{q}}\right), 37.9\left(\mathrm{CH}_{2}\right), 30.4\left(\mathrm{CH}_{3}\right), 26.3\left(\mathrm{CH}_{2}\right), 22.7\left(\mathrm{CH}_{2}\right)$.

IR (neat): $\tilde{v}=2925,2856,1605,1518,1466,1332,1192,1043,964 \mathrm{~cm}^{-1}$.

MS (EI) $m / z$ (relative intensity) 240 (100) [M] $]^{+}, 225$ (78), 197 (37), 184 (41).

HR-MS (EI): $m / z$ calcd for $\mathrm{C}_{16} \mathrm{H}_{20} \mathrm{~N}_{2}{ }^{+}[\mathrm{M}]^{+} 240.1621$, found 240.1623 .

\section{Synthesis of 1-[2-(tert-Butyl)-4-(1H-pyrazol-1-yl)phenyl]ethan-1-one (196da)}

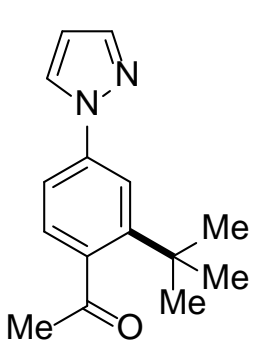

The general procedure $\mathbf{A}$ was followed using $\left[\mathrm{RuCl}_{2}(p \text {-cymene })\right]_{2}(15.3 \mathrm{mg}, 5.0$ mol \%), Piv-Val-OH (30.0 mg, $30 \mathrm{~mol} \%$ ), substrate $131 \mathrm{~d}(93 \mathrm{mg}, 0.50 \mathrm{mmol}$ ) and bromide 50a (206 mg, $1.50 \mathrm{mmol}$ ). After $20 \mathrm{~h}$, purification by column chromatography ( $n$-hexane/EtOAc $40: 1$ ) yielded 196da (46 mg, 38\%) as a white solid.

M. p.: $68-70^{\circ} \mathrm{C}$.

${ }^{1} \mathrm{H}$ NMR $\left(300 \mathrm{MHz}, \mathrm{CDCl}_{3}\right): \delta=7.91(\mathrm{dd}, J=2.5,0.7 \mathrm{~Hz}, 1 \mathrm{H}), 7.84(\mathrm{~d}, J=2.1 \mathrm{~Hz}$, $1 \mathrm{H}), 7.71(\mathrm{~d}, J=1.7 \mathrm{~Hz}, 1 \mathrm{H}$ ), 7.47 (dd, $J=8.3,2.1 \mathrm{~Hz}, 1 \mathrm{H}$ ), 7.20 (d, $J=8.3 \mathrm{~Hz}, 1 \mathrm{H}$ ), 6.45 (dd, $J=2.5,1.7$ $\mathrm{Hz}, 1 \mathrm{H}), 2.58(\mathrm{~s}, 3 \mathrm{H}), 1.40(\mathrm{~s}, 9 \mathrm{H})$.

${ }^{13} \mathrm{C} \mathrm{NMR}\left(75 \mathrm{MHz}, \mathrm{CDCl}_{3}\right): \delta=206.8\left(\mathrm{C}_{\mathrm{q}}\right), 149.1\left(\mathrm{C}_{\mathrm{q}}\right), 141.3(\mathrm{CH}), 140.4\left(\mathrm{C}_{\mathrm{q}}\right), 140.1\left(\mathrm{C}_{\mathrm{q}}\right), 127.3(\mathrm{CH})$, $126.8(\mathrm{CH}), 118.3(\mathrm{CH}), 115.7(\mathrm{CH}), 107.8(\mathrm{CH}), 36.2\left(\mathrm{C}_{\mathrm{q}}\right), 32.4\left(\mathrm{CH}_{3}\right), 31.6\left(\mathrm{CH}_{3}\right)$.

IR (ATR): $\tilde{v}=3129,2962,1691,1517,1398,1105,1047,945,760 \mathrm{~cm}^{-1}$.

MS (EI) $m / z$ (relative intensity) $242(5)\left[\mathrm{M}^{+}, 227\right.$ (100), 209 (20), 115 (8).

HR-MS (EI): $m / z$ calcd for $\mathrm{C}_{15} \mathrm{H}_{18} \mathrm{~N}_{2} \mathrm{O}^{+}[\mathrm{M}]^{+} 242.1414$, found 242.1423 .

\section{Synthesis of 1-[2-(1-Methylcyclohexyl)-4-(1H-pyrazol-1-yl)phenyl]ethan-1-one (196db)}

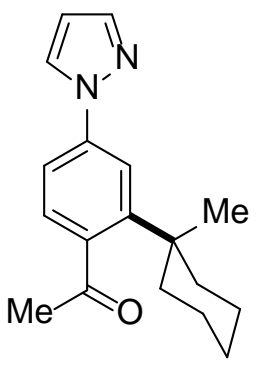

The general procedure $\mathbf{A}$ was followed using $\left[\mathrm{RuCl}_{2}(p \text {-cymene })\right]_{2}(15.3 \mathrm{mg}, 5.0$ mol \%), Piv-Val-OH (30.0 mg, $30 \mathrm{~mol} \%$ ), substrate $131 \mathrm{~d}(93 \mathrm{mg}, 0.50 \mathrm{mmol}$ ) and bromide 50b (266 mg, $1.50 \mathrm{mmol}$ ). After $20 \mathrm{~h}$, purification by column chromatography ( $n$-hexane/EtOAc $40: 1$ ) yielded 196db (30 mg, 21\%) as a white solid.

M. p.: $92-94^{\circ} \mathrm{C}$.

${ }^{1} \mathrm{H}$ NMR $\left(300 \mathrm{MHz}, \mathrm{CDCl}_{3}\right): \delta=7.93(\mathrm{~d}, J=2.4 \mathrm{~Hz}, 1 \mathrm{H}), 7.85(\mathrm{~d}, J=2.1 \mathrm{~Hz}, 1 \mathrm{H}), 7.74$ (d, $J=1.7 \mathrm{~Hz}, 1 \mathrm{H}), 7.49(\mathrm{dd}, J=8.3,2.1 \mathrm{~Hz}, 1 \mathrm{H}), 7.22(\mathrm{~d}, J=8.3 \mathrm{~Hz}, 1 \mathrm{H}), 6.48(\mathrm{dd}, J=2.5,1.7 \mathrm{~Hz}, 1 \mathrm{H}$ ), $2.59(\mathrm{~s}, 3 \mathrm{H}), 2.10-2.01(\mathrm{~m}, 2 \mathrm{H}), 1.68-1.52(\mathrm{~m}, 5 \mathrm{H}), 1.46-1.40(\mathrm{~m}, 3 \mathrm{H}), 1.37(\mathrm{~s}, 3 \mathrm{H})$. 
${ }^{13} \mathrm{C} \mathrm{NMR}\left(75 \mathrm{MHz}, \mathrm{CDCl}_{3}\right): \delta=206.9\left(\mathrm{C}_{\mathrm{q}}\right), 147.5\left(\mathrm{C}_{\mathrm{q}}\right), 141.3(\mathrm{CH}), 140.7\left(\mathrm{C}_{\mathrm{q}}\right), 140.6\left(\mathrm{C}_{\mathrm{q}}\right), 127.4(\mathrm{CH})$, $126.8(\mathrm{CH}), 119.0(\mathrm{CH}), 115.7(\mathrm{CH}), 107.8(\mathrm{CH}), 39.9\left(\mathrm{C}_{\mathrm{q}}\right), 38.4\left(\mathrm{CH}_{2}\right), 32.1\left(\mathrm{CH}_{3}\right), 29.9\left(\mathrm{CH}_{3}\right), 26.2$ $\left(\mathrm{CH}_{2}\right), 22.8\left(\mathrm{CH}_{2}\right)$.

IR (ATR): 3143, 2953, 1689, 1602, 1517, 1408, 1199, 1041, $747 \mathrm{~cm}^{-1}$.

MS (EI) $m / z$ (relative intensity) 282 (8) [M] ${ }^{+}, 267$ (100), 249 (23), 225 (18).

HR-MS (EI): $m / z$ calcd for $\mathrm{C}_{18} \mathrm{H}_{22} \mathrm{~N}_{2} \mathrm{O}^{+}[\mathrm{M}]^{+} 282.1727$, found 282.1730 .

\section{Synthesis of 1-(2-methoxy-3-(1-methylcyclohexyl)phenyl)-1H-pyrazole (196eb)}

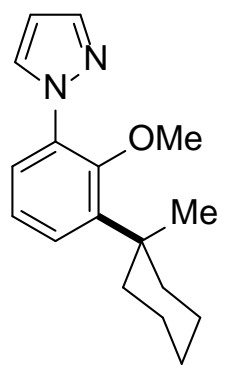

The general procedure $\mathbf{A}$ was followed using $\left[\mathrm{RuCl}_{2}(p \text {-cymene })\right]_{2}(15.3 \mathrm{mg}, 5.0$ $\mathrm{mol} \%$ ), Piv-Val-OH (30.0 mg, $30 \mathrm{~mol} \%)$, substrate $131 \mathrm{e}(90 \mathrm{mg}, 0.52 \mathrm{mmol}$ ) and bromide 50b (266 mg, $1.50 \mathrm{mmol}$ ). After $20 \mathrm{~h}$, purification by column chromatography ( $n$-hexane/EtOAc 20:1) yielded 196eb (34 mg, 24\%) as a colorless oil.

${ }^{1} \mathrm{H}$ NMR $\left(300 \mathrm{MHz}, \mathrm{CDCl}_{3}\right): \delta=7.81(\mathrm{dd}, J=2.4,0.7 \mathrm{~Hz}, 1 \mathrm{H}), 7.71(\mathrm{dd}, J=1.8,0.6 \mathrm{~Hz}$, $1 \mathrm{H}$ ), $7.37(\mathrm{dd}, J=7.8,1.7 \mathrm{~Hz}, 1 \mathrm{H}), 7.32(\mathrm{dd}, J=8.0,1.7 \mathrm{~Hz}, 1 \mathrm{H}), 7.10$ (dd, $J=8.0,8.0$ $\mathrm{Hz}, 1 \mathrm{H}), 6.45-6.43(\mathrm{~m}, 1 \mathrm{H}), 3.15(\mathrm{~s}, 3 \mathrm{H}), 2.17-2.07(\mathrm{~m}, 2 \mathrm{H}), 1.69-1.44(\mathrm{~m}, 8 \mathrm{H}), 1.29(\mathrm{~s}, 3 \mathrm{H})$.

${ }^{13} \mathrm{C} \mathrm{NMR}\left(75 \mathrm{MHz}, \mathrm{CDCl}_{3}\right): \delta=153.2\left(\mathrm{C}_{\mathrm{q}}\right), 143.1\left(\mathrm{C}_{\mathrm{q}}\right), 140.5(\mathrm{CH}), 134.6\left(\mathrm{C}_{\mathrm{q}}\right), 131.2(\mathrm{CH}), 127.4(\mathrm{CH})$, $124.8(\mathrm{CH}), 123.4(\mathrm{CH}), 106.9(\mathrm{CH}), 59.8\left(\mathrm{CH}_{3}\right), 38.9\left(\mathrm{C}_{\mathrm{q}}\right), 37.7\left(\mathrm{CH}_{2}\right), 27.3\left(\mathrm{CH}_{3}\right), 26.5\left(\mathrm{CH}_{2}\right), 22.9$ $\left(\mathrm{CH}_{2}\right)$.

IR (neat): $\tilde{v}=2924,2854,186,1518,1423,1229,1041,948,790 \mathrm{~cm}^{-1}$.

MS (EI) $m / z$ (relative intensity) $270(63)\left[\mathrm{M}^{+}, 255\right.$ (100), 237 (37), 187 (26).

HR-MS (EI): $m / z$ calcd for $\mathrm{C}_{17} \mathrm{H}_{22} \mathrm{~N}_{2} \mathrm{O}^{+}[\mathrm{M}]^{+} 270.1727$, found 270.1731 .

\section{Synthesis of 2-[3-(tert-Butyl)phenyl]pyrimidine (198aa)}

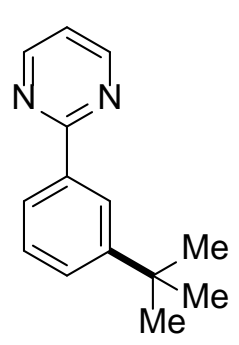

The general procedure $\mathbf{A}$ was followed using $\left[\mathrm{RuCl}_{2}(p \text {-cymene })\right]_{2}(15.3 \mathrm{mg}, 5.0$ $\mathrm{mol} \%$ ), Piv-Val-OH (30.0 mg, $30 \mathrm{~mol} \%)$, substrate $197 \mathrm{a}(78 \mathrm{mg}, 0.50 \mathrm{mmol}$ ) and bromide 50a (206 mg, $1.50 \mathrm{mmol}$ ). After $20 \mathrm{~h}$, purification by column chromatography ( $n$-hexane/EtOAc 20:1) yielded 198aa (53 mg, 50\%) as a white solid.

The general procedure B was followed using [RuCl(O-Val-Piv)(p-cymene)] (23.6 mg, $10.0 \mathrm{~mol} \%$ ), substrate $197 \mathrm{a}(78.1 \mathrm{mg}, 0.50 \mathrm{mmol}$ ) and bromide 50a (206 mg, 1.50 $\mathrm{mmol}$ ). After $20 \mathrm{~h}$, purification by column chromatography ( $n$-hexane/EtOAc 20:1) yielded 198aa (65 $\mathrm{mg}, 61 \%)$ as a white solid.

M. p.: $74-76^{\circ} \mathrm{C}$.

${ }^{1} \mathrm{H}$ NMR $\left(300 \mathrm{MHz}, \mathrm{CDCl}_{3}\right): \delta=8.79(\mathrm{~d}, J=4.8 \mathrm{~Hz}, 2 \mathrm{H}), 8.48(\mathrm{dd}, J=1.8,1.8 \mathrm{~Hz}, 1 \mathrm{H}), 8.24(\mathrm{dd}, J=7.8$, $1.5 \mathrm{~Hz}, 1 \mathrm{H}$ ), 7.52 (ddd, J = 7.8, 2.0, $1.2 \mathrm{~Hz}, 1 \mathrm{H}$ ), 7.41 (dd, $J=7.8,7.8 \mathrm{~Hz}, 1 \mathrm{H}$ ), 7.15 (dd, $J=4.8,4.8 \mathrm{~Hz}$, $1 \mathrm{H}), 1.40(\mathrm{~s}, 9 \mathrm{H})$.

${ }^{13} \mathrm{C} \mathrm{NMR}\left(75 \mathrm{MHz}, \mathrm{CDCl}_{3}\right): \delta=165.1\left(\mathrm{C}_{\mathrm{q}}\right), 157.2(\mathrm{CH}), 151.5\left(\mathrm{C}_{\mathrm{q}}\right), 137.3\left(\mathrm{C}_{\mathrm{q}}\right), 128.3(\mathrm{CH}), 127.9(\mathrm{CH})$, $125.4(\mathrm{CH}), 125.0(\mathrm{CH}), 118.9(\mathrm{CH}), 34.9\left(\mathrm{C}_{\mathrm{q}}\right), 31.4\left(\mathrm{CH}_{3}\right)$.

IR (ATR): $\tilde{v}=3069,3037,1567,1403,1259,1244,781,697 \mathrm{~cm}^{-1}$.

MS (EI) $m / z$ (relative intensity) 212 (7) [M] ${ }^{+}, 197$ (33), 182 (5), 169 (5).

HR-MS (EI): $m / z$ calcd for $\mathrm{C}_{14} \mathrm{H}_{16} \mathrm{~N}_{2}{ }^{+}[\mathrm{M}]^{+} 212.1308$, found 212.1313 . 


\section{Synthesis of 2-[3-(tert-Butyl)-4-methoxyphenyl]pyrimidine (198ba)}

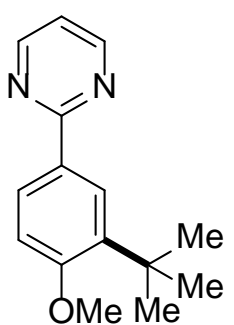

The general procedure $\mathbf{A}$ was followed using $\left[\mathrm{RuCl}_{2}(p \text {-cymene })\right]_{2}(15.3 \mathrm{mg}, 5.0$ $\mathrm{mol} \%)$, Piv-Val-OH (30.0 mg, $30 \mathrm{~mol} \%)$, substrate $197 \mathrm{~b}(93 \mathrm{mg}, 0.50 \mathrm{mmol})$ and bromide 50a (206 mg, $1.50 \mathrm{mmol}$ ). After $20 \mathrm{~h}$, purification by column chromatography ( $n$-hexane/EtOAc 20:1) yielded 198ba (53 mg, 44\%) as a colorless oil.

The general procedure B was followed using [RuCl(O-Val-Piv)(p-cymene)] $(23.6 \mathrm{mg}$, $10.0 \mathrm{~mol} \%$ ), substrate $197 \mathrm{~b}(93 \mathrm{mg}, 0.50 \mathrm{mmol}$ ) and bromide 50a (206 mg, 1.50 mmol). After $20 \mathrm{~h}$, purification by column chromatography ( $n$-hexane/EtOAc 20:1) yielded 198ba (57 $\mathrm{mg}, 47 \%)$ as a colorless oil.

${ }^{1} \mathrm{H}$ NMR $\left(300 \mathrm{MHz}, \mathrm{CDCl}_{3}\right): \delta=8.73(\mathrm{~d}, J=4.8 \mathrm{~Hz}, 2 \mathrm{H}), 8.40(\mathrm{~d}, J=2.2 \mathrm{~Hz}, 1 \mathrm{H}), 8.27(\mathrm{dd}, J=8.6,2.2 \mathrm{~Hz}$, $1 \mathrm{H}), 7.07$ (dd, $J=4.8,4.8 \mathrm{~Hz}, 1 \mathrm{H}), 6.95(\mathrm{~d}, J=8.6 \mathrm{~Hz}, 1 \mathrm{H}), 3.89(\mathrm{~s}, 3 \mathrm{H}), 1.43(\mathrm{~s}, 9 \mathrm{H})$.

${ }^{13} \mathrm{C} \mathrm{NMR}\left(75 \mathrm{MHz}, \mathrm{CDCl}_{3}\right): \delta=165.0\left(\mathrm{C}_{\mathrm{q}}\right), 160.9\left(\mathrm{C}_{\mathrm{q}}\right), 157.1(\mathrm{CH}), 138.2\left(\mathrm{C}_{\mathrm{q}}\right), 129.5\left(\mathrm{C}_{\mathrm{q}}\right), 127.5(\mathrm{CH})$, $126.7(\mathrm{CH}), 118.1(\mathrm{CH}), 111.4(\mathrm{CH}), 55.1\left(\mathrm{CH}_{3}\right), 35.0\left(\mathrm{C}_{\mathrm{q}}\right), 29.7\left(\mathrm{CH}_{3}\right)$.

IR (neat): $\tilde{v}=2966,2955,1566,1549,1395,1252,1027,797 \mathrm{~cm}^{-1}$.

MS (EI) $m / z$ (relative intensity) 242 (36) [M] ${ }^{+}, 227$ (100), 199 (23), 169 (17).

HR-MS (EI): $\mathrm{m} / z$ calcd for $\mathrm{C}_{15} \mathrm{H}_{18} \mathrm{~N}_{2} \mathrm{O}^{+}[\mathrm{M}]^{+} 242.1414$, found 242.1423 .

Synthesis of 2-[3-(tert-Butyl)-4-fluorophenyl]pyrimidine (198ca)<smiles>CC(C)(C)c1cc(-c2ncccn2)ccc1F</smiles>

The general procedure $\mathbf{A}$ was followed using $\left[\mathrm{RuCl}_{2}(p \text {-cymene })\right]_{2}(15.3 \mathrm{mg}, 5.0$ $\mathrm{mol} \%$ ), Piv-Val-OH (30.0 mg, $30 \mathrm{~mol} \%)$, substrate $197 \mathrm{c}(87 \mathrm{mg}, 0.50 \mathrm{mmol})$ and bromide 50a (206 mg, $1.50 \mathrm{mmol}$ ). After $20 \mathrm{~h}$, purification by column chromatography ( $n$-hexane/EtOAc 20:1) yielded 197ca (60 mg, 52\%) as a colorless oil.

The general procedure B was followed using [RuCl(O-Val-Piv)(p-cymene)] $(23.6 \mathrm{mg}$, $10.0 \mathrm{~mol} \%$ ), substrate $197 \mathrm{c}(87 \mathrm{mg}, 0.50 \mathrm{mmol}$ ) and bromide 50a (206 mg, 1.50 mmol). After $20 \mathrm{~h}$, purification by column chromatography ( $n$-hexane/EtOAc 20:1) yielded 198ca (82 $\mathrm{mg}, 71 \%)$ as a colorless oil.

${ }^{1} \mathrm{H}$ NMR $\left(300 \mathrm{MHz}, \mathrm{CDCl}_{3}\right): \delta=8.76(\mathrm{~d}, J=4.8 \mathrm{~Hz}, 2 \mathrm{H}), 8.43(\mathrm{dd}, J=8.3,2.3 \mathrm{~Hz}, 1 \mathrm{H}), 8.25$ (ddd, $J=8.5$, 4.7, $2.3 \mathrm{~Hz}, 1 \mathrm{H}$ ), 7.13 (dd, $J=4.8,4.8 \mathrm{~Hz}, 1 \mathrm{H}), 7.02$ (dd, $J=12.1,8.5 \mathrm{~Hz}, 1 \mathrm{H}$ ), $1.44(\mathrm{~d}, J=1.0 \mathrm{~Hz}, 9 \mathrm{H}$ ).

${ }^{13} \mathrm{C} \mathrm{NMR}\left(75 \mathrm{MHz}, \mathrm{CDCl}_{3}\right): \delta=164.0\left(\mathrm{~d},{ }^{1} J_{\mathrm{C}-\mathrm{F}}=254 \mathrm{~Hz}, \mathrm{C}_{\mathrm{q}}\right), 164.3\left(\mathrm{C}_{\mathrm{q}}\right), 157.1(\mathrm{CH}), 137.2\left(\mathrm{~d},{ }^{2} J_{\mathrm{C}-\mathrm{F}}=12\right.$ $\left.\mathrm{Hz}, \mathrm{C}_{\mathrm{q}}\right), 133.2\left(\mathrm{~d},{ }^{4} \mathrm{~J}_{\mathrm{C}-\mathrm{F}}=2 \mathrm{~Hz}, \mathrm{C}_{\mathrm{q}}\right), 127.8\left(\mathrm{~d},{ }^{3} J_{\mathrm{C}-\mathrm{F}}=10 \mathrm{~Hz}, \mathrm{CH}\right), 127.5\left(\mathrm{~d},{ }^{3} \mathrm{~J}_{\mathrm{C}-\mathrm{F}}=7 \mathrm{~Hz}, \mathrm{CH}\right), 118.7(\mathrm{CH})$, $116.5\left(\mathrm{~d},{ }^{2} \mathrm{~J}_{\mathrm{C}-\mathrm{F}}=26 \mathrm{~Hz}, \mathrm{CH}\right), 34.4\left(\mathrm{~d},{ }^{3} \mathrm{~J}_{\mathrm{C}-\mathrm{F}}=3 \mathrm{~Hz}, \mathrm{C}_{\mathrm{q}}\right), 29.9\left(\mathrm{~d},{ }^{4} \mathrm{~J}_{\mathrm{C}-\mathrm{F}}=3 \mathrm{~Hz}, \mathrm{CH}_{3}\right)$.

${ }^{19} \mathrm{~F} \mathrm{NMR}\left(282 \mathrm{MHz}, \mathrm{CDCl}_{3}\right): \delta=-106.4(\mathrm{~s})$.

IR (neat): $\tilde{v}=3036,2959,2870,1567,1415,1210,1084,799 \mathrm{~cm}^{-1}$.

MS (EI) $m / z$ (relative intensity) $230(28)\left[\mathrm{M}^{+}, 215\right.$ (100), 187 (48), 134 (10).

HR-MS (EI): $m / z$ calcd for $\mathrm{C}_{14} \mathrm{H}_{15} \mathrm{FN}_{2}{ }^{+}[\mathrm{M}]^{+} 230.1214$, found 230.1218 . 


\section{Mechanistic Studies}

Intermolecular Competition Experiment between Substrates $38 \mathrm{f}$ and $\mathbf{3 8 g}$

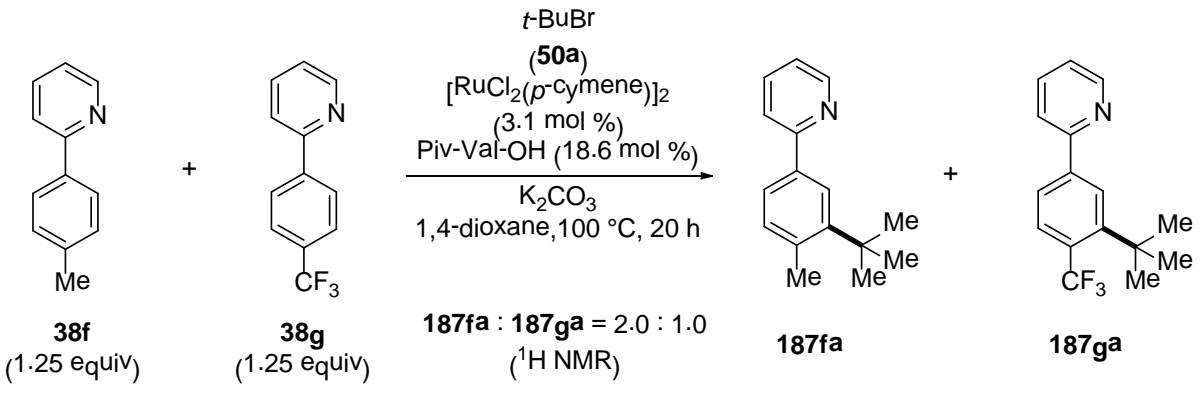

A mixture of substrates $\mathbf{3 8 f}$ (169 mg, $1.00 \mathrm{mmol}), \mathbf{3 8 g}(223 \mathrm{mg}, 1.00 \mathrm{mmol}$ ) and bromide $50 \mathrm{a}$ (110 mg, $0.80 \mathrm{mmol})$, $\left[\mathrm{RuCl}_{2}(p \text {-cymene) }]_{2}(15.3 \mathrm{mg}, 3.1 \mathrm{~mol} \%)\right.$, Piv-Val-OH (30.0 mg, $\left.18.6 \mathrm{~mol} \%\right)$ and $\mathrm{K}_{2} \mathrm{CO}_{3}$ (276 mg, $2.00 \mathrm{mmol})$ in 1,4-dioxane $\left(4.0 \mathrm{~mL}\right.$ ) was stirred at $100{ }^{\circ} \mathrm{C}$ for $20 \mathrm{~h}$ under an atmosphere of $\mathrm{N}_{2}$. At ambient temperature, EtOAc $(15 \mathrm{~mL})$ was added, and the mixture was filtered through a pad of silica gel. The solvents were removed in vacuo, and the residue was purified by column chromatography ( $n$-hexane/EtOAc 20:1). Careful ${ }^{1} \mathrm{H}$ NMR analysis disclosed a ratio of 187fa/187ga to be $2.0: 1.0$. Their spectral data were identical to those reported above.

Standard spectra
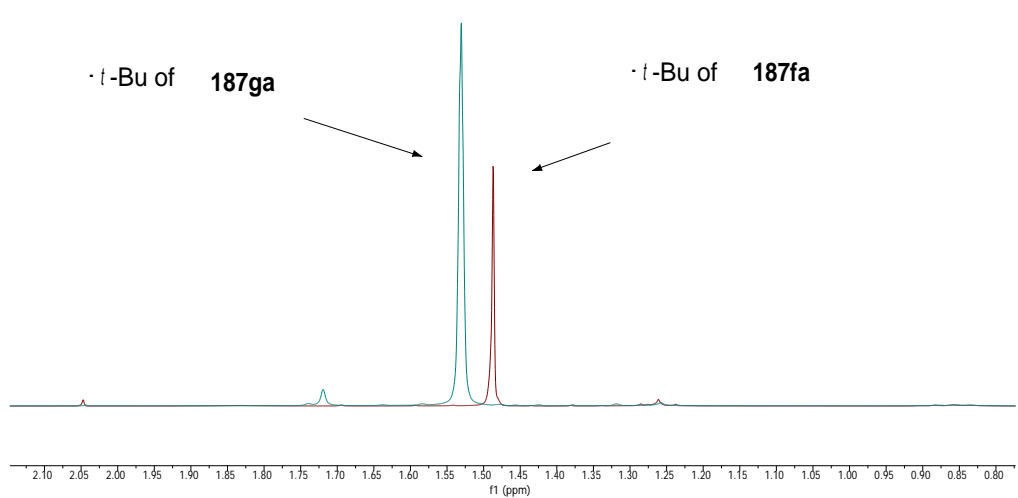


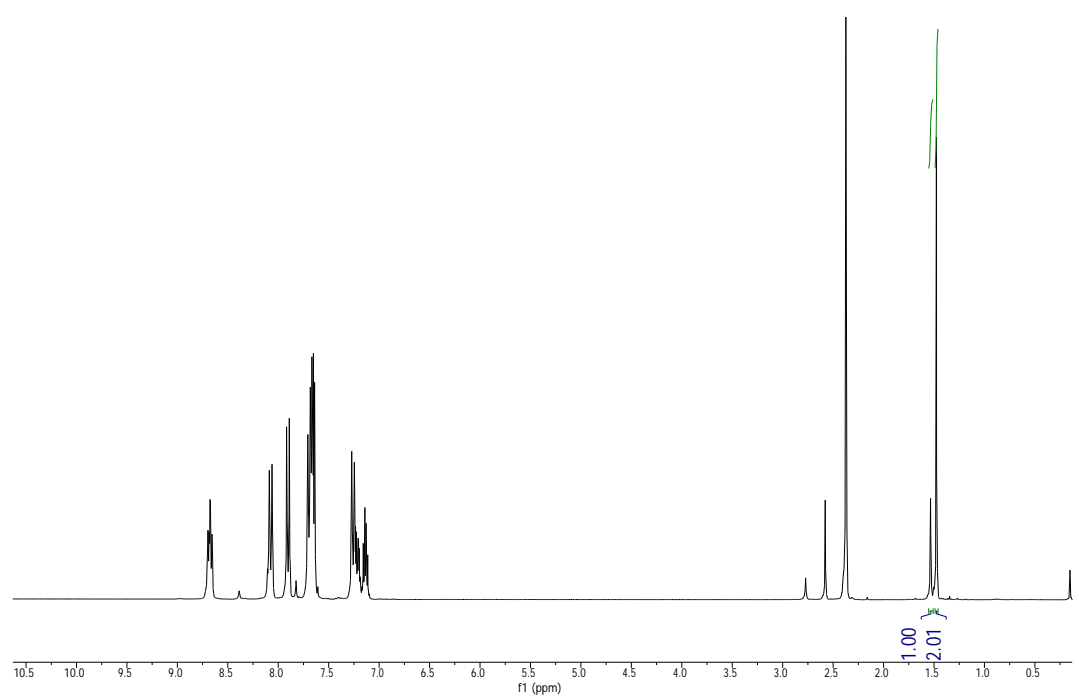

Intermolecular Competition Experiment between Substrates 38b and 38f
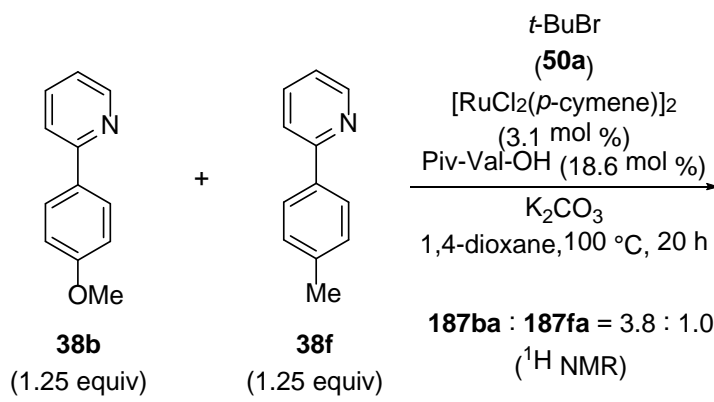

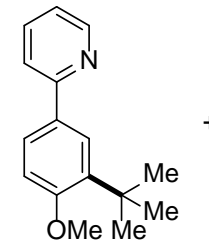

$187 \mathrm{ba}$

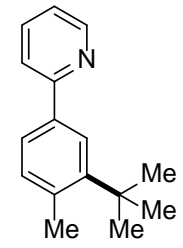

$187 \mathrm{fa}$

A mixture of substrates $\mathbf{3 8 b}(185 \mathrm{mg}, 1.00 \mathrm{mmol}), \mathbf{3 8 f}(169 \mathrm{mg}, 1.00 \mathrm{mmol}$ ) and bromide $50 \mathrm{a}$ (110 mg, $0.80 \mathrm{mmol}),\left[\mathrm{RuCl}_{2}(p \text {-cymene) }]_{2}(15.3 \mathrm{mg}, 3.1 \mathrm{~mol} \%)\right.$, Piv-Val-OH (30.0 mg, $\left.18.6 \mathrm{~mol} \%\right)$ and $\mathrm{K}_{2} \mathrm{CO}_{3}$ $(276 \mathrm{mg}, 2.00 \mathrm{mmol})$ in 1,4-dioxane $\left(4.0 \mathrm{~mL}\right.$ ) was stirred at $100{ }^{\circ} \mathrm{C}$ for $20 \mathrm{~h}$ under an atmosphere of $\mathrm{N}_{2}$. At ambient temperature, EtOAc $(15 \mathrm{~mL})$ was added, and the mixture was filtered through a pad of silica gel. The solvents were removed in vacuo, and the residue was purified by column chromatography ( $n$-hexane/EtOAc 20:1). Careful ${ }^{1} \mathrm{H}$ NMR analysis disclosed a ratio of $\mathbf{1 8 7 b a / 1 8 7 f a t o ~}$ be $3.8: 1.0$. Their spectral data were identical to those reported above.

Standard spectra

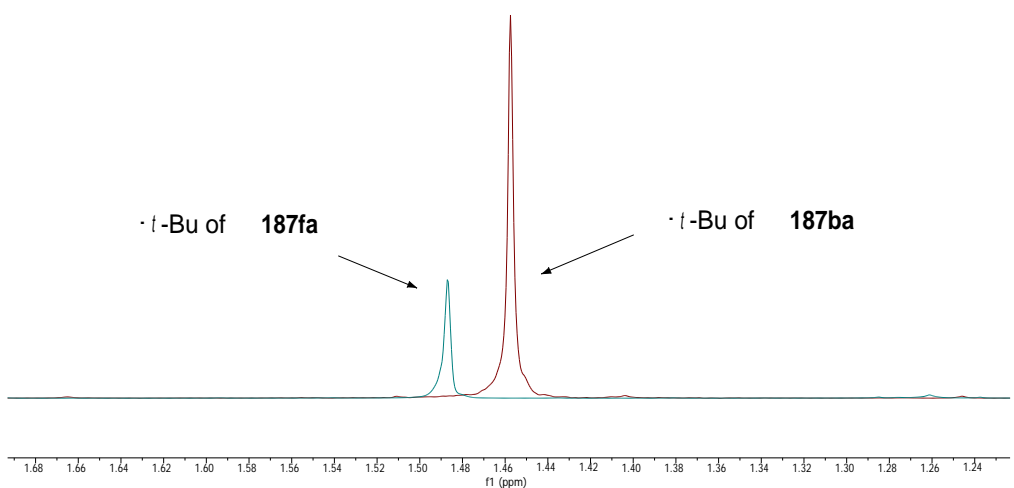




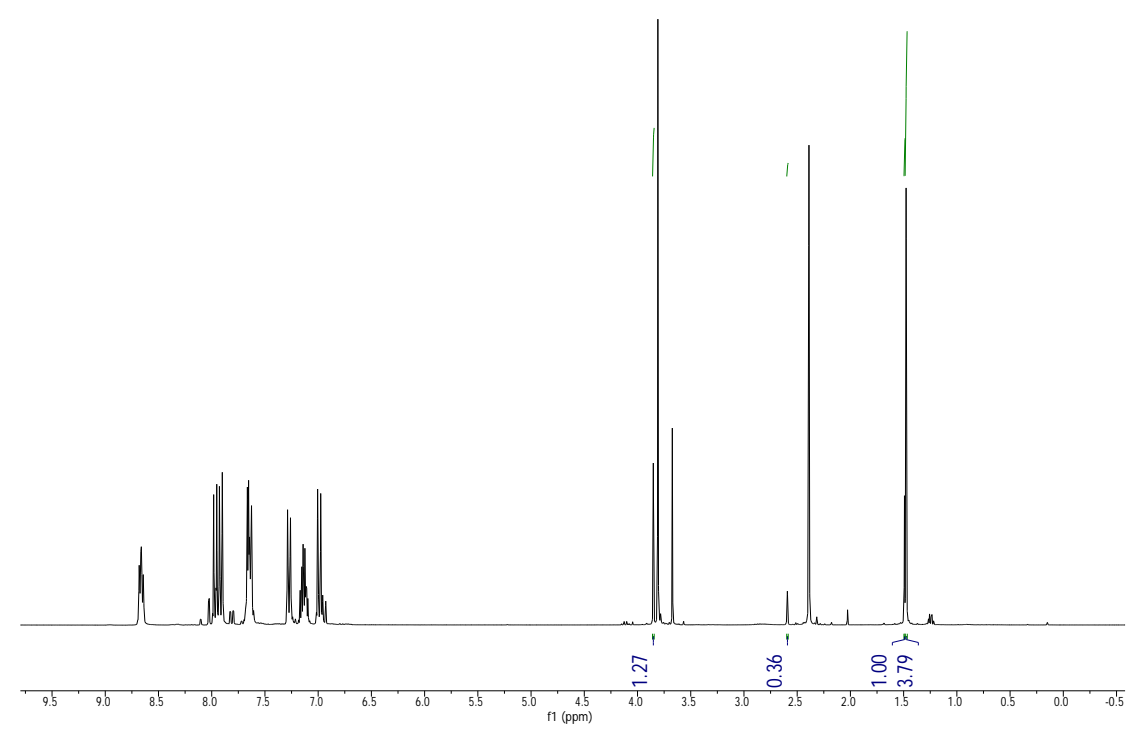

Intermolecular Competition Experiment between Substrates 38b and 38c
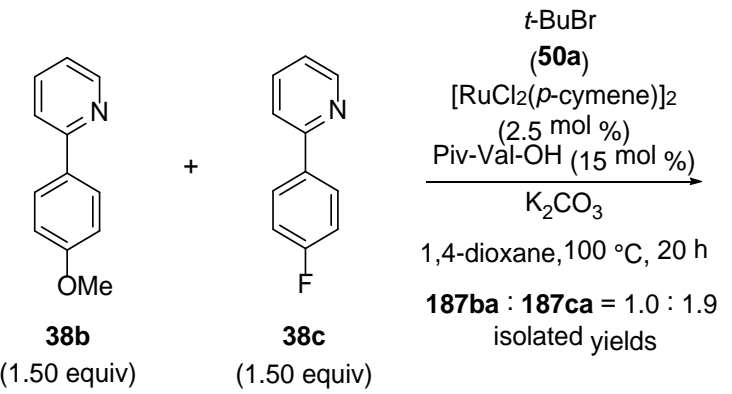

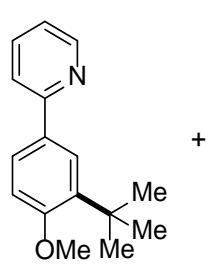

$187 \mathrm{ba}$

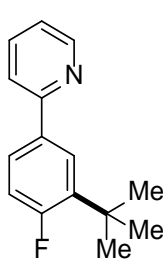

$187 \mathrm{ca}$

A mixture of substrates 38b (278 mg, $1.50 \mathrm{mmol}), 38 \mathrm{c}(260 \mathrm{mg}, 1.50 \mathrm{mmol})$ and bromide $50 \mathrm{a}(137 \mathrm{mg}$, $1.00 \mathrm{mmol}),\left[\mathrm{RuCl}_{2}(p \text {-cymene) }]_{2}(15.3 \mathrm{mg}, 2.5 \mathrm{~mol} \%)\right.$, Piv-Val-OH (30.0 mg, $15 \mathrm{~mol} \%$ ) and $\mathrm{K}_{2} \mathrm{CO}_{3}$ (276 mg, $2.00 \mathrm{mmol})$ in 1,4-dioxane $\left(4.0 \mathrm{~mL}\right.$ ) was stirred at $100{ }^{\circ} \mathrm{C}$ for $20 \mathrm{~h}$ under an atmosphere of $\mathrm{N}_{2}$. At ambient temperature, EtOAc $(15 \mathrm{~mL})$ was added, and the mixture was filtered through a pad of silica gel. The solvents were removed in vacuo, and purification of the residue by column chromatography ( $n$-hexane/EtOAc 100:1 $\rightarrow 80: 1 \rightarrow 20: 1$ ) yielded compound 187ba (34 $\mathrm{mg}, 14 \%$ ) and $187 \mathrm{ca}(60 \mathrm{mg}, 26 \%)$. The ratio of isolated products $187 \mathrm{ba}$ to $187 \mathrm{ca}$ was established to be $1.0: 1.9$. Their spectral data were identical to those reported above.

\section{Intermolecular Competition Experiment between Substrates 38a and 38c}
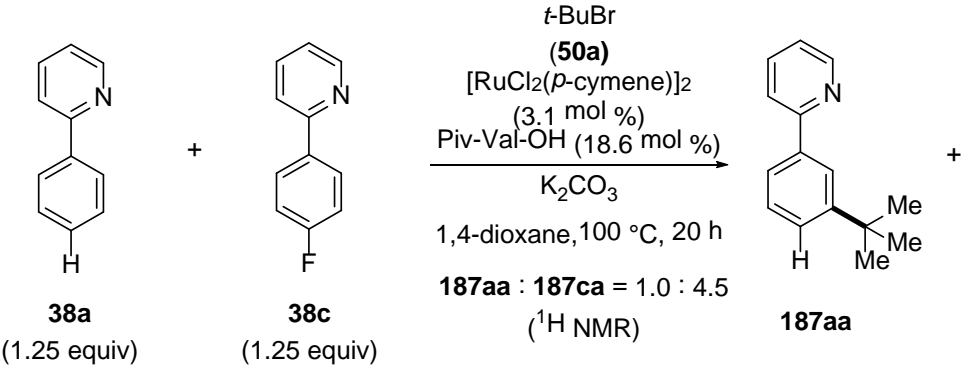

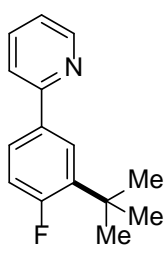

187ca

A mixture of substrates 38a (155 mg, $1.00 \mathrm{mmol}), 38 \mathrm{c}(173 \mathrm{mg}, 1.00 \mathrm{mmol})$ and bromide $50 \mathrm{a}$ (110 mg, $0.80 \mathrm{mmol}),\left[\mathrm{RuCl}_{2}(p \text {-cymene) }]_{2}(15.3 \mathrm{mg}, 2.5 \mathrm{~mol} \%)\right.$, Piv-Val-OH (30.0 mg, $30 \mathrm{~mol} \%$ ) and $\mathrm{K}_{2} \mathrm{CO}_{3}$ (276 mg, $2.00 \mathrm{mmol})$ in 1,4-dioxane $(4.0 \mathrm{~mL})$ was stirred at $100{ }^{\circ} \mathrm{C}$ for $20 \mathrm{~h}$ under an atmosphere of 
$\mathrm{N}_{2}$. At ambient temperature, EtOAc $(15 \mathrm{~mL})$ was added, and the mixture was filtered through a pad of silica gel. The solvents were removed in vacuo, and the residue was purified by column chromatography ( $n$-hexane/EtOAc 20:1). Careful ${ }^{1}$ H NMR analysis disclosed a ratio of $187 \mathrm{aa} / \mathbf{1 8 7}$ ca to be $1.0: 4.5$. Their spectral data were identical to those reported above.

Standard spectra
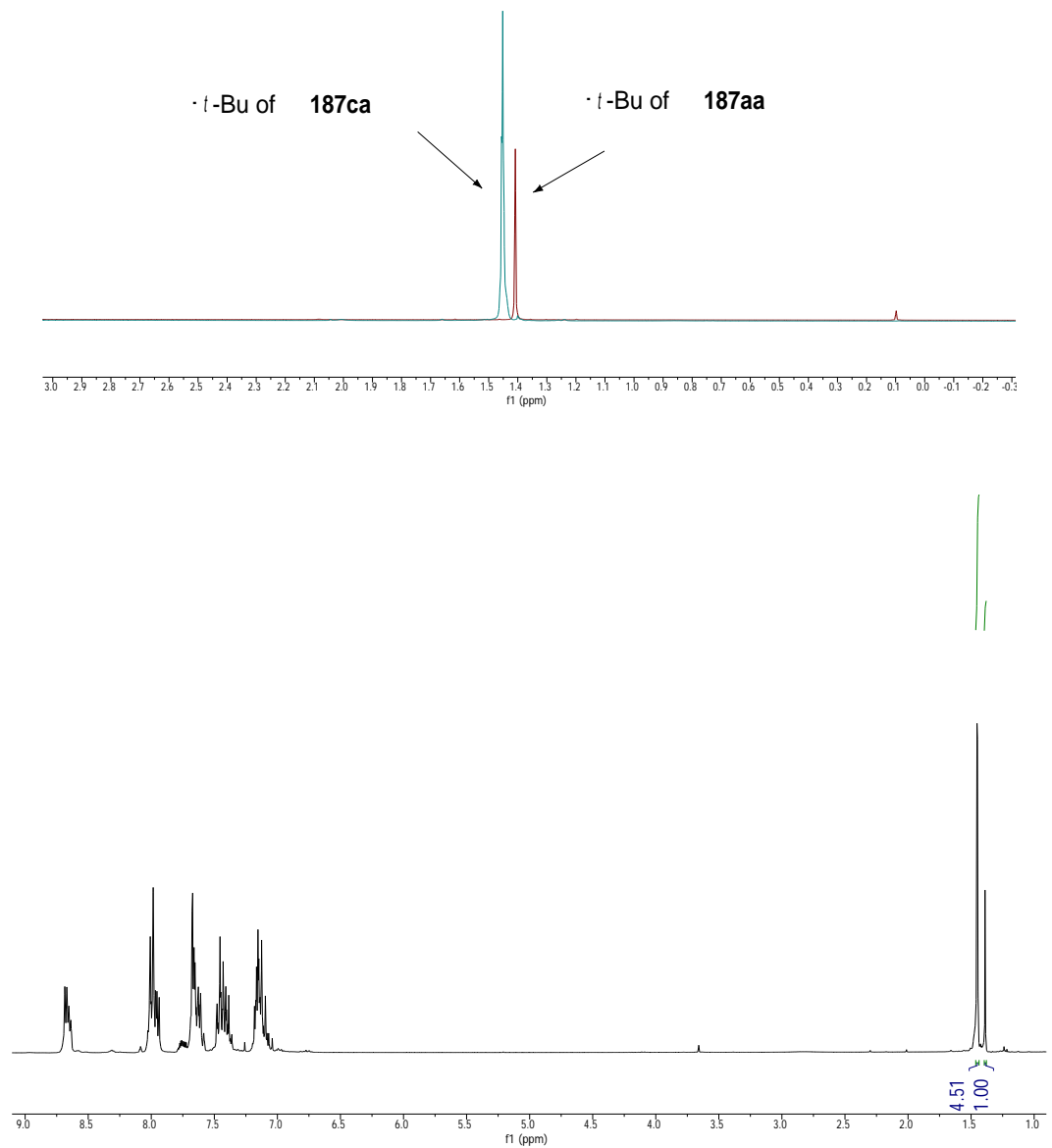

Intermolecular Competition Experiment between Tertiary Alkyl bromide 50b and Primary Alkyl Bromide 42e
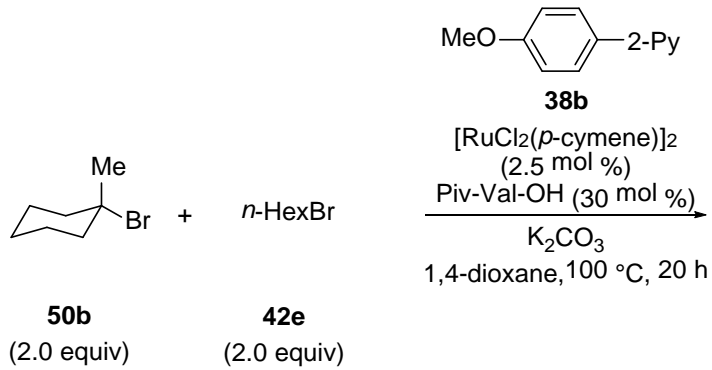

1,4-dioxane, $100{ }^{\circ} \mathrm{C}, 20 \mathrm{~h}$

(2.0 equiv) (2.0 equiv)

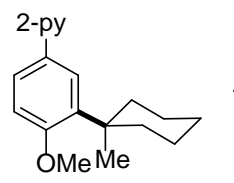

187bb: $41 \%$

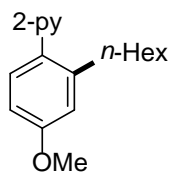

103b: $26 \%$

A mixture of substrate $\mathbf{3 8 b}(93 \mathrm{mg}, 0.50 \mathrm{mmol})$ and bromides $50 \mathrm{~b}(177 \mathrm{mg}, 1.00 \mathrm{mmol}$ ) and $42 \mathrm{e}(165$ $\mathrm{mg}, 1.00 \mathrm{mmol})$, $\left[\mathrm{RuCl}_{2}(p \text {-cymene) }]_{2}(7.7 \mathrm{mg}, 2.5 \mathrm{~mol} \%)\right.$, Piv-Val-OH (30.0 mg, $\left.30 \mathrm{~mol} \%\right)$ and $\mathrm{K}_{2} \mathrm{CO}_{3}$ $(138 \mathrm{mg}, 1.00 \mathrm{mmol})$ in 1,4 -dioxane $(2.0 \mathrm{~mL})$ was stirred at $100{ }^{\circ} \mathrm{C}$ for $20 \mathrm{~h}$ under an atmosphere of 
$\mathrm{N}_{2}$. At ambient temperature, EtOAc $(15 \mathrm{~mL})$ was added, and the mixture was filtered through a pad of silica gel. The solvents were removed in vacuo, and purification of the residue by column chromatography ( $n$-hexane/EtOAc 20:1) yielded compound 187bb (58 mg, 41\%) and 103b (35 mg, $26 \%)$ as colorless oils. The spectral data of $\mathbf{1 8 7 b b}$ was identical to those reported above.

Analytical Data for 2-(2-n-Hexyl-4-methoxyphenyl)pyridine (103b)<smiles>COc1ccc(-c2ccccn2)c(OC)c1</smiles>

${ }^{1} \mathrm{H}$ NMR $\left(300 \mathrm{MHz}, \mathrm{CDCl}_{3}\right): \delta=8.61(\mathrm{ddd}, J=4.9,1.8,0.9 \mathrm{~Hz}, 1 \mathrm{H}), 7.65(\mathrm{dt}, J=7.7$, $1.9 \mathrm{~Hz}, 1 \mathrm{H}$ ), 7.29 (dd, $J=7.9,1.0 \mathrm{~Hz}, 1 \mathrm{H}), 7.24$ (d, $J=8.3 \mathrm{~Hz}, 1 \mathrm{H}$ ), 7.15 (ddd, $J=7.6$, 4.9, $1.2 \mathrm{~Hz}, 1 \mathrm{H}), 6.80-6.72(\mathrm{~m}, 2 \mathrm{H}), 3.78(\mathrm{~s}, 3 \mathrm{H}), 2.64(\mathrm{dd}, J=8.0,7.8 \mathrm{~Hz}, 2 \mathrm{H})$, $1.45-1.33(\mathrm{~m}, 2 \mathrm{H}), 1.21-1.05(\mathrm{~m}, 6 \mathrm{H}), 0.76(\mathrm{t}, J=6.7 \mathrm{~Hz}, 3 \mathrm{H})$.

${ }^{13} \mathrm{C}$ NMR $\left(75 \mathrm{MHz}, \mathrm{CDCl}_{3}\right): \delta=160.1\left(\mathrm{C}_{\mathrm{q}}\right), 159.5\left(\mathrm{C}_{\mathrm{q}}\right), 149.0(\mathrm{CH}), 142.4\left(\mathrm{C}_{\mathrm{q}}\right), 135.9$ $(\mathrm{CH}), 133.2\left(\mathrm{C}_{\mathrm{q}}\right), 131.0(\mathrm{CH}), 124.1(\mathrm{CH}), 121.2(\mathrm{CH}), 115.2(\mathrm{CH}), 110.9(\mathrm{CH}), 55.2$ $\left(\mathrm{CH}_{3}\right), 33.1\left(\mathrm{CH}_{2}\right), 31.5\left(\mathrm{CH}_{2}\right), 31.1\left(\mathrm{CH}_{2}\right), 29.1\left(\mathrm{CH}_{2}\right), 22.4\left(\mathrm{CH}_{2}\right), 14.0\left(\mathrm{CH}_{3}\right)$.

IR (neat): $\tilde{v}=2927,2855,1607,1587,1505,1465,1427,1280,1236,1162,1045,787,749 \mathrm{~cm}^{-1}$. MS (EI) $m / z$ (relative intensity) 269 (33) [M] $]^{+}, 226$ (9), 212 (100), 197 (18), 154 (10).

HR-MS (ESI) $\mathrm{m} / \mathrm{z}$ calcd for $\mathrm{C}_{18} \mathrm{H}_{24} \mathrm{NO}^{+}[\mathrm{M}+\mathrm{H}]^{+} 270.1852$, found 270.1852 .

The spectral data were in accordance with those reported in the literature. ${ }^{140}$

Intermolecular Competition Experiment between Tertiary Alkyl Bromide 50f and Secondary Alkyl Bromide 44d

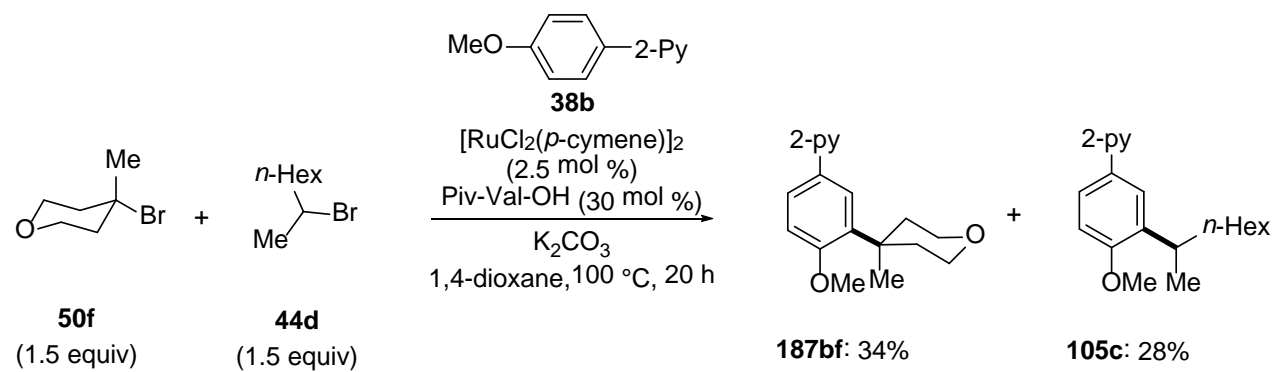

A mixture of substrate $38 \mathrm{~b}(93 \mathrm{mg}, 0.50 \mathrm{mmol}$ ), bromides $50 \mathrm{f}$ (134 mg, $0.75 \mathrm{mmol}$ ) and $44 \mathrm{~d}$ (145 mg, $0.75 \mathrm{mmol}),\left[\mathrm{RuCl}_{2} \text { (p-cymene) }\right]_{2}(7.7 \mathrm{mg}, 2.5 \mathrm{~mol} \%)$, Piv-Val-OH $(30.0 \mathrm{mg}, 30 \mathrm{~mol} \%)$ and $\mathrm{K}_{2} \mathrm{CO}_{3}(138$ $\mathrm{mg}, 1.00 \mathrm{mmol})$ in 1 ,4-dioxane $(2.0 \mathrm{~mL})$ was stirred at $100{ }^{\circ} \mathrm{C}$ for $20 \mathrm{~h}$ under an atmosphere of $\mathrm{N}_{2}$. At ambient temperature, EtOAc $(15 \mathrm{~mL})$ was added, and the mixture was filtered through a pad of silica gel. The solvents were removed in vacuo, and purification of the residue by column chromatography ( $n$-hexane/EtOAc 40:1 $\rightarrow 20: 1$ ) yielded compound $187 \mathrm{bf}(48 \mathrm{mg}, 34 \%)$ and $105 \mathrm{c}(42 \mathrm{mg}, 28 \%$ ) as colorless oils. The spectral data of $\mathbf{1 8 7 b f}$ was identical to those reported above.

\section{Analytical Data for 2-[4-Methoxy-3-(octan-2-yl)phenyl]pyridine (105c)}

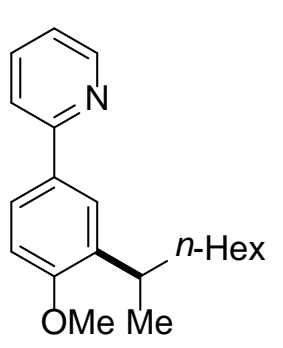

${ }^{1} \mathrm{H}$ NMR $\left(300 \mathrm{MHz}, \mathrm{CDCl}_{3}\right): \delta=8.66$ (ddd, $\left.J=4.4,1.4,1.0 \mathrm{~Hz}, 1 \mathrm{H}\right), 7.84(\mathrm{~d}, J=2.0$ $\mathrm{Hz}, 1 \mathrm{H}), 7.80(\mathrm{dt}, J=8.5,1.8 \mathrm{~Hz}, 1 \mathrm{H}), 7.75-7.63(\mathrm{~m}, 2 \mathrm{H}), 7.19-7.11(\mathrm{~m}, 1 \mathrm{H}), 6.94$ $(\mathrm{dd}, J=8.4,1.2 \mathrm{~Hz}, 1 \mathrm{H}), 3.87(\mathrm{~s}, 3 \mathrm{H}), 3.23(\mathrm{qt}, J=7.1,6.9 \mathrm{~Hz}, 1 \mathrm{H}), 1.79-1.50(\mathrm{~m}$, $2 \mathrm{H}), 1.34-1.16(\mathrm{~m}, 11 \mathrm{H}), 0.86(\mathrm{t}, J=6.4 \mathrm{~Hz}, 3 \mathrm{H})$.

${ }^{13} \mathrm{C}$ NMR $\left(75 \mathrm{MHz}, \mathrm{CDCl}_{3}\right): \delta=158.0\left(\mathrm{C}_{\mathrm{q}}\right), 157.6\left(\mathrm{C}_{\mathrm{q}}\right), 149.4(\mathrm{CH}), 136.5\left(\mathrm{C}_{\mathrm{q}}\right)$, $136.5(\mathrm{CH}), 131.7(\mathrm{CH}), 125.5\left(\mathrm{C}_{\mathrm{q}}\right), 125.2(\mathrm{CH}), 121.1(\mathrm{CH}), 119.9(\mathrm{CH}), 110.5(\mathrm{CH})$, $55.5\left(\mathrm{CH}_{3}\right), 37.1\left(\mathrm{CH}_{2}\right), 32.1(\mathrm{CH}), 31.8\left(\mathrm{CH}_{2}\right), 29.4\left(\mathrm{CH}_{2}\right), 27.7\left(\mathrm{CH}_{2}\right), 22.6\left(\mathrm{CH}_{2}\right)$,

$20.9\left(\mathrm{CH}_{3}\right), 14.1\left(\mathrm{CH}_{3}\right)$.

IR (neat): $\tilde{v}=2956,2927,2856,1606,1563,1502,1464,1431,1271,1245,781 \mathrm{~cm}^{-1}$. 
MS (EI) $m / z$ (relative intensity) 297 (27) [M] $]^{+}, 212$ (100), 197 (15), 167 (30).

HR-MS (El) m/z calculated for $\mathrm{C}_{20} \mathrm{H}_{27} \mathrm{NO}^{+}[\mathrm{M}]^{+}$297.2087; found 297.2094.

The spectral data were in accordance with those reported in the literature. ${ }^{143}$

Experiment with Deuterium-Labeled 2-Phenylpyridine $\left[D_{5}\right]-38$<smiles>[2H]c1c([2H])c([2H])c(-c2ccccn2)c([2H])c1[2H]</smiles>

$\left[D_{5}\right]^{-38 a}$

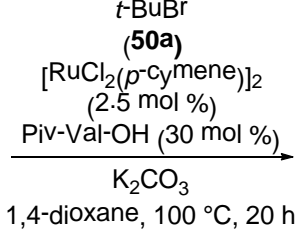

1,4-dioxane, $100^{\circ} \mathrm{C}, 20 \mathrm{~h}$

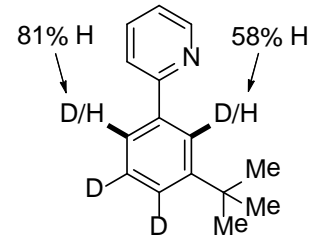

$\left[D_{n}\right]^{-187 a a: ~} 53 \%$

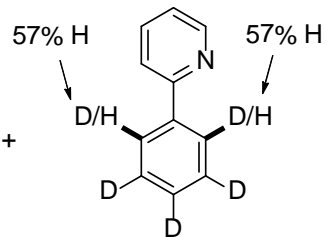

$\left[D_{n}\right]^{-38 a: ~} 19 \%$

The general procedure $\mathbf{A}$ was followed using substrate $\left[\mathrm{D}_{5}\right]-38 \mathrm{a}(80 \mathrm{mg}, 0.50 \mathrm{mmol})$ and bromide $50 \mathrm{a}$ (206 $\mathrm{mg}, 1.50 \mathrm{mmol}$ ). After $20 \mathrm{~h}$, purification by column chromatography ( $n$-hexane/EtOAc 80:1) yielded $\left[D_{n}\right]-187 a a(57 \mathrm{mg}, 53 \%)$ and reisolated $\left[D_{n}\right]-38 a(15 \mathrm{mg}, 19 \%)$ as colorless oils.

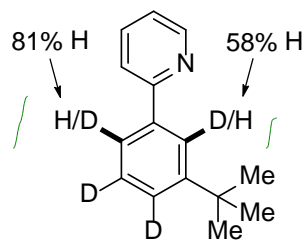
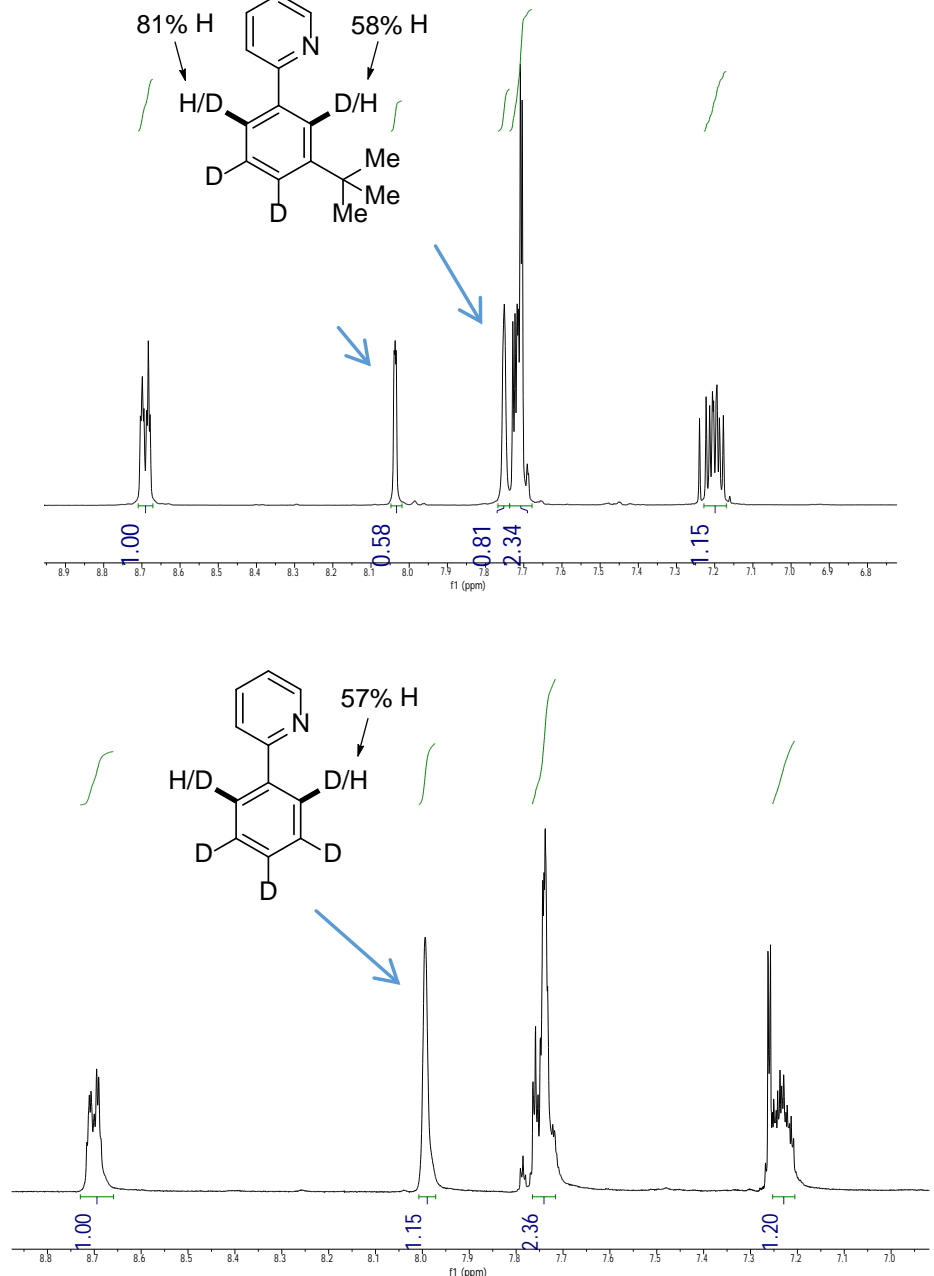

Experiment with Substrate $38 \mathrm{~b}$ in the Presence of $D_{2} O$ 
<smiles>COc1ccc(-c2ccccn2)cc1</smiles>

$38 b$

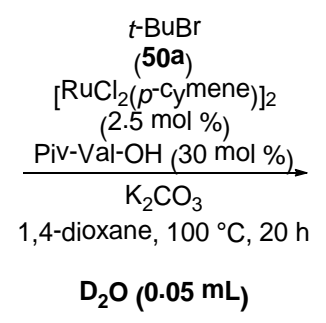

$\mathrm{D}_{2} \mathrm{O}(0.05 \mathrm{~mL})$

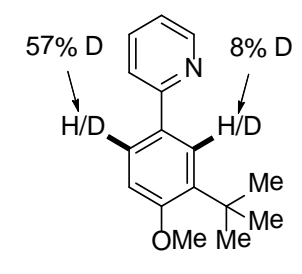

$\left[D_{n}\right]-187 b a: 4 \%$

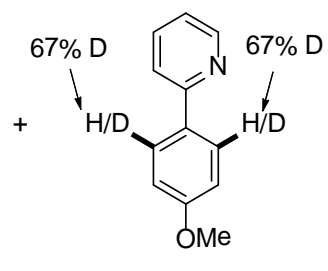

$\left[D_{n}\right]^{-38 b: ~} 82 \%$

The general procedure $\mathbf{A}$ was followed using substrate $\mathbf{3 8 b}(93 \mathrm{mg}, 0.50 \mathrm{mmol}$ ) and bromide 50a (206 $\mathrm{mg}, 1.50 \mathrm{mmol})$ in the presence of $\mathrm{D}_{2} \mathrm{O}(0.05 \mathrm{~mL})$. After $20 \mathrm{~h}$, purification by column chromatography ( $n$-hexane/EtOAc 20:1) yielded $\left[D_{n}\right]-187 b a(5 \mathrm{mg}, 4 \%)$ and reisolated $\left[D_{n}\right]-38 b(76 \mathrm{mg}, 82 \%)$ as colorless oils.
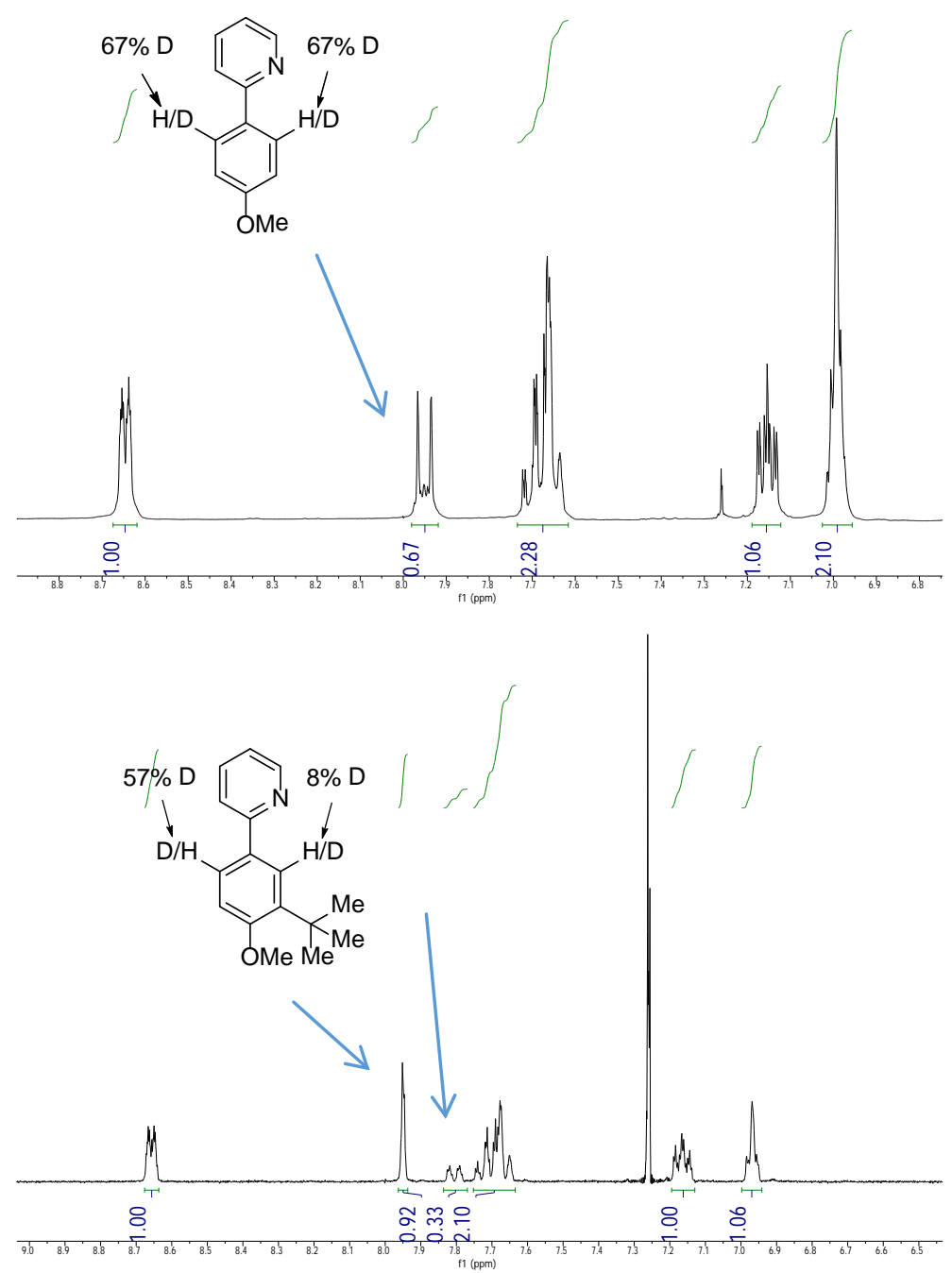

\section{Experiment with Deuterium-Labeled Phenylpyridine $\left[D_{3}\right]-38 a$}


<smiles>[2H]c1cc(-c2ccccn2)cc([2H])c1[2H]</smiles>

$\left[\mathrm{D}_{3}\right]^{-38 a}$

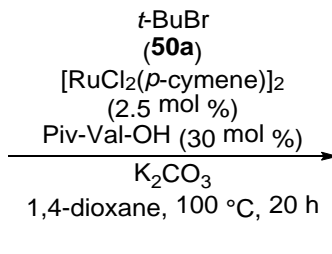

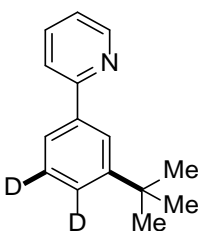

[D2]-187aa: $46 \%$<smiles>[2H]c1cc(-c2ccccn2)cc([2H])c1[2H]</smiles>

[D3]-38a: $32 \%$

The general procedure $\mathbf{A}$ was followed using substrate $\left[\mathrm{D}_{3}\right]-\mathbf{3 8 a}(75 \mathrm{mg}, 0.47 \mathrm{mmol})$ and bromide $50 \mathrm{a}$ (206 mg, $1.50 \mathrm{mmol}$ ). After $20 \mathrm{~h}$, purification by column chromatography ( $n$-hexane/EtOAc 80:1) yielded $\left[D_{2}\right]-187 a a(46 \mathrm{mg}, 46 \%)$ and reisolated $\left[D_{3}\right]-38 a(24 \mathrm{mg}, 32 \%)$ as colorless oils.

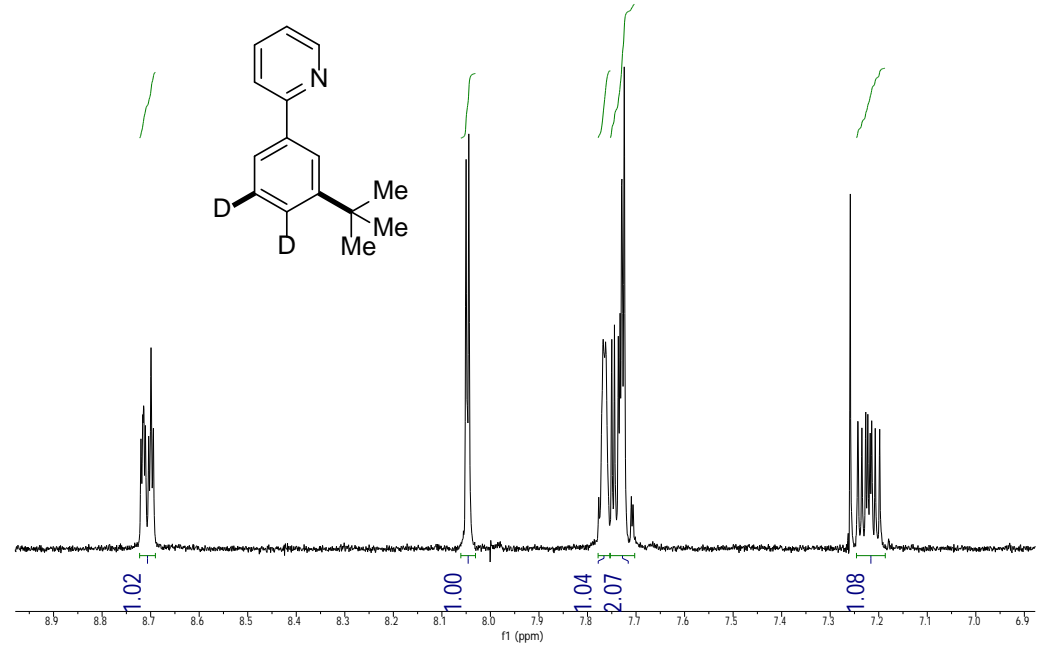

Intermolecular Competition Experiment between Substrates $\left[D_{3}\right]-38 a$ and $38 a$<smiles>c1ccc(-c2ccccn2)cc1</smiles>

$38 a$<smiles>[2H]c1cc(-c2ccccn2)cc([2H])c1[2H]</smiles>

$\left[D_{3}\right]^{-38 a}$

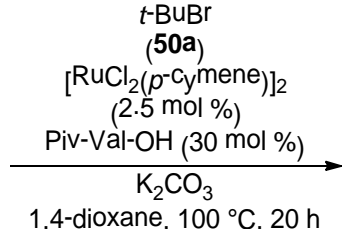

$\left[\mathrm{D}_{0}\right]^{-187 a a}:\left[\mathrm{D}_{2}\right]^{-187 a a}=1.44$ average of 2 runs

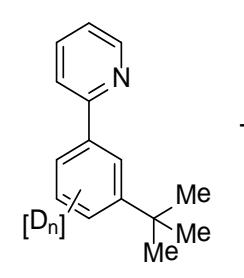

$\left[D_{n}\right]^{-187 a a: ~} 12 \%$<smiles>c1ccc(-c2cccnc2)nc1</smiles>

$\left[D_{n}\right]^{-38 a: 38 \%}$

A mixture of substrates $38 \mathrm{a}(82 \mathrm{mg}, 0.53 \mathrm{mmol}),\left[\mathrm{D}_{3}\right]-38 \mathrm{a}(84 \mathrm{mg}, 0.53 \mathrm{mmol}$ ) and bromide $50 \mathrm{a}$ (137 $\mathrm{mg}, 1.0 \mathrm{mmol}),\left[\mathrm{RuCl}_{2}(p \text {-cymene) }]_{2}(15.3 \mathrm{mg}, 2.5 \mathrm{~mol} \%)\right.$, Piv-Val-OH (60.0 mg, $\left.30 \mathrm{~mol} \%\right)$ and $\mathrm{K}_{2} \mathrm{CO}_{3}$ (276 mg, $2.00 \mathrm{mmol})$ in 1,4-dioxane $(4.0 \mathrm{~mL})$ was stirred at $100{ }^{\circ} \mathrm{C}$ for $20 \mathrm{~h}$ under an atmosphere of $\mathrm{N}_{2}$. At ambient temperature, EtOAc $(15 \mathrm{~mL})$ was added, and the mixture was filtered through a pad of silica gel. The solvents were removed in vacuo, and purification of the residue by column chromatography ( $n$-hexane/EtOAc 40:1 $\rightarrow 20: 1$ ) yielded compound $\left[\mathrm{D}_{\mathrm{n}}\right]$-187aa $(27 \mathrm{mg}, 12 \%$ ) and the reisolated $\left[D_{n}\right]-38 a(63 \mathrm{mg}, 38 \%)$ as colorless oils. The ratio of $\mathrm{H} / \mathrm{D}$ was determined by ${ }^{1} \mathrm{H}$ NMR basing for 2 individual runs. KIE value was estimated to be 1.44 . 


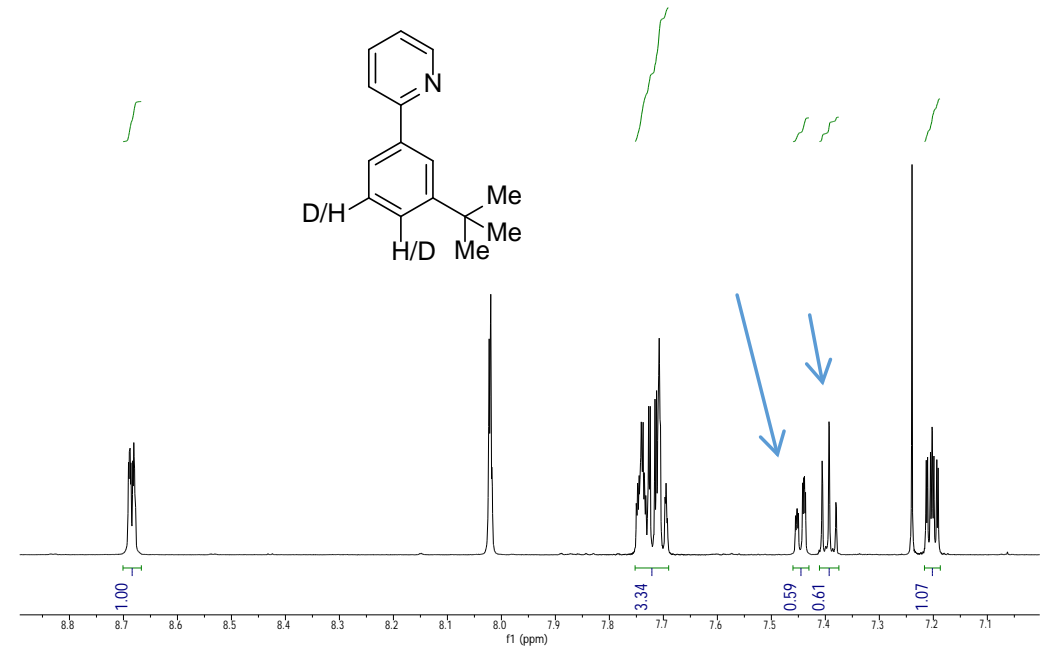

7.3.2 Analytical Data for the Products of the Ruthenium(II)-Catalyzed Direct meta-Selective Alkylation of Ketimines with Tertiary Alkyl Bromides

\section{Synthesis of 1-[4-Fluoro-3-(1-methylcyclohexyl)phenyl]ethan-1-one (189ab)}

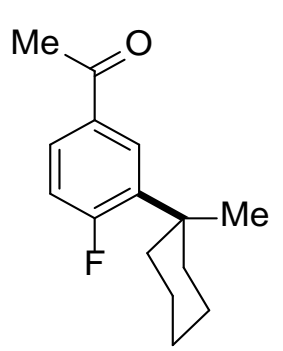

The general procedure $C$ was followed using substrate $188 \mathrm{a}(152 \mathrm{mg}, 0.50 \mathrm{mmol}$ ) and bromide $50 \mathrm{~b}(266 \mathrm{mg}, 1.50 \mathrm{mmol})$. After $20 \mathrm{~h}$, purification by column chromatography ( $n$-hexane/EtOAc 100:1) yielded 189ab (68 mg, 58\%) as a colorless oil.

${ }^{1} \mathrm{H}$ NMR $\left(300 \mathrm{MHz}, \mathrm{CDCl}_{3}\right): \delta=7.97(\mathrm{dd}, J=8.1,2.3 \mathrm{~Hz}, 1 \mathrm{H}), 7.77$ (ddd, $J=8.4$, 4.5, $2.3 \mathrm{~Hz}, 1 \mathrm{H}), 7.03(\mathrm{dd}, J=12.4,8.4 \mathrm{~Hz}, 1 \mathrm{H}), 2.57(\mathrm{~s}, 3 \mathrm{H}), 2.11-1.99(\mathrm{~m}, 2 \mathrm{H})$, $1.72-1.52(\mathrm{~m}, 5 \mathrm{H}), 1.48-1.37(\mathrm{~m}, 3 \mathrm{H}), 1.28(\mathrm{~d}, J=1.1 \mathrm{~Hz}, 3 \mathrm{H})$.

${ }^{13} \mathrm{C}$ NMR $\left(75 \mathrm{MHz}, \mathrm{CDCl}_{3}\right): \delta=197.0\left(\mathrm{C}_{\mathrm{q}}\right), 165.2\left(\mathrm{~d},{ }^{1} \mathrm{~J}_{\mathrm{C}-\mathrm{F}}=257 \mathrm{~Hz}, \mathrm{C}_{\mathrm{q}}\right), 136.9\left(\mathrm{~d},{ }^{2} J_{\mathrm{C}-\mathrm{F}}=12 \mathrm{~Hz}, \mathrm{C}_{\mathrm{q}}\right), 133.2$ $\left(d,{ }^{4} J_{C-F}=3 \mathrm{~Hz}, C_{q}\right), 129.1\left(d,{ }^{3} J_{C-F}=8 \mathrm{~Hz}, C H\right), 128.3\left(d,{ }^{3} J_{C-F}=11 \mathrm{~Hz}, \mathrm{CH}\right), 116.8\left(d,{ }^{2} J_{C-F}=26 \mathrm{~Hz}, \mathrm{CH}\right)$, $38.0\left(\mathrm{~d},{ }^{3} \mathrm{~J}_{\mathrm{C}-\mathrm{F}}=3 \mathrm{~Hz}, \mathrm{C} \mathrm{q}\right), 37.0\left(\mathrm{~d},{ }^{4} J_{\mathrm{C}-\mathrm{F}}=4 \mathrm{~Hz}, \mathrm{CH}_{2}\right), 26.5\left(\mathrm{CH}_{3}\right), 26.5\left(\mathrm{CH}_{3}\right), 26.3\left(\mathrm{CH}_{2}\right), 22.6\left(\mathrm{CH}_{2}\right)$.

${ }^{19} \mathrm{~F} \mathrm{NMR}\left(282 \mathrm{MHz}, \mathrm{CDCl}_{3}\right): \delta=-101.6(\mathrm{~s})$.

IR (neat): $\tilde{v}=2953,2870,1687,1590,1340,1280,1067,830 \mathrm{~cm}^{-1}$.

MS (EI) $m / z$ (relative intensity) 234 (24) [M] $]^{+}, 219$ (60), 178 (35), 163 (62).

HR-MS (EI): $m / z$ calcd for $\mathrm{C}_{15} \mathrm{H}_{19} \mathrm{FO}^{+}[\mathrm{M}]^{+} 234.1414$, found 234.1420 .

\section{Synthesis of 1-[3-(tert-Butyl)-4-fluorophenyl]ethan-1-one (189aa)}

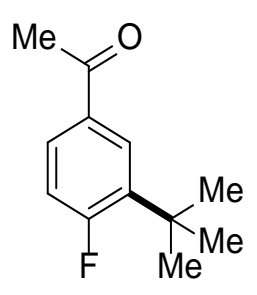

The general procedure $C$ was followed using substrate $188 \mathrm{a}(152 \mathrm{mg}, 0.50 \mathrm{mmol})$ and bromide 50a (206 mg, $1.50 \mathrm{mmol})$. After $20 \mathrm{~h}$, purification by column chromatography ( $n$-hexane/EtOAc 100:1) yielded 189aa (57 mg, 59\%) as a colorless oil.

${ }^{1} \mathrm{H} \mathrm{NMR}\left(300 \mathrm{MHz}, \mathrm{CDCl}_{3}\right): \delta=7.94$ (dd, $J=8.1,2.3 \mathrm{~Hz}, 1 \mathrm{H}$ ), 7.77 (ddd, $J=8.4,4.6$, $2.3 \mathrm{~Hz}, 1 \mathrm{H}), 7.03(\mathrm{dd}, J=12.0,8.4 \mathrm{~Hz}, 1 \mathrm{H}), 2.56(\mathrm{~s}, 3 \mathrm{H}), 1.38(\mathrm{~d}, J=1.1 \mathrm{~Hz}, 9 \mathrm{H})$.

${ }^{13} \mathrm{C}$ NMR $\left(75 \mathrm{MHz}, \mathrm{CDCl}_{3}\right): \delta=197.0\left(\mathrm{C}_{\mathrm{q}}\right), 165.1\left(\mathrm{~d},{ }^{1} \mathrm{~J}_{\mathrm{C}-\mathrm{F}}=257 \mathrm{~Hz}, \mathrm{C}_{\mathrm{q}}\right), 137.5\left(\mathrm{~d},{ }^{2} J_{\mathrm{C}-\mathrm{F}}=12 \mathrm{~Hz}, \mathrm{C}_{\mathrm{q}}\right), 133.1$ $\left(d,{ }^{4} J_{C-F}=3 \mathrm{~Hz}, C_{q}\right), 128.6\left(d,{ }^{3} J_{C-F}=11 \mathrm{~Hz}, C H\right), 127.9\left(d,{ }^{3} J_{C-F}=7 \mathrm{~Hz}, C H\right), 116.4\left(d,{ }^{2} J_{C-F}=25 \mathrm{~Hz}, \mathrm{CH}\right)$, $34.4\left(\mathrm{~d},{ }^{3} \mathrm{~J}_{\mathrm{C}-\mathrm{F}}=3 \mathrm{~Hz}, \mathrm{C} \mathrm{q}_{\mathrm{q}}\right), 29.7\left(\mathrm{~d},{ }^{4} \mathrm{~J}_{\mathrm{C}-\mathrm{F}}=4 \mathrm{~Hz}, \mathrm{CH}_{3}\right), 26.5\left(\mathrm{CH}_{3}\right)$. 
${ }^{19} \mathrm{~F}$ NMR $\left(282 \mathrm{MHz}, \mathrm{CDCl}_{3}\right): \delta=-101.6(\mathrm{~s})$.

IR (neat): $\tilde{v}=2961,2873,1683,1606,1490,1355,1235,1094,817 \mathrm{~cm}^{-1}$.

MS (EI) $m / z$ (relative intensity) 194 (18) [M] ${ }^{+}, 179$ (100), 151 (58), 136 (10).

HR-MS (EI): $m / z$ calcd for $\mathrm{C}_{12} \mathrm{H}_{15} \mathrm{FO}^{+}[\mathrm{M}]^{+} 194.1101$, found 194.1106.

\section{Synthesis of 1-[4-Fluoro-3-(tert-pentyl)phenyl]ethan-1-one (189ad)}

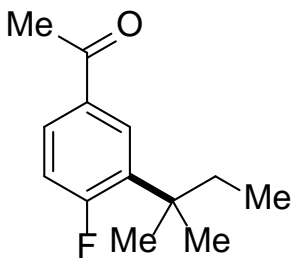

The general procedure $\mathrm{C}$ was followed using substrate $188 \mathrm{a}(152 \mathrm{mg}, 0.50$ $\mathrm{mmol}$ ) and bromide 50d (227 $\mathrm{mg}, 1.50 \mathrm{mmol})$. After $20 \mathrm{~h}$, purification by column chromatography ( $n$-hexane/EtOAc 100:1) yielded 189ad (59 mg, 57\%) as a colorless oil.

${ }^{1} \mathrm{H}$ NMR $\left(300 \mathrm{MHz}, \mathrm{CDCl}_{3}\right): \delta=7.89(\mathrm{dd}, J=8.1,2.3 \mathrm{~Hz}, 1 \mathrm{H}), 7.78$ (ddd, $J=8.4$, 4.5, $2.3 \mathrm{~Hz}, 1 \mathrm{H}$ ), 7.02 (dd, $J=12.1,8.4 \mathrm{~Hz}, 1 \mathrm{H}$ ), $2.56(\mathrm{~s}, 3 \mathrm{H}), 1.77$ (qd, $J=7.5,1.5 \mathrm{~Hz}, 2 \mathrm{H}$ ), 1.35 (d, $J=$ $1.1 \mathrm{~Hz}, 6 \mathrm{H}), 0.65(\mathrm{t}, J=7.5 \mathrm{~Hz}, 3 \mathrm{H})$.

${ }^{13} \mathrm{C} \mathrm{NMR}\left(75 \mathrm{MHz}, \mathrm{CDCl}_{3}\right): \delta=197.0\left(\mathrm{C}_{\mathrm{q}}\right), 165.0\left(\mathrm{~d},{ }^{1} \mathrm{~J}_{\mathrm{C}-\mathrm{F}}=257 \mathrm{~Hz}, \mathrm{C}_{\mathrm{q}}\right), 136.0\left(\mathrm{~d},{ }^{2} \mathrm{~J}_{\mathrm{CF}}=12 \mathrm{~Hz}, \mathrm{C}_{\mathrm{q}}\right), 133.0$ $\left(d,{ }^{4} J_{C-F}=3 \mathrm{~Hz}, C_{q}\right), 129.1\left(d,{ }^{3} J_{C-F}=8 \mathrm{~Hz}, \mathrm{CH}\right), 128.6\left(d,{ }^{3} J_{C-F}=11 \mathrm{~Hz}, \mathrm{CH}\right), 116.4\left(\mathrm{~d},{ }^{2} J_{\mathrm{C}-\mathrm{F}}=26 \mathrm{~Hz}, \mathrm{CH}\right)$, $\left.38.1\left(d^{3}\right)_{C-F}=3 \mathrm{~Hz}, C_{q}\right), 34.0\left(d,{ }^{4} J_{C-F}=4 \mathrm{~Hz}, C_{2}\right), 27.6\left(d,{ }^{4} J_{C-F}=3 \mathrm{~Hz}, C_{3}\right), 26.5\left(\mathrm{CH}_{3}\right), 9.3\left(\mathrm{CH}_{3}\right)$.

${ }^{19}$ F-NMR $\left(282 \mathrm{MHz}, \mathrm{CDCl}_{3}\right): \delta=-101.6(\mathrm{~s})$.

IR (neat): $\tilde{v}=2965,2877,1683,1604,1491,1355,1252,1094,822 \mathrm{~cm}^{-1}$.

MS (EI) m/z (relative intensity) 208 (7) [M] ${ }^{+}, 179$ (100), 151 (65), 136 (10).

HR-MS (EI): $m / z$ calcd for $\mathrm{C}_{13} \mathrm{H}_{17} \mathrm{FO}^{+}[\mathrm{M}]^{+}$208.1258, found 208.1266 .

\section{Synthesis of 1-[4-Fluoro-3-(2-methylpentan-2-yl)phenyl]ethan-1-one (189ac)}<smiles>CCCC(C)(C)c1cc(C(C)=O)ccc1F</smiles>

The general procedure $C$ was followed using substrate $188 \mathrm{a}(152 \mathrm{mg}, 0.50$ $\mathrm{mmol}$ ) and bromide 50c (248 mg, $1.50 \mathrm{mmol})$. After $20 \mathrm{~h}$, purification by column chromatography ( $n$-pentane/ether 40:1) yielded 189ac (55 mg, 49\%) as a colorless oil.

${ }^{1} \mathrm{H}$ NMR $\left(300 \mathrm{MHz}, \mathrm{CDCl}_{3}\right.$ ): $\delta=7.90(\mathrm{dd}, J=8.1,2.3 \mathrm{~Hz}, 1 \mathrm{H}$ ), 7.79 (ddd, $J=$ 8.4, 4.5, 2.3 Hz, 1H), $7.03(\mathrm{dd}, J=12.1,8.4 \mathrm{~Hz}, 1 \mathrm{H}), 2.57(\mathrm{~s}, 3 \mathrm{H}), 1.75-1.67(\mathrm{~m}, 2 \mathrm{H}), 1.37(\mathrm{~d}, J=1.1 \mathrm{~Hz}$, $6 \mathrm{H}), 1.08-0.96(\mathrm{~m}, 2 \mathrm{H}), 0.82(\mathrm{t}, J=6.9 \mathrm{~Hz}, 3 \mathrm{H})$.

${ }^{13} \mathrm{C} \mathrm{NMR}\left(75 \mathrm{MHz}, \mathrm{CDCl}_{3}\right): \delta=197.0\left(\mathrm{C}_{\mathrm{q}}\right), 164.9\left(\mathrm{~d},{ }^{1} J_{\mathrm{C}-\mathrm{F}}=257 \mathrm{~Hz}, \mathrm{C}_{\mathrm{q}}\right), 136.3\left(\mathrm{~d},{ }^{2} J_{\mathrm{C}-\mathrm{F}}=12 \mathrm{~Hz}, \mathrm{C}_{\mathrm{q}}\right), 133.0$ $\left(\mathrm{d},{ }^{4} J_{\mathrm{C}-\mathrm{F}}=3 \mathrm{~Hz}, \mathrm{C}_{\mathrm{q}}\right), 128.9\left(\mathrm{~d},{ }^{3} \mathrm{~J}_{\mathrm{C}-\mathrm{F}}=8 \mathrm{~Hz}, \mathrm{CH}\right), 128.5\left(\mathrm{~d},{ }^{3} J_{\mathrm{C}-\mathrm{F}}=11 \mathrm{~Hz}, \mathrm{CH}\right), 116.3\left(\mathrm{~d},{ }^{2} J_{\mathrm{C}-\mathrm{F}}=26 \mathrm{~Hz}, \mathrm{CH}\right)$, $44.0\left(\mathrm{~d},{ }^{3} \mathrm{~J}_{\mathrm{C}-\mathrm{F}}=4 \mathrm{~Hz}, \mathrm{C}_{\mathrm{q}}\right), 37.9\left(\mathrm{~d},{ }^{4} J_{\mathrm{C}-\mathrm{F}}=3 \mathrm{~Hz}, \mathrm{CH}_{2}\right), 28.0\left(\mathrm{~d},{ }^{4} \mathrm{~J}_{\mathrm{C}-\mathrm{F}}=3 \mathrm{~Hz}, \mathrm{CH}_{3}\right), 26.5\left(\mathrm{CH}_{3}\right), 18.3\left(\mathrm{CH}_{2}\right)$, $14.6\left(\mathrm{CH}_{3}\right)$.

${ }^{19}$ F NMR $\left(282 \mathrm{MHz}, \mathrm{CDCl}_{3}\right):-101.6(\mathrm{~s})$.

IR (neat): $\tilde{v}=2958,2931,1683,1583,1490,1355,1247,1097,958 \mathrm{~cm}^{-1}$.

MS (EI) $m / z$ (relative intensity) $222(5)\left[\mathrm{M}^{+}, 179\right.$ (100), 151 (56), 115 (6).

HR-MS (ESI): $m / z$ calcd for $\mathrm{C}_{14} \mathrm{H}_{20} \mathrm{FO}^{+}[\mathrm{M}+\mathrm{H}]^{+} 223.1493$, found 223.1493 .

\section{Synthesis of 1-[3-(5-Chloro-2-methylpentan-2-yl)-4-fluorophenyl]ethan-1-one (189ah)}<smiles>CC(=O)c1ccc(F)c(C(C)(C)CCCCl)c1</smiles>

The general procedure $\mathbf{C}$ was followed using substrate $188 \mathrm{a}$ (152 mg, 0.50 $\mathrm{mmol}$ ) and bromide $50 \mathrm{~h}(299 \mathrm{mg}, 1.50 \mathrm{mmol})$. After $20 \mathrm{~h}$, purification by column chromatography ( $n$-pentane/ether 40:1) yielded 189ah (64 mg, $50 \%)$ as a colorless oil.

${ }^{1} \mathrm{H}$ NMR $\left(300 \mathrm{MHz}, \mathrm{CDCl}_{3}\right): \delta=7.91(\mathrm{dd}, J=8.1,2.3 \mathrm{~Hz}, 1 \mathrm{H}), 7.81$ (ddd, $J=$ 
8.4, 4.5, 2.3 Hz, 1H), $7.06(\mathrm{dd}, J=12.1,8.4 \mathrm{~Hz}, 1 \mathrm{H}), 3.44(\mathrm{t}, J=6.6 \mathrm{~Hz}, 2 \mathrm{H}), 2.58(\mathrm{~s}, 3 \mathrm{H}), 1.92-1.85(\mathrm{~m}$, $2 \mathrm{H}), 1.56-1.44(\mathrm{~m}, 2 \mathrm{H}), 1.40(\mathrm{~s}, 6 \mathrm{H})$.

${ }^{13} \mathrm{C}$ NMR $\left(75 \mathrm{MHz}, \mathrm{CDCl}_{3}\right): \delta=196.7\left(\mathrm{C}_{\mathrm{q}}\right), 164.7\left(\mathrm{~d},{ }^{1} \mathrm{~J}_{\mathrm{C}-\mathrm{F}}=257 \mathrm{~Hz}, \mathrm{C}_{\mathrm{q}}\right), 135.3\left(\mathrm{~d},{ }^{2} J_{\mathrm{C}-\mathrm{F}}=12 \mathrm{~Hz}, \mathrm{C}_{\mathrm{q}}\right), 133.1$ $\left(d,{ }^{4} J_{C-F}=3 \mathrm{~Hz}, C_{q}\right), 128.8\left(d,{ }^{3} J_{C-F}=11 \mathrm{~Hz}, C H\right), 128.8\left(d,{ }^{3} J_{C-F}=8 \mathrm{~Hz}, \mathrm{CH}\right), 116.5\left(d,{ }^{2} J_{C-F}=26 \mathrm{~Hz}, \mathrm{CH}\right)$, $45.3\left(\mathrm{CH}_{2}\right), 38.7\left(\mathrm{~d},{ }^{4} J_{\mathrm{C}-\mathrm{F}}=4 \mathrm{~Hz}, \mathrm{CH}_{2}\right), 37.4\left(\mathrm{~d},{ }^{3} \mathrm{~J}_{\mathrm{C}-\mathrm{F}}=3 \mathrm{~Hz}, \mathrm{C}\right), 28.5\left(\mathrm{CH}_{2}\right), 28.0\left(\mathrm{~d},{ }^{4} J_{\mathrm{C}-\mathrm{F}}=3 \mathrm{~Hz}, \mathrm{CH}_{3}\right)$, $26.4\left(\mathrm{CH}_{3}\right)$.

${ }^{19} \mathrm{~F}$ NMR $\left(282 \mathrm{MHz}, \mathrm{CDCl}_{3}\right): \delta=-101.7(\mathrm{~s})$.

IR (neat): $\tilde{v}=2961,2874,1682,1581,1477,1258,1090,822 \mathrm{~cm}^{-1}$.

MS (EI) $m / z$ (relative intensity) 258/256 (1/3) [M] ${ }^{+}, 179$ (100), 151 (48), 115 (5).

HR-MS (ESI): $m / z$ calcd for $\mathrm{C}_{14} \mathrm{H}_{19} \mathrm{FClO}^{+}[\mathrm{M}+\mathrm{H}]^{+} 257.1103$, found 257.1103 .

\section{Synthesis of 1-[3-(3-Ethylpentan-3-yl)-4-fluorophenyl]ethan-1-one (189ae)}

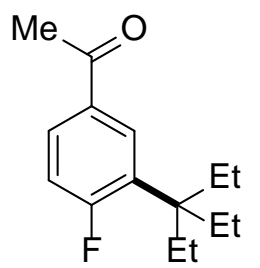

The general procedure $C$ was followed using substrate $188 \mathrm{a}(152 \mathrm{mg}, 0.50 \mathrm{mmol})$ and bromide 50e (269 mg, $1.50 \mathrm{mmol}$ ). After $20 \mathrm{~h}$, purification by column chromatography ( $n$-pentane/ether 40:1) yielded 189ae (40 mg, 34\%) as a colorless oil.

$2.3 \mathrm{~Hz}, 1 \mathrm{H}), 7.02(\mathrm{dd}, J=12.5,8.4 \mathrm{~Hz}, 1 \mathrm{H}), 2.57(\mathrm{~s}, 3 \mathrm{H}), 1.78(\mathrm{qd}, J=7.4,0.9 \mathrm{~Hz}, 6 \mathrm{H}), 0.64(\mathrm{t}, J=7.4 \mathrm{~Hz}$, $9 \mathrm{H})$.

${ }^{13} \mathrm{C}$ NMR $\left(75 \mathrm{MHz}, \mathrm{CDCl}_{3}\right): \delta=196.9\left(\mathrm{C}_{\mathrm{q}}\right), 164.7\left(\mathrm{~d},{ }^{1} J_{\mathrm{C}-\mathrm{F}}=257 \mathrm{~Hz}, \mathrm{C}_{\mathrm{q}}\right), 134.2\left(\mathrm{~d},{ }^{2} J_{\mathrm{C}-\mathrm{F}}=11 \mathrm{~Hz}, \mathrm{C}_{\mathrm{q}}\right), 132.8$ $\left(d,{ }^{4} J_{C-F}=3 \mathrm{~Hz}, C_{q}\right), 130.5\left(d,{ }^{3} J_{C-F}=8 \mathrm{~Hz}, C H\right), 128.4\left(d,{ }^{3} J_{C-F}=11 \mathrm{~Hz}, \mathrm{CH}\right), 116.3\left(d,{ }^{2} J_{C-F}=27 \mathrm{~Hz}, \mathrm{CH}\right)$, $44.4\left(\mathrm{~d},{ }^{3} J_{\mathrm{C}-\mathrm{F}}=4 \mathrm{~Hz}, \mathrm{C}_{\mathrm{q}}\right), 26.8\left(\mathrm{~d},{ }^{4} \mathrm{~J}_{\mathrm{C}-\mathrm{F}}=4 \mathrm{~Hz}, \mathrm{CH}_{2}\right), 26.6\left(\mathrm{CH}_{3}\right), 8.3\left(\mathrm{CH}_{3}\right)$.

${ }^{19} \mathrm{~F}$ NMR $\left(282 \mathrm{MHz}, \mathrm{CDCl}_{3}\right): \delta=-101.7$ (s).

IR (neat): $\tilde{v}=2965,2878,1684,1581,1469,1355,1250,1093,829 \mathrm{~cm}^{-1}$.

MS (EI) $\mathrm{m} / z$ (relative intensity) 237 (32) [M] ${ }^{+}, 207$ (52), 165 (100), 151 (77).

HR-MS (ESI): $m / z$ calcd for $\mathrm{C}_{15} \mathrm{H}_{22} \mathrm{FO}^{+}[\mathrm{M}+\mathrm{H}]^{+} 237.1649$ found 237.1649 .

\section{Synthesis of 1-[4-Fluoro-3-(2-methyl-1-phenylpropan-2-yl)phenyl]ethan-1-one (189aj)}

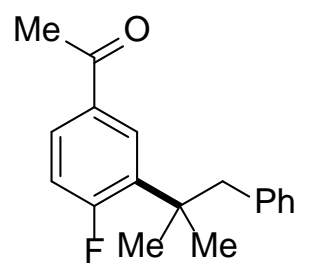

The general procedure $C$ was followed using substrate $188 \mathrm{a}$ (152 $\mathrm{mg}, 0.50$ $\mathrm{mmol}$ ) and bromide $50 \mathrm{j}(320 \mathrm{mg}, 1.50 \mathrm{mmol})$. After $20 \mathrm{~h}$, purification by column chromatography ( $n$-pentane/ether 40:1) yielded 189aj (48 mg, 36\%) as a colorless oil.

${ }^{1} \mathrm{H}$ NMR $\left(300 \mathrm{MHz}, \mathrm{CDCl}_{3}\right): \delta=7.81(\mathrm{ddd}, J=8.4,4.6,2.3 \mathrm{~Hz}, 1 \mathrm{H}), 7.68(\mathrm{dd}, J=$ 8.1, 2.3 Hz, 1H), 7.19-7.05 (m, 4H), 6.92-6.81 (m, 2H), $3.04(\mathrm{~s}, 2 \mathrm{H}), 2.49(\mathrm{~s}, 3 \mathrm{H}), 1.40(\mathrm{~d}, J=1.1 \mathrm{~Hz}$, $6 \mathrm{H})$.

${ }^{13} \mathrm{C}$ NMR $\left(75 \mathrm{MHz}, \mathrm{CDCl}_{3}\right): \delta=196.7\left(\mathrm{C}_{\mathrm{q}}\right), 164.8\left(\mathrm{~d},{ }^{1} \mathrm{~J}_{\mathrm{C}-\mathrm{F}}=256 \mathrm{~Hz}, \mathrm{C}_{\mathrm{q}}\right), 138.3\left(\mathrm{C}_{\mathrm{q}}\right), 135.6\left(\mathrm{~d},{ }^{2} \mathrm{~J}_{\mathrm{C}-\mathrm{F}}=12\right.$ $\left.\mathrm{Hz}, \mathrm{C}_{\mathrm{q}}\right), 133.1\left(\mathrm{~d},{ }^{4} \mathrm{~J}_{\mathrm{C}-\mathrm{F}}=3 \mathrm{~Hz}, \mathrm{C}_{\mathrm{q}}\right), 130.0(\mathrm{CH}), 129.0\left(\mathrm{~d},{ }^{3} \mathrm{~J}_{\mathrm{C}-\mathrm{F}}=8 \mathrm{~Hz}, \mathrm{CH}\right), 128.7\left(\mathrm{~d},{ }^{3} \mathrm{~J}_{\mathrm{C}-\mathrm{F}}=11 \mathrm{~Hz}, \mathrm{CH}\right)$, $127.5(\mathrm{CH}), 125.9(\mathrm{CH}), 116.3\left(\mathrm{~d},{ }^{2} \mathrm{~J}_{\mathrm{C}-\mathrm{F}}=26 \mathrm{~Hz}, \mathrm{CH}\right), 47.2\left(\mathrm{~d},{ }^{4} \mathrm{~J}_{\mathrm{C}-\mathrm{F}}=4 \mathrm{~Hz}, \mathrm{CH}_{2}\right), 38.8\left(\mathrm{~d},{ }^{3} \mathrm{~J}_{\mathrm{C}-\mathrm{F}}=3 \mathrm{~Hz}, \mathrm{C}_{\mathrm{q}}\right)$, $27.6\left(d^{4},{ }^{4} \mathrm{C}_{-F}=3 \mathrm{~Hz}, \mathrm{CH}_{3}\right), 26.4\left(\mathrm{CH}_{3}\right)$.

${ }^{19} \mathrm{~F} \mathrm{NMR}\left(282 \mathrm{MHz}, \mathrm{CDCl}_{3}\right): \delta=-101.0(\mathrm{~s})$.

IR (neat): $\tilde{v}=2966,2926,1683,1581,1399,1243,1089,823 \mathrm{~cm}^{-1}$.

MS (EI) $m / z$ (relative intensity) 270 (84) [M] $]^{+}, 255$ (58), 179 (47), 151 (14).

HR-MS (EI): $m / z$ calcd for $\mathrm{C}_{18} \mathrm{H}_{20} \mathrm{FO}^{+}[\mathrm{M}+\mathrm{H}]^{+} 271.1493$ found 271.1493 . 


\section{Synthesis of 1-[(3-(tert-Butyl)phenyl]ethan-1-one (189ba)}

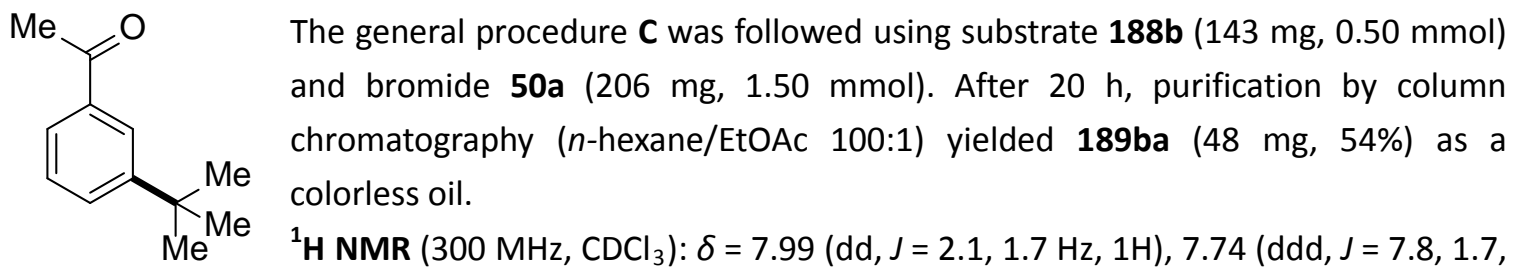
$1.1 \mathrm{~Hz}, 1 \mathrm{H}$ ), 7.59 (ddd, $J=7.8,2.1,1.1 \mathrm{~Hz}, 1 \mathrm{H}), 7.38$ (dd, $J=7.8,7.8 \mathrm{~Hz}, 1 \mathrm{H}), 2.59(\mathrm{~s}, 3 \mathrm{H}), 1.33(\mathrm{~s}, 9 \mathrm{H})$.

${ }^{13} \mathrm{C}$ NMR $\left(75 \mathrm{MHz}, \mathrm{CDCl}_{3}\right): \delta=198.5\left(\mathrm{C}_{\mathrm{q}}\right), 151.7\left(\mathrm{C}_{\mathrm{q}}\right), 137.0\left(\mathrm{C}_{\mathrm{q}}\right), 130.2(\mathrm{CH}), 128.3(\mathrm{CH}), 125.8(\mathrm{CH})$, $124.9(\mathrm{CH}), 34.8\left(\mathrm{C}_{\mathrm{q}}\right), 31.2\left(\mathrm{CH}_{3}\right), 26.7\left(\mathrm{CH}_{3}\right)$.

IR (neat): $\tilde{v}=2962,2869,1682,1581,1460,1353,1283,967,795 \mathrm{~cm}^{-1}$.

MS (EI) $m / z$ (relative intensity) 176 (21) [M] ${ }^{+}, 161$ (100), 133 (23), 115 (8).

HR-MS (EI): $m / z$ calcd for $\mathrm{C}_{12} \mathrm{H}_{16} \mathrm{O}^{+}[\mathrm{M}]^{+} 176.1196$, found 176.1203 .

\section{Synthesis of 1-[3-(tert-Butyl)phenyl]propan-1-one (189ca)}

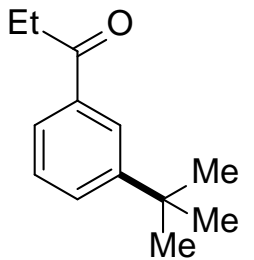

The general procedure $C$ was followed using substrate $188 \mathrm{c}(150 \mathrm{mg}, 0.50 \mathrm{mmol})$ and bromide 50a (206 mg, $1.50 \mathrm{mmol}$ ). After $20 \mathrm{~h}$, purification by column chromatography ( $n$-pentane/ether $40: 1$ ) yielded $189 \mathrm{ca}(52 \mathrm{mg}, 55 \%$ ) as a colorless oil.

${ }^{1} \mathbf{H}$ NMR $\left(300 \mathrm{MHz}, \mathrm{CDCl}_{3}\right): \delta=8.02(\mathrm{dd}, J=2.1,2.0 \mathrm{~Hz}, 1 \mathrm{H}), 7.77(\mathrm{ddd}, J=7.7,2.0$, $1.2 \mathrm{~Hz}, 1 \mathrm{H}$ ), 7.59 (ddd, $J=7.8,2.1,1.2 \mathrm{~Hz}, 1 \mathrm{H}$ ), 7.38 (dd, $J=7.8,7.8 \mathrm{~Hz}, 1 \mathrm{H}$ ), 3.01 (q, J = 7.2 Hz, 2H), $1.35(\mathrm{~s}, 9 \mathrm{H}), 1.23(\mathrm{t}, J=7.2 \mathrm{~Hz}, 3 \mathrm{H})$.

${ }^{13} \mathrm{C}$ NMR $\left(75 \mathrm{MHz}, \mathrm{CDCl}_{3}\right): \delta=201.1\left(\mathrm{C}_{\mathrm{q}}\right), 151.5\left(\mathrm{C}_{\mathrm{q}}\right), 136.7\left(\mathrm{C}_{\mathrm{q}}\right), 129.9(\mathrm{CH}), 128.2(\mathrm{CH}), 125.3(\mathrm{CH})$, $124.6(\mathrm{CH}), 34.8\left(\mathrm{C}_{\mathrm{q}}\right), 31.9\left(\mathrm{CH}_{2}\right), 31.3\left(\mathrm{CH}_{3}\right), 8.37\left(\mathrm{CH}_{3}\right)$.

IR (neat): $\tilde{v}=2963,2872,1685,1581,1459,1364,1209,850 \mathrm{~cm}^{-1}$.

MS (EI) $m / z$ (relative intensity) 190 (6) [M] $]^{+}, 161$ (100), 133 (13), 115 (10).

HR-MS (EI): $m / z$ calcd for $\mathrm{C}_{13} \mathrm{H}_{19} \mathrm{O}^{+}[\mathrm{M}+\mathrm{H}]^{+}$191.1430, found 191.1436 .

\section{Synthesis of 1-[3-(tert-Butyl)-4-methylphenyl]ethan-1-one (189da)}

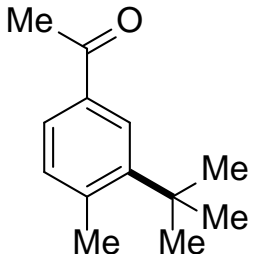

The general procedure $\mathbf{C}$ was followed using substrate $188 \mathrm{~d}(150 \mathrm{mg}, 0.50 \mathrm{mmol}$ ) and bromide 50a (206 mg, $1.50 \mathrm{mmol}$ ) in 1,4-dioxane (2 mL). After $20 \mathrm{~h}$, purification by column chromatography ( $n$-pentane/ether $40: 1$ ) yielded $189 \mathrm{da}$ (45 $\mathrm{mg}, 47 \%)$ as a colorless oil.

${ }^{1} \mathbf{H}$ NMR $\left(300 \mathrm{MHz} \mathrm{CDCl}_{3}\right): \delta=7.99(\mathrm{~d}, J=1.9 \mathrm{~Hz}, 1 \mathrm{H}), 7.65(\mathrm{dd}, J=7.8,1.9 \mathrm{~Hz}$, $1 \mathrm{H}), 7.18(\mathrm{~d}, J=7.8 \mathrm{~Hz}, 1 \mathrm{H}), 2.58(\mathrm{~s}, 3 \mathrm{H}), 2.56(\mathrm{~s}, 3 \mathrm{H}), 1.42(\mathrm{~s}, 9 \mathrm{H})$.

${ }^{13} \mathrm{C}$ NMR $\left(75 \mathrm{MHz}, \mathrm{CDCl}_{3}\right): \delta=198.1\left(\mathrm{C}_{\mathrm{q}}\right), 148.2\left(\mathrm{C}_{\mathrm{q}}\right), 142.3\left(\mathrm{C}_{\mathrm{q}}\right), 134.8\left(\mathrm{C}_{\mathrm{q}}\right), 132.8(\mathrm{CH}), 125.9(\mathrm{CH})$, $125.8(\mathrm{CH}), 36.0\left(\mathrm{C}_{\mathrm{q}}\right), 30.8\left(\mathrm{CH}_{3}\right), 26.6\left(\mathrm{CH}_{3}\right), 23.5\left(\mathrm{CH}_{3}\right)$.

IR (neat): $\tilde{v}=2960,2873,1679,1402,1353,1265,1197,1091,816 \mathrm{~cm}^{-1}$.

MS (EI) $m / z$ (relative intensity) 190 (26) [M] ${ }^{+}, 175$ (100), 147 (21), 115 (13).

HR-MS (EI): $m / z$ calcd for $\mathrm{C}_{13} \mathrm{H}_{18} \mathrm{O}^{+}[\mathrm{M}]^{+}$190.1352, found 190.1366 . 


\section{Synthesis of 1-[4-Methoxy-3-(1-methylcyclohexyl)phenyl]ethan-1-one (189eb)}

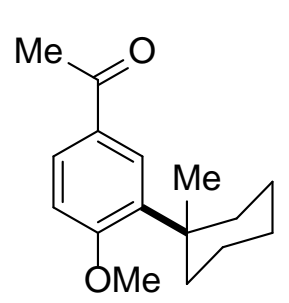

The general procedure $C$ was followed using substrate $188 \mathrm{e}(158 \mathrm{mg}, 0.50 \mathrm{mmol})$ and bromide 50b (266 mg, $1.50 \mathrm{mmol})$ in 1,4-dioxane $(2 \mathrm{~mL})$. After $20 \mathrm{~h}$, purification by column chromatography ( $n$-pentane/ether 40:1) yielded 189eb (58 $\mathrm{mg}, 47 \%$ ) as a colorless oil.

${ }^{1} \mathrm{H}$ NMR $\left(300 \mathrm{MHz}, \mathrm{CDCl}_{3}\right): \delta=7.95(\mathrm{~d}, J=2.3 \mathrm{~Hz}, 1 \mathrm{H}), 7.80(\mathrm{dd}, J=8.5,2.3 \mathrm{~Hz}$, $1 \mathrm{H}), 6.88(\mathrm{~d}, J=8.5 \mathrm{~Hz}, 1 \mathrm{H}), 3.86(\mathrm{~s}, 3 \mathrm{H}), 2.54(\mathrm{~s}, 3 \mathrm{H}), 2.13-2.03(\mathrm{~m}, 2 \mathrm{H})$, 1.77-1.65 (m, 2H), 1.60-1.30 (m, 6H), $1.27(\mathrm{~s}, 3 \mathrm{H})$.

${ }^{13} \mathrm{C} \mathrm{NMR}\left(75 \mathrm{MHz}, \mathrm{CDCl}_{3}\right): \delta=197.3\left(\mathrm{C}_{\mathrm{q}}\right), 162.7\left(\mathrm{C}_{\mathrm{q}}\right), 137.6\left(\mathrm{C}_{\mathrm{q}}\right), 129.8\left(\mathrm{C}_{\mathrm{q}}\right), 128.3(\mathrm{CH}), 128.3(\mathrm{CH})$, $111.0(\mathrm{CH}), 55.2\left(\mathrm{CH}_{3}\right), 38.3\left(\mathrm{C}_{\mathrm{q}}\right), 36.8\left(\mathrm{CH}_{2}\right), 26.6\left(\mathrm{CH}_{2}\right), 26.3\left(\mathrm{CH}_{3}\right), 25.1\left(\mathrm{CH}_{3}\right), 22.7\left(\mathrm{CH}_{2}\right)$.

IR (neat): $\tilde{v}=2923,2853,1673,1593,1492,1353,1244,1022,812 \mathrm{~cm}^{-1}$.

MS (EI) $m / z$ (relative intensity) 246 (76) [M] ${ }^{+}, 231$ (70), 163 (80), 115 (15).

HR-MS (EI): $m / z$ calcd for $\mathrm{C}_{16} \mathrm{H}_{22} \mathrm{O}_{2}{ }^{+}[\mathrm{M}]^{+} 246.1614$, found 246.1618 .

\section{Synthesis of 1-[4-Fluoro-3-(1-methylcyclohexyl)phenyl]propan-1-one (189fb)}

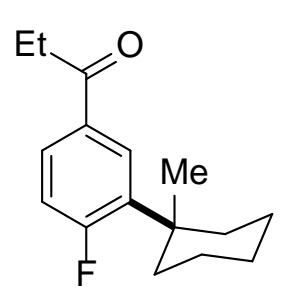

The general procedure $\mathbf{C}$ was followed using substrate $188 \mathrm{f}(159 \mathrm{mg}, 0.50 \mathrm{mmol}$ ) and bromide 50b (266 mg, $1.50 \mathrm{mmol})$. After $20 \mathrm{~h}$, purification by column chromatography ( $n$-pentane/ether 100:1) yielded $189 \mathrm{fb}(77 \mathrm{mg}, 62 \%)$ as a colorless oil.

${ }^{1} \mathbf{H}$ NMR $\left(300 \mathrm{MHz}, \mathrm{CDCl}_{3}\right): \delta=7.98(\mathrm{dd}, J=8.1,2.3 \mathrm{~Hz}, 1 \mathrm{H}), 7.78(\mathrm{ddd}, J=8.5$, 4.5, $2.3 \mathrm{~Hz}, 1 \mathrm{H}$ ), $7.02(\mathrm{dd}, J=12.3,8.4 \mathrm{~Hz}, 1 \mathrm{H}$ ), 2.96 (q, $J=7.2 \mathrm{~Hz}, 2 \mathrm{H}$ ), 2.11-2.02 $(\mathrm{m}, 2 \mathrm{H}), 1.71-1.52(\mathrm{~m}, 4 \mathrm{H}), 1.50-1.34(\mathrm{~m}, 4 \mathrm{H}), 1.28(\mathrm{~d}, J=1.0 \mathrm{~Hz}, 3 \mathrm{H}), 1.20(\mathrm{t}, J=7.2 \mathrm{~Hz}, 3 \mathrm{H})$.

${ }^{13} \mathrm{C} \mathrm{NMR}\left(75 \mathrm{MHz}, \mathrm{CDCl}_{3}\right): \delta=199.5\left(\mathrm{C}_{\mathrm{q}}\right), 165.0\left(\mathrm{~d},{ }^{1} J_{\mathrm{C}-\mathrm{F}}=257 \mathrm{~Hz}, \mathrm{C}_{\mathrm{q}}\right), 136.7\left(\mathrm{~d},{ }^{2} \mathrm{~J}_{\mathrm{C}-\mathrm{F}}=11 \mathrm{~Hz}, \mathrm{C}_{\mathrm{q}}\right), 132.8$ $\left(d,{ }^{4} J_{C-F}=3 \mathrm{~Hz}, C_{q}\right), 128.8\left(d,{ }^{3} J_{C-F}=8 \mathrm{~Hz}, C H\right), 127.7\left(d,{ }^{3} J_{C-F}=11 \mathrm{~Hz}, \mathrm{CH}\right), 116.7\left(d,{ }^{2} J_{C-F}=26 \mathrm{~Hz}, \mathrm{CH}\right)$, $37.9\left(\mathrm{~d},{ }^{3} \mathrm{~J}_{\mathrm{C}-\mathrm{F}}=3 \mathrm{~Hz}, \mathrm{C}\right), 37.0\left(\mathrm{~d},{ }^{4} \mathrm{~J}_{\mathrm{C}-\mathrm{F}}=4 \mathrm{~Hz}, \mathrm{CH}_{2}\right), 31.6\left(\mathrm{CH}_{2}\right), 26.5\left(\mathrm{CH}_{3}\right), 26.2\left(\mathrm{CH}_{2}\right), 22.5\left(\mathrm{CH}_{2}\right), 8.2$ $\left(\mathrm{CH}_{3}\right)$.

${ }^{19} \mathrm{~F} \mathrm{NMR}\left(282 \mathrm{MHz}, \mathrm{CDCl}_{3}\right): \delta=-101.4(\mathrm{~s})$.

IR (neat): $\tilde{v}=2927,2858,1685,1581,1488,1451,1228,1182,799 \mathrm{~cm}^{-1}$.

MS (EI) $m / z$ (relative intensity) $248(8)\left[\mathrm{M}^{+}, 219\right.$ (100), 163 (22), 133 (12).

HR-MS (EI): $\mathrm{m} / z$ calcd for $\mathrm{C}_{16} \mathrm{H}_{21} \mathrm{FO}^{+}[\mathrm{M}]^{+}$248.1571, found 248.1579 .

\section{Synthesis of 1-[3-(2-Methyl-4-phenylbutan-2-yl)phenyl]ethan-1-one (189bi)}

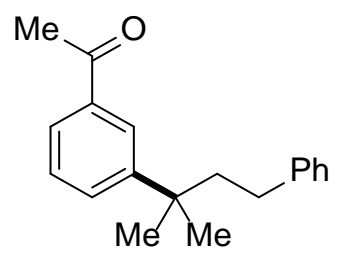

The general procedure $\mathbf{C}$ was followed using substrate $188 \mathrm{~b}(143 \mathrm{mg}, 0.50$ mmol) and bromide 50i (320 mg, $1.50 \mathrm{mmol}$ ). After $20 \mathrm{~h}$, purification by column chromatography ( $n$-pentane/ether $40: 1$ ) yielded 189bi (47 mg, 35\%) as a colorless oil.

${ }^{1} \mathbf{H}$ NMR $\left(300 \mathrm{MHz}, \mathrm{CDCl}_{3}\right): \delta=8.04-8.01(\mathrm{~m}, 1 \mathrm{H}), 7.83-7.78(\mathrm{~m}, 1 \mathrm{H})$, 7.65-7.60 (m, 1H), 7.48-7.42 (m, 1H), 7.28-7.06 (m, 5H), $2.64(\mathrm{~s}, 3 \mathrm{H}), 2.40-2.32(\mathrm{~m}, 2 \mathrm{H}), 2.01-1.94$ $(\mathrm{m}, 2 \mathrm{H}), 1.43(\mathrm{~s}, 6 \mathrm{H})$.

${ }^{13} \mathrm{C}$ NMR $\left(75 \mathrm{MHz}, \mathrm{CDCl}_{3}\right): \delta=198.2\left(\mathrm{C}_{\mathrm{q}}\right), 149.6\left(\mathrm{C}_{\mathrm{q}}\right), 142.5\left(\mathrm{C}_{\mathrm{q}}\right), 137.0\left(\mathrm{C}_{\mathrm{q}}\right), 130.6(\mathrm{CH}), 128.3(\mathrm{CH})$, $128.2(\mathrm{CH}), 128.1(\mathrm{CH}), 125.9(\mathrm{CH}), 125.5(\mathrm{CH}), 125.3(\mathrm{CH}), 46.5\left(\mathrm{CH}_{2}\right), 38.1\left(\mathrm{C}_{\mathrm{q}}\right), 31.3\left(\mathrm{CH}_{2}\right), 28.9$ $\left(\mathrm{CH}_{3}\right), 26.8\left(\mathrm{CH}_{3}\right)$.

IR (neat): $\tilde{v}=3026,2930,1682,1495,1355,1263,797,696 \mathrm{~cm}^{-1}$.

MS (EI) $m / z$ (relative intensity) $266(24)\left[\mathrm{M}^{+}, 161(100), 133(33), 105\right.$ (25). 
HR-MS (ESI): $m / z$ calcd for $\mathrm{C}_{19} \mathrm{H}_{23} \mathrm{O}^{+}[\mathrm{M}+\mathrm{H}]^{+} 267.1743$, found 267.1749 .

7.3.3 Analytical Data for the Products of the Ruthenium(II)-Catalyzed Direct meta-Selective Alkylation with Secondary Alkyl Bromides

\section{Synthesis of 1-(3-Cycloheptylphenyl)ethan-1-one (206be)}

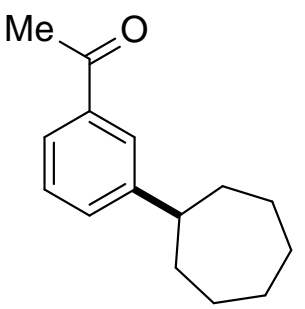

The general procedure $\mathrm{C}$ was followed using substrate $188 \mathrm{~b}(143 \mathrm{mg}, 0.50$ $\mathrm{mmol}$ ) and bromide $44 \mathrm{e}(266 \mathrm{mg}, 1.50 \mathrm{mmol})$. After $20 \mathrm{~h}$, purification by column chromatography ( $n$-hexane/EtOAc 100:1) yielded 206be (63 mg, 58\%) as a colorless oil.

${ }^{1} \mathrm{H}$ NMR $\left(300 \mathrm{MHz}, \mathrm{CDCl}_{3}\right): \delta=7.77(\mathrm{dd}, J=1.8,1.8 \mathrm{~Hz}, 1 \mathrm{H}), 7.72$ (ddd, $J=7.2$, $1.8,1.8 \mathrm{~Hz}, 1 \mathrm{H}), 7.40-7.30(\mathrm{~m}, 2 \mathrm{H}), 2.76-2.66(\mathrm{~m}, 1 \mathrm{H}), 2.57(\mathrm{~s}, 3 \mathrm{H}), 1.90-1.53$ (m, 12H).

${ }^{13} \mathrm{C}$ NMR $\left(75 \mathrm{MHz}, \mathrm{CDCl}_{3}\right): \delta=198.2\left(\mathrm{C}_{\mathrm{q}}\right), 150.3\left(\mathrm{C}_{\mathrm{q}}\right), 137.1\left(\mathrm{C}_{\mathrm{q}}\right), 131.5(\mathrm{CH}), 128.4(\mathrm{CH}), 126.3(\mathrm{CH})$, 125.7 (CH), $47.0(\mathrm{CH}), 36.7\left(\mathrm{CH}_{2}\right), 27.9\left(\mathrm{CH}_{2}\right), 27.2\left(\mathrm{CH}_{2}\right), 26.7\left(\mathrm{CH}_{3}\right)$.

IR (neat): $\tilde{v}=3352,2921,2853,1681,1582,1434,1356,1270,793 \mathrm{~cm}^{-1}$.

MS (EI) $m / z$ (relative intensity) 216 (60) [M] ${ }^{+}, 201$ (100), 146 (36), 131 (64).

HR-MS (EI): $m / z$ calcd for $\mathrm{C}_{15} \mathrm{H}_{20} \mathrm{O}^{+}[\mathrm{M}]^{+} 216.1514$, found 216.1510 .

\section{Synthesis of 1-(3-Cycloheptyl-4-methoxyphenyl)ethan-1-one (206ee)}

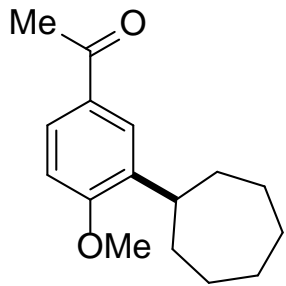

1.90-1.53 (m, 12H).

${ }^{13} \mathrm{C}$ NMR $\left(75 \mathrm{MHz}, \mathrm{CDCl}_{3}\right): \delta=197.1\left(\mathrm{C}_{\mathrm{q}}\right), 160.2\left(\mathrm{C}_{\mathrm{q}}\right), 138.2\left(\mathrm{C}_{\mathrm{q}}\right), 130.0\left(\mathrm{C}_{\mathrm{q}}\right), 127.9(\mathrm{CH}), 127.1(\mathrm{CH})$, $109.5(\mathrm{CH}), 55.5\left(\mathrm{CH}_{3}\right), 38.9(\mathrm{CH}), 35.2\left(\mathrm{CH}_{2}\right), 27.8\left(\mathrm{CH}_{2}\right), 27.4\left(\mathrm{CH}_{2}\right), 26.2\left(\mathrm{CH}_{3}\right)$.

IR (neat): $\tilde{v}=2919,2852,1672,1596,1495,1354,1241,1025,810 \mathrm{~cm}^{-1}$.

MS (EI) $m / z$ (relative intensity) 246 (95) [M] $]^{+}, 231$ (100), 161 (57), 147 (26).

HR-MS (EI): $m / z$ calcd for $\mathrm{C}_{16} \mathrm{H}_{22} \mathrm{O}_{2}{ }^{+}[\mathrm{M}]^{+} 246.1614$, found 246.1630 .

\section{Synthesis of 1-(3-Cycloheptyl-4-methylphenyl)ethan-1-one (206de)}

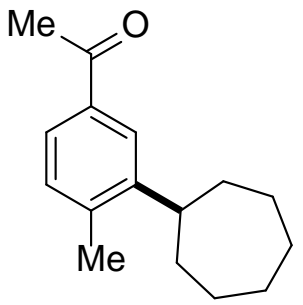

The general procedure $\mathbf{C}$ was followed using substrate $188 \mathrm{~d}(150 \mathrm{mg}, 0.50$ $\mathrm{mmol}$ ) and bromide $44 \mathrm{e}(266 \mathrm{mg}, 1.50 \mathrm{mmol})$. After $20 \mathrm{~h}$, purification by column chromatography ( $n$-hexane/EtOAc 100:1) yielded 206de (59 mg, 51\%) as a colorless oil.

${ }^{1} \mathrm{H}$ NMR $\left(300 \mathrm{MHz}, \mathrm{CDCl}_{3}\right): \delta=7.80(\mathrm{~d}, J=1.9 \mathrm{~Hz}, 1 \mathrm{H}), 7.62(\mathrm{dd}, J=7.9,1.9 \mathrm{~Hz}$, $1 \mathrm{H}), 7.17(\mathrm{~d}, J=7.9 \mathrm{~Hz}, 1 \mathrm{H}), 2.92-2.82(\mathrm{~m}, 1 \mathrm{H}), 2.55(\mathrm{~s}, 3 \mathrm{H}), 2.35(\mathrm{~s}, 3 \mathrm{H})$, 1.88-1.76 (m, 4H), 1.74-1.49 (m, 8H).

${ }^{13} \mathrm{C} \mathrm{NMR}\left(75 \mathrm{MHz}, \mathrm{CDCl}_{3}\right): \delta=198.1\left(\mathrm{C}_{\mathrm{q}}\right), 148.3\left(\mathrm{C}_{\mathrm{q}}\right), 140.4\left(\mathrm{C}_{\mathrm{q}}\right), 135.4\left(\mathrm{C}_{\mathrm{q}}\right), 130.2(\mathrm{CH}), 125.5(\mathrm{CH})$, $125.4(\mathrm{CH}), 41.7(\mathrm{CH}), 35.9\left(\mathrm{CH}_{2}\right), 27.6\left(\mathrm{CH}_{2}\right), 27.5\left(\mathrm{CH}_{2}\right), 26.5\left(\mathrm{CH}_{3}\right), 19.7\left(\mathrm{CH}_{3}\right)$.

IR (neat): $\tilde{v}=2920,2853,1678,1602,1444,1353,1242,813 \mathrm{~cm}^{-1}$.

MS (EI) $m / z$ (relative intensity) $230(42)\left[\mathrm{M}^{+}, 215\right.$ (100), 145 (40), 115 (18). 
HR-MS (EI): $\mathrm{m} / z$ calcd for $\mathrm{C}_{16} \mathrm{H}_{22} \mathrm{O}^{+}[\mathrm{M}]^{+} 230.1665$, found 230.1673 .

\section{Synthesis of 1-(2-Cycloheptyl-[1,1'-biphenyl]-4-yl)ethan-1-one (206ge)}

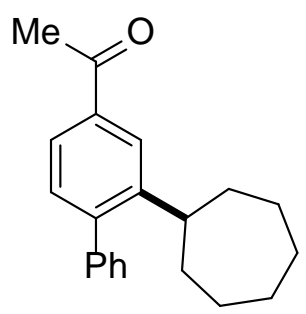

The general procedure C was followed using substrate $188 \mathrm{~g}(181 \mathrm{mg}, 0.50$ mmol) and bromide 44e (266 $\mathrm{mg}, 1.50 \mathrm{mmol}$ ). After $20 \mathrm{~h}$, purification by column chromatography ( $n$-hexane/EtOAc 100:1) yielded 206ge ( $88 \mathrm{mg}, 60 \%$ ) as a colorless oil.

${ }^{1} \mathrm{H}$ NMR $\left(300 \mathrm{MHz}, \mathrm{CDCl}_{3}\right): \delta=7.95(\mathrm{~d}, J=1.9 \mathrm{~Hz}, 1 \mathrm{H}), 7.75(\mathrm{dd}, J=8.0,1.9 \mathrm{~Hz}$, $1 \mathrm{H}), 7.46-7.32(\mathrm{~m}, 3 \mathrm{H}), 7.28-7.22(\mathrm{~m}, 3 \mathrm{H}), 2.88-2.75(\mathrm{~m}, 1 \mathrm{H}), 2.62(\mathrm{~s}, 3 \mathrm{H})$, 1.84-1.63 (m, 6H), 1.56-1.47 (m, 4H), 1.37-1.24 (m, 2H).

${ }^{13} \mathrm{C}$ NMR $\left(75 \mathrm{MHz}, \mathrm{CDCl}_{3}\right): \delta=197.9\left(\mathrm{C}_{\mathrm{q}}\right), 147.9\left(\mathrm{C}_{\mathrm{q}}\right), 145.2\left(\mathrm{C}_{\mathrm{q}}\right), 140.9\left(\mathrm{C}_{\mathrm{q}}\right), 136.4\left(\mathrm{C}_{\mathrm{q}}\right), 130.0(\mathrm{CH})$, $128.8(\mathrm{CH}), 127.9(\mathrm{CH}), 127.1(\mathrm{CH}), 126.3(\mathrm{CH}), 125.1(\mathrm{CH}), 41.6(\mathrm{CH}), 36.8\left(\mathrm{CH}_{2}\right), 27.6\left(\mathrm{CH}_{2}\right), 27.3$ $\left(\mathrm{CH}_{2}\right), 26.7\left(\mathrm{CH}_{3}\right)$.

IR (neat): $\tilde{v}=2919,2852,1681,1597,1458,1353,1277,1008,827 \mathrm{~cm}^{-1}$. MS (EI) $m / z$ (relative intensity) 292 (85) [M] ${ }^{+}, 221$ (46), 165 (41), 115 (6).

HR-MS (ESI): $m / z$ calcd for $\mathrm{C}_{21} \mathrm{H}_{25} \mathrm{O}^{+}[\mathrm{M}+\mathrm{H}]^{+}$293.1900, found 293.1905 .

\section{Synthesis of 1-(3-Cycloheptyl-4-(trifluoromethyl)phenyl)ethan-1-one (206he)}

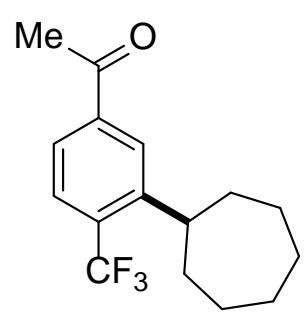

The general procedure $C$ was followed using substrate $188 \mathrm{~h}(177 \mathrm{mg}, 0.50$ $\mathrm{mmol}$ ) and bromide $44 \mathrm{e}(266 \mathrm{mg}, 1.50 \mathrm{mmol})$. After $20 \mathrm{~h}$, purification by column chromatography ( $n$-hexane/EtOAc 100:1) yielded 206he (62 mg, 44\%) as a colorless oil.

${ }^{1} \mathrm{H}$ NMR $\left(300 \mathrm{MHz}, \mathrm{CDCl}_{3}\right): \delta=7.97(\mathrm{~d}, J=1.8 \mathrm{~Hz}, 1 \mathrm{H}), 7.75$ (ddd, $J=8.2,1.8$, $0.9 \mathrm{~Hz}, 1 \mathrm{H}), 7.65(\mathrm{~d}, J=8.2 \mathrm{~Hz}, 1 \mathrm{H}), 3.14-3.02(\mathrm{~m}, 1 \mathrm{H}), 2.60(\mathrm{~s}, 3 \mathrm{H}), 1.86-1.52$ (m, 12H).

${ }^{13} \mathrm{C} \mathrm{NMR}\left(75 \mathrm{MHz}, \mathrm{CDCl}_{3}\right): \delta=197.2\left(\mathrm{C}_{\mathrm{q}}\right), 149.7\left(\mathrm{q},{ }^{3} \mathrm{~J}_{\mathrm{C}-\mathrm{F}}=2 \mathrm{~Hz}, \mathrm{C}_{\mathrm{q}}\right), 139.7\left(\mathrm{C}_{\mathrm{q}}\right), 130.7\left(\mathrm{q},{ }^{2} J_{\mathrm{C}-\mathrm{F}}=30 \mathrm{~Hz}\right.$, $\left.\mathrm{C}_{\mathrm{q}}\right), 127.7(\mathrm{CH}), 125.9\left(\mathrm{q},{ }^{3} \mathrm{~J}_{\mathrm{C}-\mathrm{F}}=6 \mathrm{~Hz}, \mathrm{CH}\right), 125.3(\mathrm{CH}), 124.1\left(\mathrm{q},{ }^{1} \mathrm{~J}_{\mathrm{C}-\mathrm{F}}=274 \mathrm{~Hz}, \mathrm{C}_{\mathrm{q}}\right), 41.7\left(\mathrm{q},{ }^{4} \mathrm{~J}_{\mathrm{C}-\mathrm{F}}=2 \mathrm{~Hz}\right.$, $\mathrm{CH}), 36.9\left(\mathrm{CH}_{2}\right), 27.6\left(\mathrm{CH}_{2}\right), 27.5\left(\mathrm{CH}_{2}\right), 26.8\left(\mathrm{CH}_{3}\right)$.

${ }^{19} \mathrm{~F} \mathrm{NMR}\left(282 \mathrm{MHz}, \mathrm{CDCl}_{3}\right): \delta=-59.5$ (s).

IR (neat): $\tilde{v}=2925,2856,1692,1574,1415,1310,1238,1154,1035,829 \mathrm{~cm}^{-1}$.

MS (EI) $m / z$ (relative intensity) 284 (35) [M] ${ }^{+}, 214$ (55), 199 (100), 151 (23).

HR-MS (ESI): $\mathrm{m} / z$ calcd for $\mathrm{C}_{16} \mathrm{H}_{19} \mathrm{~F}_{3} \mathrm{NaO}^{+}[\mathrm{M}+\mathrm{Na}]^{+} 307.1280$, found 307.1286 .

\section{Synthesis of 1-(3-Cycloheptyl-4-fluorophenyl)ethan-1-one (206ae)}

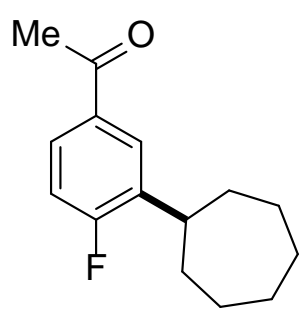

The general procedure $\mathbf{C}$ was followed using substrate $188 \mathrm{a}(152 \mathrm{mg}, 0.50$ mmol) and bromide 44e (266 mg, $1.50 \mathrm{mmol})$. After $20 \mathrm{~h}$, purification by column chromatography ( $n$-hexane/EtOAc $80: 1$ ) yielded 206ae (75 mg, 64\%) as a colorless oil.

${ }^{1} \mathrm{H}$ NMR $\left(300 \mathrm{MHz}, \mathrm{CDCl}_{3}\right): \delta=7.85(\mathrm{dd}, J=7.2,2.3 \mathrm{~Hz}, 1 \mathrm{H}), 7.73$ (ddd, $J=8.5$, 4.9, $2.3 \mathrm{~Hz}, 1 \mathrm{H}), 7.02(\mathrm{dd}, J=9.9,8.5 \mathrm{~Hz}, 1 \mathrm{H}), 3.06-2.92(\mathrm{~m}, 1 \mathrm{H}), 2.55(\mathrm{~s}, 3 \mathrm{H})$,

$1.92-1.50(\mathrm{~m}, 12 \mathrm{H})$.

${ }^{13} \mathrm{C}$ NMR $\left(75 \mathrm{MHz}, \mathrm{CDCl}_{3}\right): \delta=196.9\left(\mathrm{C}_{\mathrm{q}}\right), 163.1\left(\mathrm{~d},{ }^{1} \mathrm{~J}_{\mathrm{C}-\mathrm{F}}=253 \mathrm{~Hz}, \mathrm{C}_{\mathrm{q}}\right), 136.8\left(\mathrm{~d},{ }^{2} J_{\mathrm{C}-\mathrm{F}}=16 \mathrm{~Hz}, \mathrm{C}_{\mathrm{q}}\right), 133.5$ $\left(d,{ }^{4} J_{C-F}=3 \mathrm{~Hz}, C_{q}\right), 128.6\left(d,{ }^{3} J_{C-F}=7 \mathrm{~Hz}, \mathrm{CH}\right), 127.6\left(d,{ }^{3} J_{C-F}=10 \mathrm{~Hz}, \mathrm{CH}\right), 115.4\left(d,{ }^{2} J_{C-F}=24 \mathrm{~Hz}, \mathrm{CH}\right)$, $39.5\left(\mathrm{~d},{ }^{3} \mathrm{~J}_{\mathrm{C}-\mathrm{F}}=1 \mathrm{~Hz}, \mathrm{CH}\right), 35.2\left(\mathrm{~d},{ }^{4} \mathrm{~J}_{\mathrm{C}-\mathrm{F}}=1 \mathrm{~Hz}, \mathrm{CH}_{2}\right), 27.7\left(\mathrm{CH}_{2}\right), 27.2\left(\mathrm{CH}_{2}\right), 26.5\left(\mathrm{CH}_{3}\right)$.

${ }^{19} \mathrm{~F}$ NMR $\left(282 \mathrm{MHz}, \mathrm{CDCl}_{3}\right): \delta=-111.1(\mathrm{~s})$. 
IR (neat): $\tilde{v}=2921,2855,1682,1585,1492,1416,1355,1243,1170,1104,819 \mathrm{~cm}^{-1}$.

MS (EI) $m / z$ (relative intensity) 234 (41) [M] ${ }^{+}, 219$ (100), 164 (40), 149 (70).

HR-MS (EI): $m / z$ calcd for $\mathrm{C}_{15} \mathrm{H}_{19} \mathrm{FO}^{+}[\mathrm{M}]^{+}$234.1414, found 234.1416 .

\section{Synthesis of 1-(3-Cycloheptyl-4-fluorophenyl)propan-1-one (206fe)}

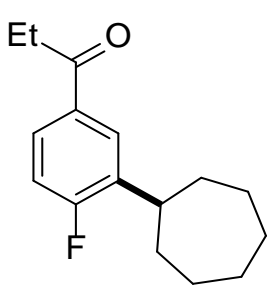

The general procedure $\mathbf{C}$ was followed using substrate $188 \mathrm{f}(159 \mathrm{mg}, 0.50 \mathrm{mmol})$ and bromide 44e $(266 \mathrm{mg}, 1.50 \mathrm{mmol})$ in 1,4-dioxane $(2 \mathrm{~mL})$. After $20 \mathrm{~h}$, purification by column chromatography ( $n$-hexane/EtOAc 100:1) yielded 206fe (77 $\mathrm{mg}, 62 \%$ ) as a colorless oil.

${ }^{1} \mathrm{H}$ NMR $\left(300 \mathrm{MHz}, \mathrm{CDCl}_{3}\right): \delta=7.86(\mathrm{dd}, J=7.3,2.3 \mathrm{~Hz}, 1 \mathrm{H}), 7.74$ (ddd, $J=8.5$, 5.0, $2.3 \mathrm{~Hz}, 1 \mathrm{H}), 7.01(\mathrm{dd}, J=9.9,8.5 \mathrm{~Hz}, 1 \mathrm{H}), 3.04-2.90(\mathrm{~m}, 3 \mathrm{H}), 1.92-1.47(\mathrm{~m}$, $12 \mathrm{H}), 1.19(\mathrm{t}, J=7.2 \mathrm{~Hz}, 3 \mathrm{H})$.

${ }^{13} \mathrm{C}$ NMR $\left(75 \mathrm{MHz}, \mathrm{CDCl}_{3}\right): \delta=199.4\left(\mathrm{C}_{\mathrm{q}}\right), 162.8\left(\mathrm{~d},{ }^{1} \mathrm{~J}_{\mathrm{C}-\mathrm{F}}=253 \mathrm{~Hz}, \mathrm{C}_{\mathrm{q}}\right), 136.6\left(\mathrm{~d},{ }^{2} \mathrm{~J}_{\mathrm{CF}}=16 \mathrm{~Hz}, \mathrm{C}_{\mathrm{q}}\right), 133.2$ $\left(d,{ }^{4} J_{C-F}=3 \mathrm{~Hz}, C_{q}\right), 128.3\left(d,{ }^{3} J_{C-F}=7 \mathrm{~Hz}, C H\right), 127.3\left(d,{ }^{3} J_{C-F}=8 \mathrm{~Hz}, C H\right), 115.3\left(d,{ }^{2} J_{C-F}=24 \mathrm{~Hz}, C H\right), 39.5$ $(\mathrm{CH}), 35.3\left(\mathrm{CH}_{2}\right), 31.7\left(\mathrm{CH}_{2}\right), 27.8\left(\mathrm{CH}_{2}\right), 27.3\left(\mathrm{CH}_{2}\right), 8.4\left(\mathrm{CH}_{3}\right)$.

${ }^{19} \mathrm{~F} \mathrm{NMR}\left(282 \mathrm{MHz}, \mathrm{CDCl}_{3}\right): \delta=-111.3(\mathrm{~s})$.

IR (neat): $\tilde{v}=2923,2855,1685,1586,1492,1350,1237,1150,797 \mathrm{~cm}^{-1}$.

MS (EI) $m / z$ (relative intensity) $248(6)\left[\mathrm{M}^{+}, 219\right.$ (100), 149 (10), 109 (13).

HR-MS (ESI): $m / z$ calcd for $\mathrm{C}_{16} \mathrm{H}_{22} \mathrm{FO}^{+}[\mathrm{M}+\mathrm{H}]^{+} 249.1649$, found 249.1654 .

\section{Synthesis of 1-(3-Cycloheptylphenyl)propan-1-one (206ce)}

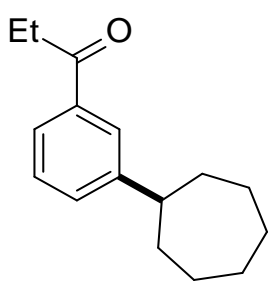

The general procedure $C$ was followed using substrate $188 \mathrm{c}(150 \mathrm{mg}, 0.50 \mathrm{mmol})$ and bromide $44 \mathrm{e}(266 \mathrm{mg}, 1.50 \mathrm{mmol}$ ). After $20 \mathrm{~h}$, purification by column chromatography ( $n$-hexane/EtOAc 100:1) yielded 206ce (61 mg, 53\%) as a colorless oil.

${ }^{1} \mathbf{H}$ NMR $\left(300 \mathrm{MHz} \mathrm{CDCl}_{3}\right.$ ) $: \delta=7.79$ (dd, $J=1.8,1.8 \mathrm{~Hz}, 1 \mathrm{H}$ ), 7.75 (ddd, $J=7.2$, $1.8,1.8 \mathrm{~Hz}, 1 \mathrm{H}), 7.40-7.30(\mathrm{~m}, 2 \mathrm{H}), 2.99(\mathrm{q}, J=7.2 \mathrm{~Hz}, 2 \mathrm{H}), 2.76-2.66(\mathrm{~m}, 1 \mathrm{H})$, $1.90-1.53(\mathrm{~m}, 12 \mathrm{H}), 1.22(\mathrm{t}, J=7.2 \mathrm{~Hz}, 3 \mathrm{H})$.

${ }^{13} \mathrm{C} \mathrm{NMR}\left(75 \mathrm{MHz}, \mathrm{CDCl}_{3}\right): \delta=201.0\left(\mathrm{C}_{\mathrm{q}}\right), 150.3\left(\mathrm{C}_{\mathrm{q}}\right), 137.0\left(\mathrm{C}_{\mathrm{q}}\right), 131.3(\mathrm{CH}), 128.4(\mathrm{CH}), 126.2(\mathrm{CH})$, 125.3 (CH), $47.0(\mathrm{CH}), 36.7\left(\mathrm{CH}_{2}\right), 31.8\left(\mathrm{CH}_{2}\right), 27.9\left(\mathrm{CH}_{2}\right), 27.2\left(\mathrm{CH}_{2}\right), 8.4\left(\mathrm{CH}_{3}\right)$.

IR (neat): $\tilde{v}=3391,2921,2853,1683,1582,1482,1348,1233,1161,781 \mathrm{~cm}^{-1}$.

MS (EI) $m / z$ (relative intensity) 230 (5) [M] ${ }^{+}, 201$ (100), 179 (13), 131 (8).

HR-MS (EI): $m / z$ calcd for $\mathrm{C}_{16} \mathrm{H}_{23} \mathrm{O}^{+}[\mathrm{M}+\mathrm{H}]^{+} 231.1743$, found 231.1749 .

\section{Synthesis of 1-(4-Cycloheptylnaphthalen-2-yl)ethan-1-one (206ie)}

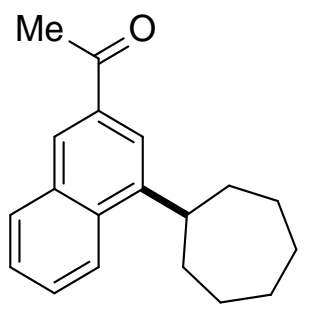

The general procedure $\mathbf{C}$ was followed using substrate $188 \mathrm{i}(168 \mathrm{mg}, 0.50$ $\mathrm{mmol}$ ) and bromide $44 \mathrm{e}(266 \mathrm{mg}, 1.50 \mathrm{mmol})$. After $20 \mathrm{~h}$, purification by column chromatography ( $n$-hexane/EtOAc 100:1) yielded 206ie (67 mg, 50\%) as a colorless oil.

${ }^{1} \mathbf{H}$ NMR $\left(300 \mathrm{MHz}, \mathrm{CDCl}_{3}\right): \delta=8.32-8.26(\mathrm{~m}, 1 \mathrm{H}), 8.13(\mathrm{~d}, J=8.6 \mathrm{~Hz}, 1 \mathrm{H})$, 8.00-7.92 (m, 2H), $7.63(\mathrm{tt}, J=8.3,1.4 \mathrm{~Hz}, 1 \mathrm{H}), 7.58-7.49(\mathrm{~m}, 1 \mathrm{H}), 3.54-3.43$ $(\mathrm{m}, 1 \mathrm{H}), 2.72(\mathrm{~s}, 3 \mathrm{H}), 2.14-1.99(\mathrm{~m}, 2 \mathrm{H}), 1.96-1.58(\mathrm{~m}, 10 \mathrm{H})$. 
${ }^{13} \mathrm{C} \mathrm{NMR}\left(75 \mathrm{MHz}, \mathrm{CDCl}_{3}\right): \delta=198.2\left(\mathrm{C}_{\mathrm{q}}\right), 146.5\left(\mathrm{C}_{\mathrm{q}}\right), 134.0\left(\mathrm{C}_{\mathrm{q}}\right), 133.4\left(\mathrm{C}_{\mathrm{q}}\right), 133.0\left(\mathrm{C}_{\mathrm{q}}\right), 130.5(\mathrm{CH})$, $128.5(\mathrm{CH}), 128.1(\mathrm{CH}), 126.0(\mathrm{CH}), 123.4(\mathrm{CH}), 120.3(\mathrm{CH}), 41.2(\mathrm{CH}), 36.3\left(\mathrm{CH}_{2}\right), 27.9\left(\mathrm{CH}_{2}\right), 27.7$ $\left(\mathrm{CH}_{2}\right), 26.6\left(\mathrm{CH}_{3}\right)$.

IR (neat): $\tilde{v}=2919,2852,1674,1457,1397,1260,1194,885 \mathrm{~cm}^{-1}$.

MS (EI) $m / z$ (relative intensity) $266(100)\left[\mathrm{M}^{+}, 209\right.$ (16), 183 (28), 153 (40).

HR-MS (EI): $m / z$ calcd for $\mathrm{C}_{19} \mathrm{H}_{22} \mathrm{O}^{+}[\mathrm{M}]^{+} 266.1665$, found 266.1661 .

\section{Synthesis of (3-Cycloheptyl-4-fluorophenyl)(phenyl)methanone (206je)}

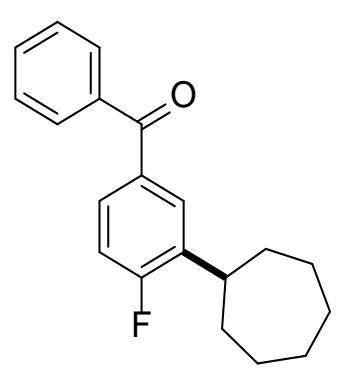

The general procedure $\mathrm{C}$ was followed using substrate $\mathbf{1 8 8 \mathrm { j }}(183 \mathrm{mg}, 0.50$ mmol) and bromide 44e (266 mg, $1.50 \mathrm{mmol})$. After $20 \mathrm{~h}$, purification by column chromatography ( $n$-hexane/EtOAc 100:1) yielded 206je (92 mg, 62\%) as a colorless oil.

${ }^{1} \mathbf{H}$ NMR $\left(300 \mathrm{MHz}, \mathrm{CDCl}_{3}\right): \delta=7.79-7.75(\mathrm{~m}, 3 \mathrm{H}), 7.62-7.56(\mathrm{~m}, 2 \mathrm{H})$, $7.52-7.46(\mathrm{~m}, 2 \mathrm{H}), 7.07(\mathrm{dd}, J=9.9,8.4 \mathrm{~Hz}, 1 \mathrm{H}), 3.10-2.99(\mathrm{~m}, 1 \mathrm{H}), 1.89-1.55$ ( $\mathrm{m}, 12 \mathrm{H})$.

${ }^{13} \mathrm{C}$ NMR $\left(75 \mathrm{MHz}, \mathrm{CDCl}_{3}\right): \delta=195.8\left(\mathrm{C}_{\mathrm{q}}\right), 162.9\left(\mathrm{~d},{ }^{1} J_{\mathrm{C}-\mathrm{F}}=253 \mathrm{~Hz}, \mathrm{C}_{\mathrm{q}}\right), 137.8\left(\mathrm{C}_{\mathrm{q}}\right), 136.8\left(\mathrm{~d},{ }^{2} J_{\mathrm{C}-\mathrm{F}}=16\right.$ $\left.\mathrm{Hz}, \mathrm{C}_{\mathrm{q}}\right), 133.7\left(\mathrm{~d},{ }^{4} J_{\mathrm{C}-\mathrm{F}}=3 \mathrm{~Hz}, \mathrm{C}_{\mathrm{q}}\right), 132.4(\mathrm{CH}), 130.5\left(\mathrm{~d},{ }^{3} \mathrm{~J}_{\mathrm{C}-\mathrm{F}}=7 \mathrm{~Hz}, \mathrm{CH}\right), 130.0(\mathrm{CH}), 129.8\left(\mathrm{~d},{ }^{3} J_{\mathrm{C}-\mathrm{F}}=10\right.$ $\mathrm{Hz}, \mathrm{CH}), 128.3(\mathrm{CH}), 115.2\left(\mathrm{~d},{ }^{2} \mathrm{~J}_{\mathrm{C}-\mathrm{F}}=24 \mathrm{~Hz}, \mathrm{CH}\right), 39.4(\mathrm{CH}), 35.2\left(\mathrm{CH}_{2}\right), 27.6\left(\mathrm{CH}_{2}\right), 27.2\left(\mathrm{CH}_{2}\right)$.

${ }^{19} \mathrm{~F} \mathrm{NMR}\left(282 \mathrm{MHz}, \mathrm{CDCl}_{3}\right): \delta=-111.8(\mathrm{~s})$.

IR (neat): $\tilde{v}=2924,2855,1657,1599,1490,1446,1281,1092,713 \mathrm{~cm}^{-1}$.

MS (EI) $m / z$ (relative intensity) $296(92)\left[\mathrm{M}^{+}, 226\right.$ (68), 149 (53), 105 (100).

HR-MS (ESI): $\mathrm{m} / \mathrm{z}$ calcd for $\mathrm{C}_{20} \mathrm{H}_{22} \mathrm{FO}^{+}[\mathrm{M}+\mathrm{H}]^{+}$297.1649, found 297.1654.

\section{Synthesis of 1-[3-(sec-Butyl)-4-fluorophenyl]ethan-1-one (206af)}<smiles>CCC(C)c1cc(C(C)=O)ccc1F</smiles>

The general procedure $\mathbf{C}$ was followed using substrate $188 \mathrm{a}(152 \mathrm{mg}, 0.50 \mathrm{mmol})$ and bromide $44 \mathrm{f}$ (103 $\mathrm{mg}, 0.75 \mathrm{mmol})$. After $20 \mathrm{~h}$, purification by column chromatography ( $n$-pentane/ $\mathrm{Et}_{2} \mathrm{O} 50: 1$ ) yielded 206af (42 mg, 43\%) as a colorless oil.

${ }^{1} \mathrm{H}$ NMR $\left(300 \mathrm{MHz}, \mathrm{CDCl}_{3}\right): \delta=7.84(\mathrm{dd}, J=7.2,2.3 \mathrm{~Hz}, 1 \mathrm{H}), 7.75$ (ddd, $J=8.5,5.0$, $2.3 \mathrm{~Hz}, 1 \mathrm{H}), 7.03(\mathrm{dd}, J=9.8,8.5 \mathrm{~Hz}, 1 \mathrm{H}), 2.98(\mathrm{dt}, J=7.1,7.1 \mathrm{~Hz}, 1 \mathrm{H}), 2.55(\mathrm{~s}, 3 \mathrm{H})$, 1.69-1.58 (m, 2H), $1.24(\mathrm{~d}, 3 \mathrm{H}, J=7.2 \mathrm{~Hz}), 0.82(\mathrm{t}, 3 \mathrm{H}, J=7.3 \mathrm{~Hz})$.

${ }^{13} \mathrm{C} \mathrm{NMR}\left(75 \mathrm{MHz}, \mathrm{CDCl}_{3}\right): \delta=196.7\left(\mathrm{C}_{\mathrm{q}}\right), 163.9\left(\mathrm{~d},{ }^{1} J_{\mathrm{C}-\mathrm{F}}=253 \mathrm{~Hz}, \mathrm{C}_{\mathrm{q}}\right), 134.5\left(\mathrm{~d},{ }^{2} J_{\mathrm{C}-\mathrm{F}}=16 \mathrm{~Hz}, \mathrm{C}_{\mathrm{q}}\right), 133.4$ $\left(d,{ }^{4} J_{C-F}=3 \mathrm{~Hz}, C_{q}\right), 128.6\left(d,{ }^{3} J_{C-F}=7 \mathrm{~Hz}, C H\right), 128.0\left(d,{ }^{3} J_{C-F}=10 \mathrm{~Hz}, \mathrm{CH}\right), 115.4\left(d,{ }^{2} J_{C-F}=24 \mathrm{~Hz}, \mathrm{CH}\right)$, $34.3\left(\mathrm{~d},{ }^{3} \mathrm{~J}_{\mathrm{C}-\mathrm{F}}=1 \mathrm{~Hz}, \mathrm{CH}\right), 29.8\left(\mathrm{CH}_{2}\right), 26.5\left(\mathrm{CH}_{3}\right), 20.4\left(\mathrm{CH}_{3}\right), 12.1\left(\mathrm{CH}_{3}\right)$.

${ }^{19} \mathrm{~F}$ NMR $\left(282 \mathrm{MHz}, \mathrm{CDCl}_{3}\right): \delta=-111.0(\mathrm{~s})$.

IR (neat): $\tilde{v}=2964,2976,1683,1606,1586,1493,1357,1283,1176,1101,820 \mathrm{~cm}^{-1}$.

MS (EI) $m / z$ (relative intensity) 194 (34) [M] ${ }^{+}, 179$ (67), 165 (100), 151 (20).

HR-MS (EI): $m / z$ calcd for $\mathrm{C}_{12} \mathrm{H}_{15} \mathrm{FO}^{+}[\mathrm{M}]^{+}$194.1101, found 194.1102 .

\section{Synthesis of 1-[4-Fluoro-3-(pentan-2-yl)phenyl]ethan-1-one (206ag)}

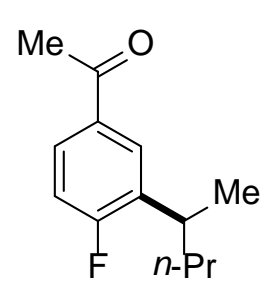

The general procedure $\mathbf{C}$ was followed using siubstrate $188 \mathrm{a}$ (152 $\mathrm{mg}, 0.50 \mathrm{mmol}$ ) and bromide $44 \mathrm{~g}(113 \mathrm{mg}, 0.75 \mathrm{mmol})$. After $20 \mathrm{~h}$, purification by column chromatography ( $n$-pentane/ $\mathrm{Et}_{2} \mathrm{O} 50: 1$ ) yielded $206 \mathrm{ag}$ (48 mg, 46\%) as a colorless oil. 
${ }^{1} \mathrm{H}$ NMR $\left(300 \mathrm{MHz}, \mathrm{CDCl}_{3}\right): \delta=7.84(\mathrm{dd}, J=7.2,2.3 \mathrm{~Hz}, 1 \mathrm{H}$ ), $7.75(\mathrm{ddd}, J=8.5,4.9,2.3 \mathrm{~Hz}, 1 \mathrm{H}$ ), 7.03 (dd, $J=9.8,8.5 \mathrm{~Hz}, 1 \mathrm{H}), 3.08(\mathrm{dt}, J=7.1,7.1 \mathrm{~Hz}, 1 \mathrm{H}), 2.56(\mathrm{~s}, 3 \mathrm{H}), 1.61-1.51(\mathrm{~m}, 2 \mathrm{H}), 1.33-1.11(\mathrm{~m}$, $5 \mathrm{H}), 0.91-0.82(\mathrm{~m}, 3 \mathrm{H})$.

${ }^{13} \mathrm{C} \mathrm{NMR}\left(75 \mathrm{MHz}, \mathrm{CDCl}_{3}\right): \delta=196.7\left(\mathrm{C}_{\mathrm{q}}\right), 163.8\left(\mathrm{~d},{ }^{1} J_{\mathrm{C}-\mathrm{F}}=253 \mathrm{~Hz}, \mathrm{C}_{\mathrm{q}}\right), 134.8\left(\mathrm{~d},{ }^{2} \mathrm{~J}_{\mathrm{C}-\mathrm{F}}=16 \mathrm{~Hz}, \mathrm{C}_{\mathrm{q}}\right), 133.5$ $\left(d,{ }^{4} J_{C-F}=3 \mathrm{~Hz}, C_{q}\right), 128.8\left(d,{ }^{3} J_{C-F}=7 \mathrm{~Hz}, \mathrm{CH}\right), 128.2\left(d,{ }^{3} J_{C-F}=10 \mathrm{~Hz}, \mathrm{CH}\right), 115.5\left(\mathrm{~d},{ }^{2} \mathrm{~J}_{\mathrm{C}-\mathrm{F}}=24 \mathrm{~Hz}, \mathrm{CH}\right)$, $39.2\left(\mathrm{~d},{ }^{4} \mathrm{~J}_{\mathrm{C}-\mathrm{F}}=1 \mathrm{~Hz}, \mathrm{CH}_{2}\right), 32.4\left(\mathrm{~d},{ }^{3} \mathrm{~J}_{\mathrm{C}-\mathrm{F}}=1 \mathrm{~Hz}, \mathrm{CH}\right), 26.6\left(\mathrm{CH}_{3}\right), 20.8\left(\mathrm{CH}_{3}\right), 20.8\left(\mathrm{CH}_{2}\right), 14.0\left(\mathrm{CH}_{3}\right)$.

${ }^{19} \mathrm{~F}$ NMR $\left(282 \mathrm{MHz}, \mathrm{CDCl}_{3}\right): \delta=-111.1(\mathrm{~s})$.

IR (neat): $\tilde{v}=2960,2873,1683,1493,1356,1284,1175,1102,820 \mathrm{~cm}^{-1}$.

MS (EI) $m / z$ (relative intensity) 208 (28) [M] ${ }^{+}, 193$ (50), 165 (100), 151 (15).

HR-MS (EI): $m / z$ calcd for $\mathrm{C}_{13} \mathrm{H}_{17} \mathrm{FO}^{+}[\mathrm{M}]^{+}$208.1258, found 208.1264 .

\section{Synthesis of 1-[4-Fluoro-3-(octan-2-yl)phenyl]ethan-1-one (206ad)}

$\mathrm{Me}=\mathrm{O}$ The general procedure $\mathrm{C}$ was followed using substrate $188 \mathrm{a}$ (152 $\mathrm{mg}, 0.50 \mathrm{mmol}$ ) and bromide 44d (145 mg, $0.75 \mathrm{mmol}$ ). After $20 \mathrm{~h}$, purification by column chromatography ( $n$-pentane/Et ${ }_{2} \mathrm{O} 40: 1$ ) yielded 206ad (50 mg, 40\%) as a colorless oil.

${ }^{1} \mathrm{H}$ NMR $\left(300 \mathrm{MHz}, \mathrm{CDCl}_{3}\right): \delta=7.84(\mathrm{dd}, J=7.2,2.3 \mathrm{~Hz}, 1 \mathrm{H}), 7.76$ (ddd, $J=8.5,4.9$, $2.3 \mathrm{~Hz}, 1 \mathrm{H}), 7.04(\mathrm{dd}, J=9.8,8.5 \mathrm{~Hz}, 1 \mathrm{H}), 3.06(\mathrm{dt}, J=7.1,7.1 \mathrm{~Hz}, 1 \mathrm{H}), 2.57(\mathrm{~s}, 3 \mathrm{H}), 1.64-1.52(\mathrm{~m}, 2 \mathrm{H})$, $1.32-1.12(\mathrm{~m}, 11 \mathrm{H}), 0.90-0.79(\mathrm{~m}, 3 \mathrm{H})$.

${ }^{13} \mathrm{C} \mathrm{NMR}\left(75 \mathrm{MHz}, \mathrm{CDCl}_{3}\right): \delta=196.7\left(\mathrm{C}_{\mathrm{q}}\right), 164.1\left(\mathrm{~d},{ }^{1} J_{\mathrm{C}-\mathrm{F}}=253 \mathrm{~Hz}, \mathrm{C}_{\mathrm{q}}\right), 134.9\left(\mathrm{~d},{ }^{2} \mathrm{~J}_{\mathrm{CF}}=16 \mathrm{~Hz}, \mathrm{C}_{\mathrm{q}}\right), 133.5$ $\left(d,{ }^{4} J_{C-F}=3 \mathrm{~Hz}, C_{q}\right), 128.6\left(d,{ }^{3} J_{C-F}=7 \mathrm{~Hz}, \mathrm{CH}\right), 128.0\left(d,{ }^{3} J_{C-F}=10 \mathrm{~Hz}, \mathrm{CH}\right), 115.4\left(\mathrm{~d},{ }^{2} J_{\mathrm{C}-\mathrm{F}}=24 \mathrm{~Hz}, \mathrm{CH}\right)$, $37.0\left(\mathrm{~d},{ }^{4} J_{\mathrm{C}-\mathrm{F}}=1 \mathrm{~Hz}, \mathrm{CH}_{2}\right), 32.7\left(\mathrm{~d},{ }^{3} \mathrm{~J}_{\mathrm{C}-\mathrm{F}}=1 \mathrm{~Hz}, \mathrm{CH}\right), 31.8\left(\mathrm{CH}_{2}\right), 29.3\left(\mathrm{CH}_{2}\right), 27.6\left(\mathrm{CH}_{2}\right), 26.6\left(\mathrm{CH}_{3}\right), 22.7$ $\left(\mathrm{CH}_{2}\right), 20.9\left(\mathrm{CH}_{3}\right), 14.1\left(\mathrm{CH}_{3}\right)$.

${ }^{19} \mathrm{~F} \mathrm{NMR}\left(282 \mathrm{MHz}, \mathrm{CDCl}_{3}\right): \delta=-111.0(\mathrm{~s})$.

IR (neat): $\tilde{v}=2959,2856,1684,1586,1493,1458,1356,1284,1106,819 \mathrm{~cm}^{-1}$.

MS (EI) $m / z$ (relative intensity) $250(23)\left[\mathrm{M}^{+}, 235\right.$ (35), 165 (100), 151 (22).

HR-MS (ESI): $m / z$ calcd for $\mathrm{C}_{16} \mathrm{H}_{24} \mathrm{FO}^{+}[\mathrm{M}+\mathrm{H}]^{+} 251.1806$, found 251.1811 .

\section{Synthesis of 1-(4-Isopropylnaphthalen-2-yl)ethan-1-one (206ih)}

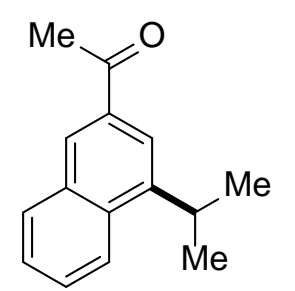

The general procedure $\mathbf{C}$ was followed using substrate $188 \mathrm{i}(168 \mathrm{mg}, 0.50 \mathrm{mmol}$ ) and bromide $44 \mathrm{~h}$ (185 $\mathrm{mg}, 1.50 \mathrm{mmol}$ ). After $20 \mathrm{~h}$, purification by column chromatography ( $n$-hexane/EtOAc 100:1) yielded 206ih ( $82 \mathrm{mg}, 77 \%$ ) as a white solid.

M. p.: $60-62^{\circ} \mathrm{C}$.

${ }^{1} \mathrm{H}$ NMR $\left(300 \mathrm{MHz}, \mathrm{CDCl}_{3}\right): \delta=8.31-8.27(\mathrm{~m}, 1 \mathrm{H}), 8.13(\mathrm{~d}, J=8.4 \mathrm{~Hz}, 1 \mathrm{H}), 7.99(\mathrm{~d}$, $J=1.7 \mathrm{~Hz}, 1 \mathrm{H}$ ), 7.98-7.92 (m, 1H), 7.62 (ddd, $J=8.5,6.8,1.5 \mathrm{~Hz}, 1 \mathrm{H}$ ), 7.52 (ddd, $J=8.0,6.8,1.2 \mathrm{~Hz}$, $1 \mathrm{H}), 3.73$ (hept, $J=6.9 \mathrm{~Hz}, 1 \mathrm{H}$ ), $2.71(\mathrm{~s}, 3 \mathrm{H}), 1.42(\mathrm{~d}, J=6.9 \mathrm{~Hz}, 6 \mathrm{H})$.

${ }^{13} \mathrm{C}$ NMR $\left(75 \mathrm{MHz}, \mathrm{CDCl}_{3}\right): \delta=198.2\left(\mathrm{C}_{\mathrm{q}}\right), 145.3\left(\mathrm{C}_{\mathrm{q}}\right), 134.0\left(\mathrm{C}_{\mathrm{q}}\right), 133.6\left(\mathrm{C}_{\mathrm{q}}\right), 132.9\left(\mathrm{C}_{\mathrm{q}}\right), 130.4(\mathrm{CH})$, $128.7(\mathrm{CH}), 128.2(\mathrm{CH}), 126.0(\mathrm{CH}), 123.3(\mathrm{CH}), 119.4(\mathrm{CH}), 28.7(\mathrm{CH}), 26.6\left(\mathrm{CH}_{3}\right), 23.4\left(\mathrm{CH}_{3}\right)$.

IR (ATR): $\tilde{v}=3063,2960,1671,1397,1271,1229,1194,1142,882 \mathrm{~cm}^{-1}$.

MS (EI) $m / z$ (relative intensity) 212 (58) [M] ${ }^{+}, 197$ (100), 152 (25), 115 (8).

HR-MS (EI): $m / z$ calcd for $\mathrm{C}_{15} \mathrm{H}_{16} \mathrm{O}^{+}[\mathrm{M}]^{+} 212.1196$, found 212.1209 . 


\section{Synthesis of 1-[4-(sec-Butyl)naphthalen-2-yl]ethan-1-one (206if)}<smiles>CCC(C)c1cc(C(C)=O)cc2ccccc12</smiles>

The general procedure $\mathbf{C}$ was followed using substrate $188 \mathrm{i}(168 \mathrm{mg}, 0.50 \mathrm{mmol})$ and bromide $44 \mathrm{f}(206 \mathrm{mg}, 1.50 \mathrm{mmol})$. After $20 \mathrm{~h}$, purification by column chromatography ( $n$-hexane/EtOAc 100:1) yielded 206if (84 mg, 74\%) as a colorless oil.

${ }^{1} \mathrm{H}$ NMR $\left(300 \mathrm{MHz}, \mathrm{CDCl}_{3}\right.$ ): $\delta=8.30(\mathrm{~d}, J=1.4 \mathrm{~Hz}, 1 \mathrm{H}$ ), 8.13 (ddd, $J=8.5,1.3,0.7$ $\mathrm{Hz}, 1 \mathrm{H}$ ), 8.00-7.90 (m, 2H), 7.61 (ddd, $J=8.5,6.8,1.5 \mathrm{~Hz}, 1 \mathrm{H}$ ), 7.52 (ddd, $J=8.0$, 6.8, 1.2 Hz, 1H), $3.50(\mathrm{dt}, J=6.9 \mathrm{~Hz}, 1 \mathrm{H}), 2.72(\mathrm{~s}, 3 \mathrm{H}), 1.97-1.80(\mathrm{~m}, 1 \mathrm{H}), 1.80-1.63(\mathrm{~m}, 1 \mathrm{H}), 1.39(\mathrm{~d}, J$ $=6.9 \mathrm{~Hz}, 3 \mathrm{H}), 0.92(\mathrm{t}, J=7.4 \mathrm{~Hz}, 3 \mathrm{H})$.

${ }^{13} \mathrm{C} \mathrm{NMR}\left(75 \mathrm{MHz}, \mathrm{CDCl}_{3}\right): \delta=198.2\left(\mathrm{C}_{\mathrm{q}}\right), 144.5\left(\mathrm{C}_{\mathrm{q}}\right), 134.1\left(\mathrm{C}_{\mathrm{q}}\right), 134.0\left(\mathrm{C}_{\mathrm{q}}\right), 133.0\left(\mathrm{C}_{\mathrm{q}}\right), 130.4(\mathrm{CH})$, $128.6(\mathrm{CH}), 128.1(\mathrm{CH}), 126.0(\mathrm{CH}), 123.3(\mathrm{CH}), 120.1(\mathrm{CH}), 35.5(\mathrm{CH}), 30.5\left(\mathrm{CH}_{2}\right), 26.6\left(\mathrm{CH}_{3}\right), 21.1$ $\left(\mathrm{CH}_{3}\right), 12.3\left(\mathrm{CH}_{3}\right)$.

IR (neat): $\tilde{v}=3056,2961,1674,1622,1425,1396,1278,1174,885 \mathrm{~cm}^{-1}$.

MS (EI) $m / z$ (relative intensity) 226 (52) [M] $]^{+}, 197$ (100), 153 (525), 127 (10).

HR-MS (EI): $\mathrm{m} / z$ calcd for $\mathrm{C}_{16} \mathrm{H}_{18} \mathrm{O}^{+}[\mathrm{M}]^{+} 226.1352$, found 226.1365 .

\section{Synthesis of 1-[4-(Pentan-2-yl)naphthalen-2-yl]ethan-1-one (206ig)}<smiles>CC(=O)c1cc(C(C)C(C)C)c2ccccc2c1</smiles>

The general procedure $\mathbf{C}$ was followed using substrate $188 \mathrm{i}(168 \mathrm{mg}, 0.50 \mathrm{mmol})$ and bromide $44 \mathrm{~g}(227 \mathrm{mg}, 1.50 \mathrm{mmol})$. After $20 \mathrm{~h}$, purification by column chromatography ( $n$-hexane/EtOAc 100:1) yielded 206ig (93 mg, 77\%) as a colorless oil.

${ }^{1} \mathbf{H}$ NMR $\left(300 \mathrm{MHz}, \mathrm{CDCl}_{3}\right): \delta=8.29(\mathrm{dd}, J=1.7,0.8 \mathrm{~Hz}, 1 \mathrm{H}), 8.17-8.10(\mathrm{~m}, 1 \mathrm{H})$, $7.98-7.92(\mathrm{~m}, 2 \mathrm{H}$ ), 7.61 (ddd, $J=8.5,6.8,1.5 \mathrm{~Hz}, 1 \mathrm{H}$ ), 7.52 (ddd, $J=8.1,6.8,1.2$ $\mathrm{Hz}, 1 \mathrm{H}), 3.59(\mathrm{dt}, J=6.9 \mathrm{~Hz}, 1 \mathrm{H}), 2.72(\mathrm{~s}, 3 \mathrm{H}), 1.90-1.77(\mathrm{~m}, 1 \mathrm{H}), 1.77-1.61(\mathrm{~m}, 1 \mathrm{H}), 1.46-1.24(\mathrm{~m}$, $5 \mathrm{H}), 0.90(\mathrm{t}, J=7.3 \mathrm{~Hz}, 3 \mathrm{H})$.

${ }^{13} \mathrm{C}$ NMR $\left(75 \mathrm{MHz}, \mathrm{CDCl}_{3}\right): \delta=198.2\left(\mathrm{C}_{\mathrm{q}}\right), 144.8\left(\mathrm{C}_{\mathrm{q}}\right), 134.0\left(\mathrm{C}_{\mathrm{q}}\right), 134.0\left(\mathrm{C}_{\mathrm{q}}\right), 133.4\left(\mathrm{C}_{\mathrm{q}}\right), 130.0(\mathrm{CH})$, $128.6(\mathrm{CH}), 128.1(\mathrm{CH}), 126.0(\mathrm{CH}), 123.3(\mathrm{CH}), 120.1(\mathrm{CH}), 40.0\left(\mathrm{CH}_{2}\right), 33.6(\mathrm{CH}), 26.6\left(\mathrm{CH}_{3}\right), 21.6$ $\left(\mathrm{CH}_{3}\right), 20.9\left(\mathrm{CH}_{2}\right), 14.3\left(\mathrm{CH}_{3}\right)$.

IR (neat): $\tilde{v}=2957,2928,1675,1623,1453,1375,1277,1194,885 \mathrm{~cm}^{-1}$.

MS (EI) $m / z$ (relative intensity) 240 (53) [M] ${ }^{+}, 197$ (100), 153 (26), 127 (11).

HR-MS (EI): $\mathrm{m} / z$ calcd for $\mathrm{C}_{17} \mathrm{H}_{20} \mathrm{O}^{+}[\mathrm{M}]^{+} 240.1509$, found 240.1523 .

\section{Synthesis of 1-(4-(Octan-2-yl)naphthalen-2-yl)ethan-1-one (206id)}

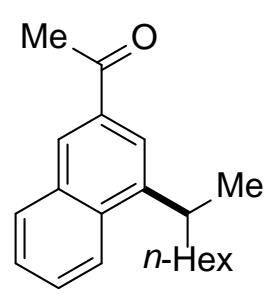

The general procedure $\mathbf{C}$ was followed using substrate $188 \mathrm{i}(168 \mathrm{mg}, 0.50 \mathrm{mmol})$ and bromide $44 \mathrm{~d}(290 \mathrm{mg}, 1.50 \mathrm{mmol})$. After $20 \mathrm{~h}$, purification by column chromatography ( $n$-hexane/EtOAc 100:1) yielded 206id (86 mg, 61\%) as a colorless oil.

${ }^{1} \mathbf{H}$ NMR $\left(300 \mathrm{MHz}, \mathrm{CDCl}_{3}\right): \delta=8.31-8.27(\mathrm{~m}, 1 \mathrm{H}), 8.17-8.10(\mathrm{~m}, 1 \mathrm{H}), 7.99-7.92$ (m, $2 \mathrm{H}$ ), 7.61 (ddd, $J=8.5,6.8,1.5 \mathrm{~Hz}, 1 \mathrm{H}$ ), 7.52 (ddd, $J=8.0,6.8,1.2 \mathrm{~Hz}, 1 \mathrm{H}$ ), $3.57(\mathrm{dt}, J=6.9 \mathrm{~Hz}, 1 \mathrm{H}), 2.72(\mathrm{~s}, 3 \mathrm{H}), 1.91-1.75(\mathrm{~m}, 1 \mathrm{H}), 1.75-1.63(\mathrm{~m}, 1 \mathrm{H}), 1.39(\mathrm{~d}, J=6.9 \mathrm{~Hz}, 3 \mathrm{H})$, $1.33-1.10(\mathrm{~m}, 8 \mathrm{H}), 0.92-0.72(\mathrm{~m}, 3 \mathrm{H})$. 
${ }^{13} \mathrm{C}$ NMR $\left(75 \mathrm{MHz}, \mathrm{CDCl}_{3}\right): \delta=198.2\left(\mathrm{C}_{\mathrm{q}}\right), 144.8\left(\mathrm{C}_{\mathrm{q}}\right), 134.0\left(\mathrm{C}_{\mathrm{q}}\right), 134.0\left(\mathrm{C}_{\mathrm{q}}\right), 133.0\left(\mathrm{C}_{\mathrm{q}}\right), 130.4(\mathrm{CH})$, $128.6(\mathrm{CH}), 128.1(\mathrm{CH}), 126.0(\mathrm{CH}), 123.2(\mathrm{CH}), 120.1(\mathrm{CH}), 37.8\left(\mathrm{CH}_{2}\right), 33.9(\mathrm{CH}), 31.8\left(\mathrm{CH}_{2}\right), 29.5$ $\left(\mathrm{CH}_{2}\right), 27.8\left(\mathrm{CH}_{2}\right), 26.6\left(\mathrm{CH}_{3}\right), 22.7\left(\mathrm{CH}_{2}\right), 21.6\left(\mathrm{CH}_{3}\right), 14.1\left(\mathrm{CH}_{3}\right)$.

IR (neat): $\tilde{v}=2956,2954,1677,1454,1352,1276,1195,885 \mathrm{~cm}^{-1}$.

MS (EI) $m / z$ (relative intensity) $282(50)\left[\mathrm{M}^{+}, 191\right.$ (100), 153 (22), 127 (5).

HR-MS (EI): $m / z$ calcd for $\mathrm{C}_{20} \mathrm{H}_{26} \mathrm{O}^{+}[\mathrm{M}]^{+} 282.1978$, found 282.1994.

\section{Synthesis of $N$-[1-(3-Cycloheptylphenyl)ethy]-3,4,5-trimethoxyaniline (207be)}<smiles>COc1cc(NC(C)c2cccc(C3CCCCCC3)c2)cc(OC)c1OC</smiles>

$52 \%)$ as a yellow oil.

The general procedure $\mathbf{C}$ was followed using $\left[\mathrm{RuCl}_{2}(p \text {-cymene) }]_{2}\right.$ (30.6 mg, 5.0 $\mathrm{mol} \%$ ), $1-\mathrm{AdCO}_{2} \mathrm{H}$ (54.1 mg, $30 \mathrm{~mol} \%$ ), substrate $188 \mathrm{~b}$ (285.3 mg, $1.0 \mathrm{mmol}$ ) and bromide $44 \mathrm{e}\left(531 \mathrm{mg}, 3.0 \mathrm{mmol}\right.$ ). After $20 \mathrm{~h}$, a solution of $\mathrm{ZnCl}_{2}$ in THF $(1.7 \mathrm{M}, 1.0 \mathrm{mmol}), \mathrm{NaBH}_{3} \mathrm{CN}(126.0 \mathrm{mg}, 2.0 \mathrm{mmol})$ and $\mathrm{MeOH}(3 \mathrm{~mL})$ were successively added to the reaction mixture at ambient temperature. The reaction mixture was stirred at ambient temperature for an additional $16 \mathrm{~h}$ and then distributed between $\mathrm{Et}_{2} \mathrm{O}(15 \mathrm{~mL})$ and sat. aq. $\mathrm{K}_{2} \mathrm{CO}_{3}(15 \mathrm{~mL})$. The aqueous phase was extracted with $\mathrm{Et}_{2} \mathrm{O}(2 \times 20 \mathrm{~mL})$, the combined organic layers were dried over $\mathrm{Na}_{2} \mathrm{SO}_{4}$ and concentrated in vacuo. Purification by column chromatography ( $n$-hexane/EtOAc 10:1) yielded 207be $(200.0 \mathrm{mg}$,

${ }^{1}$ H NMR $\left(300 \mathrm{MHz}, \mathrm{CDCl}_{3}\right): \delta=7.24-7.19(\mathrm{~m}, 1 \mathrm{H}), 7.19-7.14(\mathrm{~m}, 2 \mathrm{H}), 7.05(\mathrm{dt}, J=7.5,1.5 \mathrm{~Hz}, 1 \mathrm{H})$, $5.76(\mathrm{~s}, 2 \mathrm{H}), 4.38(\mathrm{q}, J=6.7 \mathrm{~Hz}, 1 \mathrm{H}), 3.71(\mathrm{~s}, 3 \mathrm{H}), 3.67(\mathrm{~s}, 6 \mathrm{H}), 2.68-2.61(\mathrm{~m}, 1 \mathrm{H}), 1.90-1.84(\mathrm{~m}, 2 \mathrm{H})$, $1.83-1.72(\mathrm{~m}, 2 \mathrm{H}), 1.72-1.52(\mathrm{~m}, 8 \mathrm{H}), 1.50(\mathrm{~d}, J=6.7 \mathrm{~Hz}, 3 \mathrm{H})$.

${ }^{13} \mathrm{C}$ NMR $\left(75 \mathrm{MHz}, \mathrm{CDCl}_{3}\right): \delta=153.4\left(\mathrm{C}_{\mathrm{q}}\right), 150.2\left(\mathrm{C}_{\mathrm{q}}\right), 145.1\left(\mathrm{C}_{\mathrm{q}}\right), 144.0\left(\mathrm{C}_{\mathrm{q}}\right), 129.7\left(\mathrm{C}_{\mathrm{q}}\right), 128.5(\mathrm{CH})$, 125.1 (CH), 124.3(CH), 122.7 (CH), 91.0 (CH), $60.9(\mathrm{CH}), 55.6\left(\mathrm{CH}_{3}\right), 54.4\left(\mathrm{CH}_{3}\right), 47.0(\mathrm{CH}), 36.9\left(\mathrm{CH}_{2}\right)$, 36.7 $\left(\mathrm{CH}_{2}\right), 27.9\left(\mathrm{CH}_{2}\right), 27.9\left(\mathrm{CH}_{2}\right), 27.2\left(\mathrm{CH}_{2}\right), 27.2\left(\mathrm{CH}_{2}\right), 24.7\left(\mathrm{CH}_{3}\right)$.

IR (neat): $\tilde{v}=3356,2996,2850,1599,1507,1447,1205,1126,1008,812 \mathrm{~cm}^{-1}$.

MS (EI) $m / z$ (relative intensity) 383 (92) [M] ${ }^{+}, 201$ (100), 168 (78), 119 (15).

HR-MS (EI): $\mathrm{m} / z$ calcd for $\mathrm{C}_{24} \mathrm{H}_{33} \mathrm{NO}_{3}{ }^{+}[\mathrm{M}]^{+} 383.2455$, found 383.2469.

\section{Synthesis of $\boldsymbol{N}$-[1-(3-Cycloheptyl-4-fluorophenyl)ethyl]-3,4,5-trimethoxyaniline (207ae)}<smiles>COc1cc(NC(C)c2ccc(F)c(C3CCCCCC3)c2)cc(OC)c1OC</smiles>

$61 \%)$ as a yellow solid.

M. p.: $60-62^{\circ} \mathrm{C}$.
The general procedure $\mathbf{C}$ was followed using $\left[\mathrm{RuCl}_{2} \text { (p-cymene) }\right]_{2}$ (30.6 mg, 5.0 $\mathrm{mol} \%$ ), $1-\mathrm{AdCO}_{2} \mathrm{H}(54.1 \mathrm{mg}, 30 \mathrm{~mol} \%)$, substrate $188 \mathrm{a}(303.3 \mathrm{mg}, 1.0 \mathrm{mmol})$ and bromide $44 \mathrm{e}\left(531 \mathrm{mg}, 3.0 \mathrm{mmol}\right.$ ). After $20 \mathrm{~h}$, a solution of $\mathrm{ZnCl}_{2}$ in THF $(1.7 \mathrm{M}, 1.0 \mathrm{mmol}), \mathrm{NaBH}_{3} \mathrm{CN}(126.0 \mathrm{mg}, 2.0 \mathrm{mmol})$ and $\mathrm{MeOH}(3 \mathrm{~mL})$ were successively added to the reaction mixture at ambient temperature. The reaction mixture was stirred at ambient temperature for an additional $16 \mathrm{~h}$ and then distributed between $\mathrm{Et}_{2} \mathrm{O}(15 \mathrm{~mL})$ and sat. aq. $\mathrm{K}_{2} \mathrm{CO}_{3}(15 \mathrm{~mL})$. The aqueous phase was extracted with $\mathrm{Et}_{2} \mathrm{O}(2 \times 20 \mathrm{~mL})$, the combined organic layers were dried over $\mathrm{Na}_{2} \mathrm{SO}_{4}$ and concentrated in vacuo. Purification by column chromatography ( $n$-hexane/EtOAc 10:1) yielded 207ae $(245.0 \mathrm{mg}$, . 
${ }^{1} \mathrm{H}$ NMR $\left(300 \mathrm{MHz}, \mathrm{CDCl}_{3}\right): \delta=7.19$ (dd, $J=7.1,2.3 \mathrm{~Hz}, 1 \mathrm{H}$ ), 7.11 (ddd, $J=8.4,4.9,2.3 \mathrm{~Hz}, 1 \mathrm{H}$ ), 6.91 $(\mathrm{dd}, J=10.1,8.4 \mathrm{~Hz}, 1 \mathrm{H}), 5.73(\mathrm{~s}, 2 \mathrm{H}), 4.36(\mathrm{q}, J=6.6 \mathrm{~Hz}, 1 \mathrm{H}), 4.01-3.78(\mathrm{~m}, 1 \mathrm{H}), 3.70(\mathrm{~s}, 3 \mathrm{H}), 3.67(\mathrm{~s}$, $6 \mathrm{H}), 3.01-2.90(\mathrm{~m}, 1 \mathrm{H}), 1.89-1.49(\mathrm{~m}, 12 \mathrm{H}), 1.46(\mathrm{~d}, J=6.6 \mathrm{~Hz}, 3 \mathrm{H})$.

${ }^{13} \mathrm{C} \mathrm{NMR}\left(75 \mathrm{MHz}, \mathrm{CDCl}_{3}\right): \delta=158.8\left(\mathrm{~d},{ }^{1} \mathrm{~J}_{\mathrm{C}-\mathrm{F}}=243 \mathrm{~Hz}, \mathrm{C}_{\mathrm{q}}\right), 153.5\left(\mathrm{C}_{\mathrm{q}}\right), 144.0\left(\mathrm{C}_{\mathrm{q}}\right), 140.8\left(\mathrm{~d},{ }^{4} \mathrm{~J}_{\mathrm{CF}}=3 \mathrm{~Hz}\right.$, $\left.\mathrm{C}_{\mathrm{q}}\right), 136.3\left(\mathrm{~d},{ }^{2} J_{\mathrm{C}-\mathrm{F}}=16 \mathrm{~Hz}, \mathrm{C}_{\mathrm{q}}\right), 129.8\left(\mathrm{C}_{\mathrm{q}}\right), 125.4\left(\mathrm{~d},{ }^{3} \mathrm{~J}_{\mathrm{C}-\mathrm{F}}=6 \mathrm{~Hz}, \mathrm{CH}\right), 123.8\left(\mathrm{~d},{ }^{3} J_{\mathrm{C}-\mathrm{F}}=9 \mathrm{~Hz}, \mathrm{CH}\right), 115.4$ $\left(\mathrm{d},{ }^{2} J_{\mathrm{C}-\mathrm{F}}=24 \mathrm{~Hz}, \mathrm{CH}\right), 91.0(\mathrm{CH}), 61.0(\mathrm{CH}), 55.7\left(\mathrm{CH}_{3}\right), 53.9\left(\mathrm{CH}_{3}\right), 39.7\left(\mathrm{~d},{ }^{3} \mathrm{~J}_{\mathrm{C}-\mathrm{F}}=1 \mathrm{~Hz}, \mathrm{CH}\right), 35.5\left(\mathrm{CH}_{2}\right)$, $35.3\left(\mathrm{CH}_{2}\right), 27.8\left(\mathrm{CH}_{2}\right), 27.8\left(\mathrm{CH}_{2}\right), 27.3\left(\mathrm{CH}_{2}\right), 27.3\left(\mathrm{CH}_{2}\right), 24.9\left(\mathrm{CH}_{3}\right)$.

${ }^{19} \mathrm{~F}-\mathrm{NMR}\left(282 \mathrm{MHz}, \mathrm{CDCl}_{3}\right): \delta=-121.7(\mathrm{~s})$.

IR (ATR): $\tilde{v}=3378,2921,2851,1607,1507,1411,1232,1008,792 \mathrm{~cm}^{-1}$.

MS (EI) $m / z$ (relative intensity) $401(85)\left[\mathrm{M}^{+}\right], 219$ (100), 168 (68), 119 (13).

HR-MS (EI): $m / z$ calcd for $\mathrm{C}_{24} \mathrm{H}_{32} \mathrm{FNO}_{3}{ }^{+}[\mathrm{M}]^{+} 401.2361$, found 401.2371 .

\section{Synthesis of 1-(2-Cyclobutyl-4-fluorophenyl)ethan-1-one (206aj)}

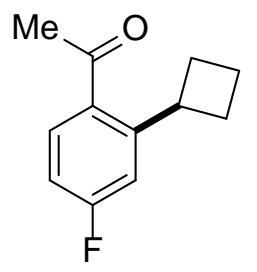

The general procedure $\mathbf{C}$ was followed using substrate $188 \mathrm{a}(152 \mathrm{mg}, 0.50 \mathrm{mmol})$ and bromide 44j (203 mg, $1.50 \mathrm{mmol}$ ). After $20 \mathrm{~h}$, purification by column chromatography ( $n$-hexane/EtOAc 100:1) yielded 206aj (48 mg, 50\%) as a colorless oil.

${ }^{1} \mathrm{H}$ NMR $\left(300 \mathrm{MHz}, \mathrm{CDCl}_{3}\right): \delta=7.55(\mathrm{dd}, J=8.5,5.8 \mathrm{~Hz}, 1 \mathrm{H}), 7.08$ (ddd, $J=10.6,2.6$, $0.8 \mathrm{~Hz}, 1 \mathrm{H}$ ), 6.88 (dddd, $J=8.5,7.8,2.6,0.6 \mathrm{~Hz}, 1 \mathrm{H}), 4.13-3.93(\mathrm{~m}, 1 \mathrm{H}), 2.51(\mathrm{~s}, 3 \mathrm{H}), 2.39-2.23(\mathrm{~m}$, $2 \mathrm{H}), 2.07-1.88(\mathrm{~m}, 3 \mathrm{H}), 1.85-1.69(\mathrm{~m}, 1 \mathrm{H})$.

${ }^{13}$ C NMR $\left(75 \mathrm{MHz}, \mathrm{CDCl}_{3}\right): \delta=200.7\left(\mathrm{C}_{\mathrm{q}}\right), 164.2\left(\mathrm{~d},{ }^{1} \mathrm{~J}_{\mathrm{C}-\mathrm{F}}=253 \mathrm{~Hz}, \mathrm{C}_{\mathrm{q}}\right), 149.3\left(\mathrm{~d},{ }^{3} \mathrm{~J}_{\mathrm{C}-\mathrm{F}}=8 \mathrm{~Hz}, \mathrm{C}_{\mathrm{q}}\right), 134.0$ $\left(d,{ }^{4} J_{C-F}=3 \mathrm{~Hz}, C_{q}\right), 130.9\left(d,{ }^{3} J_{C-F}=9 \mathrm{~Hz}, \mathrm{CH}\right), 114.6\left(\mathrm{~d},{ }^{2} J_{\mathrm{C}-\mathrm{F}}=22 \mathrm{~Hz}, \mathrm{CH}\right), 112.2\left(\mathrm{~d},{ }^{2} J_{\mathrm{C}-\mathrm{F}}=22 \mathrm{~Hz}, \mathrm{CH}\right)$, $38.2\left(d,{ }^{4} J_{C-F}=1 \mathrm{~Hz}, \mathrm{CH}\right), 29.8\left(\mathrm{CH}_{3}\right), 29.3\left(\mathrm{CH}_{2}\right), 18.0\left(\mathrm{CH}_{2}\right)$.

${ }^{19} \mathrm{~F} \mathrm{NMR}\left(282 \mathrm{MHz}, \mathrm{CDCl}_{3}\right): \delta=-108.0(\mathrm{~s})$.

IR (neat): $\tilde{v}=2923,2855,1675,1579,1495,1442,1355,1242,1130,1026,815 \mathrm{~cm}^{-1}$.

MS (EI) $m / z$ (relative intensity) 192 (8) [M] $]^{+}, 163$ (100), 149 (55), 121 (20).

HR-MS (EI): $m / z$ calcd for $\mathrm{C}_{12} \mathrm{H}_{13} \mathrm{FO}^{+}[\mathrm{M}]^{+} 192.0945$, found 192.0947 .

The spectral data were in accordance with those reported in the literature. ${ }^{118}$

\section{Synthesis of 1-(3-Cyclopentyl-4-fluorophenyl)ethan-1-one (206ak)}

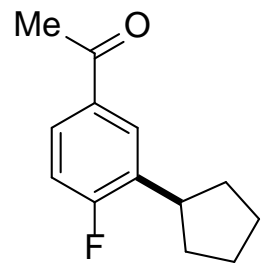

The general procedure $\mathbf{C}$ was followed using substrate $188 \mathrm{a}(152 \mathrm{mg}, 0.50 \mathrm{mmol})$ and bromide $44 \mathbf{k}(224 \mathrm{mg}, 1.50 \mathrm{mmol})$. After $20 \mathrm{~h}$, purification by column chromatography ( $n$-hexane/EtOAc 100:1) yielded 206ak (55 mg, 53\%) as a colorless oil.

${ }^{1} \mathrm{H}$ NMR $\left(300 \mathrm{MHz}, \mathrm{CDCl}_{3}\right): \delta=7.90$ (dd, $J=7.3,2.4 \mathrm{~Hz}, 1 \mathrm{H}$ ), 7.73 (ddd, $J=8.5,4.9$, $2.4 \mathrm{~Hz}, 1 \mathrm{H}), 7.04(\mathrm{dd}, J=9.9,8.5 \mathrm{~Hz}, 1 \mathrm{H}), 3.31-3.17(\mathrm{~m}, 1 \mathrm{H}), 2.57(\mathrm{~s}, 3 \mathrm{H}), 2.14-1.97(\mathrm{~m}, 2 \mathrm{H}), 1.87-1.76$ $(\mathrm{m}, 2 \mathrm{H}), 1.73-1.57(\mathrm{~m}, 4 \mathrm{H})$.

${ }^{13} \mathrm{C} \mathrm{NMR}\left(75 \mathrm{MHz}, \mathrm{CDCl}_{3}\right): \delta=199.6\left(\mathrm{C}_{\mathrm{q}}\right), 164.0\left(\mathrm{~d},{ }^{1} J_{\mathrm{C}-\mathrm{F}}=253 \mathrm{~Hz}, \mathrm{C}_{\mathrm{q}}\right), 133.4\left(\mathrm{~d},{ }^{2} J_{\mathrm{C}-\mathrm{F}}=15 \mathrm{~Hz}, \mathrm{C}_{\mathrm{q}}\right), 133.3$ $\left(\mathrm{d},{ }^{4} \mathrm{~J}_{\mathrm{C}-\mathrm{F}}=3 \mathrm{~Hz}, \mathrm{C}_{\mathrm{q}}\right), 128.5\left(\mathrm{~d},{ }^{3} \mathrm{~J}_{\mathrm{C}-\mathrm{F}}=7 \mathrm{~Hz}, \mathrm{CH}\right), 128.0\left(\mathrm{~d},{ }^{3} \mathrm{~J}_{\mathrm{C}-\mathrm{F}}=10 \mathrm{~Hz}, \mathrm{CH}\right), 115.3\left(\mathrm{~d},{ }^{2} \mathrm{~J}_{\mathrm{C}-\mathrm{F}}=24 \mathrm{~Hz}, \mathrm{CH}\right.$ ), $38.8\left(\mathrm{~d},{ }^{3} J_{\mathrm{C}-\mathrm{F}}=1 \mathrm{~Hz}, \mathrm{CH}\right), 33.1\left(\mathrm{~d},{ }^{4} \mathrm{~J}_{\mathrm{C}-\mathrm{F}}=1 \mathrm{~Hz}, \mathrm{CH}_{2}\right), 26.5\left(\mathrm{CH}_{3}\right), 25.4\left(\mathrm{CH}_{2}\right)$.

${ }^{19} \mathrm{~F} \mathrm{NMR}\left(282 \mathrm{MHz}, \mathrm{CDCl}_{3}\right): \delta=-109.7(\mathrm{~s})$.

IR (neat): $\tilde{v}=3348,2954,2871,1682,1585,1492,1356,1250,1112,822 \mathrm{~cm}^{-1}$.

MS (EI) $m / z$ (relative intensity) $206(23)\left[\mathrm{M}^{+}, 191\right.$ (100), 163 (16), 149 (20).

HR-MS (EI): $m / z$ calcd for $\mathrm{C}_{13} \mathrm{H}_{15} \mathrm{FO}^{+}[\mathrm{M}]^{+}$206.1101, found 206.1112. 


\section{Synthesis of 1-(3-Cyclohexyl-4-fluorophenyl)ethan-1-one (206ac)}<smiles>CC(=O)c1ccc(F)c(C2CCCCC2)c1</smiles>

The general procedure $C$ was followed using substrate $188 \mathrm{a}(152 \mathrm{mg}, 0.50 \mathrm{mmol})$ and bromide $44 \mathrm{c}(245 \mathrm{mg}, 1.50 \mathrm{mmol})$. After $20 \mathrm{~h}$, purification by column chromatography ( $n$-hexane/EtOAc 100:1) yielded 206ac (30 mg, 27\%) as a colorless oil.

${ }^{1} \mathrm{H}$ NMR $\left(300 \mathrm{MHz}, \mathrm{CDCl}_{3}\right.$ ): $\delta=7.86(\mathrm{dd}, J=7.3,2.3 \mathrm{~Hz}, 1 \mathrm{H}$ ), 7.75 (ddd, $J=8.5$, 5.0, $2.3 \mathrm{~Hz}, 1 \mathrm{H}), 7.03(\mathrm{dd}, J=9.9,8.5 \mathrm{~Hz}, 1 \mathrm{H}), 2.90-2.80(\mathrm{~m}, 1 \mathrm{H}), 2.55(\mathrm{~s}, 3 \mathrm{H})$,

$1.88-1.69(\mathrm{~m}, 5 \mathrm{H}), 1.54-1.20(\mathrm{~m}, 5 \mathrm{H})$.

${ }^{13} \mathrm{C} \mathrm{NMR}\left(75 \mathrm{MHz}, \mathrm{CDCl}_{3}\right): \delta=196.7\left(\mathrm{C}_{\mathrm{q}}\right), 163.6\left(\mathrm{~d},{ }^{1} J_{\mathrm{C}-\mathrm{F}}=253 \mathrm{~Hz}, \mathrm{C}_{\mathrm{q}}\right), 134.9\left(\mathrm{~d},{ }^{2} \mathrm{~J}_{\mathrm{C}-\mathrm{F}}=16 \mathrm{~Hz}, \mathrm{C}_{\mathrm{q}}\right), 133.4$ $\left(d,{ }^{4} J_{C-F}=3 \mathrm{~Hz}, C_{q}\right), 128.3\left(d,{ }^{3} J_{C-F}=7 \mathrm{~Hz}, C H\right), 128.0\left(d,{ }^{3} J_{C-F}=10 \mathrm{~Hz}, C H\right), 115.3\left(d,{ }^{2} J_{C-F}=24 \mathrm{~Hz}, C H\right)$, $37.2\left(d^{3}{ }^{3} \mathrm{C}_{\mathrm{C}-\mathrm{F}}=2 \mathrm{~Hz}, \mathrm{CH}\right), 32.9\left(\mathrm{CH}_{2}\right), 26.8\left(\mathrm{CH}_{2}\right), 26.6\left(\mathrm{CH}_{3}\right), 26.1\left(\mathrm{CH}_{2}\right)$.

${ }^{19} \mathrm{~F}$ NMR $\left(282 \mathrm{MHz}, \mathrm{CDCl}_{3}\right): \delta=-111.6(\mathrm{~s})$.

IR (neat): $\tilde{v}=2926,2852,1682,1586,1492,1355,1254,1107,820 \mathrm{~cm}^{-1}$.

MS (EI) m/z (relative intensity) 220 (23) [M] $]^{+}, 205$ (100), 149 (23), 109 (12).

HR-MS (EI): $m / z$ calcd for $\mathrm{C}_{14} \mathrm{H}_{17} \mathrm{FO}^{+}[\mathrm{M}]^{+} 220.1258$, found 220.1262 .

\section{1-(3-Cyclooctyl-4-fluorophenyl)ethan-1-one (206al)}

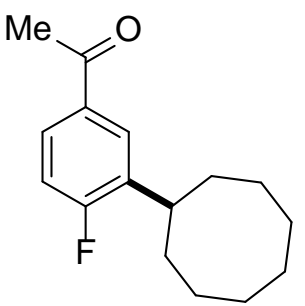

The general procedure $C$ was followed using substrate $188 \mathrm{a}(152 \mathrm{mg}, 0.50$ $\mathrm{mmol}$ ) and bromide $44 \mathrm{l}(287 \mathrm{mg}, 1.50 \mathrm{mmol})$. After $20 \mathrm{~h}$, purification by column chromatography ( $n$-hexane/EtOAc 100:1) yielded 206al (75 mg, 60\%) as a colorless oil.

${ }^{1} \mathrm{H}$ NMR $\left(300 \mathrm{MHz}, \mathrm{CDCl}_{3}\right): \delta=7.87$ (dd, $\left.J=7.3,2.4 \mathrm{~Hz}, 1 \mathrm{H}\right), 7.75$ (ddd, $J=8.5$, 4.9, $2.4 \mathrm{~Hz}, 1 \mathrm{H}), 7.03(\mathrm{dd}, J=9.9,8.5 \mathrm{~Hz}, 1 \mathrm{H}), 3.18-3.06(\mathrm{~m}, 1 \mathrm{H}), 2.57(\mathrm{~s}, 3 \mathrm{H})$,

$1.83-1.76(\mathrm{~m}, 6 \mathrm{H}), 1.70-1.56(\mathrm{~m}, 8 \mathrm{H})$.

${ }^{13} \mathrm{C}$ NMR $\left(75 \mathrm{MHz}, \mathrm{CDCl}_{3}\right): \delta=196.7\left(\mathrm{C}_{\mathrm{q}}\right), 163.1\left(\mathrm{~d},{ }^{1} J_{\mathrm{C}-\mathrm{F}}=253 \mathrm{~Hz}, \mathrm{C}_{\mathrm{q}}\right), 137.2\left(\mathrm{~d},{ }^{2} \mathrm{~J}_{\mathrm{C}-\mathrm{F}}=16 \mathrm{~Hz}, \mathrm{C}_{\mathrm{q}}\right), 133.3$ $\left(d,{ }^{4} J_{C-F}=3 \mathrm{~Hz}, C_{q}\right), 128.8\left(d,{ }^{3} J_{C-F}=7 \mathrm{~Hz}, C H\right), 127.8\left(d,{ }^{3} J_{C-F}=10 \mathrm{~Hz}, C H\right), 115.4\left(d,{ }^{2} J_{C-F}=24 \mathrm{~Hz}, C H\right)$, 37.3 (CH), 33.4 $\left(\mathrm{CH}_{2}\right), 26.7\left(\mathrm{CH}_{2}\right), 26.6\left(\mathrm{CH}_{3}\right), 26.4\left(\mathrm{CH}_{2}\right), 26.0\left(\mathrm{CH}_{2}\right)$.

${ }^{19} \mathrm{~F}$ NMR $\left(282 \mathrm{MHz}, \mathrm{CDCl}_{3}\right): \delta=-110.6(\mathrm{~s})$.

IR (neat): $\tilde{v}=2919,2852,1682,1585,1492,1355,1283,1108,822 \mathrm{~cm}^{-1}$.

MS (EI) $m / z$ (relative intensity) 248 (47) [M] $]^{+}, 233$ (38), 164 (69), 149 (100).

HR-MS (EI): $m / z$ calcd for $\mathrm{C}_{16} \mathrm{H}_{22} \mathrm{FO}^{+}[\mathrm{M}+\mathrm{H}]^{+} 249.1649$, found 249.1654 .

\section{Synthesis of 2-(2,6-Dicyclobutyl-4-methoxyphenyl)pyridine (208bj)}<smiles>COc1cc(C2CCC2)c(-c2ccccn2)c(C2CCC2)c1</smiles>

The general procedure $\mathbf{A}$ was followed using substrate $\mathbf{3 8 b}(93 \mathrm{mg}, 0.50$ $\mathrm{mmol}$ ) and bromide 44j (202 $\mathrm{mg}, 1.50 \mathrm{mmol})$. After $20 \mathrm{~h}$, purification by column chromatography ( $n$-hexane/EtOAc 20:1) yielded 208bj (75 mg, 51\%) as a colorless oil.

${ }^{1} \mathrm{H}_{\mathrm{NMR}}\left(300 \mathrm{MHz}, \mathrm{CDCl}_{3}\right): \delta=8.65$ (ddd, $J=4.9,1.9,1.0 \mathrm{~Hz}, 1 \mathrm{H}$ ), 7.66 (ddd, $J$ $=7.7,7.7,1.9 \mathrm{~Hz}, 1 \mathrm{H}$ ), 7.20 (ddd, $J=7.6,4.9,1.2 \mathrm{~Hz}, 1 \mathrm{H}$ ), 7.14 (ddd, $J=7.8$, 
7.8, $1.1 \mathrm{~Hz}, 1 \mathrm{H}), 6.76(\mathrm{~s}, 2 \mathrm{H}), 3.86(\mathrm{~s}, 3 \mathrm{H}), 3.38-3.22(\mathrm{~m}, 2 \mathrm{H}), 2.07-1.86(\mathrm{~m}, 4 \mathrm{H}), 1.81-1.57(\mathrm{~m}, 8 \mathrm{H})$.

${ }^{13} \mathrm{C}$ NMR $\left(75 \mathrm{MHz}, \mathrm{CDCl}_{3}\right): \delta=159.4\left(\mathrm{C}_{\mathrm{q}}\right), 159.3\left(\mathrm{C}_{\mathrm{q}}\right), 149.0(\mathrm{CH}), 144.9\left(\mathrm{C}_{\mathrm{q}}\right), 135.5(\mathrm{CH}), 131.1\left(\mathrm{C}_{\mathrm{q}}\right)$, $125.4(\mathrm{CH}), 121.2(\mathrm{CH}), 109.0(\mathrm{CH}), 55.2\left(\mathrm{CH}_{3}\right), 38.7(\mathrm{CH}), 30.0\left(\mathrm{CH}_{2}\right), 29.3\left(\mathrm{CH}_{2}\right), 18.0\left(\mathrm{CH}_{2}\right)$.

IR (neat): $\tilde{v}=2962,2962,1598,1453,1302,1156,1072,860 \mathrm{~cm}^{-1}$.

MS (EI) m/z (relative intensity) 293 (58) [M] ${ }^{+}, 264$ (92), 236 (100), 192 (23).

HR-MS (EI): $m / z$ calcd for $\mathrm{C}_{20} \mathrm{H}_{22} \mathrm{NO}^{+}[\mathrm{M}-\mathrm{H}]^{+} 292.1696$, found 292.1704 .

Synthesis of 2-(3-Cyclopentyl-4-methoxyphenyl)pyridine (208bk)

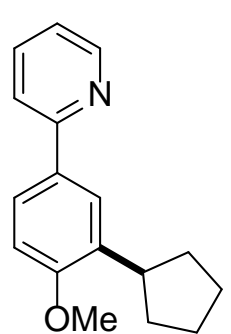

The general procedure A was followed using substrate $\mathbf{3 8 b}$ (93 $\mathrm{mg}, 0.50 \mathrm{mmol}$ ) and bromide 44k (224 mg, $1.50 \mathrm{mmol})$. After $20 \mathrm{~h}$, purification by column chromatography ( $n$-hexane/EtOAc 20:1) yielded 208bk (82 mg,65\%) as a colorless oil.

${ }^{1} \mathrm{H}$ NMR $\left(300 \mathrm{MHz}, \mathrm{CDCl}_{3}\right): \delta=8.64(\mathrm{~d}, J=4.9 \mathrm{~Hz}, 1 \mathrm{H}), 7.89(\mathrm{~d}, J=2.3 \mathrm{~Hz}, 1 \mathrm{H}), 7.77$ (dd, $J=8.5,2.3 \mathrm{~Hz}, 1 \mathrm{H}), 7.72-7.59(\mathrm{~m}, 2 \mathrm{H}), 7.13$ (ddd, $J=6.7,4.9,2.1 \mathrm{~Hz}, 1 \mathrm{H}), 6.91$ $(\mathrm{d}, J=8.5 \mathrm{~Hz}, 1 \mathrm{H}), 3.86(\mathrm{~s}, 3 \mathrm{H}), 3.42-3.28(\mathrm{~m}, 1 \mathrm{H}), 2.10-1.99(\mathrm{~m}, 2 \mathrm{H}), 1.87-1.75(\mathrm{~m}$, $2 \mathrm{H}), 1.74-1.60(\mathrm{~m}, 4 \mathrm{H})$.

${ }^{13} \mathrm{C}$ NMR $\left(75 \mathrm{MHz}, \mathrm{CDCl}_{3}\right): \delta=158.3\left(\mathrm{C}_{\mathrm{q}}\right), 157.5\left(\mathrm{C}_{\mathrm{q}}\right), 149.3(\mathrm{CH}), 136.4(\mathrm{CH}), 134.7\left(\mathrm{C}_{\mathrm{q}}\right), 131.6\left(\mathrm{C}_{\mathrm{q}}\right)$, $125.4(\mathrm{CH}), 125.2(\mathrm{CH}), 121.1(\mathrm{CH}), 119.8(\mathrm{CH}), 110.3(\mathrm{CH}), 55.5\left(\mathrm{CH}_{3}\right), 39.4(\mathrm{CH}), 33.0\left(\mathrm{CH}_{2}\right), 25.5$ $\left(\mathrm{CH}_{2}\right)$.

IR (neat): $\tilde{v}=2950,2867,1587,1462,1242,1122,777,594 \mathrm{~cm}^{-1}$.

MS (EI) $m / z$ (relative intensity) $253(100)[\mathrm{M}]^{+}, 212(83), 196(22), 167$ (33).

HR-MS (EI): $m / z$ calcd for $\mathrm{C}_{17} \mathrm{H}_{19} \mathrm{NO}^{+}[\mathrm{M}]^{+} 253.1461$, found 253.1465 .

Intermolecular Competition Experiment between Secondary Alkyl Halides 44j and 44k

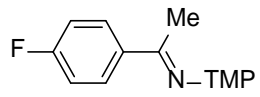

$88 \mathrm{a}$

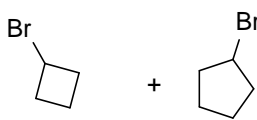

44j

(2.0 equiv)

$\left[\mathrm{RuCl}_{2}(p\right.$-cymene $\left.)\right] 2$

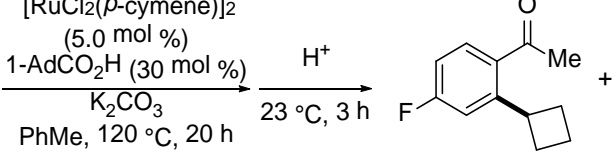

206aj

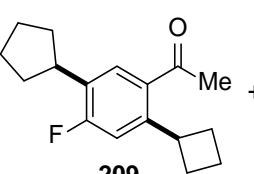

209

$47 \%$ $27 \%$<smiles>CC(=O)c1ccc(F)c(C2CCCC2)c1</smiles>

206ak

$$
\begin{aligned}
& 8 \% \\
& \text { not isolated }
\end{aligned}
$$

The general procedure $\mathbf{C}$ was followed using $\left[\mathrm{RuCl}_{2}(p \text {-cymene })\right]_{2}(30.6 \mathrm{mg}, 5.0 \mathrm{~mol} \%), 1-\mathrm{AdCO}_{2} \mathrm{H}$ (54.1 mg, $30 \mathrm{~mol} \%$ ), ketimine 188a (304 mg, $1.0 \mathrm{mmol}$ ) and bromides 44j (270 mg, $2.0 \mathrm{mmol}$ ), 44k $(298 \mathrm{mg}, 2.0 \mathrm{mmol})$. After $20 \mathrm{~h}, 2 \mathrm{~N} \mathrm{HCl}(3.0 \mathrm{~mL})$ was added, and the resulting mixture was stirred at ambient temperature for additional 3 hours, then extracted with EtOAc $(3 \times 20 \mathrm{~mL})$. The combined organic layer was dried over $\mathrm{Na}_{2} \mathrm{SO}_{4}$ and concentrated in vacuo. Purification by column chromatography ( $n$-hexane/EtOAc 100:1) yielded 206aj (63 mg, 33\%) and 209 (70 mg, 27\%) as colorless oils. The spectral data of 206aj were identical to those reported above.

\section{Analytical Data for 1-(2-Cyclobutyl-5-cyclopentyl-4-fluorophenyl)ethan-1-one (209)}<smiles>NC(=O)c1cc(C2CCCC2)c(F)cc1C1CCC1</smiles>

${ }^{1} \mathbf{H}$ NMR $\left(300 \mathrm{MHz}^{\mathrm{CDCl}}{ }_{3}\right): \delta=7.44(\mathrm{~d}, J=7.8 \mathrm{~Hz}, 1 \mathrm{H}), 7.03(\mathrm{~d}, J=12.0 \mathrm{~Hz}$, $1 \mathrm{H}), 4.06-3.93(\mathrm{~m}, 1 \mathrm{H}), 3.26-3.13(\mathrm{~m}, 1 \mathrm{H}), 2.52(\mathrm{~s}, 3 \mathrm{H}), 2.38-2.27(\mathrm{~m}, 2 \mathrm{H})$, 
2.09-1.94 (m, 5H), 1.86-1.75 (m, 3H), 1.73-1.58 (m, 4H).

${ }^{13} \mathrm{C} \mathrm{NMR}\left(75 \mathrm{MHz}, \mathrm{CDCl}_{3}\right): \delta=201.2\left(\mathrm{C}_{\mathrm{q}}\right), 162.7\left(\mathrm{~d},{ }^{1} \mathrm{~J}_{\mathrm{C}-\mathrm{F}}=251 \mathrm{~Hz}, \mathrm{C}_{\mathrm{q}}\right), 146.0\left(\mathrm{~d},{ }^{3} \mathrm{~J}_{\mathrm{C}-\mathrm{F}}=8 \mathrm{~Hz}, \mathrm{C}_{\mathrm{q}}\right), 134.0$ $\left(d,{ }^{4} J_{C-F}=3 \mathrm{~Hz}, C_{q}\right), 129.9\left(d,{ }^{2} J_{C-F}=15 \mathrm{~Hz}, C_{q}\right), 128.8\left(d,{ }^{3} J_{C-F}=7 \mathrm{~Hz}, \mathrm{CH}\right), 114.4\left(d,{ }^{2} J_{C-F}=24 \mathrm{~Hz}, \mathrm{CH}\right)$, $38.7(\mathrm{CH}), 37.8\left(\mathrm{~d},{ }^{3} J_{\mathrm{C}-\mathrm{F}}=1 \mathrm{~Hz}, \mathrm{CH}\right), 33.1\left(\mathrm{~d},{ }^{4} J_{\mathrm{C}-\mathrm{F}}=1 \mathrm{~Hz}, \mathrm{CH}_{2}\right), 29.9\left(\mathrm{CH}_{3}\right), 29.5\left(\mathrm{CH}_{2}\right), 29.4\left(\mathrm{CH}_{2}\right), 18.1$ $\left(\mathrm{CH}_{2}\right)$.

${ }^{19}$ F NMR $\left(282 \mathrm{MHz}, \mathrm{CDCl}_{3}\right): \delta=-112.5(\mathrm{~s})$.

IR (neat): $\tilde{v}=2940,2853,1584,1460,1232,1120,747,594 \mathrm{~cm}^{-1}$.

MS (EI) $m / z$ (relative intensity) 260 (26) [M] ${ }^{+}, 231$ (100), 217 (37), 149 (18).

HR-MS (ESI): $\mathrm{m} / z$ calcd for $\mathrm{C}_{17} \mathrm{H}_{22} \mathrm{FO}^{+}[\mathrm{M}+\mathrm{H}]^{+}$261.1649, found 261.1655 .

Synthesis of 1-\{4-(exo-Bicyclo[2.2.1]heptan-2-yl)naphthalen-2-yl\}ethan-1-one (206im) and 1-\{3-(exo-Bicyclo[2.2.1]heptan-2-yl)naphthalen-2-yl\}ethan-1-one (206im')

The general procedure $C$ was followed using substrate $188 \mathrm{i}(168 \mathrm{mg}, 0.50 \mathrm{mmol}$ ) and $44 \mathrm{~m}(263 \mathrm{mg}$, $1.50 \mathrm{mmol}$ ). After $20 \mathrm{~h}$, purification by column chromatography ( $n$-pentane/Et $\mathrm{t}_{2} \mathrm{O} 80: 1$ ) yielded 206im (61 mg, 46\%) and 206im' (25 mg,19\%) as colorless oils.

Analytical Data:<smiles>CC(=O)c1cc(C2CC3CCC2C3)c2ccccc2c1</smiles>

206im: ${ }^{1} \mathrm{H}$ NMR $\left(300 \mathrm{MHz}, \mathrm{CDCl}_{3}\right): \delta=8.27(\mathrm{~s}, 1 \mathrm{H}), 8.10(\mathrm{~d}, J=8.6 \mathrm{~Hz}, 1 \mathrm{H})$, 7.96-7.92 (m, 2H), 7.64-7.58 (m, 1H), 7.55-7.49 (m, 1H), 3.38-3.31 (m, 1H), $2.71(\mathrm{~s}, 3 \mathrm{H}), 2.62-2.59(\mathrm{~m}, 1 \mathrm{H}), 2.42-2.37(\mathrm{~m}, 1 \mathrm{H}), 2.02-1.92(\mathrm{~m}, 1 \mathrm{H})$, 1.74-1.61 (m, 4H), 1.57-1.47 (m, 1H), 1.44-1.38 (m, 1H), 1.33-1.27 (m, $1 \mathrm{H})$.

${ }^{13} \mathrm{C} \mathrm{NMR}\left(75 \mathrm{MHz}, \mathrm{CDCl}_{3}\right): \delta=198.2\left(\mathrm{C}_{\mathrm{q}}\right), 143.7\left(\mathrm{C}_{\mathrm{q}}\right), 134.3\left(\mathrm{C}_{\mathrm{q}}\right), 133.8\left(\mathrm{C}_{\mathrm{q}}\right)$, $133.1\left(\mathrm{C}_{\mathrm{q}}\right), 130.3(\mathrm{CH}), 128.6(\mathrm{CH}), 128.1(\mathrm{CH}), 126.1(\mathrm{CH}), 124.3(\mathrm{CH}), 119.2(\mathrm{CH}), 43.4(\mathrm{CH}), 41.6$ (CH), $39.4\left(\mathrm{CH}_{2}\right), 37.1(\mathrm{CH}), 36.6\left(\mathrm{CH}_{2}\right), 30.4\left(\mathrm{CH}_{2}\right), 29.3\left(\mathrm{CH}_{2}\right), 26.7\left(\mathrm{CH}_{3}\right)$.

IR (neat): $\tilde{v}=2950,2938,1670,1623,1353,1275,1277,1094,880 \mathrm{~cm}^{-1}$. MS (EI) $m / z$ (relative intensity) 264 (100) [M] ${ }^{+}, 184$ (73), 153 (64), 141 (64).

HR-MS (EI): $\mathrm{m} / z$ calcd for $\mathrm{C}_{19} \mathrm{H}_{20} \mathrm{O}^{+}[\mathrm{M}]^{+} 264.1509$, found 264.1514.<smiles>CC(=O)c1cc2ccccc2cc1C1CC2CCC1C2</smiles>

206im': ${ }^{1} \mathrm{H}$ NMR (300 MHz, $\left.\mathrm{CDCl}_{3}\right): \delta=8.00(\mathrm{~s}, 1 \mathrm{H}), 7.80$ (ddd, $J=8.6,7.3,1.2 \mathrm{~Hz}$, $2 \mathrm{H}$ ), $7.74(\mathrm{~s}, 1 \mathrm{H}$ ), 7.51 (ddd, $J=8.2,6.9,1.5 \mathrm{~Hz}, 1 \mathrm{H}$ ), 7.44 (ddd, $J=8.2,6.9,1.5 \mathrm{~Hz}$, $1 \mathrm{H}), 3.42-3.36(\mathrm{~m}, 1 \mathrm{H}), 2.67(\mathrm{~s}, 3 \mathrm{H}), 2.52-2.48(\mathrm{~m}, 1 \mathrm{H}), 2.36-2.32(\mathrm{~m}, 1 \mathrm{H})$, $1.88-1.79(\mathrm{~m}, 1 \mathrm{H}), 1.65-1.54(\mathrm{~m}, 4 \mathrm{H}), 1.48-1.40(\mathrm{~m}, 1 \mathrm{H}), 1.35-1.29(\mathrm{~m}, 1 \mathrm{H})$, $1.29-1.25(\mathrm{~m}, 1 \mathrm{H})$.

${ }^{13} \mathrm{C} \mathrm{NMR}\left(75 \mathrm{MHz}, \mathrm{CDCl}_{3}\right): \delta=203.2\left(\mathrm{C}_{\mathrm{q}}\right), 142.9\left(\mathrm{C}_{\mathrm{q}}\right), 138.1\left(\mathrm{C}_{\mathrm{q}}\right), 134.2\left(\mathrm{C}_{\mathrm{q}}\right), 130.4$ $\left(\mathrm{C}_{\mathrm{q}}\right), 138.8(\mathrm{CH}), 128.0(\mathrm{CH}), 127.6(\mathrm{CH}), 127.5(\mathrm{CH}), 125.9(\mathrm{CH}), 124.7(\mathrm{CH}), 43.5$ $(\mathrm{CH}), 42.3(\mathrm{CH}), 39.9\left(\mathrm{CH}_{2}\right), 37.3(\mathrm{CH}), 36.5\left(\mathrm{CH}_{2}\right), 30.7\left(\mathrm{CH}_{3}\right), 30.4\left(\mathrm{CH}_{2}\right), 29.0\left(\mathrm{CH}_{2}\right)$.

IR (neat): $\tilde{v}=2937,2928,1675,1623,1450,1375,1247,1193,775 \mathrm{~cm}^{-1}$.

MS (EI) $m / z$ (relative intensity) 264 (71) [M] ${ }^{+}, 195$ (100), 181 (27), 152 (30).

HR-MS (EI): $m / z$ calcd for $\mathrm{C}_{19} \mathrm{H}_{20} \mathrm{O}^{+}[\mathrm{M}]^{+} 264.1509$, found 264.1523 .

Intermolecular Competition Experiment between Ketimines 188b and 188a 


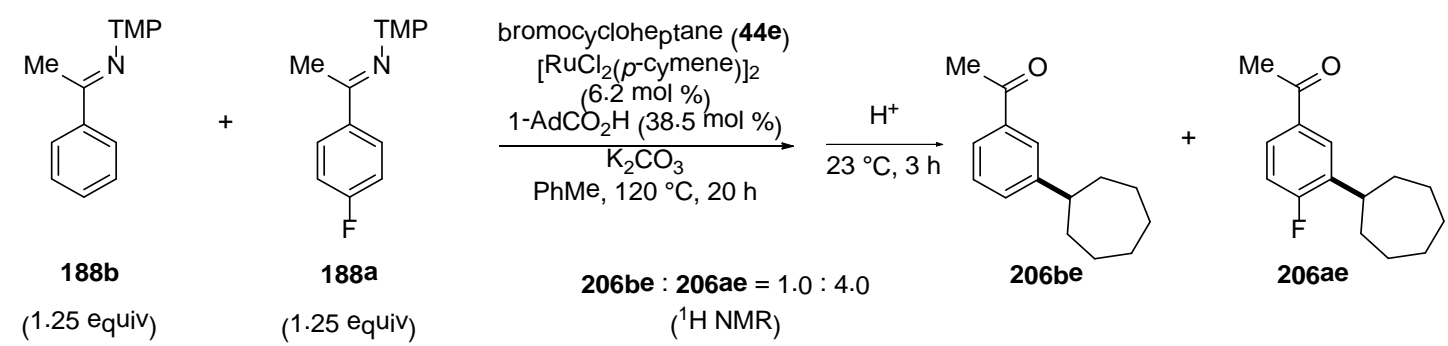

The general procedure $\mathbf{C}$ was followed using $\left[\mathrm{RuCl}_{2}(p \text {-cymene) }]_{2}(15.3 \mathrm{mg}, 6.2 \mathrm{~mol} \%), 1-\mathrm{AdCO}_{2} \mathrm{H}\right.$ (38.5 mg, $30 \mathrm{~mol} \%$ ), ketimines $188 \mathrm{~b}(143.0 \mathrm{mg}, 0.50 \mathrm{mmol})$ and 188a (152.0 mg, $0.50 \mathrm{mmol})$, bromide $44 \mathrm{e}(71.0 \mathrm{mg}, 0.4 \mathrm{mmol})$. After $20 \mathrm{~h}, \mathrm{HCl}(3.0 \mathrm{~mL}, 2 \mathrm{~N})$ was added, and the resulting mixture was stirred at ambient temperature for additional $3 \mathrm{~h}$, then extracted with EtOAc $(3 \times 20 \mathrm{~mL})$. The combined organic layer was dried over $\mathrm{Na}_{2} \mathrm{SO}_{4}$ and concentrated in vacuo. Careful ${ }^{1} \mathrm{H}$-NMR analysis displayed a ratio of $\mathbf{2 0 6} \mathrm{be} / \mathbf{2 0 6 a e}=1.0: 4.0$. Their spectral data were identical to those reported above.

\section{Intermolecular Competition Experiment between ketamine 188d and $188 \mathrm{~h}$}

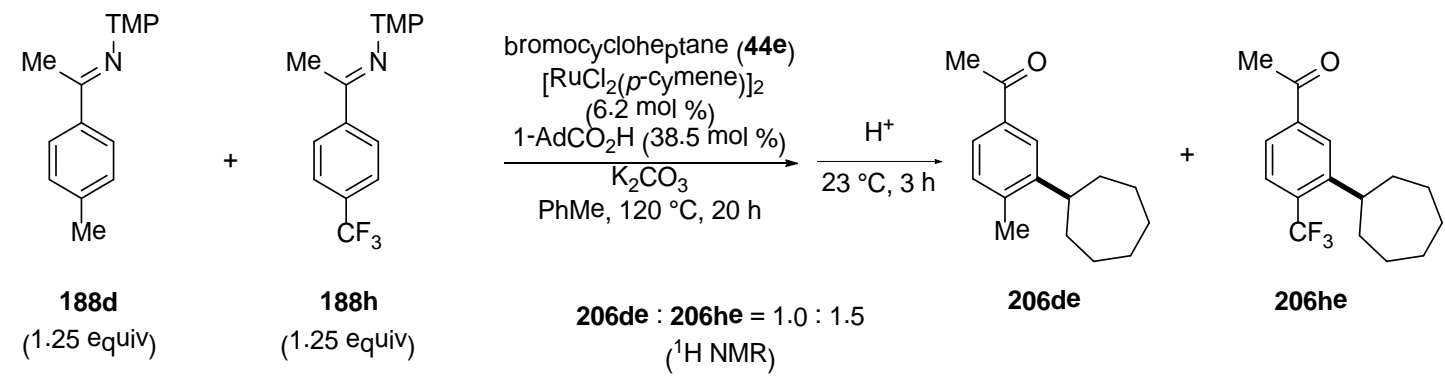

The general procedure $\mathbf{C}$ was followed, using $\left[\mathrm{RuCl}_{2}(p \text {-cymene })\right]_{2}(15.3 \mathrm{mg}, 6.2 \mathrm{~mol} \%), 1-\mathrm{AdCO}_{2} \mathrm{H}$ (27.8 mg, $38.5 \mathrm{~mol} \%)$, ketimines $188 \mathrm{~d}(150.0 \mathrm{mg}, 0.50 \mathrm{mmol})$ and $188 \mathrm{~h}(177.0 \mathrm{mg}, 0.50 \mathrm{mmol})$, bromide $44 \mathrm{e}(71.0 \mathrm{mg}, 0.4 \mathrm{mmol})$. After $20 \mathrm{~h}, \mathrm{HCl}(3.0 \mathrm{~mL}, 2 \mathrm{~N})$ was added, and the resulting mixture was stirred at ambient temperature for additional $3 \mathrm{~h}$, then extracted with EtOAc $(3 \times 20 \mathrm{~mL})$. The combined organic layer was dried over $\mathrm{Na}_{2} \mathrm{SO}_{4}$ and concentrated in vacuo. Careful ${ }^{1} \mathrm{H}$ NMR analysis

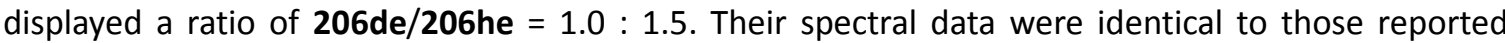
above.

\subsubsection{Analytical Data for the Products of the Ruthenium-Catalyzed Direct meta-Selective} Alkylations of $N$-(Pyrimidyl-2-yl)anilines and $N$-(Pyridin-2-yl)anilines

\section{Synthesis of $\mathbf{N}$-[3-(tert-Butyl)-4-fluorophenyl]pyrimidin-2-amine (215aa)}<smiles>CC(C)(C)c1cc(Nc2ncccn2)ccc1F</smiles>

The general procedure $\mathbf{A}$ was followed using $\left[\operatorname{RuCl}_{2}(p \text {-cymene) }]_{2}(15.3 \mathrm{mg}, 5.0 \mathrm{~mol}\right.$ $\%)$, Piv-Val-OH (30.0 mg, $30 \mathrm{~mol} \%$ ), substrate 161a ( $95 \mathrm{mg}, 0.50 \mathrm{mmol}$ ) and bromide 50a (206 mg, $1.50 \mathrm{mmol}$ ). After $16 \mathrm{~h}$, purification by column chromatography ( $n$-hexane/EtOAc/Et ${ }_{3} \mathrm{~N}$ 10:1:0.1) yielded 215 aa $(81 \mathrm{mg}, 66 \%$ ) as a yellow solid.

M. p.: $129-131^{\circ} \mathrm{C}$.

${ }^{1} \mathrm{H}$ NMR $\left(600 \mathrm{MHz}, \mathrm{CDCl}_{3}\right): \delta=8.37(\mathrm{~d}, J=4.8 \mathrm{~Hz}, 2 \mathrm{H}), 7.53-7.46(\mathrm{~m}, 2 \mathrm{H}), 7.35(\mathrm{dd}, J$ $=7.2,2.8 \mathrm{~Hz}, 1 \mathrm{H}), 6.96(\mathrm{dd}, J=12.1,8.7 \mathrm{~Hz}, 1 \mathrm{H}), 6.67(\mathrm{t}, J=4.8 \mathrm{~Hz}, 1 \mathrm{H}), 1.37(\mathrm{~d}, J=$ $1.0 \mathrm{~Hz}, 9 \mathrm{H})$.

${ }^{13} \mathrm{C}$ NMR $\left(75 \mathrm{MHz}, \mathrm{CDCl}_{3}\right): \delta=160.3\left(\mathrm{C}_{\mathrm{q}}\right), 158.1(\mathrm{CH}), 158.0\left(\mathrm{~d},{ }^{1} J_{\mathrm{C}-\mathrm{F}}=245 \mathrm{~Hz}, \mathrm{C}_{\mathrm{q}}\right), 137.3\left(\mathrm{~d},{ }^{2} \mathrm{~J}_{\mathrm{C}-\mathrm{F}}=13\right.$ 
$\left.\mathrm{Hz}, \mathrm{C}_{\mathrm{q}}\right), 134.7\left(\mathrm{~d},{ }^{4} \mathrm{~J}_{\mathrm{C}-\mathrm{F}}=3 \mathrm{~Hz}, \mathrm{C}_{\mathrm{q}}\right), 119.4\left(\mathrm{~d},{ }^{3} \mathrm{~J}_{\mathrm{C}-\mathrm{F}}=6 \mathrm{~Hz}, \mathrm{CH}\right), 119.2\left(\mathrm{~d},{ }^{3} \mathrm{~J}_{\mathrm{C}-\mathrm{F}}=9 \mathrm{~Hz}, \mathrm{CH}\right), 116.3\left(\mathrm{~d},{ }^{2} \mathrm{~J}_{\mathrm{C}-\mathrm{F}}=\right.$ $26 \mathrm{~Hz}, \mathrm{CH}), 112.2(\mathrm{CH}), 34.4\left(\mathrm{~d},{ }^{3} J_{\mathrm{C}-\mathrm{F}}=3 \mathrm{~Hz}, \mathrm{C}_{\mathrm{q}}\right), 29.9\left(\mathrm{~d},{ }^{4} \mathrm{~J}_{\mathrm{C}-\mathrm{F}}=4 \mathrm{~Hz}, \mathrm{CH}_{3}\right)$.

${ }^{19} \mathrm{~F}$ NMR $\left(282 \mathrm{MHz}, \mathrm{CDCl}_{3}\right): \delta=-116.3(\mathrm{~s})$.

IR (ATR): $\tilde{v}=3252,3080,2964,1577,1487,1420,1201,784 \mathrm{~cm}^{-1}$.

MS (EI) $m / z$ (relative intensity) 245 (100) [M] $]^{+}, 230$ (100), 188 (24), 160 (10).

HR-MS (EI): $m / z$ calcd for $\mathrm{C}_{14} \mathrm{H}_{16} \mathrm{FN}_{3}{ }^{+}[\mathrm{M}]^{+} 245.1323$, found 245.1331 .

\section{Synthesis of $\mathrm{N}$-[3-(tert-Butyl)-4-fluorophenyl]pyridin-2-amine (217)}<smiles>CC(C)(C)c1cc(Nc2ccccn2)ccc1F</smiles>

The general procedure $\mathbf{A}$ was followed using $\left[\mathrm{RuCl}_{2}(p \text {-cymene })\right]_{2}(15.3 \mathrm{mg}, 5.0$ mol \%), Piv-Val-OH (30.0 mg, $30 \mathrm{~mol} \%)$, substrate $213 \mathrm{~b}(94 \mathrm{mg}, 0.50 \mathrm{mmol}$ ) and bromide 50a (206 mg, $1.50 \mathrm{mmol}$ ). After $16 \mathrm{~h}$, purification by column chromatography ( $n$-hexane/EtOAc/Et ${ }_{3} \mathrm{~N}$ 10:1:0.1) yielded 217 (44 mg, 36\%) as a yellow solid.

M. p.: $131-133^{\circ} \mathrm{C}$.

${ }^{1} \mathrm{H}$ NMR $\left(400 \mathrm{MHz}, \mathrm{CDCl}_{3}\right): \delta=8.15$ (ddd, $\left.J=5.0,2.0,0.9 \mathrm{~Hz}, 1 \mathrm{H}\right), 7.44$ (ddd, $J=8.5$, $7.2,1.9 \mathrm{~Hz}, 1 \mathrm{H}), 7.18-7.12(\mathrm{~m}, 2 \mathrm{H}), 6.98-6.91(\mathrm{~m}, 1 \mathrm{H}), 6.82(\mathrm{~s}, 1 \mathrm{H}), 6.72(\mathrm{ddd}, J=8.5,8.5,0.9 \mathrm{~Hz}, 1 \mathrm{H})$, 6.68 (ddd, $J=7.2,5.0,0.9 \mathrm{~Hz}, 1 \mathrm{H}), 1.36(\mathrm{~d}, J=1.1 \mathrm{~Hz}, 9 \mathrm{H})$.

${ }^{13} \mathrm{C}$ NMR $\left(75 \mathrm{MHz}, \mathrm{CDCl}_{3}\right): \delta=158.2\left(\mathrm{~d},{ }^{1} J_{\mathrm{C}-\mathrm{F}}=246 \mathrm{~Hz}, \mathrm{C}_{\mathrm{q}}\right), 156.8\left(\mathrm{C}_{\mathrm{q}}\right), 148.3(\mathrm{CH}), 137.9\left(\mathrm{~d},{ }^{2} J_{\mathrm{C}-\mathrm{F}}=13\right.$ $\left.\mathrm{Hz}, \mathrm{C}_{\mathrm{q}}\right), 137.7(\mathrm{CH}), 135.8\left(\mathrm{~d},{ }^{4} \mathrm{~J}_{\mathrm{C}-\mathrm{F}}=3 \mathrm{~Hz}, \mathrm{C}_{\mathrm{q}}\right), 121.0\left(\mathrm{~d},{ }^{3} \mathrm{~J}_{\mathrm{C}-\mathrm{F}}=6 \mathrm{~Hz}, \mathrm{CH}\right), 120.5\left(\mathrm{~d},{ }^{3} \mathrm{~J}_{\mathrm{C}-\mathrm{F}}=9 \mathrm{~Hz}, \mathrm{CH}\right)$, $116.7\left(\mathrm{~d},{ }^{2} J_{\mathrm{C}-\mathrm{F}}=26 \mathrm{~Hz}, \mathrm{CH}\right), 114.6(\mathrm{CH}), 107.5(\mathrm{CH}), 34.3\left(\mathrm{~d},{ }^{3} J_{\mathrm{C}-\mathrm{F}}=3 \mathrm{~Hz}, \mathrm{C}_{\mathrm{q}}\right), 29.8\left(\mathrm{~d},{ }^{4} \mathrm{~J}_{\mathrm{C}-\mathrm{F}}=4 \mathrm{~Hz}, \mathrm{CH}_{3}\right)$.

${ }^{19} \mathrm{~F}$ NMR $\left(282 \mathrm{MHz}, \mathrm{CDCl}_{3}\right): \delta=-115.8(\mathrm{~s})$.

IR (ATR): $\tilde{v}=3225,3199,2980,1604,1578,1492,1437,1205,786 \mathrm{~cm}^{-1}$.

MS (EI) $m / z$ (relative intensity) 244 (100) [M] ${ }^{+}, 229$ (72), 188 (32), 100 (15).

HR-MS (El): $m / z$ calcd for $\mathrm{C}_{15} \mathrm{H}_{16} \mathrm{FN}_{2}{ }^{+}[\mathrm{M}-\mathrm{H}]^{+}$243.1292, found 243.1304 .

\section{Synthesis of $\boldsymbol{N}$-[4-Fluoro-3-(1-methylcyclohexyl)phenyl]pyrimidin-2-amine (215ab)}

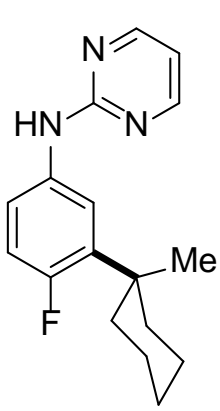

The general procedure $\mathbf{A}$ was followed using $\left[\mathrm{RuCl}_{2}(p \text {-cymene })\right]_{2}(15.3 \mathrm{mg}, 5.0$ $\mathrm{mol} \%$ ), Piv-Val-OH (30.0 mg, $30 \mathrm{~mol} \%$ ), substrate 161a (95 mg, $0.50 \mathrm{mmol}$ ) and bromide 50b (266 mg, $1.50 \mathrm{mmol}$ ). After $16 \mathrm{~h}$, purification by column chromatography ( $n$-hexane/EtOAc/Et ${ }_{3} \mathrm{~N}$ 10:1:0.1) yielded 215ab (85 mg, 60\%) as a yellow solid.

M. p.: $95-97^{\circ} \mathrm{C}$.

${ }^{1} \mathrm{H}$ NMR $\left(600 \mathrm{MHz}, \mathrm{CDCl}_{3}\right): \delta=8.37(\mathrm{~d}, J=4.8 \mathrm{~Hz}, 2 \mathrm{H}), 7.51-7.44(\mathrm{~m}, 2 \mathrm{H}), 7.39(\mathrm{dd}, J$ $=7.2,2.7 \mathrm{~Hz}, 1 \mathrm{H}), 6.95(\mathrm{dd}, J=12.5,8.7 \mathrm{~Hz}, 1 \mathrm{H}), 6.67(\mathrm{t}, J=4.8 \mathrm{~Hz}, 1 \mathrm{H}), 2.11-1.96$ $(\mathrm{m}, 2 \mathrm{H}), 1.69-1.36(\mathrm{~m}, 8 \mathrm{H}), 1.28(\mathrm{~d}, J=1.0 \mathrm{~Hz}, 3 \mathrm{H})$.

${ }^{13} \mathrm{C}$ NMR $\left(75 \mathrm{MHz}, \mathrm{CDCl}_{3}\right): \delta=160.3\left(\mathrm{C}_{\mathrm{q}}\right), 157.9(\mathrm{CH}), 157.9\left(\mathrm{~d},{ }^{1} J_{\mathrm{C}-\mathrm{F}}=244 \mathrm{~Hz}, \mathrm{C}_{\mathrm{q}}\right), 136.5\left(\mathrm{~d},{ }^{2} \mathrm{~J}_{\mathrm{C}-\mathrm{F}}=12\right.$ $\left.\mathrm{Hz}, \mathrm{C}_{\mathrm{q}}\right), 134.7\left(\mathrm{~d},{ }^{4} \mathrm{~J}_{\mathrm{C}-\mathrm{F}}=3 \mathrm{~Hz}, \mathrm{C}_{\mathrm{q}}\right), 120.4\left(\mathrm{~d},{ }^{3} \mathrm{~J}_{\mathrm{C}-\mathrm{F}}=6 \mathrm{~Hz}, \mathrm{CH}\right), 118.9\left(\mathrm{~d},{ }^{3} \mathrm{~J}_{\mathrm{C}-\mathrm{F}}=9 \mathrm{~Hz}, \mathrm{CH}\right), 116.6\left(\mathrm{~d},{ }^{2} \mathrm{~J}_{\mathrm{C}-\mathrm{F}}=\right.$ $26 \mathrm{~Hz}, \mathrm{CH}), 112.2(\mathrm{CH}), 38.0\left(\mathrm{~d},{ }^{3} \mathrm{~J}_{\mathrm{C}-\mathrm{F}}=4 \mathrm{~Hz}, \mathrm{C}\right), 37.2\left(\mathrm{~d},{ }^{4} \mathrm{~J}_{\mathrm{C}-\mathrm{F}}=4 \mathrm{~Hz}, \mathrm{CH}_{2}\right), 26.9\left(\mathrm{CH}_{3}\right), 26.4\left(\mathrm{CH}_{2}\right), 22.7$ $\left(\mathrm{CH}_{2}\right)$.

${ }^{19}$ F NMR $\left(282 \mathrm{MHz}, \mathrm{CDCl}_{3}\right): \delta=-115.6(\mathrm{~s})$.

IR (ATR): $\tilde{v}=3256,3060,2926,1578,1494,1388,1185,820 \mathrm{~cm}^{-1}$.

MS (EI) $m / z$ (relative intensity) $285(100)\left[\mathrm{M}^{+}, 270(28), 230\right.$ (30), 202 (23). 
HR-MS (EI): $m / z$ calcd for $\mathrm{C}_{17} \mathrm{H}_{20} \mathrm{FN}_{3}{ }^{+}[\mathrm{M}]^{+}$285.1636, found 285.1645.

\section{Synthesis of $\boldsymbol{N}$-[4-Fluoro-3-(tert-pentyl)phenyl]pyrimidin-2-amine (215ad)}<smiles>CCC(C)(C)c1cc(Nc2ncccn2)ccc1F</smiles>

The general procedure $\mathbf{A}$ was followed using $\left[\mathrm{RuCl}_{2} \text { (p-cymene) }\right]_{2}$ (15.3 $\mathrm{mg}, 5.0$ mol \%), Piv-Val-OH (30.0 mg, $30 \mathrm{~mol} \%)$, substrate $161 \mathrm{a}$ (95 mg, $0.50 \mathrm{mmol}$ ) and bromide $50 \mathrm{~d}(227 \mathrm{mg}, 1.50 \mathrm{mmol})$. After $16 \mathrm{~h}$, purification by column chromatography ( $n$-hexane/EtOAc/ $\mathrm{Et}_{3} \mathrm{~N}$ 10:1:0.1) yielded $215 \mathrm{ad}(75 \mathrm{mg}, 58 \%$ ) as a yellow solid.

M. p.: $94-96^{\circ} \mathrm{C}$.

${ }^{1} \mathrm{H}$ NMR $\left(600 \mathrm{MHz}^{\mathrm{CDCl}} \mathrm{CDC}_{3}\right): \delta=8.39(\mathrm{~d}, J=4.8 \mathrm{~Hz}, 2 \mathrm{H}), 7.70(\mathrm{~s}, 1 \mathrm{H}), 7.62-7.48(\mathrm{~m}$, $1 \mathrm{H}), 7.30(\mathrm{dd}, J=7.2,2.6 \mathrm{~Hz}, 1 \mathrm{H}), 6.96(\mathrm{dd}, J=12.1,8.7 \mathrm{~Hz}, 1 \mathrm{H}), 6.69(\mathrm{t}, J=4.8 \mathrm{~Hz}, 1 \mathrm{H}), 1.77(\mathrm{q}, J=7.5$ $\mathrm{Hz}, 2 \mathrm{H}), 1.34(\mathrm{~s}, 6 \mathrm{H}), 0.71(\mathrm{t}, J=7.5 \mathrm{~Hz}, 3 \mathrm{H})$.

${ }^{13} \mathrm{C}$ NMR $\left(75 \mathrm{MHz}, \mathrm{CDCl}_{3}\right): \delta=160.3\left(\mathrm{C}_{\mathrm{q}}\right), 157.9(\mathrm{CH}), 157.6\left(\mathrm{~d},{ }^{1} \mathrm{~J}_{\mathrm{C}-\mathrm{F}}=244 \mathrm{~Hz}, \mathrm{C}_{\mathrm{q}}\right), 135.7\left(\mathrm{~d},{ }^{2} \mathrm{~J}_{\mathrm{C}-\mathrm{F}}=13\right.$ $\left.\mathrm{Hz}, \mathrm{C}_{\mathrm{q}}\right), 134.7\left(\mathrm{~d},{ }^{4} J_{\mathrm{C}-\mathrm{F}}=3 \mathrm{~Hz}, \mathrm{C}_{\mathrm{q}}\right), 120.4\left(\mathrm{~d},{ }^{3} J_{\mathrm{C}-\mathrm{F}}=6 \mathrm{~Hz}, \mathrm{CH}\right), 119.0\left(\mathrm{~d},{ }^{3} J_{\mathrm{C}-\mathrm{F}}=9 \mathrm{~Hz}, \mathrm{CH}\right), 116.2\left(\mathrm{~d},{ }^{2} J_{\mathrm{C}-\mathrm{F}}=\right.$ $26 \mathrm{~Hz}, \mathrm{CH}), 112.2(\mathrm{CH}), 38.1\left(\mathrm{~d},{ }^{3} J_{\mathrm{C}-\mathrm{F}}=4 \mathrm{~Hz}, \mathrm{C}_{\mathrm{q}}\right), 34.2\left(\mathrm{~d},{ }^{4} J_{\mathrm{C}-\mathrm{F}}=4 \mathrm{~Hz}, \mathrm{CH}_{2}\right), 27.7\left(\mathrm{~d},{ }^{4} J_{\mathrm{C}-\mathrm{F}}=3 \mathrm{~Hz}, \mathrm{CH}_{3}\right), 9.5$ $\left(\mathrm{CH}_{3}\right)$.

${ }^{19}$ F NMR $\left(282 \mathrm{MHz}, \mathrm{CDCl}_{3}\right): \delta=-116.4$ (s).

IR (ATR): $\tilde{v}=3249,3039,2929,1581,1444,1384,1203,995,798 \mathrm{~cm}^{-1}$.

MS (EI) $m / z$ (relative intensity) 259 (44) [M] ${ }^{+}, 244$ (12), 230 (100), 188 (13).

HR-MS (EI): $m / z$ calcd for $\mathrm{C}_{15} \mathrm{H}_{18} \mathrm{FN}_{3}{ }^{+}[\mathrm{M}]^{+}$259.1479, found 259.1491.

\section{Synthesis of $\boldsymbol{N}$-[4-Fluoro-3-(2-methylpentan-2-yl)phenyl]pyrimidin-2-amine (215ac)}

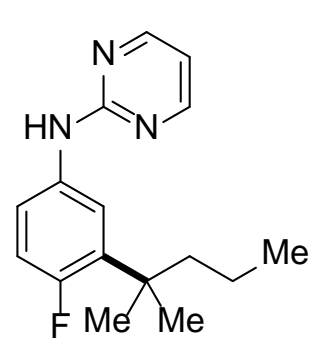

The general procedure $\mathbf{A}$ was followed using $\left[\mathrm{RuCl}_{2}(p \text {-cymene) }]_{2}(15.3 \mathrm{mg}, 5.0\right.$ mol \%), Piv-Val-OH (30.0 mg, $30 \mathrm{~mol} \%$ ), substrate $161 \mathrm{a}$ (95 mg, $0.50 \mathrm{mmol}$ ) and bromide 50c (248 $\mathrm{mg}, 1.50 \mathrm{mmol}$ ). After $16 \mathrm{~h}$, purification by column chromatography ( $n$-hexane/EtOAc/Et ${ }_{3} \mathrm{~N}$ 10:1:0.1) yielded 215ac (73 mg, 53\%) as a yellow oil.

${ }^{1}$ H NMR (400 MHz, $\mathrm{CDCl}_{3}$ ): $\delta=8.37(\mathrm{~d}, J=4.8 \mathrm{~Hz}, 2 \mathrm{H}), 7.65(\mathrm{~s}, 1 \mathrm{H}), 7.52$ (ddd, $J$ $=8.7,4.0,2.8 \mathrm{~Hz}, 1 \mathrm{H}), 7.29(\mathrm{dd}, J=7.2,2.8 \mathrm{~Hz}, 1 \mathrm{H}), 6.94(\mathrm{dd}, J=12.1,8.7 \mathrm{~Hz}$, $1 \mathrm{H}), 6.67(\mathrm{t}, J=4.8 \mathrm{~Hz}, 1 \mathrm{H}), 1.74-1.62(\mathrm{~m}, 2 \mathrm{H}), 1.33(\mathrm{~d}, J=1.1 \mathrm{~Hz}, 6 \mathrm{H}), 1.15-1.00(\mathrm{~m}, 2 \mathrm{H}), 0.82(\mathrm{t}, J=$ $7.3 \mathrm{~Hz}, 3 \mathrm{H})$.

${ }^{13} \mathrm{C}$ NMR $\left(75 \mathrm{MHz}, \mathrm{CDCl}_{3}\right): \delta=160.4\left(\mathrm{C}_{\mathrm{q}}\right), 158.0(\mathrm{CH}), 157.8\left(\mathrm{~d},{ }^{1} \mathrm{~J}_{\mathrm{C}-\mathrm{F}}=244 \mathrm{~Hz}, \mathrm{C}_{\mathrm{q}}\right), 136.1\left(\mathrm{~d},{ }^{2} \mathrm{~J}_{\mathrm{C}-\mathrm{F}}=13\right.$ $\left.\mathrm{Hz}, \mathrm{C}_{\mathrm{q}}\right), 134.8\left(\mathrm{~d},{ }^{4} \mathrm{~J}_{\mathrm{C}-\mathrm{F}}=3 \mathrm{~Hz}, \mathrm{C}_{\mathrm{q}}\right), 120.3\left(\mathrm{~d},{ }^{3} \mathrm{~J}_{\mathrm{C}-\mathrm{F}}=6 \mathrm{~Hz}, \mathrm{CH}\right), 119.1\left(\mathrm{~d},{ }^{3} J_{\mathrm{C}-\mathrm{F}}=9 \mathrm{~Hz}, \mathrm{CH}\right), 116.3\left(\mathrm{~d},{ }^{2} J_{\mathrm{C}-\mathrm{F}}=\right.$ $26 \mathrm{~Hz}, \mathrm{CH}), 112.2(\mathrm{CH}), 44.2\left(\mathrm{~d},{ }^{4} J_{\mathrm{C}-\mathrm{F}}=4 \mathrm{~Hz}, \mathrm{CH}_{2}\right), 37.8\left(\mathrm{~d},{ }^{3} J_{\mathrm{C}-\mathrm{F}}=3 \mathrm{~Hz}, \mathrm{C}_{\mathrm{q}}\right), 28.2\left(\mathrm{~d},{ }^{4} J_{\mathrm{C}-\mathrm{F}}=3 \mathrm{~Hz}, \mathrm{CH}_{3}\right)$, $18.3\left(\mathrm{CH}_{2}\right), 14.7\left(\mathrm{CH}_{3}\right)$.

${ }^{19} \mathrm{~F} \mathrm{NMR}\left(282 \mathrm{MHz} \mathrm{CDCl}_{3}\right): \delta=-116.3(\mathrm{~s})$.

IR (neat): $\tilde{v}=3270,3104,2956,1580,1489,1446,1205,992,783 \mathrm{~cm}^{-1}$.

MS (EI) $m / z$ (relative intensity) 273 (42) [M] ${ }^{+}, 230$ (100), 188 (12), 160 (5).

HR-MS (EI): $m / z$ calcd for $\mathrm{C}_{16} \mathrm{H}_{20} \mathrm{FN}_{3}{ }^{+}[\mathrm{M}]^{+}$273.1636, found 273.1635 .

\section{Synthesis of $\mathbf{N}$-[3-(5-Chloro-2-methylpentan-2-yl)-4-fluorophenyl]pyrimidin-2-amine (215ah)}<smiles>CC(C)(CCCCl)c1cc(Nc2ncccn2)ccc1F</smiles>

The general procedure A was followed using $\left[\operatorname{RuCl}_{2}(p \text {-cymene) }]_{2}(15.3 \mathrm{mg}\right.$, $5.0 \mathrm{~mol} \%$ ), Piv-Val-OH (30.0 mg, $30 \mathrm{~mol} \%$ ), substrate 161a (95 mg, 0.50 $\mathrm{mmol}$ ) and bromide $\mathbf{5 0 h}(300 \mathrm{mg}, 1.50 \mathrm{mmol}$ ). After $16 \mathrm{~h}$, purification by 
column chromatography ( $n$-hexane/EtOAc/Et $\left.{ }_{3} \mathrm{~N} 10: 1: 0.1\right)$ yielded 215ah $(99 \mathrm{mg}, 64 \%$ ) as a yellow oil. ${ }^{1} \mathrm{H}$ NMR $\left(600 \mathrm{MHz}, \mathrm{CDCl}_{3}\right): \delta=8.38(\mathrm{~d}, J=4.8 \mathrm{~Hz}, 2 \mathrm{H}), 7.55-7.43(\mathrm{~m}, 2 \mathrm{H}), 7.33(\mathrm{dd}, J=7.2,2.8 \mathrm{~Hz}$, $1 \mathrm{H}), 6.95(\mathrm{dd}, J=12.1,8.7 \mathrm{~Hz}, 1 \mathrm{H}), 6.68(\mathrm{t}, J=4.8 \mathrm{~Hz}, 1 \mathrm{H}), 3.44(\mathrm{t}, J=6.8 \mathrm{~Hz}, 2 \mathrm{H}), 1.90-1.79(\mathrm{~m}, 2 \mathrm{H})$, $1.62-1.50(\mathrm{~m}, 2 \mathrm{H}), 1.36(\mathrm{~d}, J=1.0 \mathrm{~Hz}, 6 \mathrm{H})$.

${ }^{13} \mathrm{C}$ NMR $\left(75 \mathrm{MHz}, \mathrm{CDCl}_{3}\right): \delta=160.2\left(\mathrm{C}_{\mathrm{q}}\right), 157.9(\mathrm{CH}), 157.4\left(\mathrm{~d},{ }^{1} J_{\mathrm{C}-\mathrm{F}}=245 \mathrm{~Hz}, \mathrm{C}_{\mathrm{q}}\right), 135.0\left(\mathrm{~d},{ }^{2} J_{\mathrm{C}-\mathrm{F}}=13\right.$ $\left.\mathrm{Hz}, \mathrm{C}_{\mathrm{q}}\right), 134.9\left(\mathrm{~d},{ }^{4} \mathrm{~J}_{\mathrm{C}-\mathrm{F}}=3 \mathrm{~Hz}, \mathrm{C}_{\mathrm{q}}\right), 120.0\left(\mathrm{~d},{ }^{3} \mathrm{~J}_{\mathrm{C}-\mathrm{F}}=6 \mathrm{~Hz}, \mathrm{CH}\right), 119.2\left(\mathrm{~d},{ }^{3} \mathrm{~J}_{\mathrm{C}-\mathrm{F}}=9 \mathrm{~Hz}, \mathrm{CH}\right), 116.4\left(\mathrm{~d},{ }^{2} \mathrm{~J}_{\mathrm{C}-\mathrm{F}}=\right.$ $26 \mathrm{~Hz}, \mathrm{CH}), 112.3(\mathrm{CH}), 45.6\left(\mathrm{CH}_{2}\right), 39.1\left(\mathrm{~d},{ }^{3} J_{\mathrm{C}-\mathrm{F}}=4 \mathrm{~Hz}, \mathrm{C}\right), 37.5\left(\mathrm{~d},{ }^{4} J_{\mathrm{C}-\mathrm{F}}=3 \mathrm{~Hz}, \mathrm{CH}_{2}\right), 28.8\left(\mathrm{CH}_{2}\right), 28.2$ $\left(\mathrm{d},{ }^{4} \mathrm{~J}_{\mathrm{C}-\mathrm{F}}=3 \mathrm{~Hz}, \mathrm{CH}_{3}\right)$.

${ }^{19}$ F-NMR $\left(282 \mathrm{MHz}, \mathrm{CDCl}_{3}\right): \delta=-116.6(\mathrm{~s})$.

IR (neat): $\tilde{v}=3267,3106,2960,1580,1489,1416,1297,1204,992,639 \mathrm{~cm}^{-1}$.

MS (EI) $m / z$ (relative intensity) 309/307 (13/38) [M] ${ }^{+}, 230$ (100), 188 (14), 160 (6).

HR-MS (EI): $\mathrm{m} / z$ calcd for $\mathrm{C}_{16} \mathrm{H}_{19}{ }^{35} \mathrm{CIFN}_{3}{ }^{+}[\mathrm{M}]^{+} 307.1246$, found 307.1265 .

\section{Synthesis of $\boldsymbol{N}$-[3-(2,6-Dimethylhept-5-en-2-yl)-4-fluorophenyl]pyrimidin-2-amine (215ag)}<smiles>CC(C)=CCCC(C)(C)c1cc(Nc2ncccn2)ccc1F</smiles>
The general procedure $\mathbf{A}$ was followed using $\left[\mathrm{RuCl}_{2} \text { ( } p \text {-cymene) }\right]_{2}(15.3$ $\mathrm{mg}, 5.0 \mathrm{~mol} \%$ ), Piv-Val-OH (30.0 mg, $30 \mathrm{~mol} \%$ ), substrate 161a (94.6 mg, $0.50 \mathrm{mmol}$ ) and bromide $50 \mathrm{~g}(308 \mathrm{mg}, 1.50 \mathrm{mmol})$. After $16 \mathrm{~h}$, purification by column chromatography ( $n$-hexane/EtOAc/Et $\mathrm{H}_{3} \mathrm{~N}$ 10:1:0.1) yielded $215 \mathrm{ag}(90 \mathrm{mg}, 57 \%)$ as a yellow oil.

${ }^{1} \mathrm{H}$ NMR $\left(400 \mathrm{MHz}, \mathrm{CDCl}_{3}\right): \delta=8.37(\mathrm{~d}, J=4.8 \mathrm{~Hz}, 2 \mathrm{H}), 7.65-7.51(\mathrm{~m}, 2 \mathrm{H})$, $7.29(\mathrm{dd}, J=7.2,2.8 \mathrm{~Hz}, 1 \mathrm{H}), 6.95(\mathrm{dd}, J=12.1,8.7 \mathrm{~Hz}, 1 \mathrm{H}), 6.67(\mathrm{t}, J=$ $4.8 \mathrm{~Hz}, 1 \mathrm{H}), 5.06-5.01(\mathrm{~m}, 1 \mathrm{H}), 1.75-1.71(\mathrm{~m}, 4 \mathrm{H}), 1.64-1.59(\mathrm{~m}, 3 \mathrm{H}), 1.48(\mathrm{~d}, J=1.2 \mathrm{~Hz}, 3 \mathrm{H}), 1.35(\mathrm{~d}, J$ $=1.0 \mathrm{~Hz}, 6 \mathrm{H})$.

${ }^{13} \mathrm{C}$ NMR $\left(75 \mathrm{MHz}, \mathrm{CDCl}_{3}\right): \delta=160.2\left(\mathrm{C}_{\mathrm{q}}\right), 157.9(\mathrm{CH}), 157.6\left(\mathrm{~d},{ }^{1} J_{\mathrm{C}-\mathrm{F}}=244 \mathrm{~Hz}, \mathrm{C}_{\mathrm{q}}\right), 135.7\left(\mathrm{~d},{ }^{2} J_{\mathrm{C}-\mathrm{F}}=13\right.$ $\left.\mathrm{Hz}, \mathrm{C}_{\mathrm{q}}\right), 134.7\left(\mathrm{~d},{ }^{4} \mathrm{~J}_{\mathrm{C}-\mathrm{F}}=3 \mathrm{~Hz}, \mathrm{C}_{\mathrm{q}}\right), 131.1\left(\mathrm{C}_{\mathrm{q}}\right), 124.6(\mathrm{CH}), 120.2\left(\mathrm{~d},{ }^{3} \mathrm{~J}_{\mathrm{C}-\mathrm{F}}=6 \mathrm{~Hz}, \mathrm{CH}\right), 119.0\left(\mathrm{~d},{ }^{3} J_{\mathrm{C}-\mathrm{F}}=9\right.$ $\mathrm{Hz}, \mathrm{CH}), 116.3\left(\mathrm{~d},{ }^{2} J_{\mathrm{C}-\mathrm{F}}=26 \mathrm{~Hz}, \mathrm{CH}\right), 112.3(\mathrm{CH}), 41.8\left(\mathrm{~d},{ }^{4} J_{\mathrm{C}-\mathrm{F}}=4 \mathrm{~Hz}, \mathrm{CH}_{2}\right), 37.8\left(\mathrm{~d},{ }^{3} J_{\mathrm{C}-\mathrm{F}}=3 \mathrm{~Hz}, \mathrm{C}_{\mathrm{q}}\right), 28.2$ $\left(d,{ }^{4} J_{C-F}=3 \mathrm{~Hz}, \mathrm{CH}_{3}\right), 25.7\left(\mathrm{CH}_{3}\right), 24.0\left(\mathrm{CH}_{2}\right), 17.4\left(\mathrm{CH}_{3}\right)$.

${ }^{19} \mathrm{~F} \mathrm{NMR}\left(282 \mathrm{MHz}, \mathrm{CDCl}_{3}\right): \delta=-116.3(\mathrm{~s})$.

IR (neat): $\tilde{v}=3273,2964,2863,1580,1489,1447,1417,1205,992,783 \mathrm{~cm}^{-1}$.

MS (EI) $m / z$ (relative intensity) 313 (30) [M] , 293 (18), 231 (100), 188 (16).

HR-MS (EI): $m / z$ calcd for $\mathrm{C}_{19} \mathrm{H}_{24} \mathrm{FN}_{3}{ }^{+}[\mathrm{M}]^{+}$313.1949, found 313.1967.

\section{Synthesis of $\boldsymbol{N}$-[4-Fluoro-3-(2-methyl-4-phenylbutan-2-yl)phenyl]pyrimidin-2-amine (215ai)}

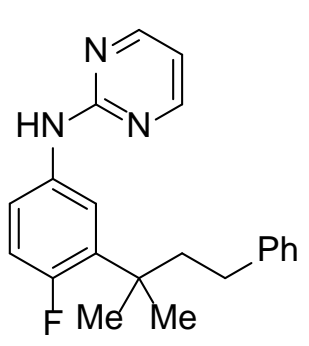

The general procedure $\mathbf{A}$ was followed using $\left[\mathrm{RuCl}_{2}(p \text {-cymene) }]_{2}(15.3 \mathrm{mg}, 5.0\right.$ mol \%), Piv-Val-OH (30.0 mg, $30 \mathrm{~mol} \%$ ), substrate 161a (95 mg, $0.50 \mathrm{mmol}$ ) and bromide $50 \mathrm{i}$ (341 $\mathrm{mg}, 1.50 \mathrm{mmol}$ ). After $16 \mathrm{~h}$, purification by column chromatography ( $n$-hexane/EtOAc/Et ${ }_{3} \mathrm{~N}$ 10:1:0.1) yielded 215ai (93 mg, 55\%) as a yellow oil.

${ }^{1} \mathrm{H}$ NMR $\left(300 \mathrm{MHz}, \mathrm{CDCl}_{3}\right): \delta=8.38(\mathrm{~d}, J=4.8 \mathrm{~Hz}, 2 \mathrm{H}), 7.55$ (ddd, $J=8.7,4.0$, $2.7 \mathrm{~Hz}, 1 \mathrm{H}), 7.39(\mathrm{dd}, J=7.2,2.8 \mathrm{~Hz}, 2 \mathrm{H}), 7.27-7.17(\mathrm{~m}, 2 \mathrm{H}), 7.17-7.06(\mathrm{~m}, 3 \mathrm{H})$, $6.99(\mathrm{dd}, J=12.1,8.7 \mathrm{~Hz}, 1 \mathrm{H}), 6.68(\mathrm{t}, J=4.8 \mathrm{~Hz}, 1 \mathrm{H}), 2.43-2.32(\mathrm{~m}, 2 \mathrm{H}), 2.13-2.00(\mathrm{~m}, 2 \mathrm{H}), 1.42(\mathrm{~d}, J$ $=1.0 \mathrm{~Hz}, 6 \mathrm{H})$.

${ }^{13} \mathrm{C}$ NMR $\left(75 \mathrm{MHz}, \mathrm{CDCl}_{3}\right): \delta=160.2\left(\mathrm{C}_{\mathrm{q}}\right), 157.9(\mathrm{CH}), 157.2\left(\mathrm{~d},{ }^{1} \mathrm{~J}_{\mathrm{C}-\mathrm{F}}=243, \mathrm{C}_{\mathrm{q}}\right), 142.8\left(\mathrm{C}_{\mathrm{q}}\right), 135.4(\mathrm{~d}$, $\left.{ }^{2} J_{C-F}=13 \mathrm{~Hz}, C_{q}\right), 134.8\left(d,{ }^{4} J_{C-F}=3 \mathrm{~Hz}, C_{q}\right), 128.2(C H), 128.1(C H), 125.4(C H), 120.1\left(d,{ }^{3} J_{C-F}=6 \mathrm{~Hz}\right.$, 
$\mathrm{CH}), 119.1\left(\mathrm{~d},{ }^{3} \mathrm{~J}_{\mathrm{C}-\mathrm{F}}=9 \mathrm{~Hz}, \mathrm{CH}\right), 116.4\left(\mathrm{~d},{ }^{2} \mathrm{~J}_{\mathrm{C}-\mathrm{F}}=24 \mathrm{~Hz}, \mathrm{CH}\right), 112.3(\mathrm{CH}), 43.9\left(\mathrm{~d},{ }^{3} J_{\mathrm{C}-\mathrm{F}}=5 \mathrm{~Hz}, \mathrm{C}_{\mathrm{q}}\right), 38.0(\mathrm{~d}$, $\left.{ }^{4} J_{\mathrm{C}-\mathrm{F}}=3 \mathrm{~Hz}, \mathrm{CH}_{2}\right), 31.8\left(\mathrm{CH}_{2}\right), 28.3\left(\mathrm{~d},{ }^{4} J_{\mathrm{C}-\mathrm{F}}=3 \mathrm{~Hz}, \mathrm{CH}_{3}\right)$.

${ }^{19} \mathrm{~F} \mathrm{NMR}\left(282 \mathrm{MHz}, \mathrm{CDCl}_{3}\right): \delta=-116.5(\mathrm{~s})$.

IR (neat): $\tilde{v}=3266,3083,2866,1579,1532,1489,1416,1204,796 \mathrm{~cm}^{-1}$.

MS (EI) $m / z$ (relative intensity) 335 (56) [M] ${ }^{+}, 231$ (100), 188 (16), 91 (42).

HR-MS (EI): $m / z$ calcd for $\mathrm{C}_{21} \mathrm{H}_{22} \mathrm{FN}_{3}{ }^{+}[\mathrm{M}]^{+} 335.1792$, found 335.1794 .

\section{Synthesis of $\boldsymbol{N}$-[3-(tert-Butyl)-4-chlorophenyl]pyrimidin-2-amine (215ba)}<smiles>CC(C)(C)c1cc(Nc2ncccn2)ccc1Cl</smiles>

The general procedure $\mathbf{A}$ was followed using $\left[\mathrm{RuCl}_{2}(p \text {-cymene })\right]_{2}(15.3 \mathrm{mg}, 5.0$ mol \%), Piv-Val-OH (30.0 mg, $30 \mathrm{~mol} \%)$, substrate 161b (103 mg, $0.50 \mathrm{mmol}$ ) and bromide 50a (206 mg, $1.50 \mathrm{mmol}$ ). After $16 \mathrm{~h}$, purification by column chromatography ( $n$-hexane/EtOAc/Et ${ }_{3} \mathrm{~N}$ 10:1:0.1) yielded 215ba (76 mg, 58\%) as a yellow solid.

M. p.: $110-112^{\circ} \mathrm{C}$.

${ }^{1} \mathrm{H}$ NMR $\left(600 \mathrm{MHz}, \mathrm{CDCl}_{3}\right): \delta=8.40(\mathrm{~d}, J=4.7 \mathrm{~Hz}, 2 \mathrm{H}), 7.66(\mathrm{~s}, 1 \mathrm{H}), 7.55(\mathrm{dd}, J=8.5$, $2.7 \mathrm{~Hz}, 1 \mathrm{H}), 7.52(\mathrm{~d}, J=2.7 \mathrm{~Hz}, 1 \mathrm{H}), 7.28(\mathrm{~d}, J=8.5 \mathrm{~Hz}, 1 \mathrm{H}), 6.70(\mathrm{t}, J=4.7 \mathrm{~Hz}, 1 \mathrm{H}), 1.47(\mathrm{~s}, 9 \mathrm{H})$.

${ }^{13} \mathrm{C}$ NMR $\left(126 \mathrm{MHz}, \mathrm{CDCl}_{3}\right): \delta=160.0\left(\mathrm{C}_{\mathrm{q}}\right), 157.9(\mathrm{CH}), 146.8\left(\mathrm{C}_{\mathrm{q}}\right), 137.8\left(\mathrm{C}_{\mathrm{q}}\right), 132.0(\mathrm{CH}), 127.0\left(\mathrm{C}_{\mathrm{q}}\right)$, $119.1(\mathrm{CH}), 118.3(\mathrm{CH}), 112.5(\mathrm{CH}), 36.16\left(\mathrm{C}_{\mathrm{q}}\right), 29.6\left(\mathrm{CH}_{3}\right)$.

IR (ATR): $\tilde{v}=3235,3164,2962,1603,1566,1526,1441,1273,1034,796 \mathrm{~cm}^{-1}$.

MS (EI) $m / z$ (relative intensity) 263/261 (33/100) [M] ${ }^{+}, 248 / 246$ (23/73), 207/205 (9/28), 117 (5/15).

HR-MS (EI): $\mathrm{m} / \mathrm{z}$ calcd for $\mathrm{C}_{14} \mathrm{H}_{16}{ }^{35} \mathrm{CIN}_{3}[\mathrm{M}]^{+} 261.10327$, found 261.1023 .

\section{Synthesis of $\boldsymbol{N}$-[4-Bromo-3-(tert-butyl)phenyl]pyrimidin-2-amine (215ca)}<smiles>CC(C)(C)c1cc(Nc2ncccn2)ccc1Br</smiles>

The general procedure $\mathbf{A}$ was followed using $\left[\mathrm{RuCl}_{2}(p \text {-cymene })\right]_{2}(15.3 \mathrm{mg}, 5.0$ $\mathrm{mol} \%$ ), Piv-Val-OH (30.0 mg, $30 \mathrm{~mol} \%)$, substrate $161 \mathrm{c}(125 \mathrm{mg}, 0.50 \mathrm{mmol}$ ) and bromide 50a (206 mg, $1.50 \mathrm{mmol}$ ). After $16 \mathrm{~h}$, purification by column chromatography ( $n$-hexane/EtOAc/Et ${ }_{3} \mathrm{~N}$ 10:1:0.1) yielded $215 \mathrm{ca}$ (70 mg, 46\%) as a yellow solid.

M. p.: $103-105^{\circ} \mathrm{C}$.

${ }^{1} \mathrm{H}$ NMR $\left(300 \mathrm{MHz}, \mathrm{CDCl}_{3}\right): \delta=8.42(\mathrm{~d}, J=4.8 \mathrm{~Hz}, 2 \mathrm{H}), 7.75(\mathrm{~s}, 1 \mathrm{H}), 7.58(\mathrm{dd}, J=2.5$

$\mathrm{Hz}, 1 \mathrm{H}), 7.56-7.45(\mathrm{~m}, 2 \mathrm{H}), 6.73(\mathrm{t}, J=4.8 \mathrm{~Hz}, 1 \mathrm{H}), 1.52(\mathrm{~s}, 9 \mathrm{H})$.

${ }^{13} \mathrm{C}$ NMR $\left(126 \mathrm{MHz}, \mathrm{CDCl}_{3}\right): \delta=160.0\left(\mathrm{C}_{\mathrm{q}}\right), 158.0(\mathrm{CH}), 148.2\left(\mathrm{C}_{\mathrm{q}}\right), 138.5\left(\mathrm{C}_{\mathrm{q}}\right), 135.9(\mathrm{CH}), 119.4(\mathrm{CH})$, $118.6(\mathrm{CH}), 115.2\left(\mathrm{C}_{\mathrm{q}}\right), 112.6(\mathrm{CH}), 36.6\left(\mathrm{C}_{\mathrm{q}}\right), 29.6\left(\mathrm{CH}_{3}\right)$.

IR (ATR): $\tilde{v}=3243,3079,2903,1574,1521,1407,1232,1012,794 \mathrm{~cm}^{-1}$.

MS (EI) $m / z$ (relative intensity) 307/305 (100/100) [M] ${ }^{+}, 292 / 290$ (44/44), 210 (68), 170 (30).

HR-MS (EI): $\mathrm{m} / z$ calcd for $\mathrm{C}_{14} \mathrm{H}_{16}{ }^{79} \mathrm{BrN}_{3}{ }^{+}[\mathrm{M}]^{+}$305.0522, found 305.0519 .

\section{Synthesis of $\boldsymbol{N}$-[3-(tert-Butyl)-4-methoxyphenyl]pyrimidin-2-amine (215da)}<smiles>COc1ccc(Nc2ncccn2)cc1C(C)(C)C</smiles>

The general procedure $\mathbf{A}$ was followed using $\left[\mathrm{RuCl}_{2}(p \text {-cymene })\right]_{2}(15.3 \mathrm{mg}, 5.0$ mol \%), Piv-Val-OH (30.0 mg, $30 \mathrm{~mol} \%)$, substrate $161 \mathrm{~d}(101 \mathrm{mg}, 0.50 \mathrm{mmol}$ ) and bromide 50a (206 mg, $1.50 \mathrm{mmol}$ ). After $16 \mathrm{~h}$, purification by column 
chromatography ( $n$-hexane/EtOAc/Et ${ }_{3} \mathrm{~N}$ 10:1:0.1) yielded $215 \mathrm{da}(70 \mathrm{mg}, 54 \%$ ) as a yellow solid.

M. p.: $134-136^{\circ} \mathrm{C}$.

${ }^{1} \mathrm{H}$ NMR $\left(300 \mathrm{MHz}, \mathrm{CDCl}_{3}\right): \delta=8.36(\mathrm{~d}, J=4.7 \mathrm{~Hz}, 2 \mathrm{H}), 7.51(\mathrm{dd}, J=8.6,1.9 \mathrm{~Hz}, 1 \mathrm{H}), 7.35-7.25(\mathrm{~m}$, $2 \mathrm{H}), 6.88(\mathrm{~d}, J=8.6 \mathrm{~Hz}, 1 \mathrm{H}), 6.64(\mathrm{t}, J=4.7 \mathrm{~Hz}, 1 \mathrm{H}), 3.83(\mathrm{~s}, 3 \mathrm{H}), 1.38(\mathrm{~s}, 9 \mathrm{H})$.

${ }^{13} \mathrm{C} \mathrm{NMR}\left(126 \mathrm{MHz}, \mathrm{CDCl}_{3}\right): \delta=160.7\left(\mathrm{C}_{\mathrm{q}}\right), 157.9(\mathrm{CH}), 154.8\left(\mathrm{C}_{\mathrm{q}}\right), 138.7\left(\mathrm{C}_{\mathrm{q}}\right), 131.5\left(\mathrm{C}_{\mathrm{q}}\right), 120.2(\mathrm{CH})$, $119.6(\mathrm{CH}), 112.0(\mathrm{CH}), 111.7(\mathrm{CH}), 55.4\left(\mathrm{CH}_{3}\right), 34.9\left(\mathrm{C}_{\mathrm{q}}\right), 29.7\left(\mathrm{CH}_{3}\right)$.

IR (ATR): $\tilde{v}=3255,3175,2955,1604,1583,1497,1275,1030,807 \mathrm{~cm}^{-1}$.

MS (EI) $m / z$ (relative intensity) 257 (100) [M] $]^{+}, 242$ (95), 227 (25), 214 (15).

HR-MS (EI): $\mathrm{m} / \mathrm{z}$ calcd for $\mathrm{C}_{15} \mathrm{H}_{19} \mathrm{~N}_{3} \mathrm{O}^{+} 257.1523$, found 257.1529 .

Synthesis of $\mathbf{N}$-[3-(tert-Butyl)phenyl]pyrimidin-2-amine (215ea)<smiles>CC(C)(C)c1cccc(Nc2ncccn2)c1</smiles>

The general procedure $\mathbf{A}$ was followed using $\left[\mathrm{RuCl}_{2}(p \text {-cymene })\right]_{2}(15.3 \mathrm{mg}, 5.0$ mol \%), Piv-Val-OH (30.0 mg, $30 \mathrm{~mol} \%)$, substrate $161 \mathrm{e}(86 \mathrm{mg}, 0.50 \mathrm{mmol})$ and bromide 50a (206 mg, $1.50 \mathrm{mmol}$ ). After $16 \mathrm{~h}$, purification by column chromatography ( $n$-hexane/EtOAc/Et ${ }_{3} \mathrm{~N}$ 10:1:0.1) yielded 215ea (60 mg, 53\%) as a yellow solid.

M. p.: $72-74^{\circ} \mathrm{C}$.

${ }^{1} \mathrm{H}$ NMR $\left(300 \mathrm{MHz}, \mathrm{CDCl}_{3}\right): \delta=8.42(\mathrm{~d}, J=4.8 \mathrm{~Hz}, 2 \mathrm{H}), 7.61-7.50(\mathrm{~m}, 3 \mathrm{H}), 7.29(\mathrm{dd}, J$ $=7.9,7.9 \mathrm{~Hz}, 1 \mathrm{H}), 7.10(\mathrm{~d}, J=7.8 \mathrm{~Hz}, 1 \mathrm{H}), 6.69(\mathrm{t}, J=4.8 \mathrm{~Hz}, 1 \mathrm{H}), 1.34(\mathrm{~s}, 9 \mathrm{H})$.

${ }^{13} \mathrm{C}$ NMR $\left(126 \mathrm{MHz}, \mathrm{CDCl}_{3}\right): \delta=160.3\left(\mathrm{C}_{\mathrm{q}}\right), 157.8(\mathrm{CH}), 151.9\left(\mathrm{C}_{\mathrm{q}}\right), 138.9\left(\mathrm{C}_{\mathrm{q}}\right), 128.4(\mathrm{CH}), 119.9(\mathrm{CH})$, $117.0(\mathrm{CH}), 117.0(\mathrm{CH}), 112.2(\mathrm{CH}), 34.7\left(\mathrm{C}_{\mathrm{q}}\right), 31.4\left(\mathrm{CH}_{3}\right)$.

IR (ATR): $\tilde{v}=3254,3100,2960,1608,1575,1429,1358,1253,780 \mathrm{~cm}^{-1}$.

MS (EI) $m / z$ (relative intensity) 227 (80) [M] ${ }^{+}, 212$ (100), 170 (25), 142 (7).

HR-MS (EI): $m / z$ calcd for $\mathrm{C}_{14} \mathrm{H}_{17} \mathrm{~N}_{3}{ }^{+}[\mathrm{M}]^{+}$227.1417, found 227.1417.

\section{Synthesis of $\boldsymbol{N}$-[3-(tert-Butyl)-2-fluorophenyl]pyrimidin-2-amine (215fa)}<smiles>CC(C)(C)c1cccc(Nc2ncccn2)c1F</smiles>

The general procedure $\mathbf{A}$ was followed using $\left[\mathrm{RuCl}_{2}(p \text {-cymene) }]_{2}(15.3 \mathrm{mg}, 5.0 \mathrm{~mol}\right.$ $\%$ ), Ad-Ile-OH (44.0 mg, $30 \mathrm{~mol} \%$ ), substrate $161 \mathrm{f}$ (95 mg, $0.50 \mathrm{mmol}$ ) and bromide 50a $(206 \mathrm{mg}, 1.50 \mathrm{mmol})$. After $16 \mathrm{~h}$, purification by column chromatography ( $n$-hexane/EtOAc/Et ${ }_{3} \mathrm{~N}$ 10:1:0.1) yielded $\mathbf{2 1 5 f a ~ ( 7 5 ~ m g , ~ 6 1 \% ) ~ a s ~ a ~ w h i t e ~ s o l i d . ~}$

M. p.: $102-104^{\circ} \mathrm{C}$.

${ }^{1} \mathrm{H}$ NMR $\left(400 \mathrm{MHz}, \mathrm{CDCl}_{3}\right): \delta=8.41(\mathrm{~d}, J=4.8 \mathrm{~Hz}, 2 \mathrm{H}), 8.26$ (ddd, $J=7.8,7.8,1.7 \mathrm{~Hz}$, $1 \mathrm{H}$ ), $7.49(\mathrm{~s}, 1 \mathrm{H}$ ), 7.05 (ddd, $J=8.0,8.0,1.1 \mathrm{~Hz}, 1 \mathrm{H}$ ), 6.94 (ddd, $J=7.8,7.8,1.7 \mathrm{~Hz}$, $1 \mathrm{H}), 6.72(\mathrm{t}, J=4.8 \mathrm{~Hz}, 1 \mathrm{H}), 1.38(\mathrm{~d}, J=1.1 \mathrm{~Hz}, 9 \mathrm{H})$.

${ }^{13} \mathrm{C}$ NMR $\left(75 \mathrm{MHz}, \mathrm{CDCl}_{3}\right): \delta=159.9\left(\mathrm{C}_{\mathrm{q}}\right), 157.8(\mathrm{CH}), 151.8\left(\mathrm{~d},{ }^{1} J_{\mathrm{C}-\mathrm{F}}=245 \mathrm{~Hz}, \mathrm{C}_{\mathrm{q}}\right), 136.5\left(\mathrm{~d},{ }^{2} J_{\mathrm{C}-\mathrm{F}}=11\right.$ $\left.\mathrm{Hz}, \mathrm{C}_{\mathrm{q}}\right), 128.2\left(\mathrm{~d},{ }^{2} \mathrm{~J}_{\mathrm{C}-\mathrm{F}}=12 \mathrm{~Hz}, \mathrm{C}_{\mathrm{q}}\right), 123.2\left(\mathrm{~d},{ }^{3} \mathrm{~J}_{\mathrm{C}-\mathrm{F}}=4 \mathrm{~Hz}, \mathrm{CH}\right), 120.1\left(\mathrm{~d},{ }^{3} \mathrm{~J}_{\mathrm{C}-\mathrm{F}}=6 \mathrm{~Hz}, \mathrm{CH}\right), 118.8(\mathrm{CH})$, $112.7(\mathrm{CH}), 34.4\left(\mathrm{~d},{ }^{3} \mathrm{~J}_{\mathrm{C}-\mathrm{F}}=2 \mathrm{~Hz}, \mathrm{C}_{\mathrm{q}}\right), 30.0\left(\mathrm{~d},{ }^{4} J_{\mathrm{C}-\mathrm{F}}=4 \mathrm{~Hz}, \mathrm{CH}_{3}\right)$.

${ }^{19} \mathrm{~F} \mathrm{NMR}\left(282 \mathrm{MHz}, \mathrm{CDCl}_{3}\right): \delta=-129.1(\mathrm{~s})$.

IR (ATR): $\tilde{v}=3264,3090,2965,1574,1535,1410,1200,997,783 \mathrm{~cm}^{-1}$.

MS (EI) $m / z$ (relative intensity) 245 (100) [M] ${ }^{+}, 230$ (95), 210 (55), 188 (77).

HR-MS (EI): $m / z$ calcd for $\mathrm{C}_{14} \mathrm{H}_{16} \mathrm{FN}_{3}{ }^{+}[\mathrm{M}]^{+} 245.1323$, found 245.1322 .

\section{Synthesis of $\boldsymbol{N}$-[3-(tert-Butyl)-2-methoxyphenyl]pyrimidin-2-amine (215ga)}<smiles>COc1c(Nc2ncccn2)cccc1C(C)(C)C</smiles>

The general procedure $\mathbf{A}$ was followed using $\left[\mathrm{RuCl}_{2}(p \text {-cymene })\right]_{2}(15.3 \mathrm{mg}, 5.0 \mathrm{~mol}$ $\%)$, Ad-lle-OH (44.0 mg, $30 \mathrm{~mol} \%)$, substrate $161 \mathrm{~g}(101 \mathrm{mg}, 0.50 \mathrm{mmol}$ ) and 
bromide 50a (206 mg, $1.50 \mathrm{mmol})$. After $16 \mathrm{~h}$, purification by column chromatography ( $n$-hexane/EtOAc/Et ${ }_{3} \mathrm{~N}$ 10:1:0.1) yielded 215ga (52 mg, 40\%) as a white solid.

M. p.: $144-146^{\circ} \mathrm{C}$.

${ }^{1} \mathrm{H}$ NMR $\left(300 \mathrm{MHz}, \mathrm{CDCl}_{3}\right): \delta=8.42(\mathrm{~d}, J=4.8 \mathrm{~Hz}, 2 \mathrm{H}), 8.07(\mathrm{dd}, J=6.1,3.5 \mathrm{~Hz}, 1 \mathrm{H}), 7.45(\mathrm{~s}, 1 \mathrm{H})$, 7.12-7.01 (m, 2H), $6.70(\mathrm{t}, J=4.8 \mathrm{~Hz}, 1 \mathrm{H}), 3.80(\mathrm{~s}, 3 \mathrm{H}), 1.41(\mathrm{~s}, 9 \mathrm{H})$.

${ }^{13} \mathrm{C} \mathrm{NMR}\left(126 \mathrm{MHz}, \mathrm{CDCl}_{3}\right): \delta=160.4\left(\mathrm{C}_{\mathrm{q}}\right), 158.1(\mathrm{CH}), 150.0\left(\mathrm{C}_{\mathrm{q}}\right), 142.7\left(\mathrm{C}_{\mathrm{q}}\right), 133.0\left(\mathrm{C}_{\mathrm{q}}\right), 123.5(\mathrm{CH})$, $121.5(\mathrm{CH}), 120.2(\mathrm{CH}), 112.4(\mathrm{CH}), 60.8\left(\mathrm{CH}_{3}\right), 35.0\left(\mathrm{C}_{\mathrm{q}}\right), 30.9\left(\mathrm{CH}_{3}\right)$.

IR (ATR): $\tilde{v}=3240,3077,2958,1599,1528,1420,1270,995,797 \mathrm{~cm}^{-1}$.

MS (EI) $m / z$ (relative intensity) 257 (18) [M] ${ }^{+}, 242$ (12), 226 (100), 210 (20).

HR-MS (EI): $m / z$ calcd for $\mathrm{C}_{15} \mathrm{H}_{19} \mathrm{~N}_{3} \mathrm{O}^{+}[\mathrm{M}]^{+} 257.1523$, found 257.1527 .

\section{Synthesis of $\mathbf{N}$-[3-(tert-Butyl)-2,4-difluorophenyl]pyrimidin-2-amine (215ha)}

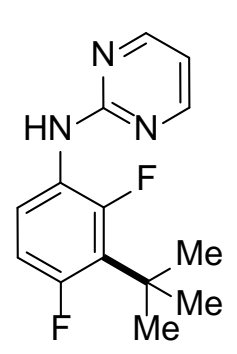

The general procedure $\mathbf{A}$ was followed using $\left[\mathrm{RuCl}_{2}(p \text {-cymene })\right]_{2}(15.3 \mathrm{mg}, 5.0 \mathrm{~mol}$ $\%$ ), Ad-lle-OH (44.0 mg, $30 \mathrm{~mol} \%$ ), substrate $161 \mathrm{~h}(104 \mathrm{mg}, 0.50 \mathrm{mmol}$ ) and bromide 50a (206 mg, $1.50 \mathrm{mmol}$ ). After $16 \mathrm{~h}$, purification by column chromatography ( $n$-hexane/EtOAc/Et ${ }_{3} \mathrm{~N}$ 10:1:0.1) yielded $215 \mathrm{ha}(72 \mathrm{mg}, 55 \%$ ) as a white solid.

M. p.: $102-104^{\circ} \mathrm{C}$.

${ }^{1} \mathrm{H}$ NMR $\left(400 \mathrm{MHz}, \mathrm{CDCl}_{3}\right): \delta=8.39(\mathrm{~d}, J=4.8 \mathrm{~Hz}, 2 \mathrm{H}), 8.13$ (ddd, $J=9.1,9.1,5.4$, $1 \mathrm{H}), 7.28(\mathrm{~s}, 1 \mathrm{H}), 6.80$ (ddd, $J=12.5,9.1,2.1 \mathrm{~Hz}, 1 \mathrm{H}), 6.71(\mathrm{t}, J=4.8 \mathrm{~Hz}, 1 \mathrm{H}), 1.46(\mathrm{dd}, J=2.3,2.3 \mathrm{~Hz}$, $9 \mathrm{H})$.

${ }^{13} \mathrm{C}$ NMR $\left(75 \mathrm{MHz}, \mathrm{CDCl}_{3}\right): \delta=160.0\left(\mathrm{C}_{\mathrm{q}}\right), 157.8(\mathrm{CH}), 156.5\left(\mathrm{dd},{ }^{1} J_{\mathrm{C}-\mathrm{F}}=245,{ }^{3} J_{\mathrm{C}-\mathrm{F}}=10 \mathrm{~Hz}, \mathrm{C}_{\mathrm{q}}\right), 152.0$ $\left(\mathrm{dd},{ }^{1} J_{\mathrm{C}-\mathrm{F}}=245,{ }^{3} \mathrm{~J}_{\mathrm{C}-\mathrm{F}}=10 \mathrm{~Hz}, \mathrm{C}_{\mathrm{q}}\right), 124.7\left(\mathrm{dd},{ }^{2} J_{\mathrm{C}-\mathrm{F}}=13,{ }^{4} J_{\mathrm{C}-\mathrm{F}}=2 \mathrm{~Hz}, \mathrm{C}_{\mathrm{q}}\right), 124.1\left(\mathrm{dd},{ }^{2} \mathrm{~J}_{\mathrm{C}-\mathrm{F}}=16,{ }^{2} J_{\mathrm{C}-\mathrm{F}}=14\right.$ $\mathrm{Hz}, \mathrm{C}_{\mathrm{q}}$ ), $119.0\left(\mathrm{dd},{ }^{3} \mathrm{~J}_{\mathrm{C}-\mathrm{F}}=11,{ }^{3} \mathrm{~J}_{\mathrm{C}-\mathrm{F}}=2 \mathrm{~Hz}, \mathrm{CH}\right), 112.8(\mathrm{CH}), 111.5\left(\mathrm{dd},{ }^{2} J_{\mathrm{C}-\mathrm{F}}=27,{ }^{4} J_{\mathrm{C}-\mathrm{F}}=3 \mathrm{~Hz}, \mathrm{CH}\right), 36.0$ $\left(\mathrm{dd},{ }^{3} J_{\mathrm{C}-\mathrm{F}}=3,{ }^{3} \mathrm{~J}_{\mathrm{C}-\mathrm{F}}=3 \mathrm{~Hz}, \mathrm{C}_{\mathrm{q}}\right), 31.1\left(\mathrm{dd},{ }^{4} \mathrm{~J}_{\mathrm{C}-\mathrm{F}}=6,{ }^{4} \mathrm{~J}_{\mathrm{C}-\mathrm{F}}=6 \mathrm{~Hz}, \mathrm{CH}_{3}\right)$.

${ }^{19} \mathrm{~F} \mathrm{NMR}\left(282 \mathrm{MHz}, \mathrm{CDCl}_{3}\right): \delta=-113.6(\mathrm{~s}),-123.7(\mathrm{~s})$.

IR (ATR): $\tilde{v}=3256,3196,3000,1582,1471,1408,1241,1001,785 \mathrm{~cm}^{-1}$.

MS (EI) $m / z$ (relative intensity) 263 (87) [M] ${ }^{+}, 248$ (100), 228 (37), 206 (32).

HR-MS (EI): $m / z$ calcd for $\mathrm{C}_{14} \mathrm{H}_{15} \mathrm{~F}_{2} \mathrm{~N}_{3}{ }^{+}[\mathrm{M}]^{+} 263.1229$, found 263.1226 .

\section{Synthesis of $\mathbf{N}$-(3-Cycloheptyl-4-fluorophenyl)pyrimidin-2-amine (220ae)}

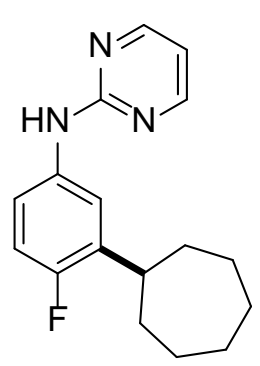

The general procedure A was followed using $\left[\mathrm{RuCl}_{2}(p \text {-cymene })\right]_{2}(15.3 \mathrm{mg}, 5.0$ mol \%), Piv-Val-OH (30.0 mg, $30 \mathrm{~mol} \%$ ), substrate 161a (95 mg, $0.50 \mathrm{mmol}$ ) and bromide 44e (266 mg, $1.50 \mathrm{mmol})$. After $16 \mathrm{~h}$, purification by column chromatography ( $n$-hexane/EtOAc/Et ${ }_{3} \mathrm{~N}$ 10:1:0.1) yielded 220ae (40 mg, 28\%) as a yellow solid.

M. p.: $121-123^{\circ} \mathrm{C}$.

${ }^{1} \mathrm{H} \mathrm{NMR}\left(400 \mathrm{MHz}, \mathrm{CDCl}_{3}\right): \delta=8.39$ (d, $\left.J=4.8 \mathrm{~Hz}, 2 \mathrm{H}\right), 7.79$ (bs, $\left.1 \mathrm{H}\right), 7.45$ (ddd, $J=$ $8.8,4.4,2.8 \mathrm{~Hz}, 1 \mathrm{H}), 7.33(\mathrm{dd}, J=6.5,2.8 \mathrm{~Hz}, 1 \mathrm{H}), 6.96(\mathrm{dd}, J=9.8,8.8 \mathrm{~Hz}, 1 \mathrm{H}), 6.68(\mathrm{t}, J=4.8 \mathrm{~Hz}, 1 \mathrm{H})$, $2.99(\mathrm{tt}, J=10.3,3.4 \mathrm{~Hz}, 1 \mathrm{H}), 1.96-1.89(\mathrm{~m}, 2 \mathrm{H}), 1.85-1.76(\mathrm{~m}, 2 \mathrm{H}), 1.73-1.53(\mathrm{~m}, 8 \mathrm{H})$.

${ }^{13} \mathrm{C} \mathrm{NMR}\left(125 \mathrm{MHz}, \mathrm{CDCl}_{3}\right): \delta=160.3\left(\mathrm{C}_{\mathrm{q}}\right), 157.9(\mathrm{CH}), 155.9\left(\mathrm{C}_{\mathrm{q}},{ }^{1} \mathrm{~J}_{\mathrm{C}-\mathrm{F}}=240 \mathrm{~Hz}\right), 136.5\left(\mathrm{C}_{\mathrm{q}},{ }^{2} \mathrm{~J}_{\mathrm{C}-\mathrm{F}}=16\right.$ $\mathrm{Hz}), 135.1\left(\mathrm{C}_{\mathrm{q}},{ }^{4} \mathrm{~J}_{\mathrm{C}-\mathrm{F}}=3 \mathrm{~Hz}\right), 119.8\left(\mathrm{CH},{ }^{3} \mathrm{~J}_{\mathrm{C}-\mathrm{F}}=5 \mathrm{~Hz}\right), 118.7\left(\mathrm{CH},{ }^{3} \mathrm{~J}_{\mathrm{C}-\mathrm{F}}=8 \mathrm{~Hz}\right), 115.3\left(\mathrm{CH},{ }^{2} J_{\mathrm{C}-\mathrm{F}}=24 \mathrm{~Hz}\right)$, 112.1 (CH), $39.6(\mathrm{CH}), 35.3\left(\mathrm{CH}_{2}\right), 27.9\left(\mathrm{CH}_{2}\right), 27.3\left(\mathrm{CH}_{2}\right)$.

${ }^{19} \mathrm{~F} \mathrm{NMR}\left(282 \mathrm{MHz}, \mathrm{CDCl}_{3}\right): \delta=-125.6(\mathrm{~s})$. 
IR (ATR): $\tilde{v}=2920,2853,1583,1537,1487,1450,1244,1198,796,554 \mathrm{~cm}^{-1}$.

MS (EI) $m / z$ (relative intensity) 285 (100) [M] ${ }^{+}, 216$ (47), 188 (18).

HR-MS (EI) $m / z$ calcd. For $\mathrm{C}_{17} \mathrm{H}_{20} \mathrm{FN}_{3}{ }^{+}[\mathrm{M}]^{+} 285.1636$, found 285.1643 .

\section{Synthesis of}

\section{1-\{4-[2-Fluoro-3-(pyrimidin-2-ylamino)phenyl]piperidin-1-yl\}-2,2-dimethylpropan-1-one (220fo)}<smiles>O=C(c1ccccc1)N1CCC(c2cccc(Nc3ncccn3)c2F)CC1</smiles>

The general procedure $A$ was followed using $\left[\mathrm{RuCl}_{2}(p \text {-cymene) }]_{2}(7.7 \mathrm{mg}, 5.0\right.$ $\mathrm{mol} \%), 1-\mathrm{AdCO}_{2} \mathrm{H}(13.5 \mathrm{mg}, 30 \mathrm{~mol} \%)$, substrate $161 \mathrm{f}(47 \mathrm{mg}, 0.25 \mathrm{mmol})$ and bromide 440 (186 $\mathrm{mg}, 0.75 \mathrm{mmol})$. After $16 \mathrm{~h}$, purification by column chromatography ( $n$-hexane/EtOAc/Et ${ }_{3} \mathrm{~N}$ 5:1:0.1) yielded 212 fo (18 mg, 20\%) as a yellow solid.

M. p.: $165-167^{\circ} \mathrm{C}$.

${ }^{1} \mathrm{H}$ NMR $\left(400 \mathrm{MHz}, \mathrm{CDCl}_{3}\right): \delta=8.42(\mathrm{~d}, J=4.8 \mathrm{~Hz}, 2 \mathrm{H}), 8.29$ (ddd, $J=8.1,8.1$, $1.5 \mathrm{~Hz}, 1 \mathrm{H}$ ), $7.32(\mathrm{~s}, 1 \mathrm{H}), 7.08$ (ddd, $J=8.0,8.0,1.0 \mathrm{~Hz}, 1 \mathrm{H}), 6.85-6.80(\mathrm{~m}, 1 \mathrm{H}), 6.75(\mathrm{t}, J=4.8 \mathrm{~Hz}, 1 \mathrm{H}$ ), 4.61-4.52 (m, 2H), 3.20-3.07 (m, 1H), 2.94-2.82 (m, 2H), 1.91-1.82 (m, 2H), 1.71-1.62 (m, 2H), 1.30 (s, 9H).

${ }^{13} \mathrm{C} \mathrm{NMR}\left(75 \mathrm{MHz}, \mathrm{CDCl}_{3}\right): \delta=176.2\left(\mathrm{C}_{\mathrm{q}}\right), 159.9(\mathrm{CH}), 158.0\left(\mathrm{C}_{\mathrm{q}}\right), 150.2\left(\mathrm{~d},{ }^{1} J_{\mathrm{C}-\mathrm{F}}=242 \mathrm{~Hz}, \mathrm{C}_{\mathrm{q}}\right), 131.5(\mathrm{~d}$, $\left.{ }^{2} J_{C-F}=13 \mathrm{~Hz}, C_{q}\right), 127.8\left(d,{ }^{2} J_{C-F}=11 \mathrm{~Hz}, C_{q}\right), 124.0\left(d,{ }^{3} J_{C-F}=4 \mathrm{~Hz}, C H\right), 120.2\left(d,{ }^{3} J_{C-F}=4 \mathrm{~Hz}, C H\right), 118.7$ (CH), $113.1(\mathrm{CH}), 45.8\left(\mathrm{CH}_{2}\right), 38.7\left(\mathrm{CH}_{2}\right), 35.8\left(\mathrm{~d},{ }^{3} \mathrm{~J}_{\mathrm{C}-\mathrm{F}}=3 \mathrm{~Hz}, \mathrm{CH}\right), 32.1\left(\mathrm{C}_{\mathrm{q}}\right), 28.5\left(\mathrm{CH}_{3}\right)$.

${ }^{19} \mathrm{~F} \mathrm{NMR}\left(282 \mathrm{MHz}, \mathrm{CDCl}_{3}\right): \delta=-138.0(\mathrm{~s})$. IR (ATR): $\tilde{v}=3247,2977,2911,1600,1574,1428,1296,1188,971,795 \mathrm{~cm}^{-1}$. MS (EI) $m / z$ (relative intensity) 356 (29) [M] ${ }^{+}, 299$ (100), 216 (77), 188 (34).

HR-MS (ESI): $m / z$ calcd for $\mathrm{C}_{20} \mathrm{H}_{26} \mathrm{FN}_{4} \mathrm{O}^{+}[\mathrm{M}+\mathrm{H}]^{+} 357.2085$, found 357.2091 .

\section{Removal of Directing Group}

meta-Alkylated product $215 \mathrm{aa}(61.3 \mathrm{mg}, 0.25 \mathrm{mmol})$ was dissolved in concentrated $\mathrm{HCl}(1 \mathrm{~mL})$ in a microwave vial. The vial was heated up to $150{ }^{\circ} \mathrm{C}$ for $1 \mathrm{~h}$ in microwave. The reaction mixture was allowed to cool to ambient temperature and poured into to EtOAc $(15 \mathrm{~mL})$, then saturated $\mathrm{NaHCO}_{3}$ solution was added until the $\mathrm{pH}$ was adjusted to 7 . Aqueous layer was extracted with EtOAc $(3 \times 10$ $\mathrm{mL}$ ), the combined organic layers were dried over $\mathrm{Na}_{2} \mathrm{SO}_{4}$ and concentrated in vacuo affording 191 (35 $\mathrm{mg}, 84 \%$ ) as a yellow oil.

\section{Analytical Data for 3-(tert-Butyl)-4-fluoroaniline (191)}<smiles>CC(C)(C)c1cc(N)ccc1F</smiles>

${ }^{1} \mathrm{H}$ NMR $\left(400 \mathrm{MHz}, \mathrm{CDCl}_{3}\right): \delta=6.77$ (ddd, $\left.J=12.2,8.5,0.3 \mathrm{~Hz}, 1 \mathrm{H}\right), 6.59$ (dd, $J=7.0$, $2.9 \mathrm{~Hz}, 1 \mathrm{H}$ ), 6.45 (ddd, $J=8.5,3.7,2.9 \mathrm{~Hz}, 1 \mathrm{H}), 3.47$ (bs, $2 \mathrm{H}), 1.32$ (d, $J=1.0 \mathrm{~Hz}, 9 \mathrm{H}$ ).

${ }^{13} \mathrm{C} \mathrm{NMR}\left(75 \mathrm{MHz}, \mathrm{CDCl}_{3}\right): \delta=155.6\left(\mathrm{~d},{ }^{1} \mathrm{~J}_{\mathrm{C}-\mathrm{F}}=244 \mathrm{~Hz}, \mathrm{C}_{\mathrm{q}}\right), 141.8\left(\mathrm{~d},{ }^{4} J_{\mathrm{C}-\mathrm{F}}=2 \mathrm{~Hz}, \mathrm{C}_{\mathrm{q}}\right)$, $137.6\left(d,{ }^{2} J_{C-F}=13 \mathrm{~Hz}, C_{q}\right), 116.5\left(d,{ }^{2} J_{C-F}=26 \mathrm{~Hz}, \mathrm{CH}\right), 114.0\left(\mathrm{~d},{ }^{3} J_{\mathrm{C}-\mathrm{F}}=6 \mathrm{~Hz}, \mathrm{CH}\right), 113.4$ $\left(d,{ }^{3} J_{C-F}=6 \mathrm{~Hz}, \mathrm{CH}\right), 34.1\left(\mathrm{~d},{ }^{3} \mathrm{~J}_{\mathrm{C}-\mathrm{F}}=3 \mathrm{~Hz}, \mathrm{C}_{\mathrm{q}}\right), 29.8\left(\mathrm{~d},{ }^{4} \mathrm{~J}_{\mathrm{C}-\mathrm{F}}=4 \mathrm{~Hz}, \mathrm{CH}_{3}\right)$.

${ }^{19} \mathrm{~F} \mathrm{NMR}\left(282 \mathrm{MHz}, \mathrm{CDCl}_{3}\right): \delta=-122.9(\mathrm{~s})$.

IR (neat): $\tilde{v}=3335,2958,2871,1670,1492,1364,1203,865 \mathrm{~cm}^{-1}$. 
MS (EI) $m / z$ (relative intensity) 167 (55) [M] ${ }^{+}, 152$ (100), 124 (70), 109 (20).

HR-MS (EI): $\mathrm{m} / z$ calcd for $\mathrm{C}_{10} \mathrm{H}_{14} \mathrm{FN}^{+}[\mathrm{M}]^{+} 167.1105$, found 167.1111.

\section{Experiment with Substrate 161a in the Presence of $D_{2} O$}

The general procedure $\mathbf{A}$ was followed using $\left[\mathrm{RuCl}_{2} \text { (p-cymene) }\right]_{2}(15.3 \mathrm{mg}, 5.0 \mathrm{~mol} \%)$, Piv-Val-OH (30.0 mg, $30 \mathrm{~mol} \%$ ), substrate 161a (95 mg, $0.50 \mathrm{mmol}$ ) and bromide 50a (206 mg, $1.50 \mathrm{mmol}$ ) and $\mathrm{D}_{2} \mathrm{O}\left(0.05 \mathrm{~mL}\right.$ ). After $20 \mathrm{~h}$, purification by column chromatography ( $n$-hexane/EtOAc/Et ${ }_{3} \mathrm{~N}$ 5:1:0.1) yielded $\left[D_{n}\right]-215 a a(12 \mathrm{mg}, 10 \%)$ and reisolated $\left[D_{n}\right]-161 a(60 \mathrm{mg}, 63 \%)$ as white solids.

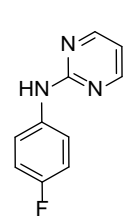

$161 \mathrm{a}$

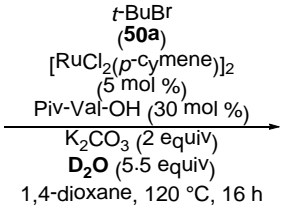

$\mathbf{D}_{2} \mathrm{O}(5.5$ equiv $)$
1,4-dioxane, $120^{\circ} \mathrm{C}, 16 \mathrm{~h}$

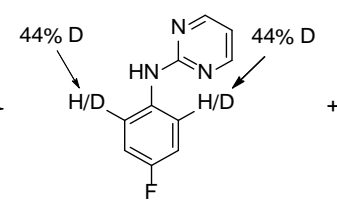

$\left[D_{n}\right]^{-161 a: ~} 63 \%$

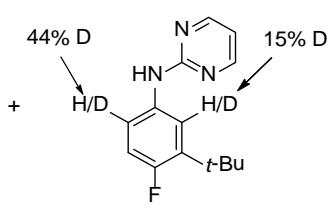

$\left[D_{n}\right]^{-215 a a: ~} 10 \%$<smiles>CC(C)(C)c1c(F)cc([18OH])c(Nc2ncccn2)c1O</smiles>
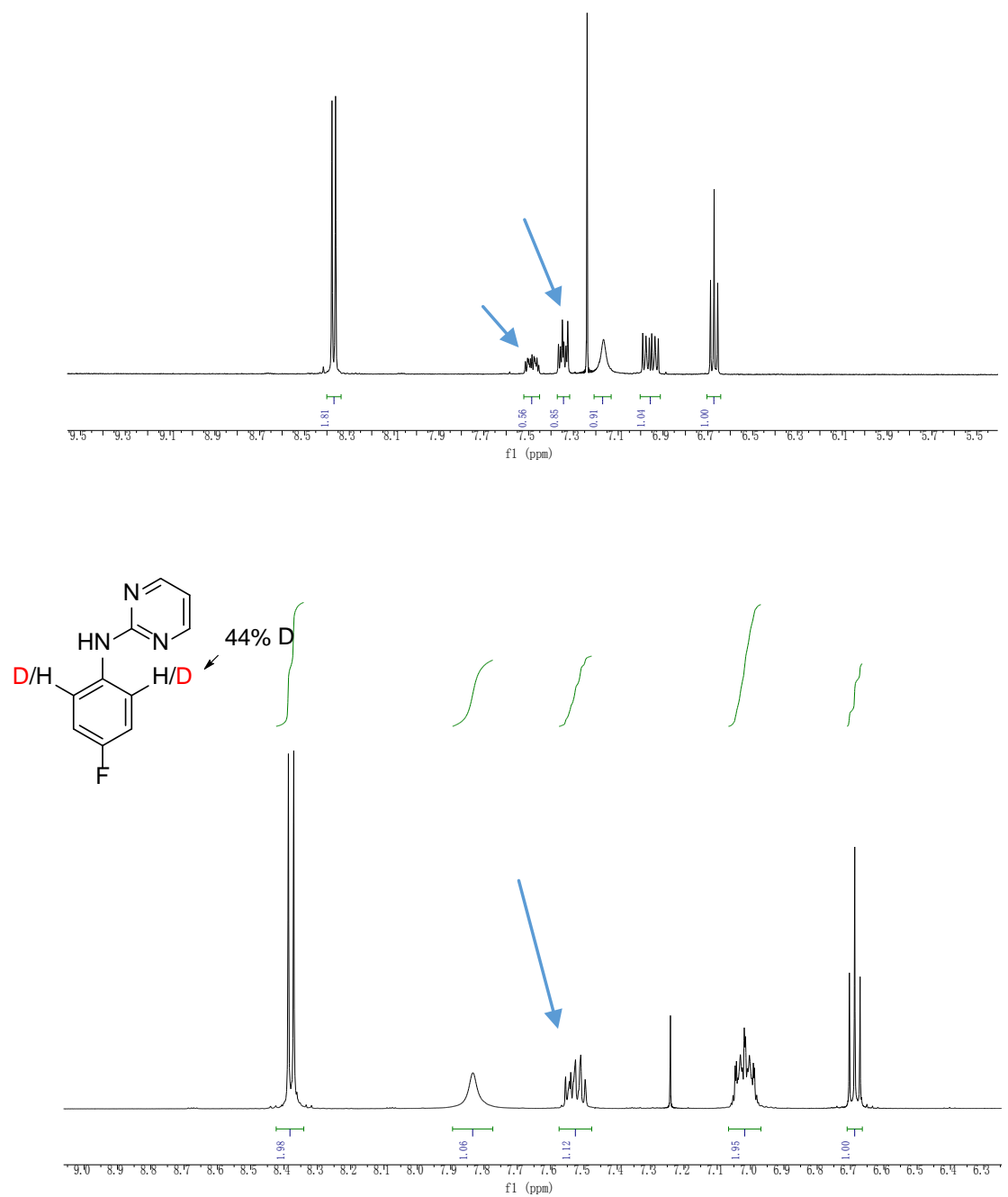


\subsubsection{Analytical Data for the Products of Ruthenium(II)-Catalyzed Oxidative Alkenylation of Aryl Carbamates}

\section{Synthesis of Ethyl (E)-3-\{2-[(N,N-Dimethylcarbamoyl)oxy)]\}-4-methylphenyl\}acrylate (193aa)}

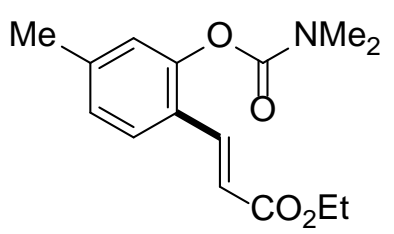

The general procedure $\mathbf{D}$ was followed using substrate $192 \mathrm{a}(90 \mathrm{mg}, 0.50$ $\mathrm{mmol}$ ) and ethyl acrylate (15a) (100 mg, $1.00 \mathrm{mmol}$ ). Purification by column chromatography ( $n$-hexane/EtOAc: $10 / 1 \rightarrow 5 / 1$ ) yielded 193aa (117 $\mathrm{mg}, 84 \%$ ) as a colorless oil.

${ }^{1} \mathrm{H}$ NMR $\left(300 \mathrm{MHz}, \mathrm{CDCl}_{3}\right): \delta=7.76(\mathrm{~d}, J=16.1 \mathrm{~Hz}, 1 \mathrm{H}), 7.46(\mathrm{~d}, J=8.0 \mathrm{~Hz}$, $1 \mathrm{H}), 6.97(\mathrm{~d}, J=8.0 \mathrm{~Hz}, 1 \mathrm{H}), 6.94(\mathrm{~s}, 1 \mathrm{H}), 6.34(\mathrm{~d}, J=16.1 \mathrm{~Hz}, 1 \mathrm{H}), 4.20(\mathrm{q}, J=7.1 \mathrm{~Hz}, 2 \mathrm{H}), 3.11(\mathrm{~s}, 3 \mathrm{H})$, $2.97(\mathrm{~s}, 3 \mathrm{H}), 2.30(\mathrm{~s}, 3 \mathrm{H}), 1.27(\mathrm{t}, J=7.1 \mathrm{~Hz}, 3 \mathrm{H})$.

${ }^{13} \mathrm{C} \mathrm{NMR}\left(75 \mathrm{MHz}, \mathrm{CDCl}_{3}\right): \delta=166.8\left(\mathrm{C}_{\mathrm{q}}\right), 154.2\left(\mathrm{C}_{\mathrm{q}}\right), 149.9\left(\mathrm{C}_{\mathrm{q}}\right), 141.7\left(\mathrm{C}_{\mathrm{q}}\right), 138.1(\mathrm{CH}), 126.9(\mathrm{CH})$, $126.5(\mathrm{CH}), 124.3\left(\mathrm{C}_{\mathrm{q}}\right), 123.7(\mathrm{CH}), 118.5(\mathrm{CH}), 60.2\left(\mathrm{CH}_{2}\right), 36.6\left(\mathrm{CH}_{3}\right), 36.3\left(\mathrm{CH}_{3}\right), 21.2\left(\mathrm{CH}_{3}\right), 14.1$ $\left(\mathrm{CH}_{3}\right)$.

IR (neat): $\tilde{v}=2934,1708,1632,1381,1149,884,619 \mathrm{~cm}^{-1}$.

MS (EI) $m / z$ (relative intensity) 277 (5) [M] ${ }^{+}, 189$ (25), 132 (5), 72 (100).

HR-MS (EI): $\mathrm{m} / z$ calcd for $\mathrm{C}_{15} \mathrm{H}_{19} \mathrm{NO}_{4}{ }^{+}[\mathrm{M}]^{+}$277.1309, found 277.1316.

Synthesis of Ethyl (E)-3-\{2-[(N,N-Dimethylcarbamoyl)oxy]phenyl\}acrylate (193ba)<smiles>CCOC(=O)C=Cc1ccccc1OC(=O)N(C)C</smiles>

The general procedure D was followed using substrate $192 \mathrm{~b}(83 \mathrm{mg}$, $0.50 \mathrm{mmol}$ ) and ethyl acrylate (15a) $(100 \mathrm{mg}, 1.00 \mathrm{mmol})$. Purification by column chromatography ( $n$-hexane/EtOAc: $10 / 1 \rightarrow 5 / 1$ ) yielded 193ba ( $89 \mathrm{mg}$, $68 \%)$ as a colorless oil.

${ }^{1} \mathrm{H}$ NMR $\left(300 \mathrm{MHz}, \mathrm{CDCl}_{3}\right): \delta=7.81(\mathrm{~d}, J=16.1 \mathrm{~Hz}, 1 \mathrm{H}), 7.58(\mathrm{dd}, J=7.8,1.7 \mathrm{~Hz}$, $1 \mathrm{H}), 7.35$ (dd, $J=7.8,7.8 \mathrm{~Hz}, 1 \mathrm{H}), 7.21-7.12(\mathrm{~m}, 2 \mathrm{H}), 6.41(\mathrm{~d}, J=16.1 \mathrm{~Hz}, 1 \mathrm{H}), 4.22(\mathrm{q}, J=7.1 \mathrm{~Hz}, 2 \mathrm{H}$ ), $3.14(\mathrm{~s}, 3 \mathrm{H}), 2.99(\mathrm{~s}, 3 \mathrm{H}), 1.29(\mathrm{t}, J=7.1 \mathrm{~Hz}, 3 \mathrm{H})$.

${ }^{13} \mathrm{C} \mathrm{NMR}\left(75 \mathrm{MHz}, \mathrm{CDCl}_{3}\right): \delta=166.8\left(\mathrm{C}_{\mathrm{q}}\right), 154.2\left(\mathrm{C}_{\mathrm{q}}\right), 150.0\left(\mathrm{C}_{\mathrm{q}}\right), 138.2(\mathrm{CH}), 130.9(\mathrm{CH}), 127.2(\mathrm{CH})$, $127.2\left(\mathrm{C}_{\mathrm{q}}\right), 125.6(\mathrm{CH}), 123.3(\mathrm{CH}), 119.7(\mathrm{CH}), 60.4\left(\mathrm{CH}_{2}\right), 36.8\left(\mathrm{CH}_{3}\right), 36.4\left(\mathrm{CH}_{3}\right), 14.2\left(\mathrm{CH}_{3}\right)$.

IR (neat): $\tilde{v}=2938,1708,1635,1149,1094,754 \mathrm{~cm}^{-1}$.

MS (EI) $m / z$ (relative intensity) 263 (5) [M] $]^{+}, 175$ (25), 118 (6), 72 (100).

HR-MS (EI): $\mathrm{m} / z$ calcd for $\mathrm{C}_{14} \mathrm{H}_{17} \mathrm{NO}_{4}{ }^{+}[\mathrm{M}]^{+} 263.1152$, found 263.1159 .

The spectral data were in accordance with those reported in the literature. ${ }^{254}$

\section{Synthesis of Ethyl (E)-3-\{2-[(N,N-Diethylcarbamoyl)oxy]phenyl\}acrylate (222ba)}<smiles>CCNC(=O)Oc1ccccc1/C=C/C(=O)OCC</smiles>

The general procedure $\mathbf{D}$ was followed using substrate $\mathbf{2 2 1 b}(97 \mathrm{mg}, 0.50 \mathrm{mmol})$ and ethyl acrylate (15a) (100 mg, $1.00 \mathrm{mmol}$ ). Purification by column chromatography ( $n$-hexane/EtOAc: $10 / 1 \rightarrow 5 / 1$ ) yielded 222ba (98 $\mathrm{mg}, 67 \%$ ) as a colorless oil.

${ }^{1} \mathbf{H}$ NMR $\left(300 \mathrm{MHz}, \mathrm{CDCl}_{3}\right): \delta=7.82(\mathrm{~d}, J=16.1 \mathrm{~Hz}, 1 \mathrm{H}), 7.60(\mathrm{dd}, J=7.8,1.7 \mathrm{~Hz}$, 1H), 7.35 (ddd, $J=7.8,7.8,1.7 \mathrm{~Hz}, 1 \mathrm{H}), 7.21-7.13(\mathrm{~m}, 2 \mathrm{H}), 6.40(\mathrm{~d}, J=16.1 \mathrm{~Hz}, 1 \mathrm{H}), 4.22(\mathrm{q}, J=7.1 \mathrm{~Hz}$, $2 \mathrm{H}), 3.49(\mathrm{q}, J=7.1 \mathrm{~Hz}, 2 \mathrm{H}), 3.37(\mathrm{q}, J=7.1 \mathrm{~Hz}, 2 \mathrm{H}), 1.33-1.25(\mathrm{~m}, 6 \mathrm{H}), 1.19(\mathrm{t}, J=7.1 \mathrm{~Hz}, 3 \mathrm{H})$.

${ }^{13} \mathrm{C} \mathrm{NMR}\left(75 \mathrm{MHz}, \mathrm{CDCl}_{3}\right): \delta=167.7\left(\mathrm{C}_{\mathrm{q}}\right), 153.5\left(\mathrm{C}_{\mathrm{q}}\right), 150.1\left(\mathrm{C}_{\mathrm{q}}\right), 138.2(\mathrm{CH}), 130.9(\mathrm{CH}), 127.3\left(\mathrm{C}_{\mathrm{q}}\right)$, 127.1 (CH), $125.5(\mathrm{CH}), 123.3(\mathrm{CH}), 119.6(\mathrm{CH}), 60.4\left(\mathrm{CH}_{2}\right), 42.3\left(\mathrm{CH}_{2}\right), 41.9\left(\mathrm{CH}_{2}\right), 14.2\left(\mathrm{CH}_{3}\right), 14.2$ 
$\left(\mathrm{CH}_{3}\right), 13.2\left(\mathrm{CH}_{3}\right)$.

IR (neat): $\tilde{v}=2978,1708,1636,1148,1038,881 \mathrm{~cm}^{-1}$.

MS (EI) m/z (relative intensity) 291 (5) [M] ${ }^{+}, 175$ (10), 118 (10), 100 (100), 72 (55), 44 (15).

HR-MS (ESI): $m / z$ calcd for $\mathrm{C}_{16} \mathrm{H}_{21} \mathrm{NNaO}_{4}{ }^{+}[\mathrm{M}+\mathrm{Na}]^{+} 314.1363$, found 314.1367 .

Synthesis of (E)-2-(3-Ethoxy-3-oxoprop-1-en-1-yl)phenyl Pyrrolidine-1-carboxylate (222ca)<smiles>CCOC(=O)C=Cc1ccccc1OC(=O)N1CCCC1</smiles>

The general procedure D was followed using substrate 221c $(96 \mathrm{mg}$, $0.50 \mathrm{mmol}$ ) and ethyl acrylate $(15 \mathrm{a})(100 \mathrm{mg}, 1.00 \mathrm{mmol})$. Purification by column chromatography ( $n$-hexane/EtOAc: $10 / 1 \rightarrow 5 / 1$ ) yielded 222ca (79 mg, $55 \%)$ as a colorless oil.

${ }^{1} \mathrm{H}$ NMR $\left(300 \mathrm{MHz}, \mathrm{CDCl}_{3}\right): \delta=7.85(\mathrm{~d}, J=16.1 \mathrm{~Hz}, 1 \mathrm{H}), 7.58(\mathrm{dd}, J=7.8,1.7 \mathrm{~Hz}$, $1 \mathrm{H}$ ), 7.34 (ddd, $J=7.8,7.8,1.7 \mathrm{~Hz}, 1 \mathrm{H}), 7.21-7.13(\mathrm{~m}, 2 \mathrm{H}), 6.40(\mathrm{~d}, J=16.1 \mathrm{~Hz}$,

$1 \mathrm{H}), 4.22(\mathrm{q}, J=7.1 \mathrm{~Hz}, 2 \mathrm{H}), 3.61(\mathrm{t}, J=6.7 \mathrm{~Hz}, 2 \mathrm{H}), 3,46(\mathrm{t}, J=6.7 \mathrm{~Hz}, 2 \mathrm{H}), 2.01-1.83(\mathrm{~m}, 4 \mathrm{H}), 1.29(\mathrm{t}, J$ $=7.1 \mathrm{~Hz}, 3 \mathrm{H})$.

${ }^{13} \mathrm{C} \mathrm{NMR}\left(75 \mathrm{MHz}, \mathrm{CDCl}_{3}\right): \delta=166.8\left(\mathrm{C}_{\mathrm{q}}\right), 152.3\left(\mathrm{C}_{\mathrm{q}}\right), 149.9\left(\mathrm{C}_{\mathrm{q}}\right), 138.4(\mathrm{CH}), 130.9(\mathrm{CH}), 127.1\left(\mathrm{C}_{\mathrm{q}}\right)$, $127.1(\mathrm{CH}), 125.4(\mathrm{CH}), 123.3(\mathrm{CH}), 119.5(\mathrm{CH}), 60.4\left(\mathrm{CH}_{2}\right), 46.5\left(\mathrm{CH}_{2}\right), 46.4\left(\mathrm{CH}_{2}\right), 25.7\left(\mathrm{CH}_{2}\right), 24.8$ $\left(\mathrm{CH}_{2}\right), 14.2\left(\mathrm{CH}_{3}\right)$.

IR (neat): $\tilde{v}=2978,1708,1635,1392,1170,757 \mathrm{~cm}^{-1}$.

MS (EI) $\mathrm{m} / \mathrm{z}$ (relative intensity) 289 (5) [M] ${ }^{+}, 175$ (13), 118 (14), 98 (100), 55 (50), 43 (44).

HR-MS (ESI): $m / z$ calcd for $\mathrm{C}_{16} \mathrm{H}_{19} \mathrm{NNaO}_{4}{ }^{+}[\mathrm{M}+\mathrm{H}]^{+} 312.1206$, found 312.1207.

\section{Synthesis of Ethyl (E)-3-\{2-[(N,N-Dimethylcarbamoyl)oxy]-3-methylphenyl\}acrylate (193ca)}<smiles>CCOC(=O)COc1c(C)cccc1/C=C/COC(C)C</smiles>

The general procedure $D$ was followed using substrate $192 \mathrm{c}(90 \mathrm{mg}, 0.50 \mathrm{mmol})$ and ethyl acrylate (15a) (100 mg, $1.00 \mathrm{mmol}$ ). Purification by column chromatography ( $n$-hexane/EtOAc: $10 / 1 \rightarrow 5 / 1$ ) yielded $193 \mathrm{ca}(97 \mathrm{mg}, 70 \%)$ as a colorless oil.

${ }^{1}$ H NMR (300 MHz, CDCl $): \delta=7.75(\mathrm{~d}, J=16.1 \mathrm{~Hz}, 1 \mathrm{H}), 7.43(\mathrm{~d}, J=8.0 \mathrm{~Hz}, 1 \mathrm{H})$, $7.21(\mathrm{~d}, J=7.6 \mathrm{~Hz}, 1 \mathrm{H}), 7.10$ (dd, $J=7.6,8.0 \mathrm{~Hz}, 1 \mathrm{H}), 6.38(\mathrm{~d}, J=16.1 \mathrm{~Hz}, 1 \mathrm{H})$,

$4.22(\mathrm{q}, J=7.1 \mathrm{~Hz}, 2 \mathrm{H}), 3.17(\mathrm{~s}, 3 \mathrm{H}), 3.00(\mathrm{~s}, 3 \mathrm{H}), 2.18(\mathrm{~s}, 3 \mathrm{H}), 1.29(\mathrm{t}, J=7.1 \mathrm{~Hz}, 3 \mathrm{H})$.

${ }^{13} \mathrm{C}$ NMR $\left(75 \mathrm{MHz}, \mathrm{CDCl}_{3}\right): \delta=166.8\left(\mathrm{C}_{\mathrm{q}}\right), 153.7\left(\mathrm{C}_{\mathrm{q}}\right), 148.8\left(\mathrm{C}_{\mathrm{q}}\right), 138.6(\mathrm{CH}), 132.7(\mathrm{CH}), 131.9\left(\mathrm{C}_{\mathrm{q}}\right)$, $127.9\left(\mathrm{C}_{\mathrm{q}}\right), 125.7(\mathrm{CH}), 124.8(\mathrm{CH}), 119.7(\mathrm{CH}), 60.3\left(\mathrm{CH}_{2}\right), 36.8\left(\mathrm{CH}_{3}\right), 36.4\left(\mathrm{CH}_{3}\right), 16.1\left(\mathrm{CH}_{3}\right), 14.2$ $\left(\mathrm{CH}_{3}\right)$.

IR (neat): $\tilde{v}=2934,1708,1635,1463,1149,1035,847 \mathrm{~cm}^{-1}$.

MS (EI) $m / z$ (relative intensity) 277 (5) [M] ${ }^{+}, 189$ (25), 160 (6), 131 (6), 72 (100).

HR-MS (EI): $m / z$ calcd for $\mathrm{C}_{15} \mathrm{H}_{19} \mathrm{NO}_{4}{ }^{+}[\mathrm{M}]^{+} 277.1309$, found 277.1316 .

\section{Synthesis of Ethyl (E)-3-\{2-[(N,N-Dimethylcarbamoyl)oxy]-[1,1'-biphenyl]-3-yl\}acrylate (193da)}<smiles>CCOC(=O)C=Cc1cccc(-c2ccccc2)c1OC(C)=O</smiles>

The general procedure $\mathbf{D}$ was followed using $192 \mathrm{~d}(121 \mathrm{mg}, 0.50 \mathrm{mmol})$ and ethyl acrylate (15a) (100 mg, $1.00 \mathrm{mmol})$. Purification by column chromatography ( $n$-hexane/EtOAc: $10 / 1 \rightarrow 5 / 1$ ) yielded 193da (130 mg, $77 \%$ ) as a colorless oil. 
${ }^{1} \mathrm{H}$ NMR $\left(300 \mathrm{MHz}, \mathrm{CDCl}_{3}\right): \delta=7.83(\mathrm{~d}, J=16.1 \mathrm{~Hz}, 1 \mathrm{H}), 7.61(\mathrm{dd}, J=7.8,1.9 \mathrm{~Hz}, 1 \mathrm{H}), 7.41-7.25(\mathrm{~m}$, $7 \mathrm{H}), 6.47(\mathrm{~d}, J=16.1 \mathrm{~Hz}, 1 \mathrm{H}), 4.24(\mathrm{q}, J=7.1 \mathrm{~Hz}, 2 \mathrm{H}), 2.90(\mathrm{~s}, 3 \mathrm{H}), 2.77(\mathrm{~s}, 3 \mathrm{H}), 1.31(\mathrm{t}, J=7.1 \mathrm{~Hz}, 3 \mathrm{H})$.

${ }^{13} \mathrm{C}$ NMR $\left(75 \mathrm{MHz}, \mathrm{CDCl}_{3}\right): \delta=166.6\left(\mathrm{C}_{\mathrm{q}}\right), 153.6\left(\mathrm{C}_{\mathrm{q}}\right), 147.3\left(\mathrm{C}_{\mathrm{q}}\right), 138.5(\mathrm{CH}), 137.3\left(\mathrm{C}_{\mathrm{q}}\right), 136.4\left(\mathrm{C}_{\mathrm{q}}\right)$, $132.3(\mathrm{CH}), 128.8(\mathrm{CH}), 128.7\left(\mathrm{C}_{\mathrm{q}}\right), 127.9(\mathrm{CH}), 127.4(\mathrm{CH}), 126.3(\mathrm{CH}), 125.9(\mathrm{CH}), 120.0(\mathrm{CH}), 60.3$ $\left(\mathrm{CH}_{2}\right), 36.5\left(\mathrm{CH}_{3}\right), 36.2\left(\mathrm{CH}_{3}\right), 14.2\left(\mathrm{CH}_{3}\right)$.

IR (neat): $\tilde{v}=2934,1709,1635,1429,1382,1148,841 \mathrm{~cm}^{-1}$.

MS (EI) $m / z$ (relative intensity) 339 (5) [M] ${ }^{+}, 251$ (25), 194 (10), 165 (10), 72 (100).

HR-MS (EI): $m / z$ calcd for $\mathrm{C}_{20} \mathrm{H}_{21} \mathrm{NO}_{4}{ }^{+}[\mathrm{M}]^{+} 339.1465$, found 339.1468 .

\section{Synthesis of Ethyl (E)-3-\{2-[(N,N-Dimethylcarbamoyl)oxy]-3-isopropylphenyl\}acrylate (193ea)}<smiles>CCCc1cccc(/C=C/C(=O)OCC)c1OC(C)=O</smiles>
The general procedure A was followed using substrate 192e (104 mg, $0.50 \mathrm{mmol}$ ) and ethyl acrylate (15a) $(100 \mathrm{mg}, 1.00 \mathrm{mmol})$. Purification by column chromatography ( $n$-hexane/EtOAc: $10 / 1 \rightarrow 5 / 1)$ yielded 193 ea $(119 \mathrm{mg}$, 78\%) as a colorless oil.

${ }^{1} \mathbf{H}$ NMR $\left(300 \mathrm{MHz}, \mathrm{CDCl}_{3}\right): \delta=7.73(\mathrm{~d}, J=16.0 \mathrm{~Hz}, 1 \mathrm{H}), 7.44(\mathrm{dd}, J=7.7,1.6$ $\mathrm{Hz}, 1 \mathrm{H}), 7.31(\mathrm{dd}, J=7.8,1.6 \mathrm{~Hz}, 1 \mathrm{H}), 7.18(\mathrm{dd}, J=7.8,7.7 \mathrm{~Hz}, 1 \mathrm{H}), 6.38(\mathrm{~d}, J=$ $16.0 \mathrm{~Hz}, 1 \mathrm{H}), 4.22(\mathrm{q}, J=7.2 \mathrm{~Hz}, 2 \mathrm{H}$ ), $3.09(\mathrm{~s}, 3 \mathrm{H}), 3.07-2.95(\mathrm{~m}, 1 \mathrm{H}), 3.01(\mathrm{~s}, 3 \mathrm{H}), 1.30(\mathrm{t}, J=7.2 \mathrm{~Hz}$, 3H). $1.20(\mathrm{~d}, J=6.9 \mathrm{~Hz}, 6 \mathrm{H})$.

${ }^{13} \mathrm{C}$ NMR $\left(75 \mathrm{MHz}, \mathrm{CDCl}_{3}\right): \delta=167.2\left(\mathrm{C}_{\mathrm{q}}\right), 154.7\left(\mathrm{C}_{\mathrm{q}}\right), 148.0\left(\mathrm{C}_{\mathrm{q}}\right), 142.4\left(\mathrm{C}_{\mathrm{q}}\right), 139.4(\mathrm{CH}), 128.7(\mathrm{CH})$, $128.6\left(\mathrm{C}_{\mathrm{q}}\right), 126.5(\mathrm{CH}), 125.1(\mathrm{CH}), 120.1(\mathrm{CH}), 60.8\left(\mathrm{CH}_{2}\right), 37.3\left(\mathrm{CH}_{3}\right), 36.9\left(\mathrm{CH}_{3}\right), 27.8\left(\mathrm{CH}_{3}\right), 23.4$ $(\mathrm{CH}), 14.7\left(\mathrm{CH}_{3}\right)$.

IR (neat): $\tilde{v}=2979,1708,1636,1392,1170,1056,911,757 \mathrm{~cm}^{-1}$.

MS (EI) $m / z$ (relative intensity) 305 (5) [M] 217 (15), 72 (100).

HR-MS (ESI): $\mathrm{m} / z$ calcd for $\mathrm{C}_{17} \mathrm{H}_{23} \mathrm{NNaO}_{4}{ }^{+}[\mathrm{M}+\mathrm{Na}]^{+} 328.1519$, found 328.1521 .

\section{Synthesis of Ethyl (E)-3-\{2-[(N,N-Dimethylcarbamoyl)oxy]-3-methoxyphenyl\}acrylate (193fa)}<smiles>CCOC(=O)/C=C/c1cccc(OC)c1OC(C)=O</smiles>
The general procedure $D$ was followed using substrate $192 \mathrm{f}(98 \mathrm{mg}, 0.50 \mathrm{mmol})$ and ethyl acrylate (15a) (100 mg, $1.00 \mathrm{mmol})$. Purification by column chromatography ( $n$-hexane/EtOAc: $10 / 1 \rightarrow 5 / 1$ ) yielded $193 f a(96 \mathrm{mg}, 65 \%)$ as a white solid.

M. p.: $99-101^{\circ} \mathrm{C}$.

${ }^{1} \mathrm{H}$ NMR $\left(300 \mathrm{MHz}, \mathrm{CDCl}_{3}\right): \delta=7.78(\mathrm{~d}, J=16.1 \mathrm{~Hz}, 1 \mathrm{H}), 7.16(\mathrm{dd}, J=8.0,2.0 \mathrm{~Hz}$, $1 \mathrm{H}), 7.11(\mathrm{dd}, J=7.6,8.0 \mathrm{~Hz}, 1 \mathrm{H}), 6.91(\mathrm{dd}, J=7.6,2.0 \mathrm{~Hz}, 1 \mathrm{H}), 6.40$ (d, $J=16.1 \mathrm{~Hz}, 1 \mathrm{H}), 4.20(\mathrm{q}, J=7.1$ $\mathrm{Hz}, 2 \mathrm{H}), 3.77(\mathrm{~s}, 3 \mathrm{H}), 3.12(\mathrm{~s}, 3 \mathrm{H}), 2.97(\mathrm{~s}, 3 \mathrm{H}), 1.27(\mathrm{t}, J=7.1 \mathrm{~Hz}, 3 \mathrm{H})$.

${ }^{13} \mathrm{C}$ NMR $\left(75 \mathrm{MHz}, \mathrm{CDCl}_{3}\right): \delta=166.6\left(\mathrm{C}_{\mathrm{q}}\right), 153.9\left(\mathrm{C}_{\mathrm{q}}\right), 152.1\left(\mathrm{C}_{\mathrm{q}}\right), 139.5\left(\mathrm{C}_{\mathrm{q}}\right), 138.2(\mathrm{CH}), 128.7\left(\mathrm{C}_{\mathrm{q}}\right)$, $125.9(\mathrm{CH}), 120.0(\mathrm{CH}), 118.5(\mathrm{CH}), 113.4(\mathrm{CH}), 60.3\left(\mathrm{CH}_{2}\right), 56.0\left(\mathrm{CH}_{3}\right), 36.7\left(\mathrm{CH}_{3}\right), 36.5\left(\mathrm{CH}_{3}\right), 14.1$ $\left(\mathrm{CH}_{3}\right)$.

IR (ATR): $\tilde{v}=2984,1715,1634,1580,1181,1059,781 \mathrm{~cm}^{-1}$.

MS (EI) $m / z$ (relative intensity) 293 (5) [M] ${ }^{+}, 205$ (12), 176 (5), 148 (5), 105 (5), 72 (100).

HR-MS (EI): $m / z$ calcd for $\mathrm{C}_{15} \mathrm{H}_{19} \mathrm{NO}_{5}{ }^{+}[\mathrm{M}]^{+} 293.1258$, found 293.1253 .

\section{Synthesis of Ethyl (E)-3-[2-( $N, N$-Dimethylcarbamoyloxy)-3-fluorophenyl]acrylate (193ga)}<smiles>CCOC(=O)/C=C/c1cccc(F)c1OC(=O)N(C)CC</smiles>
The general procedure $D$ was followed using substrate $192 \mathrm{~g}(92 \mathrm{mg}, 0.50 \mathrm{mmol})$ and ethyl acrylate (15a) (100 mg, $1.00 \mathrm{mmol})$. Purification by column 
chromatography ( $n$-hexane/EtOAc: $10 / 1 \rightarrow 5 / 1$ ) yielded 193ga (102 $\mathrm{mg}, 73 \%$ ) as a colorless oil.

${ }^{1} \mathrm{H}$ NMR $\left(300 \mathrm{MHz}, \mathrm{CDCl}_{3}\right): \delta=7.74(\mathrm{~d}, J=16.2 \mathrm{~Hz}, 1 \mathrm{H}), 7.37-7.32(\mathrm{~m}, 1 \mathrm{H}), 7.17-7.10(\mathrm{~m}, 2 \mathrm{H}), 6.42(\mathrm{~d}$, $J=16.2 \mathrm{~Hz}, 1 \mathrm{H}), 4.22(\mathrm{q}, J=7.1 \mathrm{~Hz}, 2 \mathrm{H}), 3.14(\mathrm{~s}, 3 \mathrm{H}), 3.00(\mathrm{~s}, 3 \mathrm{H}), 1.29(\mathrm{t}, J=7.1 \mathrm{~Hz}, 3 \mathrm{H})$.

${ }^{13} \mathrm{C}$ NMR $\left(75 \mathrm{MHz}, \mathrm{CDCl}_{3}\right): \delta=166.4\left(\mathrm{C}_{\mathrm{q}}\right), 155.1\left(\mathrm{~d},{ }^{1} \mathrm{~J}_{\mathrm{C}-\mathrm{F}}=250 \mathrm{~Hz}, \mathrm{C}_{\mathrm{q}}\right), 153.1\left(\mathrm{C}_{\mathrm{q}}\right), 138.8\left(\mathrm{~d},{ }^{2} \mathrm{~J}_{\mathrm{C}-\mathrm{F}}=13 \mathrm{~Hz}\right.$, $\left.\mathrm{C}_{\mathrm{q}}\right), 137.1\left(\mathrm{~d},{ }^{4} J_{\mathrm{C}-\mathrm{F}}=3 \mathrm{~Hz}, \mathrm{CH}\right), 130.0\left(\mathrm{C}_{\mathrm{q}}\right), 126.2\left(\mathrm{~d},{ }^{3} J_{\mathrm{C}-\mathrm{F}}=8 \mathrm{~Hz}, \mathrm{CH}\right), 122.4\left(\mathrm{~d},{ }^{4} \mathrm{~J}_{\mathrm{C}-\mathrm{F}}=3 \mathrm{~Hz}, \mathrm{CH}\right), 121.0$ (CH), $117.6\left(\mathrm{~d},{ }^{2} \mathrm{~J}_{\mathrm{C}-\mathrm{F}}=19 \mathrm{~Hz}, \mathrm{CH}\right), 60.5\left(\mathrm{CH}_{2}\right), 36.9\left(\mathrm{CH}_{3}\right), 36.5\left(\mathrm{CH}_{3}\right), 14.2\left(\mathrm{CH}_{3}\right)$.

${ }^{19} \mathrm{~F} \mathrm{NMR}\left(282 \mathrm{MHz}, \mathrm{CDCl}_{3}\right): \delta=-(128.1-128.2)(\mathrm{m})$.

IR (neat): $\tilde{v}=2938,1709,1639,1584,1259,1145,845 \mathrm{~cm}^{-1}$.

MS (EI) $m / z$ (relative intensity) 281 (5) [M] ${ }^{+}, 193$ (18), 164 (5), 136 (5), 107 (5), 72 (100).

HR-MS (EI): $\mathrm{m} / \mathrm{z}$ calcd for $\mathrm{C}_{14} \mathrm{H}_{16} \mathrm{FNO}_{4}{ }^{+}[\mathrm{M}]^{+}$281.1058, found 281.1060 .

\section{Synthesis of Ethyl (E)-3-\{2-[(N,N-Dimethylcarbamoyl)oxy]-3-[trifluoromethyl]phenyl\}acrylate} (193ha)<smiles>CCOC(=O)/C=C/c1cccc(C(F)(F)F)c1OCC(=O)OCC</smiles>

The general procedure $\mathbf{D}$ was followed using substrate $192 \mathrm{~h}(117 \mathrm{mg}, 0.50$ $\mathrm{mmol}$ ) and ethyl acrylate (15a) (100 mg, $1.00 \mathrm{mmol})$. Purification by column chromatography ( $n$-hexane/EtOAc: $10 / 1 \rightarrow 5 / 1$ ) yielded 193ha (107 mg, 65\%) as a colorless oil.

${ }^{1} \mathrm{H}$ NMR $\left(300 \mathrm{MHz}, \mathrm{CDCl}_{3}\right): \delta=7.77(\mathrm{~d}, J=8.0 \mathrm{~Hz}, 1 \mathrm{H}), 7.67(\mathrm{~d}, J=16.0 \mathrm{~Hz}, 1 \mathrm{H})$, $7.62(\mathrm{~d}, J=8.0 \mathrm{~Hz}, 1 \mathrm{H}), 7.29(\mathrm{dd}, J=8.0,8.0 \mathrm{~Hz}, 1 \mathrm{H}), 6.43(\mathrm{~d}, J=16.0 \mathrm{~Hz}, 1 \mathrm{H})$, $4.22(\mathrm{q}, J=7.2 \mathrm{~Hz}, 2 \mathrm{H}), 3.13(\mathrm{~s}, 3 \mathrm{H}), 2.98(\mathrm{~s}, 3 \mathrm{H}), 1.28(\mathrm{t}, J=7.2 \mathrm{~Hz}, 3 \mathrm{H})$.

${ }^{13} \mathrm{C} \mathrm{NMR}\left(75 \mathrm{MHz}, \mathrm{CDCl}_{3}\right): \delta=166.2\left(\mathrm{C}_{\mathrm{q}}\right), 153.3\left(\mathrm{C}_{\mathrm{q}}\right), 147.6\left(\mathrm{q},{ }^{4} \mathrm{~J}_{\mathrm{C}-\mathrm{F}}=2 \mathrm{~Hz}, \mathrm{C}_{\mathrm{q}}\right), 136.8(\mathrm{CH}), 130.7(\mathrm{CH})$, $130.7\left(\mathrm{C}_{\mathrm{q}}\right), 128.0\left(\mathrm{q},{ }^{3} \mathrm{~J}_{\mathrm{C}-\mathrm{F}}=5 \mathrm{~Hz}, \mathrm{CH}\right), 125.9(\mathrm{CH}), 124.5\left(\mathrm{q},{ }^{2} \mathrm{~J}_{\mathrm{C}-\mathrm{F}}=31 \mathrm{~Hz}, \mathrm{C}_{\mathrm{q}}\right), 122.8\left(\mathrm{q},{ }^{1} \mathrm{~J}_{\mathrm{C}-\mathrm{F}}=272 \mathrm{~Hz}\right.$, $\mathrm{C}), 121.4(\mathrm{CH}), 60.3\left(\mathrm{CH}_{2}\right), 36.5\left(\mathrm{CH}_{3}\right), 36.2\left(\mathrm{CH}_{3}\right), 14.2\left(\mathrm{CH}_{3}\right)$.

${ }^{19} \mathrm{~F} \mathrm{NMR}\left(282 \mathrm{MHz}, \mathrm{CDCl}_{3}\right): \delta=-62.1(\mathrm{~s})$.

IR (neat): $\tilde{v}=2940,1713,1640,1443,1329,1127,1034,979,848 \mathrm{~cm}^{-1}$.

MS (EI) $m / z$ (relative intensity) 331 (5) [M] ${ }^{+}, 243$ (20), 186 (5), 72 (100).

HR-MS (ESI): $m / z$ calcd for $\mathrm{C}_{15} \mathrm{H}_{16} \mathrm{~F}_{3} \mathrm{NNaO}_{4}{ }^{+}[\mathrm{M}]^{+} 354.0924$, found 354.0924 .

\section{Synthesis of Ethyl (E)-3-\{3-Chloro-2-[(N,N-Dimethylcarbamoyl)oxy]phenyl\}acrylate (193ia)}<smiles>CCOC(=O)/C=C/c1cccc(Cl)c1OC(=O)N(C)C</smiles>

The general procedure $D$ was followed using substrate $192 \mathrm{i}(100 \mathrm{mg}$, $0.50 \mathrm{mmol}$ ) and ethyl acrylate (15a) $(100 \mathrm{mg}, 1.00 \mathrm{mmol})$. Purification by column chromatography ( $n$-hexane/EtOAc: $10 / 1 \rightarrow 5 / 1$ ) yielded 193ia (76 mg, $51 \%)$ as a colorless oil.

${ }^{1} \mathrm{H}$ NMR $\left(300 \mathrm{MHz}, \mathrm{CDCl}_{3}\right): \delta=7.72(\mathrm{~d}, J=16.1 \mathrm{~Hz}, 1 \mathrm{H}), 7.48(\mathrm{dd}, J=8.0,1.5 \mathrm{~Hz}$, $1 \mathrm{H}), 7.40(\mathrm{dd}, J=8.0,1.5 \mathrm{~Hz}, 1 \mathrm{H}), 7.13(\mathrm{dd}, J=8.0,8.0 \mathrm{~Hz}, 1 \mathrm{H}), 6.41(\mathrm{~d}, J=16.1$ $\mathrm{Hz}, 1 \mathrm{H}), 4.22(\mathrm{q}, J=7.1 \mathrm{~Hz}, 2 \mathrm{H}), 3.17(\mathrm{~s}, 3 \mathrm{H}), 3.00(\mathrm{~s}, 3 \mathrm{H}), 1.29(\mathrm{t}, J=7.1 \mathrm{~Hz}, 3 \mathrm{H})$.

${ }^{13} \mathrm{C} \mathrm{NMR}\left(75 \mathrm{MHz}, \mathrm{CDCl}_{3}\right): \delta=166.4\left(\mathrm{C}_{\mathrm{q}}\right), 153.0\left(\mathrm{C}_{\mathrm{q}}\right), 146.4\left(\mathrm{C}_{\mathrm{q}}\right), 137.6(\mathrm{CH}), 131.3(\mathrm{CH}), 130.2\left(\mathrm{C}_{\mathrm{q}}\right)$, $128.7\left(\mathrm{C}_{\mathrm{q}}\right), 126.4(\mathrm{CH}), 125.6(\mathrm{CH}), 121.1(\mathrm{CH}), 60.5\left(\mathrm{CH}_{2}\right), 36.9\left(\mathrm{CH}_{3}\right), 36.5\left(\mathrm{CH}_{3}\right), 14.2\left(\mathrm{CH}_{3}\right)$.

IR (neat): $\tilde{v}=2938,1709,1637,1567,1438,1148,842 \mathrm{~cm}^{-1}$.

MS (EI) $m / z$ (relative intensity) 299/297 (2/5) [M] ${ }^{+}, 211 / 209$ (4/12), 154/152 (3/8), 89 (8), 72 (100).

HR-MS (EI): $m / z$ calcd for $\mathrm{C}_{14} \mathrm{H}_{16}{ }^{35} \mathrm{CINO}_{4}{ }^{+}[\mathrm{M}]^{+} 297.0762$, found 297.0761 .

\section{Synthesis of Ethyl (E)-3-\{2-[(N,N-Dimethylcarbamoyl)oxy]-5-methylphenyl\}acrylate (193ja)}<smiles>CCOC(=O)C=Cc1cc(C)ccc1OC(=O)N(C)C</smiles>

The general procedure D was followed using substrate 192j $(90 \mathrm{mg}$, 
$0.50 \mathrm{mmol}$ ) and ethyl acrylate (15a) $(100 \mathrm{mg}, 1.00 \mathrm{mmol})$. Purification by column chromatography ( $n$-hexane/EtOAc: $10 / 1 \rightarrow 5 / 1$ ) yielded $193 \mathrm{ja}(77 \mathrm{mg}, 56 \%$ ) as a colorless oil.

${ }^{1} \mathrm{H}$ NMR $\left(300 \mathrm{MHz}, \mathrm{CDCl}_{3}\right): \delta=7.77(\mathrm{~d}, J=16.1 \mathrm{~Hz}, 1 \mathrm{H}), 7.38(\mathrm{~d}, J=1.9 \mathrm{~Hz}, 1 \mathrm{H}), 7.15(\mathrm{dd}, J=8.3,1.9$ $\mathrm{Hz}, 1 \mathrm{H}), 7.01(\mathrm{~d}, J=8.3 \mathrm{~Hz}, 1 \mathrm{H}), 6.39(\mathrm{~d}, J=16.1 \mathrm{~Hz}, 1 \mathrm{H}), 4.22(\mathrm{q}, J=7.2 \mathrm{~Hz}, 2 \mathrm{H}), 3.13(\mathrm{~s}, 3 \mathrm{H}), 2.99(\mathrm{~s}$, $3 \mathrm{H}), 2.30(\mathrm{~s}, 3 \mathrm{H}), 1.29(\mathrm{t}, J=7.2 \mathrm{~Hz}, 3 \mathrm{H})$.

${ }^{13} \mathrm{C}$ NMR $\left(75 \mathrm{MHz}, \mathrm{CDCl}_{3}\right): \delta=166.8\left(\mathrm{C}_{\mathrm{q}}\right), 154.4\left(\mathrm{C}_{\mathrm{q}}\right), 147.9\left(\mathrm{C}_{\mathrm{q}}\right), 138.4(\mathrm{CH}), 135.1\left(\mathrm{C}_{\mathrm{q}}\right), 131.7(\mathrm{CH})$, $127.5(\mathrm{CH}), 126.8\left(\mathrm{C}_{\mathrm{q}}\right), 123.0(\mathrm{CH}), 119.4(\mathrm{CH}), 60.3\left(\mathrm{CH}_{2}\right), 36.7\left(\mathrm{CH}_{3}\right), 36.4\left(\mathrm{CH}_{3}\right), 20.8\left(\mathrm{CH}_{3}\right), 14.2$ $\left(\mathrm{CH}_{3}\right)$.

IR (neat): $\tilde{v}=2984,1707,1607,1497,1158,1035,1035,978,855 \mathrm{~cm}^{-1}$.

MS (EI) $m / z$ (relative intensity) 277 (3) [M] ${ }^{+}, 189$ (25), 132 (6), 72 (100).

HR-MS (EI): $m / z$ calcd for $\mathrm{C}_{15} \mathrm{H}_{19} \mathrm{NO}_{4}{ }^{+}[\mathrm{M}]^{+} 277.1309$, found 277.1316 .

\section{Synthesis of Ethyl (E)-3-\{4-[(N,N-Dimethylcarbamoyl)oxy]-[1,1'-biphenyl]-3-yl\}acrylate (193ka)}<smiles>CCOC(=O)C=Cc1cc(-c2ccccc2)ccc1OC(=O)NC</smiles>

The general procedure $\mathbf{D}$ was followed using substrate 192k $(121 \mathrm{mg}$, $0.50 \mathrm{mmol}$ ) and ethyl acrylate (15a) $(100 \mathrm{mg}, 1.00 \mathrm{mmol})$. Purification by column chromatography ( $n$-hexane/EtOAc: $10 / 1 \rightarrow 5 / 1$ ) yielded 193ka (100 $\mathrm{mg}, 59 \%$ ) as a white solid.

M. p.: $112-114^{\circ} \mathrm{C}$.

${ }^{1} \mathrm{H}$ NMR $\left(300 \mathrm{MHz}, \mathrm{CDCl}_{3}\right): \delta=7.88(\mathrm{~d}, J=16.1 \mathrm{~Hz}, 1 \mathrm{H}), 7.79(\mathrm{~d}, J=2.2 \mathrm{~Hz}, 1 \mathrm{H}), 7.59-7.52(\mathrm{~m}, 3 \mathrm{H})$, 7.46-7.39 (m, 2H), 7.37-7.31 (m, 1H), 7.24 (d, J=8.6 Hz, 1H), $6.51(\mathrm{~d}, J=16.1 \mathrm{~Hz}, 1 \mathrm{H}), 4.25(\mathrm{q}, J=7.1$ $\mathrm{Hz}, 2 \mathrm{H}), 3.17(\mathrm{~s}, 3 \mathrm{H}), 3.03(\mathrm{~s}, 3 \mathrm{H}), 1.32(\mathrm{t}, J=7.1 \mathrm{~Hz}, 3 \mathrm{H})$.

${ }^{13} \mathrm{C}$ NMR $\left(75 \mathrm{MHz}, \mathrm{CDCl}_{3}\right): \delta=166.7\left(\mathrm{C}_{\mathrm{q}}\right), 154.2\left(\mathrm{C}_{\mathrm{q}}\right), 149.4\left(\mathrm{C}_{\mathrm{q}}\right), 139.8\left(\mathrm{C}_{\mathrm{q}}\right), 138.8\left(\mathrm{C}_{\mathrm{q}}\right), 138.2(\mathrm{CH})$, $129.7(\mathrm{CH}), 128.7(\mathrm{CH}), 127.5(\mathrm{CH}), 127.4\left(\mathrm{C}_{q}\right), 127.0(\mathrm{CH}), 125.8(\mathrm{CH}), 123.6(\mathrm{CH}), 120.0(\mathrm{CH}), 60.4$ $\left(\mathrm{CH}_{2}\right), 36.8\left(\mathrm{CH}_{3}\right), 36.4\left(\mathrm{CH}_{3}\right), 14.2\left(\mathrm{CH}_{3}\right)$.

IR (ATR): $\tilde{v}=2927,1720,1700,1477,1386,1154,996,756,693 \mathrm{~cm}^{-1}$.

MS (EI) $m / z$ (relative intensity) 339 (8) [M+], 251 (15), 194 (8), 165 (8), 72 (100).

HR-MS (EI): $\mathrm{m} / z$ calcd for $\mathrm{C}_{20} \mathrm{H}_{21} \mathrm{NO}_{4}{ }^{+}\left[\mathrm{M}^{+}\right] 339.1465$, found 339.1476 .

\section{Synthesis of Ethyl (E)-3-\{2-[(N,N-Dimethylcarbamoyl)oxy]-5-methoxyphenyl\}acrylate (193la)}<smiles>CCOC(=O)/C=C/c1cc(OC)ccc1OC(=O)N(C)C</smiles>

The general procedure D was followed using substrate 1921 (98 $\mathrm{mg}$, $0.50 \mathrm{mmol})$ and ethyl acrylate $(15 \mathrm{a})(100 \mathrm{mg}, 1.00 \mathrm{mmol})$. Purification by column chromatography ( $n$-hexane/EtOAc: $10 / 1 \rightarrow 5 / 1$ ) yielded 193la (95 $\mathrm{mg}, 65 \%$ ) as a white solid.

M. p.: $52-54^{\circ} \mathrm{C}$.

${ }^{1} \mathrm{H}$ NMR $\left(300 \mathrm{MHz}, \mathrm{CDCl}_{3}\right): \delta=7.75(\mathrm{~d}, J=16.1 \mathrm{~Hz}, 1 \mathrm{H}), 7.06(\mathrm{~d}, J=2.9 \mathrm{~Hz}, 1 \mathrm{H}), 7.05(\mathrm{~d}, J=8.9 \mathrm{~Hz}, 1 \mathrm{H})$, $6.90(\mathrm{dd}, J=8.9,2.9 \mathrm{~Hz}, 1 \mathrm{H}), 6.38(\mathrm{~d}, J=16.1 \mathrm{~Hz}, 1 \mathrm{H}), 4.22(\mathrm{q}, J=7.2 \mathrm{~Hz}, 2 \mathrm{H}), 3.79(\mathrm{~s}, 3 \mathrm{H}), 3.14(\mathrm{~s}, 3 \mathrm{H})$, $2.99(\mathrm{~s}, 3 \mathrm{H}), 1.30(\mathrm{t}, J=7.2 \mathrm{~Hz}, 3 \mathrm{H})$.

${ }^{13} \mathrm{C}$ NMR $\left(75 \mathrm{MHz}, \mathrm{CDCl}_{3}\right): \delta=166.7\left(\mathrm{C}_{\mathrm{q}}\right), 156.9\left(\mathrm{C}_{\mathrm{q}}\right), 154.7\left(\mathrm{C}_{\mathrm{q}}\right), 143.9\left(\mathrm{C}_{\mathrm{q}}\right), 138.3(\mathrm{CH}), 127.9\left(\mathrm{C}_{\mathrm{q}}\right)$, $124.3(\mathrm{CH}), 119.9(\mathrm{CH}), 117.1(\mathrm{CH}), 111.1(\mathrm{CH}), 60.5\left(\mathrm{CH}_{2}\right), 55.6\left(\mathrm{CH}_{3}\right), 36.8\left(\mathrm{CH}_{3}\right), 36.4\left(\mathrm{CH}_{3}\right), 14.3$ $\left(\mathrm{CH}_{3}\right)$.

IR (ATR): $\tilde{v}=2984,1707,1607,1497,1385,1158,1035,855 \mathrm{~cm}^{-1}$.

MS (EI) $m / z$ (relative intensity) $293(10)\left[\mathrm{M}^{+}\right], 205$ (20), 176 (8), 72 (100).

HR-MS (EI): $\mathrm{m} / z$ calcd for $\mathrm{C}_{15} \mathrm{H}_{19} \mathrm{NO}_{5}{ }^{+}\left[\mathrm{M}^{+}\right] 2$ 293.1258, found 293.1254 . 
Synthesis of Ethyl (E)-3-\{2-[(N,N-Dimethylcarbamoyl)oxy]-5-fluorophenyl\}acrylate (193ma)<smiles>CCOC(=O)/C=C/c1cc(F)ccc1OC(=O)N(C)C</smiles>

The general procedure D was followed using substrate $192 \mathrm{~m}(90 \mathrm{mg}$, $0.50 \mathrm{mmol}$ ) and ethyl acrylate (15a) $(100 \mathrm{mg}, 1.00 \mathrm{mmol})$. Purification by column chromatography ( $n$-hexane/EtOAc: $10 / 1 \rightarrow 5 / 1$ ) yielded 193ma ( 84 $\mathrm{mg}, 61 \%)$ as a colorless oil.

${ }^{1} \mathbf{H}$ NMR $\left(300 \mathrm{MHz}, \mathrm{CDCl}_{3}\right): \delta=7.72(\mathrm{dd}, J=16.1,1.5 \mathrm{~Hz}, 1 \mathrm{H}), 7.25$ (dd, $J=$ 9.1, $2.9 \mathrm{~Hz}, 1 \mathrm{H}), 7.12-6.99(\mathrm{~m}, 2 \mathrm{H}), 6.37(\mathrm{~d}, J=16.1 \mathrm{~Hz}, 1 \mathrm{H}), 4.22(\mathrm{q}, J=7.2 \mathrm{~Hz}, 2 \mathrm{H}), 3.13(\mathrm{~s}, 3 \mathrm{H}), 2.99$ $(\mathrm{s}, 3 \mathrm{H}), 1.29(\mathrm{t}, J=7.2 \mathrm{~Hz}, 3 \mathrm{H})$.

${ }^{13} \mathrm{C}$ NMR $\left(75 \mathrm{MHz}, \mathrm{CDCl}_{3}\right): \delta=166.4\left(\mathrm{C}_{\mathrm{q}}\right), 159.7\left(\mathrm{~d},{ }^{1} \mathrm{~J}_{\mathrm{C}-\mathrm{F}}=248 \mathrm{~Hz}, \mathrm{C}_{\mathrm{q}}\right), 154.1\left(\mathrm{C}_{\mathrm{q}}\right), 145.9\left(\mathrm{~d},{ }^{4} \mathrm{~J}_{\mathrm{C}-\mathrm{F}}=3 \mathrm{~Hz}\right.$, $\left.\mathrm{C}_{\mathrm{q}}\right), 137.1\left(\mathrm{~d},{ }^{4} \mathrm{~J}_{\mathrm{C}-\mathrm{F}}=2 \mathrm{~Hz}, \mathrm{CH}\right), 128.8\left(\mathrm{~d},{ }^{3} \mathrm{~J}_{\mathrm{C}-\mathrm{F}}=9 \mathrm{~Hz}, \mathrm{C}_{\mathrm{q}}\right), 124.8\left(\mathrm{~d},{ }^{3} \mathrm{~J}_{\mathrm{C}-\mathrm{F}}=9 \mathrm{~Hz}, \mathrm{CH}\right), 120.9(\mathrm{CH}), 117.6(\mathrm{~d}$, $\left.{ }^{2} J_{\mathrm{C}-\mathrm{F}}=25 \mathrm{~Hz}, \mathrm{CH}\right), 113.0\left(\mathrm{~d},{ }^{2} \mathrm{~J}_{\mathrm{C}-\mathrm{F}}=25 \mathrm{~Hz}, \mathrm{CH}\right), 60.6\left(\mathrm{CH}_{2}\right), 36.8\left(\mathrm{CH}_{3}\right), 36.4\left(\mathrm{CH}_{3}\right), 14.2\left(\mathrm{CH}_{3}\right)$.

${ }^{19} \mathrm{~F} \mathrm{NMR}\left(282 \mathrm{MHz}, \mathrm{CDCl}_{3}\right): \delta=-(116.6-116.7)(\mathrm{m})$.

IR (neat): $\tilde{v}=2938,1709,1637,1483,1385,1145,1033,865,751 \mathrm{~cm}^{-1}$.

MS (EI) $m / z$ (relative intensity) 281 (5) [M] ${ }^{+}, 193$ (8), 164 (5), 136 (5), 107 (5), 72 (100).

HR-MS (EI): $\mathrm{m} / \mathrm{z}$ calcd for $\mathrm{C}_{14} \mathrm{H}_{16} \mathrm{FNO}_{4}{ }^{+}[\mathrm{M}]^{+} 281.1058$, found 281.1073 .

\section{Synthesis of Ethyl (E)-3-\{5-Bromo-2-[(N,N-dimethylcarbamoyl)oxy]phenyl\}acrylate (193na)}<smiles>CCOC(=O)/C=C/c1cc(Br)ccc1OC(=O)N(C)C</smiles>

The general procedure $D$ was followed using substrate $192 \mathrm{n}(122 \mathrm{mg}$, $0.50 \mathrm{mmol}$ ) and ethyl acrylate (15a) $(100 \mathrm{mg}, 1.00 \mathrm{mmol})$. Purification by column chromatography ( $n$-hexane/EtOAc: $10 / 1 \rightarrow 5 / 1$ ) yielded 193na (103 $\mathrm{mg}, 60 \%)$ as a white solid.

M. p.: $107-109^{\circ} \mathrm{C}$.

${ }^{1} \mathrm{H}$ NMR $\left(300 \mathrm{MHz}, \mathrm{CDCl}_{3}\right): \delta=7.69(\mathrm{~d}, J=16.1 \mathrm{~Hz}, 1 \mathrm{H}), 7.69(\mathrm{~d}, J=2.4 \mathrm{~Hz}, 1 \mathrm{H}), 7.42(\mathrm{dd}, J=8.7,2.4$ $\mathrm{Hz}, 1 \mathrm{H}), 7.03(\mathrm{~d}, J=8.7 \mathrm{~Hz}, 1 \mathrm{H}), 6.38(\mathrm{~d}, J=16.1 \mathrm{~Hz}, 1 \mathrm{H}), 4.21(\mathrm{q}, J=7.2 \mathrm{~Hz}, 2 \mathrm{H}), 3.11(\mathrm{~s}, 3 \mathrm{H}), 2.97(\mathrm{~s}$, $3 \mathrm{H}), 1.28(\mathrm{t}, \mathrm{J}=7.2 \mathrm{~Hz}, 3 \mathrm{H})$.

${ }^{13} \mathrm{C}$ NMR $\left(75 \mathrm{MHz}, \mathrm{CDCl}_{3}\right): \delta=166.3\left(\mathrm{C}_{\mathrm{q}}\right), 153.7\left(\mathrm{C}_{\mathrm{q}}\right), 148.9\left(\mathrm{C}_{\mathrm{q}}\right), 136.7(\mathrm{CH}), 133.5(\mathrm{CH}), 129.8(\mathrm{CH})$, $129.2\left(\mathrm{C}_{\mathrm{q}}\right), 125.0(\mathrm{CH}), 120.9(\mathrm{CH}), 118.6\left(\mathrm{C}_{\mathrm{q}}\right), 60.6\left(\mathrm{CH}_{2}\right), 36.8\left(\mathrm{CH}_{3}\right), 36.4\left(\mathrm{CH}_{3}\right), 14.2\left(\mathrm{CH}_{3}\right)$.

IR (ATR): $\tilde{v}=2932,1699,1474,1384,1215,1107,973,855 \mathrm{~cm}^{-1}$.

MS (EI) $m / z$ (relative intensity) 343/341 (5/5) [M] ${ }^{+}, 255 / 253$ (15/15), 198/196 (5/5), 89 (6), 72 (100).

HR-MS (EI): $m / z$ calcd for $\mathrm{C}_{14} \mathrm{H}_{16}{ }^{79} \mathrm{BrNO}_{4}{ }^{+}[\mathrm{M}]^{+} 341.0257$, found 341.0265 .

\section{Synthesis of Ethyl (E)-3-\{2-[(N,N-Dimethylcarbamoyl)oxy]-3,4-dimethylphenyl\}acrylate (1930a)}<smiles>CCOCC=Cc1ccc(C)c(C)c1OC(C)=O</smiles>
The general procedure $\mathbf{D}$ was followed using substrate $1920(97 \mathrm{mg}$, $0.50 \mathrm{mmol}$ ) and ethyl acrylate $(15 \mathrm{a})(100 \mathrm{mg}, 1.00 \mathrm{mmol})$. Purification by column chromatography ( $n$-hexane/EtOAc: $10 / 1 \rightarrow 5 / 1$ ) yielded $1930 a$ (114 mg, 78\%) as a white solid.

The general procedure $\mathbf{E}$ was followed using substrate $1920(97 \mathrm{mg}$, $0.50 \mathrm{mmol})$ and ethyl acrylate (15a) $(100 \mathrm{mg}, 1.00 \mathrm{mmol})$. Purification by column chromatography ( $n$-hexane/EtOAc: $10 / 1 \rightarrow 5 / 1$ ) yielded 1930a $(64 \mathrm{mg}, 44 \%$ ) as a white solid. M. p.: $63-65^{\circ} \mathrm{C}$.

${ }^{1} \mathrm{H}$ NMR $\left(300 \mathrm{MHz}, \mathrm{CDCl}_{3}\right): \delta=7.72(\mathrm{~d}, J=16.1 \mathrm{~Hz}, 1 \mathrm{H}), 7.35(\mathrm{~d}, J=7.8 \mathrm{~Hz}, 1 \mathrm{H}), 7.00(\mathrm{~d}, J=7.8 \mathrm{~Hz}, 1 \mathrm{H})$, $6.35(\mathrm{~d}, J=16.1 \mathrm{~Hz}, 1 \mathrm{H}), 4.21(\mathrm{q}, J=7.2 \mathrm{~Hz}, 2 \mathrm{H}), 3.18(\mathrm{~s}, 3 \mathrm{H}), 3.00(\mathrm{~s}, 3 \mathrm{H}), 2.26(\mathrm{~s}, 3 \mathrm{H}), 2.06(\mathrm{~s}, 3 \mathrm{H})$, $1.29(\mathrm{t}, J=7.2 \mathrm{~Hz}, 3 \mathrm{H})$.

${ }^{13} \mathrm{C} \mathrm{NMR}\left(75 \mathrm{MHz}, \mathrm{CDCl}_{3}\right): \delta=166.9\left(\mathrm{C}_{\mathrm{q}}\right), 154.0\left(\mathrm{C}_{\mathrm{q}}\right), 148.5\left(\mathrm{C}_{\mathrm{q}}\right), 140.7\left(\mathrm{C}_{\mathrm{q}}\right), 138.9(\mathrm{CH}), 130.3\left(\mathrm{C}_{\mathrm{q}}\right)$, 
$127.3(\mathrm{CH}), 125.4\left(\mathrm{C}_{\mathrm{q}}\right), 123.9(\mathrm{CH}), 118.5(\mathrm{CH}), 60.2\left(\mathrm{CH}_{2}\right), 36.8\left(\mathrm{CH}_{3}\right), 36.4\left(\mathrm{CH}_{3}\right), 20.2\left(\mathrm{CH}_{3}\right), 14.2$ $\left(\mathrm{CH}_{3}\right), 12.4\left(\mathrm{CH}_{3}\right)$.

IR (ATR): $\tilde{v}=2926,1704,1631,1453,1313,1156,978,862 \mathrm{~cm}^{-1}$.

MS (EI) $m / z$ (relative intensity) 291 (5) [M] ${ }^{+}, 203$ (15), 174 (5), 72 (100).

HR-MS (EI): $m / z$ calcd for $\mathrm{C}_{16} \mathrm{H}_{21} \mathrm{NO}_{4}{ }^{+}[\mathrm{M}]^{+} 291.1465$, found 291.1472 .

\section{Synthesis of Ethyl (E)-3-\{1-[(N,N-Dimethylcarbamoyl)oxy]naphthalen-2-yl\}acrylate (193pa)}<smiles>CCOC(=O)/C=C/c1ccc2ccccc2c1OC(=O)N(C)C</smiles>

The general procedure $\mathbf{D}$ was followed using $\left[\mathrm{RuCl}_{2}(p \text {-cymene) }]_{2}\right.$ (15.3 $\mathrm{mg}, 5.0 \mathrm{~mol} \%$ ), AgSbF 6 (34.4 mg, $20 \mathrm{~mol} \%$ ), substrate 192p (108 mg, $0.50 \mathrm{mmol}$ ) and ethyl acrylate (15a) (100 mg, $1.00 \mathrm{mmol})$. Purification by column chromatography ( $n$-hexane/EtOAc: $10 / 1 \rightarrow 5 / 1$ ) yielded 193pa (119 $\mathrm{mg}, 76 \%)$ as a white solid.

The general procedure $\mathbf{E}$ was followed using substrate $192 \mathrm{p}(108 \mathrm{mg}, 0.50 \mathrm{mmol}$ ) and ethyl acrylate (15a) (100 mg, $1.00 \mathrm{mmol}$ ). Purification by column chromatography ( $n$-hexane/EtOAc: 10/1 $\rightarrow 5 / 1$ ) yielded 193pa ( $82 \mathrm{mg}, 54 \%$ ) as a white solid.

M. p.: $86-88^{\circ} \mathrm{C}$.

${ }^{1} \mathbf{H}$ NMR $\left(300 \mathrm{MHz}, \mathrm{CDCl}_{3}\right): \delta=7.98(\mathrm{~d}, J=16.1 \mathrm{~Hz}, 1 \mathrm{H}), 7.89-7.80(\mathrm{~m}, 2 \mathrm{H}), 7.74-7.66(\mathrm{~m}, 2 \mathrm{H})$, 7.56-7.48 (m, 2H), $6.54(\mathrm{~d}, J=16.1 \mathrm{~Hz}, 1 \mathrm{H}), 4.28(\mathrm{q}, J=7.2 \mathrm{~Hz}, 2 \mathrm{H}), 3.35(\mathrm{~s}, 3 \mathrm{H}), 3.09(\mathrm{~s}, 3 \mathrm{H}), 1.35(\mathrm{t}, J$ $=7.2 \mathrm{~Hz}, 3 \mathrm{H})$.

${ }^{13} \mathrm{C}$ NMR $\left(75 \mathrm{MHz}, \mathrm{CDCl}_{3}\right): \delta=166.9\left(\mathrm{C}_{\mathrm{q}}\right), 154.3\left(\mathrm{C}_{\mathrm{q}}\right), 146.7\left(\mathrm{C}_{\mathrm{q}}\right), 138.1(\mathrm{CH}), 135.3\left(\mathrm{C}_{\mathrm{q}}\right), 128.0(\mathrm{CH})$, $127.4(\mathrm{CH}), 127.1(\mathrm{CH}), 126.1(\mathrm{CH}), 124.0\left(\mathrm{C}_{\mathrm{q}}\right), 124.0\left(\mathrm{C}_{\mathrm{q}}\right), 122.8(\mathrm{CH}), 122.2(\mathrm{CH}), 119.9(\mathrm{CH}), 60.5$ $\left(\mathrm{CH}_{2}\right), 37.0\left(\mathrm{CH}_{3}\right), 36.7\left(\mathrm{CH}_{3}\right), 14.3\left(\mathrm{CH}_{3}\right)$.

IR (ATR): $\tilde{v}=2962,1712,1631,1441,1393,1294,1032,872,751 \mathrm{~cm}^{-1}$.

MS (EI) m/z (relative intensity) 313 (5) [M] ${ }^{+}, 225$ (12), 196 (8), 168 (10), 139 (10), 72 (100).

HR-MS (EI): $m / z$ calcd for $\mathrm{C}_{18} \mathrm{H}_{19} \mathrm{NO}_{4}^{+}[\mathrm{M}]^{+} 313.1309$, found 313.1317.

Synthesis of Ethyl (E)-3-\{1-[(N,N-Dimethylcarbamoyl)oxy]-4-methoxynaphthalen-2-yl\} acrylate (193qa)<smiles>CCOC(=O)/C=C/c1cc(OC)c2ccccc2c1OC(=O)N(C)C</smiles>

The general procedure $\mathbf{D}$ was followed using $\left[\mathrm{RuCl}_{2}(p \text {-cymene) }]_{2}\right.$ (15.3 $\mathrm{mg}, 5.0 \mathrm{~mol} \%), \mathrm{AgSbF}_{6}$ (34.4 mg, $20 \mathrm{~mol} \%$ ), substrate 192q (123 mg, $0.50 \mathrm{mmol}$ ) and ethyl acrylate (15a) (100 mg, $1.00 \mathrm{mmol})$. Purification by column chromatography ( $n$-hexane/EtOAc: $10 / 1 \rightarrow 5 / 1$ ) yielded 193qa (116 $\mathrm{mg}, 68 \%)$ as a yellow solid.

M. p.: $131-133^{\circ} \mathrm{C}$.

${ }^{1} \mathbf{H}$ NMR $\left(300 \mathrm{MHz}_{\mathrm{CDCl}}\right): \delta=8.23-8.18(\mathrm{~m}, 1 \mathrm{H}), 7.95(\mathrm{~d}, J=16.0 \mathrm{~Hz}, 1 \mathrm{H}), 7.80-7.75(\mathrm{~m}, 1 \mathrm{H})$, 7.55-7.45 (m, 2H), $6.89(\mathrm{~s}, 1 \mathrm{H}), 6.49(\mathrm{~d}, J=16.0 \mathrm{~Hz}, 1 \mathrm{H}), 4.27(\mathrm{q}, J=7.2 \mathrm{~Hz}, 2 \mathrm{H}), 3.98(\mathrm{~s}, 3 \mathrm{H}), 3.31(\mathrm{~s}$, $3 \mathrm{H}), 3.06(\mathrm{~s}, 3 \mathrm{H}), 1.34(\mathrm{t}, J=7.2 \mathrm{~Hz}, 3 \mathrm{H})$.

${ }^{13} \mathrm{C}$ NMR $\left(75 \mathrm{MHz}, \mathrm{CDCl}_{3}\right): \delta=166.8\left(\mathrm{C}_{\mathrm{q}}\right), 154.6\left(\mathrm{C}_{\mathrm{q}}\right), 153.2\left(\mathrm{C}_{\mathrm{q}}\right), 140.7\left(\mathrm{C}_{\mathrm{q}}\right), 138.4(\mathrm{CH}), 128.5\left(\mathrm{C}_{\mathrm{q}}\right)$, $127.5(\mathrm{CH}), 127.5\left(\mathrm{C}_{\mathrm{q}}\right), 126.8(\mathrm{CH}), 123.5\left(\mathrm{C}_{\mathrm{q}}\right), 122.4(\mathrm{CH}), 122.0(\mathrm{CH}), 119.3(\mathrm{CH}), 99.5(\mathrm{CH}), 60.5$ $\left(\mathrm{CH}_{2}\right), 55.5\left(\mathrm{CH}_{3}\right), 37.0\left(\mathrm{CH}_{3}\right), 36.7\left(\mathrm{CH}_{3}\right), 14.3\left(\mathrm{CH}_{3}\right)$.

IR (ATR): $\tilde{v}=2937,1717,1702,1633,1511,1446,1288,1088,820 \mathrm{~cm}^{-1}$.

MS (EI) $m / z$ (relative intensity) 343 (10) [M] ${ }^{+}, 255$ (5), 226 (8), 198 (5), 183 (10), 72 (100).

HR-MS (EI): $m / z$ calcd for $\mathrm{C}_{19} \mathrm{H}_{21} \mathrm{NO}_{5}{ }^{+}[\mathrm{M}]^{+} 343.1414$, found 343.1415 . 
Synthesis of Ethyl (E)-3-\{4-Chloro-1-[(N,N-Dimethylcarbamoyl)oxy]naphthalen-2-yl\}acrylate (193ra)<smiles>CCOC(=O)/C=C/c1cc(Cl)c2ccccc2c1OC(C)=O</smiles>
The general procedure $\mathbf{D}$ was followed using $\left[\mathrm{RuCl}_{2} \text { ( } p \text {-cymene) }\right]_{2}(15.3$ $\mathrm{mg}, 5.0 \mathrm{~mol} \%), \operatorname{AgSbF}_{6}(34.4 \mathrm{mg}, 20 \mathrm{~mol} \%)$, substrate $192 \mathrm{r}(123 \mathrm{mg}$, $0.50 \mathrm{mmol}$ ) and ethyl acrylate (15a) $(100 \mathrm{mg}, 1.00 \mathrm{mmol})$. Purification by column chromatography ( $n$-hexane/EtOAc: $10 / 1 \rightarrow 5 / 1$ ) yielded 193ra (128 mg, 75\%) as a yellow solid.

M. p.: $127-129^{\circ} \mathrm{C}$.

${ }^{1}{ }_{H}$ NMR $\left(300 \mathrm{MHz}, \mathrm{CDCl}_{3}\right): \delta=8.21(\mathrm{~d}, J=8.6 \mathrm{~Hz}, 1 \mathrm{H}), 7.87(\mathrm{~d}, J=16.0 \mathrm{~Hz}, 1 \mathrm{H}), 7.88-7.84(\mathrm{~m}, 1 \mathrm{H})$, $7.77(\mathrm{~s}, 1 \mathrm{H}), 7.65-7.54(\mathrm{~m}, 2 \mathrm{H}), 6.50(\mathrm{~d}, J=16.0 \mathrm{~Hz}, 1 \mathrm{H}), 4.26(\mathrm{q}, J=7.2 \mathrm{~Hz}, 2 \mathrm{H}), 3.33(\mathrm{~s}, 3 \mathrm{H}), 3.06(\mathrm{~s}$, $3 \mathrm{H}), 1.33(\mathrm{t}, J=7.2 \mathrm{~Hz}, 3 \mathrm{H})$.

${ }^{13} \mathrm{C}$ NMR $\left(75 \mathrm{MHz}, \mathrm{CDCl}_{3}\right): \delta=166.6\left(\mathrm{C}_{\mathrm{q}}\right), 154.1\left(\mathrm{C}_{\mathrm{q}}\right), 145.6\left(\mathrm{C}_{\mathrm{q}}\right), 136.9(\mathrm{CH}), 132.2\left(\mathrm{C}_{\mathrm{q}}\right), 129.9\left(\mathrm{C}_{\mathrm{q}}\right)$, $129.0\left(\mathrm{C}_{\mathrm{q}}\right), 128.4(\mathrm{CH}), 127.8(\mathrm{CH}), 125.0(\mathrm{CH}), 124.4\left(\mathrm{C}_{\mathrm{q}}\right), 122.9(\mathrm{CH}), 122.7(\mathrm{CH}), 120.7(\mathrm{CH}), 60.6$ $\left(\mathrm{CH}_{2}\right), 37.0\left(\mathrm{CH}_{3}\right), 36.7\left(\mathrm{CH}_{3}\right), 14.3\left(\mathrm{CH}_{3}\right)$.

IR (ATR): $\tilde{v}=2976,1728,1704,1593,1453,1393,1255,1088,754 \mathrm{~cm}^{-1}$.

MS (EI) $m / z$ (relative intensity) 349/347 (5) [M] $]^{+}, 261 / 259$ (2/5), 232/230 (2/5), 139 (10), 72 (100).

HR-MS (EI): $\mathrm{m} / z$ calcd for $\mathrm{C}_{18} \mathrm{H}_{18}{ }^{35} \mathrm{CINO}_{4}{ }^{+}[\mathrm{M}]^{+} 347.0919$, found 347.0920 .

\section{Synthesis of Ethyl (E)-3-\{3-[(N,N-Dimethylcarbamoyl)oxy]naphthalen-2-yl\}acrylate (193sa)}<smiles>CCOC(=O)C=Cc1cc2ccccc2cc1OC(=O)N(C)C</smiles>

The general procedure $\mathbf{D}$ was followed using $\left[\mathrm{RuCl}_{2} \text { (p-cymene) }\right]_{2}(15.3$ $\mathrm{mg}, 5.0 \mathrm{~mol} \%$ ), $\mathrm{AgSbF}_{6}(34.4 \mathrm{mg}, 20 \mathrm{~mol} \%$ ), substrate 192s (108 mg, $0.50 \mathrm{mmol}$ ) and ethyl acrylate $(15 \mathrm{a})(100 \mathrm{mg}, 1.00 \mathrm{mmol})$. Purification by column chromatography ( $n$-hexane/EtOAc: $10 / 1 \rightarrow 5 / 1$ ) yielded 193sa (137 mg, 87\%) as a white solid.

The general procedure $\mathbf{E}$ was followed using substrate $192 \mathrm{~s}(108 \mathrm{mg}, 0.50 \mathrm{mmol})$ and ethyl acrylate (15a) $(100 \mathrm{mg}, 1.00 \mathrm{mmol})$. Purification by column chromatography ( $n$-hexane/EtOAc: $10 / 1 \rightarrow 5 / 1$ ) yielded 193sa (78 $\mathrm{mg}, 50 \%$ ) as a white solid.

M. p.: $82-84^{\circ} \mathrm{C}$.

${ }^{1}$ H NMR $\left(300 \mathrm{MHz}, \mathrm{CDCl}_{3}\right): \delta=8.07(\mathrm{~s}, 1 \mathrm{H}), 7.92(\mathrm{~d}, J=16.1 \mathrm{~Hz}, 1 \mathrm{H}), 7.80(\mathrm{~d}, J=8.0 \mathrm{~Hz}, 1 \mathrm{H}), 7.73(\mathrm{~d}$, $J=7.5 \mathrm{~Hz}, 1 \mathrm{H}), 7.60(\mathrm{~s}, 1 \mathrm{H}), 7.49-7.38(\mathrm{~m}, 2 \mathrm{H}), 6.57(\mathrm{~d}, J=16.1 \mathrm{~Hz}, 1 \mathrm{H}), 4.26(\mathrm{q}, J=7.2 \mathrm{~Hz}, 2 \mathrm{H}), 3.19(\mathrm{~s}$, $3 \mathrm{H}), 3.03(\mathrm{~s}, 3 \mathrm{H}), 1.32(\mathrm{t}, J=7.2 \mathrm{~Hz}, 3 \mathrm{H})$.

${ }^{13} \mathrm{C} \mathrm{NMR}\left(75 \mathrm{MHz}, \mathrm{CDCl}_{3}\right): \delta=166.7\left(\mathrm{C}_{\mathrm{q}}\right), 154.4\left(\mathrm{C}_{\mathrm{q}}\right), 147.2\left(\mathrm{C}_{\mathrm{q}}\right), 138.9(\mathrm{CH}), 134.4\left(\mathrm{C}_{\mathrm{q}}\right), 130.9\left(\mathrm{C}_{\mathrm{q}}\right)$, $128.1(\mathrm{CH}), 128.0(\mathrm{CH}), 127.4(\mathrm{CH}), 127.3(\mathrm{CH}), 127.0\left(\mathrm{C}_{\mathrm{q}}\right), 126.0(\mathrm{CH}), 120.2(\mathrm{CH}), 120.2(\mathrm{CH}), 60.4$ $\left(\mathrm{CH}_{2}\right), 36.8\left(\mathrm{CH}_{3}\right), 36.5\left(\mathrm{CH}_{3}\right), 14.2\left(\mathrm{CH}_{3}\right)$.

IR (ATR): $\tilde{v}=2987,1711,1638,1440,1270,1157,979,860,734 \mathrm{~cm}^{-1}$.

MS (EI) $m / z$ (relative intensity) $313(10)\left[\mathrm{M}^{+}, 225\right.$ (20), 196 (8), 168 (10), 139 (10), 72 (100).

HR-MS (EI): $\mathrm{m} / z$ calcd for $\mathrm{C}_{18} \mathrm{H}_{19} \mathrm{NO}_{4}{ }^{+}[\mathrm{M}]^{+} 313.1309$, found 313.1318 .

Synthesis of Ethyl (E)-3-\{6-Bromo-3-[(N,N-dimethylcarbamoyl)oxy]naphthalen-2-yl\}acrylate (193ta)<smiles>CCOC(=O)C=Cc1cc2ccc(Br)cc2cc1OC(N)=O</smiles>

The general procedure $\mathbf{D}$ was followed using $\left[\mathrm{RuCl}_{2}(p \text {-cymene })\right]_{2}$ (15.3 mg, $5.0 \mathrm{~mol} \%$ ), $\mathrm{AgSbF}_{6}$ (34.4 mg, $20 \mathrm{~mol} \%$ ), substrate $192 \mathrm{t}$ 
(147 mg, $0.50 \mathrm{mmol}$ ) and ethyl acrylate (15a) (100 mg, $1.00 \mathrm{mmol}$ ). Purification by column chromatography ( $n$-hexane/EtOAc: $10 / 1 \rightarrow 5 / 1$ ) yielded 193 ta (143 mg, 73\%) as a white solid.

M. p.: $120-122^{\circ} \mathrm{C}$.

${ }^{1}$ H NMR $\left(300 \mathrm{MHz} \mathrm{CDCl}_{3}\right): \delta=7.92(\mathrm{~s}, 1 \mathrm{H}), 7.92(\mathrm{~s}, 1 \mathrm{H}), 7.86(\mathrm{~d}, J=16.0 \mathrm{~Hz}, 1 \mathrm{H}), 7.59-7.53(\mathrm{~m}, 2 \mathrm{H})$, 7.49 (d, J = 8.7 Hz, 1H), 6.52 (d, J=16.0 Hz, 1H), 4.25 (q, J= 7.2 Hz, 2H), $3.18(\mathrm{~s}, 3 \mathrm{H}), 3.03(\mathrm{~s}, 3 \mathrm{H}), 1.32$ $(\mathrm{t}, J=7.2 \mathrm{~Hz}, 3 \mathrm{H})$.

${ }^{13} \mathrm{C}$ NMR $\left(75 \mathrm{MHz}, \mathrm{CDCl}_{3}\right): \delta=166.5\left(\mathrm{C}_{\mathrm{q}}\right), 154.1\left(\mathrm{C}_{\mathrm{q}}\right), 147.5\left(\mathrm{C}_{\mathrm{q}}\right), 138.3(\mathrm{CH}), 132.7\left(\mathrm{C}_{\mathrm{q}}\right), 131.9\left(\mathrm{C}_{\mathrm{q}}\right)$, $130.6(\mathrm{CH}), 130.0(\mathrm{CH}), 128.9(\mathrm{CH}), 128.0\left(\mathrm{C}_{\mathrm{q}}\right), 126.8(\mathrm{CH}), 121.0(\mathrm{CH}), 120.2(\mathrm{CH}), 119.8\left(\mathrm{C}_{\mathrm{q}}\right), 60.5$ $\left(\mathrm{CH}_{2}\right), 36.9\left(\mathrm{CH}_{3}\right), 36.5\left(\mathrm{CH}_{3}\right), 14.2\left(\mathrm{CH}_{3}\right)$.

IR (ATR): $\tilde{v}=2927,1730,1633,1481,1362,1161,1052,884 \mathrm{~cm}^{-1}$.

MS (EI) $m / z$ (relative intensity) 393/391 (5/5) [M] ${ }^{+}, 303$ (10), 276/274 (5/5), 248/246 (8/8), 72 (100).

HR-MS (EI): $m / z$ calcd for $\mathrm{C}_{18} \mathrm{H}_{18}{ }^{79} \mathrm{BrNO}_{4}{ }^{+}[\mathrm{M}]^{+} 391.0414$, found 391.0411 .

\section{Synthesis of Ethyl (E)-3-\{3-[(N,N-Dimethylcarbamoyl)oxy]-[1,1'-biphenyl]-4-yl\}acrylate (193ua)}<smiles>CCOC(=O)/C=C/c1ccc(-c2ccccc2)cc1OC(=O)N(C)C</smiles>

The general procedure D was followed using substrate $192 \mathrm{u}(121 \mathrm{mg}$, $0.50 \mathrm{mmol}$ ) and ethyl acrylate (15a) (100 mg, $1.00 \mathrm{mmol})$. Purification by column chromatography ( $n$-hexane/EtOAc: $10 / 1 \rightarrow 5 / 1$ ) yielded 193ua (165 $\mathrm{mg}, 97 \%)$ as a white solid.

The general procedure E was followed using substrate 192u (121 mg, $0.50 \mathrm{mmol}$ ) and ethyl acrylate (15a) $(100 \mathrm{mg}, 1.00 \mathrm{mmol})$. Purification by column chromatography ( $n$-hexane/EtOAc: $10 / 1 \rightarrow 5 / 1$ ) yielded 193ua (116 $\mathrm{mg}, 68 \%$ ) as a white solid.

M. p.: $110-112^{\circ} \mathrm{C}$.

${ }^{1} \mathbf{H}$ NMR $\left(300 \mathrm{MHz}, \mathrm{CDCl}_{3}\right): \delta=7.85(\mathrm{~d}, J=16.0 \mathrm{~Hz}, 1 \mathrm{H}), 7.66(\mathrm{~d}, J=8.2 \mathrm{~Hz}, 1 \mathrm{H}), 7.60-7.56(\mathrm{~m}, 2 \mathrm{H})$, 7.47-7.37 (m, 4H), 7.36-7.30 (m, 1H), $6.46(\mathrm{~d}, J=16.0 \mathrm{~Hz}, 1 \mathrm{H}), 4.25(\mathrm{q}, J=7.2 \mathrm{~Hz}, 2 \mathrm{H}), 3.18(\mathrm{~s}, 3 \mathrm{H})$, $3.03(\mathrm{~s}, 3 \mathrm{H}), 1.32(\mathrm{t}, \mathrm{J}=7.2 \mathrm{~Hz}, 3 \mathrm{H})$.

${ }^{13} \mathrm{C}$ NMR $\left(75 \mathrm{MHz}, \mathrm{CDCl}_{3}\right): \delta=166.8\left(\mathrm{C}_{\mathrm{q}}\right), 154.2\left(\mathrm{C}_{\mathrm{q}}\right), 150.4\left(\mathrm{C}_{\mathrm{q}}\right), 144.0\left(\mathrm{C}_{\mathrm{q}}\right), 139.3\left(\mathrm{C}_{\mathrm{q}}\right), 137.9(\mathrm{CH})$, $128.8(\mathrm{CH}), 128.0(\mathrm{CH}), 127.6(\mathrm{CH}), 127.0(\mathrm{CH}), 126.0\left(\mathrm{C}_{\mathrm{q}}\right), 124.3(\mathrm{CH}), 121.8(\mathrm{CH}), 119.4(\mathrm{CH}), 60.4$ $\left(\mathrm{CH}_{2}\right), 36.8\left(\mathrm{CH}_{3}\right), 36.5\left(\mathrm{CH}_{3}\right), 14.2\left(\mathrm{CH}_{3}\right)$.

IR (ATR): $\tilde{v}=2982,1631,1610,1483,1383,1157,893,762 \mathrm{~cm}^{-1}$.

MS (EI) m/z (relative intensity) 339 (5) [M] ${ }^{+}, 251$ (20), 194 (8), 165 (10),72 (100).

HR-MS (EI): $m / z$ calcd for $\mathrm{C}_{20} \mathrm{H}_{21} \mathrm{NO}_{4}^{+}[\mathrm{M}]^{+} 339.1465$, found 339.1470.

\section{Synthesis of Ethyl (E)-3-\{4-Bromo-2-[(N,N-dimethylcarbamoyl)oxy]phenyl\}acrylate (193va)}<smiles>CCOC(=O)/C=C/c1ccc(Br)cc1OC(=O)N(C)C</smiles>

The general procedure D was followed using substrate 192v (122 mg, $0.50 \mathrm{mmol}$ ) and ethyl acrylate (15a) (100 mg, $1.00 \mathrm{mmol})$. Purification by column chromatography ( $n$-hexane/EtOAc: $10 / 1 \rightarrow 5 / 1$ ) yielded 193va (101 $\mathrm{mg}, 59 \%)$ as a white solid.

M. p.: $68-70^{\circ} \mathrm{C}$.

${ }^{1} \mathbf{H}$ NMR (300 MHz, $\left.\mathrm{CDCl}_{3}\right): \delta=7.71(\mathrm{~d}, J=16.1 \mathrm{~Hz}, 1 \mathrm{H}), 7.43(\mathrm{~d}, J=8.4 \mathrm{~Hz}, 1 \mathrm{H}), 7.35-7.28(\mathrm{~m}, 2 \mathrm{H})$, $6.38(\mathrm{~d}, J=16.1 \mathrm{~Hz}, 1 \mathrm{H}), 4.20(\mathrm{q}, J=7.2 \mathrm{~Hz}, 2 \mathrm{H}), 3.11(\mathrm{~s}, 3 \mathrm{H}), 2.98(\mathrm{~s}, 3 \mathrm{H}), 1.28(\mathrm{t}, J=7.2 \mathrm{~Hz}, 3 \mathrm{H})$.

${ }^{13} \mathrm{C}$ NMR $\left(75 \mathrm{MHz}, \mathrm{CDCl}_{3}\right): \delta=166.5\left(\mathrm{C}_{\mathrm{q}}\right), 153.6\left(\mathrm{C}_{\mathrm{q}}\right), 150.2\left(\mathrm{C}_{\mathrm{q}}\right), 137.1(\mathrm{CH}), 128.9(\mathrm{CH}), 128.1(\mathrm{CH})$, $126.7(\mathrm{CH}), 126.3\left(\mathrm{C}_{\mathrm{q}}\right), 123.9\left(\mathrm{C}_{\mathrm{q}}\right), 120.1(\mathrm{CH}), 60.5\left(\mathrm{CH}_{2}\right), 36.8\left(\mathrm{CH}_{3}\right), 36.4\left(\mathrm{CH}_{3}\right), 14.2\left(\mathrm{CH}_{3}\right)$.

IR (ATR): $\tilde{v}=2939,1713,1636,1590,1370,1146,1032,889,815 \mathrm{~cm}^{-1}$.

MS (EI) $m / z$ (relative intensity) 343/341 (5) [M] ${ }^{+}, 255 / 253$ (15/15), 198/196 (5/5), 89 (8), 72 (100). 
HR-MS (EI): $m / z$ calcd for $\mathrm{C}_{14} \mathrm{H}_{16}{ }^{79} \mathrm{BrNO}_{4}{ }^{+}[\mathrm{M}]^{+} 341.0257$, found 341.0278 .

\section{Synthesis of Ethyl (E)-3-\{2-[(N,N-Dimethylcarbamoyl)oxy]-4-iodophenyl\}acrylate (193wa)}<smiles>CCOC(=O)C=Cc1ccc(I)cc1OC(=O)N(C)C</smiles>

The general procedure D was followed using substrate 192w (146 mg, $0.50 \mathrm{mmol}$ ) and ethyl acrylate (15a) $(100 \mathrm{mg}, 1.00 \mathrm{mmol})$. Purification by column chromatography ( $n$-hexane/EtOAc: $10 / 1 \rightarrow 5 / 1$ ) yielded 193wa (104 $\mathrm{mg}, 53 \%)$ as a yellow solid.

M. p.: $84-86^{\circ} \mathrm{C}$.

${ }^{1} \mathbf{H}$ NMR $\left(300 \mathrm{MHz} \mathrm{CDCl}_{3}\right): \delta=7.70(\mathrm{~d}, J=16.1 \mathrm{~Hz}, 1 \mathrm{H}), 7.53-7.49(\mathrm{~m}, 2 \mathrm{H}), 7.28(\mathrm{~d}, J=8.9 \mathrm{~Hz}, 1 \mathrm{H})$, $6.40(\mathrm{~d}, J=16.1 \mathrm{~Hz}, 1 \mathrm{H}), 4.21(\mathrm{q}, J=7.2 \mathrm{~Hz}, 2 \mathrm{H}), 3.11(\mathrm{~s}, 3 \mathrm{H}), 2.99(\mathrm{~s}, 3 \mathrm{H}), 1.29(\mathrm{t}, J=7.2 \mathrm{~Hz}, 3 \mathrm{H})$.

${ }^{13} \mathrm{C}$ NMR $\left(75 \mathrm{MHz}, \mathrm{CDCl}_{3}\right): \delta=166.5\left(\mathrm{C}_{\mathrm{q}}\right), 153.7\left(\mathrm{C}_{\mathrm{q}}\right), 149.9\left(\mathrm{C}_{\mathrm{q}}\right), 137.3(\mathrm{CH}), 134.8(\mathrm{CH}), 132.5(\mathrm{CH})$, $128.2(\mathrm{CH}), 127.0\left(\mathrm{C}_{\mathrm{q}}\right), 120.2(\mathrm{CH}), 95.5\left(\mathrm{C}_{\mathrm{q}}\right), 60.5\left(\mathrm{CH}_{2}\right), 36.8\left(\mathrm{CH}_{3}\right), 36.5\left(\mathrm{CH}_{3}\right), 14.2\left(\mathrm{CH}_{3}\right)$.

IR (ATR): $\tilde{v}=2938,1707,1636,1477,1370,1147,1032,868 \mathrm{~cm}^{-1}$.

MS (EI) $m / z$ (relative intensity) 389 (5) [M] ${ }^{+}, 301$ (20), 243 (5), 72 (100).

HR-MS (EI): $m / z$ calcd for $\mathrm{C}_{14} \mathrm{H}_{16} \mathrm{INO}_{4}{ }^{+}[\mathrm{M}]^{+} 389.0119$, found 389.0117 .

Synthesis of Ethyl (E)-3-\{7-[(N,N-Dimethylcarbamoyl)oxy]-4-methyl-2-oxo-2H-chromen-8-yl\}acrylate (193xa)<smiles>CCOC(=O)C=Cc1c(OC(N)=O)ccc2c(C)cc(=O)oc12</smiles>

The general procedure $\mathbf{D}$ was followed using $\left[\mathrm{RuCl}_{2}(p \text {-cymene })\right]_{2}$ (15.3 mg, $5.0 \mathrm{~mol} \%), \mathrm{AgSbF}_{6}$ (34.4 mg, $20 \mathrm{~mol} \%$ ), substrate 192x (117 mg, $0.47 \mathrm{mmol}$ ) and ethyl acrylate (15a) (100 mg, $1.00 \mathrm{mmol}$ ). Purification by column chromatography ( $n$-hexane/EtOAc: $10 / 1 \rightarrow 5 / 1$ ) yielded 193xa (96 mg, 59\%) as a yellow solid.

M. p.: $201-203^{\circ} \mathrm{C}$.

${ }^{1} \mathbf{H}$ NMR $\left.\left(300 \mathrm{MHz}^{\mathrm{CDCl}}\right)_{3}\right): \delta=7.88(\mathrm{~d}, J=16.5 \mathrm{~Hz}, 1 \mathrm{H}), 7.58(\mathrm{~d}, J=$ $8.9 \mathrm{~Hz}, 1 \mathrm{H}), 7.16(\mathrm{~d}, J=8.9 \mathrm{~Hz}, 1 \mathrm{H}), 6.95(\mathrm{~d}, J=16.5 \mathrm{~Hz}, 1 \mathrm{H}), 6.27(\mathrm{~d}, J=1.2 \mathrm{~Hz}, 1 \mathrm{H}), 4.25(\mathrm{q}, J=7.2 \mathrm{~Hz}$, $2 \mathrm{H}), 3.17(\mathrm{~s}, 3 \mathrm{H}), 3.02(\mathrm{~s}, 3 \mathrm{H}), 2.42(\mathrm{~d}, J=1.2 \mathrm{~Hz}, 3 \mathrm{H}), 1.32(\mathrm{t}, J=7.2 \mathrm{~Hz}, 3 \mathrm{H})$.

${ }^{13} \mathrm{C}$ NMR $\left(75 \mathrm{MHz}, \mathrm{CDCl}_{3}\right): \delta=167.3\left(\mathrm{C}_{\mathrm{q}}\right), 159.7\left(\mathrm{C}_{\mathrm{q}}\right), 153.4\left(\mathrm{C}_{\mathrm{q}}\right), 152.7\left(\mathrm{C}_{\mathrm{q}}\right), 152.6\left(\mathrm{C}_{\mathrm{q}}\right), 152.2\left(\mathrm{C}_{\mathrm{q}}\right)$, $132.2(\mathrm{CH}), 125.5(\mathrm{CH}), 125.5(\mathrm{CH}), 119.3(\mathrm{CH}), 117.6\left(\mathrm{C}_{\mathrm{q}}\right), 116.6\left(\mathrm{C}_{\mathrm{q}}\right), 114.3(\mathrm{CH}), 60.7\left(\mathrm{CH}_{2}\right), 37.0$ $\left(\mathrm{CH}_{3}\right), 36.6\left(\mathrm{CH}_{3}\right), 19.0\left(\mathrm{CH}_{3}\right), 14.3\left(\mathrm{CH}_{3}\right)$.

IR (ATR): $\tilde{v}=2980,1726,1703,1629,1382,1296,1152,1032,869 \mathrm{~cm}^{-1}$.

MS (EI) $m / z$ (relative intensity) 345 (5) [M] ${ }^{+}, 257(10), 228$ (5), 172 (5), 72 (100), 43 (7).

HR-MS (EI): $m / z$ calcd for $\mathrm{C}_{18} \mathrm{H}_{19} \mathrm{NO}_{6}{ }^{+}[\mathrm{M}]^{+} 345.1207$, found 345.1208 .

\section{Synthesis of Ethyl (E)-3-\{2-[(N,N-Dimethylcarbamoyl)oxy]-4,5-dimethylphenyl\}acrylate (193ya)}<smiles>CCOC(=O)/C=C/c1cc(C)c(C)cc1OC(=O)N(C)C</smiles>

The general procedure D was followed using substrate 192y $(97 \mathrm{mg}$, $0.50 \mathrm{mmol}$ ) and ethyl acrylate (15a) $(100 \mathrm{mg}, 1.00 \mathrm{mmol})$. Purification by column chromatography ( $n$-hexane/EtOAc: $10 / 1 \rightarrow 5 / 1$ ) yielded 193ya (126 mg, 87\%) as a white solid.

M. p.: $86-88^{\circ} \mathrm{C}$.

${ }^{1} \mathrm{H}$ NMR $\left(300 \mathrm{MHz}, \mathrm{CDCl}_{3}\right): \delta=7.75(\mathrm{~d}, J=16.1 \mathrm{~Hz}, 1 \mathrm{H}), 7.35(\mathrm{~s}, 1 \mathrm{H}), 6.91(\mathrm{~s}, 1 \mathrm{H}), 6.36(\mathrm{~d}, J=16.1 \mathrm{~Hz}$, $1 \mathrm{H}), 4.22(\mathrm{q}, J=7.2 \mathrm{~Hz}, 2 \mathrm{H}), 3.14(\mathrm{~s}, 3 \mathrm{H}), 3.00(\mathrm{~s}, 3 \mathrm{H}), 2.23(\mathrm{~s}, 3 \mathrm{H}), 2.22(\mathrm{~s}, 3 \mathrm{H}), 1.30(\mathrm{t}, J=7.2 \mathrm{~Hz}, 3 \mathrm{H})$.

${ }^{13} \mathrm{C}$ NMR $\left(75 \mathrm{MHz}, \mathrm{CDCl}_{3}\right): \delta=167.1\left(\mathrm{C}_{\mathrm{q}}\right), 154.6\left(\mathrm{C}_{\mathrm{q}}\right), 148.1\left(\mathrm{C}_{\mathrm{q}}\right), 140.5\left(\mathrm{C}_{\mathrm{q}}\right), 138.4(\mathrm{CH}), 134.1\left(\mathrm{C}_{\mathrm{q}}\right)$, 
$128.0(\mathrm{CH}), 124.4\left(\mathrm{C}_{\mathrm{q}}\right), 124.2(\mathrm{CH}), 118.4(\mathrm{CH}), 60.3\left(\mathrm{CH}_{2}\right), 36.8\left(\mathrm{CH}_{3}\right), 36.5\left(\mathrm{CH}_{3}\right), 19.9\left(\mathrm{CH}_{3}\right), 19.2$ $\left(\mathrm{CH}_{3}\right), 14.3\left(\mathrm{CH}_{3}\right)$.

IR (ATR): $\tilde{v}=2937,1702,1630,1498,1452,1154,1029,991,875 \mathrm{~cm}^{-1}$.

MS (EI) $m / z$ (relative intensity) 291 (5) [M] ${ }^{+}, 203$ (30), 174 (5), 146 (6), 72 (100).

HR-MS (EI): $m / z$ calcd for $\mathrm{C}_{16} \mathrm{H}_{21} \mathrm{NO}_{4}{ }^{+}[\mathrm{M}]^{+} 291.1471$, found 291.1482 .

The spectral data were in accordance with those reported in the literature. ${ }^{254}$

\section{Synthesis of Ethyl (E)-3-\{5-[(N,N-Dimethylcarbamoyl)oxy]benzo[d][1,3]dioxol-4-yl\}acrylate (193za)}<smiles>CCOC(=O)/C=C/c1c(OC(N)=O)ccc2c1OCO2</smiles>
The general procedure D was followed using substrate 1922 (105 mg, $0.50 \mathrm{mmol}$ ) and ethyl acrylate (15a) $(100 \mathrm{mg}, 1.00 \mathrm{mmol})$. Purification by column chromatography ( $n$-hexane/EtOAc: $10 / 1 \rightarrow 5 / 1$ ) yielded 193za (100 mg, 65\%) as a white solid.

The general procedure $\mathbf{E}$ was followed using substrate $192 z$ (105 mg, $0.50 \mathrm{mmol}$ ) and ethyl acrylate (15a) (100 mg, $1.00 \mathrm{mmol})$. Purification by column chromatography ( $n$-hexane/EtOAc: $10 / 1 \rightarrow 5 / 1$ ) yielded $193 z a(65 \mathrm{mg}, 42 \%$ ) as a white solid.

M. p.: $115-117^{\circ} \mathrm{C}$.

${ }^{1} \mathrm{H}$ NMR $\left(300 \mathrm{MHz}^{\mathrm{CDCl}}{ }_{3}\right): \delta=7.59(\mathrm{~d}, J=16.1 \mathrm{~Hz}, 1 \mathrm{H}), 6.75(\mathrm{~d}, J=8.4 \mathrm{~Hz}, 1 \mathrm{H}), 6.73(\mathrm{~d}, J=16.1 \mathrm{~Hz}$, $1 \mathrm{H}), 6.57(\mathrm{~d}, J=8.4 \mathrm{~Hz}, 1 \mathrm{H}), 6.05(\mathrm{~s}, 2 \mathrm{H}), 4.22(\mathrm{q}, J=7.2 \mathrm{~Hz}, 2 \mathrm{H}), 3.13(\mathrm{~s}, 3 \mathrm{H}), 2.98(\mathrm{~s}, 3 \mathrm{H}), 1.29(\mathrm{t}, J=$ $7.2 \mathrm{~Hz}, 3 \mathrm{H})$.

${ }^{13} \mathrm{C}$ NMR $\left(75 \mathrm{MHz}, \mathrm{CDCl}_{3}\right): \delta=167.3\left(\mathrm{C}_{\mathrm{q}}\right), 154.7\left(\mathrm{C}_{\mathrm{q}}\right), 147.0\left(\mathrm{C}_{\mathrm{q}}\right), 145.2\left(\mathrm{C}_{\mathrm{q}}\right), 144.2\left(\mathrm{C}_{\mathrm{q}}\right), 133.4(\mathrm{CH})$, $122.7(\mathrm{CH}), 115.3(\mathrm{CH}), 112.3\left(\mathrm{C}_{\mathrm{q}}\right), 108.9(\mathrm{CH}), 102.2\left(\mathrm{CH}_{2}\right), 60.4\left(\mathrm{CH}_{2}\right), 36.9\left(\mathrm{CH}_{3}\right), 36.5\left(\mathrm{CH}_{3}\right), 14.3$ $\left(\mathrm{CH}_{3}\right)$.

IR (ATR): $\tilde{v}=2909,1714,1633,1457,1304,1201,1162,977,862 \mathrm{~cm}^{-1}$.

MS (EI) $m / z$ (relative intensity) 307 (5) [M] ${ }^{+}, 219$ (5), 190 (8), 72 (100), 43 (7).

HR-MS (EI): $m / z$ calcd for $\mathrm{C}_{15} \mathrm{H}_{17} \mathrm{NO}_{6}{ }^{+}[\mathrm{M}]^{+} 307.1050$, found 307.1059.

\section{Deprotection of Carbamate 193aa}

To a solution of the carbamate $193 a a(170 \mathrm{mg}, 0.61 \mathrm{mmol})$ in $\mathrm{EtOH}(5 \mathrm{~mL})$ was added $\mathrm{NaOH}(245 \mathrm{mg}$, $6.13 \mathrm{mmol})$. The reaction mixture was stirred at $80{ }^{\circ} \mathrm{C}$ for $15 \mathrm{~h}$. At ambient temperature, EtOH was evaporated under reduced pressure, the residue was diluted with $\mathrm{H}_{2} \mathrm{O}(20 \mathrm{~mL})$, and the excess of $\mathrm{NaOH}$ was neutralized at $0{ }^{\circ} \mathrm{C}$ using a solution of $\mathrm{HCl}(5 \mathrm{~mL}, 2 \mathrm{~N})$. The aqueous solution was extracted with $\mathrm{Et}_{2} \mathrm{O}(3 \times 20 \mathrm{~mL})$, and the combined organic layers were washed with brine, dried over $\mathrm{Na}_{2} \mathrm{SO}_{4}$, and evaporated under reduced pressure. The crude product was washed with $\mathrm{CH}_{2} \mathrm{Cl}_{2}$ to afford 223 ( $80 \mathrm{mg}, 74 \%$ ) as a yellow solid.

Analytical Data for (E)-3-(2-Hydroxy-4-methylphenyl)acrylic acid (223)<smiles>Cc1ccc(/C=C/C(=O)O)c(O)c1</smiles>
M. p.: $191-193^{\circ} \mathrm{C}$.

${ }^{1}$ H NMR (300 MHz, d $d^{6}$-DMSO): $\delta=12.04\left(s_{b r}, 1 H\right), 10.00(s, 1 H), 7.78(d, J$ $=16.1 \mathrm{~Hz}, 1 \mathrm{H}), 7.43(\mathrm{~d}, J=8.0 \mathrm{~Hz}, 1 \mathrm{H}), 6.71(\mathrm{~s}, 1 \mathrm{H}), 6.65(\mathrm{~d}, J=8.0 \mathrm{~Hz}, 1 \mathrm{H})$, $6.43(\mathrm{~d}, J=16.1 \mathrm{~Hz}, 1 \mathrm{H}), 2.23(\mathrm{~s}, 3 \mathrm{H})$.

${ }^{13} \mathrm{C}$ NMR (75 MHz, DMSO): $\delta=168.0\left(\mathrm{C}_{\mathrm{q}}\right), 156.4\left(\mathrm{C}_{\mathrm{q}}\right), 141.4\left(\mathrm{C}_{\mathrm{q}}\right), 139.5(\mathrm{CH}), 128.5(\mathrm{CH}), 120.3(\mathrm{CH})$, $118.2\left(\mathrm{C}_{\mathrm{q}}\right), 117.0(\mathrm{CH}), 116.4(\mathrm{CH}), 21.0\left(\mathrm{CH}_{3}\right)$.

IR (ATR): $\tilde{v}=2925,1660,1601,1421,1298,1259,1205,986,854 \mathrm{~cm}^{-1}$.

MS (EI) $m / z$ (relative intensity) 178 (35) [M] ${ }^{+}, 160$ (47), 132 (100), 104 (32), 77 (30), 43 (18). 
HR-MS (EI): $\mathrm{m} / z$ calcd for $\mathrm{C}_{10} \mathrm{H}_{10} \mathrm{O}_{3}{ }^{+}[\mathrm{M}]^{+} 178.0624$, found 178.0634 .

Intermolecular Competition Experiment with Carbamates 192I and 192a'<smiles>COc1ccc(OC(=O)OCCCCC(=O)Oc2ccc(C(F)(F)F)cc2)cc1</smiles>

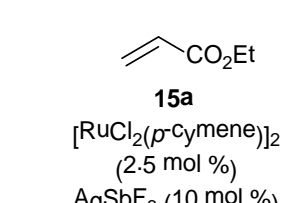<smiles>CCOC(=O)Oc1ccc(OC)cc1C=CCN(C)C</smiles><smiles>CCOC(=O)C=Cc1cc(C(F)(F)F)ccc1OC(=O)N(C)C</smiles>

193a'a: $17 \%$

A mixture of substrates $192 \mathrm{l}(195 \mathrm{mg}, 1.00 \mathrm{mmol}), 192 \mathrm{a}^{\prime}$ (233 mg, $1.00 \mathrm{mmol}$ ), ethyl acrylate (15a) (50 mg, $0.50 \mathrm{mmol}),\left[\mathrm{RuCl}_{2}(p \text {-cymene) }]_{2}(7.7 \mathrm{mg}, 2.5 \mathrm{~mol} \%), \mathrm{AgSbF}_{6}(17.2 \mathrm{mg}, 10 \mathrm{~mol} \%)\right.$ and $\mathrm{Cu}(\mathrm{OAC})_{2} \cdot \mathrm{H}_{2} \mathrm{O}(200 \mathrm{mg}, 1.00 \mathrm{mmol})$ in DME $(3.0 \mathrm{~mL})$ was stirred at $110{ }^{\circ} \mathrm{C}$ for $24 \mathrm{~h}$ under an atmosphere of $\mathrm{N}_{2}$. At ambient temperature, EtOAc $(15 \mathrm{~mL})$ was added, and the mixture was filtered through a pad of silica gel. The solvents were removed in vacuo. Purification of the residue by column chromatography ( $n$-hexane/EtOAc: $10 / 1$ ) yielded 193la (119 mg, $81 \%$ ) as a white solid and 193a'a (28 $\mathrm{mg}, 17 \%)$ as a white solid. The spectral data of 193la were identical to those reported above.

\section{Analytical Data for Ethyl (E)-3-\{2-[(N,N-Dimethylcarbamoyl)oxy]-5-(trifluoromethyl)phenyl\}acrylate} (193a'a)<smiles>CCOC(=O)/C=C/c1cc(C(F)(F)F)ccc1OC(=O)N(C)C</smiles>

M. p.: $107-109^{\circ} \mathrm{C}$.

${ }^{1} \mathrm{H}$ NMR $\left(300 \mathrm{MHz}, \mathrm{CDCl}_{3}\right): \delta=7.83(\mathrm{~d}, J=1.9 \mathrm{~Hz}, 1 \mathrm{H}), 7.80(\mathrm{~d}, J=16.3$ $\mathrm{Hz}, 1 \mathrm{H}), 7.59(\mathrm{dd}, J=8.6 \mathrm{~Hz}, 1.9 \mathrm{~Hz}, 1 \mathrm{H}), 7.30(\mathrm{~d}, J=8.6 \mathrm{~Hz}, 1 \mathrm{H}), 6.48(\mathrm{~d}, J$ $=16.3 \mathrm{~Hz}, 1 \mathrm{H}), 4.24(\mathrm{q}, J=7.2 \mathrm{~Hz}, 2 \mathrm{H}), 3.15(\mathrm{~s}, 3 \mathrm{H}), 3.01(\mathrm{~s}, 3 \mathrm{H}), 1.30(\mathrm{t}, J$ $=7.2 \mathrm{~Hz}, 3 \mathrm{H})$.

${ }^{13} \mathrm{C} \mathrm{NMR}\left(75 \mathrm{MHz}, \mathrm{CDCl}_{3}\right): \delta=166.3\left(\mathrm{C}_{\mathrm{q}}\right), 153.5\left(\mathrm{C}_{\mathrm{q}}\right), 152.3\left(\mathrm{C}_{\mathrm{q}}\right), 136.8(\mathrm{CH}), 127.9\left(\mathrm{q},{ }^{2} J_{\mathrm{C}-\mathrm{F}}=33 \mathrm{~Hz}, \mathrm{C}_{\mathrm{q}}\right)$, $127.9\left(\mathrm{C}_{\mathrm{q}}\right), 127.5\left(\mathrm{q},{ }^{3} \mathrm{~J}_{\mathrm{C}-\mathrm{F}}=4 \mathrm{~Hz}, \mathrm{CH}\right), 124.5\left(\mathrm{q},{ }^{3} \mathrm{~J}_{\mathrm{C}-\mathrm{F}}=4 \mathrm{~Hz}, \mathrm{CH}\right), 124.0(\mathrm{CH}), 123.6\left(\mathrm{q},{ }^{1} J_{\mathrm{C}-\mathrm{F}}=272 \mathrm{~Hz}, \mathrm{C}_{\mathrm{q}}\right)$, 121.6 (CH), $60.8\left(\mathrm{CH}_{2}\right), 36.9\left(\mathrm{CH}_{3}\right), 36.5\left(\mathrm{CH}_{3}\right), 14.2\left(\mathrm{CH}_{3}\right)$.

${ }^{19} \mathrm{~F}-\mathrm{NMR}\left(282 \mathrm{MHz}, \mathrm{CDCl}_{3}\right): \delta=-62.5(\mathrm{~s})$.

IR (ATR): $\tilde{v}=2943,1702,1486,1334,1110,1008,858,858 \mathrm{~cm}^{-1}$.

MS (EI) $\mathrm{m} / \mathrm{z}$ (relative intensity) 331 (5) [M] ${ }^{+}, 243$ (18), 186 (8), 72 (100).

HR-MS (ESI): $\mathrm{m} / z$ calcd for $\mathrm{C}_{15} \mathrm{H}_{16} \mathrm{~F}_{3} \mathrm{NNaO}_{4}{ }^{+}[\mathrm{M}+\mathrm{Na}]^{+}$354.0924, found 354.0924. 
Intermolecular Competition Experiment with Carbamates $192 \mathrm{f}$ and $192 \mathrm{~h}$<smiles>COc1ccccc1OC(=O)N(C)C</smiles>

$192 f$ (2.0 equiv)

$+$<smiles>CNC(=O)Oc1ccccc1C(F)(F)F</smiles>

$192 \mathrm{~h}(2.0$ equiv $)$

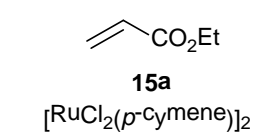

$(2.5 \mathrm{~mol} \%)$

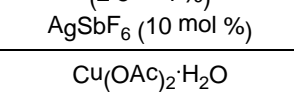

$\mathrm{DME}, 110^{\circ} \mathrm{C}, 24 \mathrm{~h}$<smiles>CCOC(=O)/C=C/c1cccc(OC)c1OC(=O)N(C)C</smiles>

193fa: $55 \%$

$+$<smiles>CCOC(=O)C=Cc1cccc(C(F)(F)F)c1OC(=O)N(C)C</smiles>

193ha: $13 \%$

A mixture of substrates $192 \mathrm{f}$ (195 mg, $1.00 \mathrm{mmol}$ ), $192 \mathrm{~h}$ (233 mg, $1.00 \mathrm{mmol}$ ), ethyl acrylate (15a) (50 $\mathrm{mg}, 0.50 \mathrm{mmol}),\left[\mathrm{RuCl}_{2}(p \text {-cymene })\right]_{2}(7.7 \mathrm{mg}, 2.5 \mathrm{~mol} \%), \mathrm{AgSbF}_{6}(17.2 \mathrm{mg}, 10 \mathrm{~mol} \%)$ and $\mathrm{Cu}(\mathrm{OAC})_{2} \cdot \mathrm{H}_{2} \mathrm{O}(200 \mathrm{mg}, 1.00 \mathrm{mmol})$ in DME $(3.0 \mathrm{~mL})$ was stirred at $110{ }^{\circ} \mathrm{C}$ for $24 \mathrm{~h}$ under an atmosphere of $\mathrm{N}_{2}$. At ambient temperature, EtOAc $(15 \mathrm{~mL})$ was added, and the mixture was filtered through a pad of silica gel. The solvents were removed in vacuo. Purification of the residue by column chromatography ( $n$-hexane/EtOAc: $10 / 1$ ) yielded $193 \mathrm{fa}(81 \mathrm{mg}, 55 \%$ ) as a white solid and 193ha (21 $\mathrm{mg}, 13 \%)$ as a colorless oil. Their spectral data were identical to those reported above.

Experiment with Deuterium-Labeled Substrate $\left[D_{5}\right]-221 b$<smiles>[2H]c1c([2H])c([2H])c(OC(=O)NCC)c([2H])c1[2H]</smiles>

[D5]-221b

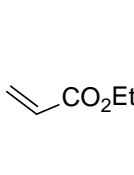

$15 \mathrm{a}$
$\left[\mathrm{RuCl}_{2}(p \text {-cymene) }]_{2}\right.$ $(2.5 \mathrm{~mol} \%)$

$\mathrm{AgSbF}_{6}(10 \mathrm{~mol} \%)$

$\mathrm{Cu}(\mathrm{OAC}))_{2} \cdot \mathrm{H}_{2} \mathrm{O}$ DME, $110^{\circ} \mathrm{C}, 7 \mathrm{~h}$ $37 \%$

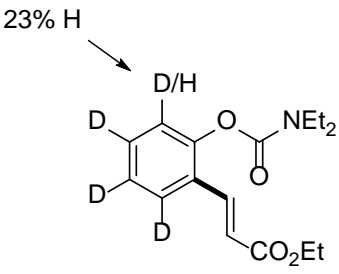

$[\mathrm{Dn}]-222 \mathrm{ba}$

The general procedure $\mathbf{D}$ was followed using substrate $\left[\mathrm{D}_{5}\right]-\mathbf{2 2 1 b}(99 \mathrm{mg}, 0.50 \mathrm{mmol})$ and ethyl acrylate (15a) $(100 \mathrm{mg}, 1.00 \mathrm{mmol}$ ). Purification by column chromatography ( $n$-hexane/EtOAc: $10 / 1 \rightarrow 5 / 1$ ) yielded [Dn]-222 ba (55 mg, 37\%) as a colorless oil.

\subsubsection{Analytical Data for the Products of Ruthenium(II)-Catalyzed Isoquinoline Synthesis}

\section{Synthesis of 9-Methyl-2,3-diphenyl-8,9-dihydro-7H-benzo[de]quinoline (176ba)}<smiles>CC1CCc2cccc3c(-c4ccccc4)c(-c4ccccc4)nc1c23</smiles>

The representative procedure $\mathbf{F}$ was followed using substrate $194 \mathrm{~b}(88 \mathrm{mg}, 0.50$ $\mathrm{mmol}$ ) and diphenylacetylene (155a) (178 mg, $1.00 \mathrm{mmol}$ ). Purification by column chromatography ( $n$-hexane/EtOAc: $40 / 1$ ) yielded 176 ba (157 mg, 94\%) as a yellow solid.

M. p.: $145-147^{\circ} \mathrm{C}$.

${ }^{1} \mathbf{H}$ NMR $\left(300 \mathrm{MHz}, \mathrm{CDCl}_{3}\right): \delta=7.51-7.46(\mathrm{~m}, 2 \mathrm{H}), 7.45-7.28(\mathrm{~m}, 7 \mathrm{H}), 7.25-7.12(\mathrm{~m}, 4 \mathrm{H}), 3.54-3.41(\mathrm{~m}$, $1 \mathrm{H}), 3.36-3.24(\mathrm{~m}, 1 \mathrm{H}), 3.23-3.11(\mathrm{~m}, 1 \mathrm{H}), 2.43-2.31(\mathrm{~m}, 1 \mathrm{H}), 2.12-1.99(\mathrm{~m}, 1 \mathrm{H}), 1.63-1.56(\mathrm{~m}, 3 \mathrm{H})$. 
${ }^{13} \mathrm{C}$ NMR $\left(75 \mathrm{MHz}, \mathrm{C}_{2} \mathrm{D}_{2} \mathrm{Cl}_{4}, 100{ }^{\circ} \mathrm{C}\right): \delta=162.0\left(\mathrm{C}_{\mathrm{q}}\right), 148.7\left(\mathrm{C}_{\mathrm{q}}\right), 141.3\left(\mathrm{C}_{\mathrm{q}}\right), 138.0\left(\mathrm{C}_{\mathrm{q}}\right), 138.0\left(\mathrm{C}_{\mathrm{q}}\right)$, $136.2\left(\mathrm{C}_{\mathrm{q}}\right), 131.2(\mathrm{CH}), 130.3(\mathrm{CH}), 129.3(\mathrm{CH}), 128.4\left(\mathrm{C}_{\mathrm{q}}\right), 127.9(\mathrm{CH}), 127.0(\mathrm{CH}), 126.7(\mathrm{CH}), 126.4$ $(\mathrm{CH}), 124.3(\mathrm{CH}), 123.3(\mathrm{CH}), 123.0\left(\mathrm{C}_{\mathrm{q}}\right), 37.4(\mathrm{CH}), 30.8\left(\mathrm{CH}_{2}\right), 27.8\left(\mathrm{CH}_{2}\right), 19.6\left(\mathrm{CH}_{3}\right)$.

IR (ATR): $\tilde{v}=2929,1604,1577,1442,1377,1306,1178,1071,1023,767,699 \mathrm{~cm}^{-1}$.

MS (EI) $m / z$ (relative intensity) 335 (91) [M] ${ }^{+}, 334$ (100), 320 (50), 241 (8), 43 (13).

HR-MS (EI): $m / z$ calcd for $\mathrm{C}_{25} \mathrm{H}_{20} \mathrm{~N}^{+}[\mathrm{M}-\mathrm{H}]^{+} 334.1590$, found 334.1608 .

The spectral data were in accordance with those reported in the literature..$^{255}$

\section{Synthesis of 3,4-Diphenyl-1-n-propylisoquinoline (176ca)}<smiles>CCCc1nc(-c2ccccc2)c(-c2ccccc2)c2ccccc12</smiles>

The representative procedure $\mathbf{F}$ was followed using substrate $194 \mathrm{c}(82 \mathrm{mg}, 0.50$ mmol) and diphenylacetylene (155a) (178 mg, $1.00 \mathrm{mmol}$ ). Purification by column chromatography ( $n$-hexane/EtOAc: 50/1) yielded $176 \mathrm{ca}(144 \mathrm{mg}, 89 \%)$ as a yellow solid.

M. p.: $118-120^{\circ} \mathrm{C}$.

${ }^{1} \mathrm{H}$ NMR $\left(300 \mathrm{MHz}, \mathrm{CDCl}_{3}\right): \delta=8.23-8.14(\mathrm{~m}, 1 \mathrm{H}), 7.64-7.56(\mathrm{~m}, 1 \mathrm{H}), 7.54-7.45(\mathrm{~m}, 2 \mathrm{H}), 7.37-7.22(\mathrm{~m}$, $5 \mathrm{H}), 7.20-7.05(\mathrm{~m}, 5 \mathrm{H}), 3.32(\mathrm{t}, J=7.7 \mathrm{~Hz}, 2 \mathrm{H}), 1.95(\mathrm{dt}, J=7.7,7.3 \mathrm{~Hz} 2 \mathrm{H}), 1.08(\mathrm{t}, J=7.3 \mathrm{~Hz}, 3 \mathrm{H})$.

${ }^{13} \mathrm{C} \mathrm{NMR}\left(75 \mathrm{MHz}, \mathrm{CDCl}_{3}\right): \delta=161.3\left(\mathrm{C}_{\mathrm{q}}\right), 149.3\left(\mathrm{C}_{\mathrm{q}}\right), 141.1\left(\mathrm{C}_{\mathrm{q}}\right), 137.8\left(\mathrm{C}_{\mathrm{q}}\right), 136.3\left(\mathrm{C}_{\mathrm{q}}\right), 131.4(\mathrm{CH})$, $130.3(\mathrm{CH}), 129.6(\mathrm{CH}), 128.9\left(\mathrm{C}_{\mathrm{q}}\right), 128.2(\mathrm{CH}), 127.5(\mathrm{CH}), 127.5(\mathrm{CH}), 127.1(\mathrm{CH}), 126.9(\mathrm{CH}), 126.3$ $(\mathrm{CH}), 125.6\left(\mathrm{C}_{\mathrm{q}}\right), 125.2(\mathrm{CH}), 37.7\left(\mathrm{CH}_{2}\right), 23.2\left(\mathrm{CH}_{2}\right), 14.5\left(\mathrm{CH}_{3}\right)$.

IR (ATR): $\tilde{v}=3063,2962,1612,1568,1550,1444,1385,1087,1031,757,697 \mathrm{~cm}^{-1}$.

MS (EI) $m / z$ (relative intensity) 323 (22) [M] $]^{+}, 295$ (100), 308 (16), 252 (7).

HR-MS (EI): $m / z$ calcd for $\mathrm{C}_{24} \mathrm{H}_{20} \mathrm{~N}^{+}[\mathrm{M}-\mathrm{H}]^{+} 322.1590$, found 322.1607 .

\section{Synthesis of 1-n-Butyl-3,4-diphenylisoquinoline (176da)}<smiles>CC(C)Cc1nc(-c2ccccc2)c(-c2ccccc2)c2ccccc12</smiles>

The representative procedure $\mathbf{F}$ was followed using substrate $194 \mathrm{~d}(89 \mathrm{mg}, 0.50$ $\mathrm{mmol}$ ) and diphenylacetylene (155a) (178 mg, $1.00 \mathrm{mmol})$. Purification by column chromatography ( $n$-hexane/EtOAc: $40 / 1$ ) yielded $176 \mathrm{da}(151 \mathrm{mg}, 89 \%$ ) as a yellow solid.

The representative procedure $\mathbf{G}$ was followed using substrate $194 \mathrm{~d}(89 \mathrm{mg}, 0.50$ $\mathrm{mmol}$ ) and diphenylacetylene (155a) (178 $\mathrm{mg}, 1.00 \mathrm{mmol})$. Purification by column chromatography ( $n$-hexane/EtOAc: $40 / 1$ ) yielded $176 \mathrm{da}(144 \mathrm{mg}, 85 \%$ ) as a yellow solid.

M. p.: $78-80^{\circ} \mathrm{C}$.

${ }^{1}{ }_{H}$ NMR $\left(300 \mathrm{MHz}, \mathrm{CDCl}_{3}\right): \delta=8.27-8.21(\mathrm{~m}, 1 \mathrm{H}), 7.69-7.64(\mathrm{~m}, 1 \mathrm{H}), 7.60-7.54(\mathrm{~m}, 2 \mathrm{H}), 7.40-7.31(\mathrm{~m}$, $5 \mathrm{H}), 7.26-7.15(\mathrm{~m}, 5 \mathrm{H}), 3.42(\mathrm{t}, J=8.0 \mathrm{~Hz}, 2 \mathrm{H}), 2.02-1.90(\mathrm{~m}, 2 \mathrm{H}), 1.58(\mathrm{dt}, J=7.7,7.3 \mathrm{~Hz}, 2 \mathrm{H}), 1.04(\mathrm{t}$, $J=7.3 \mathrm{~Hz}, 3 \mathrm{H})$.

${ }^{13} \mathrm{C} \mathrm{NMR}\left(75 \mathrm{MHz}, \mathrm{CDCl}_{3}\right): \delta=161.5\left(\mathrm{C}_{\mathrm{q}}\right), 149.3\left(\mathrm{C}_{\mathrm{q}}\right), 141.1\left(\mathrm{C}_{\mathrm{q}}\right), 137.7\left(\mathrm{C}_{\mathrm{q}}\right), 136.3\left(\mathrm{C}_{\mathrm{q}}\right), 131.4(\mathrm{CH})$, $130.3(\mathrm{CH}), 129.6(\mathrm{CH}), 128.8\left(\mathrm{C}_{\mathrm{q}}\right), 128.2(\mathrm{CH}), 127.5(\mathrm{CH}), 127.5(\mathrm{CH}), 127.0(\mathrm{CH}), 126.8(\mathrm{CH}), 126.3$ $(\mathrm{CH}), 125.4(\mathrm{C}), 125.2(\mathrm{CH}), 35.5\left(\mathrm{CH}_{2}\right), 32.1\left(\mathrm{CH}_{2}\right), 23.1\left(\mathrm{CH}_{2}\right), 14.1\left(\mathrm{CH}_{3}\right)$.

IR (ATR): $\tilde{v}=3061,2958,2876,1611,1504,1442,1382,1337,1172,1073,763,697 \mathrm{~cm}^{-1}$.

MS (EI) $m / z$ (relative intensity) 337 (6) [M] ${ }^{+}, 308$ (10), 295 (100), 252 (6).

HR-MS (EI): $m / z$ calcd for $\mathrm{C}_{25} \mathrm{H}_{22} \mathrm{~N}^{+}[\mathrm{M}-\mathrm{H}]^{+} 336.1747$, found 336.1747 .

\section{Synthesis of 1-Isopropyl-3,4-diphenylisoquinoline (176ea)}<smiles>CCCc1nc(-c2ccccc2)c(-c2ccccc2)c2ccccc12</smiles> 
mmol), diphenylacetylene (155a) (178 mg, $1.00 \mathrm{mmol}$ ) and molecular sieves $4 \AA$ (100 mg). Purification by column chromatography ( $n$-hexane/EtOAc: $400 / 1$ ) yielded $176 e a$ (70 mg, 43\%) as a yellow solid.

M.p.: $140-142^{\circ} \mathrm{C}$.

${ }^{1}{ }^{H}$ NMR $\left(300 \mathrm{MHz}, \mathrm{CDCl}_{3}\right): \delta=8.32-8.24(\mathrm{~m}, 1 \mathrm{H}), 7.68-7.62(\mathrm{~m}, 1 \mathrm{H}), 7.58-7.51(\mathrm{~m}, 2 \mathrm{H}), 7.47-7.39$ (m, 2H), 7.39-7.31 (m, 3H), 7.28-7.20 (m, 2H), 7.20-7.13 (m, 3H), $4.02(\mathrm{dt}, J=6.7,6.7 \mathrm{~Hz}, 1 \mathrm{H}), 1.52$ (d, $J=6.7 \mathrm{~Hz}, 6 \mathrm{H})$.

${ }^{13} \mathrm{C}$ NMR $\left(75 \mathrm{MHz}, \mathrm{CDCl}_{3}\right): \delta=164.8\left(\mathrm{C}_{\mathrm{q}}\right), 148.4\left(\mathrm{C}_{\mathrm{q}}\right), 141.2\left(\mathrm{C}_{\mathrm{q}}\right), 138.0\left(\mathrm{C}_{\mathrm{q}}\right), 136.4\left(\mathrm{C}_{\mathrm{q}}\right), 131.3(\mathrm{CH})$, $130.5(\mathrm{CH}), 129.3(\mathrm{CH}), 128.3\left(\mathrm{C}_{\mathrm{q}}\right), 128.2(\mathrm{CH}), 127.3(\mathrm{CH}), 127.0(\mathrm{CH}), 126.8(\mathrm{CH}), 126.4(\mathrm{CH}), 126.2$ $(\mathrm{CH}), 124.69\left(\mathrm{C}_{\mathrm{q}}\right), 124.43(\mathrm{CH}), 31.4(\mathrm{CH}), 22.34\left(\mathrm{CH}_{3}\right)$.

IR (ATR): $\tilde{v}=3073,2969,1551,1446,1381,1258,1104,1007,866 \mathrm{~cm}^{-1}$.

MS (EI) $m / z$ (relative intensity) 322 (100) [M] ${ }^{+}, 295$ (86), 252 (13), 176 (8).

HR-MS (EI): $m / z$ calcd for $\mathrm{C}_{24} \mathrm{H}_{20} \mathrm{~N}^{+}[\mathrm{M}-\mathrm{H}]^{+} 322.1590$, found 322.1596 .

\section{Synthesis of 1-Cyclopropyl-3,4-diphenylisoquinoline (176fa)}<smiles>c1ccc(-c2nc(C3CC3)c3ccccc3c2-c2ccccc2)cc1</smiles>

The representative procedure $\mathbf{F}$ was followed using substrate $194 \mathrm{f}(81 \mathrm{mg}, 0.50$ mmol), diphenylacetylene (155a) (178 mg, $1.00 \mathrm{mmol})$ and molecular sieves $4 \AA$ (100 mg). Purification by column chromatography (n-hexane/EtOAc: 200/1) yielded $\mathbf{1 7 6 f a}(135 \mathrm{mg}, 84 \%$ ) as a yellow solid.

M. p.: $148-150^{\circ} \mathrm{C}$.

${ }^{1} \mathrm{H}$ NMR $\left(300 \mathrm{MHz}, \mathrm{CDCl}_{3}\right): \delta=8.50(\mathrm{dd}, J=7.2,2.0 \mathrm{~Hz}, 1 \mathrm{H}), 7.69-7.62(\mathrm{~m}, 1 \mathrm{H})$, 7.62-7.51 (m, 2H), 7.42-7.27 (m, 5H), 7.27-7.21 (m, 2H), 7.20-7.08 (m, 3H), 2.89-2.74 (m, $1 \mathrm{H})$, $1.44-1.32(\mathrm{~m}, 2 \mathrm{H}), 1.18-1.05(\mathrm{~m}, 2 \mathrm{H})$.

${ }^{13} \mathrm{C}$ NMR $\left(75 \mathrm{MHz}, \mathrm{CDCl}_{3}\right): \delta=160.6\left(\mathrm{C}_{\mathrm{q}}\right), 148.7\left(\mathrm{C}_{\mathrm{q}}\right), 141.2\left(\mathrm{C}_{\mathrm{q}}\right), 138.0\left(\mathrm{C}_{\mathrm{q}}\right), 136.1\left(\mathrm{C}_{\mathrm{q}}\right), 131.4(\mathrm{CH})$, $130.4(\mathrm{CH}), 129.6(\mathrm{CH}), 128.2(\mathrm{CH}), 128.0\left(\mathrm{C}_{\mathrm{q}}\right), 127.3(\mathrm{CH}), 127.0(\mathrm{CH}), 126.8(\mathrm{CH}), 126.3(\mathrm{CH}), 126.3$ $\left(\mathrm{C}_{\mathrm{q}}\right), 126.2(\mathrm{CH}), 124.8(\mathrm{CH}), 13.6(\mathrm{CH}), 9.4\left(\mathrm{CH}_{2}\right)$.

IR (ATR): $\tilde{v}=3055,1611,1568,1547,1444,1410,1318,1261,1075,1014,767,694 \mathrm{~cm}^{-1}$.

MS (EI) $m / z$ (relative intensity) 321 (68) [M] ${ }^{+}, 320$ (100), 278 (5), 243 (8), 152 (5), 43 (13).

HR-MS (EI): $m / z$ calcd for $\mathrm{C}_{24} \mathrm{H}_{18} \mathrm{~N}^{+}[\mathrm{M}-\mathrm{H}]^{+} 320.1434$, found 320.1438 .

The spectral data were in accordance with those reported in the literature. ${ }^{256}$

\section{Synthesis of 1-Cyclohexyl-3,4-diphenylisoquinoline (176ga)}<smiles>c1ccc(-c2nc(C3CCCCC3)c3ccccc3c2-c2ccccc2)cc1</smiles>

The representative procedure $\mathbf{F}$ was followed using substrate $194 \mathrm{~g}(102 \mathrm{mg}, 0.50$ mmol), diphenylacetylene (155a) (178 mg, $1.00 \mathrm{mmol}$ ) and molecular sieves $4 \AA$ (100 mg). Purification by column chromatography (n-hexane/EtOAc: 200/1) yielded 176ga (147 $\mathrm{mg}, 81 \%$ ) as a yellow solid.

M. p.: $158-160^{\circ} \mathrm{C}$.

${ }^{1} \mathbf{H}$ NMR $\left(300 \mathrm{MHz}, \mathrm{CDCl}_{3}\right): \delta=8.31-8.25(\mathrm{~m}, 1 \mathrm{H}), 7.68-7.62(\mathrm{~m}, 1 \mathrm{H}), 7.58-7.49$ $(\mathrm{m}, 2 \mathrm{H}), 7.46-7.40(\mathrm{~m}, 2 \mathrm{H}), 7.38-7.32(\mathrm{~m}, 3 \mathrm{H}), 7.26-7.20(\mathrm{~m}, 2 \mathrm{H}), 7.20-7.14(\mathrm{~m}$, $2 \mathrm{H}), 3.68-3.57(\mathrm{~m}, 1 \mathrm{H}), 2.12-1.75(\mathrm{~m}, 7 \mathrm{H}), 1.64-1.31(\mathrm{~m}, 3 \mathrm{H})$.

${ }^{13} \mathrm{C} \mathrm{NMR}\left(75 \mathrm{MHz}, \mathrm{CDCl}_{3}\right): \delta=164.4\left(\mathrm{C}_{\mathrm{q}}\right), 148.6\left(\mathrm{C}_{\mathrm{q}}\right), 141.3\left(\mathrm{C}_{\mathrm{q}}\right), 138.1\left(\mathrm{C}_{\mathrm{q}}\right), 136.5\left(\mathrm{C}_{\mathrm{q}}\right), 131.4(\mathrm{CH})$, $130.6(\mathrm{CH}), 129.3(\mathrm{CH}), 128.25(\mathrm{CH}), 128.23\left(\mathrm{C}_{\mathrm{q}}\right), 127.4(\mathrm{CH}), 127.0(\mathrm{CH}), 126.8(\mathrm{CH}), 126.5(\mathrm{CH}), 126.2$ (CH), $124.7\left(\mathrm{C}_{\mathrm{q}}\right), 124.5(\mathrm{CH}), 41.8(\mathrm{CH}), 32.5\left(\mathrm{CH}_{2}\right), 26.9\left(\mathrm{CH}_{2}\right), 26.3\left(\mathrm{CH}_{2}\right)$.

IR (ATR): $\tilde{v}=2924,2850,1670,1612,1551,1504,1446,1373,1334,1260,1029,758,696 \mathrm{~cm}^{-1}$. 
MS (EI) $m / z$ (relative intensity) 362 (50) [M] ${ }^{+}, 334$ (13), 308 (100), 295 (50), 280 (8), 43 (6).

HR-MS $\left(\mathrm{EI}^{+}\right): \mathrm{m} / z$ calcd for $\mathrm{C}_{27} \mathrm{H}_{24} \mathrm{~N}^{+}[\mathrm{M}-\mathrm{H}]^{+} 362.1903$, found 362.1903 .

The spectral data were in accordance with those reported in the literature. ${ }^{256}$

\section{Synthesis of 1-Benzyl-3,4-diphenylisoquinoline (176ha)}<smiles>c1ccc(Cc2nc(-c3ccccc3)c(-c3ccccc3)c3ccccc23)cc1</smiles>

The representative procedure $\mathbf{F}$ was followed using substrate $194 \mathrm{~h}$ (106 mg, 0.50 $\mathrm{mmol}$ ), diphenylacetylene (155a) (178 mg, $1.00 \mathrm{mmol}$ ) and molecular sieves $4 \AA$ (100 mg). Purification by column chromatography (n-hexane/EtOAc: 100/1) yielded $176 \mathrm{ha} \mathrm{(100} \mathrm{mg}, 54 \%$ ) as a yellow solid.

M. p.: $118-120^{\circ} \mathrm{C}$.

${ }^{1} \mathrm{H}$ NMR $\left(300 \mathrm{MHz}, \mathrm{CDCl}_{3}\right): \delta=8.26-8,19(\mathrm{~m}, 1 \mathrm{H}), 7.69-7.62(\mathrm{~m}, 1 \mathrm{H}), 7.56-7.46$ $(\mathrm{m}, 2 \mathrm{H}), 7.46-7.39(\mathrm{~m}, 4 \mathrm{H}), 7.39-7.14(\mathrm{~m}, 11 \mathrm{H}), 4.79(\mathrm{~s}, 2 \mathrm{H})$.

${ }^{13} \mathrm{C} \mathrm{NMR}\left(75 \mathrm{MHz}, \mathrm{CDCl}_{3}\right): \delta=159.1\left(\mathrm{C}_{\mathrm{q}}\right), 149.4\left(\mathrm{C}_{\mathrm{q}}\right), 140.9\left(\mathrm{C}_{\mathrm{q}}\right), 139.7\left(\mathrm{C}_{\mathrm{q}}\right), 137.5\left(\mathrm{C}_{\mathrm{q}}\right), 136.7\left(\mathrm{C}_{\mathrm{q}}\right)$, $131.3(\mathrm{CH}), 130.4(\mathrm{CH}), 129.7(\mathrm{CH}), 129.6\left(\mathrm{C}_{\mathrm{q}}\right), 129.0\left(\mathrm{C}_{\mathrm{q}}\right), 128.7(\mathrm{CH}), 128.4(\mathrm{CH}), 128.2(\mathrm{CH}), 127.6$ (CH), $127.2(\mathrm{CH}), 127.0(\mathrm{CH}), 126.6(\mathrm{CH}), 126.4(\mathrm{CH}), 126.2(\mathrm{CH}), 125.7(\mathrm{CH}), 42.4\left(\mathrm{CH}_{2}\right)$.

IR (ATR): $\tilde{v}=3024,1616,1576,1554,1521,1493,1490,1473,1440,1376,1072,754,697 \mathrm{~cm}^{-1}$.

MS (EI) $m / z$ (relative intensity) 370 (100) [M] ${ }^{+}, 293$ (7), 265 (6), 91 (5), 43 (13).

HR-MS $\left(\mathrm{EI}^{+}\right): \mathrm{m} / z$ calcd for $\mathrm{C}_{28} \mathrm{H}_{20} \mathrm{~N}^{+}[\mathrm{M}-\mathrm{H}]^{+} 370.1590$, found 370.1584 .

\section{Synthesis of 6-Bromo-1-methyl-3,4-diphenylisoquinoline (176ia)}<smiles>Cc1nc(-c2ccccc2)c(-c2ccccc2)c2cc(Br)ccc12</smiles>

The representative procedure $\mathbf{F}$ was followed using substrate $194 \mathbf{i}(107 \mathrm{mg}$, $0.50 \mathrm{mmol}$ ), diphenylacetylene (155a) (178 $\mathrm{mg}, 1.00 \mathrm{mmol}$ ) and molecular sieves $4 \quad \AA \quad(100 \mathrm{mg})$. Purification by column chromatography ( $n$-hexane/EtOAc: $20 / 1$ ) yielded $176 i a(102 \mathrm{mg}, 55 \%)$ as a yellow solid.

M. p.: $193-195^{\circ} \mathrm{C}$.

${ }^{1} \mathrm{H}$ NMR $\left(300 \mathrm{MHz}, \mathrm{CDCl}_{3}\right): \delta=8.06(\mathrm{~d}, J=8.9 \mathrm{~Hz}, 1 \mathrm{H}), 7.80(\mathrm{~d}, J=2.0 \mathrm{~Hz}, 1 \mathrm{H}), 7.67(\mathrm{dd}, J=8.9,2.0 \mathrm{~Hz}$, $1 \mathrm{H}), 7.39-7.30(\mathrm{~m}, 5 \mathrm{H}), 7.23-7.14(\mathrm{~m}, 5 \mathrm{H}), 3.06(\mathrm{~s}, 3 \mathrm{H})$.

${ }^{13} \mathrm{C} \mathrm{NMR}\left(75 \mathrm{MHz}, \mathrm{CDCl}_{3}\right): \delta=157.6\left(\mathrm{C}_{\mathrm{q}}\right), 150.5\left(\mathrm{C}_{\mathrm{q}}\right), 140.5\left(\mathrm{C}_{\mathrm{q}}\right), 137.3\left(\mathrm{C}_{\mathrm{q}}\right), 136.7\left(\mathrm{C}_{\mathrm{q}}\right), 131.2(\mathrm{CH})$, $130.0(\mathrm{CH}), 129.9(\mathrm{CH}), 128.3(\mathrm{CH}), 128.3(\mathrm{CH}), 128.2\left(\mathrm{C}_{\mathrm{q}}\right), 127.6(\mathrm{CH}), 127.4(\mathrm{CH}), 127.2(\mathrm{CH}), 127.1$ $(\mathrm{CH}), 125.0\left(\mathrm{C}_{\mathrm{q}}\right), 124.5\left(\mathrm{C}_{\mathrm{q}}\right), 22.8\left(\mathrm{CH}_{3}\right)$.

IR (ATR): $\tilde{v}=3064,1597,1561,1481,1445,1386,1329,1259,1071,1029,751,697 \mathrm{~cm}^{-1}$.

MS (EI) $m / z$ (relative intensity) 375/373 (100/100) [M] ${ }^{+}, 293$ (26), 252 (28), 189 (15), 43 (56).

HR-MS (ESI): $\mathrm{m} / z$ calcd for $\mathrm{C}_{22} \mathrm{H}_{17}{ }^{79} \mathrm{BrN}^{+}[\mathrm{M}+\mathrm{H}]^{+} 374.0539$, found 374.0538 .

The spectral data were in accordance with those reported in the literature. ${ }^{257}$

\section{Synthesis of 1-Methyl-3,4-diphenyl-5H-pyrido[4,3-b]indole (176ja)}

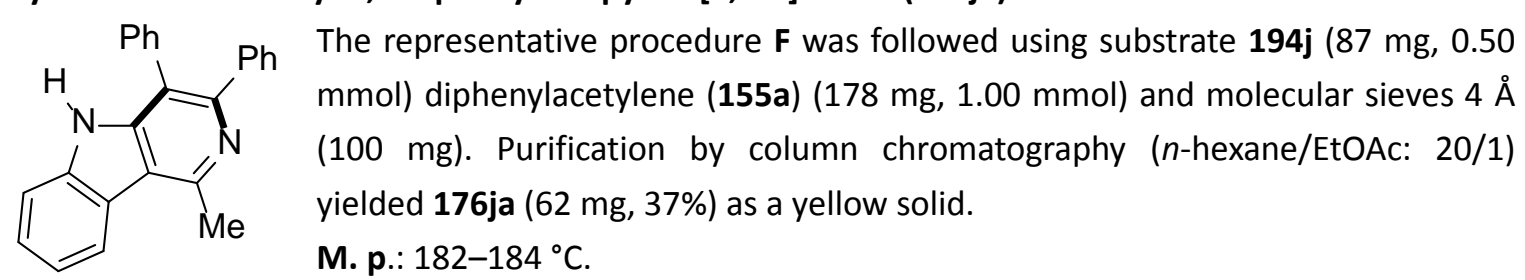

${ }^{1} \mathrm{H}$ NMR $\left(300 \mathrm{MHz}, \mathrm{CDCl}_{3}\right): \delta=8.47(\mathrm{~s}, 1 \mathrm{H}), 8.18(\mathrm{dd}, J=7.8,1.0 \mathrm{~Hz}, 1 \mathrm{H}), 7.50-7.26(\mathrm{~m}, 10 \mathrm{H})$, 7.22-7.13 (m, 3H), $3.13(\mathrm{~s}, 3 \mathrm{H})$. 
${ }^{13} \mathrm{C}$ NMR $\left(75 \mathrm{MHz}, \mathrm{CDCl}_{3}\right): \delta=151.9\left(\mathrm{C}_{\mathrm{q}}\right), 151.5\left(\mathrm{C}_{\mathrm{q}}\right), 143.8\left(\mathrm{C}_{\mathrm{q}}\right), 140.4\left(\mathrm{C}_{\mathrm{q}}\right), 139.5\left(\mathrm{C}_{\mathrm{q}}\right), 136.1\left(\mathrm{C}_{\mathrm{q}}\right)$, $130.3(\mathrm{CH}), 130.2(\mathrm{CH}), 129.0(\mathrm{CH}), 127.6(\mathrm{CH}), 127.4(\mathrm{CH}), 127.1(\mathrm{CH}), 126.0(\mathrm{CH}), 122.6\left(\mathrm{C}_{\mathrm{q}}\right), 122.3$ $(\mathrm{CH}), 120.8(\mathrm{CH}), 116.9\left(\mathrm{C}_{\mathrm{q}}\right), 116.82\left(\mathrm{C}_{\mathrm{q}}\right), 110.81(\mathrm{CH}), 23.8\left(\mathrm{CH}_{3}\right)$.

IR (ATR): $\tilde{v}=3640,3050,1594,1492,1405,1234,1118,1020,793 \mathrm{~cm}^{-1}$.

MS (EI) $m / z$ (relative intensity) $334(30)[M]^{+}, 291$ (5), 167 (8), 77 (2).

HR-MS (EI): $m / z$ calcd for $\mathrm{C}_{24} \mathrm{H}_{19} \mathrm{~N}_{2}{ }^{+}[\mathrm{M}+\mathrm{H}]^{+} 335.1543$, found 335.1541 .

\section{Synthesis of 1-Methyl-3,4-diphenylisoquinoline (176aa)}<smiles>Cc1nc(-c2ccccc2)c(-c2ccccc2)c2ccccc12</smiles>

The representative procedure $\mathbf{G}$ was followed using substrate 194a $(68 \mathrm{mg}, 0.50$ mmol) diphenylacetylene (155a) $(178 \mathrm{mg}, 1.00 \mathrm{mmol})$. Purification by column chromatography ( $n$-hexane/EtOAc: 20/1) yielded 176aa (96 mg, 65\%) as a yellow solid.

M. p.: $152-155^{\circ} \mathrm{C}$.

${ }^{1} \mathrm{H}$ NMR $\left(300 \mathrm{MHz}, \mathrm{CDCl}_{3}\right): \delta=8.23-8.20(\mathrm{~m}, 1 \mathrm{H}), 7.71-7.67(\mathrm{~m}, 1 \mathrm{H}), 7.63-7.57(\mathrm{~m}, 2 \mathrm{H}), 7.44-7.32(\mathrm{~m}$, $5 \mathrm{H}), 7.29-7.17(\mathrm{~m}, 5 \mathrm{H}), 3.11(\mathrm{~s}, 3 \mathrm{H})$.

${ }^{13} \mathrm{C}$ NMR $\left(75 \mathrm{MHz}, \mathrm{CDCl}_{3}\right): \delta=157.7\left(\mathrm{C}_{\mathrm{q}}\right), 149.4\left(\mathrm{C}_{\mathrm{q}}\right), 141.0\left(\mathrm{C}_{\mathrm{q}}\right), 137.6\left(\mathrm{C}_{\mathrm{q}}\right), 136.0\left(\mathrm{C}_{\mathrm{q}}\right), 131.4(\mathrm{CH})$, $130.2(\mathrm{CH}), 129.9(\mathrm{CH}), 129.1\left(\mathrm{C}_{\mathrm{q}}\right), 128.1(\mathrm{CH}), 127.6(\mathrm{CH}), 127.1(\mathrm{CH}), 126.9(\mathrm{CH}), 126.5(\mathrm{CH}), 126.2$ $(\mathrm{CH}), 126.1\left(\mathrm{C}_{\mathrm{q}}\right), 125.5(\mathrm{CH}), 22.7\left(\mathrm{CH}_{3}\right)$.

IR (ATR): $\tilde{v}=3025,1567,1389,1334,1072,1026,765,695,612,563,496 \mathrm{~cm}^{-1}$.

MS (EI) $m / z$ (relative intensity) 295 (50) [M] ${ }^{+}, 294$ (100), 278 (5), 252 (17), 177 (15), 43 (14).

HR-MS (EI): $m / z$ calcd for $\mathrm{C}_{22} \mathrm{H}_{17} \mathrm{~N}^{+}[\mathrm{M}]^{+} 295.1356$, found 295.1348 .

The spectral data were in accordance with those reported in the literature. ${ }^{255}$

\section{Synthesis of 1,6-Dimethyl-3,4-diphenylisoquinoline (176ka)}<smiles>Cc1ccc2c(C)nc(-c3ccccc3)c(-c3ccccc3)c2c1</smiles>

The representative procedure $\mathbf{G}$ was followed using substrate $194 \mathbf{k}(75 \mathrm{mg}$, $0.50 \mathrm{mmol}$ ) and diphenylacetylene (155a) $(178 \mathrm{mg}, 1.00 \mathrm{mmol})$. Purification by column chromatography ( $n$-hexane/EtOAc: 10/1) yielded 176ka (124 mg, 80\%) as a white solid.

M. p.: $160-163^{\circ} \mathrm{C}$.

${ }^{1} \mathrm{H}$ NMR $\left(300 \mathrm{MHz}, \mathrm{CDCl}_{3}\right): \delta=8.09(\mathrm{~d}, J=9.2 \mathrm{~Hz}, 1 \mathrm{H}), 7.44-7.39(\mathrm{~m}, 2 \mathrm{H}), 7.39-7.30(\mathrm{~m}, 5 \mathrm{H})$, 7.25-7.14 (m, 5H), $3.05(\mathrm{~s}, 3 \mathrm{H}), 2.43(\mathrm{~s}, 3 \mathrm{H})$.

${ }^{13} \mathrm{C}$ NMR $\left(75 \mathrm{MHz}, \mathrm{CDCl}_{3}\right): \delta=157.3\left(\mathrm{C}_{\mathrm{q}}\right), 149.5\left(\mathrm{C}_{\mathrm{q}}\right), 141.1\left(\mathrm{C}_{\mathrm{q}}\right), 140.1\left(\mathrm{C}_{\mathrm{q}}\right), 137.7\left(\mathrm{C}_{\mathrm{q}}\right), 136.2\left(\mathrm{C}_{\mathrm{q}}\right)$, 131.4 (CH), $130.2(\mathrm{CH}), 128.7\left(\mathrm{C}_{\mathrm{q}}\right), 128.6(\mathrm{CH}), 128.1(\mathrm{CH}), 127.5(\mathrm{CH}), 127.0(\mathrm{CH}), 126.8(\mathrm{CH}), 125.4$ $(\mathrm{CH}), 125.0(\mathrm{CH}), 124.5\left(\mathrm{C}_{\mathrm{q}}\right), 22.6\left(\mathrm{CH}_{3}\right), 22.1\left(\mathrm{CH}_{3}\right)$.

IR (ATR): $\tilde{v}=3062,1495,1444,1385,1336,1071,1029,813,767,755,696,614 \mathrm{~cm}^{-1}$.

MS (EI) $m / z$ (relative intensity) 309 (40) [M] ${ }^{+}, 308$ (100), 293 (5), 265 (5), 252 (12), 43 (4).

HR-MS (ESI): $m / z$ calcd for $\mathrm{C}_{23} \mathrm{H}_{20} \mathrm{~N}^{+}[\mathrm{M}+\mathrm{H}]^{+} 310.1590$, found 310.1592 .

The spectral data were in accordance with those reported in the literature. ${ }^{255}$

\section{Synthesis of 1-Ethyl-6-fluoro-3,4-diphenylisoquinoline (176la)}<smiles>CCc1nc(-c2ccccc2)c(-c2ccccc2)c2cc(F)ccc12</smiles>
The representative procedure $\mathbf{G}$ was followed using substrate 1941 ( $83 \mathrm{mg}, 0.50$ $\mathrm{mmol}$ ) and diphenyl acetylene (155a) $(178 \mathrm{mg}, 1.00 \mathrm{mmol})$. Purification by column chromatography ( $n$-hexane/EtOAc: $15 / 1 \rightarrow 12 / 1$ ) yielded 176la $(98 \mathrm{mg}$, $60 \%)$ as a white solid. 
M. p.: $141-142^{\circ} \mathrm{C}$.

${ }^{1} \mathrm{H}$ NMR $\left(300 \mathrm{MHz}, \mathrm{CDCl}_{3}\right): \delta=8.27(\mathrm{dd}, J=9.2,5.7 \mathrm{~Hz}, 1 \mathrm{H}), 7.45-7.10(\mathrm{~m}, 12 \mathrm{H}), 3.42(\mathrm{q}, J=7.5 \mathrm{~Hz}$, $2 \mathrm{H}), 1.53(\mathrm{t}, J=7.5 \mathrm{~Hz}, 3 \mathrm{H})$.

${ }^{13} \mathrm{C} \mathrm{NMR}\left(75 \mathrm{MHz}, \mathrm{CDCl}_{3}\right): \delta=163.0\left(\mathrm{~d},{ }^{1} J_{\mathrm{C}-\mathrm{F}}=245 \mathrm{~Hz}, \mathrm{C}_{\mathrm{q}}\right), 162.0\left(\mathrm{C}_{\mathrm{q}}\right), 150.7\left(\mathrm{C}_{\mathrm{q}}\right), 140.8\left(\mathrm{C}_{\mathrm{q}}\right), 138.4(\mathrm{~d}$, $\left.{ }^{3} J_{\mathrm{C}-\mathrm{F}}=10 \mathrm{~Hz}, \mathrm{C}_{\mathrm{q}}\right), 137.3\left(\mathrm{C}_{\mathrm{q}}\right), 131.2(\mathrm{CH}), 130.3(\mathrm{CH}), 128.7\left(\mathrm{~d},{ }^{4} \mathrm{~J}_{\mathrm{C}-\mathrm{F}}=5 \mathrm{~Hz}, \mathrm{C}_{\mathrm{q}}\right), 128.4(\mathrm{CH}), 128.2(\mathrm{~d}$, $\left.{ }^{3} J_{C-F}=10 \mathrm{~Hz}, \mathrm{CH}\right), 127.6(\mathrm{CH}), 127.3(\mathrm{CH}), 127.1(\mathrm{CH}), 122.5\left(\mathrm{~d},{ }^{4} J_{\mathrm{C}-\mathrm{F}}=1 \mathrm{~Hz}, \mathrm{C}_{\mathrm{q}}\right), 116.6\left(\mathrm{~d},{ }^{2} J_{\mathrm{C}-\mathrm{F}}=25 \mathrm{~Hz}\right.$, $\mathrm{CH}), 110.0\left(\mathrm{~d},{ }^{2} J_{\mathrm{C}-\mathrm{F}}=22 \mathrm{~Hz}, \mathrm{CH}\right), 28.9\left(\mathrm{CH}_{2}\right), 13.9\left(\mathrm{CH}_{3}\right)$.

${ }^{19} \mathrm{~F}$ NMR $\left(282 \mathrm{MHz}, \mathrm{CDCl}_{3}\right): \delta=-107.9(\mathrm{~s})$.

IR (ATR): $\tilde{v}=2973,1619,1573,1447,1386,1182,1072,876,788,753,697 \mathrm{~cm}^{-1}$.

MS (EI) $m / z$ (relative intensity) 327 (53) [M] ${ }^{+}, 326$ (100), 311 (12), 298 (10), 98 (10), 57 (10).

HR-MS (ESI): $\mathrm{m} / z$ calcd for $\mathrm{C}_{23} \mathrm{H}_{19} \mathrm{FN}^{+}[\mathrm{M}+\mathrm{H}]^{+} 328.1496$, found 328.1498 .

\section{Synthesis of 6-(Trifluoromethyl)-1-methyl-3,4-diphenylisoquinoline (176ma)}<smiles>Cc1nc(-c2ccccc2)c(-c2ccccc2)c2cc(C(F)(F)F)ccc12</smiles>
The representative procedure $\mathbf{G}$ was followed using substrate $194 \mathrm{~m}(102 \mathrm{mg}$, $0.50 \mathrm{mmol}$ ) and diphenylacetylene (155a) $(178 \mathrm{mg}, 1.00 \mathrm{mmol})$. Purification by column chromatography ( $n$-hexane/EtOAc: $12 / 1$ ) yielded $176 \mathrm{ma}(86 \mathrm{mg}$, $47 \%)$ as an orange solid.

M. p.: $109-114^{\circ} \mathrm{C}$.

${ }^{1} \mathrm{H}$ NMR $\left(300 \mathrm{MHz}, \mathrm{CDCl}_{3}\right): \delta=8.31(\mathrm{~d}, J=8.8 \mathrm{~Hz}, 1 \mathrm{H}), 7.96(\mathrm{~d}, J=1.8 \mathrm{~Hz}, 1 \mathrm{H})$, $7.75(\mathrm{dd}, J=8.8,1.8 \mathrm{~Hz}, 1 \mathrm{H}), 7.40-7.33(\mathrm{~m}, 5 \mathrm{H}), 7.23-7.16(\mathrm{~m}, 5 \mathrm{H}), 3.10(\mathrm{~s}, 3 \mathrm{H})$.

${ }^{13} \mathrm{C} \mathrm{NMR}\left(75 \mathrm{MHz}, \mathrm{CDCl}_{3}\right): \delta=157.8\left(\mathrm{C}_{\mathrm{q}}\right), 150.9\left(\mathrm{C}_{\mathrm{q}}\right), 140.4\left(\mathrm{C}_{\mathrm{q}}\right), 136.5\left(\mathrm{C}_{\mathrm{q}}\right), 135.4\left(\mathrm{C}_{\mathrm{q}}\right), 131.5\left(\mathrm{q},{ }^{2} \mathrm{~J}_{\mathrm{C}-\mathrm{F}}\right.$ $=32 \mathrm{~Hz}, \mathrm{Cq}), 131.2(\mathrm{CH}), 130.2(\mathrm{CH}), 129.7\left(\mathrm{C}_{\mathrm{q}}\right), 128.5(\mathrm{CH}), 127.7(\mathrm{CH}), 127.6(\mathrm{CH}), 127.3(\mathrm{CH}), 127.0$ $\left(\mathrm{C}_{\mathrm{q}}\right), 126.8(\mathrm{CH}), 123.9\left(\mathrm{q},{ }^{3} \mathrm{~J}_{\mathrm{C}-\mathrm{F}}=5 \mathrm{~Hz}, \mathrm{CH}\right), 123.8\left(\mathrm{~d},{ }^{1} \mathrm{~J}_{\mathrm{C}-\mathrm{F}}=272 \mathrm{~Hz}, \mathrm{C}_{\mathrm{q}}\right), 122.2\left(\mathrm{q},{ }^{3} \mathrm{~J}_{\mathrm{C}-\mathrm{F}}=3 \mathrm{~Hz}, \mathrm{CH}\right)$, $22.8\left(\mathrm{CH}_{3}\right)$.

${ }^{19} \mathrm{~F} \mathrm{NMR}\left(282 \mathrm{MHz}, \mathrm{CDCl}_{3}\right): \delta=-62.9(\mathrm{~s})$.

IR (ATR): $\tilde{v}=2958,1555,1336,1305,1257,1176,1155,1134,1082,909,769,696,618 \mathrm{~cm}^{-1}$.

MS (EI) $m / z$ (relative intensity) 363 (50) [M] ${ }^{+}, 362$ (100), 252 (8), 146 (5), 43 (5).

HR-MS (EI): $\mathrm{m} / z$ calcd for $\mathrm{C}_{23} \mathrm{H}_{1} \mathrm{~F}_{3} \mathrm{~N}^{+}[\mathrm{M}]^{+} 363.1229$, found 363.1219 .

The spectral data were in accordance with those reported in the literature. ${ }^{257}$

\section{Synthesis of 5,6-(Methylenedioxy)-1-methyl-3,4-diphenylisoquinoline (176na)}

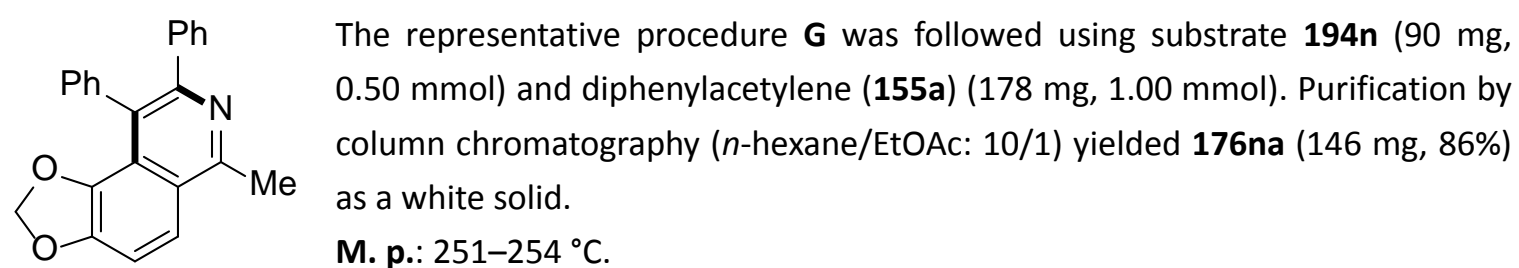

${ }^{1} \mathrm{H}$ NMR $\left(300 \mathrm{MHz}, \mathrm{CDCl}_{3}\right): \delta=7.82(\mathrm{~d}, J=8.8 \mathrm{~Hz}, 1 \mathrm{H}), 7.37-7.06(\mathrm{~m}, 11 \mathrm{H}), 5.83(\mathrm{~s}, 2 \mathrm{H}), 2.99(\mathrm{~s}, 3 \mathrm{H})$.

${ }^{13} \mathrm{C} \mathrm{NMR}\left(75 \mathrm{MHz}, \mathrm{CDCl}_{3}\right): \delta=157.7\left(\mathrm{C}_{\mathrm{q}}\right), 150.2\left(\mathrm{C}_{\mathrm{q}}\right), 147.6\left(\mathrm{C}_{\mathrm{q}}\right), 141.7\left(\mathrm{C}_{\mathrm{q}}\right), 140.8\left(\mathrm{C}_{\mathrm{q}}\right), 138.4\left(\mathrm{C}_{\mathrm{q}}\right)$, $131.1(\mathrm{CH}), 130.2(\mathrm{CH}), 127.5(\mathrm{CH}), 127.0(\mathrm{CH}), 126.8(\mathrm{CH}), 126.7(\mathrm{CH}), 124.8\left(\mathrm{C}_{\mathrm{q}}\right), 123.2\left(\mathrm{C}_{\mathrm{q}}\right), 122.5$ $\left(\mathrm{C}_{\mathrm{q}}\right), 120.9(\mathrm{CH}), 110.8(\mathrm{CH}), 101.4\left(\mathrm{CH}_{2}\right), 23.4\left(\mathrm{CH}_{3}\right)$. IR (ATR): $\tilde{v}=2899,1626,1549,1512,1432,1383,1353,1279,1209,1119,1049,794 \mathrm{~cm}^{-1}$. MS (EI) $m / z$ (relative intensity) 339 (100) [M] , 338 (98), 310 (18), 292 (14), 176 (5).

HR-MS (EI): $m / z$ calcd for $\mathrm{C}_{23} \mathrm{H}_{17} \mathrm{NO}_{2}{ }^{+}[\mathrm{M}]^{+} 339.1254$, found 339.1252 . 


\section{Synthesis of 1,7-Dimethyl-3,4-diphenylisoquinoline (1760a)}

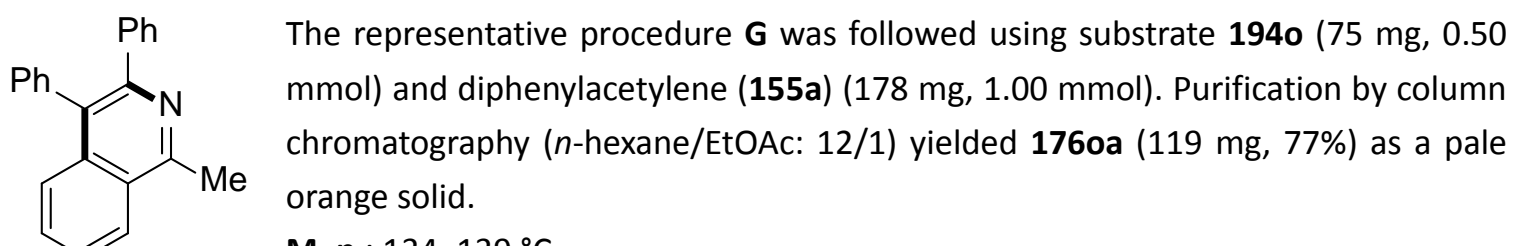
M. p.: $134-139^{\circ} \mathrm{C}$.

${ }^{1}{ }^{H}$ NMR $\left(300 \mathrm{MHz}, \mathrm{CDCl}_{3}\right): \delta=7.96(\mathrm{dq}, J=1.8,0.9 \mathrm{~Hz}, 1 \mathrm{H}), 7.57(\mathrm{~d}, J=8.6 \mathrm{~Hz}, 1 \mathrm{H})$, 7.45-7.30 (m, 6H), 7.26-7.14 (m, 5H), $3.06(\mathrm{~s}, 3 \mathrm{H}), 2.57(\mathrm{~s}, 3 \mathrm{H})$.

${ }^{13} \mathrm{C} \mathrm{NMR}\left(75 \mathrm{MHz}, \mathrm{CDCl}_{3}\right): \delta=156.9\left(\mathrm{C}_{\mathrm{q}}\right), 148.6\left(\mathrm{C}_{\mathrm{q}}\right), 141.0\left(\mathrm{C}_{\mathrm{q}}\right), 137.7\left(\mathrm{C}_{\mathrm{q}}\right), 136.3\left(\mathrm{C}_{\mathrm{q}}\right), 134.1\left(\mathrm{C}_{\mathrm{q}}\right)$, $132.0(\mathrm{CH}), 131.3(\mathrm{CH}), 130.2(\mathrm{CH}), 129.0\left(\mathrm{C}_{\mathrm{q}}\right), 128.1(\mathrm{CH}), 127.5(\mathrm{CH}), 127.0(\mathrm{CH}), 126.7(\mathrm{CH}), 126.2$ $\left(\mathrm{C}_{\mathrm{q}}\right), 126.0(\mathrm{CH}), 124.4(\mathrm{CH}), 22.7(\mathrm{CH} 3), 21.8\left(\mathrm{CH}_{3}\right)$. IR (ATR): $\tilde{v}=3023,2914,1551,1504,1442,1386,1321,1073,1027,831 \mathrm{~cm}^{-1}$. MS (EI) $m / z$ (relative intensity) 309 (65) [M] ${ }^{+}, 293$ (8), 265 (5), 252 (15), 146 (5), 100 (100). HR-MS (ESI): $m / z$ calcd for $\mathrm{C}_{23} \mathrm{H}_{20} \mathrm{~N}^{+}[\mathrm{M}+\mathrm{H}]^{+} 310.1590$, found 310.1592 . The spectral data were in accordance with those reported in the literature. ${ }^{258}$

\section{Synthesis of 1-Methyl-3,4-di-n-propylisoquinoline (176ad)}

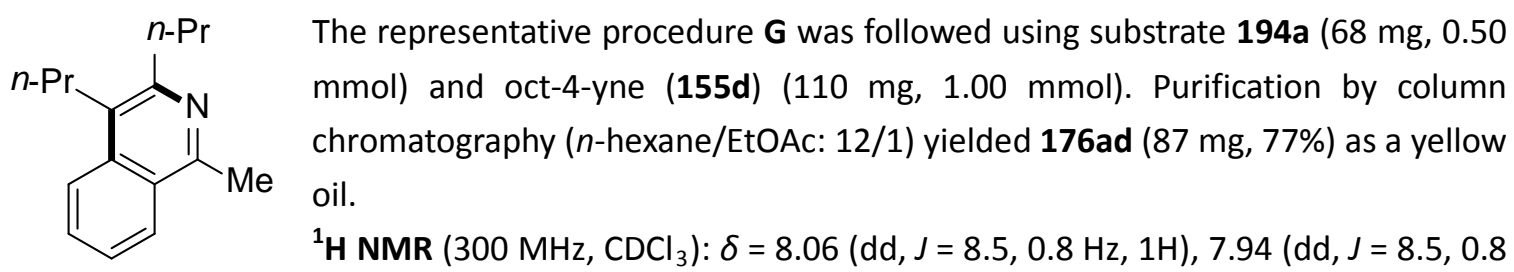
$\mathrm{Hz}, 1 \mathrm{H}$ ), 7.3 (ddd, $J=8.2,6.9,1.2 \mathrm{~Hz}, 1 \mathrm{H}), 7.47$ (ddd, $J=8.2,6.9,1.2 \mathrm{~Hz}, 1 \mathrm{H}), 3.01-2.92(\mathrm{~m}, 2 \mathrm{H})$, 2.92-2.84 (m, 2H), $2.89(\mathrm{~s}, 3 \mathrm{H}), 1.84-1.72(\mathrm{~m}, 2 \mathrm{H}), 1.71-1.58(\mathrm{~m}, 2 \mathrm{H}), 1.07(\mathrm{t}, J=6.7 \mathrm{~Hz}, 3 \mathrm{H}), 1.03(\mathrm{t}, J$ $=7.1 \mathrm{~Hz}, 3 \mathrm{H})$.

${ }^{13} \mathrm{C}$ NMR $\left(75 \mathrm{MHz}, \mathrm{CDCl}_{3}\right): \delta=155.6\left(\mathrm{C}_{\mathrm{q}}\right), 151.7\left(\mathrm{C}_{\mathrm{q}}\right), 135.4\left(\mathrm{C}_{\mathrm{q}}\right), 129.3(\mathrm{CH}), 126.1\left(\mathrm{C}_{\mathrm{q}}\right), 126.1(\mathrm{CH})$, $126.0\left(\mathrm{C}_{\mathrm{q}}\right), 125.2(\mathrm{CH}), 123.5(\mathrm{CH}), 37.4\left(\mathrm{CH}_{2}\right), 29.8\left(\mathrm{CH}_{2}\right), 24.2\left(\mathrm{CH}_{2}\right), 23.8\left(\mathrm{CH}_{2}\right), 22.4\left(\mathrm{CH}_{3}\right), 14.6$ $\left(\mathrm{CH}_{3}\right), 14.4\left(\mathrm{CH}_{3}\right)$.

IR (neat): $\tilde{v}=2957,2870,1617,1568,1454,1391,1333,1027,754,614 \mathrm{~cm}^{-1}$.

MS (EI) m/z (relative intensity) 227 (40) [M] ${ }^{+}, 212$ (80), 198 (100), 184 (50), 171 (55), 128 (23), 115 (16).

HR-MS (EI): $m / z$ calcd for $\mathrm{C}_{16} \mathrm{H}_{21} \mathrm{~N}^{+}[\mathrm{M}]^{+}$227.1669, found 227.1674.

The spectral data were in accordance with those reported in the literature..$^{255}$

\section{Synthesis of 4-n-Butyl-3-(4-methoxyphenyl)-1-methylisoquinoline (176ae)}<smiles>CCC(C)Cc1c(-c2ccc(OC)cc2)nc(C)c2ccccc12</smiles>

The representative procedure $\mathbf{G}$ was followed using substrate $194 \mathrm{a}(68 \mathrm{mg}, 0.50$ $\mathrm{mmol})$ and 1-( $p$-tolyl)-1-hexyne (155e) $(172 \mathrm{mg}, 1.00 \mathrm{mmol})$. Purification by column chromatography ( $n$-hexane/EtOAc: $12 / 1$ ) yielded 176ae (70 mg, $46 \%$ ) as an orange oil.

${ }^{1} \mathrm{H}$ NMR $\left(300 \mathrm{MHz}, \mathrm{CDCl}_{3}\right): \delta=8.14(\mathrm{dd}, J=8.6,0.9 \mathrm{~Hz}, 1 \mathrm{H}), 8.04(\mathrm{dt}, J=8.6,0.9$ 
$\mathrm{Hz}, 1 \mathrm{H}), 7.70$ (ddd, $J=8.3,6.8,1.3 \mathrm{~Hz}, 1 \mathrm{H}), 7.56$ (ddd, $J=8.3,6.8,1.2 \mathrm{~Hz}, 1 \mathrm{H}), 7.39(\mathrm{~d}, J=8.1 \mathrm{~Hz}, 2 \mathrm{H})$, $7.25(\mathrm{~d}, J=8.1 \mathrm{~Hz}, 2 \mathrm{H}), 3.03-2.91(\mathrm{~m}, 2 \mathrm{H}), 2.95(\mathrm{~s}, 3 \mathrm{H}), 2.41(\mathrm{~s}, 3 \mathrm{H}), 1.70-1.56(\mathrm{~m}, 2 \mathrm{H}), 1.34(\mathrm{dt}, J=$ 7.3, 7.3 Hz, 2H), $0.86(t, J=7.3 \mathrm{~Hz}, 3 \mathrm{H})$.

${ }^{13} \mathrm{C}$ NMR $\left(75 \mathrm{MHz}, \mathrm{CDCl}_{3}\right): \delta=155.6\left(\mathrm{C}_{\mathrm{q}}\right), 150.9\left(\mathrm{C}_{\mathrm{q}}\right), 139.0\left(\mathrm{C}_{\mathrm{q}}\right), 136.9\left(\mathrm{C}_{\mathrm{q}}\right), 135.4\left(\mathrm{C}_{\mathrm{q}}\right), 129.6(\mathrm{CH})$, $129.1(\mathrm{CH}), 128.7(\mathrm{CH}), 127.2\left(\mathrm{C}_{\mathrm{q}}\right), 126.5\left(\mathrm{C}_{\mathrm{q}}\right), 126.2(\mathrm{CH}), 126.0(\mathrm{CH}), 124.2(\mathrm{CH}), 33.4\left(\mathrm{CH}_{2}\right), 28.3$ $\left(\mathrm{CH}_{2}\right), 23.0\left(\mathrm{CH}_{2}\right), 22.5\left(\mathrm{CH}_{3}\right), 21.2\left(\mathrm{CH}_{3}\right), 13.8\left(\mathrm{CH}_{3}\right)$.

IR (neat): $\tilde{v}=2955,2923,2869,1614,1563,1513,1438,1391,1333,1026,825,755 \mathrm{~cm}^{-1}$.

MS (EI) m/z (relative intensity) 289 (50) [M] , 260 (70), 246 (100), 231 (30), 216 (8).

HR-MS (EI): $m / z$ calcd for $\mathrm{C}_{21} \mathrm{H}_{23} \mathrm{NO}^{+}[\mathrm{M}]^{+} 305.1774$, found 305.1771.

\section{Synthesis of 4-(4-Chloro-n-butyl)-1-methyl-3-phenylisoquinoline (176af)}<smiles>Cc1nc(-c2ccccc2)c(CCCCCl)c2ccccc12</smiles>
The representative procedure $\mathbf{G}$ was followed using substrate 194a (68 $\mathrm{mg}, 0.50 \mathrm{mmol}$ ) and 6-chloro-1-phenylhexyne (155f) $(193 \mathrm{mg}, 1.00$ mmol). Purification by column chromatography (n-hexane/EtOAc: $12 / 1$ ) yielded 176af (112 $\mathrm{mg}, 72 \%$ ) as a yellow oil.

${ }^{1}$ H NMR (300 MHz, $\left.\mathrm{CDCl}_{3}\right): \delta=8.16(\mathrm{ddd}, J=8.4,1.3,0.8 \mathrm{~Hz}, 1 \mathrm{H}), 8.04$ (dd, $J=8.4,0.8 \mathrm{~Hz}, 1 \mathrm{H}), 7.73(\mathrm{ddd}, J=8.4,6.9,1.3 \mathrm{~Hz}, 1 \mathrm{H}), 7.59$ (ddd, $J=8.4,6.9,1.3 \mathrm{~Hz}, 1 \mathrm{H}$ ), 7.53-7.34 (m, 5H), $3.42(\mathrm{t}, J=6.2 \mathrm{~Hz}, 2 \mathrm{H}), 3.03-2.95(\mathrm{~m}, 2 \mathrm{H}), 2.97(\mathrm{~s}, 3 \mathrm{H}), 1.86-1.68(\mathrm{~m}, 4 \mathrm{H})$.

${ }^{13} \mathrm{C}$ NMR $\left(75 \mathrm{MHz}, \mathrm{CDCl}_{3}\right): \delta=156.1\left(\mathrm{C}_{\mathrm{q}}\right), 151.1\left(\mathrm{C}_{\mathrm{q}}\right), 141.6\left(\mathrm{C}_{\mathrm{q}}\right), 135.2\left(\mathrm{C}_{\mathrm{q}}\right), 129.9(\mathrm{CH}), 129.2(\mathrm{CH})$, $128.2(\mathrm{CH}), 127.5(\mathrm{CH}), 126.6\left(\mathrm{C}_{\mathrm{q}}\right), 126.4\left(\mathrm{C}_{\mathrm{q}}\right), 126.3(\mathrm{CH}), 126.2(\mathrm{CH}), 124.0(\mathrm{CH}), 44.4\left(\mathrm{CH}_{2}\right), 32.3$ $\left(\mathrm{CH}_{2}\right), 28.1\left(\mathrm{CH}_{2}\right), 27.5\left(\mathrm{CH}_{2}\right), 22.5\left(\mathrm{CH}_{3}\right)$. IR (neat): $\tilde{v}=2953,1614,1561,1504,1437,1391,1331,1027,756 \mathrm{~cm}^{-1}$.

MS (EI) m/z (relative intensity) 311/309 (14/41) [M] ${ }^{+}, 246$ (95), 232 (100), 217 (16), 202 (6), 189 (6). HR-MS (EI): $m / z$ calcd for $\mathrm{C}_{20} \mathrm{H}_{20}{ }^{35} \mathrm{CIN}^{+}[\mathrm{M}]^{+} 309.1279$, found 309.1297.

\subsubsection{Selected NMR Spectra}

nOe 187ba

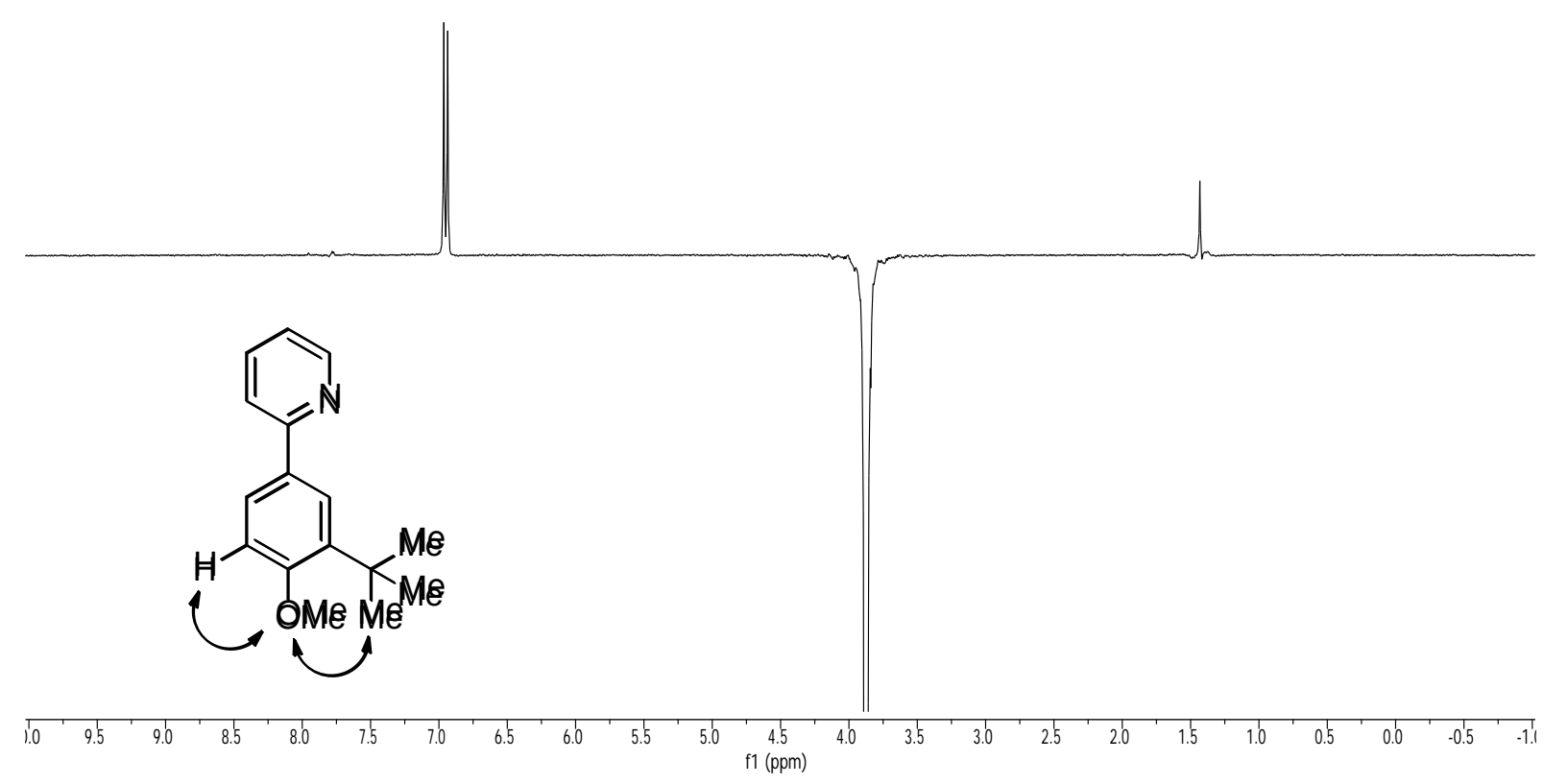




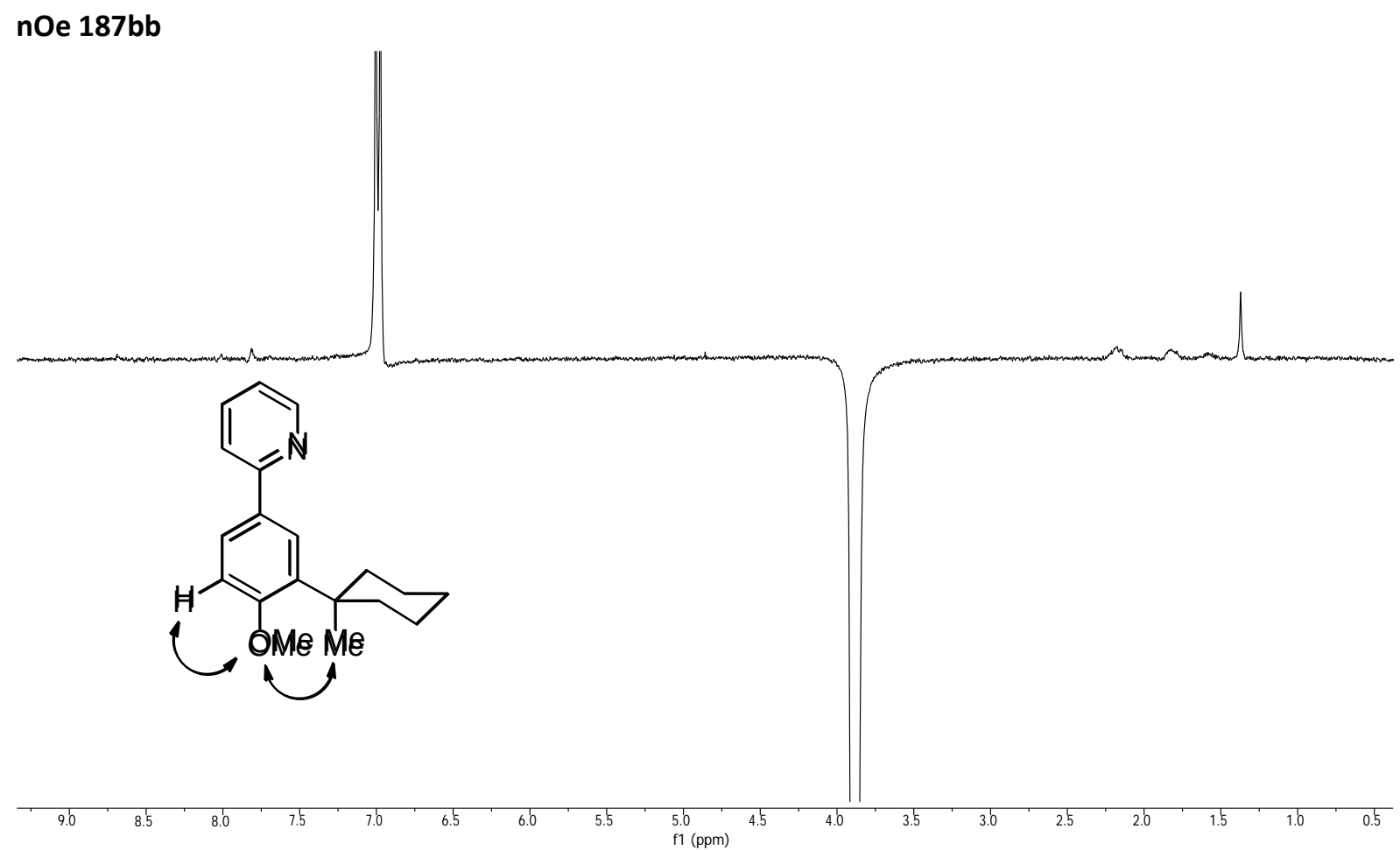

nOe 187bj 


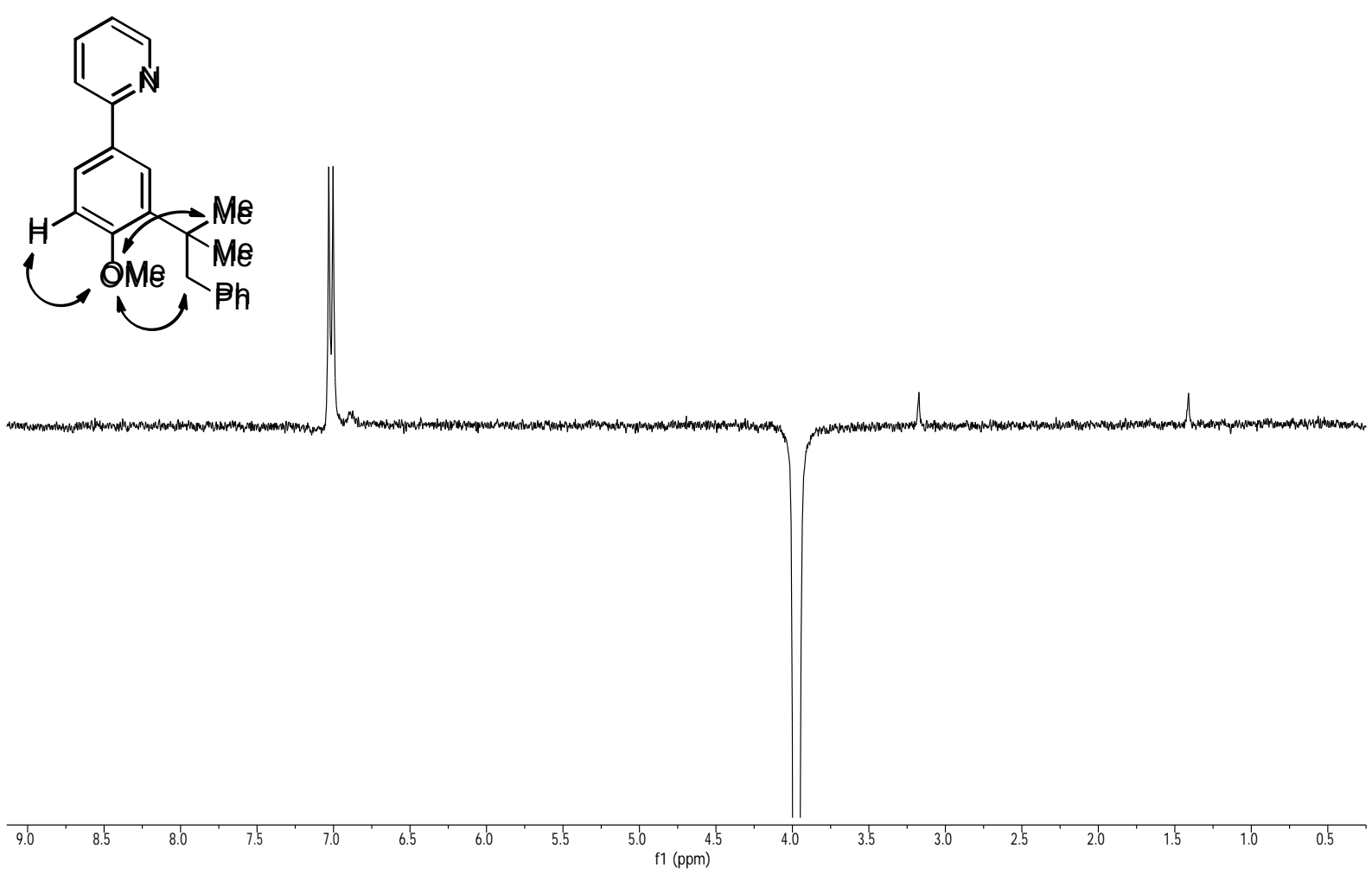

nOe 187aa

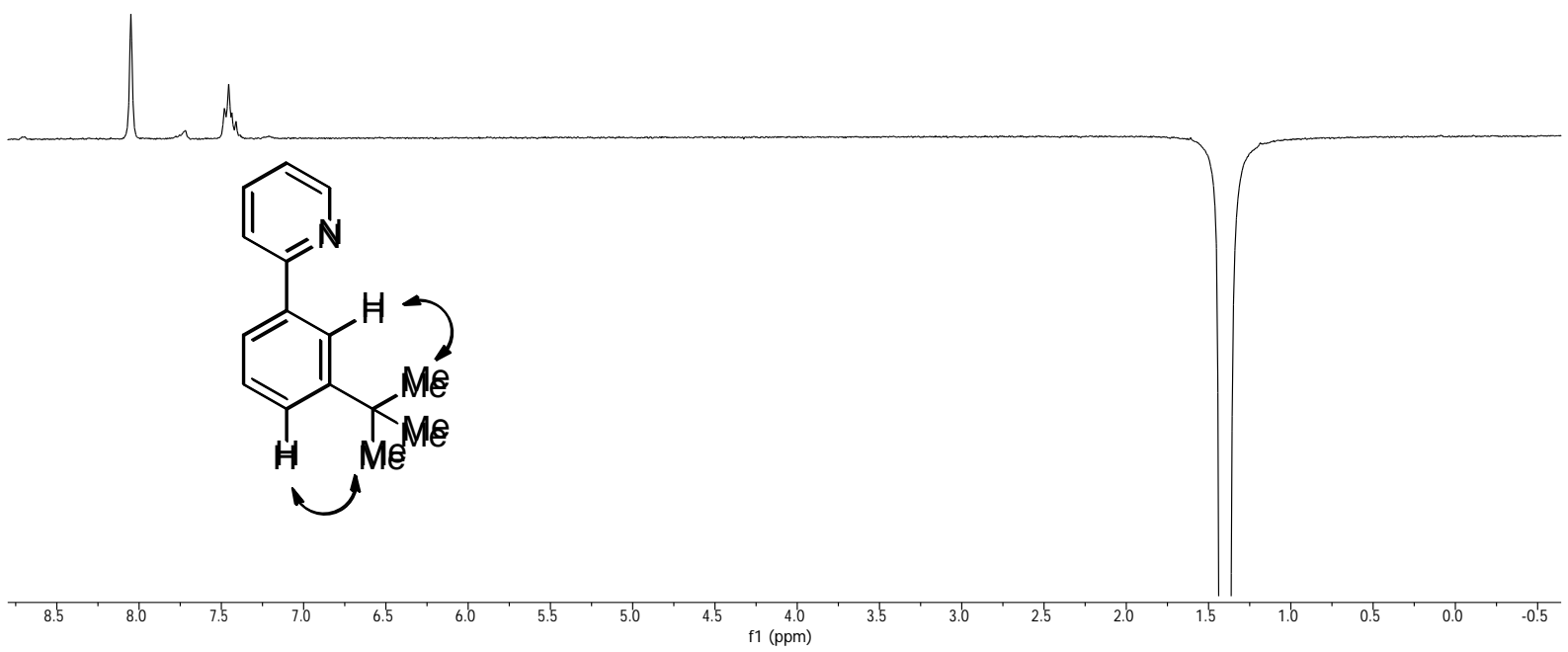


nOe 187da

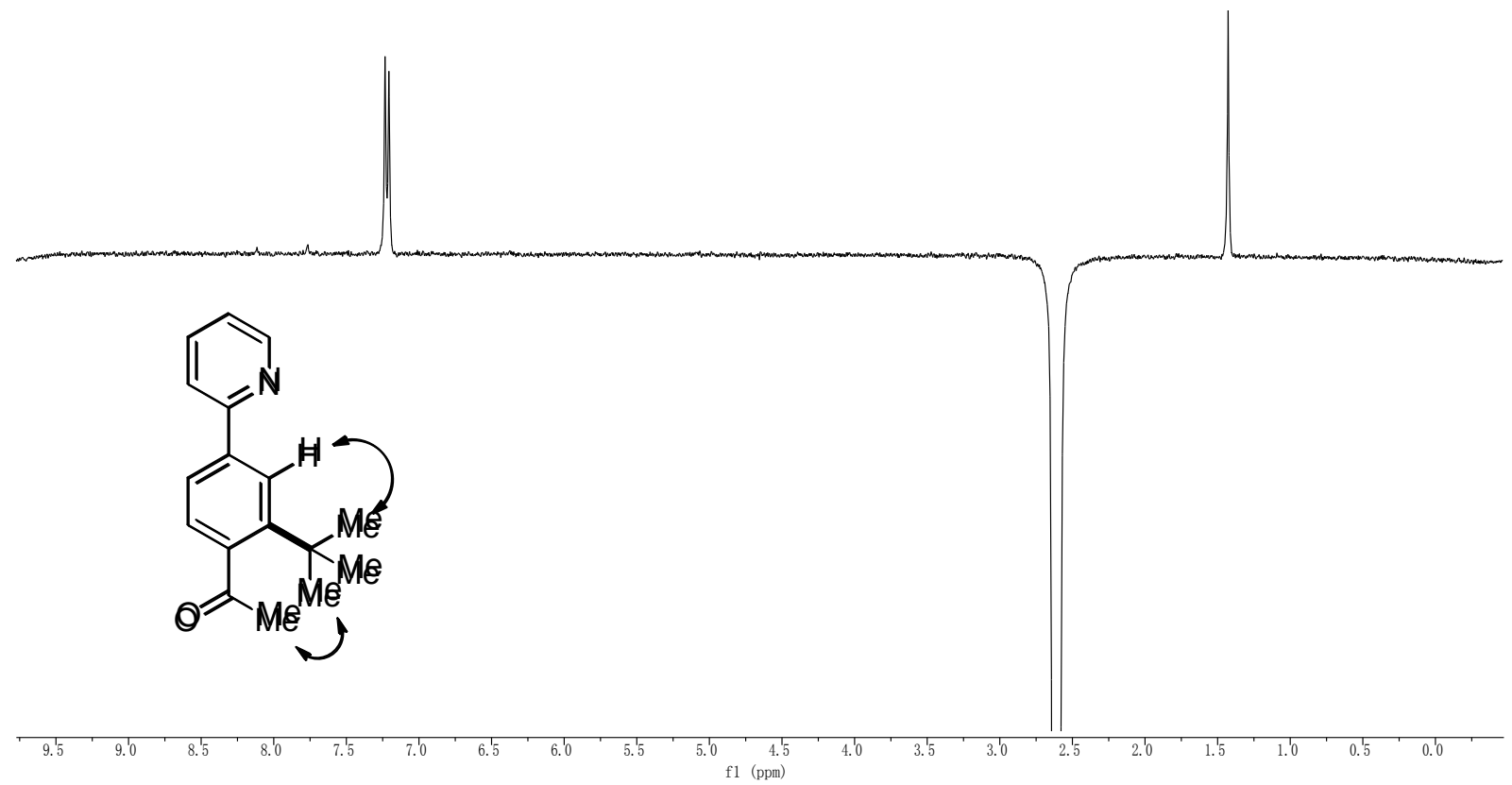

nOe 187ea

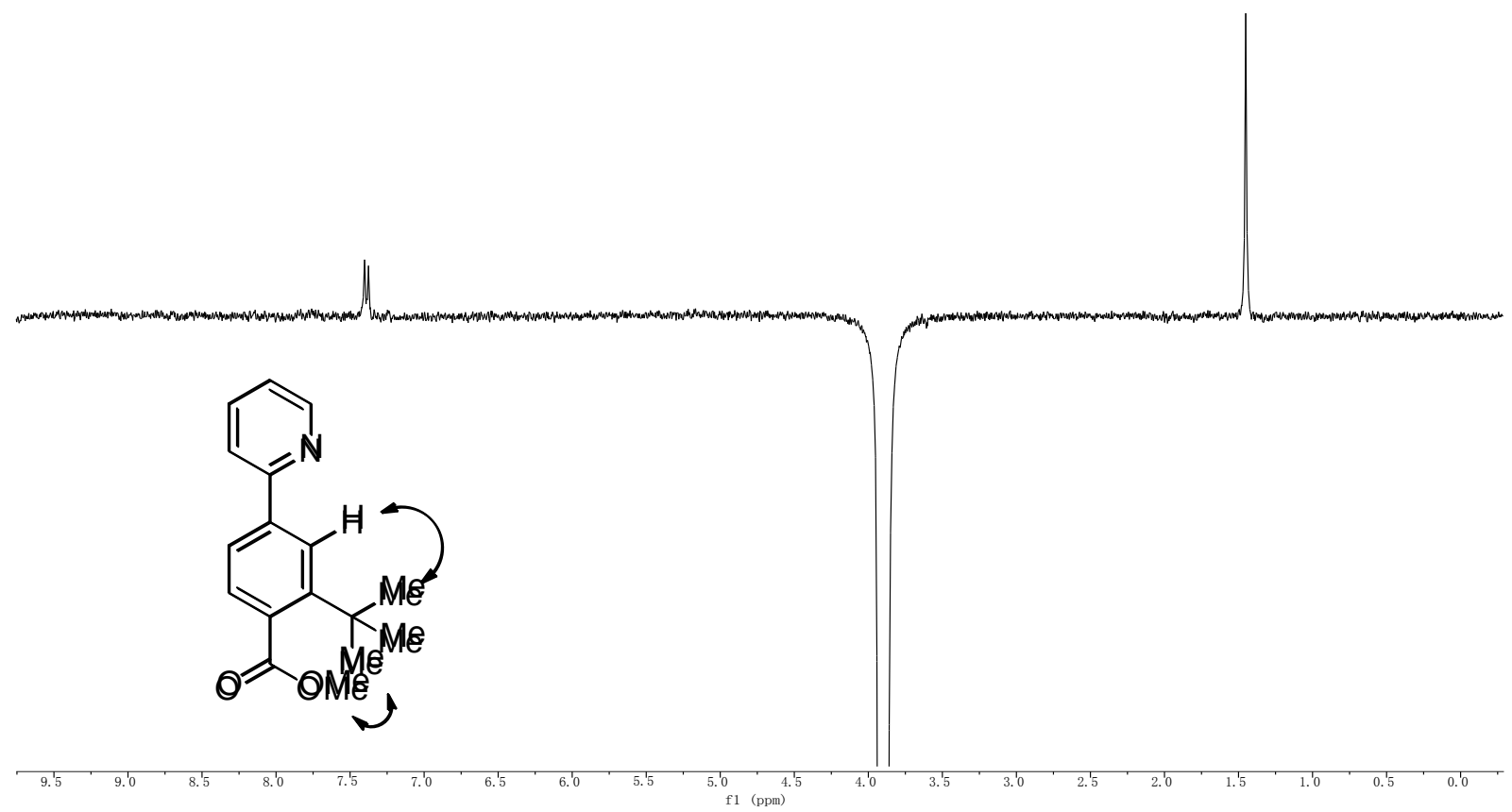

HMBC 187ja 


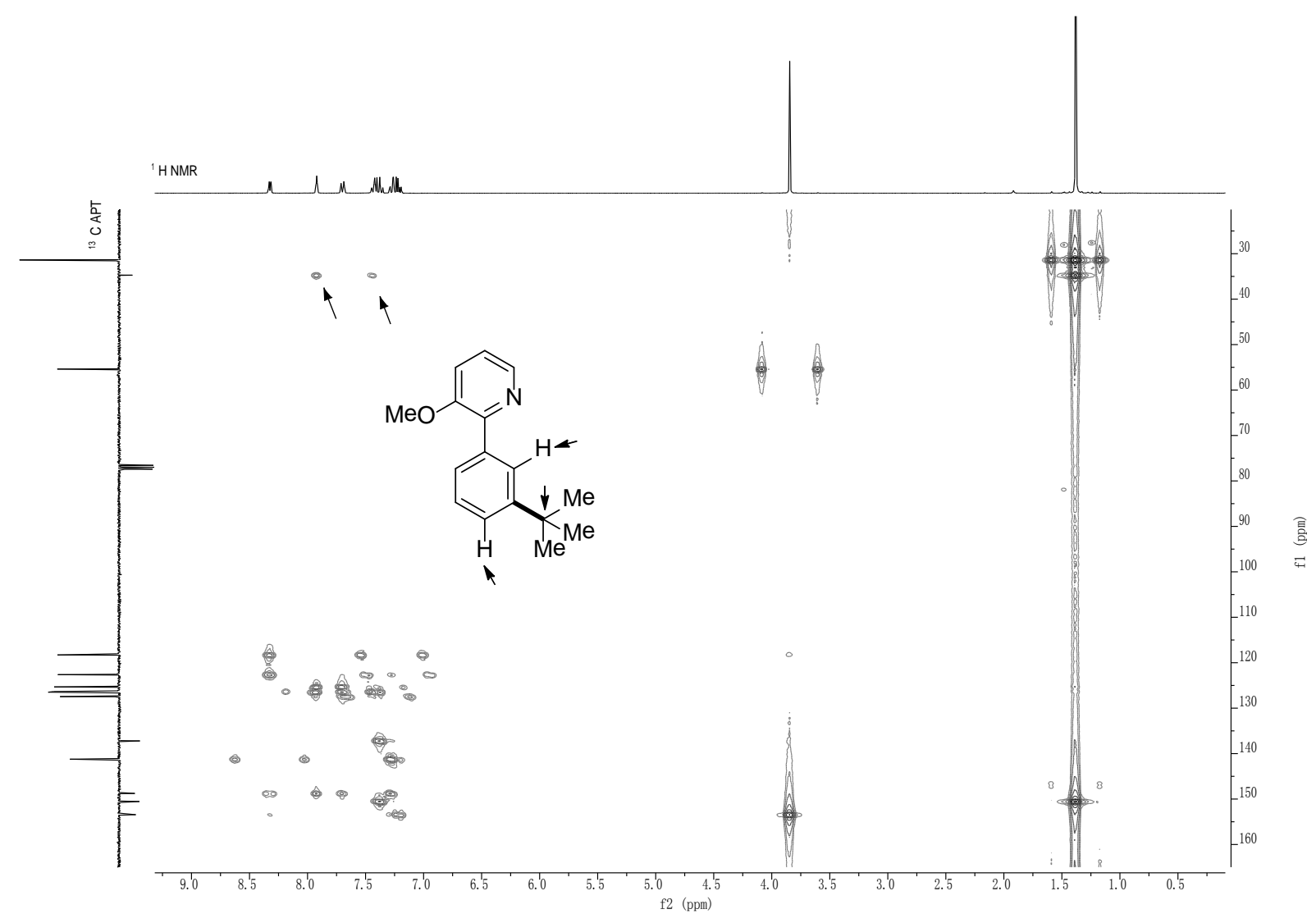

nOe 187qb

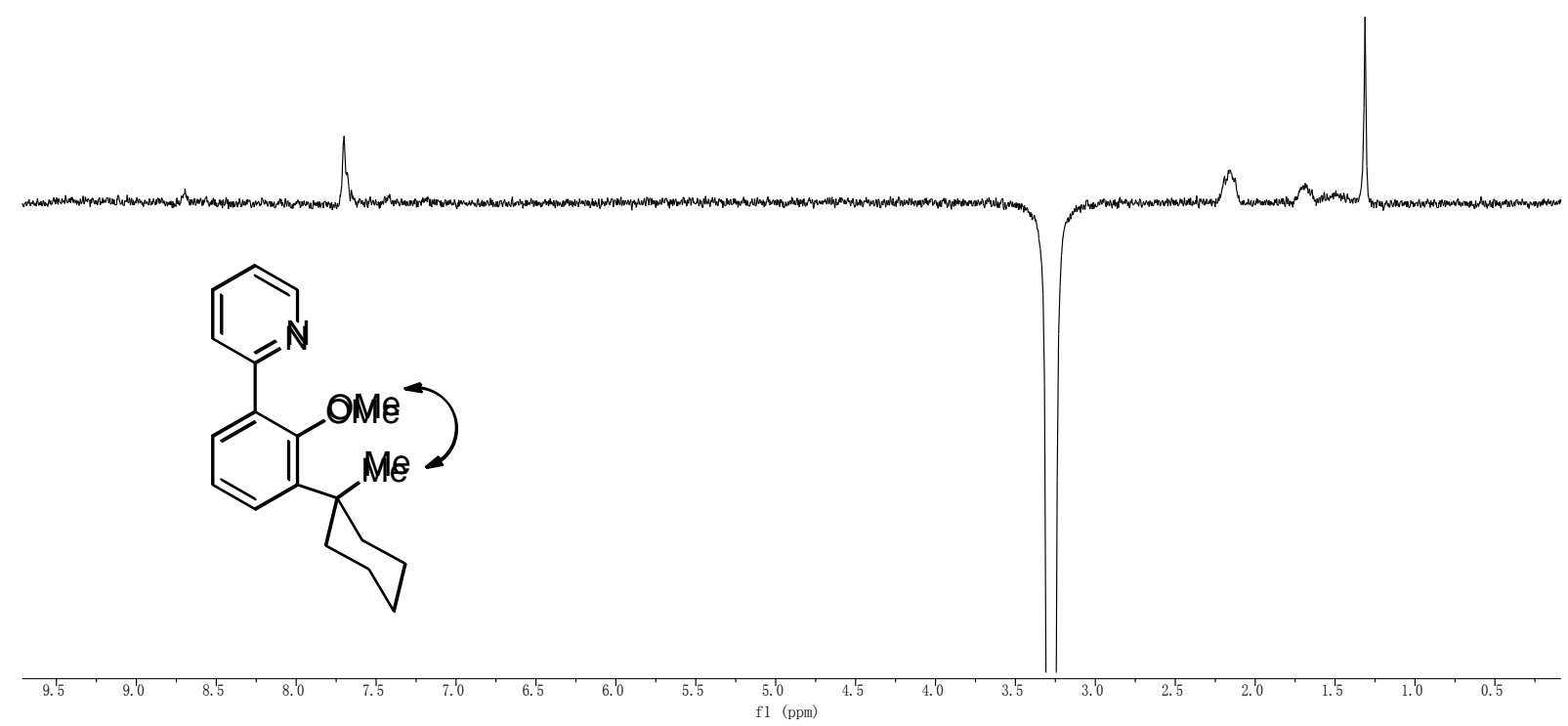


nOe 187rb

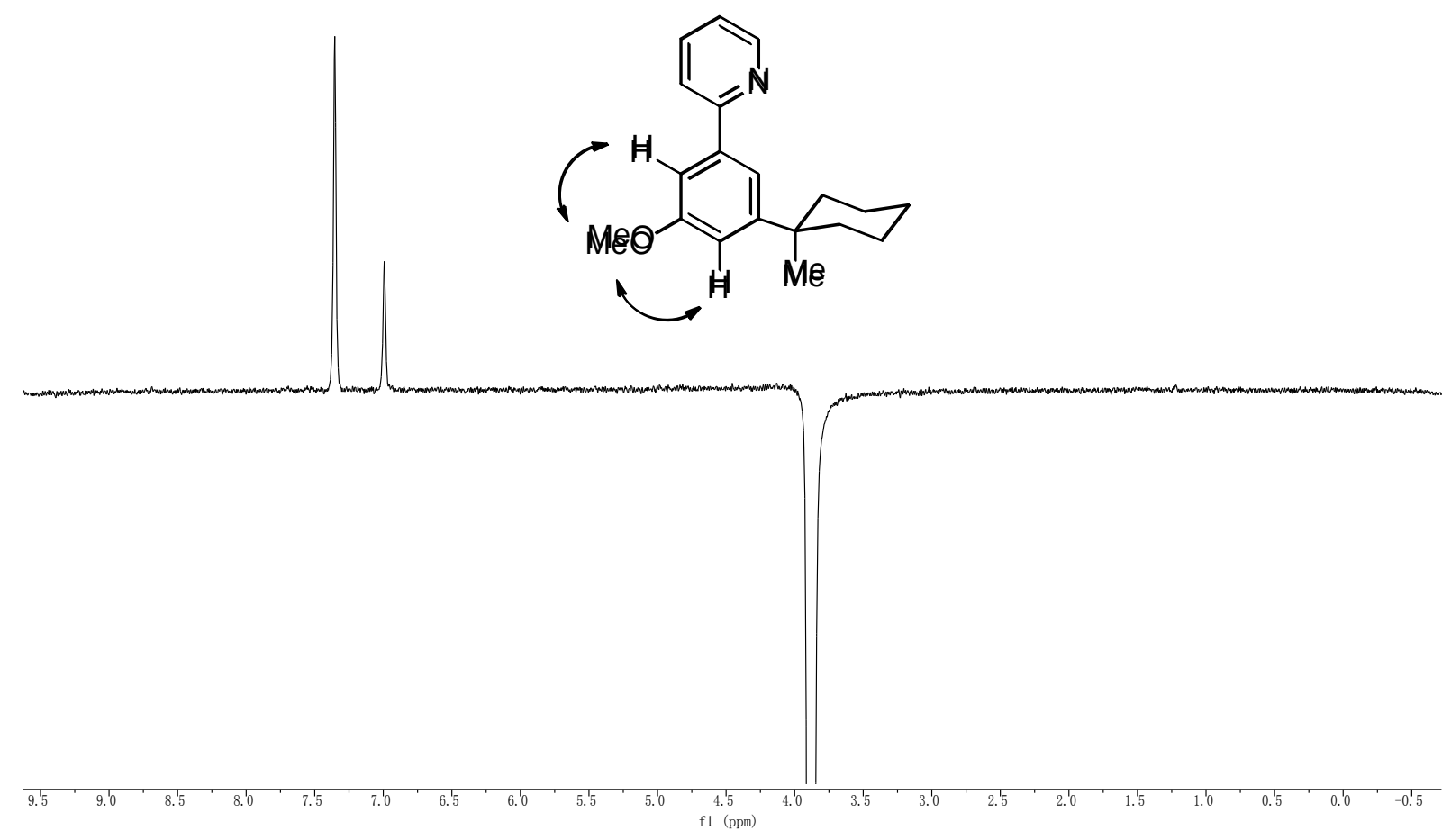

nOe 187ta

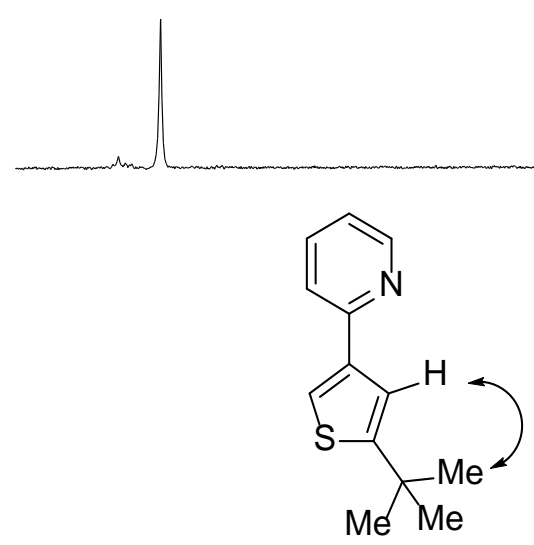

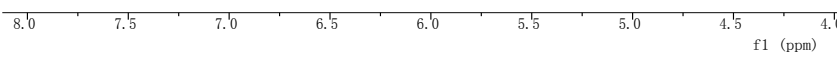

HMBC 187ta 


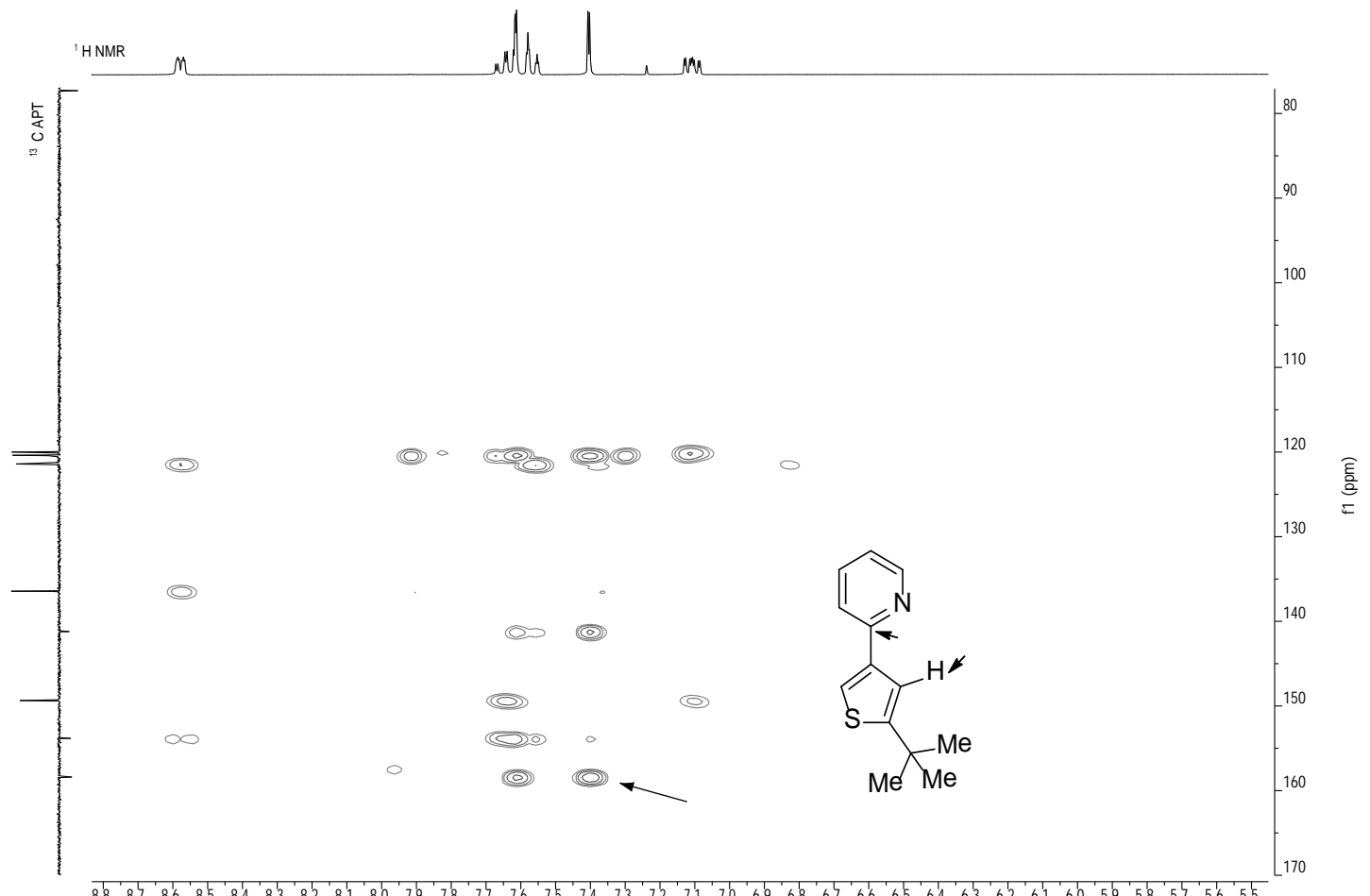

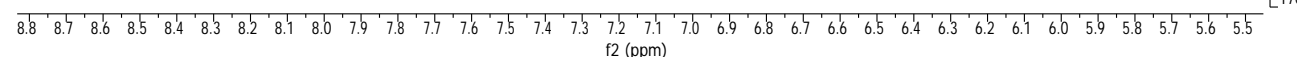

nOe $196 b a$

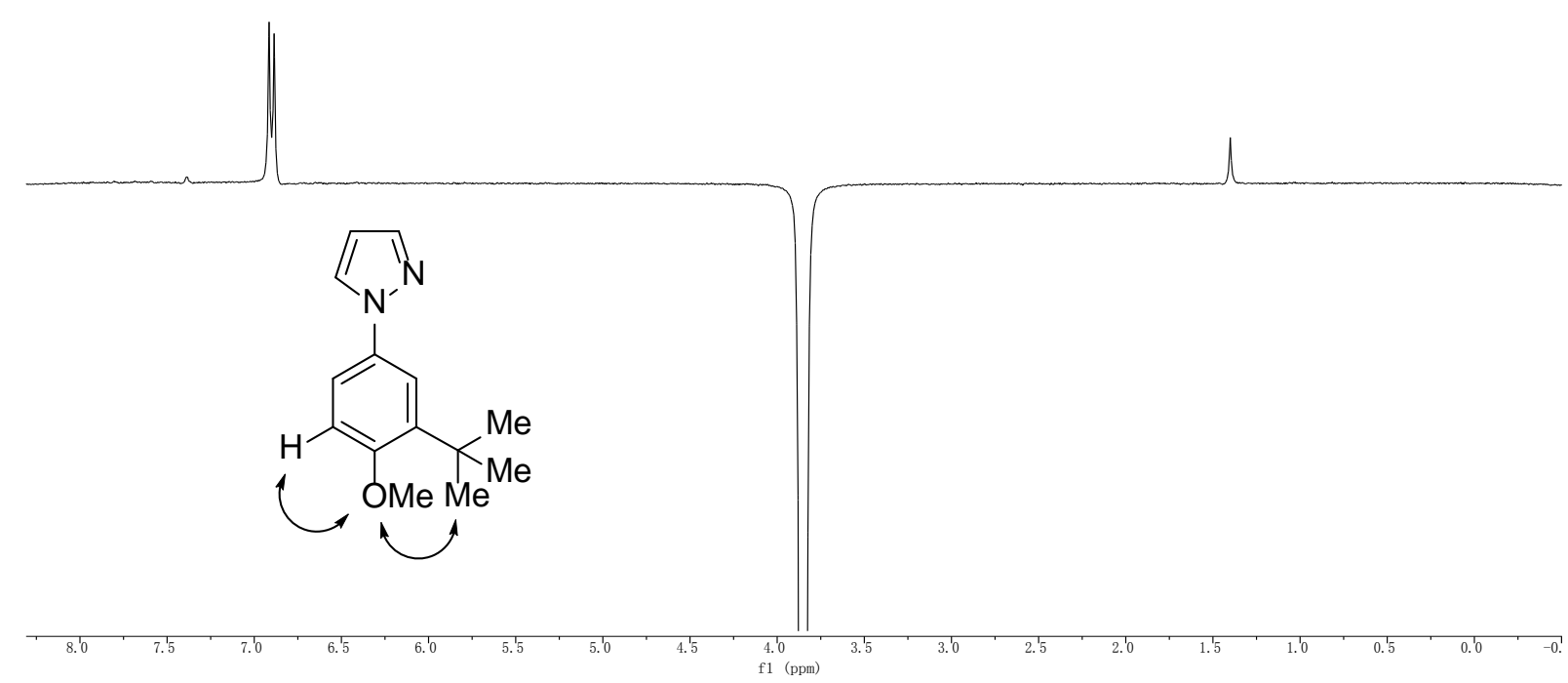


nOe 196ca

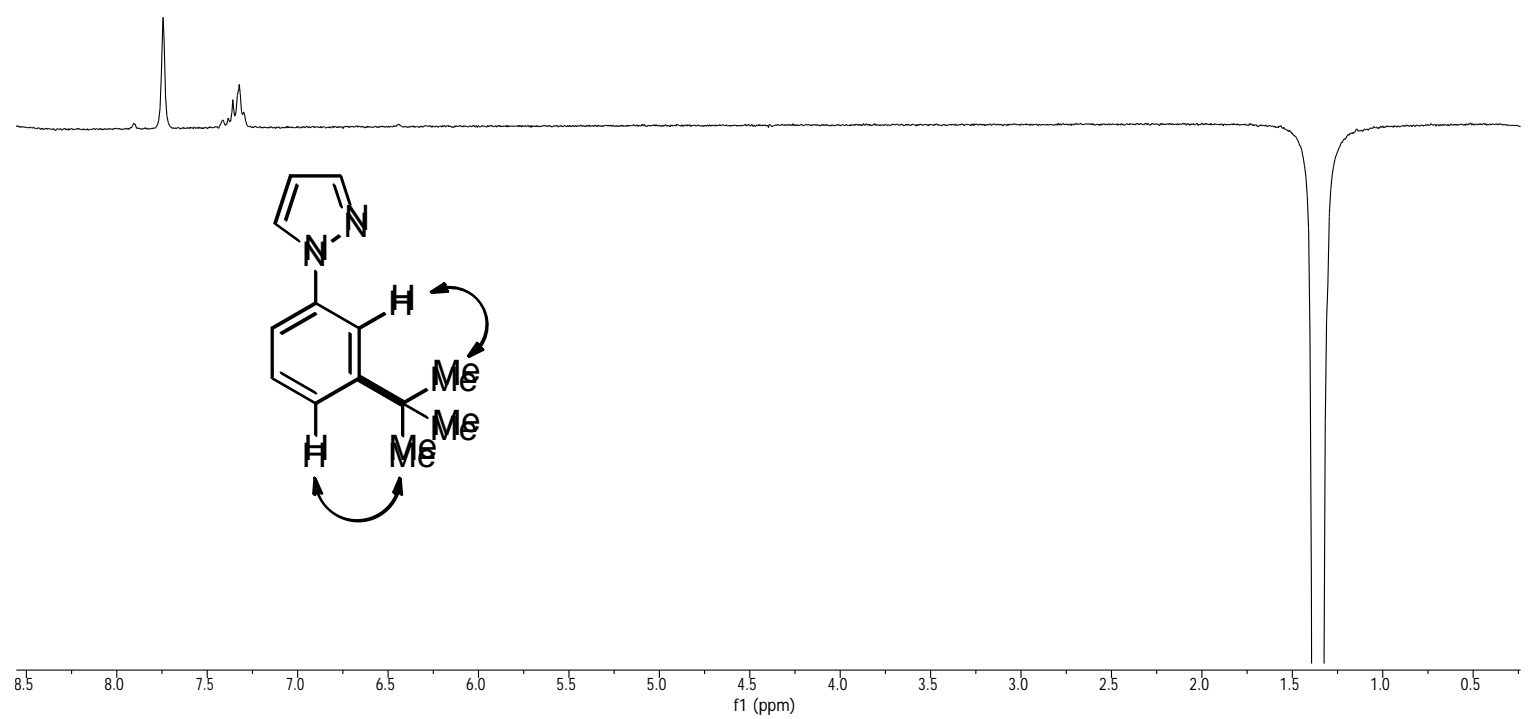

nOe 196eb

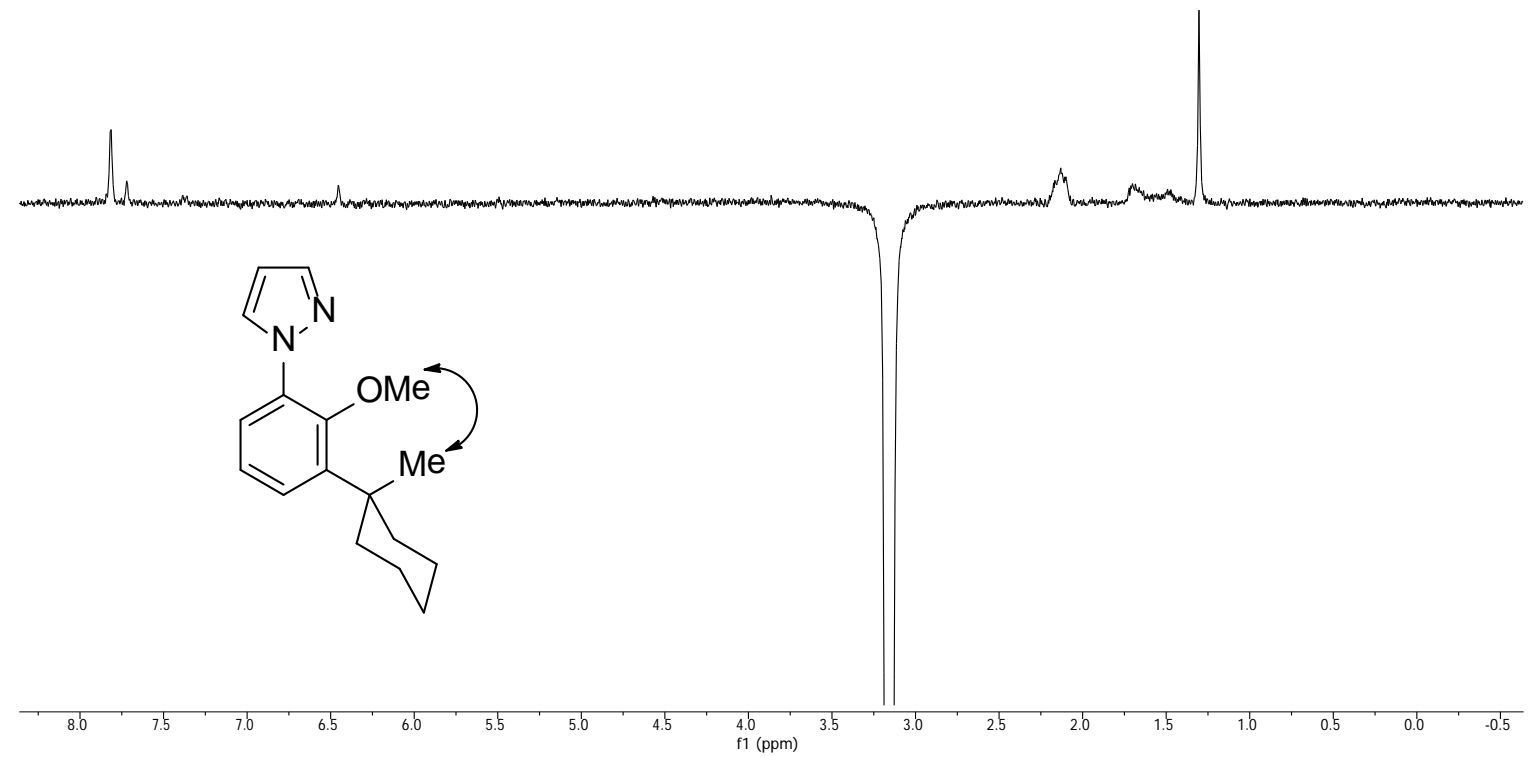


nOe 198aa

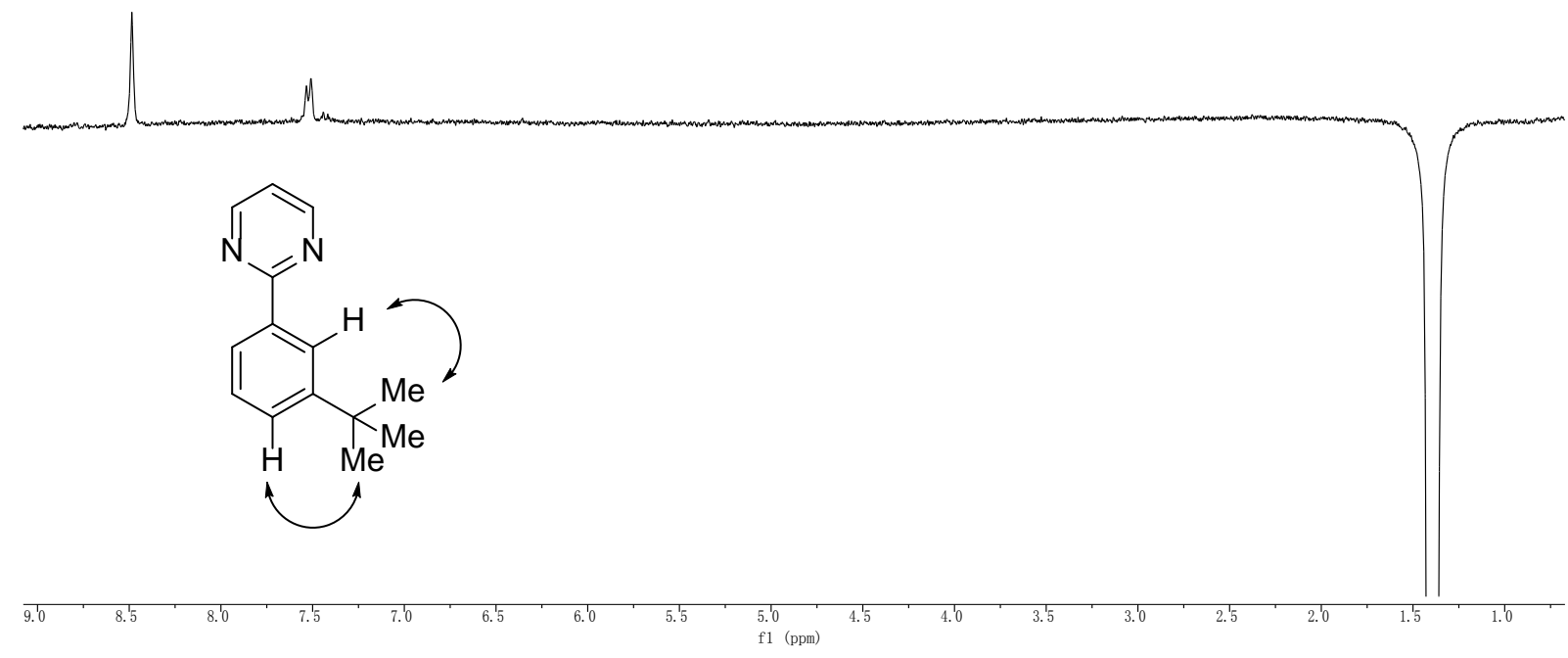

nOe 198ba

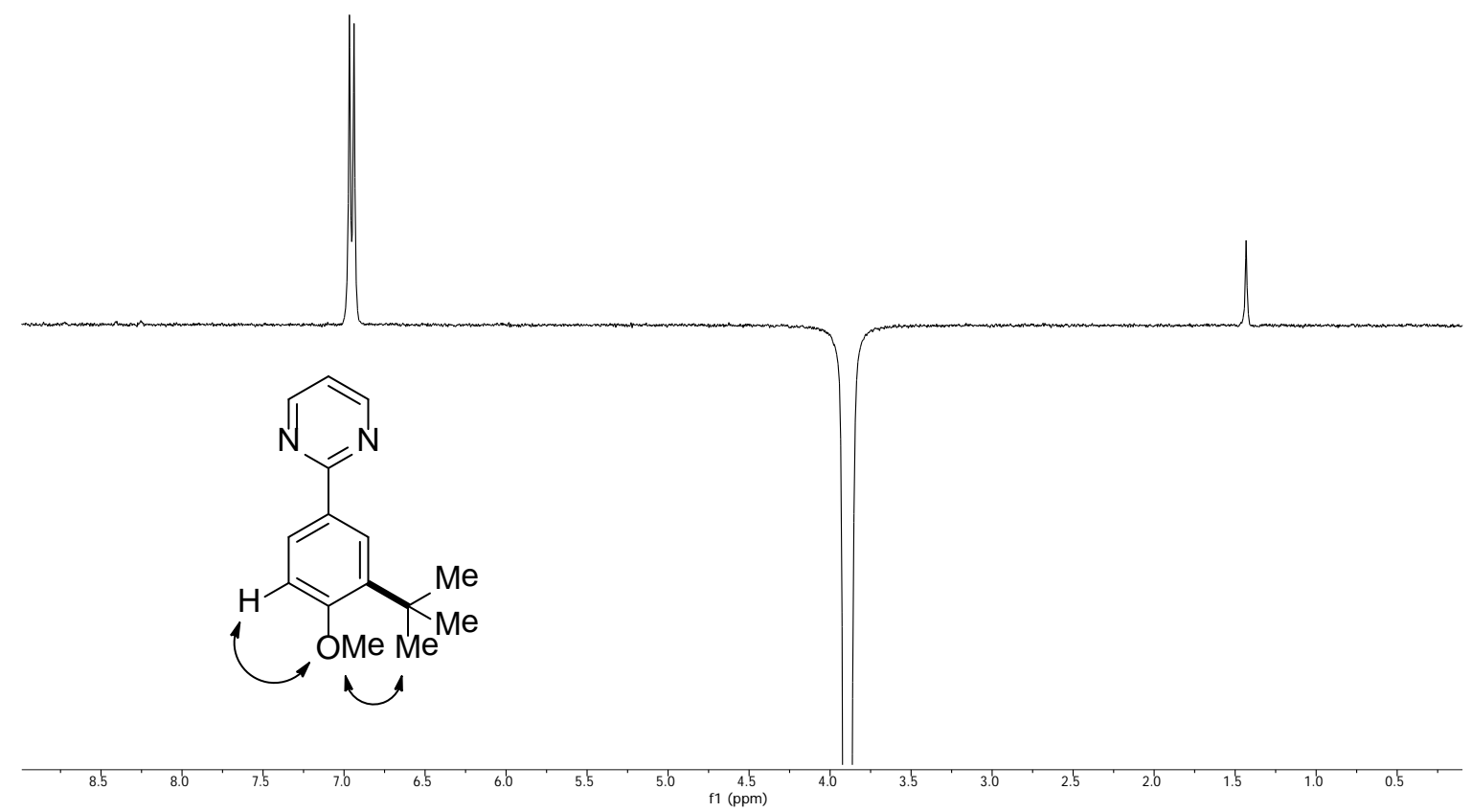




\section{NOESY 189ca}

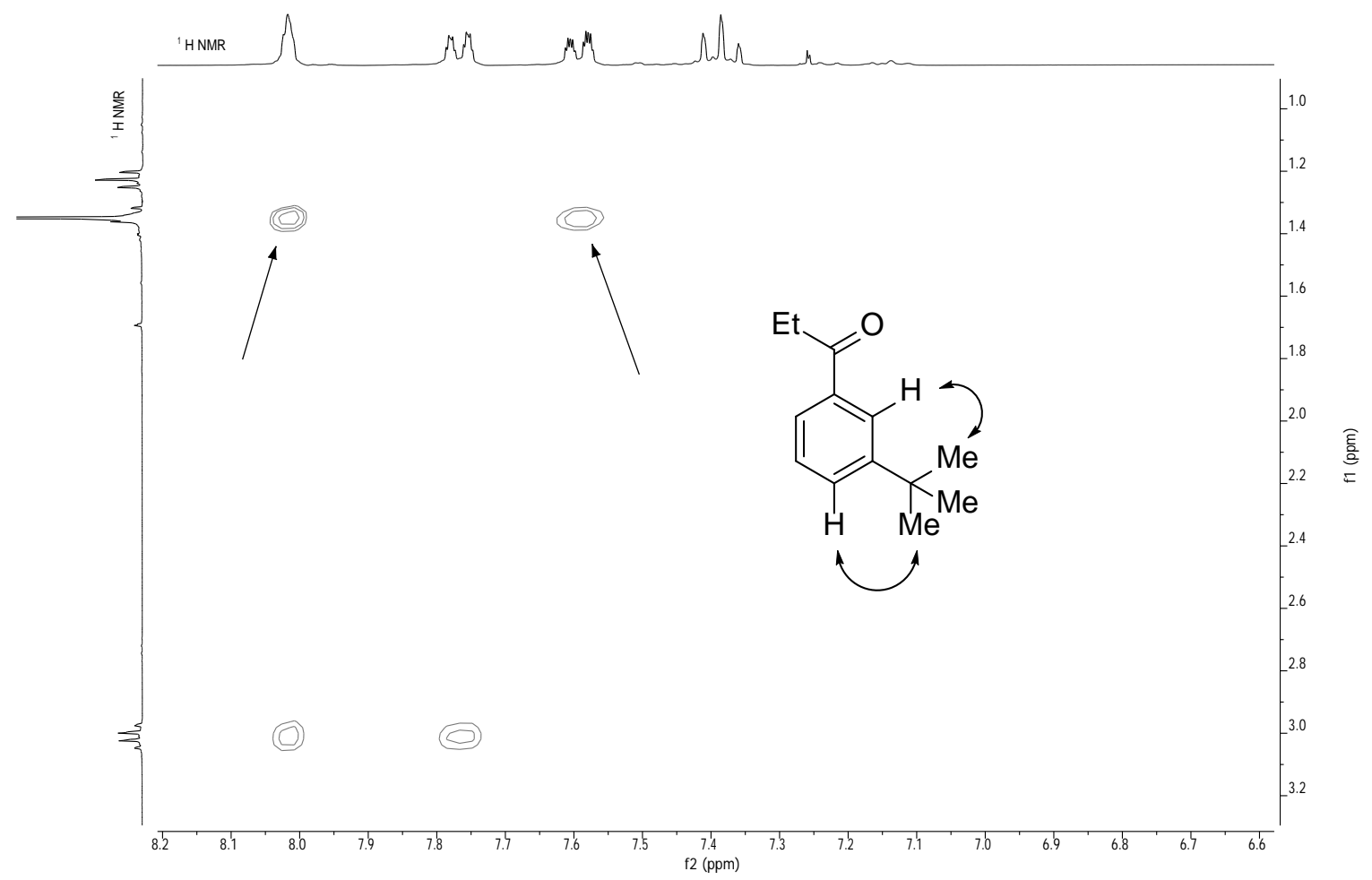

NOESY 189da

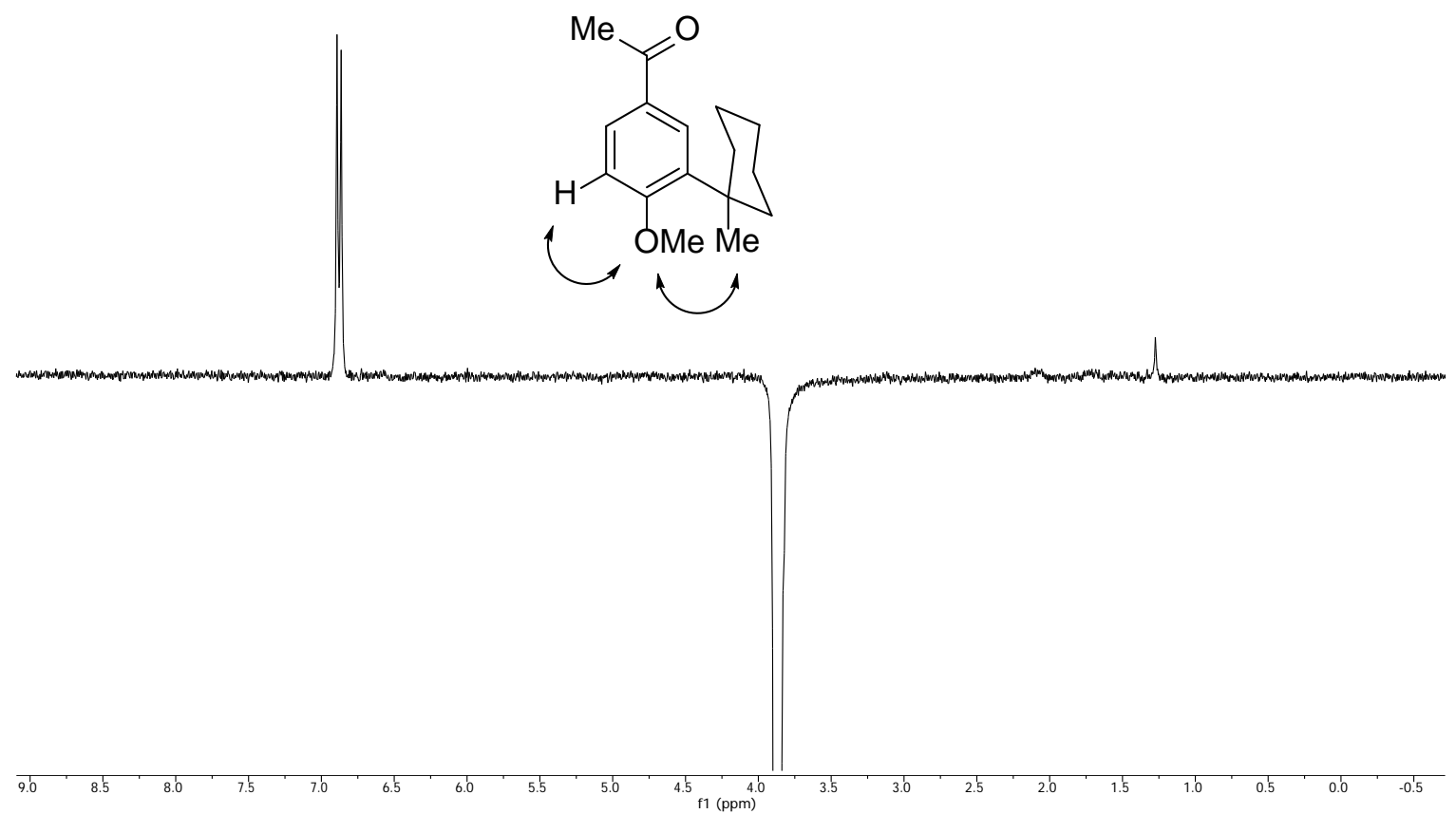

nOe 206ee 


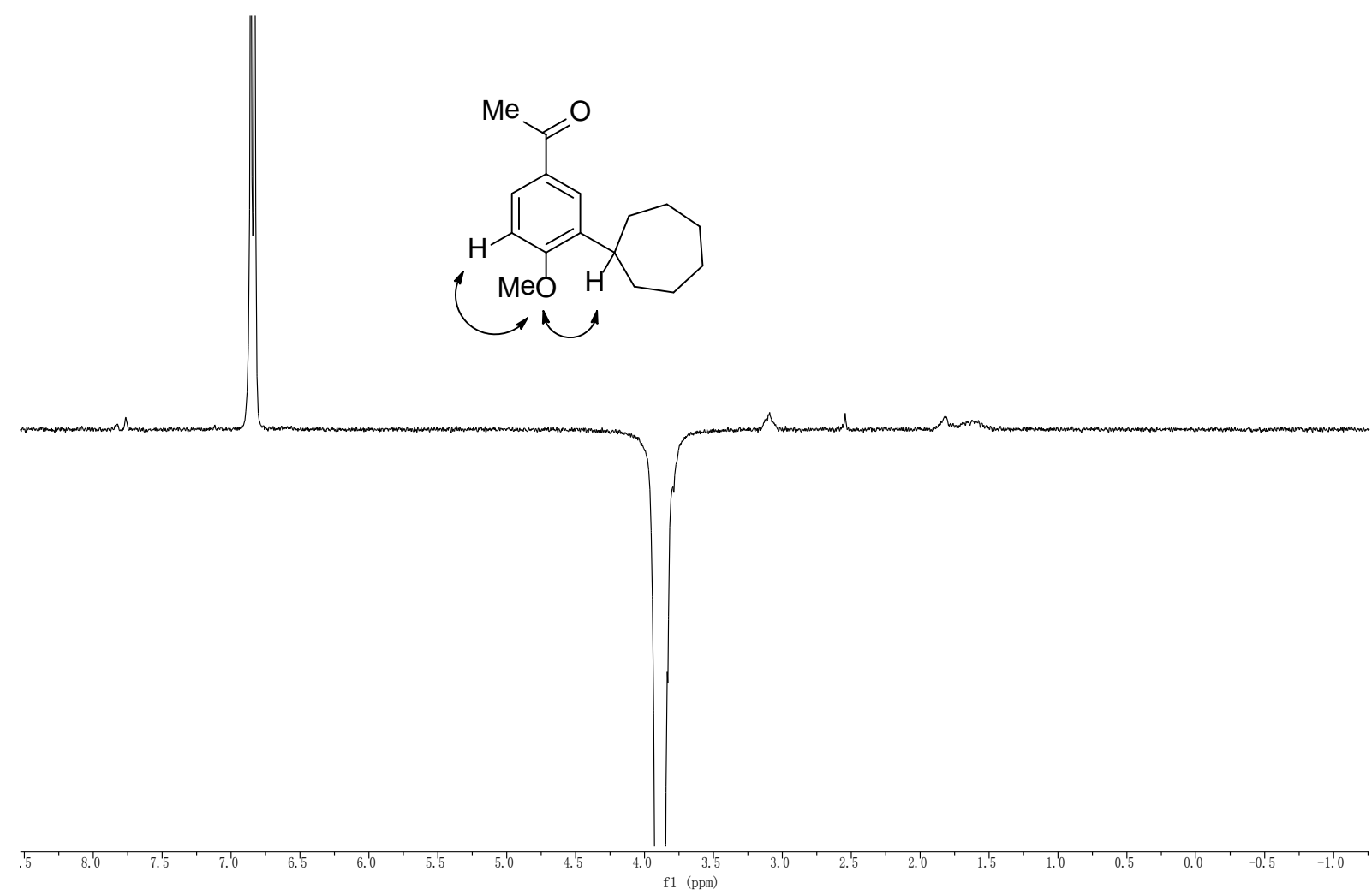

NOESY 206ce

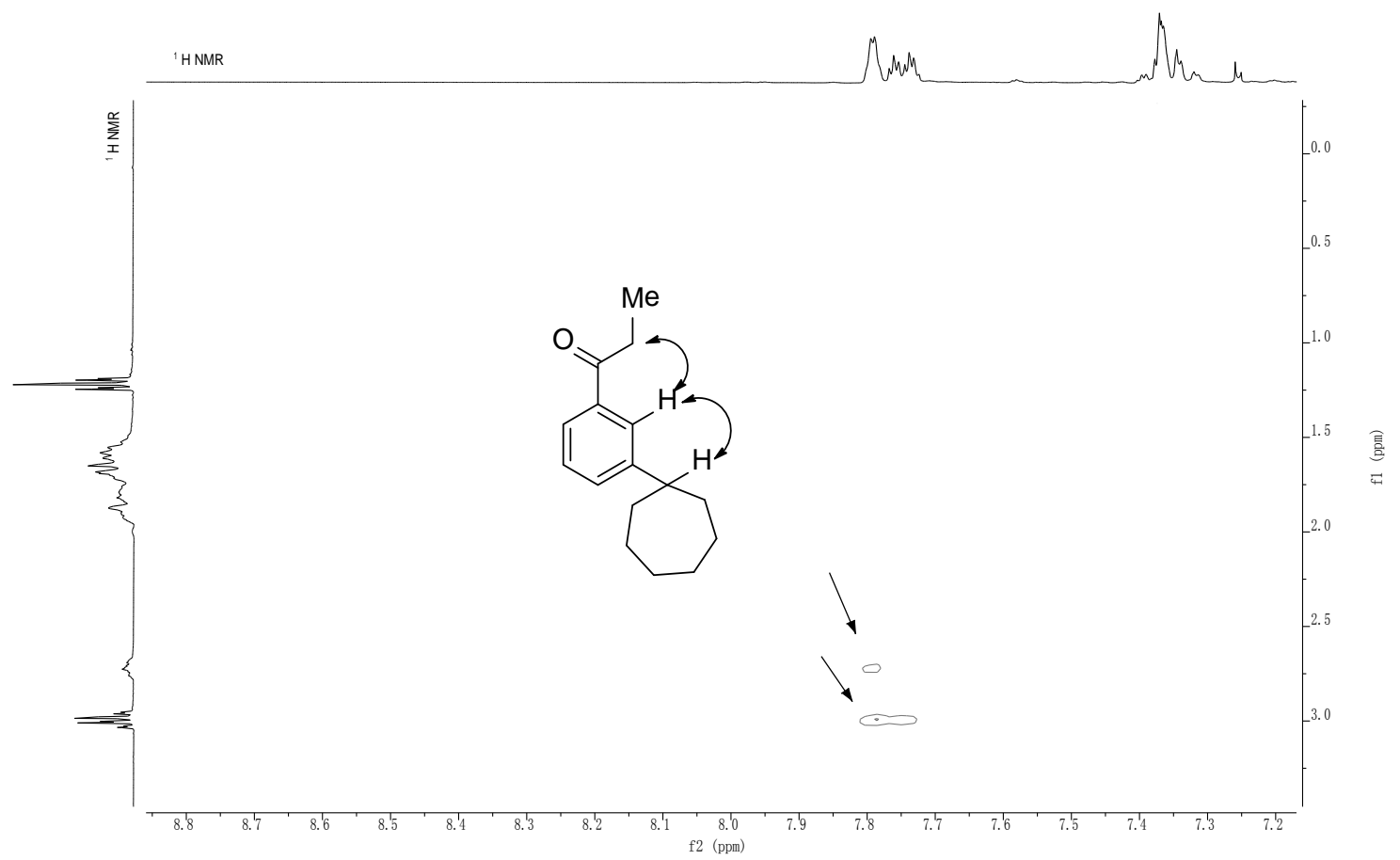

- 168 - 


\section{NOESY 206ie}

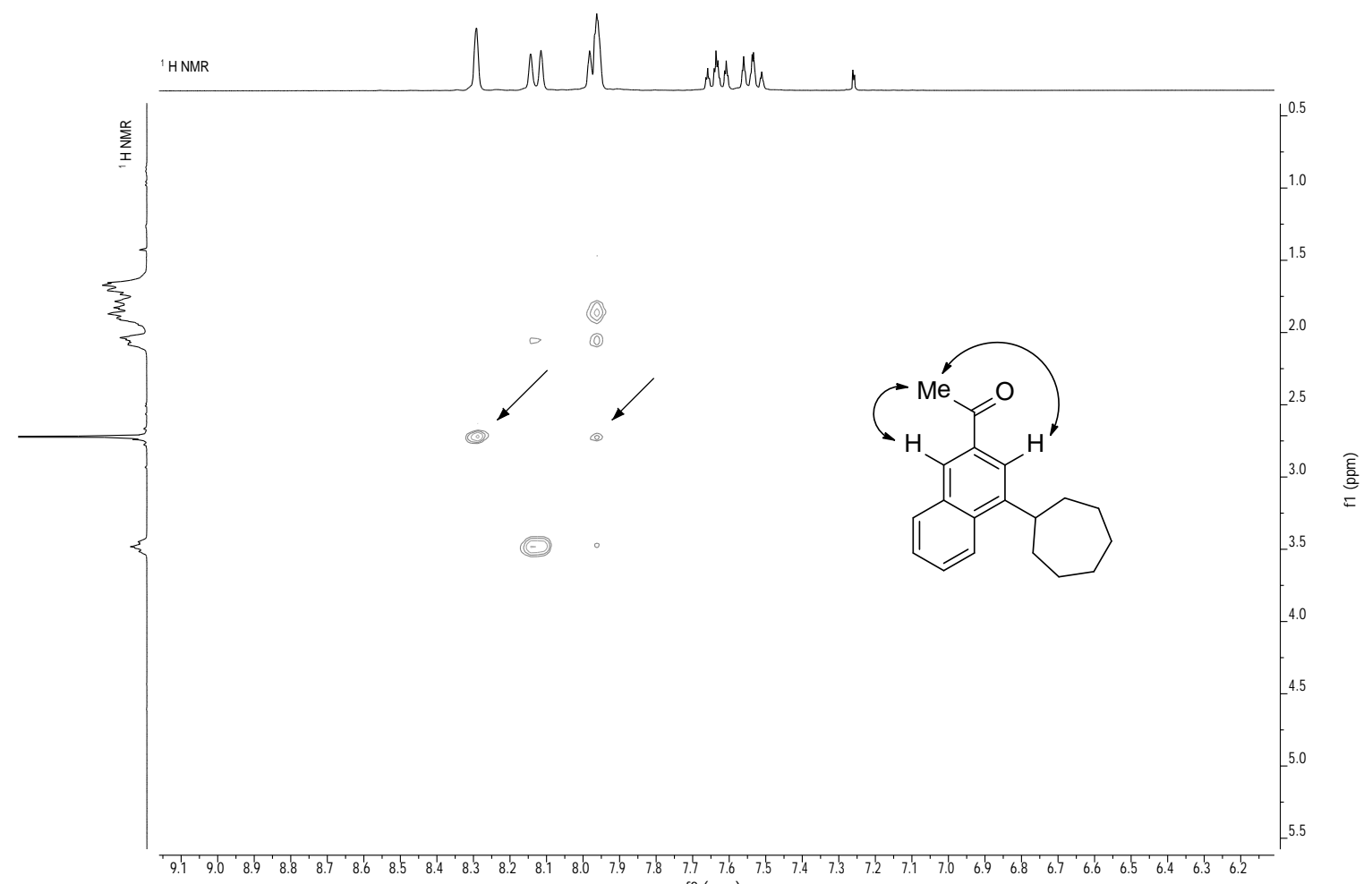

nOe 206ad
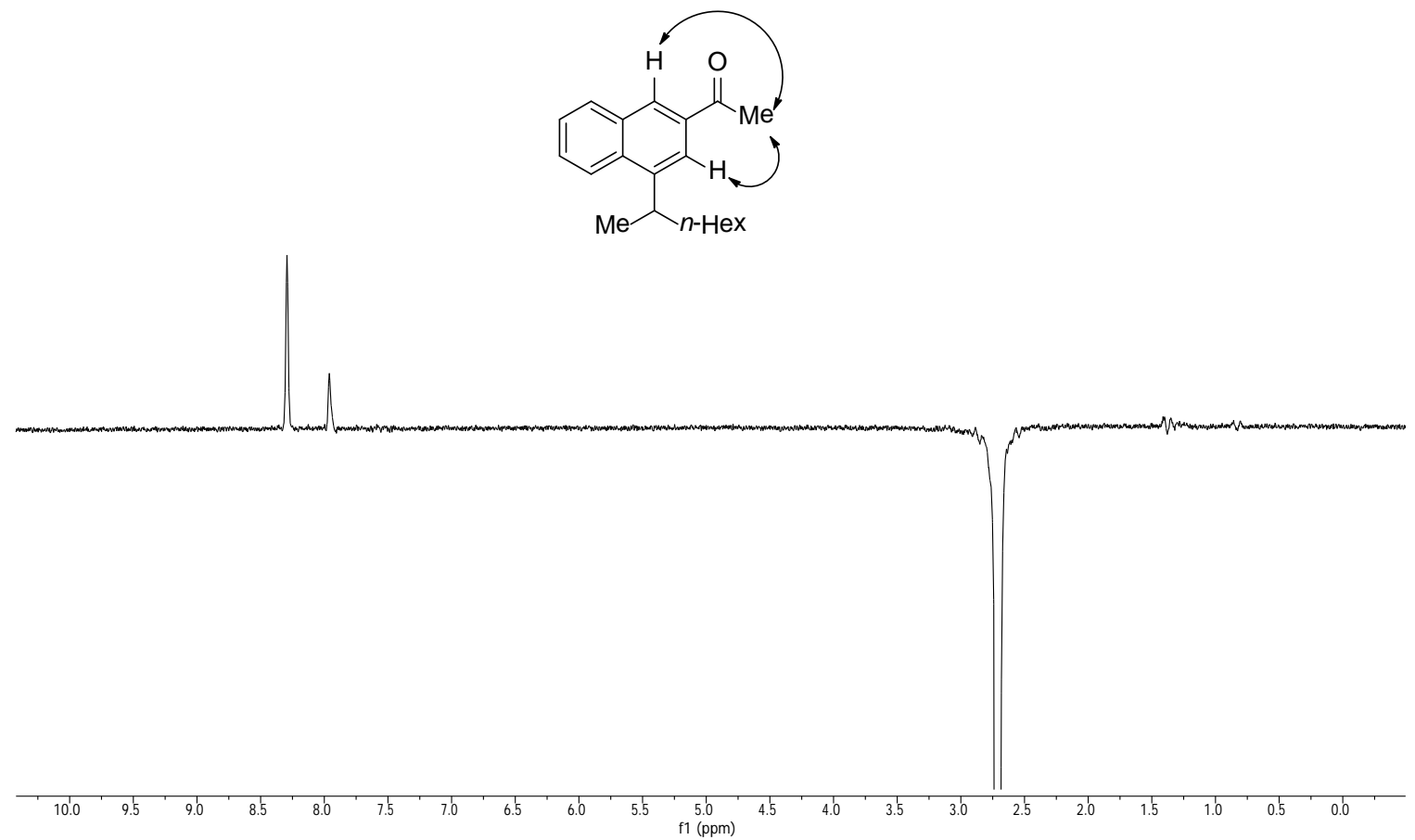
NOESY 208bj

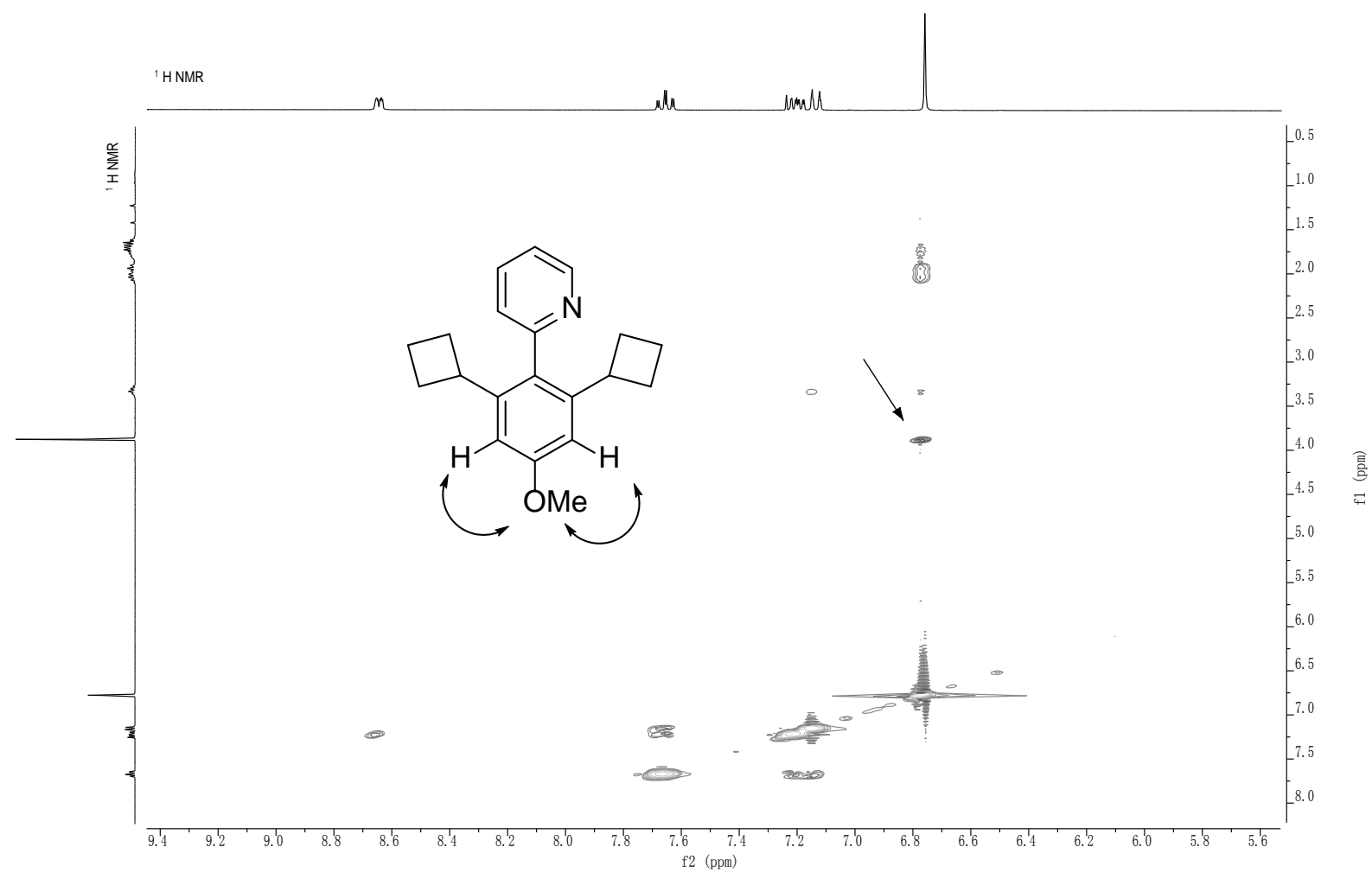

NOESY 208bk

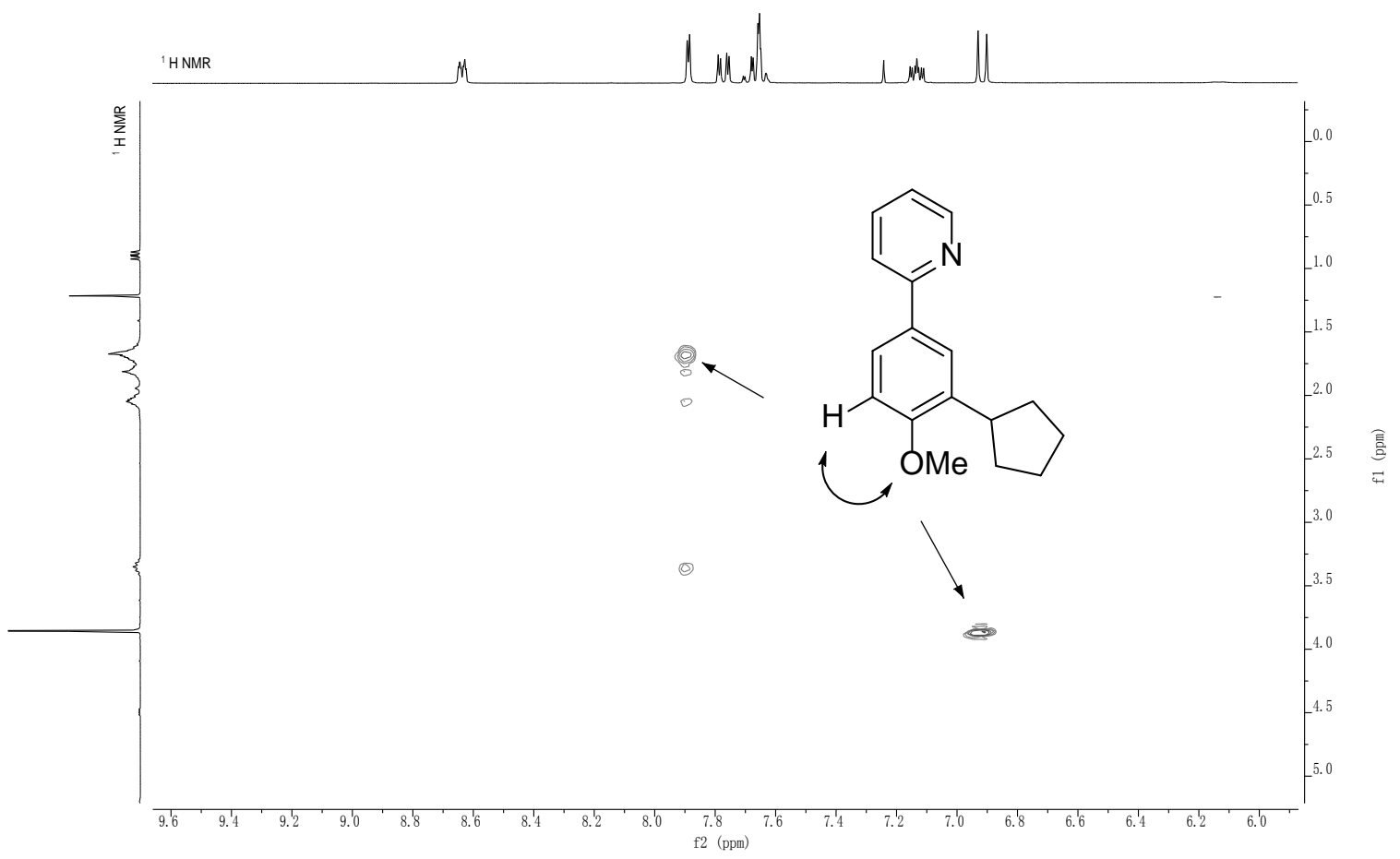

- 170 - 


\section{NOESY 209}

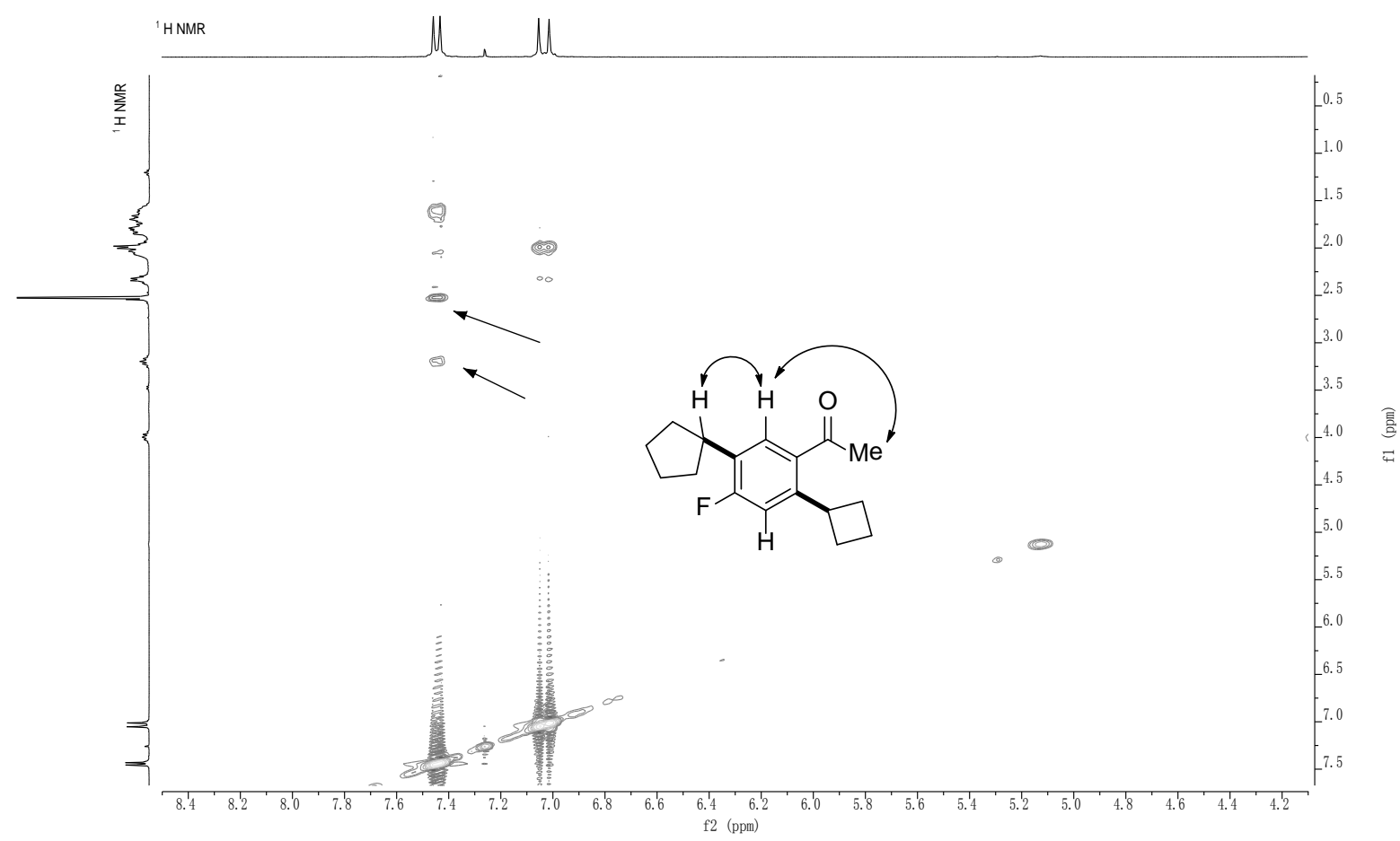

NOESY 215ea 


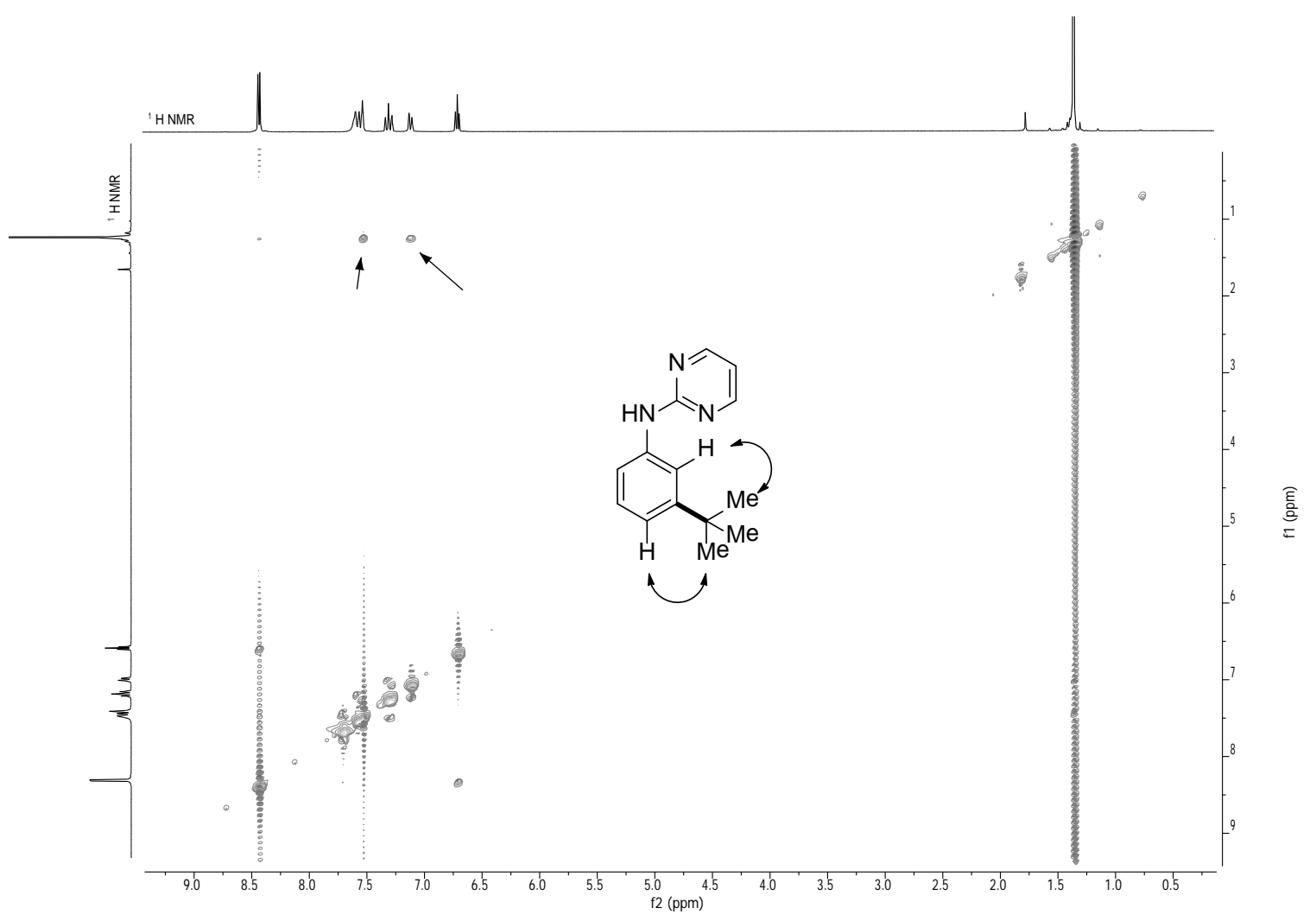

NOESY 215da

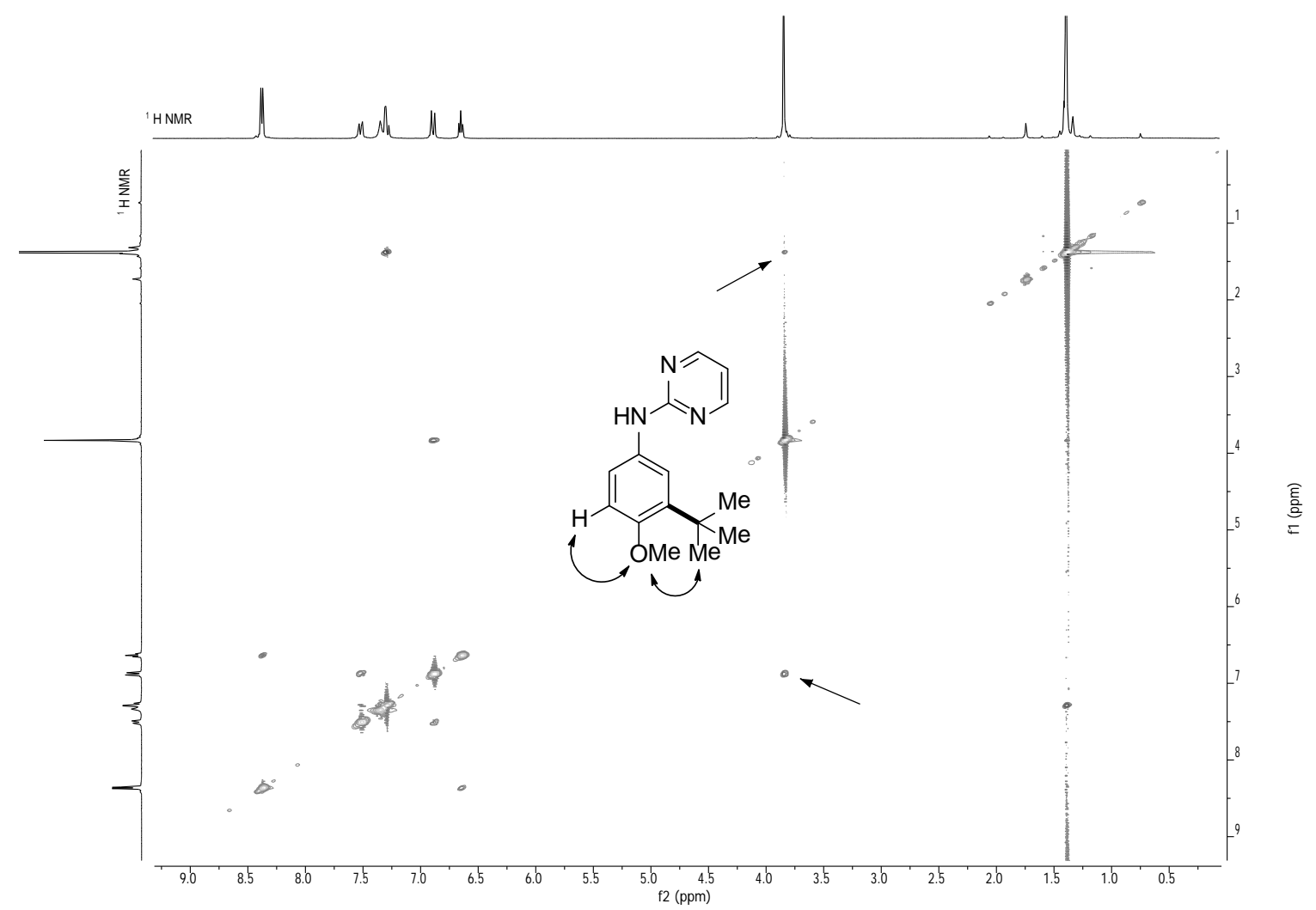

nOe 215ga 


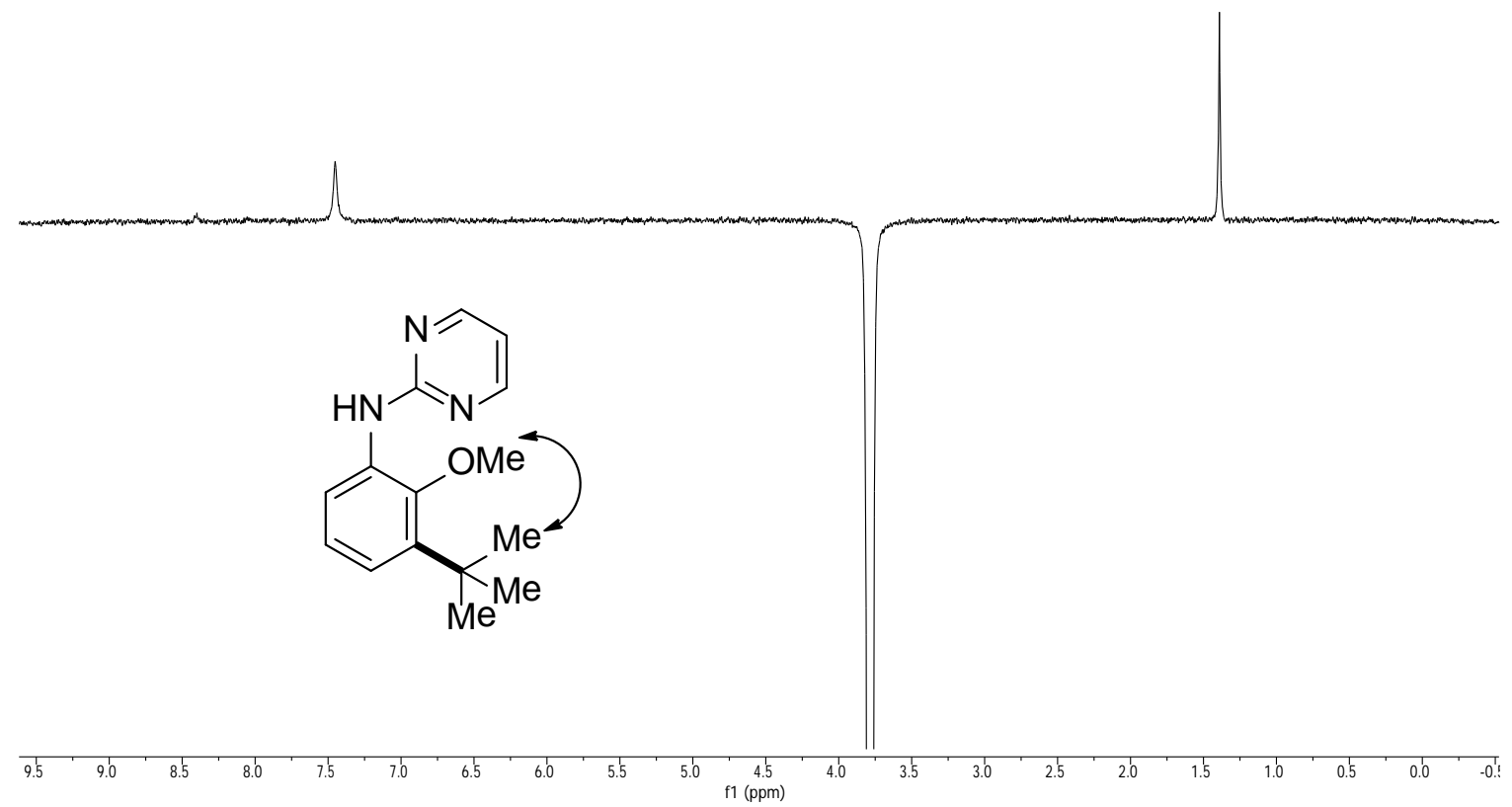

${ }^{15} \mathrm{~N},{ }^{1} \mathrm{H}-\mathrm{HMBC} 215 \mathrm{ba}$

$15 \mathrm{~N}, 1 \mathrm{H}-\mathrm{hmbc}: \quad 1 \mathrm{jf} 41$ in $\operatorname{cdcl} 3$

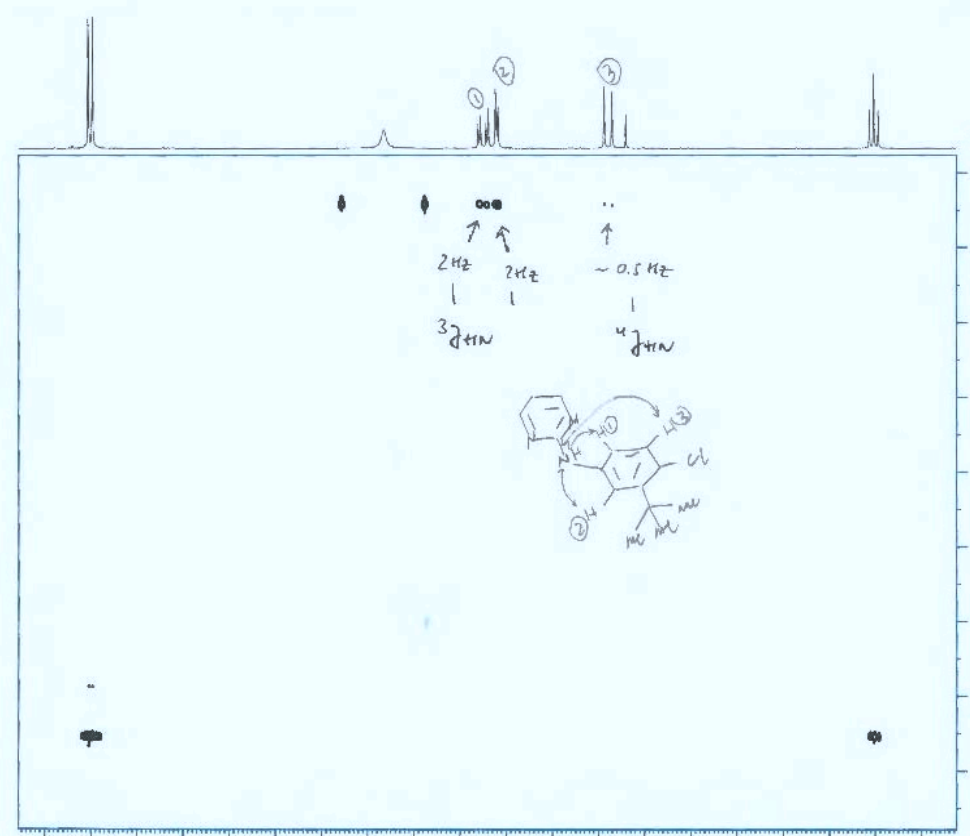

BRUKER

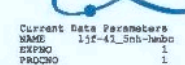
ppmiato-

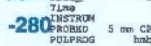

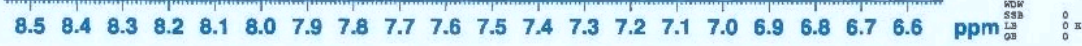




\section{List of Abbreviations}

\begin{tabular}{|c|c|}
\hline$\AA$ & Ångström \\
\hline Ac & acetyl \\
\hline Ad & adamantyl \\
\hline Alk & alkyl \\
\hline Am & amyl \\
\hline AMLA & ambiphilic metal-ligand activation \\
\hline aq. & aqueous \\
\hline $\operatorname{Ar}$ & aryl \\
\hline APT & attached proton test \\
\hline atm & atmospheric pressure \\
\hline ATR & attenuated total reflectance \\
\hline BDMAEE & bis(2-dimethylaminoethyl)ether \\
\hline BHT & 2,6-di-tert-butyl-4-methylphenol \\
\hline BINAP & 2,2'-bis(diphenylphosphino)-1,1'-binaphthyl \\
\hline $\mathrm{Bn}$ & benzyl \\
\hline Boc & tert-butyloxycarbonyl \\
\hline BQ & benzoquinoline \\
\hline $\mathrm{Bu}$ & butyl \\
\hline $\mathrm{Bz}$ & benzoyl \\
\hline$c-$ & cyclo \\
\hline CDC & cross-dehydrogenative coupling \\
\hline calc. & calculated \\
\hline cat. & catalytic \\
\hline CMD & concerted-metalation-deprotonation \\
\hline cod & 1,5-cyclooctadien \\
\hline conv. & conversion \\
\hline$C p^{*}$ & cyclopentadienyl \\
\hline Cy & cyclohexyl \\
\hline$\delta$ & chemical shift \\
\hline$d$ & doublet \\
\hline DCE & 1,2-dichloroethane \\
\hline dd & doublet of doublet \\
\hline DFT & density functional theory \\
\hline DG & directing group \\
\hline Diglyme & bis(2-methoxyethyl)ether \\
\hline DMA & $\mathrm{N}, \mathrm{N}$-dimethylacetamide \\
\hline DME & dimethoxyethane \\
\hline DMF & $N, N$-dimethylformamide \\
\hline DMSO & dimethyl sulfoxide \\
\hline DMPU & 1,3-dimethyl-3,4,5,6-tetrahydro-2(1H)-pyrimidinone \\
\hline DoM & directed ortho metalation \\
\hline dppbz & 1,2-bis(diphenylphosphino)benzene \\
\hline
\end{tabular}




\begin{tabular}{|c|c|}
\hline dpph & 2,2-diphenyl-1-picrylhydrazyl \\
\hline dppf & 1,1'-bis(diphenylphosphino)ferrocene \\
\hline dppp & 1,3-bis(diphenylphosphino)propane \\
\hline $\mathrm{dt}$ & doublet of triplet \\
\hline $\mathrm{E}$ & electrophile \\
\hline Ed. & edition \\
\hline EI & electron ionization \\
\hline equiv & equivalent \\
\hline ESI & electronspray ionization \\
\hline Et & ethyl \\
\hline FG & functional group \\
\hline g & gram \\
\hline GC & gas chromatography \\
\hline $\mathrm{h}$ & hour \\
\hline Hal & halogen \\
\hline Het & hetero(aryl) \\
\hline Hept & heptyl \\
\hline Hex & hexyl \\
\hline HPLC & high performance liquid chromatography \\
\hline HR-MS & high resolution mass spectrometry \\
\hline $\mathrm{Hz}$ & Hertz \\
\hline$i$ & iso \\
\hline IES & internal electrophilic substitution \\
\hline Ile & isoleucine \\
\hline IR & infrared spectroscopy \\
\hline J & coupling constant \\
\hline KIE & kinetic isotope effect \\
\hline $\mathrm{L}$ & ligand \\
\hline Leu & leucine \\
\hline$m$ & meta \\
\hline $\mathrm{m}$ & multiplet \\
\hline M & molar \\
\hline$[\mathrm{M}]^{+}$ & molecular ion peak \\
\hline $\mathrm{Me}$ & methyl \\
\hline Mes & mesityl \\
\hline $\mathrm{mg}$ & milligram \\
\hline $\mathrm{MHz}$ & megahertz \\
\hline $\min$ & minute \\
\hline $\mathrm{mL}$ & milliliter \\
\hline $\mathrm{mmol}$ & millimol \\
\hline M. p. & melting point \\
\hline MPAA & monoprotected amino acid \\
\hline MPV & membrane pump vacuum \\
\hline MS & mass spectrometry \\
\hline
\end{tabular}




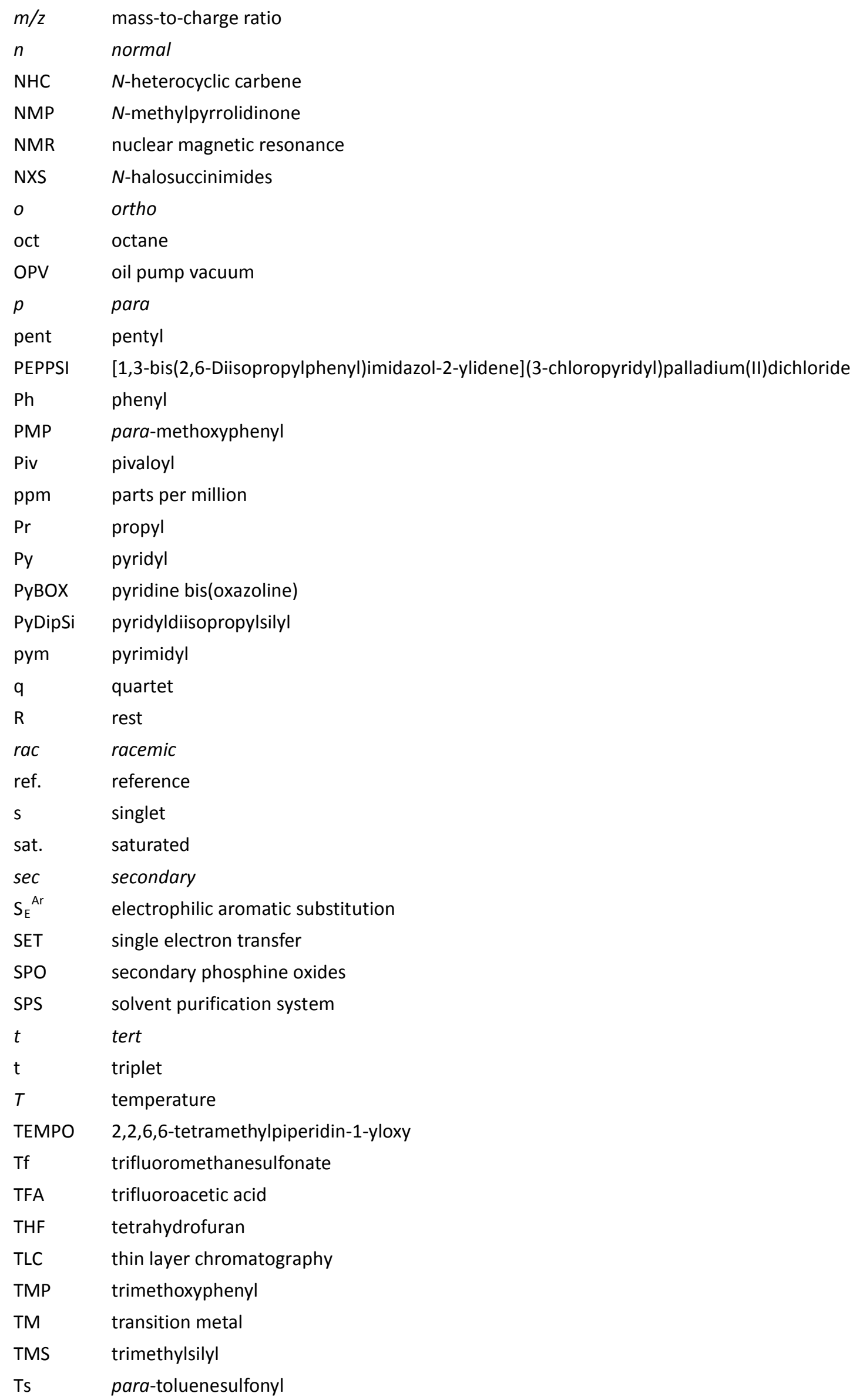




$\begin{array}{ll}\text { TS } & \text { transition state } \\ \tilde{V} & \text { absorption } \\ \text { Val } & \text { valin } \\ \text { wt\% } & \text { weight by volume } \\ \mathrm{X} & \text { (pseudo)halide }\end{array}$




\section{References}

(1) Modern Arylation Methods; Ackermann, L., ed.; Wiley, Weinheim, 2009.

(2) Martin, R.; Buchwald, S. L. Acc. Chem. Res. 2008, 41, 1461-1473.

(3) Knappke, C. E. I.; Jacobi von Wangelin, A. Chem. Soc. Rev. 2011, 40, 4948-4962.

(4) Enthaler, S.; Company, A. Chem. Soc. Rev. 2011, 40, 4912-4924.

(5) Torborg, C.; Beller, M. Adv. Synth. Catal. 2009, 351, 3027-3043.

(6) Busacca, C. A.; Fandrick, D. R.; Song, J. J.; Senanayake, C. H. Adv. Synth. Catal. 2011, 353, 1825-1864.

(7) Johansson Seechurn, C. C. C.; Kitching, M. O.; Colacot, T. J.; Snieckus, V. Angew. Chem. Int. Ed. 2012, 51, 5062-5085.

(8) Negishi, E.-i. Angew. Chem. Int. Ed. 2011, 50, 6738-6764.

(9) Suzuki, A. Angew. Chem. Int. Ed. 2011, 50, 6722-6737.

(10) Mizoroki, T.; Mori, K.; Ozaki, A. Bull. Chem. Soc. Jpn. 1971, 44, 581-581.

(11) Heck, R. F.; Nolley, J. P. J. Org. Chem. 1972, 37, 2320-2322.

(12) King, A. O.; Okukado, N.; Negishi, E.-i. J. Chem. Soc., Chem. Commun. 1977, 683-684.

(13) Miyaura, N.; Suzuki, A. J. Chem. Soc., Chem. Commun. 1979, 866-867.

(14) Trost, B. M. Acc. Chem. Res. 2002, 35, 695-705.

(15) Wender, P. A.; Verma, V. A.; Paxton, T. J.; Pillow, T. H. Acc. Chem. Res. 2008, 41, 40-49.

(16) Lyons, T. W.; Sanford, M. S. Chem. Rev. 2010, 110, 1147-1169.

(17) Ackermann, L. Chem. Rev. 2011, 111, 1315-1345.

(18) Gunay, A.; Theopold, K. H. Chem. Rev. 2010, 110, 1060-1081.

(19) Arockiam, P. B.; Bruneau, C.; Dixneuf, P. H. Chem. Rev. 2012, 112, 5879-5918.

(20) Engle, K. M.; Mei, T.-S.; Wasa, M.; Yu, J.-Q. Acc. Chem. Res. 2011, 45, 788-802.

(21) De Sarkar, S.; Liu, W.; Kozhushkov, S. I.; Ackermann, L. Adv. Synth. Catal. 2014, 356, 1461-1479.

(22) Ackermann, L. J. Org. Chem. 2014, 79, 8948-8954.

(23) Gao, K.; Yoshikai, N. Acc. Chem. Res. 2014, 47, 1208-1219.

(24) Thirunavukkarasu, V. S.; Kozhushkov, S. I.; Ackermann, L. Chem. Commun. 2014, 50, $29-39$.

(25) Li, C.-J. Acc. Chem. Res. 2009, 42, 335-344.

(26) Yeung, C. S.; Dong, V. M. Chem. Rev. 2011, 111, 1215-1292.

(27) Girard, S. A.; Knauber, T.; Li, C.-J. Angew. Chem. Int. Ed. 2014, 53, 74-100.

(28) Balcells, D.; Clot, E.; Eisenstein, O. Chem. Rev. 2010, 110, 749-823.

(29) Gaunt, J. C.; Shaw, B. L. J. Organomet. Chem. 1975, 102, 511-516.

(30) Sokolov, V. I.; Troitskaya, L. L.; Reutov, O. A. J. Organomet. Chem. 1979, 182, 537-546.

(31) Boutadla, Y.; Davies, D. L.; Macgregor, S. A.; Poblador-Bahamonde, A. I. Dalton Trans. 2009, 5820-5831.

(32) Lapointe, D.; Fagnou, K. Chem. Lett. 2010, 39, 1118-1126.

(33) Oxgaard, J.; Tenn, W. J.; Nielsen, R. J.; Periana, R. A.; Goddard, W. A. Organometallics 2007, 26, 1565-1567.

(34) Ryabov, A. D. Chem. Rev. 1990, 90, 403-424.

(35) Ackermann, L. Top. Organomet. Chem. 2007, 24, 35-60.

(36) Gilman, H.; Bebb, R. L. J. Am. Chem. Soc. 1939, 61, 109-112. 
(37) Wittig, G.; Fuhrmann, G. Chem. Ber. 1940, 73, 1197-1218.

(38) Groom, K.; Hussain, S. M. S.; Morin, J.; Nilewski, C.; Rantanen, T.; Snieckus, V. Org. Lett. 2014, 16, 2378-2381.

(39) Flemming, J. P.; Berry, M. B.; Brown, J. M. Org. Biomol. Chem. 2008, 6, 1215-1221.

(40) Neufeldt, S. R.; Sanford, M. S. Acc. Chem. Res. 2012, 45, 936-946.

(41) Zhang, Y.-H.; Shi, B.-F.; Yu, J.-Q. J. Am. Chem. Soc. 2009, 131, 5072-5074.

(42) Zhang, S.; Shi, L.; Ding, Y. J. Am. Chem. Soc. 2011, 133, 20218-20229.

(43) Catellani, M.; Frignani, F.; Rangoni, A. Angew. Chem. Int. Ed. 1997, 36, 119-122.

(44) Catellani, M.; Motti, E.; Della Ca', N. Acc. Chem. Res. 2008, 41, 1512-1522.

(45) Martins, A.; Mariampillai, B.; Lautens, M. Top. Curr. Chem. 2010, 292, 1-33.

(46) Dong, Z.; Dong, G. J. Am. Chem. Soc. 2013, 135, 18350-18353.

(47) Hartwig, J. F. Acc. Chem. Res. 2008, 41, 1534-1544.

(48) Cornella, J.; Righi, M.; Larrosa, I. Angew. Chem. Int. Ed. 2011, 50, 9429-9432.

(49) Luo, J.; Preciado, S.; Larrosa, I. J. Am. Chem. Soc. 2014, 136, 4109-4112.

(50) Luo, J.; Preciado, S.; Larrosa, I. Chem. Commun. 2015, 51, 3127-3130.

(51) Yang, J. Org. Biomol. Chem. 2015, 13, 1930-1941.

(52) Julia-Hernandez, F.; Simonetti, M.; Larrosa, I. Angew. Chem. Int. Ed. 2013, 52, 11458-11460.

(53) Schranck, J.; Tlili, A.; Beller, M. Angew. Chem. Int. Ed. 2014, 53, 9426-9428.

(54) Cho, J. Y.; Tse, M. K.; Holmes, D.; Maleczka, R. E., Jr.; Smith, M. R. Science 2002, 295, 305-308.

(55) Ishiyama, T.; Takagi, J.; Hartwig, J. F.; Miyaura, N. Angew. Chem. Int. Ed. 2002, 41, 3056-3058.

(56) Cheng, C.; Hartwig, J. F. Science 2014, 343, 853-857.

(57) Martínez, C.; Muñiz, K. ChemCatChem 2013, 5, 3502-3503.

(58) Hartwig, J. F. Acc. Chem. Res. 2011, 45, 864-873.

(59) Leow, D.; Li, G.; Mei, T. S.; Yu, J.-Q. Nature 2012, 486, 518-522.

(60) Wan, L.; Dastbaravardeh, N.; Li, G.; Yu, J. Q. J. Am. Chem. Soc. 2013, 135, 18056-18059.

(61) Tang, R. Y.; Li, G.; Yu, J.-Q. Nature 2014, 507, 215-220.

(62) Yang, G.; Lindovska, P.; Zhu, D.; Kim, J.; Wang, P.; Tang, R. Y.; Movassaghi, M.; Yu, J. Q. J. Am. Chem. Soc. 2014, 136, 10807-10813.

(63) Deng, Y.; Yu, J.-Q. Angew. Chem. Int. Ed. 2015, 54, 888-891.

(64) Lee, S.; Lee, H.; Tan, K. L. J. Am. Chem. Soc. 2013, 135, 18778-18781.

(65) Phipps, R. J.; Gaunt, M. J. Science 2009, 323, 1593-1597.

(66) Lee, E. Y.; Park, J. ChemCatChem 2011, 3, 1127-1129.

(67) Duong, H. A.; Gilligan, R. E.; Cooke, M. L.; Phipps, R. J.; Gaunt, M. J. Angew. Chem. Int. Ed. 2011, 50, 463-466.

(68) Ciana, C.-L.; Phipps, R. J.; Brandt, J. R.; Meyer, F.-M.; Gaunt, M. J. Angew. Chem. Int. Ed. 2011, 50, 458-462.

(69) Zhao, X.; Dimitrijević, E.; Dong, V. M. J. Am. Chem. Soc. 2009, 131, 3466-3467.

(70) Saidi, O.; Marafie, J.; Ledger, A. E.; Liu, P. M.; Mahon, M. F.; Kociok-Kohn, G.; Whittlesey, M. K.; Frost, C. G. J. Am. Chem. Soc. 2011, 133, 19298-19301.

(71) Reynolds, W. R.; Liu, P. M.; Kociok-Köhn, G.; Frost, C. G. Synlett 2013, 24, 2687-2690.

(72) Clark, A. M.; Rickard, C. E. F.; Roper, W. R.; Wright, L. J. Organometallics 1999, 18, 2813-2820.

(73) Gagliardo, M.; Snelders, D. J. M.; Chase, P. A.; Klein Gebbink, R. J. M.; van Klink, G. P. M.; van Koten, G. Angew. Chem. Int. Ed. 2007, 46, 8558-8573.

(74) Friedel, C.; Crafts, J. M. Compt Rend 1877, 84, 1392-1395. 
(75) Tsuchimoto, T.; Tobita, K.; Hiyama, T.; Fukuzawa, S.-i. Synlett 1996, 1996, 557-559.

(76) Bandini, M.; Melloni, A.; Umani-Ronchi, A. Angew. Chem. Int. Ed. 2004, 43, 550-556.

(77) Rueping, M.; Nachtsheim, B. J. Beilstein J. Org. Chem. 2010, 6, No. 6.

(78) Ariafard, A.; Lin, Z. Organometallics 2006, 25, 4030-4033.

(79) Kochi, J. K.; Tamura, M. J. Am. Chem. Soc. 1971, 93, 1485-1487.

(80) Ishiyama, T.; Abe, S.; Miyaura, N.; Suzuki, A. Chem. Lett. 1992, 21, 691-694.

(81) Frisch, A. C.; Beller, M. Angew. Chem. Int. Ed. 2005, 44, 674-688.

(82) Terao, J.; Kambe, N. Bull. Chem. Soc. Jpn. 2006, 79, 663-672.

(83) Rudolph, A.; Lautens, M. Angew. Chem. Int. Ed. 2009, 48, 2656-2670.

(84) Zhou, J.; Fu, G. C. J. Am. Chem. Soc. 2003, 125, 14726-14727.

(85) Fischer, C.; Fu, G. C. J. Am. Chem. Soc. 2005, 127, 4594-4595.

(86) Wilsily, A.; Tramutola, F.; Owston, N. A.; Fu, G. C. J. Am. Chem. Soc. 2012, 134, 5794-5797.

(87) Dai, X.; Strotman, N. A.; Fu, G. C. J. Am. Chem. Soc. 2008, 130, 3302-3303.

(88) Lou, S.; Fu, G. C. J. Am. Chem. Soc. 2010, 132, 1264-1266.

(89) Caeiro, J.; Pérez Sestelo, J.; Sarandeses, L. A. Chem. Eur. J. 2008, 14, 741-746.

(90) Tasker, S. Z.; Standley, E. A.; Jamison, T. F. Nature 2014, 509, 299-309.

(91) Yang, C.-T.; Zhang, Z.-Q.; Liang, J.; Liu, J.-H.; Lu, X.-Y.; Chen, H.-H.; Liu, L. J. Am. Chem. Soc. 2012, 134, 11124-11127.

(92) Nakamura, M.; Matsuo, K.; Ito, S.; Nakamura, E. J. Am. Chem. Soc. 2004, 126, 3686-3687.

(93) Ohmiya, H.; Yorimitsu, H.; Oshima, K. J. Am. Chem. Soc. 2006, 128, 1886-1889.

(94) Rodríguez, N.; Ramírez de Arellano, C.; Asensio, G.; Medio-Simón, M. Chem. Eur. J. 2007, 13, 4223-4229.

(95) Zultanski, S. L.; Fu, G. C. J. Am. Chem. Soc. 2013, 135, 624-627.

(96) Jones, G. D.; Martin, J. L.; McFarland, C.; Allen, O. R.; Hall, R. E.; Haley, A. D.; Brandon, R. J.; Konovalova, T.; Desrochers, P. J.; Pulay, P.; Vicic, D. A. J. Am. Chem. Soc. 2006, 128, 13175-13183.

(97) Lin, X.; Phillips, D. L. J. Org. Chem. 2008, 73, 3680-3688.

(98) Schley, N. D.; Fu, G. C. J. Am. Chem. Soc. 2014, 136, 16588-16593.

(99) Ashby, E. C. Acc. Chem. Res. 1988, 21, 414-421.

(100) Ackermann, L. Chem. Commun. 2010, 46, 4866-4877.

(101) Song, Z. Z.; Wong, H. N. C. J. Org. Chem. 1994, 59, 33-41.

(102) Hennessy, E. J.; Buchwald, S. L. J. Am. Chem. Soc. 2003, 125, 12084-12085.

(103) Hwang, S. J.; Cho, S. H.; Chang, S. J. Am. Chem. Soc. 2008, 130, 16158-16159.

(104) Hwang, S. J.; Kim, H. J.; Chang, S. Org. Lett. 2009, 11, 4588-4591.

(105) Verrier, C.; Hoarau, C.; Marsais, F. Org. Biomol. Chem. 2009, 7, 647-650.

(106) Lapointe, D.; Fagnou, K. Org. Lett. 2009, 11, 4160-4163.

(107) Vechorkin, O.; Proust, V.; Hu, X. Angew. Chem. Int. Ed. 2010, 49, 3061-3064.

(108) Yao, T.; Hirano, K.; Satoh, T.; Miura, M. Chem. Eur. J. 2010, 16, 12307-12311.

(109) Ackermann, L.; Punji, B.; Song, W. Adv. Synth. Catal. 2011, 353, 3325-3329.

(110) Ren, P.; Salihu, I.; Scopelliti, R.; Hu, X. Org. Lett. 2012, 14, 1748-1751.

(111) Xiao, B.; Liu, Z. J.; Liu, L.; Fu, Y. J. Am. Chem. Soc. 2013, 135, 616-619.

(112) Wu, X.; See, J. W. T.; Xu, K.; Hirao, H.; Roger, J.; Hierso, J.-C.; Zhou, J. Angew. Chem. Int. Ed. 2014, 53, 13573-13577.

(113) Jiao, L.; Bach, T. J. Am. Chem. Soc. 2011, 133, 12990-12993.

(114) Jiao, L.; Herdtweck, E.; Bach, T. J. Am. Chem. Soc. 2012, 134, 14563-14572. 
(115) Tremont, S. J.; Hayat ur, R. J. Am. Chem. Soc. 1984, 106, 5759-5760.

(116) Zhang, Y. H.; Shi, B. F.; Yu, J. Q. Angew. Chem. Int. Ed. 2009, 48, 6097-6100.

(117) Chen, Q.; Ilies, L.; Nakamura, E. J. Am. Chem. Soc. 2010, 133, 428-429.

(118) Gao, K.; Yoshikai, N. J. Am. Chem. Soc. 2013, 135, 9279-9282.

(119) Gao, K.; Yamakawa, T.; Yoshikai, N. Synthesis 2014, 46, 2024-2039.

(120) Punji, B.; Song, W.; Shevchenko, G. A.; Ackermann, L. Chem. Eur. J. 2013, 19, 10605-10610.

(121) Zhu, R. Y.; He, J.; Wang, X. C.; Yu, J. Q. J. Am. Chem. Soc. 2014, 136, 13194-13197.

(122) Zaitsev, V. G.; Shabashov, D.; Daugulis, O. J. Am. Chem. Soc. 2005, 127, 13154-13155.

(123) Rouquet, G.; Chatani, N. Angew. Chem. Int. Ed. 2013, 52, 11726-11743.

(124) Gu, Q.; Al Mamari, H. H.; Graczyk, K.; Diers, E.; Ackermann, L. Angew. Chem. Int. Ed. 2014, 53, 3868-3871.

(125) Shabashov, D.; Daugulis, O. J. Am. Chem. Soc. 2010, 132, 3965-3972.

(126) Zhao, Y.; Chen, G. Org. Lett. 2011, 13, 4850-4853.

(127) Tran, L. D.; Daugulis, O. Angew. Chem. Int. Ed. 2012, 51, 5188-5191.

(128) Zhang, S. Y.; He, G.; Nack, W. A.; Zhao, Y.; Li, Q.; Chen, G. J. Am. Chem. Soc. 2013, 135, 2124-2127.

(129) Zhang, S. Y.; Li, Q.; He, G.; Nack, W. A.; Chen, G. J. Am. Chem. Soc. 2013, 135, 12135-12141.

(130) Chen, K.; Hu, F.; Zhang, S.-Q.; Shi, B.-F. Chem. Sci. 2013, 4, 3906-3911.

(131) Chen, K.; Shi, B. F. Angew. Chem. Int. Ed. 2014, 53, 11950-11954.

(132) Aihara, Y.; Chatani, N. J. Am. Chem. Soc. 2013, 135, 5308-5311.

(133) Song, W.; Lackner, S.; Ackermann, L. Angew. Chem. Int. Ed. 2014, 53, 2477-2480.

(134) Wu, X.; Zhao, Y.; Ge, H. J. Am. Chem. Soc. 2014, 136, 1789-1792.

(135) Ilies, L.; Matsubara, T.; Ichikawa, S.; Asako, S.; Nakamura, E. J. Am. Chem. Soc. 2014, 136, 13126-13129.

(136) Monks, B. M.; Fruchey, E. R.; Cook, S. P. Angew. Chem. Int. Ed. 2014, 53, 11065-11069.

(137) Fruchey, E. R.; Monks, B. M.; Cook, S. P. J. Am. Chem. Soc. 2014, 136, 13130-13133.

(138) Ackermann, L.; Vicente, R.; Althammer, A. Org. Lett. 2008, 10, 2299-2302.

(139) Ackermann, L.; Vicente, R.; Potukuchi, H. K.; Pirovano, V. Org. Lett. 2010, 12, 5032-5035.

(140) Ackermann, L.; Novak, P.; Vicente, R.; Hofmann, N. Angew. Chem. Int. Ed. 2009, 48, 6045-6048.

(141) Ackermann, L.; Novák, P. Org. Lett. 2009, 11, 4966-4969.

(142) Ackermann, L.; Hofmann, N.; Vicente, R. Org. Lett. 2011, 13, 1875-1877.

(143) Hofmann, N.; Ackermann, L. J. Am. Chem. Soc. 2013, 135, 5877-5884.

(144) Li, C.-J.; Trost, B. M. Proc. Natl. Acad. Sci. 2008, 105, 13197-13202.

(145) Heck, R. F. J. Am. Chem. Soc. 1968, 90, 5518-5526.

(146) Heck, R. F. J. Am. Chem. Soc. 1969, 91, 6707-6714.

(147) Trost, B. Science 1991, 254, 1471-1477.

(148) Moritani, I.; Fujiwara, Y. Tetrahedron Lett. 1967, 8, 1119-1122.

(149) Fujiwara, Y.; Moritani, I.; Matsuda, M. Tetrahedron 1968, 24, 4819-4824.

(150) Fujiwara, Y.; Noritani, I.; Danno, S.; Asano, R.; Teranishi, S. J. Am. Chem. Soc. 1969, 91, 7166-7169.

(151) Le Bras, J.; Muzart, J. Chem. Rev. 2011, 111, 1170-1214.

(152) Boele, M. D. K.; van Strijdonck, G. P. F.; de Vries, A. H. M.; Kamer, P. C. J.; de Vries, J. G.; van Leeuwen, P. W. N. M. J. Am. Chem. Soc. 2002, 124, 1586-1587.

(153) Wang, D.-H.; Engle, K. M.; Shi, B.-F.; Yu, J.-Q. Science 2010, 327, 315-319.

(154) Zheng, C.; You, S.-L. RSC Advances 2014, 4, 6173-6214.

(155) Shi, B.-F.; Zhang, Y.-H.; Lam, J. K.; Wang, D.-H.; Yu, J.-Q. J. Am. Chem. Soc. 2010, 132, 460-461. 
(156) Wasa, M.; Engle, K. M.; Yu, J.-Q. J. Am. Chem. Soc. 2010, 132, 3680-3681.

(157) Song, G.; Wang, F.; Li, X. Chem. Soc. Rev. 2012, 41, 3651-3678.

(158) Colby, D. A.; Tsai, A. S.; Bergman, R. G.; Ellman, J. A. Acc. Chem. Res. 2011, 45, 814-825.

(159) Matsumoto, T.; Periana, R. A.; Taube, D. J.; Yoshida, H. J. Catal. 2002, 206, 272-280.

(160) Ueura, K.; Satoh, T.; Miura, M. Org. Lett. 2007, 9, 1407-1409.

(161) Patureau, F. W.; Glorius, F. J. Am. Chem. Soc. 2010, 132, 9982-9983.

(162) Kozhushkov, S. I.; Ackermann, L. Chem. Sci. 2013, 4, 886-896.

(163) Weissman, H.; Song, X.; Milstein, D. J. Am. Chem. Soc. 2000, 123, 337-338.

(164) Kwon, K.-H.; Lee, D. W.; Yi, C. S. Organometallics 2010, 29, 5748-5750.

(165) Ackermann, L.; Pospech, J. Org. Lett. 2011, 13, 4153-4155.

(166) Hashimoto, Y.; Ueyama, T.; Fukutani, T.; Hirano, K.; Satoh, T.; Miura, M. Chem. Lett. 2011, 40, 1165-1166.

(167) Hashimoto, Y.; Ortloff, T.; Hirano, K.; Satoh, T.; Bolm, C.; Miura, M. Chem. Lett. 2012, 41, 151-153.

(168) Zhao, P.; Niu, R.; Wang, F.; Han, K.; Li, X. Org. Lett. 2012, 14, 4166-4169.

(169) Ackermann, L.; Wang, L.; Wolfram, R.; Lygin, A. V. Org. Lett. 2012, 14, 728-731.

(170) Zhang, J.; Loh, T. P. Chem. Commun. 2012, 48, 11232-11234.

(171) Li, B.; Ma, J.; Wang, N.; Feng, H.; Xu, S.; Wang, B. Org. Lett. 2012, 14, 736-739.

(172) Yang, F.; Ackermann, L. J. Org. Chem. 2014, 79, 12070-12082.

(173) Graczyk, K.; Ma, W.; Ackermann, L. Org. Lett. 2012, 14, 4110-4113.

(174) Padala, K.; Pimparkar, S.; Madasamy, P.; Jeganmohan, M. Chem. Commun. 2012, 48, 7140-7142.

(175) Padala, K.; Jeganmohan, M. Org. Lett. 2011, 13, 6144-6147.

(176) Hu, X.-H.; Zhang, J.; Yang, X.-F.; Xu, Y.-H.; Loh, T.-P. J. Am. Chem. Soc. 2015, 137, 3169-3172.

(177) Arockiam, P. B.; Fischmeister, C.; Bruneau, C.; Dixneuf, P. H. Green Chem. 2011, 13, 3075-3078.

(178) Ma, W.; Ackermann, L. Chem. Eur. J. 2013, 19, 13925-13928.

(179) Li, X. G.; Liu, K.; Zou, G.; Liu, P. N. Eur. J. Org. Chem. 2014, 35, 7878-7888.

(180) Tirler, C.; Ackermann, L. Tetrahedron. 2015, DOI: 10.1016/j.tet.2015.02.033.

(181) Ackermann, L.; Potukuchi, H. K. Org. Biomol. Chem. 2010, 8, 4503-4513.

(182) Ueyama, T.; Mochida, S.; Fukutani, T.; Hirano, K.; Satoh, T.; Miura, M. Org. Lett. 2011, 13, 706-708.

(183) Lanke, V.; Prabhu, K. R. Org. Lett. 2013, 15, 2818-2821.

(184) Li, B.; Ma, J.; Xie, W.; Song, H.; Xu, S.; Wang, B. J. Org. Chem. 2013, 78, 9345-9353.

(185) Li, J.; John, M.; Ackermann, L. Chem. Eur. J. 2014, 20, 5403-5408.

(186) Ma, W.; Mei, R.; Tenti, G.; Ackermann, L. Chem. Eur. J. 2014, 20, 15248-15251.

(187) Suzuki, C.; Morimoto, K.; Hirano, K.; Satoh, T.; Miura, M. Adv. Synth. Catal. 2014, 356, 1521-1526.

(188) Li, H.; Xie, X.; Wang, L. Chem. Commun. 2014, 50, 4218-4221.

(189) Mehta, V. P.; Garcia-Lopez, J. A.; Greaney, M. F. Angew. Chem. Int. Ed. 2014, 53, 1529-1533.

(190) Reddy, M. C.; Jeganmohan, M. Org. Lett. 2014, 16, 4866-4869.

(191) Quin, L. D.; Tyrell, J. A. Fundamentals of Heterocyclic Chemistry; John Wiley \& Sons Inc.: New York, 2010.

(192) Nakamura, I.; Yamamoto, Y. Chem. Rev. 2004, 104, 2127-2198.

(193) Gulevich, A. V.; Dudnik, A. S.; Chernyak, N.; Gevorgyan, V. Chem. Rev. 2013, 113, 3084-3213.

(194) Gutekunst, W. R.; Baran, P. S. Chem. Soc. Rev. 2011, 40, 1976-1991.

(195) Cacchi, S.; Fabrizi, G. Chem. Rev. 2005, 105, 2873-2920.

(196) Zeni, G.; Larock, R. C. Chem. Rev. 2006, 106, 4644-4680.

(197) Larock, R. C.; Yum, E. K. J. Am. Chem. Soc. 1991, 113, 6689-6690. 
(198) McMurray, L.; O'Hara, F.; Gaunt, M. J. Chem. Soc. Rev. 2011, 40, 1885-1898.

(199) Chen, D. Y. K.; Youn, S. W. Chem. Eur. J. 2012, 18, 9452-9474.

(200) Yamaguchi, J.; Yamaguchi, A. D.; Itami, K. Angew. Chem. Int. Ed. 2012, 51, 8960-9009.

(201) Ueura, K.; Satoh, T.; Miura, M. J. Org. Chem. 2007, 72, 5362-5367.

(202) Stuart, D. R.; Bertrand-Laperle, M.; Burgess, K. M. N.; Fagnou, K. J. Am. Chem. Soc. 2008, 130, 16474-16475.

(203) Satoh, T.; Miura, M. Chem. Eur. J. 2010, 16, 11212-11222.

(204) Patureau, F. W.; Glorius, F.; Wencel-Delord, J. Aldrichim. Acta 2012, 45, 31-41.

(205) Ackermann, L.; Vicente, R.; Kapdi, A. R. Angew. Chem. Int. Ed. 2009, 48, 9792-9826.

(206) Ackermann, L. Acc. Chem. Res. 2014, 47, 281-295.

(207) Ackermann, L.; Lygin, A. V.; Hofmann, N. Angew. Chem. Int. Ed. 2011, 50, 6379-6382.

(208) Li, B.; Roisnel, T.; Darcel, C.; Dixneuf, P. H. Dalton Trans. 2012, 41, 10934-10937.

(209) Li, B.; Feng, H.; Wang, N.; Ma, J.; Song, H.; Xu, S.; Wang, B. Chem. Eur. J. 2012, 18, 12873-12879.

(210) Ackermann, L.; Lygin, A. V.; Hofmann, N. Org. Lett. 2011, 13, 3278-3281.

(211) Ackermann, L.; Lygin, A. V. Org. Lett. 2012, 14, 764-767.

(212) Ackermann, L.; Pospech, J.; Graczyk, K.; Rauch, K. Org. Lett. 2012, 14, 930-933.

(213) Chinnagolla, R. K.; Jeganmohan, M. Chem. Commun. 2012, 48, 2030-2032.

(214) Thirunavukkarasu, V. S.; Donati, M.; Ackermann, L. Org. Lett. 2012, 14, 3416-3419.

(215) Nakanowatari, S.; Ackermann, L. Chem. Eur. J. 2014, 20, 5409-5413.

(216) Wang, L.; Ackermann, L. Org. Lett. 2013, 15, 176-179.

(217) Park, Y.; Jeon, I.; Shin, S.; Min, J.; Lee, P. H. J. Org. Chem. 2013, 78, 10209-10220.

(218) Manikandan, R.; Jeganmohan, M. Org. Lett. 2014, 16, 3568-3571.

(219) Reddy, M. C.; Manikandan, R.; Jeganmohan, M. Chem. Commun. 2013, 49, 6060-6062.

(220) Li, J.; Ackermann, L. Tetrahedron 2014, 70, 3342-3348.

(221) Ma, W.; Graczyk, K.; Ackermann, L. Org. Lett. 2012, 14, 6318-6321.

(222) Ackermann, L.; Wang, L.; Lygin, A. V. Chem. Sci. 2012, 3, 177-180.

(223) Reddy Chidipudi, S.; Khan, I.; Lam, H. W. Angew. Chem. Int. Ed. 2012, 51, 12115-12119.

(224) Nan, J.; Zuo, Z.; Luo, L.; Bai, L.; Zheng, H.; Yuan, Y.; Liu, J.; Luan, X.; Wang, Y. J. Am. Chem. Soc. 2013, 135, 17306-17309.

(225) Warratz, S.; Kornhaaß, C.; Cajaraville, A.; Niepötter, B.; Stalke, D.; Ackermann, L. Angew. Chem. Int. Ed. 2015, 54, 5513-5517.

(226) Patureau, F. W.; Glorius, F. Angew. Chem. Int. Ed. 2011, 50, 1977-1979.

(227) Guimond, N.; Gouliaras, C.; Fagnou, K. J. Am. Chem. Soc. 2010, 132, 6908-6909.

(228) Ackermann, L.; Fenner, S. Org. Lett. 2011, 13, 6548-6551.

(229) Li, B.; Feng, H.; Xu, S.; Wang, B. Chem. Eur. J. 2011, 17, 12573-12577.

(230) Zhang, Z.; Jiang, H.; Huang, Y. Org. Lett. 2014, 16, 5976-5979.

(231) Dersnah, D. F.; Baird, M. C. J. Organomet. Chem. 1977, 127, C55-C58.

(232) Sheldrick, W. S.; Heeb, S. Inorg. Chim. Acta 1990, 168, 93-100.

(233) Singh, K. S.; Dixneuf, P. H. ChemCatChem 2013, 5, 1313-1316.

(234) Clot, E.; Eisenstein, O.; Jasim, N.; Macgregor, S. A.; McGrady, J. E.; Perutz, R. N. Acc. Chem. Res. 2011, 44, 333-348.

(235) Dijksman, A.; Marino-González, A.; Mairata i Payeras, A.; Arends, I. W. C. E.; Sheldon, R. A. J. Am. Chem. Soc. 2001, 123, 6826-6833.

(236) Cheng, G.-J.; Yang, Y.-F.; Liu, P.; Chen, P.; Sun, T.-Y.; Li, G.; Zhang, X.; Houk, K. N.; Yu, J.-Q.; Wu, Y.-D. J. 
Am. Chem. Soc. 2013, 136, 894-897.

(237) Hofmann, N. Carboxylate-Assisted Ruthenium-Catalyzed C-H Bond meta-Alkylations and Oxidative Annulations. Dissertation, Georg-August-Universität Göttingen, 2013.

(238) Song, W.; Ackermann, L. Chem. Commun. 2013, 49, 6638-6640.

(239) Li, J.; Kornhaaß, C.; Ackermann, L. Chem. Commun. 2012, 48, 11343-11345.

(240) Rousseau, G.; Breit, B. Angew. Chem. Int. Ed. 2011, 50, 2450-2494.

(241) Zhang, F.; Spring, D. R. Chem. Soc. Rev. 2014, 43, 6906-6919.

(242) Rosen, B. M.; Quasdorf, K. W.; Wilson, D. A.; Zhang, N.; Resmerita, A.-M.; Garg, N. K.; Percec, V. Chem. Rev. 2011, 111, 1346-1416.

(243) Song, W.; Ackermann, L. Angew. Chem. Int. Ed. 2012, 51, 8251-8254.

(244) Levy, C. C.; Weinstein, G. D. Biochemistry 1964, 3, 1944-1947.

(245) Kornhaaß, C.; Li, J.; Ackermann, L. J. Org. Chem. 2012, 77, 9190-9198.

(246) Sonoda, M.; Kakiuchi, F.; Chatani, N.; Murai, S. J. Organomet. Chem. 1995, 504, 151-152.

(247) Kim, J. Y.; Park, S. H.; Ryu, J.; Cho, S. H.; Kim, S. H.; Chang, S. J. Am. Chem. Soc. 2012, 134, 9110-9113.

(248) Engle, K. M.; Wang, D.-H.; Yu, J.-Q. J. Am. Chem. Soc. 2010, 132, 14137-14151.

(249) Ghattas, G.; Chen, D.; Pan, F.; Klankermayer, J. Dalton Trans. 2012, 41, 9026-9028.

(250) Wang, H.; Wang, Y.; Peng, C.; Zhang, J.; Zhu, Q. J. Am. Chem. Soc. 2010, 132, 13217-13219.

(251) Owen, D. A.; Montana, J. G.; Keily, J. F.; Watson, R. J.; Baxter, A. D. Hydroxamic and carboxylic acid derivatives having MMP and TNF inhibitory activity. Patent US 6566384 B1, 2003.

(252) García, F.; McPartlin, M.; Morey, J. V.; Nobuto, D.; Kondo, Y.; Naka, H.; Uchiyama, M.; Wheatley, A. E. H. Eur. J. Org. Chem. 2008, 2008, 644-647.

(253) Zhang, G.; Wen, X.; Wang, Y.; Mo, W.; Ding, C. J. Org. Chem. 2011, 76, 4665-4668.

(254) Feng, C.; Loh, T.-P. Chem. Commun. 2011, 47, 10458-10460.

(255) Parthasarathy, K.; Cheng, C.-H. J. Org. Chem. 2009, 74, 9359-9364.

(256) Too, P. C.; Chua, S. H.; Wong, S. H.; Chiba, S. J. Org. Chem. 2011, 76, 6159-6168.

(257) Too, P. C.; Wang, Y.-F.; Chiba, S. Org. Lett. 2010, 12, 5688-5691.

(258) Zhang, X.; Chen, D.; Zhao, M.; Zhao, J.; Jia, A.; Li, X. Adv. Synth. Catal. 2011, 353, 719-723. 


\section{Acknowledgements}

First and foremost, I would like to extend my sincere gratitude to Prof. Dr. Lutz Ackermann, who has offered me this fascinating opportunity to carry out my PhD study here at University of Goettingen, shared all those creative ideas, enlightening suggestions and helpful discussions throughout my research and generously offered financial support for the last stage of my stay so that I can focus on finishing my work.

I am also grateful to Prof. Dr. Frank Meyer for kindly accepting to be the second referee of this thesis, and also the second supervisor for my work.

Great gratitude for Prof. Dr. Hartmut Laatsch, Prof. Dr. Dietmar Stalke, Prof. Dr. Ulf Diederichsen and Dr. Alexander Breder, who has agreed to be on my review committee. I look forward to all the challenging questions at my defense and their intriguing opinions about my research.

I thank Dr Sergei Kozhushkov for correcting this manuscript, and also my colleague Suman, Fanzhi, Phani, Svenja, Sachiyo, Weiping and Hui for their generous help and advice on this thesis.

In addtion, China Scholarship Council's financial support for my last three years' study is appreciated.

What's more, during my staying here, there are people who have offered me great help in my daily life, to whom I'd like to extend my gratitudes.

I deeply thank Ms. Gabriele Keil-Knepel for her patience with all the paper work and kind help whenever I encountered any problem in daily life.

I thank Mr. Stefan Beußhausen for the technical assistance with the computer, software and network and Mr. Karsten Rauch for his helpful suggestions concerning the lab work.

I thank the NMR and Mass Department for measurements of my samples, particularly Mr. Machinek for kindly helping me determining complicate structures without any hesitation.

Through this opportunity, I'd like to thank all who has positive influence on me, both colleagues and friends.

Dr. Christoph Kornhaaß, thank you for your guidance and instructions when I first entered the lab. Only with your kind help that I can get familiar with the new working environment that fast. I also thank you for your efforts on our alkenylation project and your Rock \& Roll music. Although we have a little bit difference in music taste, your choice is much better than the boring radios which repeat over and over again.

I sincerely thank Suman, Svenja and Daniel for your efforts on the meta-alkylation project. Despite - 185 - 
that we haven't really figured out how this chemistry worked, I really enjoyed discussing it with you guys.

I thank Eloisa for helping me with the chemistry research and work, bringing laughter to the lab, sharing good music and making me talk all the time. Thanks to you, I finally got the chance to know all those bars and clubs.

I thank all my nice colleagues in the Ackermann Group, past and present, for the nice working atmosphere and the help in chemistry.

Thank all my Chinese friends and colleagues in Goettingen for making me feel like home. Especially Weifeng, Chunxiao, Lianhui, Yingjun and Jason, thank you for all the wonderful journeys and your companionship through my hard times.

Deep gratitude to my family for your unconditional love and support. I could not do this without all of you encouraging me all the time and bringing me peace in mind. I also thank all my good friends in China, US and Europe, I really enjoy our friendship and all the unforgettable memories over the years. Hope we can meet each other more often.

Finally, I would like to thank all the people who have offered me help over the past 30 years, whether mentioned or not, it's all of you who make me who I am today. 


\section{Resume}

Date of Birth: May 21 $1^{\text {st }}, 1986$

Place of Birth: Yancheng, Jiangsu (China. PR)

Nationality: Chinese

\section{Education}

09/2011 - present

Doctoral study under the supervision of Prof. Dr. Lutz Ackermann Georg-August-Universität Göttingen, Germany

Thesis: "Ruthenium(II)-Catalyzed Direct C-H meta-Alkylations, Alkenylations and Alkyne Annulations"

$09 / 2008-06 / 2011$

M. Sc. in Organic Chemistry

Advisor: Prof. Dr. Yixiang Cheng

Nanjing University, China. PR

Thesis: "Synthesis of Polymer-Based Fluorescence Sensor for $\mathrm{Hg}^{2+}$-Ion Detection"

09/2004-06/2008 B. Sc. in Chemistry

Advisor: Prof. Dr. Leyong Wang

Nanjing University, China. PR

Thesis: "Research on Synthesis of Phosphine Ligands and Asymmetric Catalysis"

\section{Publications}

1. J. Li, L. Ackermann. "Ruthenium(II)-Catalyzed meta-Selective C-H Alkylation of Aromatic Imines with Secondary and Tertiary Alkyl Halides" Manuscript in Preparation.

2. J. Li, S. Warratz, D. Zell, S. De Sarkar, L. Ackermann. "Tertiary Alkyl Halides for meta-Selective C-H Alkylation" Manuscript in Preparation.

3. J. Li, C. Kornhaaß, L. Ackermann. "Ruthenium-catalyzed Oxidative C-H Alkenylation of Aryl Carbamates" Chem. Commun. 2012, 48, 11343-11345.

4. C. Kornhaaß, J. Li, L. Ackermann, "Cationic Ruthenium Catalysts for Alkyne Annulations with Oximes by C-H/N-O Functionalizations" J. Org. Chem. 2012, 77, 9190-9198.

5. J. Li, J. Meng, X. Huang, Y. Cheng. "A highly selective fluorescent sensor for $\mathrm{Hg}^{2+}$ based on the water-soluble poly(p-phenyleneethynylene)" Polymer 2010, 51, 3425-3430. 